UNIVERSITY OF B.C. LIBRARY

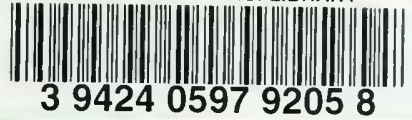

STLRAGE ITEM

PKULESSINU-DNE

$1 P L-A 15 C$

U.B.C. LIBRARY 


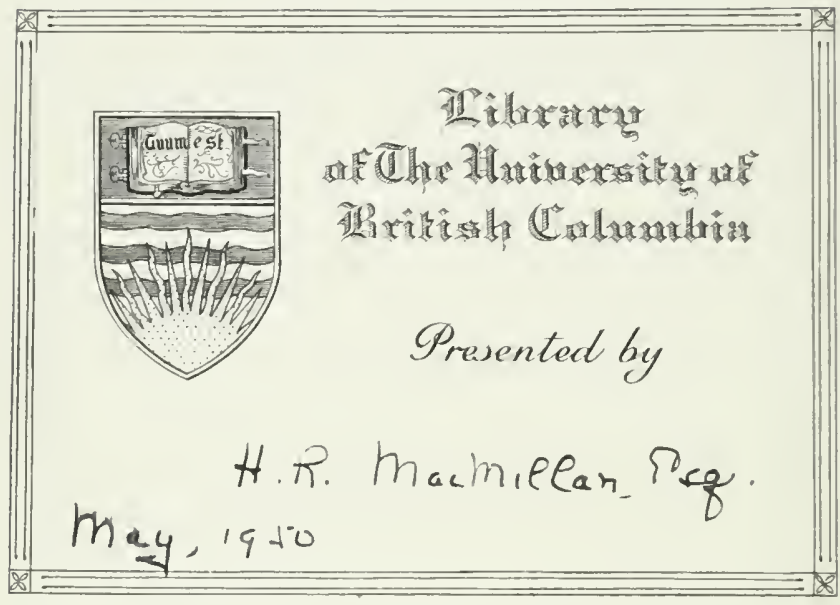

The UP. SR. Vlens. Villen

Bedtertion in Sorestry

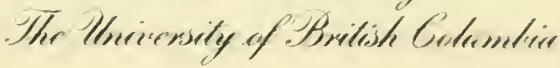


Digitized by the Internet Archive in 2010 with funding from University of British Columbia Library 





\section{G. LAPIE}

Chargé de cours à l'Ecole Nationale des Eaux et Forêts.

\section{A. MAIGE}

Professeur de Botanique

à la Faculté des Sciences de Poitiers.

\section{FLORE}

FORESTIÈRE

\section{$\equiv \mathrm{DE}$}

\section{L'ALGÉRIE}

Comprenant les arbres, arbustes et arbrisseaux les plus répandus

EN TUNISIE, AU MAROC ET DANS LE MIDI DE LA FRANCE

881 FIGURES ET UNE CARTE

E. ORLHAC, EDITEUR 


\section{FLORE FORESTIÈRE DE LALGÉRIE}

Tunisie, Maroc et Midi de la France 


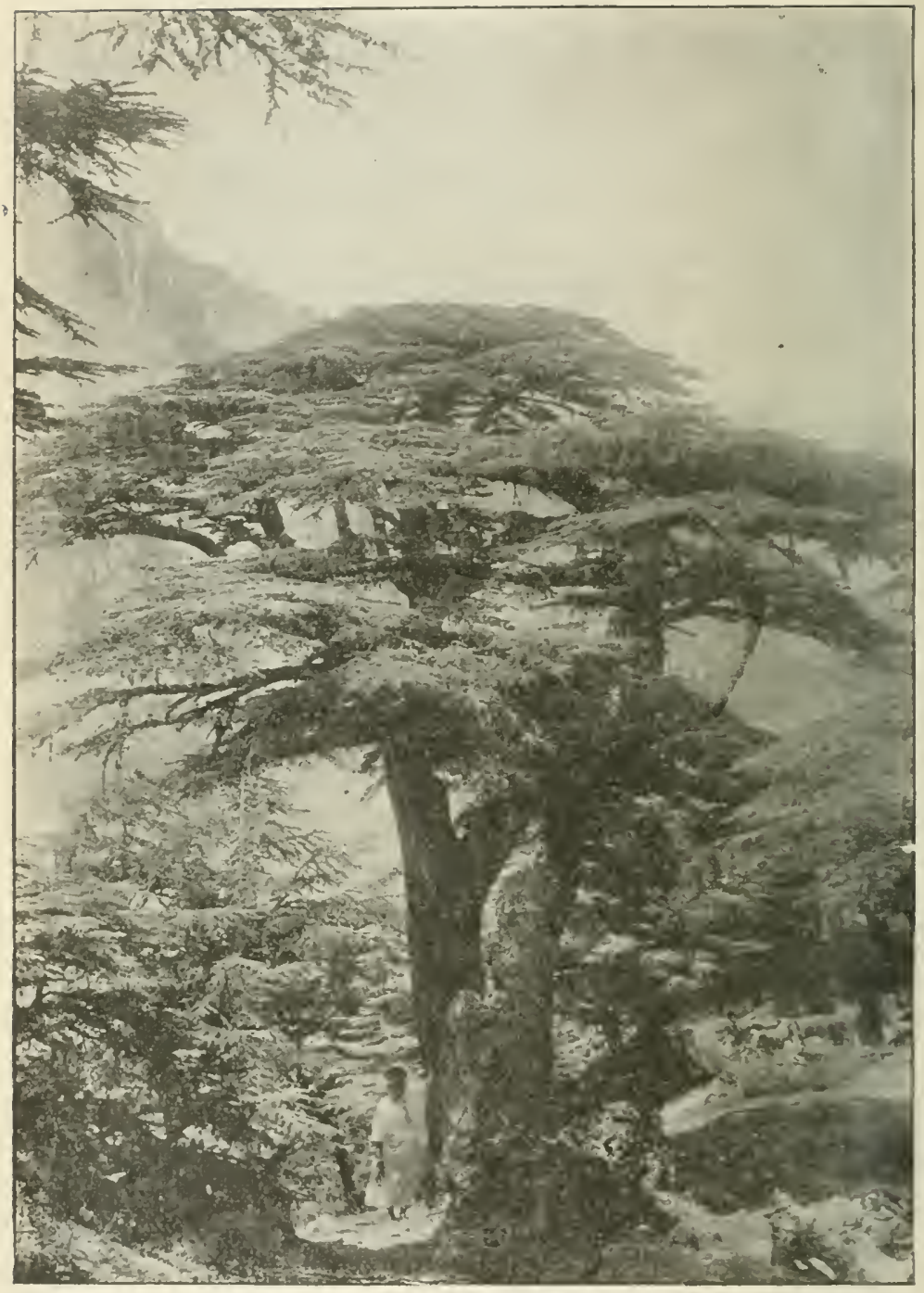

Forêt de Cìdres (1)jurjura). 
Ouvrage publiẻ sous les auspices du Gouvernement général de l'Algérie

\section{FLORE FORESTIERE ILLUSTRÉE}

Comprenant tontes les espèces ligneuses

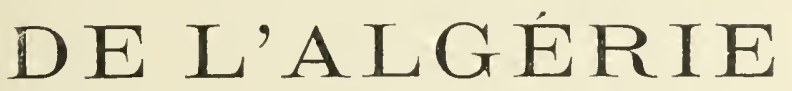

et les espèces ligneuses les plus répandues

en Tunisie, au Maroc et dans le Midi de la France

POUR LA DÉTERMINATION FACILE, SANS L'EMPLOI

DE MOTS TECHNIQUES, DE TOUTES LES ESPĖCES DÉCRITES

\section{G. LAPIE}

Docteur is sciences

Inspecteur des Eaux et Forêts

Chargé de cours à l'École Nationale des

Eaux et Forèts
PAI

\section{A. MAlGE}

Professeur de Botanique à la Faculté des Sciences de Poitiers

Directeur de la Station de Biologie

végétale de Mauroc

Ouvrage précédé de Nolions de Bolanique appliquée à la Sylviculture, et accompagné de clefs permettant la détermination en hiver des essences à feuilles caduques et la reconnaissance des principaux bois.

881 figures, et une carte de l'Al gèrie

\section{PARIS}

\section{E. ORLHAC, EDITEUR}

Librairie générale de l'Enseignement

$$
\text { 1, RUE DANTE, } 1
$$





\section{AVER'TISSEMENT}

La Flore forestière de l'Algérie n'est pas un ouvrage de haute portée scientifique appelé à faciliter les recherches des naturalistes déjà versés dans l'étude de la Botanique. Ce livre a été écrit spécialement pour les forestiers qui sont appelés à exercer leurs fonctions dans la colonie; il est destiné aux Officiers des Eaux et Forèts qui, déjà initiés à l'étude des sciences naturelles, connaissent la flore de la France, mais se trouvent pris au dépourru quand ils débarquent sur la terre africaine, et surtout aux Préposés qui n’ont pas bénéficié de la même éducation scientifique. mais qui, aimant la forèt, sont désireux de connąitre les éléments qui la composent. Trop souvent, en effet, le nom des plantes qui frappent journellement leurs regards demeure pour eux une énigme. Cette flore rendra aussi des services, croyons-nous, à tous ceux qui, initiés ou non à la Botanique, s'intéressent à la nature et recherchent les bois comme but de leur's promenades.

L'ouvrage est divisé en deux parties :

La première partie débute par des notions de Botanique écrites surtout pour les personnes qui n’ont jamais abordé l'étude des plantes; nous arons cherché à réunir, dans ces quelques pages, les définitions indispensables ponr l'utilisation des clefs de détermination et les notions sur la vie des plantes les plus utiles au forestier.

Les chapitres qui suirent sont consacrés à l'examen des végétaux ligneux de l'Algérie, en y comprenant les espèces suffrutescentes, c'est-à-dire ligneuses ì la base de la 
tige seulement. On sait combien les plantes de cette catégorie sont répandues dans la région méditerranéenne; la ligne de démarcation avec les espèces herbacées est souvent délicate à établir, et rarie mème a vec les pays étudiés. Bien que certaines de ces plantes ne présentent qu'une minime importance pour le forestier, nous avons cherché à englober dans cette flore, en nous basant sur les savants ouvrages de MM. Battandier et Trabut, toutes les espèces ligneuses ou sous-ligneuses du'Tell et des Hauts Plateaux; mais nous avons particulièrement décrit et représenté par des figures les espèces qui sont d'un intérêt primordial par leurs dimensions, par les produits qu'elles donnent. ou encore par leur abondance.

Celte première partie se termine par quelques notions de géographie botanique et par les indications indispensables pour l'usage des flores et la confection d'un herbier.

La deuxième parlie est uniquement composée de clefs générales et de tables; une première clef est destinée à la détermination des échantillons munis des organes de reproduction, suivant la méthode employée dans les flores essentiellement pratiques de M. Gaston Bonnier. Cette clef comprend, outre les espèces spontanées en Algérie, un certain nombre d'essences qui y sont fréquemment cultivées et que l'on est exposé à rencontrer le long des routes, des voies ferrées et aux abords des habitations.

Mais les arbres que le forestier doit reconuaitre ne portent souvent ni fleurs ni fruits; c'est pourquoi nous avons établi une deuxième clef qui permet la détermination des principales espèces lignneuses, à l'aide des caractères des rameaux et des feuilles.

La troisième table est destinće à la détermination, en hiver, des arbres à feuilles caduques. 
Une dernière clef permet la détermination des principaux bois indigènes, autant qu'il est possible de le faire. sans le secours du microscope. Il est presque indispensable de s'exercer à l'usage de ce tableau à l'aide d'échan tillons de bois dont on connaît l'espèce par avance; la clel deviendra ensuite un aide mémoire facile à utiliser.

La recherche de la famille à laquelle appartient une plante, n'est pas toujours une tâche facile pour le débutant, et l'emploi d'une flore ne devient réellement commode que lorsqu'on peut d'un coup d'ocil reconnaître de quel groupe dépend l'espèce à étudier. C'est pourquoi nous arons résumé les caractères essentiels des familles dans un tableau sommaire que nous engageons les novices à parcourir souvent.

Pour constituer une ouvre réellement pratique, la flore de l'Algérie devait renfermer beancoup de figures: les ouvrages de MI. Gaston Bonnier, la flore de France de M. l'abbé Coste, nous ont fourni de nombreux clichés; les dessins originaux des plantes spéciales à l'Algérie sont dus à la plume de M. Ferrand, chef des travaux graphiques au Service géologique de l'Algérie; M. Armand. préparateur à la Faculté des Sciences de P'oitiers, a dessiné les croquis inédits intercalés dans les clefs.

Nous derons d’ailleurs témoigner tout spécialement notre gratitude à M. Gaston Bonnier qui, avec la haute expérience qu’il possède dans l’art de mettre la science à la portée de tous, nous a prodigué les conseils les plus utiles, à MM. Battandier et Trabut, qui nous ont lait bénéficier de leur connaissance approfondie de la flore de l'Algérie, à M. Pitard qui a bien voulu nous documenter sur les plantes du Maroc, a MM. René Maire et G. Nicolas qui nous ont procurè divers échantillons et lourni d'utiles renseignements. 
Nous ne saurions oublier non plus les encouragements et le précieux appui que nous a donnés dès le début II. Boutilly, alors Chef du Service technique des Forêts à Alger.

Le nombre des figures, la disposition des clefs et surtout l'intercalation de petits croquis dans les tableaux soulevaient des difficultés de réalisation relativement considérables. C'est gràce aux propositions de M. liuss, Directeur des Forêts de l'Algérie, et à l'aimable insistance de ses collaborateurs que cette flore a été honorée d'une souscription par M. le Gouverneur Général de l'Algérie ¿ qui nous devons exprimer ici notre sincère reconnaissance.

Peut-être, malgré nos efforts, le lecteur trouvera-t-il des lacunes dans nos explications; peut-être aussi les clefs qui nous ont paru claires, lui sembleront-elles parsemées d'embùches: nous n'arons pas la prétention d'aroir écrit une ouvre sans reproche, mais nous nous estimerons heu. reux si ce modeste ourrage peut contribuer à mettre la Botanique en honneur auprès des forestiers algériens, leur permettant ainsi d'apprécier davantage la forêt, en la comprenant mieux.

Décembre 1914. 


\section{PREMIERE PARTIE \\ NOTIONS DE BOTANIQUE APPLIQUÉE \\ A LA SYLVICULTURE}

\section{CHAPITRE PREMIER \\ GÉNÉRALITÉS}

LE RÉGNE VÉGÉTAL. - Les objets qui composent l'univers se présentent á nos regards sous deux aspects bien distincts :

$1^{\circ}$ Les corps bruts ou minéranx, masses inertes qui forment le règne minéral ;

$2^{\circ}$ Les corps vivants, parmi lesquels on distingue les végétaux, compris dans le régne végélal, et les animaux, qui constituent le règne animal.

Ces deux derniers règnes paraissent au premier abord bien différents : les animaux sont doués de sensibilité ; ils exécutent des mouvements volontaires; ils se nourrissent d'une façon spéciale; ils ne renferment pas cette matière verte appelée chlorophylle qui colore beaucoup de plantes. Mais si, au lieu de comparer les arbres qui constituent la forèt avec les animaux que nous avons coutume d'y observer, nous mettons en parallèle des êtres d'organisation de plus en plus simple, la différence devient moins frappante : déjà les éponges et les autres animaux fixés ont une sensibilité très dégradée et un aspect qui se rapproche de celui des plantes, et si nous passons à l'examen de ces organismes infiniment petits que l'on désigne dans le langage courant sous le nom de microbes, la distinction devient très délicate. Une étude complète permet de constater que les caractères que nous avons signalés, si saillants au premier abord, ne permettent pas d'établir une limite entre les deux règnes vivants et a amené les naturalistes à baser la distinction entre l'animal et le végétal sur l'absence 
ou la présence de la cellulose, matière organique de composition analogue à celle de l'amidon ${ }^{1}$.

L'étude des plantes constitue une science qui s'appelle la Bolanique. Celle des animaux est du domaine de la Zoologie. Ajoutons dès maintenant que les plantes vertes, grâce à la chaleur et à la lumière que leur procure le soleil, ont la propriété de croître aux dépens des matières brutes contenues dans l'air et dans le sol; l'homme et les animaux les utilisent ensuite pour leur alimentation; elles sont donc le lien nécessaire entre le règne minéral et le règne animal.

Cette constatation nous dispensera d'insister sur les avantages que l'on peut tirer de l'élude de la Botanique.

Il suffira également de rappeler l'utilité générale de la forêt et l'importance des produits que l'homme en extrait pour établir l'intérêt tout spécial que présente l'étude des plantes qui la composent ; cette étude constitue une science appliquée qui est la Bolanique foreslière.

L'observation des êtres vivants à l'aide d'instruments grossissants, contribue encore à montrer que les liens qui existent entre les animaux et les végétaux sont des plus étroits, car leur structure intime est la même : les uns et les autres sont formés de cellules.

LA GELLULE. - LES TISSUS. - En étudiant au microscope une partie très jeune d'un végétal, on constate d'ordinaire la présence d’innombrables cloisons séparant de très petits compartiments (Fig. 1); cette structure est dite cloisonnée ou cellulaire?

Chaque compartiment est plein d'une sorte de liquide épais et rempli de granules : e'est la matière vivante ou protoplasma (p, Fig. 1). Sa composition se rapproche de celle des matières albuminoïdes dont le blanc d'œuf est un exemple bien connu.

Le protoplasma a la proprićté de respirer. de se nourrir et de se inouvoir comme l'ètre vivant tout entier.

Dans sa masse, on distingue un petit corps plus dense et de structure compliquée appelé noyan ( $n$, Fig. 1).

1. Le coton et la moelle de sureau ancienne sont formes de cellulose presque pure.

2. Chez certains végétanx infërieurs, il n'existe pas de cloisonnement; on dit alors que la structure est continue. 
Les cloisons ( $m$, fig. 1) sont formées de cellulose, matière que nous avons déjà citée.

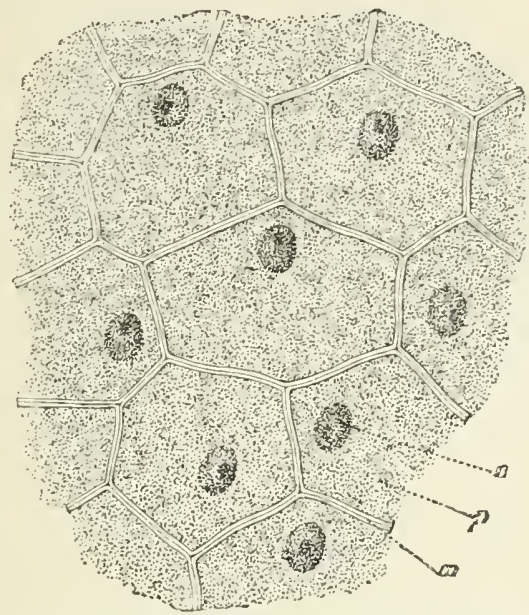

Excmple de cellules vẻgétales (jeune tige d'Ail coupée en travers): $m$, membrane; $p$, protoplasma; $n$, noyau.

Fig. 1.

Chaque petit compartiment, constitué par un noyau du protoplasma et sa cloison propre, s'appelle une cellule.

En devenant plus âgée (Fig. 2 à 5 ), la cellule grandit ${ }^{4}$; à son

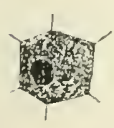

A

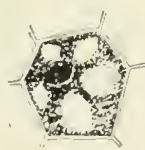

[3

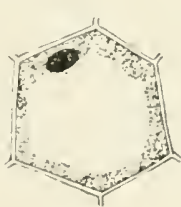

C

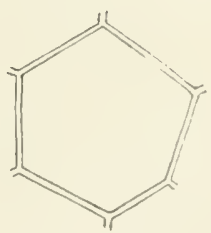

D)

Etats suceessifs de l'évolution dine cellule: A, jeune cellule remplie de protoplasma sans vacuoles; $B$, cellule plus âgée où sont apparues des vacuoles remplies de suc cellulaire; C, cellule encore plus âgée, le protoplasma et le noyau sont refoulés contre la paroi, les vacuoles se sont fusionnées en une seule au centre de la cellule; 1), collule morte.

Fig. 2 à 5.

1. Les cellnles se multiplient par l'apparition d'une nouvelle cloison partageant en deux la cavilé de la vésicule primitive. Cetle division est précédée de celle du noyau qui comprend une snite de phases que nous ne pouvons décrire ici. 
intérieur un nouveau liquide apparaît, c'est le suc cellulaire; peu à peu le protoplasma est refoulé contre la paroi qui subit

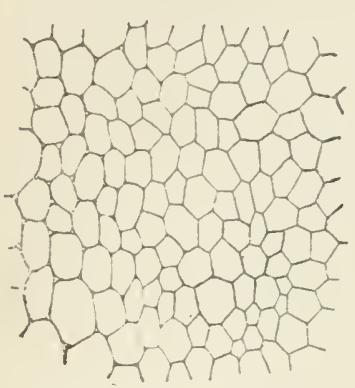

Coupe transversale dans du parenchyme. Fig. 6. elle-même fréquemment des modifications et s'imprègne de nuatières nouvelles. Souvent la eavité des cellules ne renferme plus que de l'air; telles sont les cellules qui constituent la moelle de sureau et que l'on peut observer avee une forte loupe.

Une cellule qui ne contient plus de protoplasma est une cellule morte.

Cet ensemble eloisonné que nous avons décrit forme un tissu. Si le tissu comprend des cellules à parois minces dont les dimensions sont seusiblement les mêmes en tous sens, il est appelé parenchyme (Fig. 6). Les vides qui se produisent entre les cellules sont dits méats.

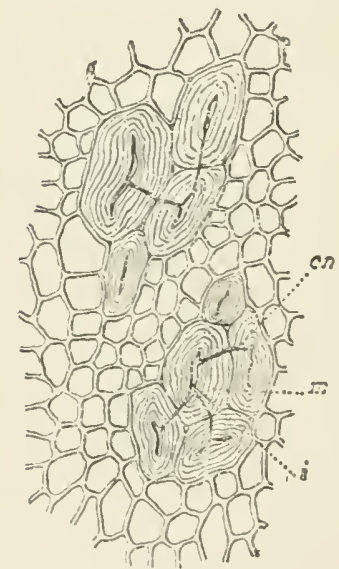

Fibres coupées Irausversalement.

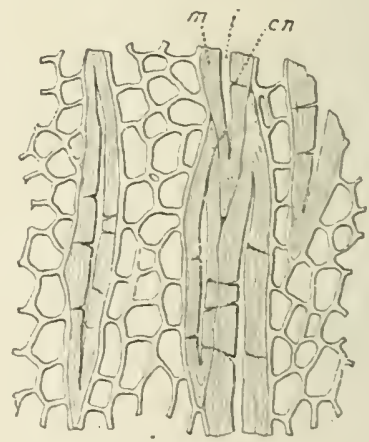

Fibres coupees

$m$, membrane épaissie ; cn, petits canaux communiquanl avec lintérieur $i$ Fig. 7. des fibres. Fig. S.

Souvent les cellules s'allongent et s'effilent aux extrémités, lcur paroi s'épaissit en rẻtrécissant la cavité et s'imprègne d'une matière spéciale, la lignine, qui augnente leur dureté; ces cellules modifiées sont les fibres (Fig. 7 et $\$$ ) ; assemblées en 
faisceaux et placées bout à bout, elles constituent le tissu fondamental du bois dit tissu fibreux; c'est suivant la direction de ces fibres que le bois se fend, et ce sont elles qui soutiennent la plante.

D'autres cellules se superposent en files ; les cloisons trans-

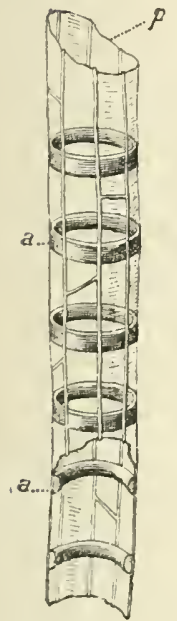

A

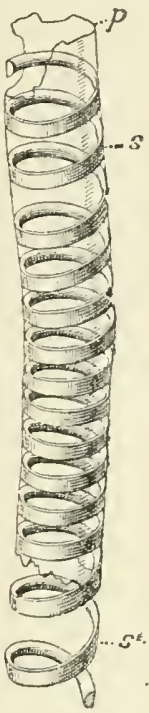

B

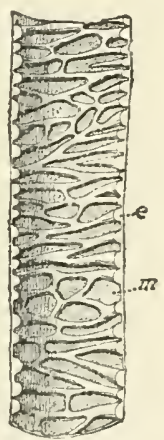

C.

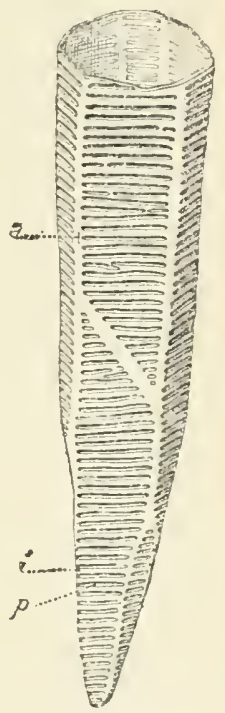

D

Diffërents types de vaisseaux. A, vaisseau annelè : $a$, anneaux d'épaississements internes; $p$, partie restée mince. - B, vaisseau spiralé : $s, s$ ' spirales d'épaississements internes; $p$, partie restée mincc. - C, vaisseau réticulé: $e$, réseau d épaississement interne; $m$, parlic restée mince. D, vaisseau scalariforme: $i$, partic's épaissies de la membrane fornant comme les barreaux d'une échclle: $p$, parties minces; $a$, angles épaissis.

Fig. 9 à 12 .

versales ainsi que le protoplasma et le noyau disparaissent ; il résulte de celte juxtaposition un canal continu où peuvent circuler les liquides. On distingue ces petits tubes ou vaisseaux. dans le bois, même à l'ccil nu; ils forment le tissu vasculaire.

l'enveloppe des cellules qui le composent peut s'épaissir, mais souvent l'épaississement n'est pas uniforme; il se fait inégalement sur les différentes parties de la membrane; il en résulte des sculptures en creux ou en relief que l'on observe sur les parois des vaisseaux (Fig. 9 à 12 ). 
Les parties vivantes des végétaux qui sont en contact avec

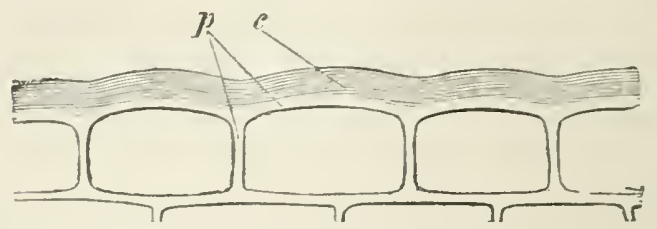

Fragment de coupe montrant l'épiderme $c$, cuticule; $p$, paroi latérale des cellules.

Fig. 13.

l'extérieur sont recouvertes d'une couche de ccllules aplaties

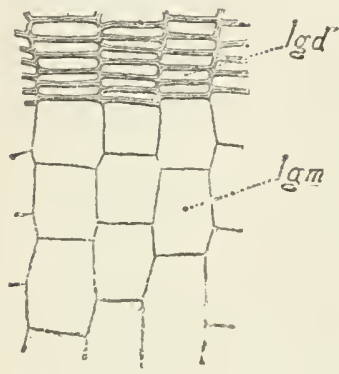

Fragment de lissu subéreux du Chêne-liẻge : lgd, liège dur; $\operatorname{lgm}$, liège mou.

Fig. 14 . qui forment l'épiderme (Fig. 13). La cellulose des cellules épidermiques se transforme vers l'extérieur en une matière spéciale appelée cutine; la partie superficielle de la membrane prend le nom de culicule; clle protège le corps de la plante.

Dans certains cas, l'enveloppe des cellules se change en une substance jaune et élastique; l'ensemble des cellules ainsi modifiées forme le lissu subéreux ou liège (Fig. 14), qui a également un rôle de protection. Le grand développement que prend ce tissu chez le Chêne-liège permet son utilisation industrielle.

CLASSIFICATION. - Les types de plantes sont excessivement nombreux, et il a fallu pour lesétudier les réunir en groupes; c'est le but de la classification.

Tout le monde a la notion de l'espéce (le Chène-liège, le Chène zéen sont des espèces différentes), mais cette notion reste suuvent assez vague, il importe de la préciser. "Tous les individus animaux ou végétaux qui descendent de mèmes parents présentent des caractères communs. Ce sont les caractères de l'espèce. "

Cuvier, célèbre naturaliste du début du $\mathrm{x}^{\mathrm{e}} \mathrm{x}^{\mathrm{e}}$ siècle, a défini l'espèce : la réunion des itres vivants descendus les uns des autres on de parents communs, et de ceux qui leur ressemblent autant qu'ils se ressemblent entre eux. 
Le mot essence est souvent employé pour désigner les espèces forestières.

Les espèces qui se ressemblent sont réunies entre elles pour former un genre, par exemple le genre Chêne.

Les botanistes désignent les plantes par le nom du genre et celui de l'espèce mis à la suite l'un de l'autre. Exemple: le Chêne (nom de genre), Kermès (nom de l'espèce), et afin de se comprendre plus facilement les naturalistes des différents pays ont adopté la langue latine; c'est ainsi qu'ils appellent le Chène Kermès Quercus coccifera.

Une même espèce peut avoir èté désignée sous des nonıs différents; afin d'éviter toute confusion, on fait suivre le nom de l'espèce du nom de son parrain. Ce nom s'écrit par abréviation. La lettre L, qui dans les flores suit les mots Quercus coccifera, signifie Linné 1.

Les genres voisins forment une famille; les familles se réunissent en ordles ; ceux-ci en classes; enfin les classes en embranchements. On peut aussi distinguer des tribus, groupes intermédiaires entre les genres et les familles.

Nous verrons que le genre Chêne appartient à la famille des Cupulifères, à l'ordre des A pétales, à la classe des Dicotylédones, à l'embranchement des Phanéroganes.

Certaines considérations, et en particulier l'étude des fossiles, c'est-à-dire des débris animaux ou végétaux très anciens que l'on trouve enfouis dans le sol, nous indiquent que les ètres vivants qui ont habité notre globe n'ont pas toujours présenté les niêmes formes; ils ont donc varié avec le temps; et nous constatons encore à notre époque des modifications qui nous amènent à distinguer plusieurs variétés dans une mème espèce.

La plupart des savants admettent aujourd'hui que les êtres qui ont apparu les premiers étaient très simples. De proche en proche, ou par variation brusque, des êtres plus compliqués seraient nés les uns des autres. La variété des formes s'est produite sous linlluence du climat, de la nourriture, elc. Les plus forts ont obligé les plus faibles á émigrer ou à disparaitre.

Les especes actuelles descendraient ainsi toutes d'une même souche.

1. Linné, illustre naturaliste suédois du xvrn ${ }^{\theta}$ sic̀cle. 
Si l'on admet cette théorie de ladescendance, la classification cesse d'être une séche énumération; ce n'est plus un simple catalogue constitué pour faciliter l'étude, mais l'ébauche d'un arbre généalogique qui tendra à réunir les êtres vivants suivant leurs liens de parenté et à nous révéler leur histoire.

LES DEUXGRANDES DIVISIONS DU REGNE VÉGÉTAL. - Certaines plantes, telles que les arbres de nos forêts, possèdent une racine, une tige et des feuilles et portent à une certaine époque des fleurs qui contiennent les organes de reproduction. Ces plantes font partie du grand groupe des végélaux supérieurs ou Phanérogames. Les plantes sans fleurs sont dites Cryplogames.

Les principaux caractères employés pour la classification des végétaux supérieurs sont tirés de la fleur.

Les dispositions spéciales qui assurent la multiplication et la reproduction des Cryptogames sont également utilisées dans la classification.

On considère les Plonérogames comme se groupant en un seul embranchement; les Cryptogames, sur lesquels nous allons jeter un coup d'œil rapide. en forment trois.

\section{CHAPITRE II}

\section{LES PLANTES SANS FLEURS OU CRYPTOGAMES}

\section{GARAGTÉRES GÉNERAUX. - DIVISION. -}

Ce groupe comprend des êtres d'organisation très variable, dont la multiplication s'effectue généralement à l'aide de corpuscules très petits appelés spores, qui naissent sur la plante mère tantót isolés, tantôt par groupes et renfermés dans des poches. En plaçant un Champignon de couche sur une feuille de papier, on peut recueillir les spores qui s échappent des lames du chapeau.

On peut, en outre, observer chez beaucoup d'espèces des éléments màles et femelles correspondant à ceux que nous étudierons chez les plantes à lleurs.

Les Cryptogames les plus simples n'ont ni racine, ni tige, ni feuilles distinctes ; la plante est formée d'une masse ou d'une 
lame à contour variable que l'on appelle thalle; elle ne comprend jamais de vaisseaux ; c'est quelquefois une cellule

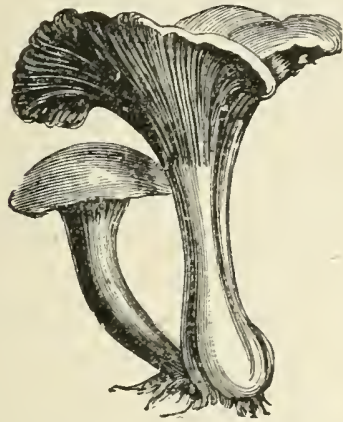

Exemple de Thallophyte: Champignon (Chanterelle).

Fig. 15.

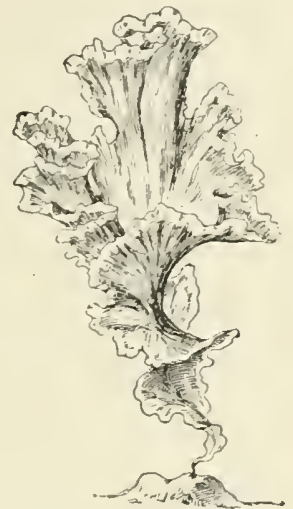

Exemple de Thallophyte: Algue Ulve).

Fig. 16.

unique ; ces êtres peu compliqués constituent l'embranchement des Thallophytes (Fig. 15 et 16). (Exemple : les Champignons, les Algues.)

Chez d'autres Cryptogames, on distingue une tige et des feuilles, mais la racine n'existe pas; comme chez les Thallo-

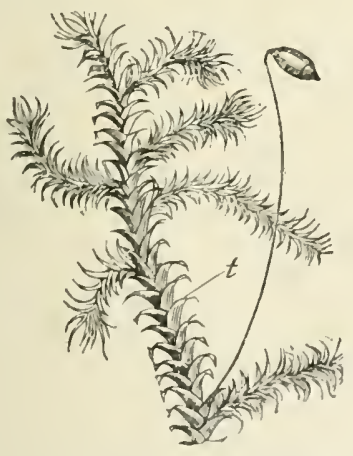

Exemple de Muscince: Mousse (Hypnum); $t$, tige feurlèe.

Fig. 17.

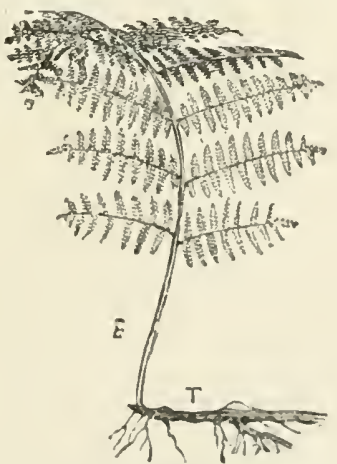

Exemple de Cryptogame vasculaire (Fougère aigle); ' $T$, lige portant des racines; $F$, feuille.

Fig. 18 
phytes les vaisseaux manquent; ces végétaux déjà plus compliqués forment l'embranchement des Muscinées (Fig. 17).

Le $3^{\mathrm{e}} \mathrm{embranchement}$ comprend des plantes à racines, tiges et feuilles; on distingue des vaisseaux dans leurs tissus, ce sont les Cryplogames vasculaires (Fig. 18), dont la Fougère est le type; ils se rapprochent beaucoup des Phanérogames.

\section{EMBRANCHEMENT DES THALLOPHYTES.}

- Il comprend 2 classes : les Champignons et les Algues : les premiers ne renferment pas de matière verte ou chlorophylle; les Algues au contraire en sont pourvues.

Classe des Champignons. - La plupart des Champignons sont composés de deux parties: d'un réseau filamen-

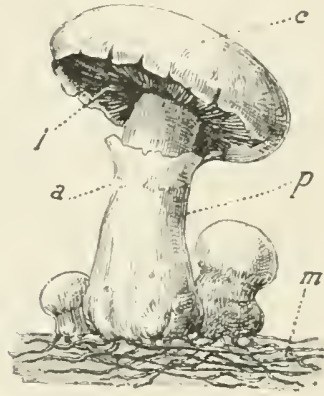

Champignon de couche: $m$, mycélium ; $p$, pied; $c$, chapeau.

Fï. 19.

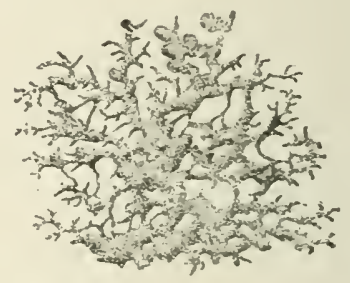

Thalle de Myxomycèle.

Fig. 20.

teux (ou mycelinnn) vulgairement connu sous le nom de blanc de champignon et l'une partie qui porte les organes de reproduction; cette dernière se compose souvent chezles espèces qui couvrent le tapis de nos forits d'un pied et d'un chapeau (Fig. 19).

Classification. - On distingue 4 ordres de Champignons : $1^{\circ}$ les liyxomycètes (Fig. 20), formes très simples, sans mycélium, de consistance gélatineuse, telles que les masses que l'on observe dans les tanneries et qui sont connues sous le nom de fleur de tan.

Citons aussi ces plaques gélatineuses rouges, jaunes ou 
blanches qui apparaissent à l'automne sur les feuilles mortes ou les fragments d'écorce mouillés.

$2{ }^{\circ}$ Les Oomycéles, qui présentent sur des parties différentes de la plante des éléments mâles et femelles dont l'union constitue un œuf $^{1}$ (Fig. 21), susceptible de résister aux circonstances défavorables et de se développer pour constituer un

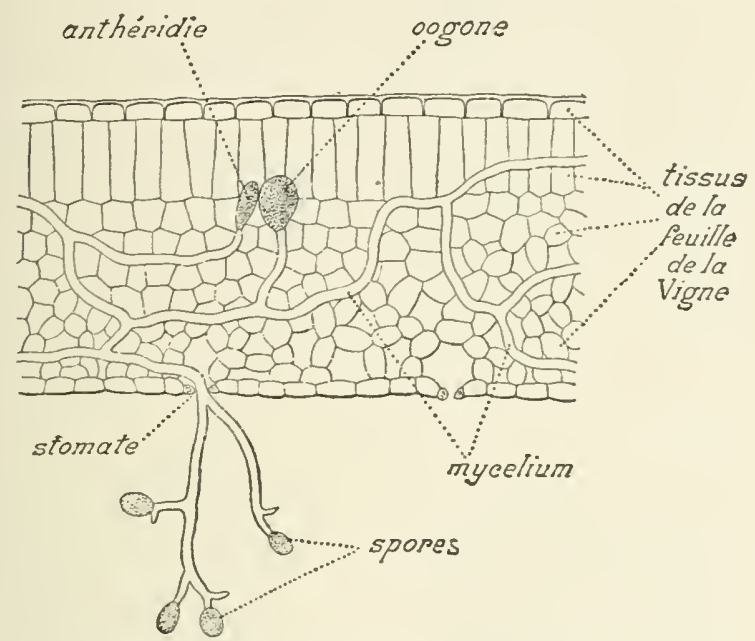

Coupe dans une feuille de Vigne atteinte du mildiou montrant le mycélium du Champignon qui produit à l'extérieur de la feuille des spores, et à l'interieur un a'uf formé par la fusion d'un élément mâle (anthériclie) et de l'élément femelle (oosphère) renfermé dans l'oogone.

Fig. '21.

nouvel individu lorsque les conditions deviennent ì nouveau propices.

La famille des Mucorinées, comprenantertaines moisissures, et celle des Péronosporées composées d'espèces qui occasionnent différentes maladies, en particulier le mildiou de la Vigne (Fig. 21), font partic de cet ordre.

$3^{\circ}$ Les Basidiomycéles comprennent des espéces de grandes dimensions généralement à chapeau. L'Agaric chumpítre et l'Oronge en sont des types classiques; chez ces deux Champi-

1. L'œuf est le résultat de l'union de deux éléments, l'un mile, l'autre femelle, dont la fusion constitue la fécondation. 
gnons, la face inférieure du chapeau est garnie de lames ou feuillets rayonnants; ces lames portent des cellules de forme spéciale nommées basides sur lesquelles se développent les corps reproducteurs ou spores (Fig. 22).

On rattache aux Basidionycètesles Urédinées, qui forment des

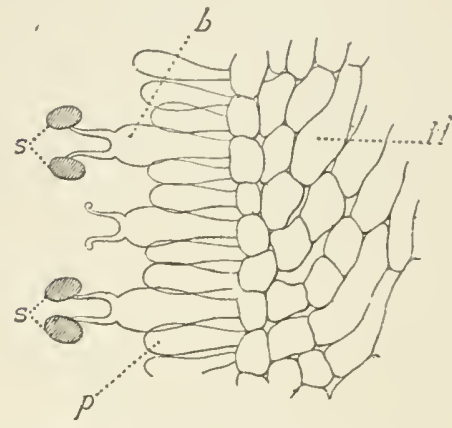

Coupe dans une lame du chapeau d'un Champignon de couclue: 11 , tissu formant la lame; $b$, basides; $s$, spores; $p$, cellule slérile.

Fig. '2.

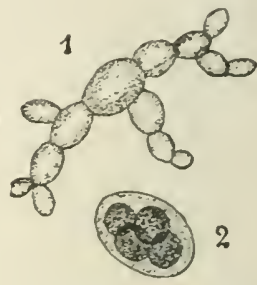

Levure de bière: 1 , mycélium : '2, asque.

Fig. '23.

taches de rouille sur les plantes qu'elles infestent, et les Ustilaginées qui causent le charbon des végétaux.

$4^{\circ}$ Les Ascomycètes, dont les spores se forment dans de grandes cellules appelées asques. La Levure de bière (Fig. 23), l'Ergot (que l'on rencontre sur le Seigle, le Diss, etc.), la Truffe, sont les types des trois principales familles de cet ordre.

Parasites et Saprophytes. - Dépourvus de la matière verte qui permet aux autres régétaux de tirer de l'air une partie de leur nourriture (voir Chapitre V'), les Champignons doivent vivre aux dépens d'êtres vivants, on les appelle alors parasites, ou se nourrir de matières animales ou végétales en décomposition ; ces derniers, dits saprophytes. peuvent ètre utiles à la forèt en accélérant la décomposition de l'lumus.

Les Champignons parasites causent des maladies à l'homme, aux animaux et surtont aux plantes. Certains présentent dans leur vie des phases absolument différentes : ainsi une des es- 
pèces qui causent la rouille du Blé effectue une partie de son évolution sur l'Épine-vinette.

Les Champignons peuvent être des parasites superficicls ne pénétrant leur hôte que localement, à l'aide de suçoirs, ou bien s’établir complètement à l'intérieur des tissus.

Il est à remarquer que certains parasites peuvent devenir saprophytes et réciproquement; il n'y a donc pas de limite bien tranchée entre les deux catégories.

Maladies causées par les Champignons. - Nous citerons seulement parmi les maladies causées aux plantes agricoles ou forestières par les Champignons : le inildiou et l'oïdium de la Vigne, le charbon des céréales, l'ergot, les rouilles des arbres et des céréales.

Les Champignons s'attaquent également au bois : ce sont ceux qui provoquent les chancres et les pourritures du tronc des arbres.

Les pourritures sont la conséquence de la pénétration du

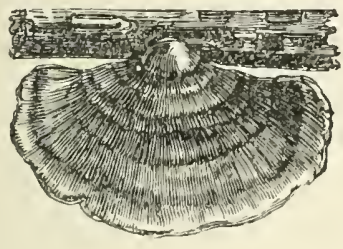

Chapeau de Polypore vu par-dessus.

Fig. '24.

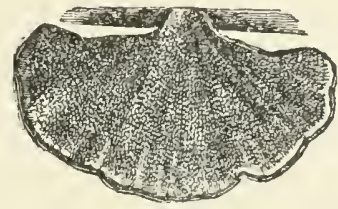

Chapeau de Polypore vu par-dessous.

Fig. 25.

mycélium dans les tissus ; souvent rien ne les révèle au delıors jusqu'au moment où les fructifications apparaissent à l'extérieur; on dit alors que l'arbre porte des épaulettes, par allusion à la forme des chapeaux de Polypores accolés à l'écorce.

Suivant la couleur que prend le bois, la pourriture est dite blanche, rouge, noire, et même verte ou bleue; la pourriture dite blanche peut prendre une teinte jaune, et donne quelquelois au bois un aspect nacré.

Certains Cryptogames s'attaquent aux racines ; d'autres, redoutables dans les pépinières, infestent les jeunes plants. Il en est qui se propageant dans le bois mis en auvre, com- 
promettent la durée des charpentes et occasionnent ainsi des accidents.

On observe fréquemment sur les racines des arbres de nombreux filaments de mycélium; cette association intime de Champignons avec les racines des végétaux supérieurs s'appelle mycorhize: nous y reviendrons.

C'est encore un Champignon qui rend parfois lumineux à l'obscuritẻ un bois en décomposition.

Les Champignons s'attaquent moins fréquemment aux animaux qu'aux plantes; cependant les épidémies provoquées par certains d'entre eux peuvent arrêter les invasions d'insectes.

Les Champignons déterminent chez l'homme diverses affections, entre autres celles connues sous le nom de teignes et le muguet des enfants; on les observe dans certaines tumeurs.

Champignons comestibles. - Il existe des Champignons comestibles, mais il importe d'être prudent et de ne manger que ceux que l'on connaît bien, si l'on veut éviter des accidents souvent mortels. Il est impossible de donner des règles générales basées sur l'odeur, la saveur et la couleur qui permettent de distinguer les Champignons comestibles de ceux qui sont vénéneux. Le fait qu'il noircit les objets en argent ou qu'il les laisse intacts n'indique pas, comme on le croit trop souvent, qu'un Champignon est dangereuxou qu'il ne l'est pas. Les Insectes et les Limaces sattaquent fort bien aux espèces dangereuses pour l'homme : leur absence ou leur présence n'est donc pas un signe à utiliser.

Deux espèces croissant à peu de distance peuvent être l'une comestible, l'autre très vénéneuse; le seul moỹen de savoir si un Champignon est dangereux consiste à utiliser les caractères botaniques.

Les Champignons que l'on mange ou que l'on peut être tentẻ de manger sont des Ascomycètes ou des Basidionycètes.

Parmi les Ascomycètes, l'ERgot déjà citéest fort dangereux. mais on ne l'ingère d'habitude que tout à fait involontairement, quand il est broyé avec le grain et se tronve ainsi mêlé à la farine. La Moknles (Fig. 26) a causé des accidents en Allemagne parce qu'elle était mangée crue aussitòt la récolte: il n'y a aucun danger à la consommer cuite, ou mème crue si elle est séchéc. 
Les Basidiomycètes peuvent, au point de vue qui nous occupe, être divisés en Basidiomycètes à chapeau et Basidiomycètes à

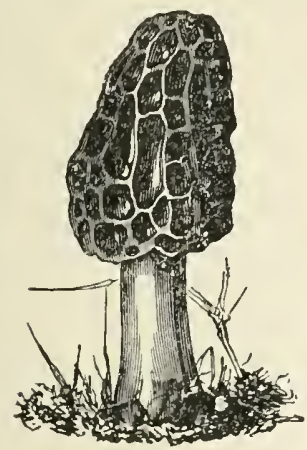

Morille.

Fig. 26.

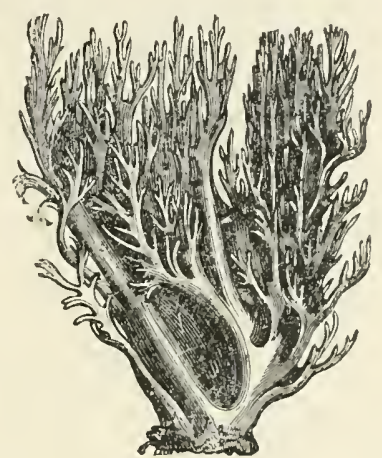

Clavaire.

Fig. 27.

forme irrégulière, sans chapeau. A ce dernier groupe appartiennent les Claavaires (Fig. 27) (vulgairement Chou-fleur) dont aucune espèce n'est vénéneuse.

Chez les espèces à chapeaux, l'appareil qui porte les spores se trouve toujours à la face inférieure du chapeau, mais présente un aspect variable. Tantôt on constate la présence de petits tubes serrés fort nombreux (Polypores, voir Fig. 25), tantôt ce sont des sortes de poils hérissés (Hydnes, Fig. 28), tantôt des lamelles rayonnantes (Agarics).

Au type Polypore appartiennent les Bolets (Fig. 29 et 30), parni lesquels on peut citer le

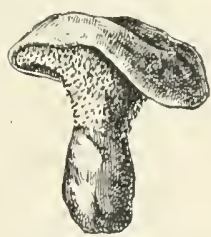

Hyane

Fig. 28. Cère (Fig. 29), le Bolet ghanuli, le Bolet amem (Fig. 30). On recommande généralement de s'abstenir des Bolets qui bleuissent lorsqu'on les coupe ; nais il ne semble pas que les espèces algériennes soient susceptibles de causer des empoisonnements; les Hydnes sont également comestibles.

C'est parmi les Champignons ì lamelles rayonnantes que se trouvent les espéces dangerenses, localisées d'ailleurs dans les genres Amanite et Volvaire. Lorsqu'on récolte un Cliampignon à chapeau garni à la face inférieure de lamelles rayonnantes 
il importe de dégager soigneusement le pied et de vérifier s'il est entouré d'une sorte de bourse ou volve : dans ce cas,

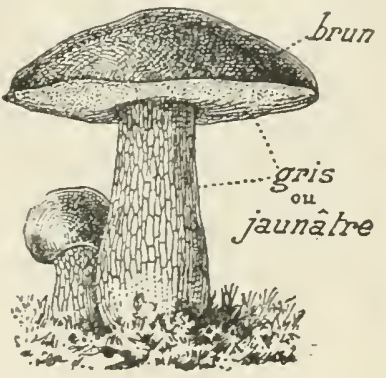

Bolet comestible ou cêpe.

Fig. 29.

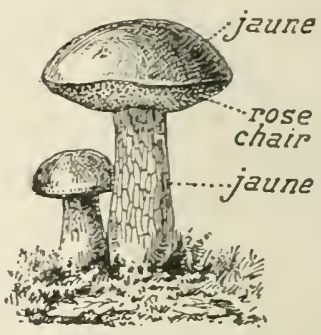

Bolet amer (réputé vénéneux).

Fig. 30 .

on est en présence de l'un des deux genres dangereux ${ }^{1}$. II existe, il est vrai, des Amanites comestibles tels que : l'Oroxge

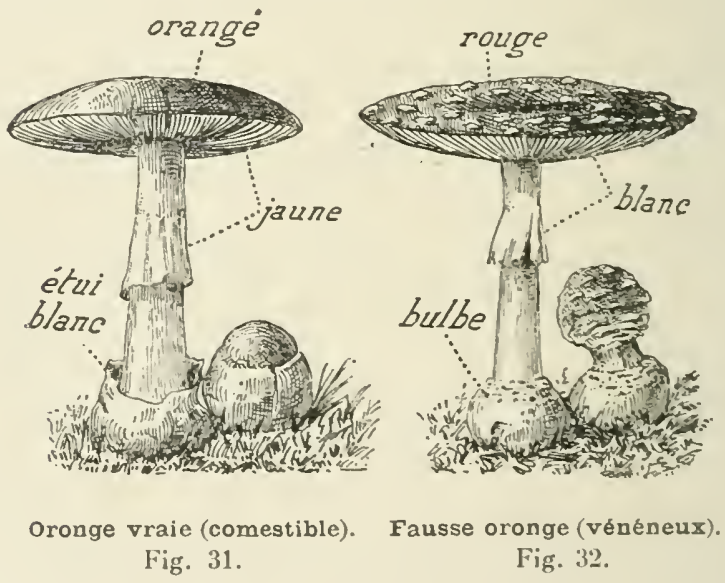

1. Cette volve, qui chez le Clampignon bien diveloppé ne forme plus qu'un élui au pied, provient d'une membrane qui entoure complitement le Champignon quand il est jeune et qui se déchire ensuite. 11 arrive que la volve, éclatunt de bonne heure, ne laisse comme traces que des écailles, ou pustules, sur le chapeau ou à la base du pied, ou mème un simple rebord sur cette dernière. Il ne laut pas confondre ce rebord avec l'anneau qui se trouve sur le haut ou vers le milieu du pied chez. l'Agaric champètre, la graude Lépiote, etc., conme chez les Amanites. 
vraie (Fig. 31), l'Auanite ovoïde, l'Amanite a étur, l'A manite RoUgeatre; mais si on ne les connaît pas bien, mieux vaut s'abstenir de les récolter, car une espèce voisine, la FAusse Oronge (fig. 32) est vénéneuse ; l'Amanite phalloïde (fig. 33) est aussi une espèce extrèmement vénéneuse et cause la plupart des em poisonnements signalés en Algérie.

Comme Champiguons à chapeau garni de feuillets, couram-

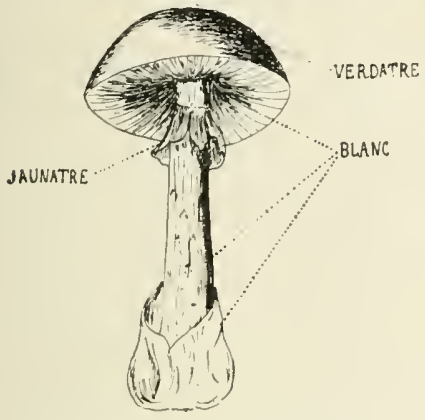

Amanite phalloïde (vénéneux).

Fig. 33.

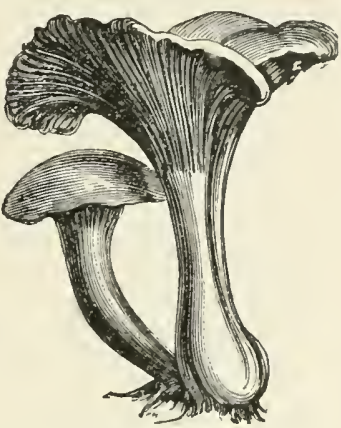

Chanterelle ou Gyrole (comestible).

Fig. 34.

ment consommés dans la colonie, on peut citer : l'AGaric Chanpètre (dit Champignon de couche), l'Oronge rraie, la Chanterelle ou Gyrole (Fig. 34), l'Armillatre chaussée (ou Champiguon de Cèdre), le Lactaire sangun, le Pleurote de la Férule, la Grande Lépiote et quelques Tricholones.

Classe des Algues. - Les Algues vivent surtout dans l'eau, douce ou salée, mais on en trouve aussi dans l'air humide, sur les rochers et sur les écorees des arbres.

Les matières verdâtres ou fleur d'eau qui couvrent souvent en abondance la surface des mares sont formées d'Algues; il en est de même des enduits noirâtres et visqueux qui recouvrent les parois humides.

Les Fucus ou Varechs, les Ulves (Fig. 35), sont des Algues marines bien connues.

Les plantes de cette classe sont quelquefois composées d'une simple vésicule. souvent de filaments ou de lanières dapparences très variées. 
A la matière verte ou chlorophylle qu'elles renferment, peut se joindre une autre matiere colorante ou pigment qui modifie leur aspect. On les a subdivisées en quatre ordres :

$1^{\circ}$ Les Algues bleues ou Cyanoplyycées que l'on rencontre fréquemment dans les eaux des sources chaudes;

$2^{\circ}$ Les Algues verles ou Chlorophycées, abondantes à la surface des caux ;

$3^{\circ}$ Les Algues ronges ou Rhodophycées existent dans la mer, souvent à une certaine profondeur:

$4^{\circ}$ Les Algues brunes ou Phéophycées se trouvent fréquem-

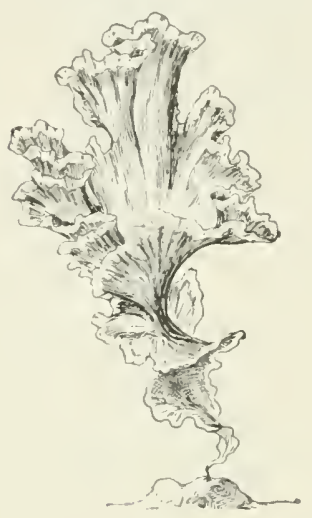

Ulve.

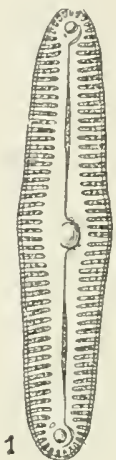

Diatomé : 1 , vue de face: 2 , vue de profil.

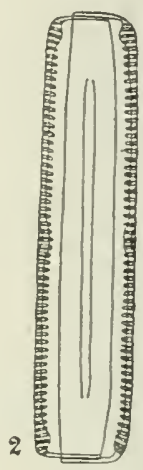

Fig. 36 à 37 .

Fig. 35.

ment à une profondeur intermédiaire, entre les Aígues vertes et les Algues rouges.

Les Algues brunes comprennent les Diatomées, êtres micros. copiques incrustés de silice ${ }^{1}$ et dont les carapaces en s'accumulant au fond de l'eau ont constitué les dépòts de tripoli.

C'est aux Algues bleues que l'on rattache les Bactéries (plus exactement Bactériacées) qui cependant ne contiennent pas de chlorophylle.

Bactéries. - Ces ètres infimes, généralement désignés sous le nom un peu vague de microbes, présentent des formes très

1. La silice est un corps très répandu dans la nature qui conslilue le sable, le grrès, la pierre meulière, le silex, ete. 
variables : tantôt ils sont globuleux ; tantôt en forme de bâtonnets, droits, courbes ou enroulés; ils peuvent être isolés ou réunis par groupes.

Répandus partout dans l'univers, aussi bien dans l'air et dans les eaux qu'à la surface de la terre et de tous les objets qui nous entourent, ils sont redoutables par les maladies infec-

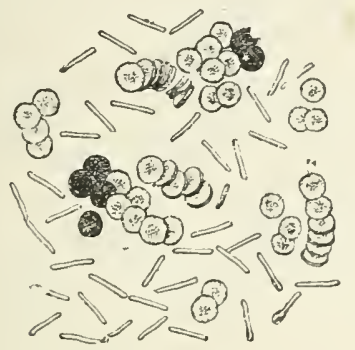

Bactériacée qui cause la maladie du charbon (Bacilledu charbon) au milieu des globules du sang.

Fig. 38.

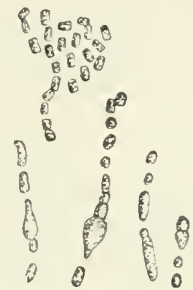

Binctériacée qui produit la fermentalion du vin en vinaigre (Mlıcrocoque du vinaigre).

Fig. 39.

tieuses (Fig. 38) qu'ils engendrent chez l'homme et chez les animaux, quelquefois chezles plantes. Mais tous ne sont pas nuisibles; il en est d'indifférents, et aussi beaucoup d'utiles (Fig. 39).

Un gramme de terre humide peut, d'après M. Kayser, con-

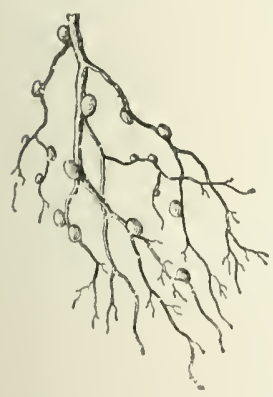

Racine de Pois portant de nombreuses nodosités.

Fig. 40. tenir de 1 à 50 millions de germes. Ce sont ces êtres infiniment petits qui désagrègent les débris animaux et végétaux, qui jonchent le sol de la forêt, et les transformenten aliments susceptibles d'être directement absorbés par les végétaux supéricurs.

Enfin il existe dans les nodosités (Fig. 40) qui courrent les racines des plantes de la famille des Légu- IBactéroimineuses des microbes que l'on a des désignés sous le nom de Bacléroïdes nodosité. (Fig.41); ce sont des Bactériacées Fig. 41. 
en forme de bâtonnets, $\mathrm{U}$ ou $\mathrm{Y}$, qui activent la végétation de leurs hôtes en fixant l'azote ${ }^{1}$ de l'air, comme de leur côté les Légumineuses subviennent en partie à l'alimentation de ces Bactéroïdes; l'association est utile à chacun; cette vie commune s'appelle symbiose.

Le ròle des microbes est si varié que l'on peut conclure que toute vie est impossible à la surface de la terre sans leur intervention.

Lichens. - Nous ne pourons, en terminant l'étude de ce premier embranchement, passer sous silence les associations

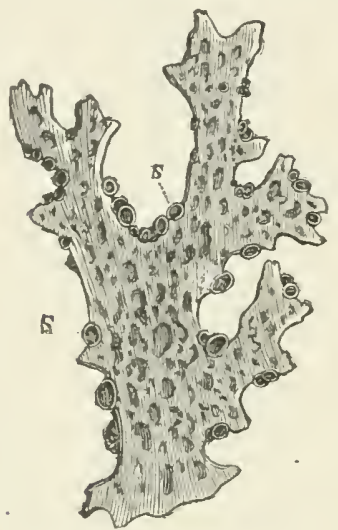

Lichen foliacé (Sticta pulmonacea).

Fig. 4‥

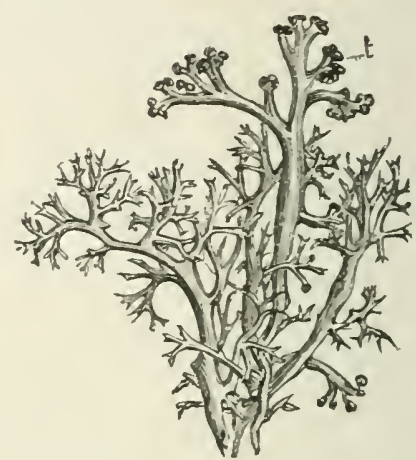

Lichen fruticuleux (Cladonia rangiferina ou Lichen des Rennes).

Fig. 43 .

singulières formées d'une Algue verte et d'un Champiguon auxquelles on a donné le nom de Lichens.

Très communs en lorèt, on les trouve fixés sur l'écoree des arbres ou aux rochers, tantòt verts, tantôt gris ou jaunes. On les rencontre encoredans les régions très sèches et sur les sommets dénudés des hautes montagnes Ils sont dits foliacés (Fig. 42) lorsqu'ils ressemblent à une lame plus ou moins régulière, aplatic et ridée; cruslacés s'ils ont l'aspect d'une croùte ; fruticuleux (Fig. 43) s'ils présentent des ramifications

1. On sait que les deux principaux éléments de l'air sont l'oxygène el l'azole. 
buissonnantes. Les formes chevelues qu'affectent les Lichens fruticuleux donnent un aspect caractéristique aux arbres dont ils couvrent les branches. D'autres, mous et transparents, sont dits gélatineux.

Les Lichens jouent un grand rôle dans la formation de la terre végétale. Ils ont, en effet, le pouvoir de se développer sur les surfaces les plus dénudées et d'y constituer par la décomposition de la roche et celle de leurs propres débris un commencement de sol végétal où les mousses et d'autres végétaux peuvent s'installer par la suite. Une grande abondance de Lichens fruticuleux peut devenir nuisible aux arbres en entretenant sur l'écorce une humidité prolongée; mais ce phénomène est généralementl'indice, et non la cause, d'une végétation médiocre, résultat de conditions peu favorables.

Les Lichens peuvent être employés pour l'alimentation; non seulement les Rennes vont les chercher sous la neige, dans les régions polaires, mais les peuples du Nord les récoltent pour s'en nourrir; ils en font des pâtes alimentaires, des bouillies ou des gelées préparées avec du lait, après avoir fait disparaître le principe amer de ces plantes par macération dans l'eau. En Suède, on en extrait de l'alcool.

La fameuse manne des Hébreux était peut-être le Lichen de Pallas que l'on a vu transporté dans les airs par les vents qui le détachent des montagnes.

Dans nos régions, on a préconisé le mélange de certains Lichens avec le fourrage des animaux. Le Lichen d'Islande, pauvre en principe amer, est employé en pâtisserie pour la préparation de crèmes sans ơufs ; il est aussi utilisé en médecine (pâte de Lichen).

Les propriétés tinctoriales des Lichens sont nombreuses ; on en extrait l'orseille et le tournesol. Leur mucilage ${ }^{1}$ peut remplacer, dit-on, la gonme arabique et la colle forte.

EMBRANGHEMENT DES MUSGINEES.- Il comprend les Mousses et les Hépatiques.

Classes des Mousses. - Les Mousses vivent en touffes sur le sol, sur les rochers et sur l'écorce des arbres. Elles

1. On appelle ainsi les substances visqueuses qui existent che\% beaucoup de végélaux. 
abondent en forêt, et en général dans les endroits humides : on en trouve même dans l'eau des ruisseaux et des mares; elles croissent aussi quelquefois dans les endroits secs.

Elles se composent de petites tiges feuillées. souvent grêles, plus ou moins ramifiées, non munies de racines, mais portant des filaments dits rhizoïdes qui s'enfoncent dans le sol (Fig. 44). On constate souvent sur les Mousses la présence de petites masses renflées portées chacune à l'extrémité d'une petite tige sans feuilles; cette sorte d'urne, appelée sporo-

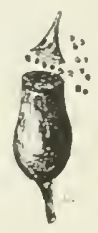

Sporogones'ouvrant pour mettre les spores en liberlé.

Fig. 45.

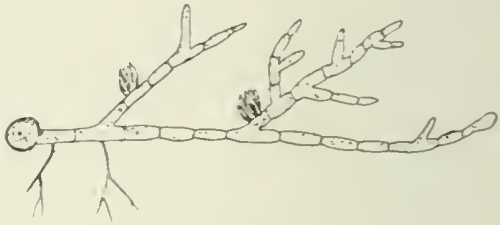

Spore germant pour former un protonema sur lequel on distingue deux jeunes pousses de tiges feuillées.

Fig. 46.

gone ${ }^{1}$, contient de petits corpuscules ou spores qui se disséminent bientòt (Fig. 45). En germant, chacune d'elles donne naissance à un filament vert qui se ramifie, c'est le prolonema: il se produit á la surface de ses rameaux de petits tubercules qui se développent par la suite pour donner de nouvelles Mousses (Fig. 46).

Les Mousses contribuent à la formation d'une garniture spongieuse sur le sol des forêts ; elles favorisent ainsil'inliltration de l'eau et s'opposent à son ruissellement.

Certaines Mousses sont employées comme engrais.

Classe des Hépatiques. - Ces petites plantes (Fig. $4 \overline{\text { }}$ ) sont vertes comme les. Mousses et présentent le mème mode de

1. Les Nousses présentent des éléments miles et femelles; l'auf qui résulte de leur union se développe et produit un sporogone. 
développement; elles peuvent en avoir l'aspect, mais avec les feuilles insérées obliquement sur la tige, ou bien encore être réduites à un simple thalle dont l'apparence les rapproche des Thallophytes étudiés précédemment.

\section{EM B R A N G EM ENT DES} GRYPTOGAMES VASGULAIRES. - Cet embranchement comprend trois classes: les Fougères. les Prêles et les Lycopodes. Nous étudierons plus spécialement les Fougères et les Prèles. Ces plantes se trouvent surtout dans les endroits humides.

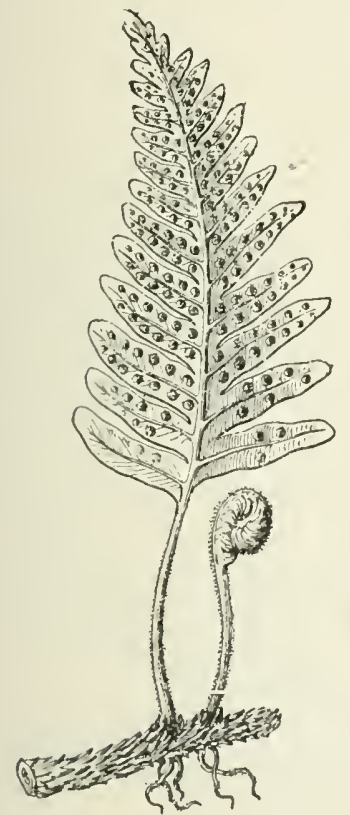

Fougère (Polypode) montrant le rhizome, les racines et les fuilles qui portent en dessous des groupes de sporanges ou sores.

Fig. 48.

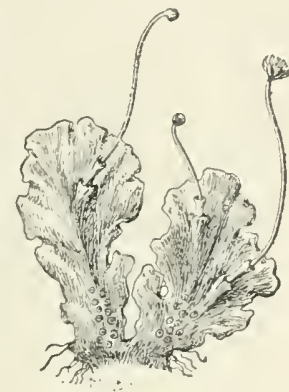

Thalle d'Hépatique montrant vers le haul le sporogone el vers le bas les rhizoïdes.

Fig. 47.

\section{- Les diverses}

espèces qui habitent nos forèts ont une tige souterraine horizontale, c'est ce qu'on appelle un rhizome; cette tige couchée porte des racines et des feuilles; ces dernières, souvent très découpées, sont enroulées en crosse dans leur jeunesse. Leur face inférieure porte les organes de reproduction (Fig. 48): tout le monde a observé ces petites taches jaunes on brunes, granuleuses, tantòt rondes,

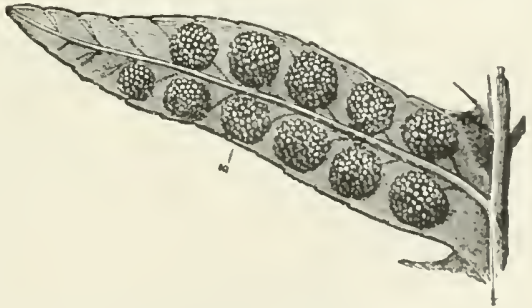

Lobe des feuilles vir par dessous; s un des sores.

lïig. 49. 
tantòt allongées, que l'on appelle sores (Fig. 49). Ce sont des groupes de minuscules petits sacs ou sporanges qui renfer-

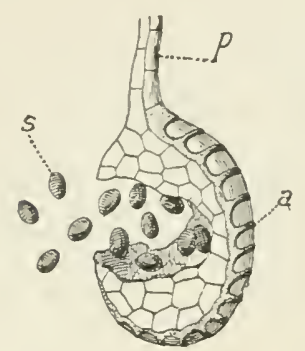

Sporange vu au microscope; $p$, pied du sporange; $s$, spore; $\alpha$, anneau qui provoque l'ouverture de sporange.

Fig. 50.

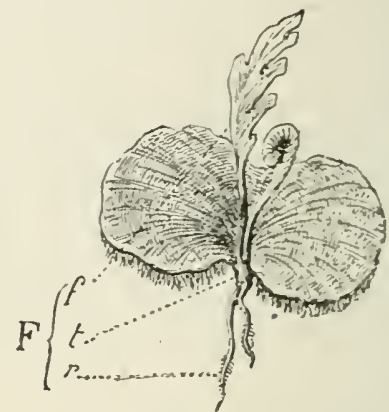

Prothalle sur lequel s'est développée une jeune Fougère $\mathrm{F}$; $t$, lige ; $f$, feuille ; $r$, racine de la jeune Fougère.

Fig. 51.

ment des spores. Les sores sont sourent protégés par une membrane qui les recouvre plus ou moins complètement.

Les spores, mises en liberté par l'ouverture des sporanges (Fig. 50), se disséminent: chacune d'elles donne naissance à une lame verte appeléc prothalle (Fig. 51), sur laquelle se développent des éléments mâles et des éléments fenelles; de leur union résulte un ouf qui en germant reproduit la Fougère feuillẻe.

Il existe en Algérie une quinzaine de genres de Fougères:

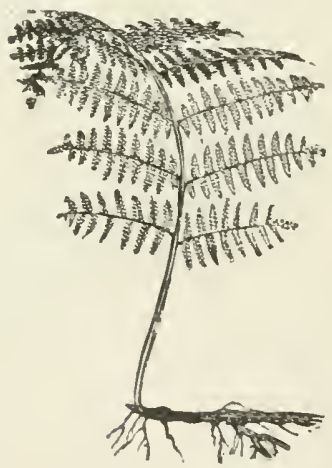

Fougère aigle.

Fig. 52.

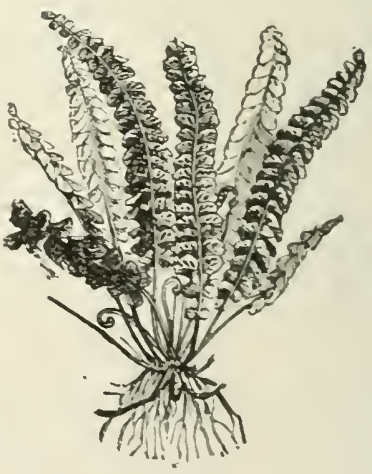

Capillaìre.

Fig. 53. 
La Forgère aigle (Pteris aquilina, Fig. 52) prend un grand développement dans les forêts du littoral de l'Algérie.

L'espèce bien connne en France sous le nom de Fougìre MALE 1 n'existe pas en Algérie ; mais une espèce voisine (Polystichum aculeatum) est commune dans les montagnes du littoral.

La Fovgėre fenelde (Athyrium Filix-femina) se rencontre dans les montagnes de l'Est et en Kabylie. Quelques autres espèces sont très répandues. Exemples : Asplesilum Trichomanes, Adiantum Capillus-Veneris Capillaire, Fig. 53).

Classe des Prêles. - Ces plantes (Fig. 54) présentent

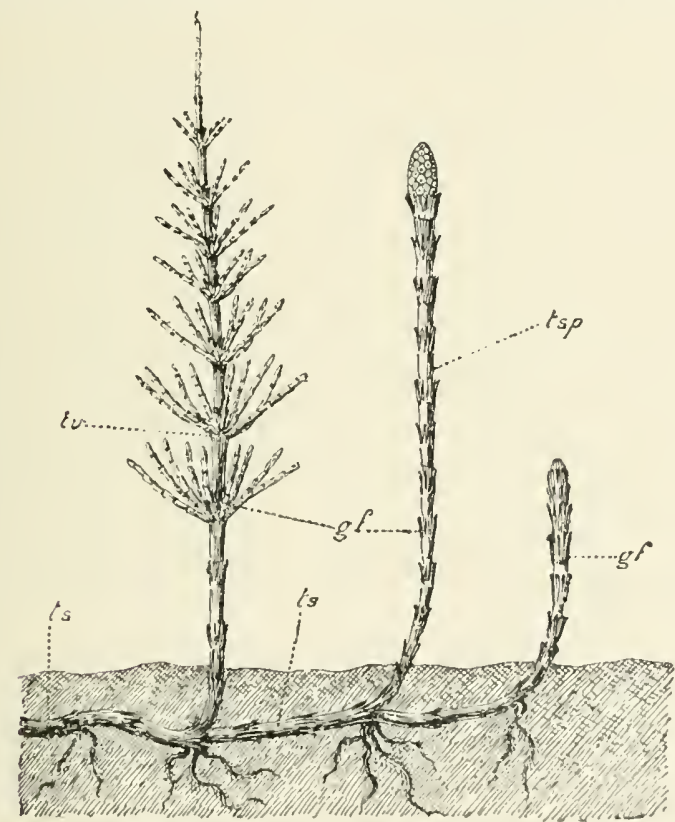

Prêle : $t s$, tiges souterrainc's; $l v$, tiges végétatives portant des rameaux en verticilles; $t$ sp, liges fruclities terminées par une masse de sporanges; $g f$, collerettes de feuilles.

Fig. 54 .

1. La Fougère mâle et la Fougire femelle sont denx especes absolument distinctes, et il ne faudrait pascroire que la première est uneplante màle et la deuxieme une plante fomclle; chacune de ces deux plantes produit des éléments mâles et femelles destincis ì perpituer l'espicice. 
également des rhizomes, ou tiges souterraines, qui émettent de distance en distance des tiges aériennes creuses, striées et portant des nœuds. Ces tiges sont munies de petites feuilles très réduites qui forment des collerettes au-dessus de chaque noud.

Les rameaux prennent naissance au-dessous des collerettes et sont disposés en verticille, c'est-à-dire qu un certain nombre d'entre eux sont attachés à la mème hauteur tout autour de la tige.

Les sporanges, au lieu d'ètre groupés sous les feuilles comme chez les Fougères, sont placés sous les écailles d'une sorte d'épi qui est porté à l'extrémité de tiges souvent dilférentes des autres.

Cette classe ne comprend que le genre Prèle vulgairement appelé queue de cheval. La Prèle élevée (Equisetum maximum) est commune au bord des ruisseaux.

Nous ne saurinnsterminer ce chapitre sans rappeler que les Prèles et les Fougères étaient autrefois extrèmenınt répandues et présentaient des dimensions considérables. On retrouve leurs empreinles dans la houille qu'elles ont contribué à forner. Il existe encore actuellement, dans les régions chaudes, des Fougères qui atteignent un grand développement : mais en France et en Algérie nous ne possédons parmi les Cryptogames aucune espèce arborescente. Les Phanérogames constituent seules les arbres de nos forèts.

\section{CHAPITRE III}

\section{LES PLANTES A FLEURS OU PHANÉROGAMES RACINE - TIGE - FEUILLE}

Les Plıanérogames ont, comme les Cryptogames vasculaires, une racine, une tige et des feuilles, mais elles ont en plus des lleurs.

LA RAGINE. - La racine est généralement enfoncée dans le sol. Elle se prolonge à sa partie supérieure par la tige, dont elle est séparée par une région appelée collet. Lallonge- 
ment de la racine s'effectue dans une zone voisine de la pointe. En examinant une jeune racine (Fig. 55), qui s'est développée dans du terreau par exemple, on constate que son extrémité est couverte d'une sorte de capuchon ou coiffe, d'ordinaire de couleur foncée. Un peu plus haut, on voit un duvet formé de poils dits poils radicaux ou absorbants, parce qu'ils ont l'im-

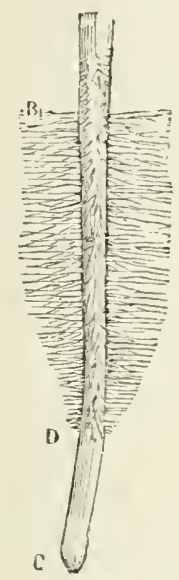

Exxrémilé d'une jeune racine; $\mathrm{C}$, coilte: $\mathrm{BD}$, région pilifère.

Fig. 55.

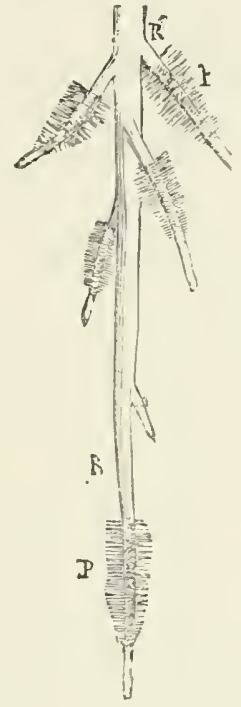

Racine principale $\mathrm{R}$ et radicelles telles que $R^{\prime} C^{\prime}$; P, P', poils absorbants.

Iig. 56 .

portante mission de puiser dans le sol la nourriture de la plante.

La racine peut rester simple ou se couvrir de racines secondaircs ou radicelles (Fig. 56) qui présentent le mème aspect que les racines principales. Ces ranifications sont susceptibles de porter à leur tour des racines tertiaires, etc.

La racine principale ou pivot s'enfonce verticalement dans le sol, mais elle peut disparaitte avec l'àge, laissant la place aux radicelles qui pénètrent bientòt le sol dans toutes les dircetions.

En pratique, on distingue les espèces qui ont un enracine- 
ment profond ou pivolant et celles dont les racines sont tracantes, c'est-à-dire superficielles.

L'ensemble des jeunes racines couvertes de poils radicaux constitue le chevelu. Les jeunes arbres que l'on transplante doivent présenter un chevelu abondant '.

LA TIGE. - La tige s'élève généralement au-dessus du

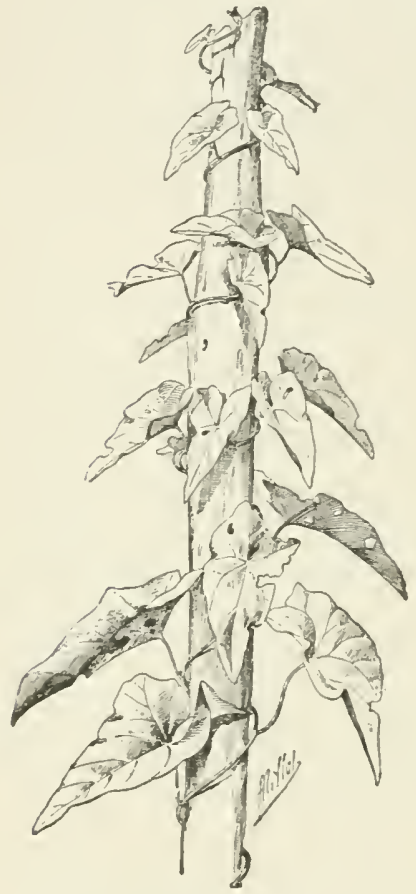

Tige volubile du Liseron des hajes.

Fig. 57 .

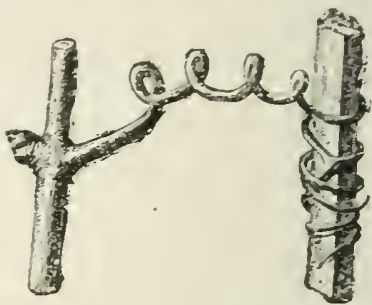

Tige grimpant à l'aide de vrilles qui s'enroulent autour des supports roisins (Vigne.)

Fig. 38.

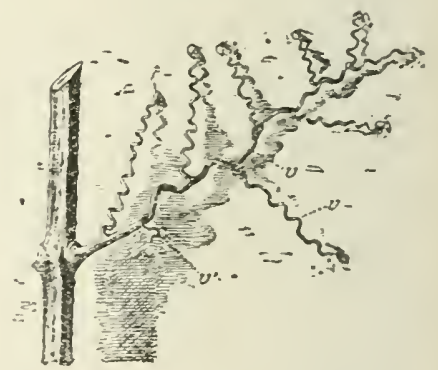

Tige grimpant à l'aide de vrilles $v \cdot v^{\prime}$. doul les extrémilés se fixenl sur le support (mur) par des ampoules adhèsives (Vigne vierge.)

Fig. 59.

sol en sens inverse de la racine, mais elle peut ètre rampante ; il existe même des tiges horizontales et souterraines que nous avons désignées sous le nom de rhizomes en décrivant les Fougères (voir fig. 52). D'autres tiges, dites grimpantes, ne s'élèrent

1. La structure de la racine prisente de grandes analogies avec celle de la tige dont nous allons donner un aperçu; cest pourquoi nous l'avons passée sous silence dans cet exposé nécessairement lrès incomplet. 
qu'en s'appuyant sur un support; enfin les tiges volubiles ont la propriété de s'enrouler autour des corps environnants. (Exemples divers de tiges grimpantes : Fig. 57 à 59.)

On divise les tiges d'après leur consistance en tiges ligneuses et herbacées. Les premières ont la dureté du bois et persistent plusieurs années, quelıuefois plusieurs siècles.

Les dernières, vertes et relativement tendres, meurent tous les ans, sauf cependant dans les régions tropicales où elles peuvent subsister plusieurs années.

Lorsıu'une tige, ou l'extrémité d'une tige, passc de l'état herbacé à l'état ligneux, on dit qu'elle s'aon̂le.

Les plantes ligneuses (c'est-à-dire celles dont la tige est ligneuse) intéressent surtout le forestier ; on les divise en plusieurs catégories :

L'arbre est une plante ligneuse à tige unique et dépourvue de branches vers le bas, atteignant au moins 7 mètres de hauteur.

On nomme arbustes des plantes ligneuses également à tige unique, mais de moindre hauteur; si la tige se ramifie dès la base, c'est un arbrissean.

On appelle souvent sons-arbrisseanx les végétaux ligneux dont la hauteur ne dépasse pas 1 mètre. Nous préférons réserver ce terme pour désigner les plantes sous-ligneuses ou sonsfrutescentes, c'est-à-dire ligneuses seulement dans la partie voisine du sol. Dans ce cas, les rameaux qui portent les fleurs meurent chaque année après la maturation des fruits, et il ne subsiste pendant la mauvaise saison qu'une courte tige appeléc à développer de nouvelles pousses l'annéc suivante.

En Sylviculture, on distingue dans l'arbre : le fül, partic de la tige verticale non ramifiée, et la cime ou houppier, constitué par les ramifications qui surmontent le fût Ce dernier peut done, suivant les sujets, se prolonger jusqu'au sommet de l'arbre ou cesser au contraire beaucoup plus bas.

Le mot trone est un terme de technologie qui s'applique à la partic de la tige susceptible de donner du bois d'ouvre.

Bourgeons. - La tige porte à son extrémité supérieure un bourgeon terminal $\mathrm{Fig}$. $60, \mathrm{~B})$, composé de jeunes feuilles très rapprochées (Fig. 61) et souvent abritées sous des écailles. 
A mesure que l'extrémité de la tige s'allonge, ces feuilles s étalent et s'espacent.

Outre cet accroissement qui se produit dans le bourgeon terminal, la tige a la propriété d'augmenter de longueur dans la

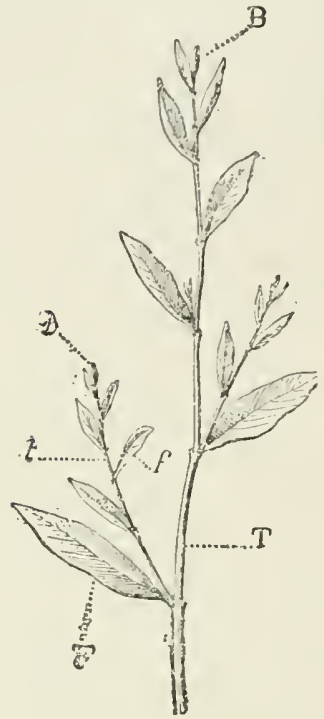

Tige principale $\mathrm{T}$ portant des leuilles $\mathrm{F}$ et lerminée en $\mathrm{B}$ par le bourgeon terminal; $l$ tige seeondaire ou branche portant des feuilles $f$ et terminée par un bourgeon $b$.

Fig. 60 .

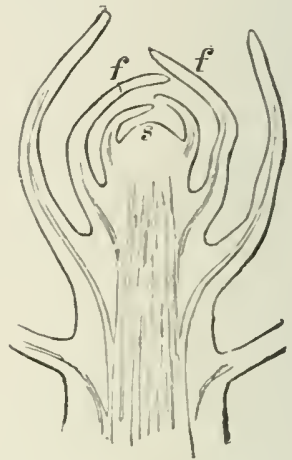

Coupe dans le bourgeon terminal: $s$, sommet de lis lige; $f$, jeunce feuilles.

Fig. 61.

partie jeune située an-dessous du bourgeon terminal ; les parties plus àgées n'ont pas cette faculté.

Il existe également des bourgeons latéraux, c'est-à-dire placés le long des rameaux. Ils se trouvent d'ordinaire à l'aisselle des feuilles; on les appelle alors bourgeons arillaires. Ils sont constitués conme le bourgeon terminal et donuent naissance à des branches ${ }^{1}$ (Fig. 60 et 62 ).

1. Outre les bourgeons ì fenilles dits aussi bonrgeons a bois, il en est qui ne donnent que des fleurs, on les appelle bonlons ; ils sont d'ordinaire plus rentles que les précédents. Enfin il existe des bonrgeons mixles qui produisent d'abord des feuilles, puis des fleurs. 
Celles qui acquièrent le plus de développement s'appellent branches principales. Ces dernières peuvent à

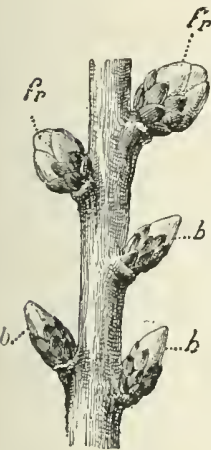

Bourgeons axillaires d'une branche de loirier; $b$, bourgeons produisan I de longues pousses portan l seulement des feuilles (bourgeons à bois); $f r$, bourgeons donnant des pousses courles avec feuilles el fleurs (bourgeous à fruils.)

$$
\begin{array}{r}
\text { Fig. 62. } \quad \text { c o } \mathrm{u}- \\
\quad \mathrm{r} \text { a } \mathrm{m}-
\end{array}
$$

ment la tige des plantes ligneuses conme formée de bois et l'écorce. Cependant si l'on arrache un morceau sur le trone d'un arbre, on constate qu'une couche, souvent mince, de nature spéciale et se détachant d'ordinaire en lanière, existe entre l'écorce proprement dite et le bois, c'est le liber.

Si l'arbre examiné est

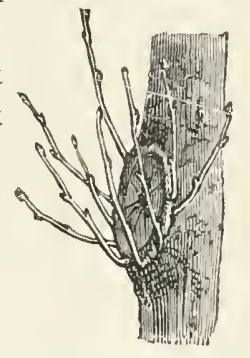

Rameaux nés de bourgeons advenlifs cléveloppés aulour d'une cicatrice.

Fig. 63. en un point quelconque d'une Nous reviendrons sur ces deux catégories

Structure de la tige. - ()n con-

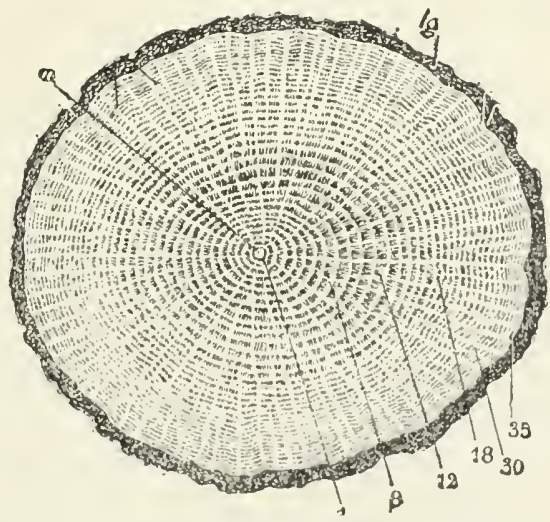

Coupe en travers d'une lige de Chène de 35 ans : 1 à 35 eouches successives; $m$, moelle; $l g$, licgre.

Fig. (6.1 
un Chêne-liège, l'écorce est représentée par le liège et le liber par le tan.

On distingue done sur la section d'une tige ligneuse : le bois au centre, l'écorce à l'extérieur et le liber resserré entre les deux.

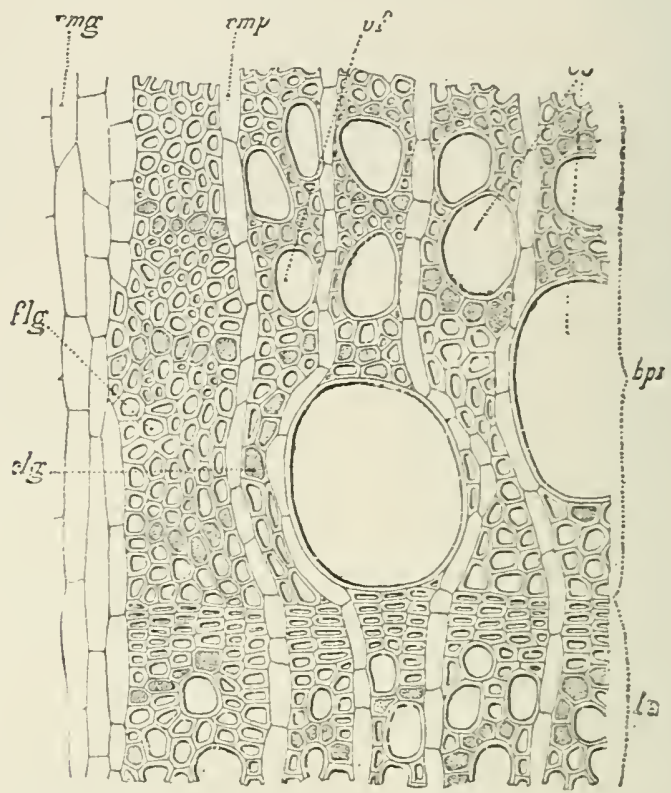

Structure du bois de Chêne en coupe transversale : $v f$, vo, vaisseaux; $f l g$, fibres ligneuses : clg, parencbyme ligneux; $r m g, r m p$, rilyons médullaires; $b p r$, bois de prinlemps; $b a$, bois d'aulomne.

Fig. 6.5.

Le bois apparait en couches concentriques traversées par des stries rayonnantes ou rayons méclullaires (Fig. 6t).

Chaque couche, ou mieux chaque couronne représente l'accroissement d'une année; les dernières formées sont à l'extérieur. On peut done calculer l'âge d'un arbre en comptant sur la souche le nombre de ces couronnes.

Chez beaucoup d'essences, le bois du centre de la tige ou bois de cœul est plus foncé, plus résistant et plus sec que le bois plus jeune qui l'entoure ; ce dernier est appelé anbier.

Contrairement au bois, le liber s'accroit par sa partic in- 
terne ; il comprend de minces feuillets comparables à ceux d'un livre ${ }^{1}$.

Sur le Chène-liège, on peut décompter l'àge de l'écorce, ou

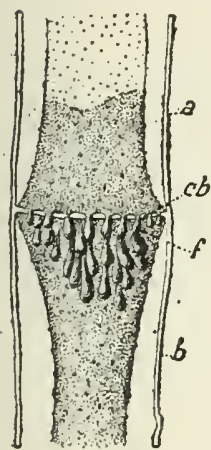

Coupe longiludinale d'un tube criblé: $a, b$, parois; $c b$, erible ; $f$, substance albuminoïde traversant le crible.

Fig. 66. liège, comme celle du bois, à l'aide des accroissements annuels; mais les couches les plus récentes sont à la partie interne.

En étudiant les couches annuelles du bois au microscope, chez un Chène par exemple (Fig. 65), on constate qu'elles sont formées de vaisseaux à parois épaissies, de fibres ligneuses et de $p a-$ renchyme ligneux; c'est ce dernier qui forme à lui seul les rayons médullaires.

La portion intérieure de chaque accroissement, c'està-dire celle qui se forme au printemps, renferme les plus gros canaux; le bois qui se forme ensuite, dit bois dautomne, surtout riche en fibres

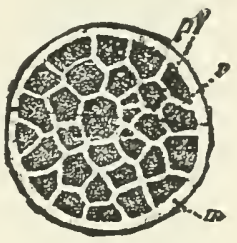
et en parenchyme, est plus

Crible vu de face : $m$, paroi de la cellule; $p f$, perforations séparées par le réscau cellulosique $r$.

Fig. 67.

foncé et offre une texture plus serrée ${ }^{2}$; c'est cette différence entre le bois de printemps et le bois d'automme qui permet de distinguer les limites des accroissements annuels.

Les couches du liber sont formées des mêmes éléments que celles du bois, mais les vaisseaux qu'elles renferment, dits tubes criblés, diffèrent des canaux du bois (Fig. 66 et 67 ).

Quant au liège,il est formé de cellules mortes, aplaties, régu-

1. Le mot latin liber signifie livre.

2. Lëpaisseur des couches annuclles varie beaucoup avec les conditions de végétation. Or il est ì noter que che\% certains bois l'uillus, ehez les Chênes en parliculier, l'épaisseur do liı couche du bois de printemps ne varie pas beancoup avec les circonstances; c'est celle du bois d'automne qui augmente ou duminue suivant que l'accroissement tolal de l'année est plus ou moins considérable. Le bois d’automne étant le plus dur, il en résulte que le hois des Chènes est d'aulant plus dur que la croissance a ćté rapide. Che\% les résineux, éest au conlraire le hois de printenups qui gagne en épaisseur lorsque l'accroissement est rapide. 11 en resulte que plus un arbre de celle catégorie s'accroit rapidement, phus son hois est tendre. 
lièrement disposées ( $l g$, Fig. 68 bis) et remplies d'air. Ce tissu serré est parsemé d'îlots où les cellules sont arrondies et sépa-

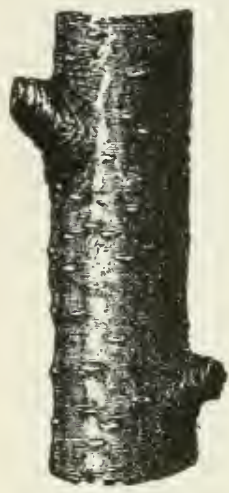

Aspect extérieur des lenticelles.

Fig. 68.

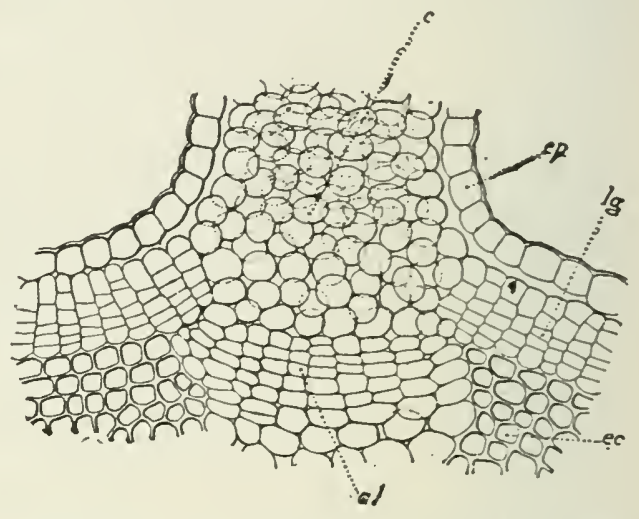

Coupe dans une lenticelle: $c$, cellules arrondies de la lenticelle; $e p$, épiderme; lg, liège ; $e c$, écorce.

Fig. 68 bis.

rées ; ce sont les lenticelles (Fig.68 et 68 bis), dont le ròle est de mettre le corps de la plante en communication avec l'extérieur. Elles se présentent à la vue sous forme de petits canaux remplis d'une poussière brunâtre.

LA FEUILLE. - Les feuilles sont portées par la tige

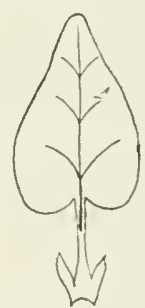
ou par les rameaux; elles comprennent (Fig. 69) une partie d'ordinaire plane et membraneuse appelée limbe, et une queue ou pétiole qui s'élargit en gaine vers son point d'attache sur la tige. Le pétiole peut manquer, la feuille est alors sessile.

Sur le limbe, on distingue des còtes ou nervares plus ou moins apparentes. La nerFigure schèmatique vation, c'est-à-dire la disposition des nervures, de feuille mon- est pennée (Fig. 70) quand le pétiole se protrant le limbe, le la gine longe dans le limbe en une còte prineipale qui porte deux doù se détachent latéralement des nervures slipules.

Fig. 69. secondaires disposées comme les barbes d'une plume.

Elle est palmée (Fig. 71) quand il existe plusieurs fortes 
nervures partant de la base du limbe et disposées comme les doigts de la main.

Quand les nervures restent à la mème distance l'une de

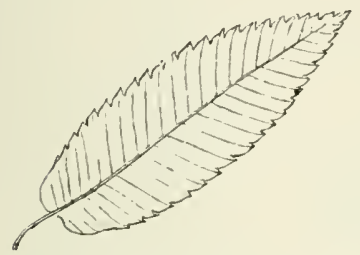

Feuille à nervation pennée el à limbe denlé.

Fig. 70 .

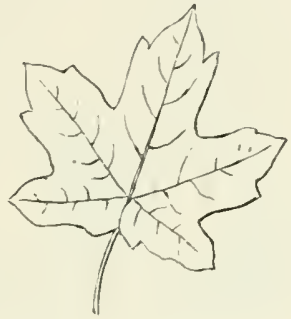

Feuille à nervation palmée et à limbe lobé.

Fig. 71 .

l'autre sur presque toute la longueur du limbe, la nervation est parallèle.

Il y a une relation entre la disposition des nervures et la forme du limbe ; ce dernier peut être linéaire (étroit et allongé, à bords parallèles, Fig. 72), lancéolé (en forme defer de lance,

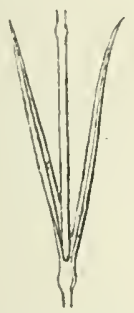

Feuilles ì limbe linéaire.

lig. 7'.

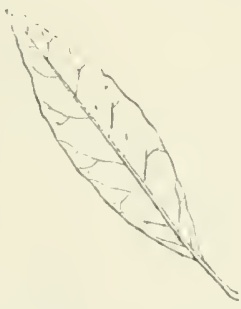

Fenille à limbe lancéole. Fig. 73

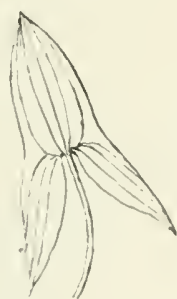

Feuille à limbe silgitle.

Fig. 74 .

Fig. 73), sugitté (en ler de flèche, Fig. 74). ovale (en forme d'œut, la partic la plus large étant près du pétiole, Fig. 75, obovale (mème forme avec la partic la plus étroite vers le pétiole, Fig. 76), spatule (étroit a la base, large au sommet comme une spatule, Fig. 77), corde (en forme de cour renverse, Fig. 78).

La fenille est entiere (Fig 7.5 et $7($ i) si les burds du limbe ne 
sont pas découpés, dentée s'ils sont pourvus de dents (Fig. 70),

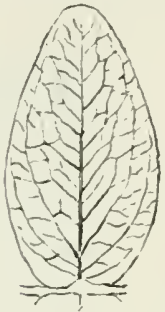

Feuille à limbe ovale el enlier.

Fig. 75 .

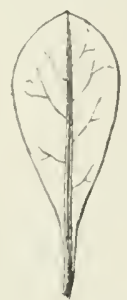

Feuille à limbe obovale el entier.

Fig. 76 .

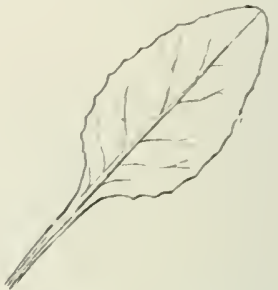

Feuille à limbe spatulè

Fig. 77.

sinuée süls sont flexueux (Fig. 79). Elle peut aussi être divisée en lobes séparés par des coupures plus ou moins profondes (Fig. 71). Si cette division est poussée à l'extrême, la feuille devient composée, c'est-à-dire formée de petites feuilles ou

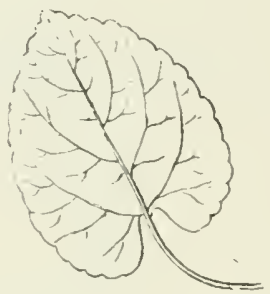

Feuille à limbe cordè. Fig. 78 .

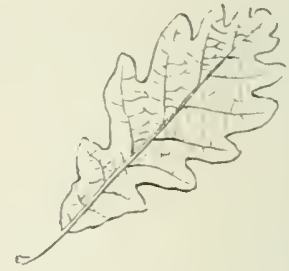

Feuille à bords sinuẻs.

Fig. 79 .

folioles distinetes. (Exemples : feuilles de Frêne, de Caroubier, de Pistachier. Suivant la disposition des folioles, la feuille composée est dite pennée (Frêne, Fiğ. S0) oll palmée (Marronnier d'Inde, Fig. 81).

Les feuilles sont souvent couvertes de poils. On appelle stipules (Fig. 82) de petites feuilles ou de simples écailles qui se trouvent au point d'attache des feuilles sur la lige ou sur les rameaux ; elles fournissent un caractère utile pour la détermination des plantes. Les feuilles, les folioles ou les rameaux peuvent subir des modifications et devenir des milles (Figs. Sij), 
sortes de filaments qui se roulent en spirale sur les corps voi-

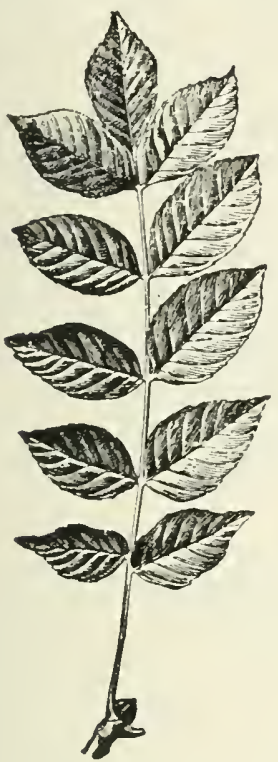

Feuille composèe pennèe de Frêne.

Fig. 80 .

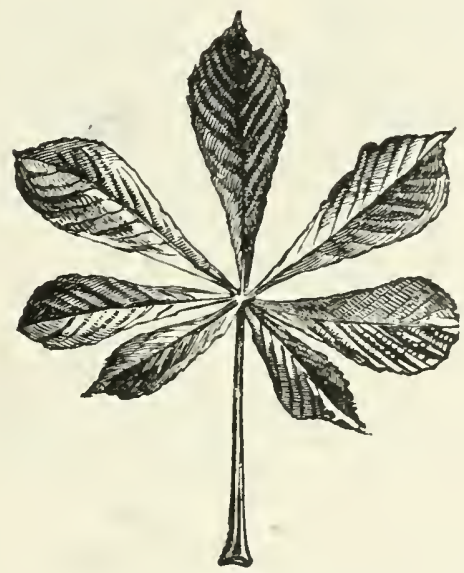

Fetuille composée palmée de Márronnier.

Fig. 81.

sins, ou se transformer en épines. Certains arbres, tels que les Acacias, les Eucalyptus, possèdent des feuilles dont le limbe

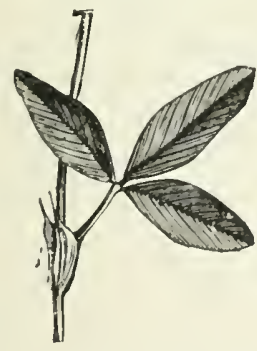

Feuille de Tréfle montrant les stipules.

Fig. 82.

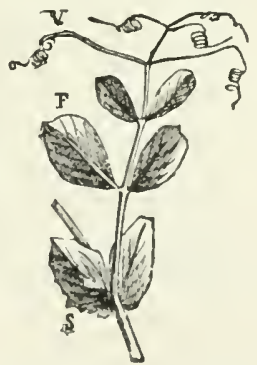

Feuille composée de Pois : $V$, folioles transformées en villes; $l i$, folioles ordinaires; S, stipules. Fig. 83. 
se réduit ou disparaît mème complètement, pour être remplacé, au point de vue physiologique, par le pétiole qui prend une

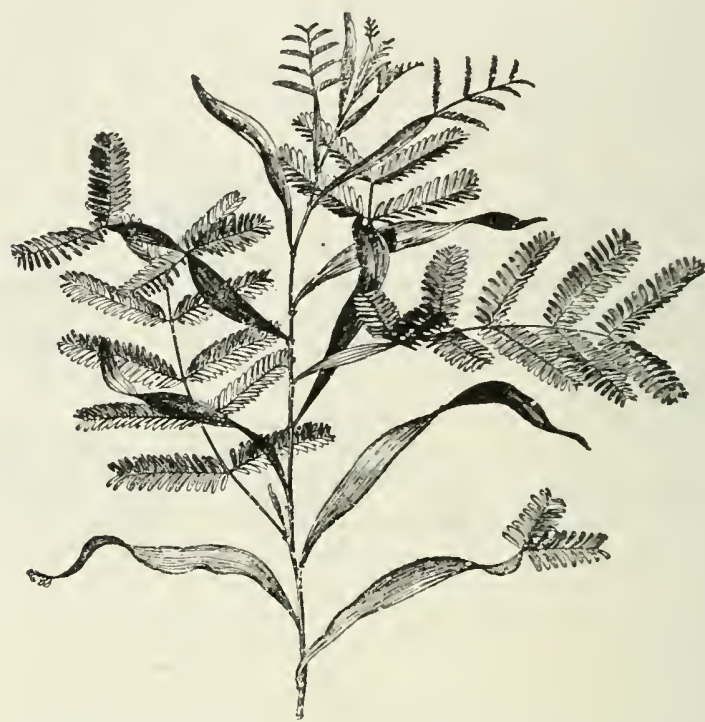

Rameau d'Acacia montrant les feuilles normales à nombreuses petites folioles, les phyllodes el toules les transitions entre ces deux organes.

Fig. 84 .

forme aplatie. On donne aux feuilles spéciales provenant de cet aplatissement le nom de phyllodes (Fig. 8t).

Dans l'Asperge, le Fragon, la feuille tout entière est réduite à une écaille, et ce sont alors de courts rameaux qui poussent à son aisselle qui remplissent ses fonctions dans la nutrition de la plante. On donne le nom de cladodes à ces rameaux spéciaux, qui chez le Fragon sont aplatis et simulent des feuilles (voir Chap. vin).

La disposition des feuilles sur les rameaux varie avec les espèces; le plus souvent, chez les arbres de nos forèts, elles sont alternes (Fig. 85), c'est-à-dire disposées isolément ; dans d'autres cas Exemple : Frène, Olivier, Erable), elles sont opposées (Fig. 86): chaque nœud porte deux feuilles placées l'une en face de l'autre; s̈il en existe plus de deux disposées en 
couronne à la même hauteur, elles sont verticillées. (Exemple Laurier-rose, Fig. 87.)

La durée des feuilles est limitée; si elles vivent plus d'un an,

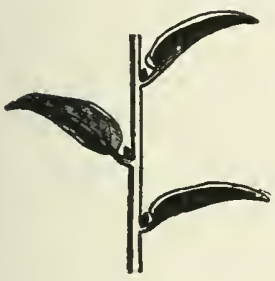

Feuilles alternes.

Fig. 85 .

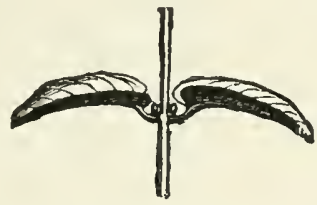

Feuilles opposées.

Fig. 86.

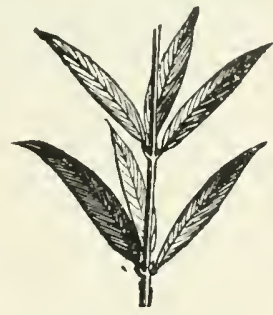

Feuilles vertieillées par trois.

Fig. 87.

l'arbre n'est jamais dépourvu de teuilles et sa cime reste verte toute l'annẻe ; il est dit à feuilles persistantes (Chêne-liège, Olivier, Pin); si elles meurent et tombent à l'automne, l'arbre est à feuilles caduques.

Les feuilles jaunies peuvent rester longtemps adhérentes

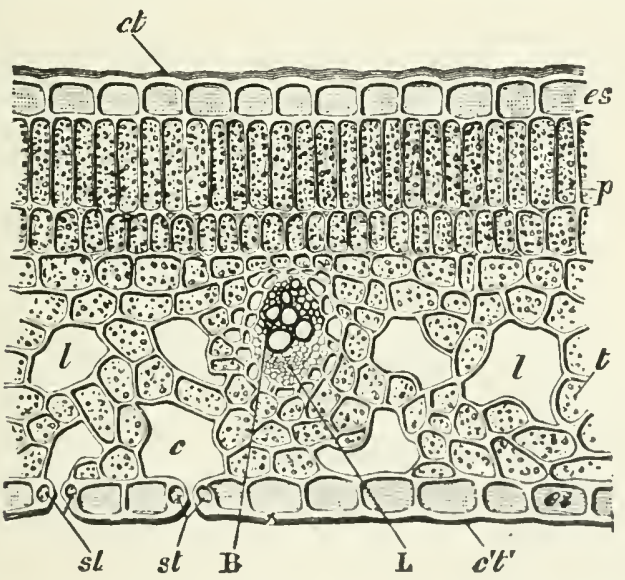

Coupe dans une fenille : es, épiderme supérieur ; $e i$, épiderme inférieur; $c l$, culticule ; st, stomales ; $p$, tissu en palissade,$l$, tissu lacuneux; $l$, c, lacunes; $B$, bois : 1 , liber.

liig. 88. 
aux branches ; on les appelle feuilles marcescentes. (Chêne-zéen.)

L'ensemble des branches couvertes de feuilles ćtablit audessus du sol une sorte d'écran auquel on donne le nom de couvert. L'épaisseur du couvert d'un arbre varie beaucoup

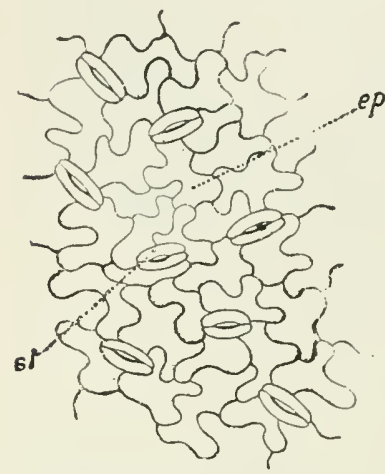

Epiderme $e p$, vu de face et montrant les stomates $s t$.

Fig. 89. avec la nature, la disposition et l'abondance de son feuillage

Structure de la feuille. Les canaux du bois et du liber de la tige se prolongent dans le pétiole et les nervures des feuilles.

La limbe (Fig. 88) est formé de parenchyme dit chlorophyllien à cause de la matière verte qu'il renferme.

Les cellules qui le composent sont généralement serrées les unes contre les autres, comme les pieux d'une palissade, vers la face supérieure; elles sont au contraire très irrégulières et laissent entre clles de nom.

breuses lacunes vers la face inférieure La feuille est couverte d'un épiderme percé, à la surface inférieure surtout, d'ouvertures minuscules limitées par deux cellules en forme de haricots, ce sont les stomates (Fig. 89).

\section{CHAPITRE IV}

\section{LA FLEUR, LE FRUIT ET LA GRAINE}

LA FLEUR. - Les fleurs des arbres forestiers n'ont pas d'ordinaire les brillantes couleurs de celles que l'on admire dans les jardins : beaucoup d'entre elles présentent la mème teinte que les feuilles et frappent peu les regards. Certaines espèces, comme les fruitier's ${ }^{1}$, possèdent cependant des fleurs complètes.

1. On appelle ainsi en Sylviculture les arbres fruitiers (Mlerisier. Alisier, Sorbier) qui croissent ì l'état sauvage dans les forêts. 
Examinons une fleur de Merisier (Fig. 90): elle est portée sur une queue ou pédoncule au sommet duquel on distingue de l'extérieur à l'intérieur : $1^{\circ}$ une collerette formée de cinq petites feuilles vertes ou sépales, c'est le calice :

$2^{\circ}$ Une autre enveloppe la corolle, composée de cinq pétales blancs;

$3^{\circ}$ A lintérieur se trouvent les organes mâles ou étamines.

Chaque étamine (Fig. 91) com-

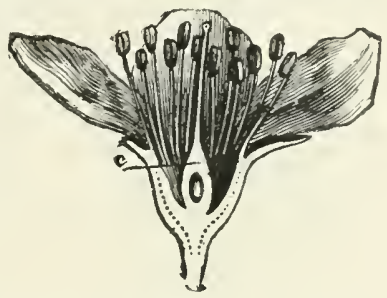

Fleur de Merisier : $c$, ovaire.

Fig. 90. prend un mince filament ou filet et à l'extrémité de celui-ci un double renflement ou anthère:

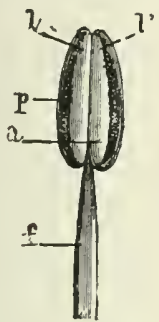

Etamine: $f$, filet; $a$, anthère; $l, l$. loges de l'anthère ouvertes et laissant voir le pollen $p$.

Fig. 91. petit sac à deux loges dont on a comparé la forme à celle d'un pain fendu.

Les loges de l'anthère renferment une poussière jaune dite pollen.

$4^{\circ}$ Enfin, au centre de la fleur, se trouve l'organe femelle nommé pistil. Il comprend un corps renflé appelé ovaire, $(c$, Fig. 90) surmonté d'un appendice effilé ou style, dont l'extrémité visqueuse est le sligmale.

A l'intéricur de l'ovaire, existent deux petits corps arrondis, ce sont les ovules. Chez d autres plantes, ils existent en nombre beaucoup plus grand. La fleur de Merisier ayant cinq sépales et cinq pétales, on dit pour abréger qu'elle est construite sir le type cinq.

Les différentes parties de la lleur sont constituées par des feuilles modifiẻes. Supposons, par exemple, une feuille sans pétiole, à pointe effilée se repliant sur elle-même de façonà rapprocher et souder ses bords, et nous concevons comment une feuille peut être transformée en un pistil semblable à celui de la lleur du Merisier.

Les ovules représentent des folioles charnues insérées sur le pourtour de la feuille et rejetées en dedans par la soudure de ses bords; ces derniers forment à l'intérieur de l'ovaire deux bourrelets appelés placentas.

L'ovaire n'est pas toujours simple, comme dans la fleur étu- 
diée, il peut être formé de plusieurs carpelles (Fig. 92), c'està-dire de plusieurs feuilles repliées et juxlaposées, qui

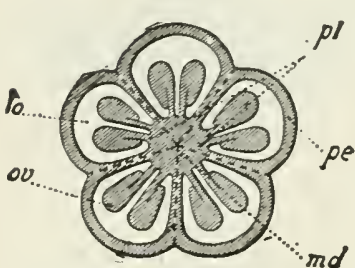

Ovaire à cinq carpelles : lo, cavité d'un carpelle; ov, ovule; $p l$, placentas; $p e$, paroi des carpelles: md, partie interne des carpelles.

Fig. 92.

restent libres ou se soudent plus ou moins complètement, de telle sorte que les ovaires, les styles et les stigmates peurent être réunis, ou bien les ovaires et les styles, ou bien les ovaires seulement.

Les différentes parties de la fleur se répartissent d'après leur rôle en deux groupes bien distincts : les organes sexuels (étamines et pistil) indispensables à la reproduction de l'espèce et les enveloppes florales ou périanthe (calice et corolle) qui ne font que protéger les premiers. Ces enveloppes peuvent faire défaut dans les fleurs dites incomplètes.

Les étamines et le pistil peuvent ètre placés sur des fleurs différentes; elles sont alors unisexuées, les unes mâles, les autres femelles. La fleur du Merisier, qui présente les deux sexes, est au contraire hermaphrodite.

Si les fleurs mâles et femelles, bien que distinctes, sont placées sur le même pied, la plante est dite monoïque (Chène, Cèdre. Pin); elle est dioïque si les fleurs à pistils et les fleurs à étamines sont sur des pieds différents (Peuplier, Saule). Enfin une espèce peut être polygame, c'est-à-dire prẻsenter des fleurs hermaphrodites et d'autres unisexuées. Le Frène, par exemple, présente des pieds de trois sortes : hermaphrodites. måles et femelles; il est dit polygame dioïque.

Les feuilles voisines des fleurs affectent souvent une forme spéciale, on les appelle bractées (Fig. 93 à 95).

Inflorescence. - Les fleurs se groupent de façon différente sur la tige et les rameaux; leur disposition générale prend le nom d'inflorescence.

On appelle inflorescences définies ou cymes celles dans lesquelles la tige et les rameaux se terminent chacun par une fleur. C'est seulement à l'aisselle des feuilles placées à la base des fleurs déjà formèes que pourront naître de nouvelles fleurs. 
Dans les inflorescences indéfinies, au contraire, la tige et les rameaux peuvent se développer indéfiniment à leurs extrémités. La grappe en est le type.

Dans la grappe (Fig. 93) proprement dite, une tige, ou mieux, un axe porte des pédoncules de longueur régulière-
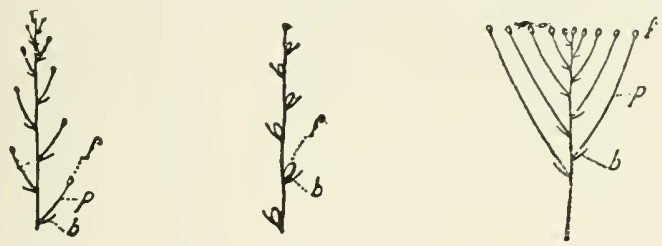

Grappe: $b$, bractéc; Epi : $b$, bractée; $p$, pédoncule : $f$, fleur.

$f$, fleur.

Fig. 93.

Fig. 94 .

Corymbe : $b$, bractẻe ;

$p$, pédoncule : $f$,

Fig. 95 .

ment décroissante à mesure que l'on se rapproche du sommet; chacun d'eux est terminé par une fleur. Les fleurs les plus rapprochées du sommet sont les plus jeunes.

L'épi (Fig 94) est une grappe à fleurs sessiles, c'est-à-dire sans pédoncule.

Le corymbe (Fig. 95) comprend des ramifications partant de divers points de l'axe mais arrivant toutes à la même hauteur.

Si les ramifications partent d'un point unique de l'axe, l'inflo-

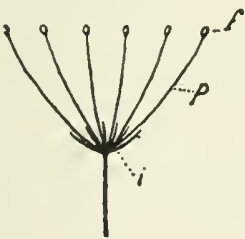

Ombelle: $i$, involucre; $p$, pédoncule : $f$, fleur.

Fig. 96.

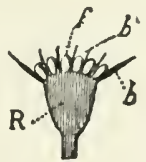

Capitule : $\mathrm{R}$, réceptacle; $b, b^{\prime}$ bractée; $f$, tleur.

Fig. 97.

rescence ressemble à un parasol; elle est dite ombelle (Fig. 96).

Dans le capitule' (Fig. 97), les fleurs sont sessiles et réunies

1. Voir à la faunille des Composées, l'élude plus détaillée de l'inflorescence en capitule. 
les unes à côté des autres sur l'extrémité de la tige fleurie élargie en un plateau ou réceptacle.

L'ensemble est entouré par une collerette de bractées dite involucre.

Le chaton (Fig. 98 à 99), très répandu chez les arbres fores-

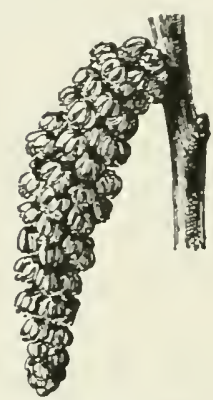

Chaton mâle de Noyer. Fig. 98 .

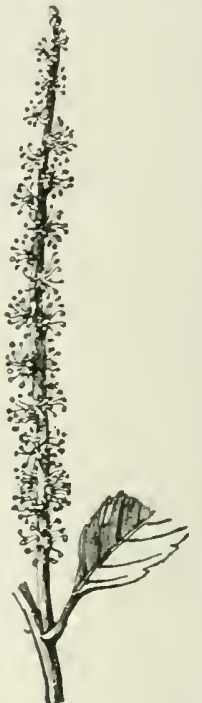

Chaton màle de Chåtaignier.

Fig. 99.

tiers, est un épi composé de fleurs unisexuées et qui peut se détacher pour tomber entier après la floraison (Chène, Saule, Noyer. Châtaignier).

Fécondation. - Reprenons la fleur de Merisier déjá décrite; lorsque les anthères des étamines arrivent à maturité, on les voit s'entr'ouvrir et mettre le pollen en liberté. Quelques grains de cette poussière jaune peuvent en s'échappant toucher le stignate; ils sont retenus par l'enduit visqueux qui le couvre. Fréquemment le pollen est transportẻ sur des fleurs voisines soit par le vent, soit par les insectes!

1. Le pollen peul ainsi être transporlti sur les tleurs d'une antre plante; celle-ci peut ne pas être de la mème espèce que celle qui a fourni le pollen: dans ce cas, la fécondation n’aura généralement pas lieu ; cependanl s̈il s'agil de parents asse\% proches (Chêne-liège et Chẻne afarès par exemple) elle pourra se produire el la graine qui en résultera donnera naissancé à un sujet prèsentaut des caraclères mixles appelè hybride. 
Les grains de pollen germent (Fig. 100) à la faveur du liquide porté par le stigmate; chacun d'eux émet un prolongement tubuleux ou tube pollinique qui pénètre à travers les tissus du style jusque dans la cavité de l'ovaire. Il arrive

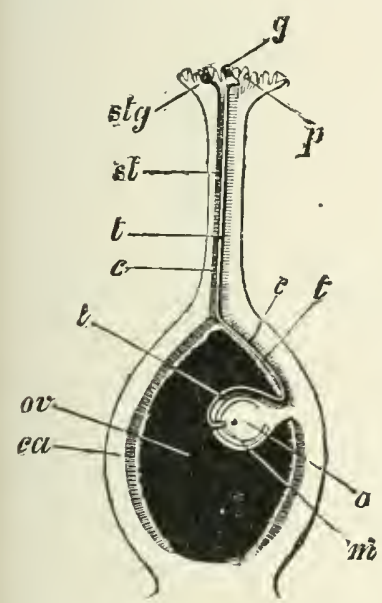

Fécondation : $g$, grain de pollen; $t$, tube pollinique; stg, sligmate; $c$, tissu conducteur : $c a, o v$, paroi et cavilé de l'ovaire; $s l$, style : $o$, ovule; $m$, extrémité de l'ovule par où pènètre le tube pollinique.

Fig. 101.

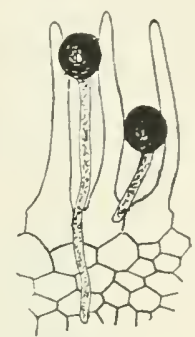

Grains de pollen germant sur le stigmate.

Fig. 100. transforme progressivement en graine. L'ovaire prend dès lors le nom de fruit : sa paroi augmente de volume et constitue autour des graines une enveloppe appelée péricarpe.

LE FRUIT. - Le fruit est sec ou charnu. Les fruits charnus sont ceux dont le péricarpe est gonflé de sucs. On distingue dans cette catégorie les baies ou fruits à pépin (raisin) et les drupes ou fruits à noyau (pêche).

Les fruits secs non susceptibles de s'ouvrir sont appelés akènes (chataigne, gland, noisette) (Fig. 102 et 103)

On appelle samare (Fig. 104) un akène muni d'une ou de plusieurs ailes (Erable, Pin).

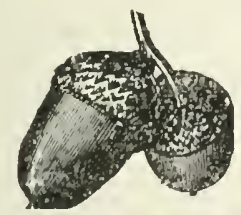

Akine de Chène (gland). Fig. 102 .

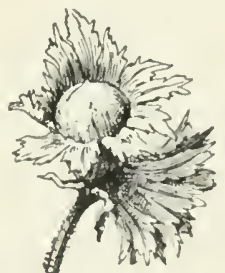

Akène de Noisclier (noiselte). lig. 10\%.

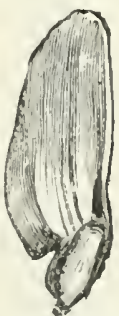

Simare de P'ir.

Fig. 104 . 
Le caryopse est un akène dont la graine est soudée au péricarpe (Blé).

Les fruits secs qui s'ouvrent ou capsules prennent différents noms suivant le mode d'ouverture : le follicule (Fig. 105)

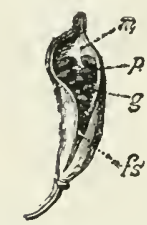

Follicule : $f s$, fente : $g$. graines : $p$, placentas : $m$, milieu du carpelle.

Fig. 105.

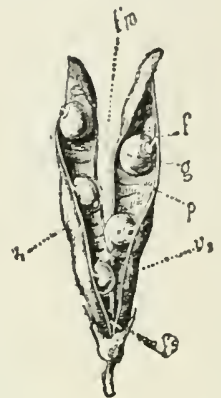

Gousse : $f s, f m$, les deux fentes: $v_{1}, v_{2}$ les deux valves : $g$. graines : $f$, pédicelles des graines.

Fig. 106.

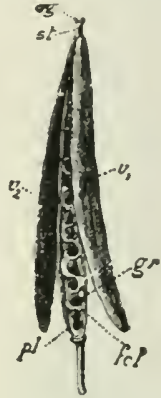

Silique $: v_{1}, v_{2}$, les deux valves:gr. graines: $p l, f c l$, cadre portant les graines : $s l, s g$, style et stigmate.

Fig. 107.

s'ouvre par une seule fente verticale; la gousse (Fig. 106) par deux fentes longitudinales opposées.

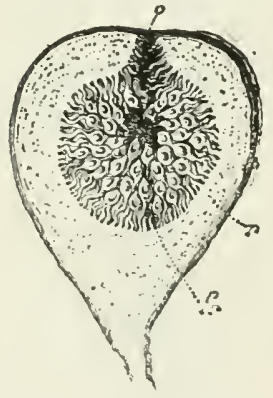

Coupe d'une inflorescence de Figuier (tigue) : $r$, receplacle : $f r$, akènes, ouverture au milieu du réceplacle.

Fig. 108.
La silique (Fig. 107) s'ourre par quatre fentes de façon à laisser à l'extrémité du pédoncule une sorte de cadre portant les graines sur ses bords. Le fruit du Plantain s'ouvre par une fente circulaire qui détache comme une sorte de couvercle à la partie supérieure du fruit: les capsules qui s'ourrent ainsi sont appelées pyxides. Enfin le fruit du Coquelicot s'ouvre par de petits trous ou pores disposés à sa partie supérieure, c'est une capsule poricide.

Les fruits d'une seule pièce sont dits simples; ceux qui présentent plusieurs carpelles séparés provenant d'une mème 
fleur sont dits fruits multiples.'(fraises ') ; si au contraire les fruits de plusieurs fleurs se réunissent en une masse unique, on lui donne le nom de fruit composé (figue) (Fig. 108).

LA GRAINE. - Prenons comme exemple une graine de Ricin (Fig. 109 à 111) ou d'Olivier. La partie essentielle de la

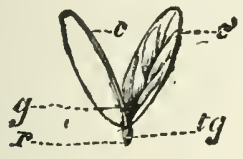

A

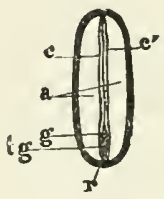

B

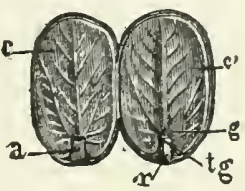

C

Embryon et graine de Ricin: A, embryon ; B, graine coupée en long perpendiculairement aux cotylédons: $C$, graine coupée et ouverte entre les deux cotylédons (le cotylédon e est détaché du reste de l'embryon par la section faite dans la graine). $-r$, radicule : $t g$, tigelle; $c$, cotylédons : $g$, gemmule ; $a$, albumen.

Fig. 109 i 111.

graine est l'embryon, plante en miniature au sommet de laquelle on distingue un petit bourgeon ou gemmule, dans

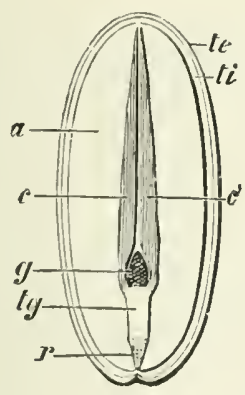

A

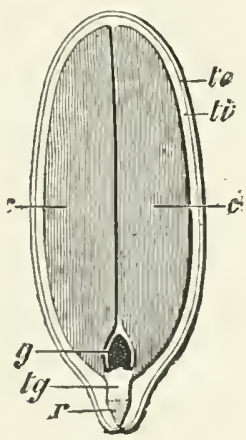

13

Coupes scluématiques de graines à albumen $\mathrm{A}$, ou sans albuucn 13 : te, tégument externe; $t i$, tigument, interne: $a$, allumen : $r$ radicule; $t g, \mathbf{l i -}$ gelle ; $c, c^{\prime}$, cotyledous ; $g$, gemunule.

fig. 112 i 113 .

1. Dams la fraise, c'est l'extrémité du pédoncule ou riceptacle qui s'acervit at forme lat partie pulpeuse; cette dernière est parsemce de petits akentes issus d'unc lleur unique. Daus la ligne, c'est au contraire à l'interieur d'un respectable creux en forme de poire que sont disposes des alienes la's petits proveuint do fleurs nombreuses et serrés. 
lequel on peut souvent reconnaître quelques jeunes feuilles serrées; en dessous deux lobes, appelés colylédons, représentent les premières feuilles de la plante: une petite tige ou tigelle leur fait suite. L'embryon se termine par une ébauche de racine ou radicule.

Le reste de la graine est occupé par l'albumen, tissu dans lequel la jeune plantule puisera sa première nourriture; dans ce cas les cotylédons sont peu volumineux; mais souvent (Chêne, Cerisier) ils absorbent l'albumen avant maturation de la graine; ils sont alors épais et charnus et occupent presque la totalité de la graine.

L'embryon et l'albumen, s'il existe, sont entourés par des enveloppes qui constituent les téguments de la graine (Fig. 112 à 113).

\section{CHAPITRE V}

\section{GERMINATION ET DÉVELOPPEMENT DES ARBRES. - PRO- CÉDÉS DE MULTIPLICATION. - RESPIRATION. - TRANS. PIRATION. - NUTRITION ET ROLE DE LA LUMIĖRE.}

GERMINATION. - Les graines mùres, oulesfruits tout entiers, se détachent de la plante Les semences lourdes (Ex. : glands) tombent directement sur le sol, tandis que le vent peut entraîner au loin celles qui sont légères et ailées. (Ex. : graines de Pins.) Les fruits charnus sont fréquemment dévorés par les Oiseaux qui transportent ainsi les graines. Les Mammifères, les caux qui ruissellent. se chargent également de la dissénination des semences.

Les graines sont souvent légèrement enterrées par les pluies ou les animaux: mais malgré cela beaucoup d'entre elles ne rencontrent pas un milieu farorable à leur développenent. el perdent au bout d'un temps plus ou moins long la faculté de germer.

Quelques-unes trouvent de l'humidité et une température convenable: elles se gonflent et passent alors it un ètat de vie 
active qui se manifeste par l'accroissement de la respiration, un dégagement de chaleur et l'apparition de certains ferments capables de digérer les réserves.

Les phénomènes extérieurs qui suivent varient avec les

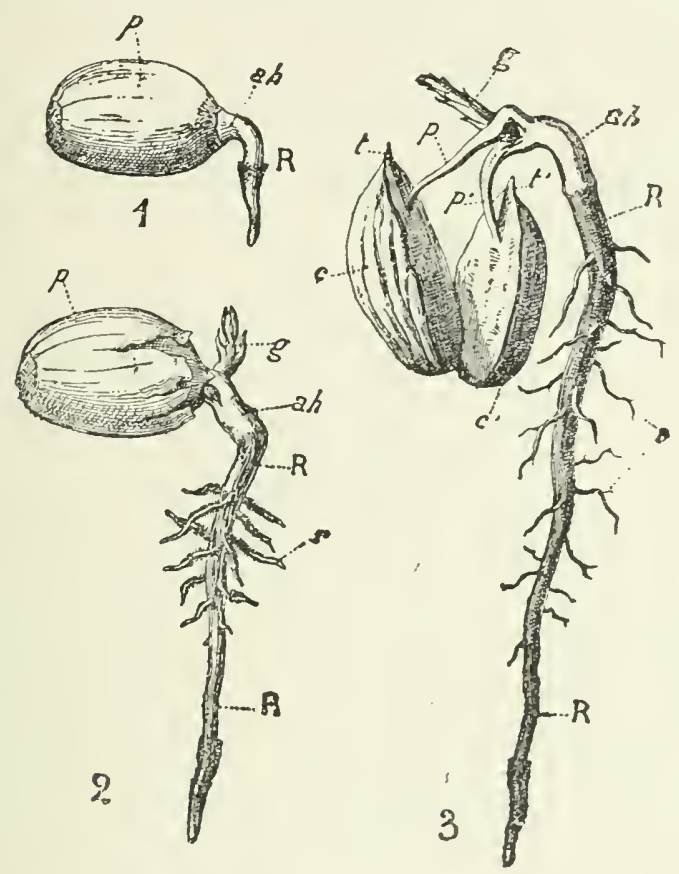

Germination du Clichne: 1,2,3, états successifs : 12, racine principale provenant du développement de la radicule: ah, ligelle développée : $g$, pousse feuillée provenant de la gemmule : $c, t, p$, et $c^{\prime}, t^{\prime}, p^{\prime}$, cotylédons.

Fig. 114 à 116 .

espèces; si nous observons un gland de Chène (Fig. 114 à 116), nous voyons la radicule sortir du gland entrouvert et s'enfoncer dans le sol. Huit jours plus tard, la ligelle se dégage, se dresse et porte bientòt des feuilles, tandis que les deux cotylédons, restés en terre, sèpuisent de toutes les matières qu'ils contiennent au profit de la jeune plante; ils pourrissent ensuite. 
Chez les Pins (Fig. 117), la tigelle, en s'allongeant, élève la

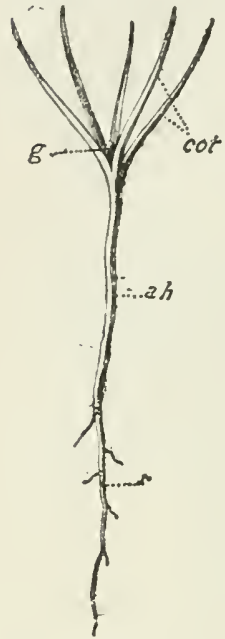

Germination du Pin, lorsque la gemmule $g$ n'estpas encore développée: $r$, racine principale provenant de la radicule: $a h$, tigelle développée au-dessus du sol: cot, cotylédons.

Fig. 117. graine au-dessus du sol; les cotylédons, plus nombreux que ceux du Chêne, forment bientôt au sommet de la tige un faisceau de feuilles allongées et réunies au début par leur extrémité supérieure que coiffent les téguments de la graine.

Il est à remarquer que certaines graines ne peuvent germer immédiatement après leur chute ou leur cueillette: ainsi la semence de Frêne n'est ordinairement utilisable que la deuxième année.

Les graines qui ont été soumises à un grand froid germent plus vite que les autres; il en est de même pour le développement des bourgeons des arbres.

\section{DEVELOPPEMENT DES AR-} BRES. - Les forestiers appellent brin de semence ou simplement brin tout arbre issu d'une graine; le jeune brin est dit robuste s'il a besoin d'une lumière assez intense dès le début de sa vie, et délical si au contraire il exige de l'ombre pendant les premières années de son existence.

Revenons au coin de forêt où nous avons déjà observé la germination d'un gland; les jeunes brins de Chêne qui s'y sont développés ont, au bout d'un an, atteint un ou deux décimètres de hauteur, quelquefois plus. Les arbres feuillus croissent assez vite; les résineux se développent beaucoup plus lentement durant les premières années. Quelle que soit d'ailleurs l'espèce envisagée, les jeunes brins émettent progressivement des rameaux qui couvrent d'abord la tige sur toute sa hauteur. Bientòt les rameaux des brins voisins se rejoignent, ne laissant plus d'espace découvert entre eux et formant un fourré, ensemble confus de jeunes sujets de hauteurs inégales.

Plus tard, les branches basses privées de lumière meurent et disparaissent, les tiges sallongent, ce sont des gaules, et l'ensemble s'appelle un gaulis. Quand ces baguetles auront 
grossi et atteint un décimètre de diamètre, elles formeront un perchis. Enfin, lorsque les fùts seront complètement constitués, le massif sera devenu une haute futaic. Les arbres ont alors atteint l'âge mûr et donnent d'abondantes semences.

Des nombreux brins qui constituaient le fourré, la plupart ont disparu ; dans un peuplement ${ }^{1}$ serré, les arbres ont à soutenir un combat sans répit, la cime de chacun d'eux cherchant à percer et à s'étaler le plus possible à la iumière. Au cours de cette lutte les plus faibles sont bientôt dépassés par les cimes des sujets plus vigoureux et périssent tôt ou tard; il résulte de cette compétition un allongement rapide des tiges aux dépens de leur grosseur; le phénomène de l'élagage naturel, que nous avons signalé dès le début du gaulis, se produit avec intensité, c'est-à-dire que les branches inférieures, privées de lumière par les cimes voisines, se dessèchent rapidement; le houppier est réduit à un bouquet inséré à l'extrémité du fût.

Quand̀ le peuplement est devenu vieille futaie, les arbres sont proches de leur maturité et peu à peu dépérissent; ce fait se produit souvent vers 150 ans, quelquefois vers 300 ans seulement ou même plus tard.

PROCEDES DE MULTIPLICATION. - La graine seule peut donner naissance à un nouvel arbre, mais il existe des procédés de rajeunissement et de multiplication.

Rejets et drageons. - Lorsqu'on coupe un arbre au ras de terre, il se produit, si les conditions sont propices, des jeunes pousses dites rejets qui croissent sur la souche du suje t coupé soit par développement de bourgeons proventifs, soit par la formation de bourgeons adventifs.

La faculté de donner des rejets existe généralement chez les arbres feuillus, tout au moins lorsqu'ils ne sont pas trop âgés, mais clle est plus rare et limitée à certaines espèces chez les résincux.

Quand le rejet naît près de terre, il peut entrel en con-

1. On appelle ainsi l'ensemble des tiges qui s'èlèvent sur le sol forestier. 
tact avec le sol et émettre directement des racines qui en font un sujet indépendant. Toutefois la longévité reste moindre que celle des brins de semence. Il est à noter que durant les premières années le rejet croît beaucoup plus vite que le semis.

La jeune pousse peut se développer directement sur la racine, plus ou moins loin de la souche; elle prend alors le nom de drageon. Les arbres peuvent drageonner sans avoir été recépés.

Bouturage et marcottage. - Toute portion de plante mise en terre et capable de s'organiser en une plante com-

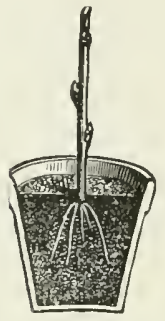

Bouture : un rameau détaché d'une plante el enfoncé en terre peut produire des racines.

Fig. 118.

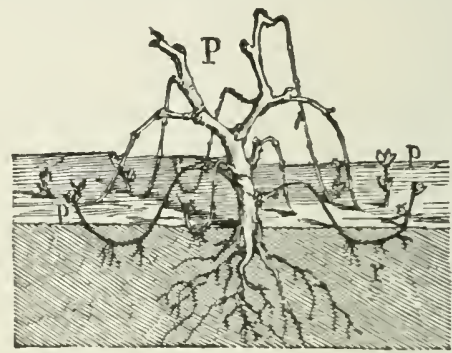

Marcottage : $p$, rameau de la planle $P$ enlonce en terre et produisant des racines $r$.

Fig. 119.

plète constitue une boulure (Fig. 118). On emploie généralement une branche munie de bourgeons ou mème de feuilles.

La bouture ordinaire se fait avec un rameau de l'année: la bouture en plançon est une branche déjà grosse et atteignant 3 et 4 mètres de hauteur.

Le marcollage (Fig. 119) est une opération peu différente consistant à courber une branche pour en enterrer une partie; des racines se développent sur la portion mise dans le sol; on sépare alors la marcotte de la plante mere.

Greffage. - Si la bouture, au lieu d'itre mise en terre, est transportée sur une autre plante, on obtient une greffe (Fig. 120125). On appelle sujet le pied sur lequel est placée la greffe et 
greffon le rameau à transplanter; sujet et greffon doivent, pour

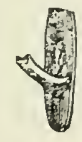

A

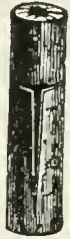

13

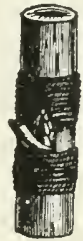

C

Greffe en écusson: en A est le greflon, e'est-à-dire un bourgeon avec un fragment adhérent de l'arbre que l'on veut multiplier: en $B$ est le sujet dont l'écorce a élé fendue pour reevoir le greffon: en C le greffon a èlé introduit dans la fente du sujet contre lequel il est maistenu étroilement par une ligature; la greffe est faite.

Fig. 120 à 122 .

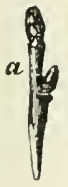

A

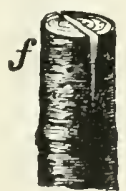

13

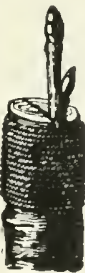

C

Greffe en fente : en A est le greffon e'est-à-dire un fragment de rameau de l'arbre que l'on veut nultiplier: en 13 est le sujet dont la tige a élé fendue en $f$ pour recevoir le greffon a : en C la grefle est faite et le greffon est serré étroitement dans la fente par une ligature.

Fig. 123 ì 125 .

que l'opération réussisse, présenter une assez étroite parenté (Ex. : on peut greffer le Châtaignier sur le Chène zéen.)

Le bouturage, le marcottage et le greflage ne sont employés par le forestier que dans des cas exceptionnels; les rejets et les drageons, au contraire, jouent un ròle important dans la culture des bois ; c'est sur leur développement qu'est basé le traitement des forêts en laillis.

RESPIRATION ET TRANSPIRATION. - Les plantes respirent, c'est-à-dire qu'elles absorbent l'oxygene de l'air ' et rendent de l'acide carbonique à l'atmosphère,

1. L'air est un mélange de plusieurs g:az; il est formé d'azole ou gaz mort (4/5 environ), ainsi appelé parce qu’il est impropre à entrelenir la vie, 
comme les animaux. Elles exhalent aussi de la vapeur d'eau ; ce dernier phénomène, appelé transpiration, se fait à la surface des feuilles et principalement par la voie des stomates; la transpiration est plus forte à la lumière que dans l'obscurité.

NUTRITION ET ROLE DE LA LUMIERE. L'eau transpirée par les plantes est puisée dans le sol par les

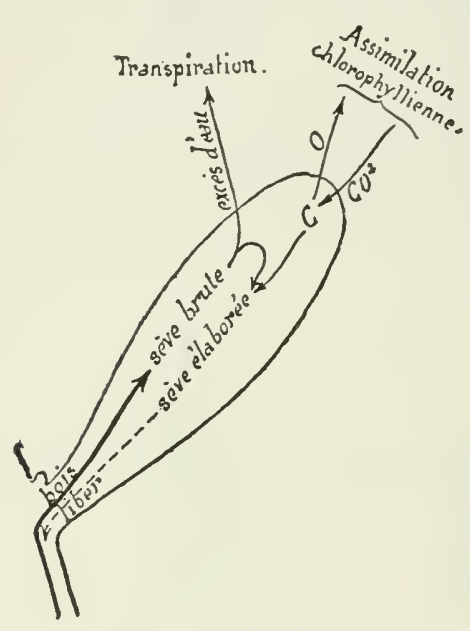

Figure théorique montrant le parcours de la sève brute et de la séve élaborée. C carbone, $\mathrm{O}$ oxygène, $\mathrm{CO}^{2}$ acide carbonique.]

Fig. 126. poils absorbants des racines. Cette eau contient des matières minérales en dissolution ${ }^{1}$; les niycorhizes ${ }^{2}$ servent également d'intermédiaire entre le sol et l'arbre en permettant à ce dernier d'utiliser plus facilement les matières nutritives contenues dans le terreau de la forêt.

Le liquide absorbé s'élève dans la tige en circulant dans les canaux du bois : cest la sève brute. Elle gagne les feuilles où une grande partie de l'eau s'évapore par transpiration (Fig. 126).

Les feuilles, grâce à la matière verte ou chlorophylle qu'elles contiennent, ont la faculté de décomposer l'acide carbonique de l'atmosphère sous l'action de la lumière, de rejeter l'oxygène et d'assimiler, c'est-à-dire de fixer le carbone

et d'oxygène ou gaz vivifiant; ce dernier joue un róle essentiel dans la combustion et dans la respiration qui n'est qu'une combustion lente : lorsqu'on brùle un morceau de charbon, le carbone (ou charbon pur) se combine avec l'oxygene de l'air ; il se forme de l'acide carbonique ; c'est d'une façon analogue, mais plus complexe, que ce gaz se forme dans nos tissus et dans les tissus végétaux.

L'air contient donc de l'acide carbonique $13 / 10.000$ environ', résultat des combustions qui constituent nos moyens de chauflage et d'èclairage, de la respiration des êtres vivants, des fermentations et de la décomposition des matières organiques.

1. Il a été dit précédemment (page 19) que les plantes de la amille des leégumineuses peuvent, en outre, utiliser l'azote de l'air par l'intermédiaire des organismes contenus dans les nodosités de leurs racines.

2. Voir page 14. 
en le combinant aux éléments de l'eau pour former des substances nutritives telles que les sucres.

Ce phénomène spécial, qui est l'inverse de la respiration, constitue l'assimilation chlorophyllienne (Fig. 126).

Dès lors la sève brute, que nous avons suivie jusque dans les feuilles, se trouve enrichie et transformée en sève élaborée ou nourricière (Fig. 126), qui gagne les diverses parties de l'arbre pour y distribuer les matériaux nécessaires à l'accroissement.

La sève élaborée circule entre le bois et l'écorce dans les canaux du liber ; l'enlèvement de ce dernier provoque la mort de l'arbre par privation de nourriture.

Sur son trajet, la sève nourricière abandonne les matẻriaux destinés à la formation de nouvelles couches de bois, de liber et d'écorce, c'est-à-dire à l'accroissement en diamètre. Elle alimente les bourgeons et provoque ainsi l'accroissement en longueur ${ }^{1}$.

Le développement de la plante est influencé par l'électricité atmosphérique, et l'on admet que cette dernière active la circulation des liquides dans les tissus végétaux. On a de longue date remarqué l'action bienfaisante d'une pluie d'orage sur les récoltes.

En semant des Épinards autour d'une perche formant paratonnerre, et dite géomagnétifère, on a constaté une accélération de la végétation et une augmentation de rendement.

Les arbres soutirent également l'électricité atmosphérique à leur profit ; par contre, Grandeau a démontré que les arbres soustraient à l'influence électrique les plantes qu'ils dominent. Cet isolement, analogue à celui résultant d'une cage métallique, s'étendrait même au delà du périmètre directement surmonté par la cime de l'arbre.

Les substances qui ne sont pas consommées immédiatement pour la croissance de la plante constituent des réserves qui peuvent ensuite rentrer dans la circulation pour être à leur tour utilisées.

1. Les prineipaux éléments qui constituent les plantes supérieures el qui, par suite, sont utilisables pour leu alimentation sont : le earbone, l'hydrogène, l'oxygène, l'azole, le soufre, le phosphore, le chlore, le siliciun, le potassium, le calcium, le magnésium, le fer. 
L'activité de la végétation varie avec les saisons : les plantes qui sont dégarnies de leurs feuilles en hiver paraissent même à cette époque dépourvues de vie; celle-ci n'est toutefois que ralentie ; la plante sommeille, altendantque le soleil du printemps lui rende son activité et la couvre de fleurs.

C'est, en effet, le soleil qui est la source de toute énergie sur la terre; il nous donne la chaleur et la lumière que lion peut confondre en un seul terme, la radiation.

Non seulement une certaine température est nécessaire pour que les arbres fleurissent et fructifient, mais l'expérience a démontré depuis longtemps qu'une lumière abondante favorise la fructification; aussi a-t-on soin, pour obtenir des jeunes semis sous une vieille futaie, d'ourrir dans le massif des trouées qui donnent un éclairement suffisant et délivrent les porte-graines de la concurrence de leurs voisins; ils peuvent ainsi réaliser l'effort nécessaire à une grande fécondité.

Lorsque les semis se sont produits sous la futaie, on se garde bien d'enlever aussitôt tous les vieux arbres; une lumière trop intense nuirait aux jeunes brins, surtout s'ils sont délicals.

Par la suite cependant ils exigent une radiation intense et le couvert constitué par les vieux arbres doit disparaitre; mais si les jeunes arbres sont trop serrés, leur sommet seul sera fortement éclairé; là seulement les feuilles pourront se développer; les tiges s'allongeroilt rapidement, mais resteront grêles; pour abrẻger les phases d'une lutte que nous avons déjà esquissée et dont le peuplement tout entier aurait à souffrir, l'homme intervient et pratique des éclaircies, opérations qui consistent à enlever une partie des tiges.

La lumière et la transpiration (dont l'intensité est en partie sous la dépendance (le laction de la lumière) sont particulicrement nécessaires à la formation du tissu de soulien qui donne au bois sa consistance.

Toutefois un excès de lumière prèsente des inconvénients; il ne nuit pas seulement anx jeunes brins délicats, il s'oppose aussi à l'allongement des tiges; les arbres isolés sont courts, trapus, empàtés au pied et munis de grosses branches dès la base, tandis que les mèmes espèces en massif possèdent un fùt très allongé et dénudé; mais si l'un de ces arbres se trouve 
subitement isolé ou tout au moins complètement éclairé, son fût se couvre rapidement sur toute la longue ur de petits rameaux dits branches gourmandes.

Nous savons déjà que toutes les espèces ne réagissent pas de la même façon vis-à-vis de la lumière; qüil existe des jeunes plants robustes, d'autres délicats; il y a de plus une relation assez générale entre le tempérament du jeune plant et l'épaisseur du couvert de l'arbre pour une même espèce : les essences à convert léger produisent des jeunes planls qui demandent le plein découvert, c'est-à-dire robustes; au contraire, les essences à convert épais ont des jeunes plants délicats, redoutant une lumière trop intense au début de leur existence.

De ce rapide aperçu nous tirerons les conclusions suivantes :

$1^{\circ}$ L'arbre a besoin de trouver l'eau en quantité suffisante dans la terre, et le dessecchement du sol cause la perte de la forêt ; c'est pourquoi le sylviculteur doit s'opposer à l'enlèvement du sous-bois ${ }^{1}$, de la mousse et de la couverture morte (terreau et débris végétaux et animaux) qui protègent le sol forestier. Le terreau ne conserve pas seulement l'humidité au sol : il fournit aux arbres d'abondants principes nutritifs.

$2^{\circ}$ L'art du forestier consiste en grande partie à doser la lumière aux peuplements dont il a la gestion.

\section{CHAPITRE VI}

\section{CLASSIFICATION DES PLANTES A FLEURS OU PHANÉROGAMES}

L'embranchement des Phanérogames se divise en deux sousembrancliements.

$1^{\circ}$ Les Angiospermes, plantes dont les fleurs présentent des ovules enfermés dans un ovaire. La plantule comprend un ou

1. Le sous-bois est, il est vrai, dangereux au point de vue des incendies, mais la forêt renât d'ordinaire de ses cendres; elle disparail sans relour cles régions desséchées. 
deux cotylédons. C'est à ce groupe qu'appartient le Merisier dont la fleur nous a servi de type.

$2^{\circ}$ Les Gymnospermes, plantes à fleurs dont les ovules ne sont pas entourés d'une enveloppe fermée, mais simplement portés par des écailles. Le nombre des cotylédons est variable. (Exemple : les Pins.)

GYMNOSPERMES. - Les Gynnospermes comprennent trois familles : $1^{\circ}$ les Gnétacées, représentées en Algérie par le genre Ephedra sur lequel nous reviendrons; $2^{\circ}$ les

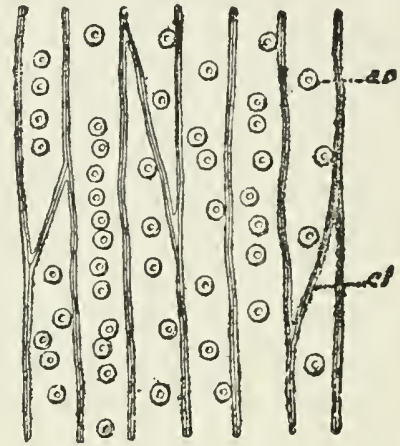

Coupe longitudinale dans le bois du Pin faile suivant l'axe de la tige: $\mathrm{cl}$, cloisons séparant les trachéides : ar, ponctuattions vues de face.
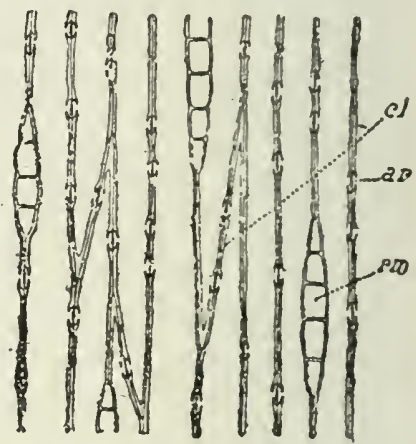

Coupe longitudinale dans le bois de Pin faite perpendiculairement aus rayons médullaires : $c l$, cloisons separant les trachéides: $r m$, rayons médullaires; $a r$, ponctuations vues en coupe.

Fig. 128.

Fig. 127 .

Cycadées, localisées sous les tropiques; $3^{\circ}$ les Conifères, tris importantes au point de vue forestier (Pins, Cèdres, Sapins, Genévriers, etc.). Leur organisation diflère sensiblement de celle des plantes déjà étudiées; prenons le Pin comme exemple.

Le bois ne présente pas de vaisseaux proprement dits; il est formé de cellules allongées, intermédiaires entre les fibres et les vaisseaux, que l'on nomme trachéides. La membrane des trachéides est couverte de ponctuations (Fig. 127 et 12S).

Les rayons médullaires sont peu développés.

Les feuilles sont en forme d'aiguilles et souvent désignées sous ce nom. 
La plante tout entière est riche en matière résineuse contenue dans des canaux résinifères.

Les fleurs sont unisexuées, c'est-à-dire qu'il existe des fleurs mâles et des fleurs femelles séparées.

Les premières se présentent sous forme d'une petite masse allongée composée d'un axe et d'écailles. Chaque écaille porte à sa face inférieure deux sacs gonflés de pollen et constitue par suite une étamine (Fig. 129).

Les deuxièmes sont groupées sur un même rameau pour former un cône (Fig. 130). Chaque fleur femelle est située à

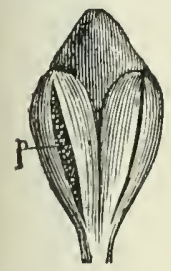

Elamine du Pin : $p$, pollen.

Fig. 129 .

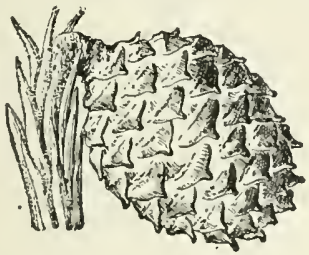

Inflorescence femelle de Pin.

Fig. 130.

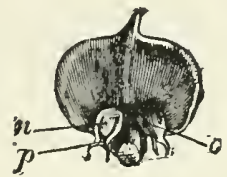

Carpelle de Pin $: n$, $o$, ovules ; $p$, tégumenl de l'ovule $n$.

Fig. 131.

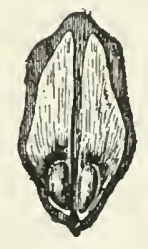

Eeaille du Pin portant les 2 graines.

Fig. 132.

l'aisselle d'une bractée; elle se compose d'un carpelle en forme d'écrille qui porte 2 ovules (Fig. 131).

Quand les ovules se transforment en graines, les écailles qui les portent deviennent épaisses et dures; le cône de Pin prend dès lors l'aspect bien connu. A maturité, les ćcailles s'écartent sous l'action du soleil et les graines, prolongées en ailes (Fig. 132), s'échappent de l'inllorescence.

ANGIOSPERMES. - Les Angiospermes se divisent en deux classes : les Monocotylédones ou plantes dont l'embryon ne présente qu'un cotylédon et les Dicotylédones dont l'embryon a deux cotylédons.

Monocotylédones. - Ce caractère de l'embryon, qui pourra paraître peu commode à observer, correspond à d'autres différences beaucoup plus faciles à apprécier: les feuilles des Monocotylédones, souvent étroites et allongées Ex. : le Blé), sont en général à nervures parallèles, tandis que la nervation des feuilles des Dicotylédones est ramifiéc. 
Les sépales, pétales, étamines et carpelles, e'est-à-dire les diverses parties de la fleur, sont dans presque tous les cas au nombre de trois (ou multiples de trois) chez les Monocotylèdones et de qualre ou cinq (ou d'un multiple ou sous-multiple de ces chiffres) chez les Dicotylédones.

Les sépales et les pétales sont fréquemment de même cou. leur chez les Monocotylédones.

La tige de celles-ci (Palmier) ne présente pas d'accroissements annuels semblables à ccux des Dicotylédones (Chène) ou des Gymnospermes (Pin); on n'y remarque qu'une écorce entourant une sorte de moelle générale parcourue elle-même par de nombreux faisceaux; ces derniers renferment à la fois les vaisseaux du bois et les tubes criblés du liber.

Les Monocotylédones ne comprennent pas d'essences forestières proprement dites croissant naturellementen Algérie; les plantes arborescentes de cette classe sont surtout répandues sous les tropiques.

Dicotylédones. - On les divise en trois sous-classes basées sur la disposition des enveloppes florales (calice et corolle).

$1^{\circ}$ Les Apétales, plantes chez lesquelles les enveloppes de la fleur manquent ou ne sont représentées que par des organes verts comparables à des sépales (Chêne, Mûrier, Fig. 133 et 133 bis.) Le calice et la corolle existent dans les deux autres groupes.

$2^{\circ}$ Les Dialypétales présentent une corolle formée de pièces distinctes; chaque pélale peut ètre arraché séparément sans entraîner les autres. (Merisier, Fig. 137.)

A

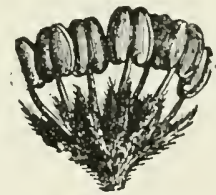

B

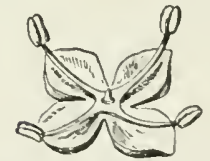

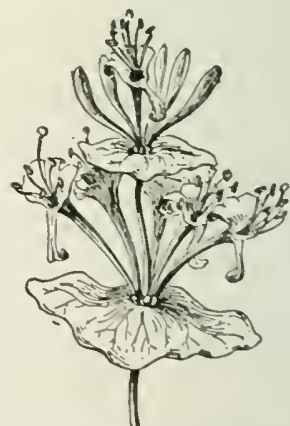

Fleurs apétales: A Chène, B Murier. Fleurs gamopilales de Chèrefeuille. Fig. 133 et 133 bis.
Fig. 134 . 
$3^{\circ}$ Les Gamopétales ont au contraire une corolle composée de pétales soudés entre eux ${ }^{1}$ (Chèvrefeuille, Fig. 134).

Chacun de ces trois groupes peut être subdivisé en deux d'après la façon dont les pétales et les étamines sont insérés sur l'axe de la fleur; suivant ce mode d'insertion, l'ovaire peut paraitre se trouver au-dessus ou au-dessous du point d'attache du surplus de la fleur (Fig. 135 et 136) ; nous nous servirons de ce caractère pour distinguer les Gamopétales à ovaire supère

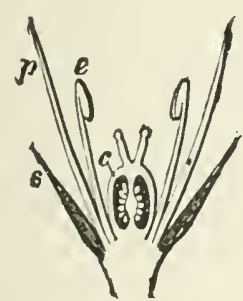

Coupe theorique d'une fleur à ovaire supère : $s$, sépale : $p$, pétale : $e$, élamine : c, carpelle.

Fig. 135 .

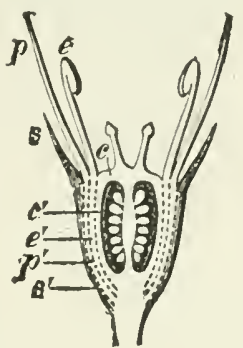

Nème figure pour une fleur à ovaire infère: $s^{\prime}, p^{\prime}, e^{\prime} . e^{\prime}$, parlies des sépales, pétales. étamines et carpelles qui sont soudées entre elles.

Fig. 136.

(c'est-à-dire à ovaire situé au-dessus de la fleur) et les Gamopétales à ovaire irfère (c'est-à-dire à ovaire situé au-dessous de la fleur).

On peut diviser de même les deux autres groupes; mais nous adopterons une autre division; nous dislinguerons parmi les Dialypélales :

jo Les Thalamiflores: les étamines et la corolle sont insérées sur l'axe et non soudées au calice. L'ovaire est done supère.

20 Les Calyciflores: les étamines et la corolle sont insérées sur une sorte de collerette ou de cupule formée par la base du calice. Cette collerette peut ètre adlıérente à l'oraire el celui-ci

1. Celte elassilicalion n'a rien d'absolu, el certaines cspèces, que les botanisles sont d'accord pour ranger parmi les Dialypétales, ont les pétales plus ou moins soudés à la base ; en outre, il exisle des Apélales que d'autres caraelères rallachent aux Dialỵpélales el que l'ou considère comme des Dialypétales à corolle avortće. 
est alors infère (Fig. 138), mais elle peut aussi laisser l'ovaire libre, il est alors supère (Fig. 137).

On classe quelquefois les Gamopétales et les Dialypétales suivant la situation des étamines qui est hypogyne si ces

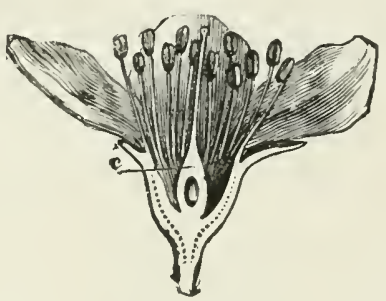

Fleur de Merisier (Dialypétale calyciflore à ovaire supère).

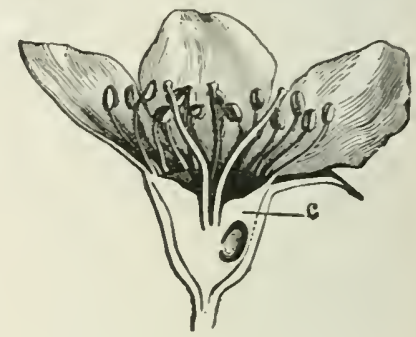

Fleur de Poirier (Dialypétale calyciflore à ovaire infère). c, ovaile.

Fig. 137.

Fig. 138.

organes sont insérés sous l'ovaire, périgyne dans le cas contraire ${ }^{1}$.

Les Apétales peuvent se diviser en Antentacées, plantes dont les fleurs mâles sont disposées en chaton et en non-Amentacées, plantes qui ne présentent pas ce caractère.

Les Amentacées présentent une grande importance au point de vue forestier; elles constituent, avec les Conifères, l'ensemble des essences sociales à grandes dimensions que nous aurons à décrire dans les chapitres suivants?

1. Sur les fleurs à ovaire infère les étamines sont fixées au-dessus de l'ovaire (étamines épigynes). Sur les fleurs ì ovaire supère elles sont fixées autour de l'ovaire chez les Calyciflores (étamiues périgynes) et en dessous de l'ovaire chez les Thalamiflores (étamines hypogynes). Dans la pratique, les étamines épigynes et périgynes sont réunies sous le nom de périgynes.

La synonymie est dans l'ensemble la suivante :
Dialypétales hypogynes $=$ Thalamiflores.
Dialypétales périgynes $=$ Calycillores.
Gamopétales hypogynes $=$ Gamopétales à oraire supère.
Gamopétales périgynes $=$ Gamopétales à ovaire infère.

Chez les Gamopétales, les étamines sont fréquemment insérées sur la corolle : d'où le nom de Corolliflores quelquefois employé.

2. Dans ces chapitres, nous avons indiqué en gros earactẻres les noms français des espèces spontanėes importantes, et en caractères plus petits ceux des espèces spontanées d'intérêt moindre et ceux des espèces introduites. 


\section{CHAPITRE VII}

\section{LES GYMNOSPERMES}

On peut résumer ainsi l'exposé fait au chapitre précédent : les Gymnospermes sont des plantes sans ovaire, ni style, ni stigmate, à ovules nus, à fleurs unisexuées, sans calice ni corolle. Nous dirons d'abord quelques mots des Ephedra, puis nous étudierons l'importante famille des Conifères.

GNETACÉES. - Les Ephedra sont des arbustes sans feuilles, à rameaux articulés, rappelant les Prêles par leur port ; ils se distinguent des Conifères par la présence, autour de l'ovule, d'une enveloppe ouverte seulement à sa partie supé-

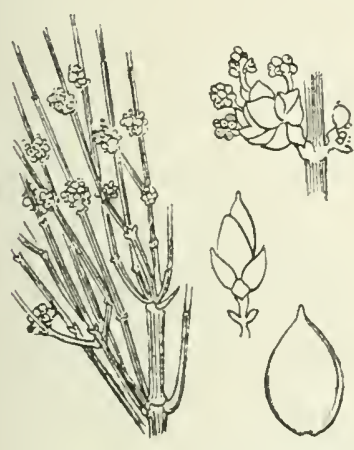

Ephedra nebrodensis.

Fig. 139.

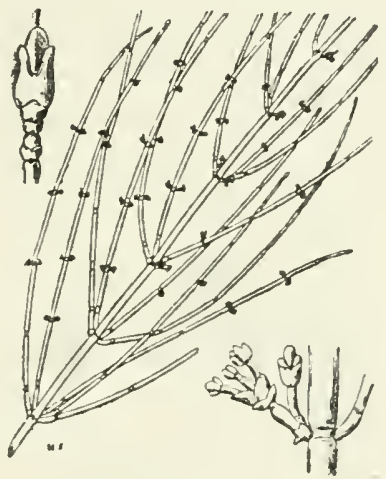

Ephedra fragilis.

Fig. 140.

rieure et formant une sorte d'ovaire incomplet. Ils font ainsi transition entre les Gymnospermes et les Angiospermes.

On les rencontre surtout sur les sables du littoral et dans le Sahara, sauf l'Ephedra nebrodensis qui est confiné dans les montagnes calcaires.

L'Ephedra altissima Desf., grande plante sarmenteuse, s'élève quelquefois dans les arbres jusqu'à 8 à 12 mètres.

L'Ephedra nebrodensis Tin. (Fig. 139) forme au contraire des buissons denses de 20 à 60 centimètres de lrauteur.

L'Ephedra fragilis Desf. (Fig. 140) est un arbuste rameux 
pouvant atteindre de grandes dimensions en s'appuyant souvent sur d'autres plantes.

CONIFERES. - Ce sont des arbres ou arbrisseaux toujours verts (les espèces algériennes du moins) à feuilles en forme d'aiguilles ou d'écailles, secrétant en général de la résine. Un type de fleurs et de fruits a été précédemment décrit page 59 .

Les Conifères se divisent en 3 tribus :

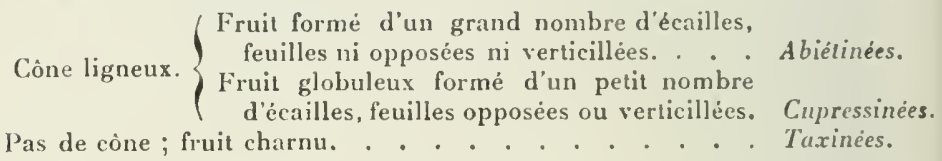

Les Abiétinées sont de grands arbres à tige élancée, à feuilles étroites et persistantes. Cette tribu est représentée en Algérie par les trois genres : Sapin (Abies), Cèdre (Cedrus) et Pin (Pinus).

Le SAPIN DE NUMIDIE (Abies numidica De Lannoy) (Fig. 141) est un grand arbre à cime allongée conique très

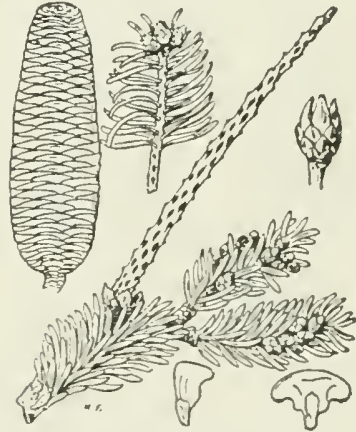

Abies numidica.

Fïg. 141.

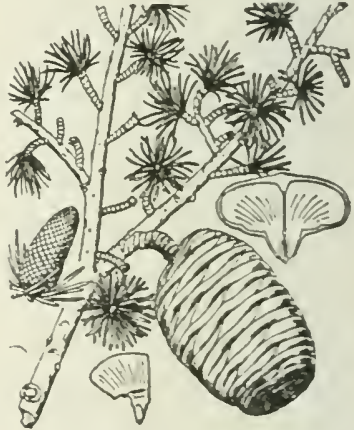

Cedrus atlantica.

Fig. 142.

touffue, à branches verticillées, à feuilles longtemps persistantes (10-12 ans), longues de 12 millimètres environ et préscntant, a la face inférieure, deux lignes blanchitres. Les chatons màles sont rouge pourpre; les chatons femelles, verdàtres. Le còne, dressé sur les rameaux, est brun clair à maturité; ses écailles tombent avec les graines. 
Cette essence est localisée sur le Babor et le Tababor où elle est associée au Cèdre et au Chêne zéen: elle n'est pas assez répandue pour avoir une valeur économique.

Une espèce voisine, l'Abies marocuna Trabut a été signallée au Maroc.

Le CẺDRE DE L'ATLAS (Cedrus atlantica Manetti, (Fig. 142) peut atteindre 40 mètres de hauteur: sa tige trapue porte de longues branches robustes, horizontales. Les jeunes arbres ont la pousse terminale inclinée, plus tard la cime prend une forme étalée caractéristique. Les feuilles sont persistantes et de deux sortes : les unes, longues de 25 à 40 millimètres, sont solitaires; les autres, de 15 à 20 millimètres, sont disposées en petits bouquets à l'extrémité de courts rameaux. Le couvert est assez épais. Les chatons màles jaunàtres sont dressés ; les chatons femelles sont rougeàtres et se transforment en cônes bruns, dressés, se désarticulant à l'humidité. La floraison a lieu en automne; les graines ne mûrissent que la deuxième année.

Le Cèdre de l'Atlas se rencontre sur les montagnes les plus élevées de l'Algérie, généralement entre 1.200 et 1.800 mètres d'altitude (voir chap. xil).

Cette espèce diffère peu dú Cèdre du Liban que l'on trouve en Orient.

Le bois de Cèdre est blanc à l'état d'aubier, mais le cœur est brun et incorruptible, grâce à la térébenthine qu'il contient et qui lui donne son odeur aromatique. Cette proprićté permet d'exploiter comme bois-d'wuvre des arbres morts depuis vingt-cing ans et plus.

Le bois du Cèdre acquiert une grande dureté quand il a séjourné dans l'eau. Il est susceptible d'un beau poli ; actucllement on l'emploie surtout pour la fabrication de traverses de chemin de fer et de pavés. Il ne donne qu'un chaulfage médiocre; son charbon n'est pas apprécié.

Une variété, dite Cèdre rouge, existant dans la région de Batna, présente un bois rosé à odeur de Genévrier.

Les Pins sont des arbres à cime pyramidale, aiguë, ì l'état jeune, s'étalant ou s'arrondissant plus tard ; les branches sont verticillées et étalées, le couvert clair; les fécuilles en aiguilles, persistantes, sont réunies a la base par '2 à ij dans une gaine 
membraneuse. Les fleurs ont été décrites (page 59); les cônes restent petits jusqu'à l'été de l'année qui suit celle de la floraison; e'est à cette époque que s'aclıève la fécondation et les cònes grossissent alors rapidement pour mûrir à l'automne.

Les Pins sont des essences sociales très importantes au point de vue forestier; deux espèces seulement sont spontanées en Algèrie :

Le PIN D'ALEP (Pinus halepensis Mill.) (Fig. 143) est un arbre à écorce d'un gris argenté. Les feuilles disposées par

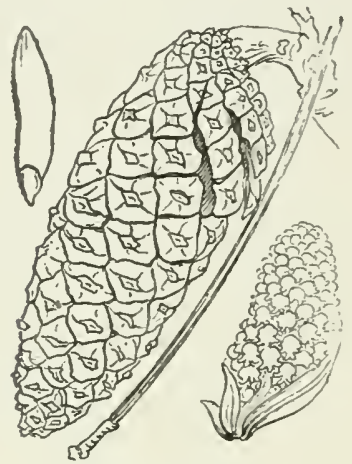

Pinus halepensis.

Fig. 143.

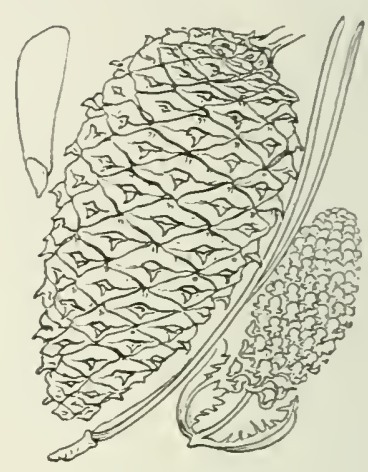

Plnus Pinaster.

Fig. 144.

deux ont de 6 à 10 centimètres, elles sont étroites et molles, de couleur vert clair.

Les chatons mâles, roussàtres, ont de 6 à 10 millimètres; les chatons femelles, violacés, 10 millimètres environ. Le còne ( 8 à 12 centimètres) est rouge brun luisant, à écailles presque plates.

Cette essence est très répandue en Algérie (voir chap. xir). C'est un arbre à couvert léger et à tempérament robuste, résistant bien à la sécheresse et à la chaleur. Il peut dans de bonnes conditions atteindre un grand développement, mais on le rencontre fréquemment dans les sols arides où les autres essences ne peuvent prospérer. C'est surtout une espèce des terrains calcaires.

La fructification est abondante et pricoce, les jeunes plants robustes. 
Le bois du Pin d'Alep est de qualité médiocre; il est surtout utilisé pour la fabrication des caisses. Il est peu apprécié pour le chauffage des habitations et comme charbon; seules, les usines l'utilisent volontiers parce qu'il flambe bien.

L'écorce, riche en tanin, est utilisée par les indigènes pour la préparation des peaux.

Le gemmage du Pin d'Alep, abandonné en France, se pratique actuellement en Oranie ; et cet arbre parait appelé, de ce fait, à prendre de l'importance en Algérie.

Le PIN MARITIME (Pinas maritima Lam, ou Pinus Pinaster Soland) (Fig. 144) a l'écorce profondément gerçurée, écailleuse ; ses feuilles, raides et épaisses, sont disposées par 2 et longues de 10 à 20 centimètres. Les chatons mâles. jaunâtres, ont 1 centimètre environ; les chatons femelles, rouge violet, sont petits. Le cône (12 à 18 centimètres), d'un roux vif, luisant, présente des écailles à mamelon central nettement saillant.

Le Pin maritime est, en Algćrie, localisé sur le littoral constantinois où il forme quelques massifs de médiocre importance et composés surtout d'arbres de faible dimension (voir chap. xi1). On le rencontre aussi sur le littoral tunisien, et il a été signalé au Maroc près de Tetuan. En France il fait l'objet d'exploitations importantes, grâce à la résine qu'il produit en abondance.

Ses racines développées et sa croissance rapide permettent de l'cmployer avec succès pour la fixation des dunes.

On a introduit en Algérie plusieurs espèces de Pins: le PIN PIgNox (Pinus Pinea L.) (Fig. 145), dit P'in parasol à cause du port étalé de ses rameaux, est spontané en France sur le littoral méditerranéen: le cône presque globuleux renferme de grosses graines comestibles zgonzgou des Arabes).

Le Pix remarquable (Pinus insignis Dougl.), originaire de l'Amérique du Nord, est un bel

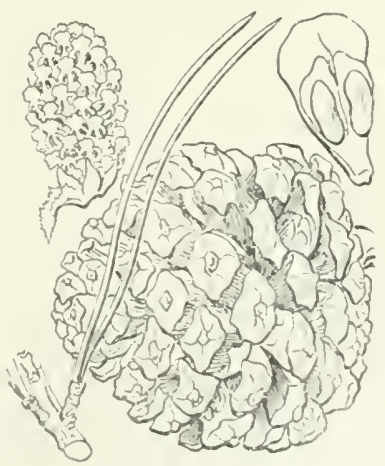

Pinus Pinea.

l:igs. 145. 
arbre à port pyramidal, à feuilles nombreuses et pressées.

Le Pin a loxgues feulles (Pinus longifolia Roxb.) est une espèce de la région de l'Himalaya; ses feuilles très développées, fines et pendantes, lui donnent un aspect caractéristique.

Le Pin des Canaries (Pinus canariensis Chr. Smith.) croît à Ténériffe au-dessus de 1.000 mètres d'altitude; il a été introduitil y a un demi-siècle en Algérie.

Le Pin Lakicio (Pims Laricio Poir.), dont il existe plusieurs variétés, est répandu en France et constitue en Corse d'importantes forêts; on le rencontre exceptionnellement planté en Algérie ${ }^{1}$.

Les Cupressinées présentent des feuilles persistantes. opposées ou verticillées, formées d'aiguilles étroites, aiguës, ou d'écailles imbriquées, e'est-à-dire se recouvrant en partie conme les tuiles d'un toit.

Les genres Genévrier (Juniperus) et Thuya (Callitris) sont seuls spontanés en Algérie. Les Cyprès (Cupressus) sont fréquemment cultivés.

Les Genévriers sont des arbres ou arbrisseaux très rameux, à floraison généralement dioüque, à chatons màles petits et jaunâtres, à chatons femelles formés d'écailles verdàtres, peu nombreuses, devenant charnues et se soudant entre elles pour former à maturité une sorte de baie. On rencontre quatre espèces en Algérie :

Le GENÉVRIER OXYCĖDRE (Juniperus Orycedrus L.) (Fig. 146) est un arbrisseau ou un petit arbre dressẻ, à feuilles par trois, terminées en pointe aiguë, marquées au-dessus de deux bandes blanchitres séparíes par la nervure médiane verte. Les fruits sont rouges et luisants à maturité (\$ a a 10 millimètres). On trouve sur les sables du littoral une variété à fruits plus gros et à feuilles plus larges (Juniperus macro('arpa Sibth et Sm.).

1. Les Araucarias sont quelquefois cultives en Algerie el daus 1. Midi

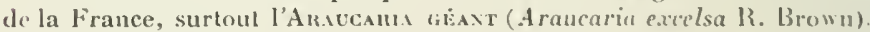

I a régularité de la disposition des brauches par étages superposés. sur une tige très droile, lonue i cel arbre un aspect parliculier.

Les feuilles en aiguilles, pelites el serrés, sont recourbès el ligèrement piquantes. 
Le Genévrier Oxycèdre est très répandu en Algérie (voir chap. xil). Son bois homogène et à grain fin est employé en ébénisterie ct pour la fabrication des crayons. Il est assez apprécié pour lechauffage et donne un charbon de bonne qualité. On en extrait, par distillation, I'huile de Cade, produit pharmaccutique.

Le GENÉVRIER COMMUN (Juniperus communis L. (Fig. 147) est un arbrisseau dont les feuilles, par trois,

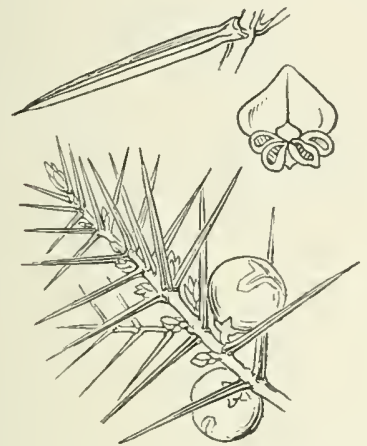

Junipэrus Oxycedrus.

Fig. 146.

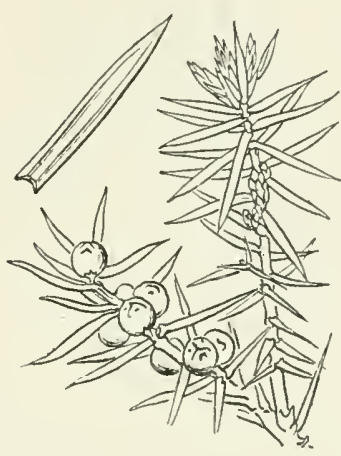

Juniperus communis.

Fig. 147.

terminécs en pointe aiguë, ne portent à la face supéricure qu'unc seule bande.blanchâtre (ou deux presque réunies). Lc fruit (5 à 7 millimètres) est noir bleuàtre à maturité.

Cette espèce est confinéc, en Algéric, sur les hautes montagnes du Djurjura et de l'Aurès.

On prépare une liqueur en laissant macérer les fruits mûrs dans du cognac pendant quelques jours. Les infusions de fruits (10 a 20 grammes pour 1 litre d'eau) et les décoctions de bois sont utilisées comme diurétiques et toniques.

Le GENÉVRIER DE PHÉNICIE (Juniperus phanicea L.) (Fig. 148) est un arbrisseau touffu ou un arbuste à feuilles, les unes en aiguilles, ne se développant que dans le jeune âge, les autres en écailles très petites, très imbriquées, opposées, formant le feuillage de l'arbre après les prenières années. Le fruit globuleux est rouge et luisant à maturité. 
Cette espèce, très répandue sur le littoral et les montagnes du Sud, fournit un bois utilisé comme combustible et un charbon estimé :

Le GENÉVRIER THURIFÈRE (Juniperus thurifera L.) (Fig. 149) est un arbuste ou un petit arbre à branches très

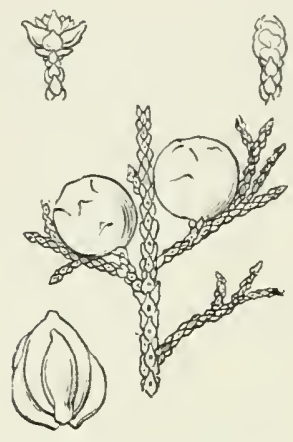

Juniperus phœnicea.

Fig. 148.

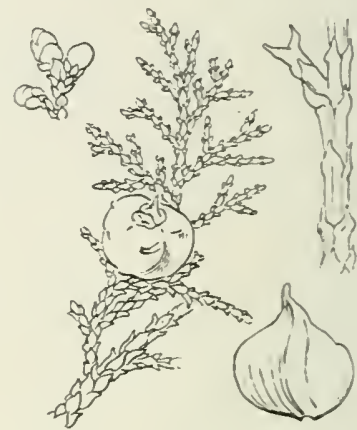

Juniperus thurifera.

Fig. 149.

étalées à feuilles aiguës, làchement imbriquées, étalées à leur partie supérieure. Les fruits sont d'un brun bleu.

Cette espèce est confinéc en Algérie dans les montagnes de

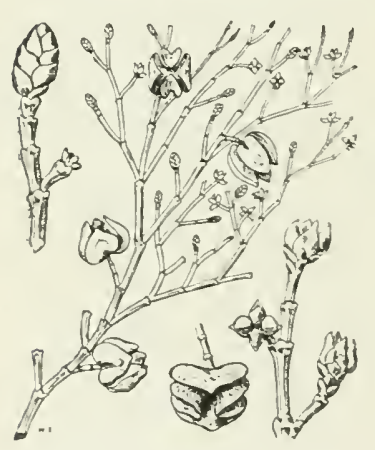

Callitris quadrivalvis.

Fig. 150 . l'Aurès Sgag, Médina, Djebel Mahmel), où elles forment souvent des arbres gros et courts.

Le THUYA D'ALGÉRIE (Callitris quadrivalvis Vent. ou Tetraclinis articulata Vahl.) (Fig 150) est un arbuste, ou un arbre à cime pyramidale, s'étalant en parasol chez les sujets àgés. Les rameaux sont articulés et grêles; les feuilles opposées sont soudées au rameau; l'extrémité seule est libre et forme une petite écaille triangulaire. La floraison est monoìque sur des rameaux différents. Les chatons mâles sont petits; les chatons femelles, composés de quatre écailles en croix, se séparant à maturité, donnent un fruit de forme caractéristique. 
Cette essence est surtout abondante dans l'Algérie occidentale. Toutefois elle existe par pieds isolés ou par petits bouquets jusqu'à l'entrée de la Kabylie (Dellys, Palestro) et dans la vallée de l'Oued Sahel jusque vers Maillot, puis disparaît dans le département de Constantine, pour reparaître sous le climat plus chaud de la Tunisie. Contrairement à la grande majorité des Conifères, elle rejette abondamment de souche.

C'est une espèce peu exigeante, à enracinement profond.

Le bois, blanc à l'état d'aubier, brun à l'état parfait, est imprégné de térébenthine, ce qui le rend indestructible et lui communique une odeur caractéristique. Il fournit un chauffage excellent et un charbon de bonne qualité.

Les souches dénudées peuvent former des broussins atteignant un grand volume et fournissant un très beau bois de placage, que les anciens connaissaient sous le nom de " citre".

Le Thuya d'Algérie fournit une résine dure, blanche appelée sandaraque et utilisée dans la fabrication des vernis.

Le Thuya GÉANT (Thuya gigantea Nutt), originaire de l'Amérique du Nord, est un très bel arbre d'ornement. On cultive plusieurs espèces de ce genre en Algéric et dans le midi de la France.

Le genre Cyprès comprend des arbres à feuilles en forme d'écailles se recouvrant étroitement; les cònes sont en boules et s'ouvrent par séparation des écailles implantées comme des clous à large tète.

Le Cýprès toujours vert (C. sempervirens L.) ou Cyprès commun présente deux variétés différant beaucoup par le port et dont on fait quelquefois des espèces distinctes : le Cyprès horizontal, à rameaux étalés, et le Cyprès fastigié ou pyramidal, à rameaux dressés. Le premier était autrefois considéré commel'arbre màle et le deuxième comme l'arbre femelle; en réalité, chaque arbre porte des fleurs des deux sexes, mais on conserve encore les nonıs de Cyprès mâle et Cyprès femelle. Le bois du Cyprès commun, à odeur agrẻable, était très employẻ dans l'antiquité et est encore très recherché. La variété pyramidale, souvent utilisée comme brise-vent, estaussi très répandue dans les cinstières. Cette circonstance ne doit pas la faire confondre avec le Crphès fuxibne (C. funcbris 
Endl., arbre de Chine utilisé dans ce pays pour l'ornement des tombeaux.

Le Cýprès funèbre se distingue d'ailleurs facilement du précédent par ses rameaux retombants qui lui ont valu le nom de Cyprès pleureur.

Le Cýprès de Laybert ou Cyprès a gros frutts (C. Lambertiana Carr., ou macrocarpa Hartw.), dont le port rappelle de loin celui d'un jeune Cèdre, est originaire de l'Amérique du Nord; le bois de cette essence, assezfréquemment plantée en Algérie, est réputé.

Le Cyprès de Portugal (C. lusitanica Mill), appelé aussi

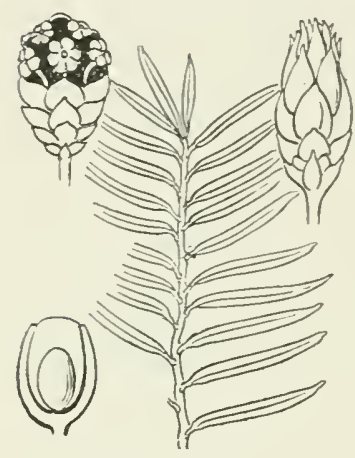

Taxus baccata.

Fig. 151.

Cyprès glauque, est originaire de l'Inde et a été introduit en Portugal au $x^{\prime}{ }^{e}$ siècle dans le jardin de l'Abbaye de Bussaco: d'où son nom vulgaire de "Cèdre de Bussaco »; c'est un arbre à branches pendantes portant de jeunes rameaux d'un vert glauque.

Les Taxinées sont représentées, en Algérie, par une seule espéce:

L'IF Comulx (Taxus baccata L. (Fig. 151) est un arbuste ou un arbre à feuillage sombre; les feuilles vert foncé en dessus, clair en dessous, sont linéaires et disposées sur deux rangs opposés. La floraison est dioïque: les chatons màles sont globuleux et jaunâtres; les chatons femelles présentent six bractées imbriquées entourant un ovule unique. Le fruit, charnu, d'abord vert, devient rouge à maturité.

Cette essence n'est spontanée en Algérie que sur les hautes montagnes (Atlas de Blida, Djurjura, Babors, Aurès).

Son bois est recherché par l'ébénisterie : il ne sécrète pas de suc résineux.

L'If convient très bien pour la confection des haies defantaisie.

Ses organes verts renferment un principe toxique qui peut causer des empoisonnements du bétail. Les fruits ont des propriétés abortives. 


\section{CHAPITRE VIII}

\section{LES MONOCOTYLÉDONES}

Cette classe, dont les caractères ont èté donnés au chap. vi, (page 59) se divise en trois groupes :

$1^{\circ}$ Les Monocotylédones à fleurs vivement colorées;

$2^{\circ}$ Les Monocotylédones dont les enveloppes florales, vertes ou brunâtres, sont peu apparentes ;

$3^{\circ}$ Les Monocotylédones dont les fleurs n'ont pas de corolle.

Les MONOCOTYLÉDONES à flents vivement colorées comprennent quatre familles principales.

Planles à ovaire supèré

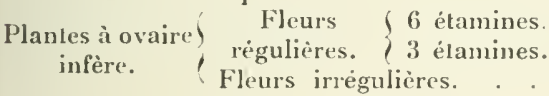

Liliacées.

Amaryllidées.

Iridees.

Orchidées.

Les trois sépales étant de mêne couleur, en général, que les trois pétales, la lleur semble posséder six pétales.

LILIAGEES. - On peut diviser les Liliacées en trois tribus.

Celle des Liliées (Ex. : Lis, Asphodèle, Ail, Poireau, Oignon, Scille) et celle des Colchicées (Ex. : Colchique) ne présentent pas de plantes ligneuses. Dans la tribu des Asparagées, caractérisée par le fruit qui est une baie, nous avons trois genres à signaler.

Dans le genre Asperge (Asparagus), les feuilles sont réduites à des écailles et les organes que l'on prend d'ordinaire pour des feuilles linéaires sont, en réalité, des rameaux modiliẻs que l'on appelle cladodes.

Quatre espèces algériennes sont ligneuses. L'A sl'EkGE A Feunles angulis (Asparagus arutifolius L.) (Fig.152), at tiges llexueuses et sarmenteuses et l'ASPEnge BLANCHE (Asparagus albus L.) (Fig. 153), à tiges blanches, robustes, en buissons serrés, sont de beaucoup les plus répandues. Leurs jeunes tiges ou lurions sont comestibles.

L'Asparagus horridus L. est une espèce buissonnante dont les épines atteignent 2 à 4 centimètres de longueur que l'on 
rencontre, çà et là, en particulier de Blida au Chéliff, dans la région de Boghar et dans celle d'Oran

L'Asparagus altissimus Munby est grimpant ; ses tiges

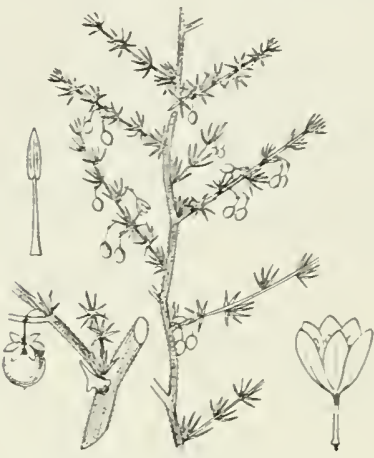

Asparagus acutifolius.

Fig. 152.

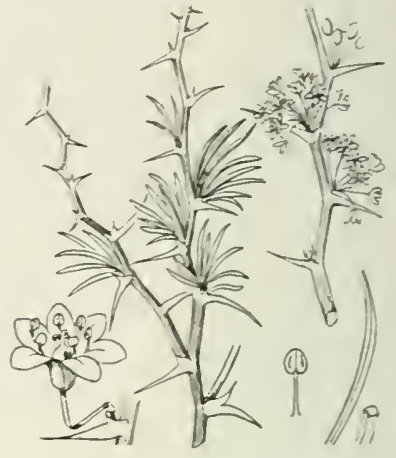

Asparagus albus.

Fig. 153.

grêles atteignent 4 mètres; on le rencontre aux environs d'Oran, à Arzew, etc.

Le Genre Fragon (Ruscus) comprend des sous-arbrisseaux toujours verts dont les cladodes aplatis qui ont l'aspect de véritables feuilles, portent sur leurs faces les fleurs et les fruits (baies rouges).

Le Fragon piquant ou Petit Houx (Ruscus aculealus L.) (Fig. 154) porte les fleurs à la face supérieure de ses fausses

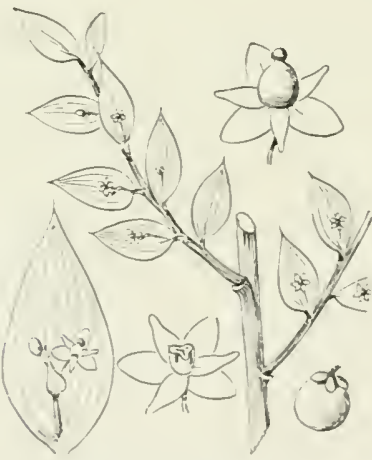

Ruscus aculeatus.

Fig. 154 .

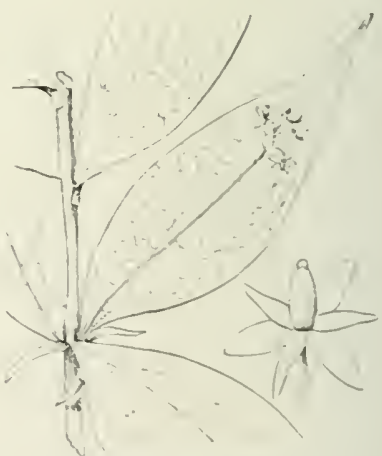

Ruscus Hypoglossum

Fig. 15.\%. 
feuilles qui sont rigides et piquantes; on le rencontre çà et là en montagne.

Le Fragon Hypoglosse (Ruscus Hypoglossum L.) (Fig. 155), dont les fleurs sont à la face inférieure des fausses feuilles, porte des fruits rappelant de petites cerises. Les cladodes sont grands et mous; on le rencontre surtout dans les stations humides de la région du Chêne-liège.

Le Genre Smilax n'est représenté que par une espèce; le

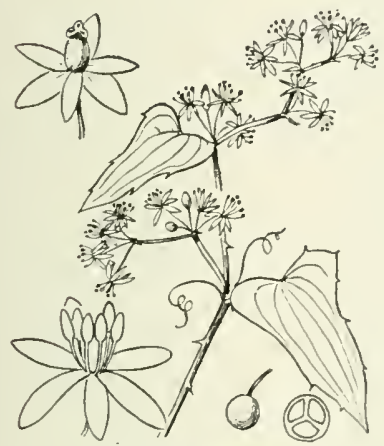

Smilax aspera.

Fig. 156 .

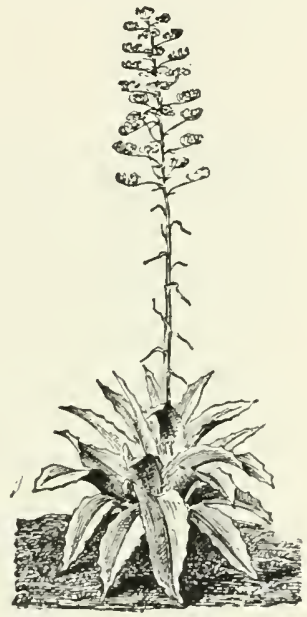

Agave americana.

Fig. 157 .

Smlax rude ou Liseron épineux (Smilax aspera L.) (Fig. 156). très connu sous le nom de Salsepareille ${ }^{1}$; c'est une liane à feuilles en cœur plus ou moins épineuse qui rend souvent impénétrables les lorèts du littoral.

C'est à la famille des AMARYLLIDÉES, dont le Narcisse est un exemple bien connu, quappartient le genre Agave qui comprend de grandes plantes à feuilles charnues originaires d'Amérique, souvent plantẻes en Algérie, désignées à tort sous le nom d'Aloès. L'espèce la plus répandue est l'Agave Americana L. (Fig. 157).

1. La raeine de Salsepareille, utilisée en médecine, provient de l'Anérique du sud et des Antilles. 
Les IRIDEES (Iris, Safran) et les ORCHIDEES (Ophrys, Orchis) ne comprennent pas de plantes ligneuses spontanées en Algérie. La Vanille, qui fournit des fruits aronıtiques, est une Orchidée d'Amérique.

Parmi les MONOCOTYLÉDONES à enveloppes florales peu apparentes, nous citerons la famille des JONCACÉES.

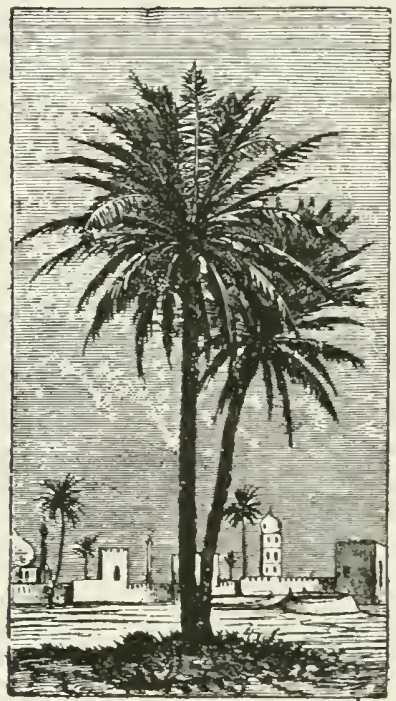

Phœnix dactylifera.

Fig. $15 \mathrm{~s}$.

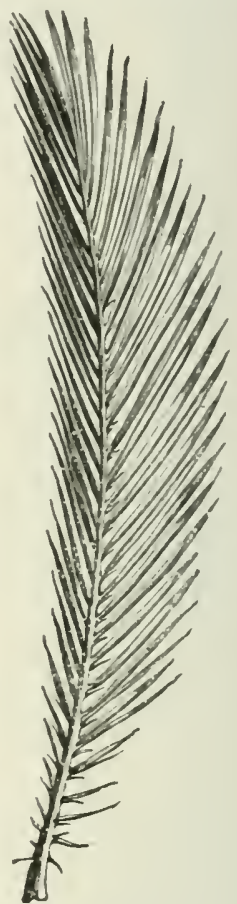

Feuille de Phonix dactylifera.

Fig. 159 .

comprenant les Jones, herbes de marais, et nous dirons quelques mots de celle des PALMIERS.

Le Palmer dattier (Phanix dactylifera L.) (Fig. 158 et 159), bien connu par son fruit la datte, n’est pas spontané; il ne mûrit que dans le sud de l'Algérie, el constitue la principale culture des oasis. 
Le PALMIER NAIN (Chamerops humilis L.) est une plante buissonnante, à feuilles en éventail (Fig 160), extrêmement répandue dans les départements d'Oran et d'Alger. Cultivé, il peut atteindre plusieurs mètres de hauteur.

Le bourgeon terminal de cette espèce est comestible, mais le Palmier nain est surtout exploité pour la filasse (crin végétal) que l'on tire de ses feuilles. Elles servent aussi pour la confection d'objets de vannerie.

Le Phonix canariensis Hort. est quelquefois cultivé en Algérie; de

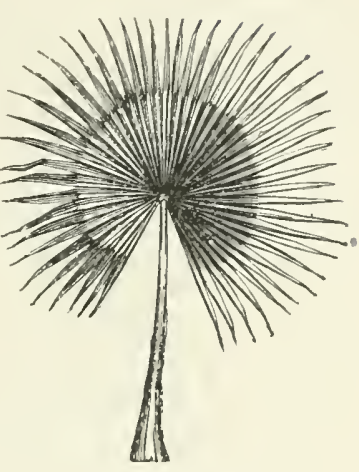

Feuille de Chamarops humilis.

Fig. 160. nombreuses espèces de Palmiers sont d'ailleurs employées pour l'ornement.

Les MONOCOTYLÉDONES à fleurs sans rorolle sont représentées en Algérie par la famille des GRAMINEES. Les plantes de cette famille sont répandues sur toute la surface du globe; elles forment la plus grande partie de ce que l'on appelle ordinairement "le gazon " et comprennent les espèces les plus utiles à l'homme. Elles sont cultivées depuis la plus haute antiquité. Comme exemple citons : le Blé, le Seigle, l'Orge et l'Avoine.

Ce sont des plantes herbacées ou rarement ligneuses; leur tige, creuse et entrecoupée de nouds pleins, s'appelle chaume. Lesfeuilles, longues, à nervures parallèles, sont alternes; elles comprennent une gaine entourant la tige et un limbe. Le sommet de la gaine présente souvent une partie libre, membraneuse, dite ligule (Fig. 161).

Les lleurs sont groupées en épillels, c'est-à-dire en petites grappes dans lesquelles les pédoncules des lleurs sont tellement courts que ces dernières paraissent appliquées contre l'axe.

Les épillets sont à leur tour réunis soit en épis (Ex. : le Blé, Fig. 162), soit en panicules, grappes irrégulières et plus ou moins rameuses (Ex.: l'A voine). 
En étudiant un épillet de Blé (Fig. 163), on voit qu'il porte à sa base deux petites feuilles dites glumes; au-dessus sont d'autres petites feuilles ou bractées dites glumelles, se faisant

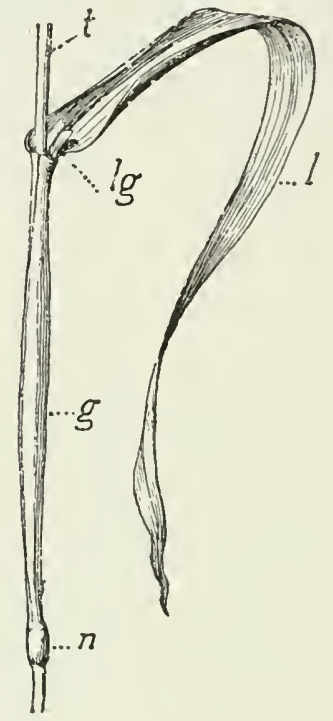

Feuille de Graminée (Blé) : $l$, limbe: $l g$, ligule: $g$, gaine: $n$, noud ; $t$, lige.

Fig. 161.

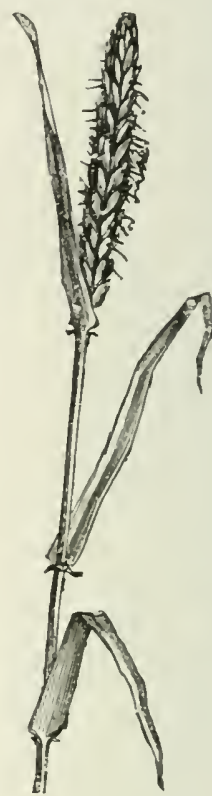

Inflorescence de Blè.

Fig. 162.

face deux par deux; chacun de ces groupes de deux glumelles enveloppe une fleur (Fig. 164) composée de trois étamines et d'un ovaire portant au sommet deux stigmates plumeux et enveloppé à la base par deux nouvelles petites bractées, les glumellules.

Les arêtes que présentent souvent les épis sont portẻes par les glumelles, quelquefois par les glumes.

Le fruit des Graminées a pour type le grain de Blé; il est appelé caryopse.

L'Alfa et le Diss sont deux Graminées extrèmement importantes en Algérie; nous signalerons aussi les Roseaux à cause de leur consistance ligneuse. 
L'ALFA (Stipa tenacissima L.) (Fig. 165) est une herbe vivace à rhizome rameux, dont les feuilles, d'abord vertes et planes, blanchissent sous l'influence de la sécheresse; les deux

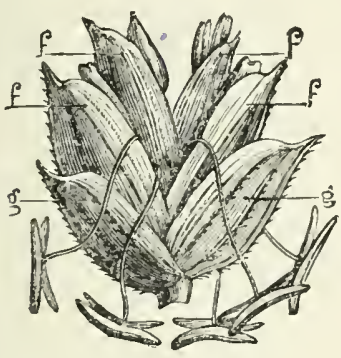

Epillet de Blè : $f$, fleurs : $g$, glumes.

Fig. 163.

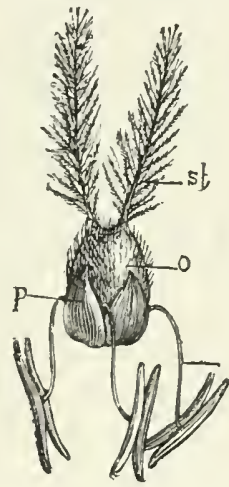

Fleur de IBlé : $p$, glumellule : $e$, ètamine: $o$, ovaire; st, stigmate.

Fig. 164.

bords se rapprochent alors et le limbe devient cylindrique et dur, terminé par une pointe piquante.

Les épillets, réunis en panicules, sont à une seule fleur; la glumelle inférieure est terminée par une arête genouillée.

L'Alfa est surtout une plante des Hauts Plateaux; toutefois dansle département d'Oran on le rencontre jusqu'au bord de la mer.

La gaine et le limbe de la feuille se séparent facilement, ce qui permet de récolter ce dernier, qui est utilisé en vannerie, corderie, sparterie, et mème pour la fabrication des tentures et tapis. On en fait aussi un papier d'excellente qualité. L'exploitation de l'Alfa constitue une industrie importante en Oranie.

Arrachées avec le bout des tiges, les feuilles d'Alfa sont utilisées comme fourrage par les indigènes.

Le DISS (Ampelodesmos tenax Link.) (Fig. 166) constitue de grosses toulfes répandues dans les bois et les pàtures du Tell. C'est une herbe vivace à longues feuilles rigides; les épillets, souvent violacés, sont disposés en une grande panicule portée sur une hampe allongée. 
Le Diss maintient bien le sol sur les pentes rapides, mais il a lïnconvénient de fournir aux incendies un aliment facile. Les feuilles servent à la nourriture du bétail et á la confec-

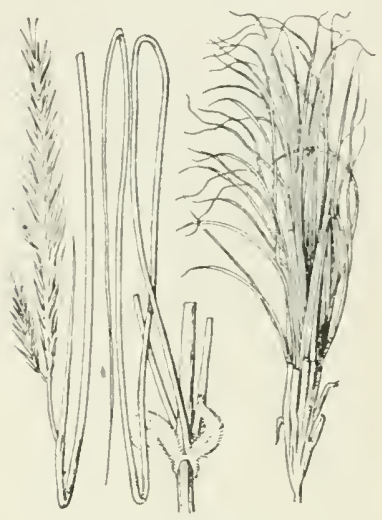

Stipa tenaclssima.

Fig. 165 .

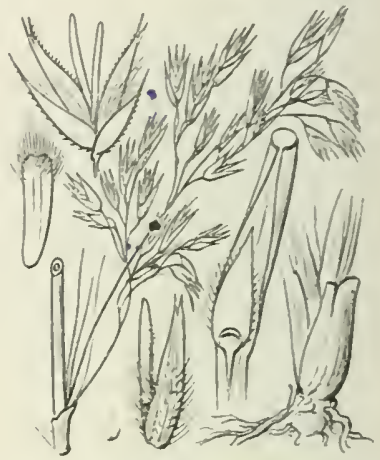

Ampelodesmos tenax.

Fig.166.

tion des gourbis; les indigènes fabriquent des paillassons avec les hampes.

Le Roseau commun ou Roseau à balai (Phragmites communis Trin.) atteint 6 mètres et plus de hauteur ; il est abondant au bord des fossés et des rivières. On le rencontre aussi dans les marais, les chotts, etc.

Le Roseau de Provexce ou Canne de Provence, Roseau à quenouille (Arundo Donax L.) atteint 3 à 5 mètres de hauteur; il croît en Kabylie dans les lieux humides et est fréquemment cultivé.

Le Roseau de Mauritanie (Arundo Pliniana Turr.) n'atteint guère que 2 ou 3 mètres; il est assez commun au bord des cours d'eau.

Ces différents roseaux sont utilisés pour faire des clòtures et des abris.

Les Bambous (Bambusa) sont des Graminées originaires des pays chauds à chaumes très élevés et de consistance ligneuse. Les feuilles, généralement lancéolées, sont portées par des branches ramiliées qui prennent naissance au niveau des nouds. 
Plusicurs espèces croissent facilement en Algérie, stirtout dans les terrains siliceux et frais : tels sont les Bambusa arundinacea Retz. Bambusa vulgaris Wendl., etc.

Les chaumes sont utilisés pour la fabrication de cannes, de meubles, de clòtures, de conduites d'eau, de manches légers et d'ustensiles divers.

On fabrique en Chine, avec les fibres, un papier dit de soic, très recherché.

\section{CHAPITRE IX \\ DICOTYLÉDONES : LES APÉTALES}

Nous distinguerons, comme il a été dit précédemment (page 62 , les Apétales amentacées, dont les fleurs, les mâles tout au moins, sont disposées en chatons, et les Apétales non amenlacées qui ne présentent pas ce caractère.

\section{§1. - Amentacées.}

La famille des CUPULIFERES comprend des arbres ou arbrisscaux à feuilles alternes, entières ou dentées, janais composées. Ce sont des plantes monoüques, c’est-à-dire que le mème sujet porte les fleurs nâles et femelles; les premières sont en épis pendants (chatons); les secondes, à ovaire infère, sont solitaires, en épis ou en capitules.

La famille comprend trois tribus que plusieurs auteurs élèvent au rang de familles :

Fruit à cupule $\left\{\begin{array}{c}\text { Fleurs mâles dépourvues de calice; un ovule par car- } \\ \text { pelle : tribu des Corylies (ou famille des Corylaceses } \\ \text { Fleurs toutes pourves de calice; deux ovules par car- } \\ \text { pelle: tribu des Quercées (ou Cupulifères proprement } \\ \text { dils) }\end{array}\right.$ Fruit sans cupule : Iribu des Beilulies (ou famille des Bélulacécs).

La tribu des Corylées n'est représentée en Algéric par aucune espèce spontanée; elle comprend le Charme et le CouFLOHE HORESTIEUE 
drier (Noisetier) abondants en France; ce dernier se rencontre quelquefois en Algérie, mais il a été importé.

La tribu des Quercées renferme les Chênes et le Châtaignier.

Le Hêtre, qui constitue en Europe des massifs étendus, manque dans le Nord de l'A frique.

Le genre Chêne (Quercus) est composé d'arbres à feuilles dentées ou crénelées (c'est-à-dire à dents larges et arrondies'. Les chatons mâles, simples et pendants, sont réunis en faisceaux aux extrémités des pousses de l'année précédente, ou solitaires à la base des nouvelles pousses. Chaque fleur màle

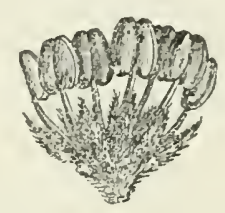

Fleur mâle de Chêne.

Fig. 167 .

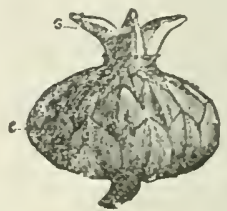

Fleur femelle de Chêne : $s$, sligmate; $c$, cupule.

Fig. 168.

(Fig. 16ī) est composée d'un calice formé de quatre à neuf petits sépales verts et contenant un groupe de quatre à neuf étamines.

Les fleurs femelles réunies en petits épis isolés à l'aisselle des feuilles de l'extrémité des jeunes pousses, sont globuleuses et entourées de bractées (Fig. 168). Les sépales, unis à l'ovaire, forment de petites dents à la base du style; celui-ci se divise en trois stigmates rouges. L'ovaire est à trois loges renfermant chacune deux orules.

A près la fécondation, un seul ovule se développe pour don. ner naissance à un gland dont la cupule est formée par les bractées qui entouraient la fleur.

Les Chênes sont des arbres à bois lourd, dur et serré, devenant brun à l'ètat parfait.

Cinq espèces sont spontanées en Algérie : deux, le Chêne zéen et le Chêne Afarès sont à feuilles caduques. Le Chèneliège, le Chêne vert et le Chène Kermès sont à feuilles persistantes.

Le CHÊNE.LIEGE (Querens Suber L.) (Fig. 169) est un 
arbre trapu de 15 à 20 mètres de hauteur. La feuille est coriace, d'ordinaire petite et bien dentée, verte en dessus, blanchàtre en dessous. Le gland, surmonté d'une pointe courte, velue dans toute sa longueur, est à demi enfoncé dans la cupule dont lesécailles, peu saillantes à la base, deviennent plus allongées vers le haut. Ce fruit est quelquefois doux; sa maturation sc fait en une année.

L'enracinement puissant du Querens Suber lui permet de sinstaller dans les endroits les plus rocheux; il présente une

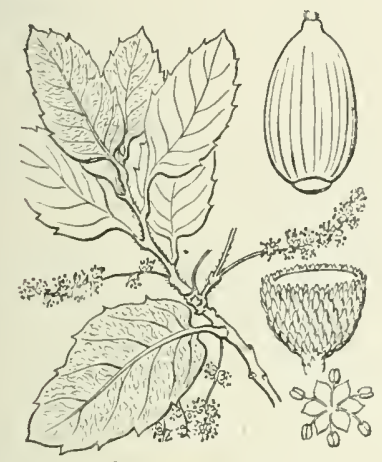

Quercus Suber.

Fï. 169.

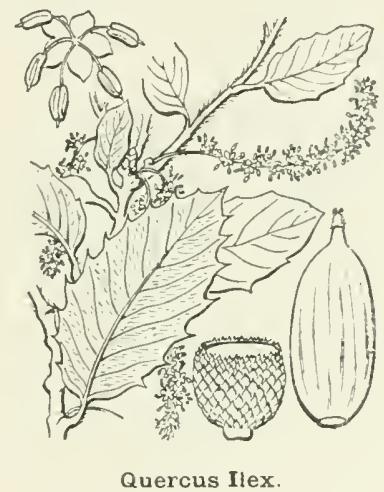

Fig. 170.

belle végétation en terrain siliceux; on ne le rencontre pas daus les sols calcaires.

Le Chène-liège repousse bien de souche; les jeunes plants sont robustes et le couvert léger; il en résulte que les peuplements de cette espèce sont généralement envahis par les essences secondaires.

L'ćcorce, connue sous le nom de "liège », constitue un produit de grande valeur; le liber est exploité comme écorce à tan.

Le bois, pesant et sujet à se toumenter, est rarement utilisé dans l'industrie; d'ailleurs les trones sont souvent cariés.

Écorcé, c'est un excellent bois de chauffage. Le Chêne-liège fournit enfin un charbon estimé. (Répartition géographique, voir chap. xis.) 
Cette essence peut donner avec le Chène Afarès des hybrides que l'on a classés en deux catégories sous les noms de Chêxe de Numide (Quercus mumidica Trabut) et de Chèxe Kabýle (Quercus kabylica'Trabut).

Le premier a l'aspect d'un Chêne Afarès à petites feuilles et porte une écorce se rapprochant de celle du Chène-liège : le second a l'aspect d'un Chêne-liège, mais son écorce est inutilisable.

Le CHENE VER'T ou CHENE YEUSE (Quercus llex L.) (Fig. 170) peut atteindre les mêmes dimensions que le précédent; toutefois on le trouve souvent à l'état de broussailles.

La feuille, plus ou moins épineuse, ressemble à celle du Cliène-liège, mais elle a d'ordinaire sept à dis nervures, tandis que celle de ce dernier n'en a que cinq à sept.

Le gland est surmonté d'une forte pointe, velue seulement à l'extrémité, et enfoncé, quelquefois profondément, dans une cupule à écailles petites et peu saillantes. La maturation est annuelle; la fructification abondante.

Le Chène vert, très répandu sur les sols calcaires, se rencontre aussi sur les grès. Il résiste mieux que le Chêne-liège aux expositions chaudes et supporte mieux le froid et la sécheresse.

Le couvert est assez épais.

C'est un arbre qui rejette très bien de souche et donne d'abondants drageons.

L'aubier est moins coloré que le bois de cœur, mais ne s'en distingue pas aussinettement que chez le Chène-liège. Le bois est dur, compact et se gerce facilement; bien débité, il est d'un fort bel aspect. On l'emploie comme bois d'ourrage.

Excellent pour le chauffage, il produit aussi un charbon recherché. (Répartition géographique : voir chap. xur.)

Le Cintexe Ballote (Quercus Ballola Desf.) est une variété de Chêne vert fort commune en Algérie, se distinguant par ses glands plus gros, à saveur douce, dont les indigènes font une grande consommation :

Le CHENE KERMES (Quereus coccifera L.) (Fig 171) se rencontre surtout à l'état de broussailles; il ne dépasse gènéralement pas 4 mètres de hauteur; lorsque ce Chène atteint de 
plus grandes dimensions, il est souvent appelé Fanx Lermes (Quercus pseudo-coccifera Desf.).

Les feuilles bordées de dents épineuses sont vertes sur les deux faces. Les glands mettent deux ans pour mûrir ; leur cupule est hérissée d'écailles pointues, aplaties ou recourbées.

Cette essence se rencontre dans les sols secs et pierreux; elle supporte bien le calcaire, mais elle prospère aussi dans les sables des dunes.

Le Chène Kermès rejette de souche et drageonne abondamment.

Le bois, excellent pour le chauffage, ressemble beaucoup a

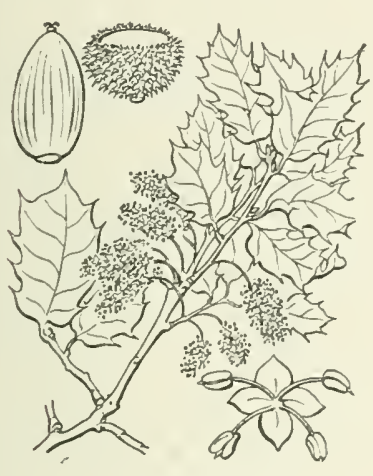

unercus coccifera.

Fig. 171.

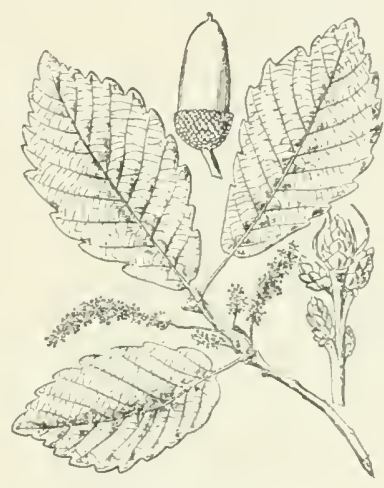

Quercus Mirbeckii.

Fig. 1\%2.

celui du Chêne Yeuse. L'écorce est recherchée pour le tannage, mais, à cause de la faible dimension des tiges, on récolte surtout l'écorce des racines appelée garonille.

Ce Chène porte dans certains pays un insecte appele Kermes (vulgairement: graine d'écarlate). La femelle, qui se fixe sur les rameanx, etait autrefois recherchéc pour la fabrication d'une teinlure rouge; on en roit peu en Ilgérie. Répartition géographique : voir clsap. xn.)

Le CHENE ZEEN (Onerens Mirberlii Dur.) (Fig 17'2) atleint 30 mètres de hautcur et ressenble beaucoup au Chène rourre de France; toutefuis les feuilles du Zéen sont plus coriaces el. au lieu de cing à huit paires de nervures, en portent dix à quatorze, régulières et bien marquées jusquau bord. La 
feuille est pétiolée, grande, sinuée, généralenıent marcessente.

Les glands sont agglomérés et presque sessiles; la cupule courte présente des écailles peu saillantes. La maturation est annuelle; la fructification abondante.

Ce Chêne possède un enracinement puissant; son bois, lourd et nerveux, est sujet à se gercer et à se tourmenter; on l'utilise surtout pour la confection des traverses de chemin de fer; convenablement traité, il peut fournir un bois d'ouvre de belle qualité.

Il donne un bon chauffage et un charbon recherché.

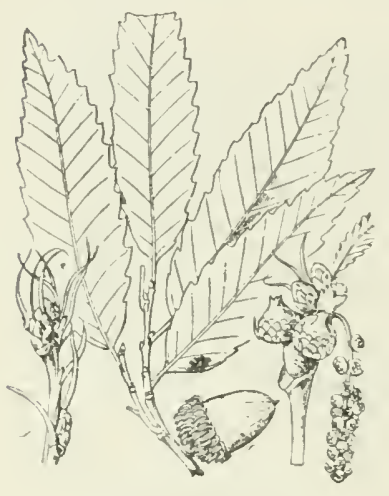

Quercus Afarès.

Fig. 173 .

Le liber est quelquefois exploité comme écorce à tan.

Les excroissances arrondies que l'on observe très fréquemment sur les rameaux du Chêne zéen sont dues à la piqûre d"insectes du genre Cynips; ces galles, qui donnent asile à de jeunes larres, sont riches en acides tanniques. (Répartition géographique : roir chap. xiı.)

Le CHÈNE AFARES (Querens Afarès Pomel) (Fig. 173), quelquefois confondu avec le Clic̀ne à feuilles de Chàtaignier (Qucreus ('astancerfolia Coss.) du Caucase, dont il est un peu différent, est, comme le Chêne zéen, un arbre de première grandeur mais à branches moins étalées que ce dernier et à port plus pyramidal.

Les feuilles, vertes et luisantes en dessus, blane verdìtre en dessous, sont bordées de dents triangulaires.

Les glands mettent deux ans pour mùrir ; les écailles de la cupule sont prolongèes en lanières allongées, robustes et anguleuses.

Les glandées ont lieu tous les trois ou quatre ans.

L'aubier est abondant et le bois, rouge-brun, moins apprécié que celui dı Chène zéen ; toutefois il se fend bien et pourrait ètre employé pour la construction. Le tan produit par le 
liber est peu employé. L'écorce de l'arbre, qui rappelle quelque peu celle du Chêne-liège par son aspect, ne présente qu'un liège sec et fragile, complètement inutilisable. (Répartition géographique : voir chap. xir.)

Le genre Châtaignier n'est représenté que par une espèce, le CHATAIGNIER COMMUN (Castanea vulgaris Lam.) (Fig. 174), grand arbre à écorce fendillée grisâtre dont les feuilles vertes et luisantes sur les deux faces sont longues, pointues et bordées de fortes dents.

Les fleurs mâles forment de longs chatons dressés; les

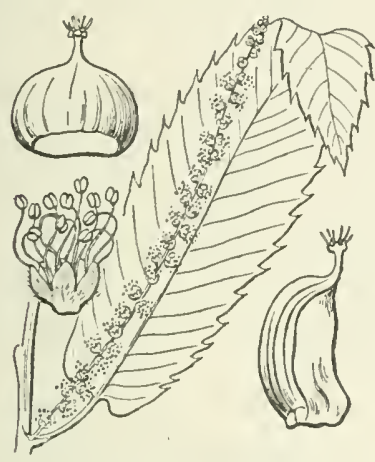

Castanea vulgaris.

Fig. 174

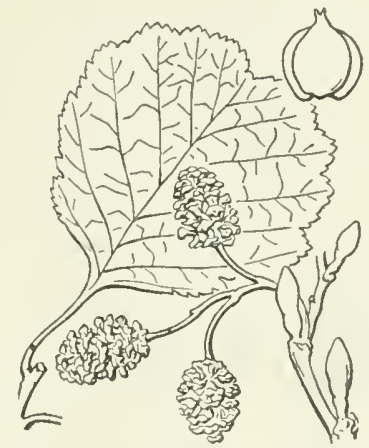

Alnus glutinosa.

Ifig. 175 .

fleurs femelles sont réunies par trois ; les fruits sont groupés de même sorte dans une enveloppe épineuse.

Le Châtaignier aime les terres meubles et profondes; il redoute le calcaire. Rarement spontané en Algérie (Edough près Bône, Bouzaréa au-dessus d'Alger) et en 'lunisie (Ain Draham), il est fréquemment planté dans le Tell, nais son bois est trop rare dans la colonie pour donner lieu à une utilisation industrielle On sait que la chàtaigne est comestible; améliorće par la culture, elle devient le marron; dans ce cas, chaque enveloppe épineuse ne contient plus qu'un seul fruit.

La tribu des Bétulées est représentée par un genre comprenant une seule espèce :

L'A UNE GLUTINEUX (Almus glulinosa Gartner) (Fig. 17.5) est un arbre de taille moyenne, à écorce brunitre, dont les 
feuilles visqueuses, surtout pendant la jeunesse, verles sur les deux faces, sont ovales et tronquées, souvent mème échancrées à l'extrémité.

Les fleurs sont disposées au bout des pousses de l'année, les chatons mâles au sommet, les femelles au-dessous.

Les fleurs mâles, groupées trois par trois à l'aisselle de bractées, forment un chaton serré. Chaque fleur comprend une enveloppe de quatre pièces et quatre étamines.

Les fleurs lemelles, composées d'un ovaire à deuxloges, sont réunies deux par deux à l'aisselle d'écailles épaisses; le chaton se transforme à maturation en un petit còne, portant deux graines à la base de chaque écaille.

On rencontre cette essence dans les stations humides du Tell oriental, surtout au bord des ravins et des cours d'eau.

Le bois, de teinte rouge clair, est très cassant; il se conserve bien sous l'eau. C'est un combustible brûlant vite avec une

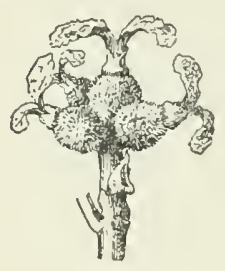

Flenrs femelles de Noyer.

Fig. 176. forte chaleur : le charbon est médiocre.

L'écorce est riche en tanin, mais donne un cuir sans souplesse; on l'utilise pour préparer une teinture noire 1.

\section{La famille des JUGLANDÉES com-} prend des arbres à feuilles composées; le fruit est une drupe.

Le Noyer connex (Juglans regia L.) est souvent cultivé en Algérie, en particulier dans les montagnes de la Kabylic, ses fleurs mâles sont disposées en épis allongés (Fig. 98, p. 44) et ses fleurs femelles en petits groupes de 1 à 4 (Fig. 176). Non seulement la noix est comestible, mais on en tire aussi de

1. Il convient de signater à còté de la famille des Cupulifires celle des CASUARINÉES, qui ne comprend que le genre Casuarina. Ce sonı des arbres australiens dont on rencontre souvent des plantalions en Algérie. Leur porl tout spécial permet de les reconnaitre facilement. Ils ressemblent à des Coniféres, à cause de leurs rameaux fins el allonges que l'on peut confondre à distance avec des feuilles en aiguilles, mais qui, vus de près. ressemblent plutò à ceux des Priles. Les fiuilles sont representies par de petites dents disposées en courome.

Le Casuanua equisetifolia Forst., el surloul le Casuarina temissima Hort., sont les deux espeices les plus cultivées en Algérie. 
l'huile. Le brou ou partic extérieure de la noix verte, ainsi que les feuilles vertes, préparés en décoction (15à 20 grammes de feuilles ou 30 à 60 grammes de brou par litre d'eau), sont toniques et dépuratifs.

La famille des SALIGINÉE est composée de plantes dioïques, cest-à-direque les fleurs màles et femelles se trouvent sur des sujets différents. Les fleurs, disposées en chaton. n'ont pas de périanthe; le fruit s'ouvre par deux valves.

Deux genres existent en Algérie :

Genre Saule : Les chatons sont dressés; la lleur mâle com-

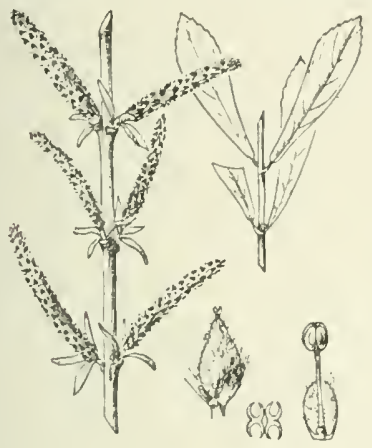

Salix purpurea.

Fig. 177.

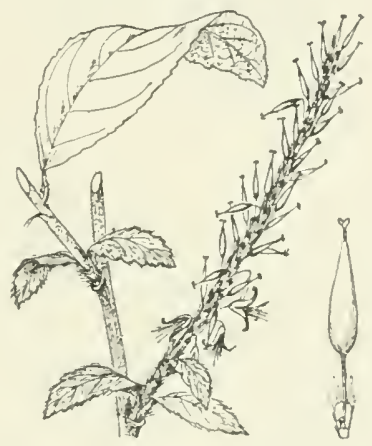

Salix pedicellat?.

Fig. 178.

prend deux (quelquefois trois ou cinq) élamines abritées par une bractée. La fleur femelle est réduite à un ovaire à une loge contenant de nombreux ovules. Le fruit est une capsule s'ourrant par deux fentes et renfermant des graines surmontées d'une aigrette dressée.

Les Saules sont des arbres, plus souvent des arbustes ou des arbrisseaux, à feuilles alternes et allongées. Il en existe plus de cent espèces dont l'étude est rendue difficile par la présence de nombreux liybrides.

Cinc espèces sont spontanées en Algérie : seuls, le SAULE POURPRE (Salix purpurea L.) (Fig. 177) et surtout le SALLI PÉDICELLÉ: (Salix pedicellala Desf.) (Fig 17S) sont communs ; le SAULE BLiNC (Salix alba L.) (Fig. 179) est spontané et cultivé. 
Le Saule cendré (Salix cinerea L.) (Edough près Bòne) et

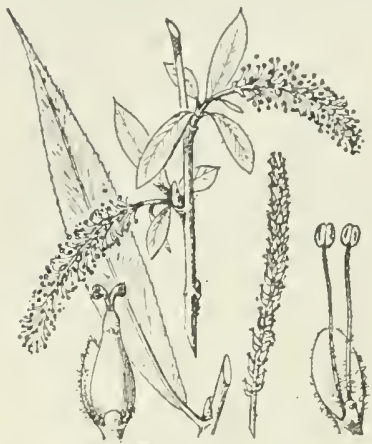

Salix alba.

Fig. 179 le Saule Amandier (Salix amygdalina L.) (Edough, Maison-Carrée, vallée de la Seybouse) sont rares.

Le Saule blanc seul atteint les dimensions d'un arbre; les autres sont des arbrisseaux répandus dans les endroits humides et utilisables pour la fixation des berges des cours d'eau. Les espéces dont les rameaux sont effilés sont utilisées en vannerie : l'Osier jaune (Salix vilellina L.) est une variété du Saule blanc.

Le Sacle fragile (Salix fragilis L.) présente également une varièté à rameaux flexibles et allongés, mais de couleur rougeâtre : c'est l'Osier rouge (‘. pendula Ser.).

Le Saule pleureur (Salix babylonica L.), voisin de ce dernier, a été introduit dans la colonie.

C'est avec l'ćcorce de certains Saules que l'on prépare le cuir de Russie dont le parfum est obtenu en l'imprégnant d'huile de Bouleau.

Genre Peuplier. - Les Peupliers sont des arbres généralement de grande taille à feuilles beaucoup moins allongées que celles des Saules, souvent même aussi larges que longues. Les chatons sont pendants. Les fleurs sont constituées comme dans le genre Salix; toutefois l'ovaire est entouré d'une petite coupe ef les étamines sont plus nombreuses (de six à trente). Le fruit est une cupule à deux ou quatre valves; les graines sont petites et munies d'une houppe de poils blanes.

Le PEUPLIER BLANC (Populus alba L.) (Fig. 180), souvent désigné à tort en Algérie sous le nom de Tremble, est un arbre élevé á écorce d'abord lisse, puis se crevassant en losange. Les jeunes pousses sont blanches cotonneuses; les feuilles, ovales ou presque orbiculaires, à bord plus ou moins découpé, sont blanches et couvertes de duret en dessous; elles ont un pétiole arrondi.

Le Peuplier blanc est plutòt un arbre de prairie qu'une essence forestiere; on le reproduit surtont par boutures. 
Laubier et le bois parfait sont peu distincts; cette espèce

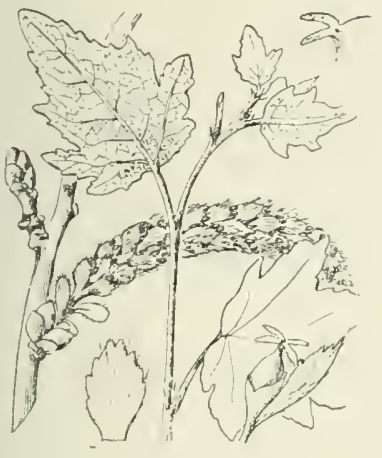

Populus alba.

Fig. 180.

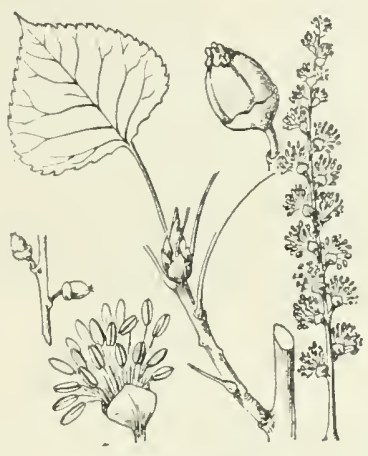

Populus nigra.

Fig. 181.

fournit de la planche légère, du bois de menuiserie, d'ébénisterie et de tour.

Le PEUPLIER NOIR (Populus nigra L) (Fig. 181) est un grand arbre à bourgeons et pousses sans poils, visqueux, à feuilles ovales triangulaires, régulièrement crénelées, vertes et luisantes sur les deux faces; le pétiole est comprimé au somnet.

On le rencontre au bord des ravins et à l'embouchure des oueds de la région montagneuse. Une variété pyramidale (Populus pyramidulis Bozier), c'est-ì-dire à rameaux dressés, connuc sous le nom de Peuplier n'Italie, se rencontre çà ct là, surtout en Kabylie.

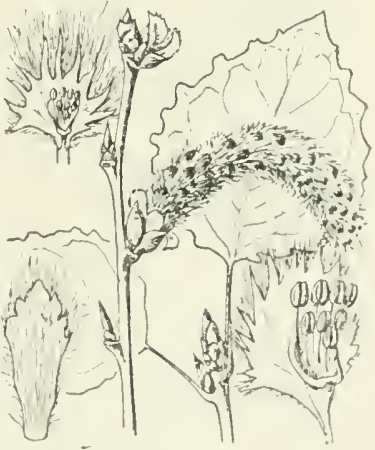

Populus Tremula.

lig. 182.

Le PEUPLIER TREMBLE (Populus Tremula L.) (Fig. 182) est un arbre de moyenne taille, à feuilles ordinairement presque rondes, très mobiles, généralement vertes sur les deux faces. Le pétiole est comprimé sur le còté, ce đqui explique la mobilité des feuilles.

Cette essence, à couvert léger, est très rare en Algérie. (Sommet du Babor et du 'Tababor). 
La famille des PLATANEES comprend des arbres à feuilles ayant les nervures disposées en éventail. Les fleurs sont disposées en masses globuleuses.

Le genre Platane présente une espéce fréquemment plantée en Algérie comme arbre d'arenue: le PlataNe d'Orirext (Platanus orientalis L.) est un grand arbre à croissance rapide qui se dépouille de son écorce par grandes plaques, ce qui donne au trone un aspect spécial. Les feuilles sont divisées en trois à cinq lobes dentés.

\section{\$2. - Apélales non amenlacées.}

URTICACÉES. - L'Orme, le Micocoulier, le Mùrier et le Figuier, qui sont les arlores les plus communs de ce groupe, sont souvent rangés dans desfamilles distinctes, nous

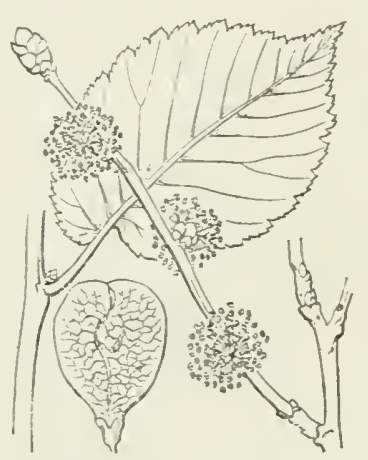

Ulmus campe ris.

Fig. 183. les considérerons comme faisant tous partie de la famille des Urticacées çui peut dès lors ètre divisée en plusieurs tribus:

Tribu des Ulmées. - Les Ormes ou Ormeaux ne sont représentés en Algérie que par une espèce: L'ORME CHAMPETRE ou Orme rouge (Llmus campestris L.) (Fig. 183) est un grand arbre à cime fournie, à feuilles simples doublement dentées en scie, rudes au toucher et inéquilatérales à la base.

Les lleurs sont groupées sur les rameaux de l'année précédente dépourvus de feuilles. Chacune d'elles comprend une enveloppe verdàtre de quatre ou cing pieces à lintérieur de laquelle on distingue quatre ou cinq étamines et un craire libre à une loge surmonté d'un stigmate bifide (c'est-a-dire fendu en deux).

Le fruit, entouré d'une aile ćchancrée, est une samare. La fructification est très aboudante.

L'écorce de cet arbre, très crevassée, se recourre quelquefois d'un liège brun et friable; l'écorce des jeunes rameaux 
est alors profondément creusée et leur donne un aspect ailé (variété suberosa).

L'Orme, souvent planté en bordure des routes, est surtout un arbre des stations humides; dans les lieux secs, il reste petit, sa feuille est réduite; on lui donne alors le nom de "tortillard".

L'aubier de l'Orme champêtre est blanc jaunâtre; le bois parfait, rougeàtre, est recherché pour le charronnage; le bois des "tortillards" est employé pour faire les moyeux.

La tribu des Celtidées comprend le MICOCOULIER (Cellis auslralis L.) (Fig. 184), arbre à écorce lisse et grisâtre, à feuilles inéquilatérales et dentées comme celles de l'Orme, mais plus effilées, d'un vert foncé en dessus, vert grisâtre en dessous.

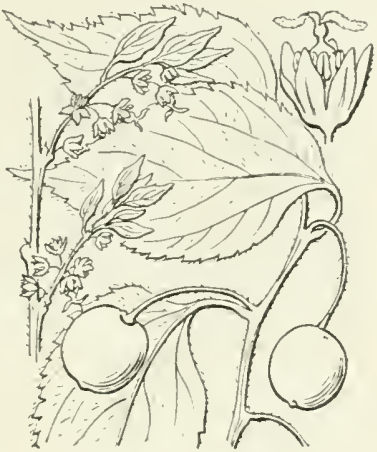

Cellis australis.

Fig. 184.

Les fleurs, isolées à l'aisselle des feuilles et portées sur un long pédoncule, sont à cinq divisions. Le fruit, globuleux et brunâtre, à saveur un peu fade, a les dimensions d'un gros pois et peut être mangé.

Le bois du Micocoulier est utilisé pour le charronnage; sa grande souplesse le fait rechercher pour la fabrication des avirons, des fourches, des manclies de foucts, etc.

C'est aussi un arbre des stations fraîches; on le rencontre depuis Alger et la Chilfa jusque dans la région de Bòne.

Tribu des Morées. - Chez l'Orme et le Micocoulier, les étamines et le pistil sont réunis dans la même fleur ; au conIraire les Morées et les Artocarpées sont des plantes à lleurs

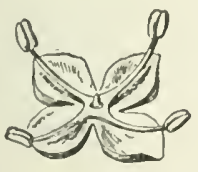

Fileur mâle de Morus alla.

Fig. 185.

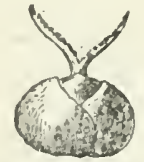

Fleur femelle de Mlorus albil.

lig. 185 bis.

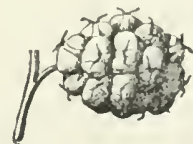

Fruits de Morus alba.

Fig. 186. 
unisexuées (Fig. 185 et 185 bis). Leur fruit, au lieu d'être formé d'un carpelle unique, est composé (Fig. 1866).

Genre Morus. - Les Mûriers sont monoïques. Deux espèces sont cultivées en Algérie, aucune n'est spontanée. Le Mùmer blanc (Morns alba L.), originaire d'Asic, a étéapporté en Occident au moment de l'introduction du Ver à soie, que l'on alimente avec sa feuille. Les fruits sont petits.

Le Mûrien xonk (.Morus nigra L.) a des fruits plus gros, acidulés, comestibles.

Ces Mùriers ont l'aubier blanc; le bois parfait, qui est jaune, brunil en vicillissant (ce caractère est surtout prononcé pour le Múrier noir); on l'emploie pour le charronnage et la fabrication des meubles.

Genre Broussonetia. - Le Mûrien a PAPIER (Broussonetia papyrifera Vent.), cultivé et mème subspontané en Algérie, est un arbre dioïque remarquable par la forme variée de ses feuilles. Ses fibres libériennes sont employées en Orient pour la fabrication du papier et des étoffes. Le bois a peu de valeur.

Tribu des Artocarpées. - Le genre Ficus est composé

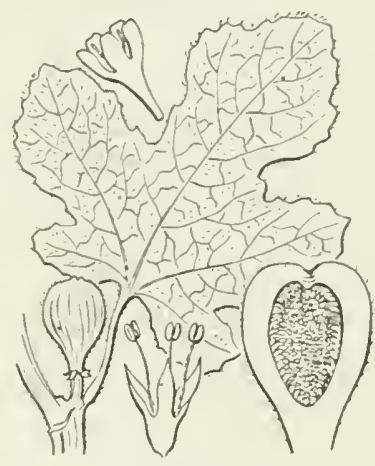

Ficus Carica.

l:ig. 187.

d'arbres et d'arbrisseaux dont les fleurs sont renfermées dans un réceptacle charnu, creux, percé en haut d'une seule petite ouverture. Chez le FIGUIER COMMUN (Ficus Ca. rica L.) (Fig. 187), ce rèceptacle, en forme de poire, est très déreloppé; d'abord âcre et rempli de suc laiteux, il devient mou et succulent, et constitue alors la figue comestible, dont il existe de nombreuses variétés.

Le Figuier, originaire de l'Asie occidentale, est depuis longtemps acclimaté dans l'Afrique du Nord, où il est l'objet d'une culture impor. tante, particulièrement dans la Kabylie du Djurjura.

Le genre Ficus comprend plus de 600 espèces exotiques; plusicurs sont plantẻes en Algérie dans les jardins ou les avenues, tels sont le Ficus clastica Roxb. connu sous le nom de 
"Caoutchouc», et fréquemment cultivé en pot dans les appartements; le Ficus religiosa L., dont la feuille est assez semblable à celle du Peuplier noir, mais se termine par une pointe effilée; le $F$. sycomorus L., le $F$. macrophylla Roxb., le $F$. rubiginosa Desf., le $F$. lavigala Vahl, le $F$. retusa L.

SALSOLAGÉES. - L'enveloppe des fleurs, plus ou moins verte, est composée de deux à cinq sépales libres ou peu soudés; il existe autant d'étamines; l'ovaire à une loge n'est généralement pas soudéau calice; le fruit est à une seule graine.

Bien qu'elle comprenne d'assez nombreuses plantes ligneuses, cette famille est peu importante au point de rue forestier. Nous citerons dix genres:

L'Oreobliton thesioides Dur. et Moq. (Fig. 188) est un sous-arbrisseau à rameaux grêles, nombreux, fenillés jusqu'au

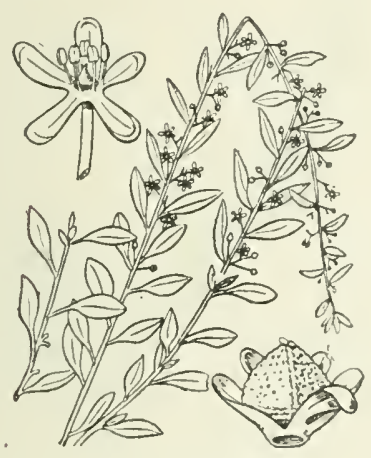

Oreobliton thesioides.

Fivig. 188.

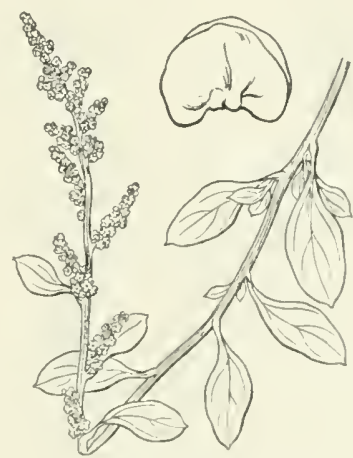

Atriplex Halimus.

Fig. 189.

sommet. Les fleurs sont petites et portées sur un long pédicelle. L'Oréobliton est assez rare et se rencontre génèralement dans les rochers (Mila, El-Kantara, région de Tebessa).

Le genre Atriplex comprend plusieurs plantes connues sous le nom d'Arroches; laissant de côté les espèces herbacées, nons derons mentionner : l'ARROCHE HALIME (Atriplex Hulimus L.) (Fig. 189), arbuste rameux argenté, fort commun en 
Algérie, servant de nourriture au hétail et quelquefois planté comme haie; l'ArRoche a PETITES Fecilles (Atriplex parvifolius Lowe), sous-arbrisseau plus modeste et moins abondant (environs de Bòne); l'Atriplex portulacoides L. (Fig. 190) qui ressemble à l'Arroche Halime, mais beaucoup plus humble et plus rare.

Ces plantes sont des halophytes, c'est-à-dire des espèces des terrains salés.

Le Polycnemon Fontanesi Dur. et Moq. est une petite plante rameuse, à feuilles denses et imbriquées ressemblant. bien que plus étroites, à celles du Genévrier. On le rencontre şà et là dans les broussailles de la région sèche (région de Maillot, Garrouban).

La SALicorne a gros ÉP1S (Arthrocnemon macroslachyum

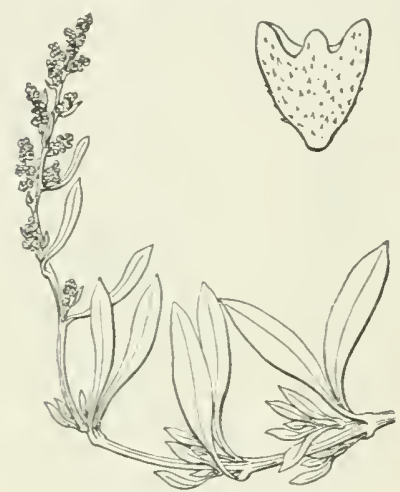

Atriplex portulacoides.

Fig. 190.

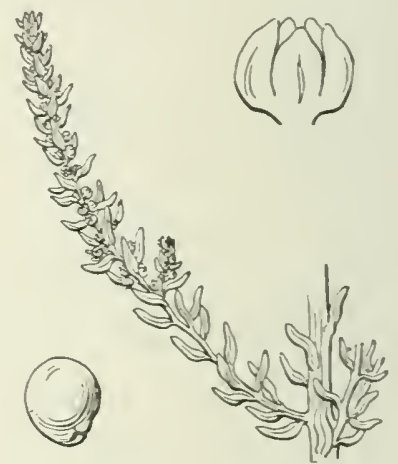

Suæda fruticosa.

Fig. 191.

Moq.) est une plante à tiges ligneuses, dressées ou tombantes, qui est répandue dans les terrains salès.

La Saliconxe ligneuse (Salicornia frulicosa L.) ressemble à la précédente, mais est plus grêle, elle croit dans les mèmes stations.

Le genre Suæda comprend des plantes rameuses, à feuilles charnues, habitant aussi le bord de la mer ou les terrains salés de l'intérieur. Le Suæda frulicosa L. (Fig. 191) est une plante d'un vert sombre, à feuilles de 1 centimètre, tandis que le Suxda pruinosa Lange a les feuilles plus courtes, imbriquées, 
glauques et pruineuses. On le considère quelquefois comme une simple variété de la précédente espèce. Le Sureda vcra Moq. paraîl localisé aux environs de Mostaganem.

Le genre voisin Salsola présente 8 espèces en Algérie. Nous mentionnerons le Salsola oppositifolia Desf., de l'Oranie el des Hauts Plateaux, qui atteint $1 \mathrm{~m}$. 50, et le Salsola vermiculata Forsk., espèce buissonnante répandue dans les terrains secs et un peu salés de toute la colonie.

L'Haloxylon articulatum Boiss. diffère des Salsola par ses rameaux articulés; c'est un arbrisseau rameux à feuilles opposées et soudées, apparentes seulement sous forme d'écailles laineuses en dedans. Le calice est muni d'ailes membraneuses brillantes.

Le Noxa spinosissima Moq. a ses ramuscules terminés en épine; les feuilles, alternes, sont pâles et réunies par faisceaux. Cette espèce et la précédente se rencontrent sur les Hauts Plateaux; mais l'Haloxylon est plus répandu.

Les Anabasis sont surtout connus en Algérie par l'Anabasis articulatı Mog., espèce à rameaux droits et rigides, à calice fructifère muni d'ailes de nuance variable. L'Anabasis prostrata Pomel, signalé aux environs d'Arzew, à rameaux flexueux charnus, possède un calice à ailes rouges brillantes; l'Anaba. sis aphylla L., à tiges molles et longues, est localisé dans les terrains à phosphates.

La famille des PHYTOLACGEES comprend surtout des especces tropicales: le Plytolacca dioüca L., vulgairement Bellomiza (Bella sombra), est un grand arbre remarquable par son trone fortement empàté à la base ; les feuilles alternes ovoüdes ont un pétiole court.

Les fleurs sont verdàtres et formées soit d'étamines insérées sur un disque charnu, soit de carpelles verticillés donnant une baie incolore. Cette espéce est fréquemment plantée sur les places publiques et les avenues des villes du littoral.

Chez les POLYGONEES le calice herbacé, ou plus ou moins coloré, présente 3 à 6 sépales, quelquefois disposés cll deux rangées ou verticilles, l'intéricure enveloppant le fruit; il 
existe 4 à 16 étamines; l'ovaire renferme un ovule. Les tiges, généralement noueuses et articulées, portent des feuilles alternes munies à la base d'un ochrea, c'est-à-dire d'une gaine formée par la soudure des stipules.

Le genre Rumex, auquel appartient l'Oseille, présente des fleurs à 6 sépales, dont 3 , dits valves, entourent le fruit. Les espèces herbacées sont nombreuses; le Rumex Aristidis Coss. (Fig. 192) est une plante sous-frutescente localisée sur le littoral de l'Est.

Dans le genre Renouée (Polygonum) les sépales (4 à 9) n'af-

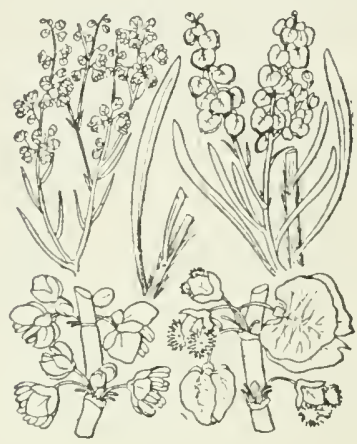

Rumex Aristidis.

Fig. 192 .

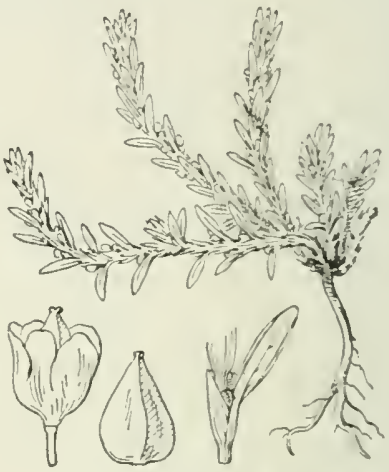

Polygonum maritimum.

Fig. 193.

fectent pas la forme de valves. Le Polygonum maritimum L. (Fig. 193) est un sous-arbrisseau des sables maritimes à entrenœuds rapprochés et à feuilles épaisses. Le Polygonum equisetiforme Sibth. et Sm. est remarquable par sa grosse souche à écorce d'Aune. Les fleurs sont roses, quelquefois blanches.

Les ARISTOLOCHIÉES ont des fleurs hermaphrodites à enveloppe (périanthe) irrégulière; les étamines sont soudées en colonne avec les styles. Dans le genre Aristoloche (Aristolochia), le seul qui nous intéresse, le périanthe a la forme d'un cornet rentlé; les feuilles sont en cœur, sans stipules.

Les Aristolochia altissina Desf. et Aristolochia batica L. sont des plantes volubiles à tiges ligneuses; la première, très 
commune, grimpe haut dans les arbres; la deuxième, localisée dans l'Ouest (Oran, Nemours, Tlemeen), habite surtout les rochers.

La famille des LAURINÉES est représentée en Algérie par le LAURIER SAUCE (Laurtus nobilis L.) (Fig. 194), arbre aromatique à feuilles alternes, coriaces, persistantes, elliptiques-lancéolées, à court pétiole. Les fleurs, d'ordinaire dioïques, sont blanchâtres ou verdâtres, odorantes et disposées en petites ombelles; il existe huit à douze étamines; l'ovaire présente une seule loge ; le fruit est une baie noire.

Cet arbre est commun dans les stations fraîches des forêts du littoral; les feuilles sont utilisées,

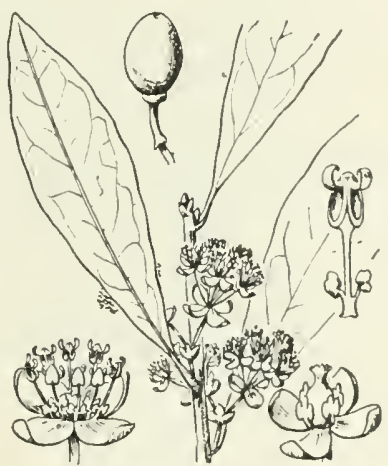

Laurus nobilis.

Fig. 194. non seulement pour la préparation des aliments, mais comme remède digestif, expectorant, diurétique et sudorifique (infusion de 10 à 20 grammes par litre d'eau).

Les THYMÉLÉAGEES 1 sont des arbrisseaux à écorce fibreuse, tenace, souvent vésicante. Le calice présente quatre à cinq divisions; les étamines sont au nombre de huit à dix; l'ovaire, libre, est généralement à une loge. Il existe deux genres en Algérie : les Passerines (Thymeliea ou Passerina) ont un fruit sec; les Daphnés (Daplne) un fruit charnu à noyau (drupe).

La Passerine nérissíe (Thymeláa hirsula L.) (Fig. 195 peut atteindre $1 \mathrm{~m} .50$; c'est un arbrisseau rameux à feuilles coriaces, épaisses, imbriquées au sommet des rameaux, très répandu en Algérie.

La Passerine a petites feulles (Thymelax microply lla

1. La famille des PROTÉACÉES, qui comprend un millier d'espèces exotiques, est représentée dans les plantitions davenues en Algérie par lo Grevillea robusla Cunn. 
Coss.) (Fig. 196) est un arbrisseau de 0 m. 30 à 1 m. 20 à rameaux effilés et soyeux, à feuilles ovales ou oblongues non imbriquées, très répandu dans les Hauts Plateaux.

Le Thymelica nitida Desf., especce d'Oranie, est une plante

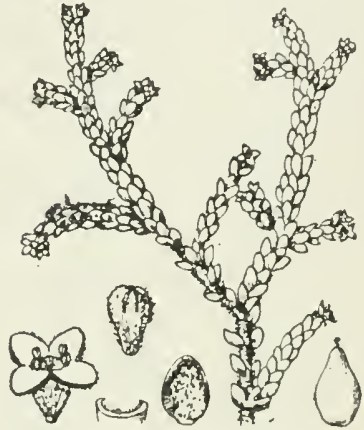

Thymelwa hirsuta.

Fig. 195.

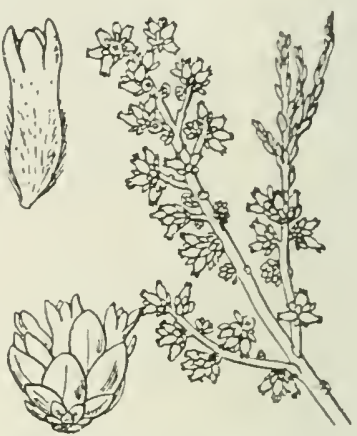

Thymelæa micropbylla.

Fig. 196.

soyeuse et brillante, tandis que le Th. virescens Coss. des montagnes du Sud est à peu près glabre (c'est-à-dire sans poils. Tous deux ont les feuilles imbriquées, au moins sur les jeunes

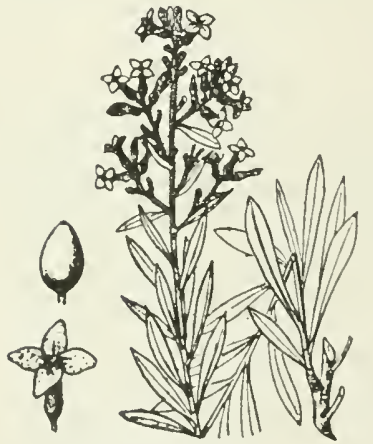

Daphne Gnidium.

Fig. 197. rameaux. Le Thymelia virgata Desf. (Tlemcen, Aïn-el-Hadjar près Saïda, Djelfa, Sétif) présente des rameaux à fleurs herbacés, mais la souche est ligneuse. Le Thymelita Tarton-raira All., rare en Algérie (Berouaghia, Constantine, Djelfa et au sud de Sebdou), est un sousarbrisseau soyeux à feuilles blanchàtres, relativement grandes $(2$ à 3 centimètres) et à nervures parallèles saillantes.

Le Daphne Gnidium L. (Fig. 197), vulgairement GAROU ou Sainbois, est un arbrisseau à tiges dressées, ayant souvent $0 \mathrm{~m}$. 50 à 1 mètre, mais pouvant dépasser celte taille. Les fleurs sont blanches; le fruit cst une baie rouge.

Cette plante, commune dans le Tell, est employée comme 
vésicant (tremper l'écorce dans de l'eau ou du vinaigre et l'appliquer sur la peau); on s'en sert aussi comme purgatif, mais à l'intérieur c'est un remède dangereux.

Le Daphne oleoides Schreb. (Fig. 198) est un sous-arbrisseau

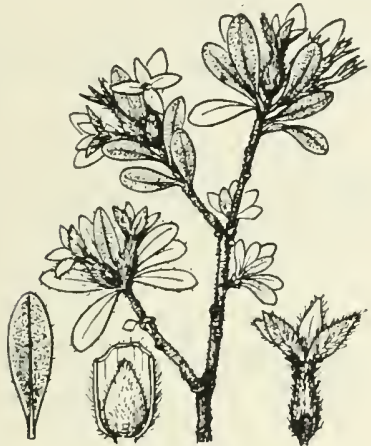

Dapkne oleoides.

Fig. 198.

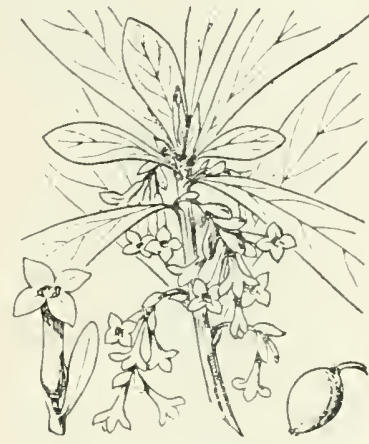

Daphne Laureola.

Fig. 199.

bas, à feuilles assez semblables à celles du Buis, à baie rouge. Très rare en Algérie, il a été trouvé à Tirourda (Djurjura) et au Tababor

Le Daphne Lanreola L. (Fig. 199) ou Launier des bors a de grandes feuilles de 6 à 12 centimètres; les fleurs sont d'un jaune verdâtre, la baie noire ; ce Daphné est localisé en Algérie sur les hautes montagnes.

Parmi les ÉLÉAGNEES, nous citerons le genre Elieagnus comprenant des arbres et des arbrisseaux, dont les feuilles, couvertes de poils en écusson, présentent un aspect argenté caractéristique. Le Chalef ou Olivier de Bohème (Elixagnus angustifolia L.) (Fig 200), petit arbre à fleurs argentées au dehors, jaunes en dedans, est quelquefois cultivé en Algérie, surtout dans le Sud.

Les LORA N THACEES de nos régions sont des plantes parasites sur les rameaux des arbres, toujours vertes, à feuilles simples, entières et opposées ; les tiges sont plusieurs fois bifurquées (dichotomes) et à rameaux articulés. 
Le Gur blaxc ou Gui des Druides (Viscum album L.), répandu en France sur le Sapin, les arbres fruitiers, les Peupliers, etc. (heaucoup plus rare sur le Chêne), est exceptionnel en Algérie. On n'en connaît qu'une station sur Lentisque dans les gorges du Guergour (près Lafayette).

Le Gur de r'Oxycédre (Arcenthobium Oxycedri M. Bieb.) (Fig. 201) est une petite plante de 5 à 12 centimètres, dont les

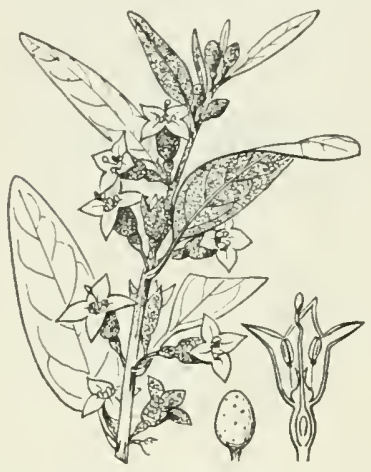

Elæagnus angustifolla.

Fig. 200.

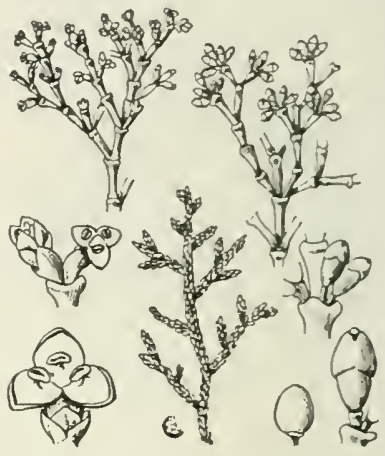

Arceuthoblum Oxycedr1.

Fig. 201.

feuilles sont réduites à des écailles, croissant sur les rameaux du Genévrier Oxycèdre (Djurjura, Aurès, Teniet-el-Had!.

Les SANTALACÉES, bien que possédant des racines, sont en mème temps parasites sur les racines d'autres plantes.

Les 0syris, seul genre à citer, sont dioïques; le calice est formé de 3 à 4 sépales soudés ; les fleurs mâles comprennent 3 à 4 étamines insérées sur un disque ; les fleurs femelles un ovaire infère à une loge surmonté de 3 stigmates et entouré de 3 étamines avortées.

Le ROUVET (Osyris alba L.) (Fig. 202) est un arbrisseau à tiges effilées, vertes, anguleuses; les feuilles sont ètroites ; les fleurs jaunàtres; le fruit globuleux, un peu aplati, est gros comme un pois. Cette espèce est assez commune, surtout dans les terrains humides du Petit Atlas.

L'Osyris lanceolata Hochs. et Steud. (Fig. 203) est un 
arbuste toujours vert dont le tronc atteint 10 à 12 décimètres de tour. Les feuilles lancéolées aiguës rappellent par leur

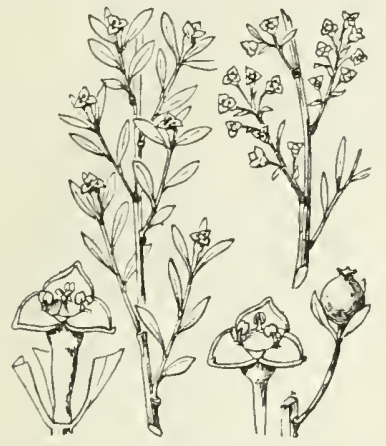

Osyris alba.

Fig. 202.

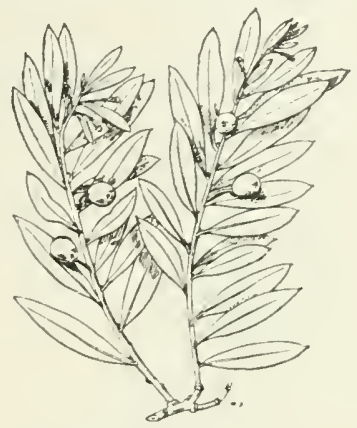

Osyris lanceolata.

Fig. 203.

orme celles du Myrte, mais leur teinte est glauque. Cette espèce se rencontre dans le Tell, surtout à l'ouest d'Alger (Soumata, Hanmam Rhira, Ténès, etc.); le bois sert aux indigènes à préparer une boisson analogue au café.

Les EUPHORBIAGEES constituent une grande famille, comprenant au noins 3.000 espèces, mais peu intéressante, dans nos régions surtout, au point de vue économique. Les fleurs sont unisexuées; le nombre des étamines est variable; l'ovaire à 2 ou 3 loges, non soudé au calice, donne naissance à une capsule s'ouvrant par autant de coques qu'il y a de carpelles et laissant une colonnette sur la tige.

Dans le genre Euphorbe (Euphorbia), il existe une fleur fenelle au milieu de plusieurs fleurs mâles réunies dans un involucre dont les quatre ou cinq divisions alternent avec autant de glandes jaunâtres de forme variable.

Les Euphorbes sont des plantes à suc laiteux, irritant et vésicant, dont on se sert pour faire disparaitre les verrues. Les graines, quelquefois employées comme purgatif, peuvent produire des empoisonnements.

L'Euphorbia Bivonie Steud. (Oran, Chenoua près Cherchell, Pointe Pescade près Alger, Bou-Zegza en Kabylie, Aurès, etc.) qui, par le port, rappelle le Duphne Gnidium est un arbrisseau 
¿̇ petites ombelles jaunâtres. L'Euphorbia squamigera Lois. (Rio-Salado, Beni-Saf à l'ouest d'Oran) présente au contraire de grandes ombelles. Ce sont deux espéces des rochers calcaires.

L' Euphorbia dendroides L. (Fig. 204), arbrisseau à rameaux

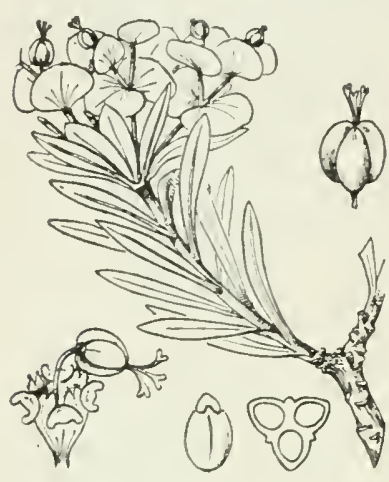

Euphorbia dendroides.

Fig. 204.

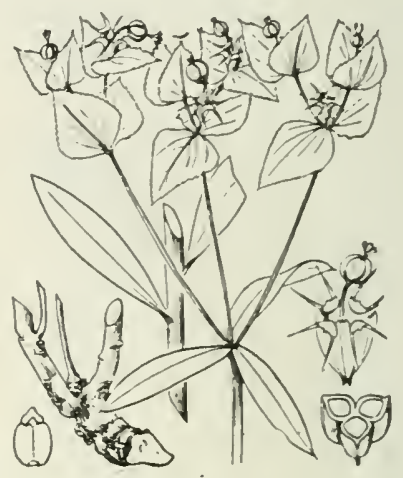

Euphorbia erracina.

Fig. 20 s.

épais et rougeâtres, croìt sur les falaises maritimes de Ténès à Bône.

Les Euphorbua terracina L. (Fig. 205), à souche épaisse, et Enphorbia paniculata Desf., à tige un peu ligneuse à la base, sont très communes en Algérie.

Le genre Securinega comprend des arbres ou arbrisseaux à lleurs dioïques, à rameaux disposés sur deux rangs opposés (distiques) sourent épineux. Le Securinega buxifolic J. Müller est un arbrisseau rameux, épineux au sommet, à feuilles distiques et semblables à celles du Buis, localisé dans la région de Bône, la Calle.

Le Ricin comucx (Ricinus communis L.) (Fig. 206), dont les feuilles divisées en lobes sont bien connues, n'est pas une plante spontanée en Algérie, mais il s'est fréquemment propagé aux abords des habitations.

Diverses espéces de Ricin sont cultivées dans les jardins et au bord des voies ferrées.

L'huile de Ricin, extraite de la graine par pression a froid, sert à la fabrication dessarons, comme huile à brûler, pour 
graisser les cuirs, etc. Cette huile est purgative à la dose de 40 grammes.

Le Burs toujours vert (Buxus sempervirens L.)(Fig. 207) peut être rangé parmi les Euphorbiacées, bien que l'on distingue souvent une famille des BUXACEES. Ciest un arbrisseau,

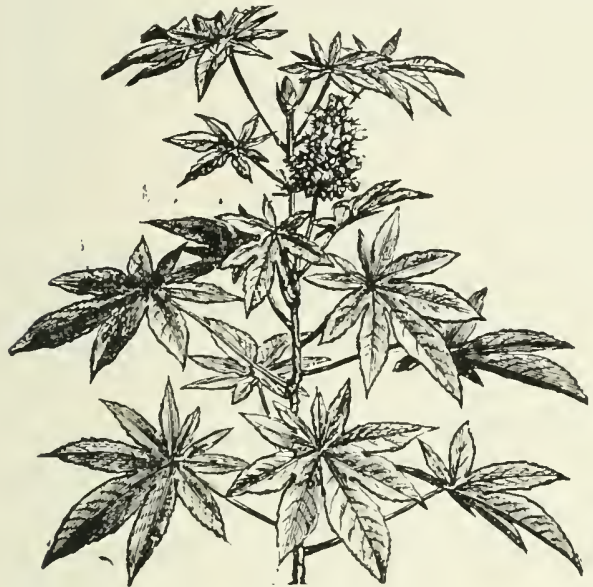

Rlcinus communis.

Fig. 206.

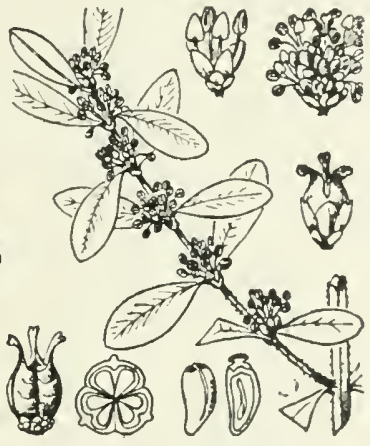

Buxus sempervirens.

Fig. 207.

quelquefois un arbuste, touffu à feuilles opposées, petites, entières, coriaces, luisantes et persistantes ; les fleurs jaunâtres, réunies en glomérules, sont monoïques. Le bois jaune, très dur, est recherché par les tourneurs et les tabletiers; les feuilles sont purgatives.

Le Buis, répandu dans une grande partie de la France, est rare en Algéric (gorges du Guergour, Tababor, Mahdids), les indigènes en font des manches de couteaux.

Une variété naine est employée dans les jardins pour crẻer des bordures. 


\section{CHAPITRE $\mathrm{X}$}

\section{DICOTYLÉDONES : LES DIALYPÉTALES}

Nous distinguerons, comme il a été dit précédemment, les Dialypétales thalamiflores dans lesquelles les étamines et la corolle, non soudées au calice, sont fixées sur le sommet du pédoncule, et les Dialypélales calyciflores dans lesquelles les pièces précédentes sont attachées sur une sorte de collerette ou de cupule formée par la base du calice.

\section{\$1. - Dialypétales thalamiflores.}

La famille des RENONGULAGÉE comprend des plantes à fleurs, ordinairement régulières, pourvues de nonıbreux carpelles libres et d'un grand nombre d'ètamines à anthère tournée vers l'extérieur de la fleur.

Ce sont généralement des plantes herbacées, parfois ligneuses et grimpantes, renfermant souvent des substances âcres et toxiques.

Le genre Clématite comprend des espèces sarmenteuses grimpant dans les haies et les buissons à l'aide des pétioles de leurs feuilles qui s'enroulent en vrilles autour des supports qu'ils rencontrent; leurs fleurs, dépourvues de pétales, présentent 4 sépales de coloration verdàtre ou blanche, de nom-

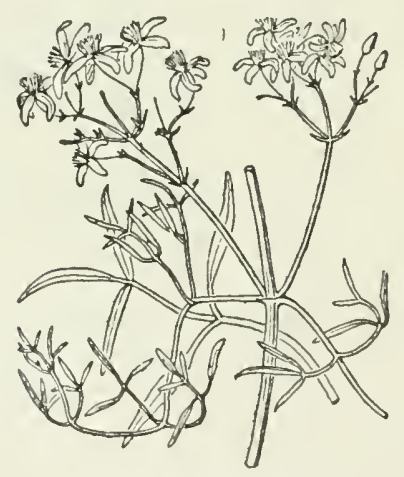

Clematis Flammula.

Fig. 208.

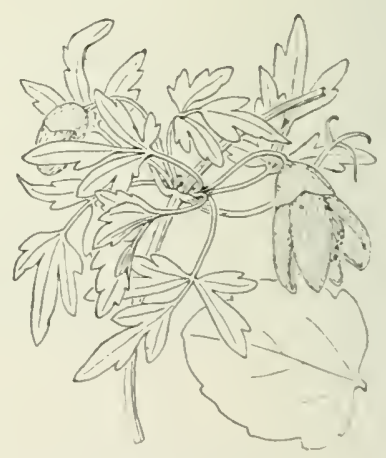

Clematis Cirrhosa.

Fig. 209 
breuses étamines et de nombreux carpelles terminés à maturité par une aigrette plumeuse.

La CLEMATITE FLAMMETTE (Clematis Flammula L.) (Fig. 208) est reconnaissable à ses feuilles composées bipennées (c'est-à-dire deux fois pennées) et à ses fleurs en grappes. Elle est souvent employée pour garnir les palissades et les tonnelles.

La CLÉMATITE A VRILLES (Clematis cirrhosa I.) (Fig. 209), répandue comme la précédente dans les haies et broussailles du 'Tell, s'en distingue facilement par ses grandes fleurs solitaires et ses feuilles simples partagées en 3 lobes dentés.

Les feuilles de cette espèce et de la précédente sont vésicantes et vénéneuses à l'état vert; sèches, elles sont susceptibles d'être consommées par le bétail.

Les Clématites peuvent devenir nuisibles en entravant la végétation des arbres qu'elles couvrent.

La famille des BERBÉRIDEES comprend en Algérie une seule espèce ligneuse, l'ÉPINE-viNetTe d'Espagne (Berberis hispanica Boiss.) (Fig. 210) que l'on rencontre dans la haute région montagneuse, généralement sous la forme de buissons. Cet arbrisseau, qui ressemble beaucoup à l'Épine-vinette de France (Berberis vulgaris L.), est épineux, à feuilles simples, dentées; le bois est d'un beau jaune et les baies peuvent être utilisées pour faire des confitures ou une limonade rafraîchissante. Les feuilles sont souvent recouvertes de taclıes causées par un Champignon parasite qui sous une autre forme détermine une rotille

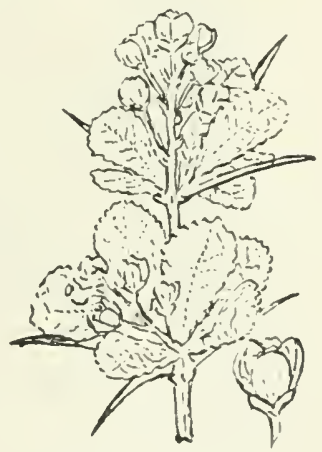

Berberis hispanica.

Fig. 210. du Blé; l'Épine-vinette favorise donc cette maladic et l'on conseille de la bannir du voisinage des cultures.

Les GRUGIFÉRES constituent une famille extrêmement homogène, reconnaissable facilement à ses fleurs dont le 
périanthe comprend 4 sépales et 4 pétales disposés en croix

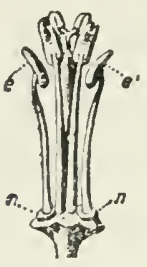

Étamines de Crucifère : e é, étamines plus petiles: $n$, glande à nectar.

Fig. 211. et dont les étamines sont au nombre de six : 4 grandes et 2 petites (Fig. 211).

Le fruit est une silique tantòt allongée, tantòt très courte et dite alors silicule.

Le genre Chou (Brassica), qui a fourni tant de variétés utiles à l'homme, comprend en Algérie quelques rares espèces sousligneuses telles que le Brassica fruticulosa Cyr. (Fig. 212), qui présente plusieurs variétés que l'on rencontre d'Oran à Bòne et même dans le Sud; le Brassica insularis Moris, signalé au pied de l'Edough, près Bòne; le Brassica scopulorum Coss. qui croit aux iles Habibas et aux environs d'Oran.

Le Diplotaxis a feullees téxues (Diplotaxis tenuifolia D. C.) (Fig. 213), probablement subspontané en Algérie (Fort

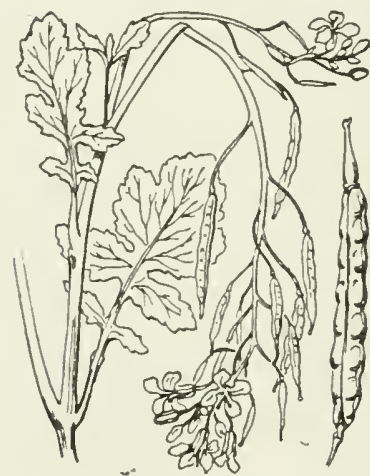

Brassica fruticulosa.

Fig. 212.

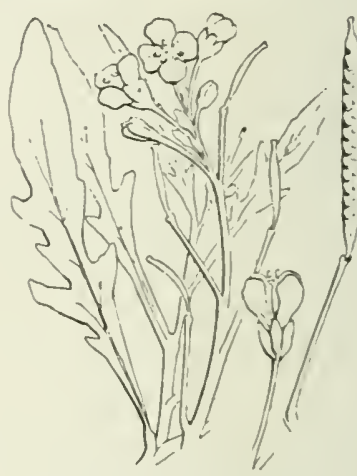

Diplotaxis tenuifolla.

Fig. '213.

l'Empereur, près Alger), est, comme les précédentes, une plante ligneuse à la base seulement; c'est une espèce qui peut atteindre quatre-vingts centimètres de hauteur, à fleurs grandes et odorantes, d'une couleur jaune soufre ; les feuilles glauques, divisées, énıettent une odeur forte.

Le genre Vélar (Erysimum) ne renferme en Algérie qu'une seule espèce qui nous intéresse, le V'Élar a GRANDEs 
FLeURS (Erysimum grandiflorum Desf.) que l'on rencontre généralement en montagne; une variété puissante (var. elatum Pom.) croît au bord de la mer, près de Mostaganem.

Le genre Alysson (Alyssum) est représenté par trois espèces dont la plus ligneuse est l'Alysson ÉprNeux (Alyssum spinosum L.) (Fig. 214) qui forme çà et là, sur les hauts sommets du Djurjura et des Babors, des buissons de 40 à 50 centimètres de hauteur.

L'Alyssum cochlealum Coss, est un sous-arbrisseau de

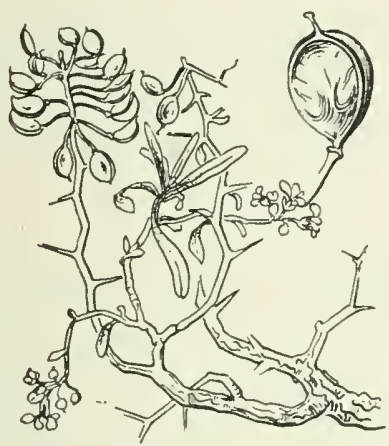

Alyssum spinosum.

Fig. 214.

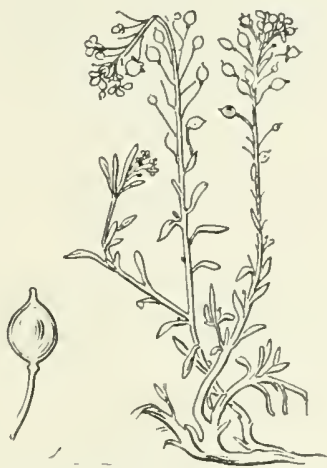

Alyssum maritimum.

Fig. 215.

l'Aurès et de la région montagneuse qui avoisine Djelfa; l'Alysson maritine (Alyssim marilimum L.) (Fig. 215), dont les rameaux sont à peine ligneux à la base, est une espèce extrèmement commune dans le Tell.

Citons enfin, pour terminer, le Moricandia suffrulicosa D. C. (variété du $M$. arvensis), plante ligneuse à la base, du bord des rivières du 'Tell, assez commune ègalement sur les Hauts Plateaux, le Lepidium subulatum L., petit arbrisseau de 1 à 3 décimètres, assez répandu sur les Hauts Plateaux et l'lberis ciliata L., plante sous-frutescente à grandes fleurs blanches, roses ou violacées que l'on trouve dans la région montagneuse et sur les Hauts Plateaux.

La petite famille des GAPPARIDÉES est représentée en Algérie par le CAPRIER ÉPINEUX (Capparis spinosa L.) 


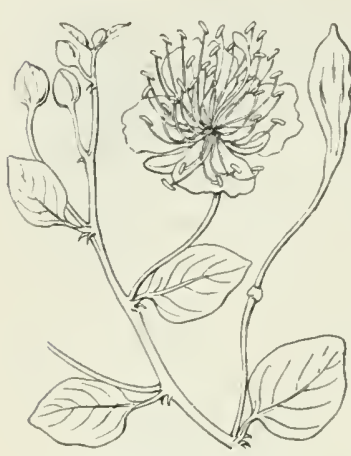

Capparis spinosa.

Fig. 216.

(Fig. 216), arbrisseau sarmenteux assez fréquent sur les rochers et les pentes escarpées du Tell. Les feuilles présentent deux épines à la base de leur pétiole; les fleurs blanches, souvent rosées, ont quatre sépales et quatre pétales comme celles des Crucifères, mais de nombreuses étamines. Les boutons floraux de cette plante, récoltés encore bien fermés et confits dans le vinaigre, forment les cripres utilisées en cuisine, et ses baies, conservées de la même façon, sont aussi employées sous le nom de cornichons de câpre.

La famille des GISTINÉES comprend de nombreuses espèces ligneuses qui sont réparties en quatre genres différents.

Les Cistes sont des sous-arbrisseaux rameux qui habitent les forêts de la région méditerranéenne où leur abondance favorise souvent le développement des incendies; leur taille ne dépasse pas généralement 1 mètre à $1 \mathrm{~m}$. 50, et leurs fleurs blanches, jaunes, roses ou pourpres sont grandes et élégantes, mais à corolle très caduque.

Le CISTE HÉTÉROPHYLLE (Cistus helerophyllus Desf.) est une espèce à fleurs grandes, roses, assez fréquente aux environs d'Alger (Bois de Boulogne, Guyotville, El Affroun, etc.).

Le CISTE POLYMORPHE (Cislus polymorphas Willk.) (Fig. 217), répandu dans les stations sèches, diffère du précédent par la base de ses pétioles qui est dilatée en une gaine ample et assez longue.

Le CISTE CO'TONNEUX (Cislus albidus L.) (Fig. 218), assez comnun aux environs d'Alger et très abondant dans les forêts de Pins d'Alep de la région de Maillot, se reconnaît facilement à la pubescence veloutée, épaisse, qui le recouvre. Ses feuilles, ainsi que celles de l'espèce précédente, sont quelquefois utilisées en guise de thé par les indigènes. 
Le Ciste crêpu (Cistus crispus L.) qui possède comme les précédents des fleurs roses, est très rare en Algẻrie. On le

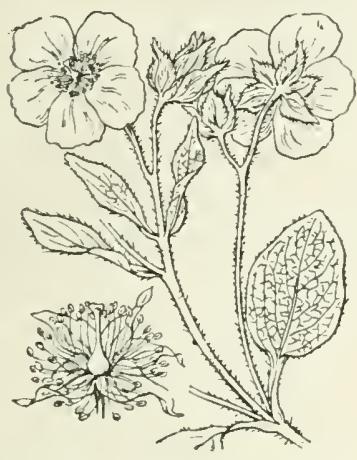

Cistus poly morphus.

Fig. 217.

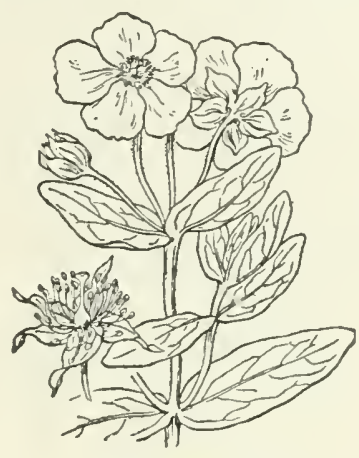

Cistus albidus.

Fig. 218.

rencontrait à Saoula, près d'Alger, mais les plantations de Vigne l'ont fait disparaitre de cette localité.

Le CISTE DE MONTPELLIER (Cistus monspeliensis L.)

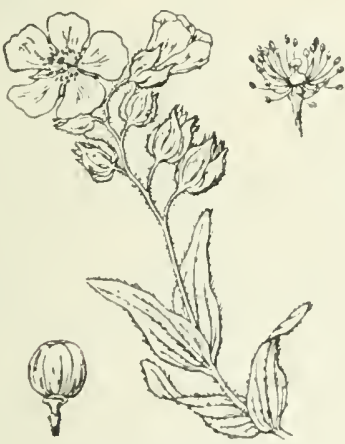

Cistus monspeliensis.

Fig. 219.

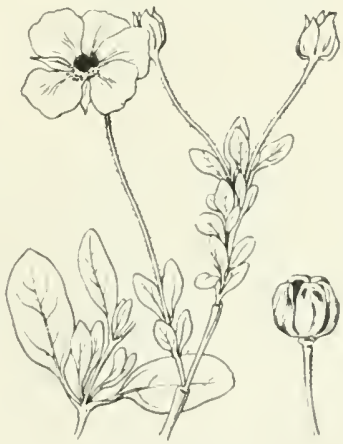

Cistus salvizelolius.

Fig. 220.

(Fig. 219), qui appartient à la série des Cistes á fleurs blanches, forme à lui seul une part notable de nos broussailles.

Les terrains qu’il recouvre sont généralement réputés sans valeur; en réalité, cette espèce se multiplie abondamment sur les sols asséchés par suite de la destruction de la forèt. 
Le CISTE A FEUILLES DE SAUGE (Cistus salvixfolins L.) (Fig. 220), également très répandu, diffère des précédents par ses fleurs plus grandes et ses feuilles plus larges, gaufrées et pétiolées.

Le Ciste de Munby (Cistus Munbyi Ponı.) se rencontre aux environs d'Alger et en Oranie.

Le Ciste de L'Échuse (Cislus Clusii Dun.) croit dans les forêts de la région de Maillot, à Boghar, à Marnia, etc.

Le Ciste varié (Cislus varius Pourret) (Fig. 221) est

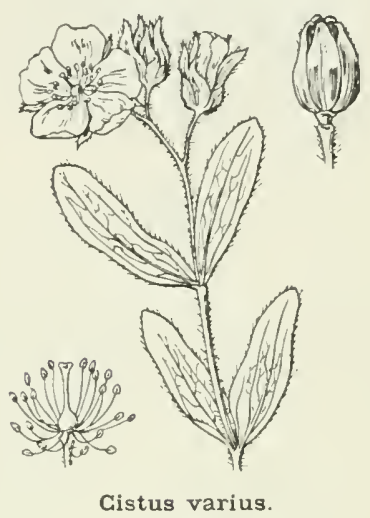

Fig. 221.

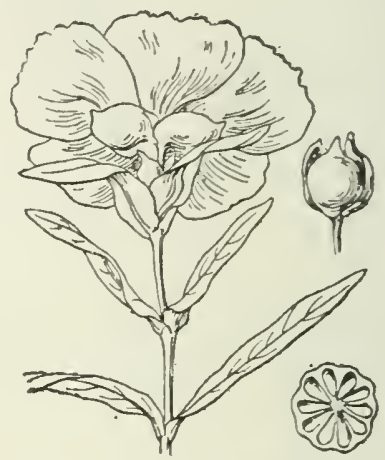

Clstus ladaniferus.

Fig. 222.

rare; on le rencontre en montagne, notamment au Zaccar de Miliana et à la Glacière Laval, au-dessus de Blida.

Le CISTE A GOMNE (Cistus ladaniferus L.) (Fig. 222) est un élégant arbrisseau à fleurs très grandes, dépassant souvent 6 centimètres de diamètre, complètement blanches ou tachées de rouge à la base des pétales.

Cette espèce, commune dans l'ouest de l'Algérie, disparait à mesure que l'on se déplace vers l'Est; les feuilles sécrètent une sorte de résine qui peut être cmployée en parfumerie.

Les Cistes s'hybrident entre eux.

Les Helianthèmes sont pour la plupart des plantes qui, par l'exiguitté de leur taille, méritent à peine de prendre rang parmi les végétaux ligneux, cependant l'Helaxtùie a Feuilles d'Halime que l'on classe souvent dans le genre spécial Halimium sous le nom d'Haliminn halimifolium Willk. 
(Fig. 223) est un sous-arbrisseau de 4 à 8 décimètres de hauteur, croissant çà et là en assez abondantes colonies (littoral à l'est de Djidjelli, Dahra, Sersou). Les feuilles opposées, sans stipules, sont tomenteuses argentées. Les fleurs jaunâtres, disposées en grappes, présentent des taches noires à la base.

L'Hélanthèse a feulles de Latande (Helianlhemum

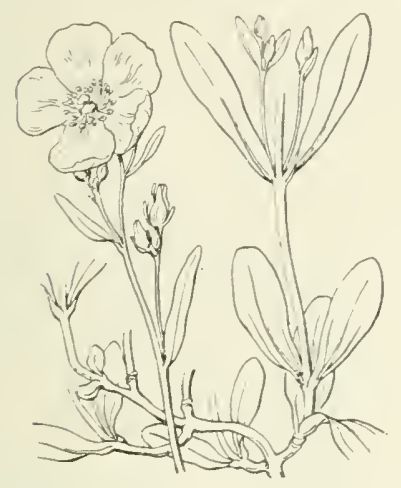

Helianthemum halimifolium.

Fig. '23.

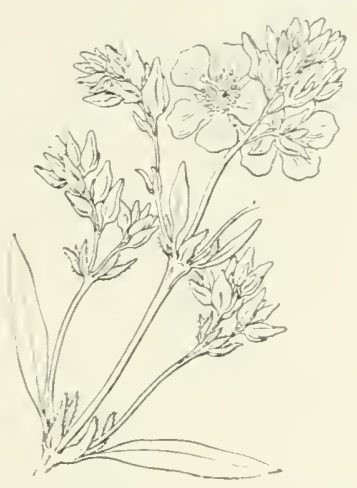

Helianthemum lavandulitolium.

Fig. 224.

lavandulrefolium D. C.) (Fig. 224) est un sous-arbrisseau à feuilles opposées, stipulées, linéaires ou presque, cendrées en dessus, blanches tomenteuses en dessous; ses lleurs jaunes sont dispoșées en grappes serrées argentées (région d'Alger, de Constantine, Dahra). L'Helianlhemum Lippii Ball. est surtout répandu sur les Hauts Plateaux; il en existe toutefois une variété à rameaux rouges à la Macta (Oran) et à Zamori (Alger).

Les Helianthenum Pomeridianum Dunal, Helianthemum Capul felis Boiss., Helianlhemum polyanthos Dun., II. origanifolinm Lam., H. squamatum Pers., H. viscarinm Boiss. et Reut., sont des espéces rares, spéciales à l’Oranie.

L'Hémanthìne vegane (Helianhemum valgare Pers.) et l'Heliunthenum rubellum Pers. se rencontrent généralement à une certaine allitude.

L'Ilelianthenum canum Dun. parait localisé dans une sta- 
tion unique du Djurjura (Askhadjenı), à l'ouest du col de Tirourda.

Le genre Fumana comprend des sous-arbrisseaux à feuilles linéaires et à fleurs jaunes qui diffèrent des Hélianthèmes par la stérilité des étamines extérieures de la fleur.

Le Fumaxa glutinedx (Fumana glutinosa Boiss.) est une espèce très commune; c'est un sous-arbrisseau très bas à feuilles linéaires ou presque, à tiges dressées poussant en touffes serrées, visqueuses dans le haut ainsi que les pédicelles floraux et les sépales. On le trouve dans les lieux secs, parni

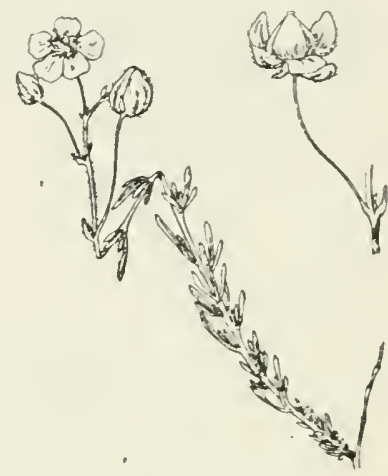

Fumana lævipcs.

Fig. 205.

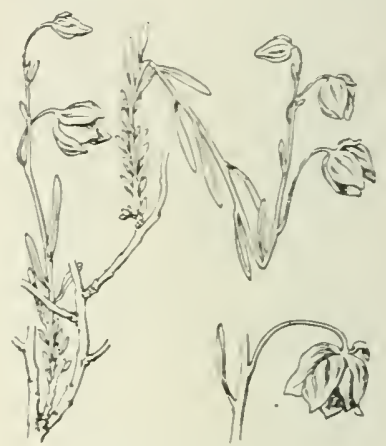

Fumana spachii.

Fig. 226.

les broussailles, et sur les rochers, ainsi que le FuMANA A PÉDoxcules Grêles (Fumana lrvipes Spach) (Fig. 225).

Le Fumana d'Arabie (Fumana arabica Spach) et le Fumanu Spachii Gren. et God. (Fig. 226) sont assez rares ; le premier ne se rencontre que dans le sud-est de la province de Cons. tantine; le second existe dans la région d'Alger, à Teniet, au Djurdjura, à Tlemcen.

Le Fumana calycina Claus. se distingue de tous les autres par sa taille plus élevée qui atteint jusquà 1 mètre et par ses fleurs plus grandes de couleur safranée Irégion d'Alger, Miliana, Maillot).

La petite famille des VIOLARIÉES ne présente qu'une seule espèce sous-ligneuse, assez répandue dans les 
broussailles du littoral occidental : la V'́olette A RBopescexte (Viola arborescens L.) (Fig. 227), petite plante de 1 à 2 décimètres, dont la lige demi-couchée porte des feuilles étroites, dentées, courtement pétiolées et des fleurs médiocres d'un bleu pâle.

\section{La famille des POLYGA-}

LEES n'est pas mieux représentée que la précédente. Une seule espèce est à mentionner, le Polygala Munbyana Boiss., plante à souche ligneuse émettant de nombreuses tiges anguleuses qui portent des grappes de grandes

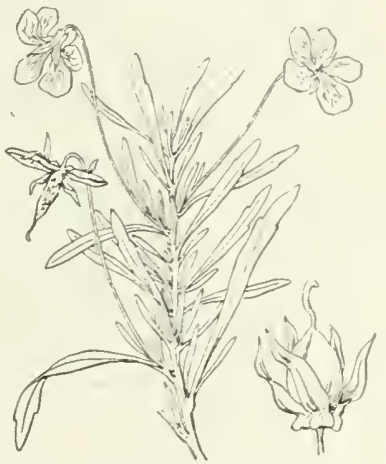

Viola arborescens.

Fig. 227.

fleurs (16-18 millimètres) roses ou jaunes. On la rencontre dans les broussailles du littoral, de Cherchell à Tenés et près d'Oran.

Les MALVACÉS forment une famille bien caractérisée

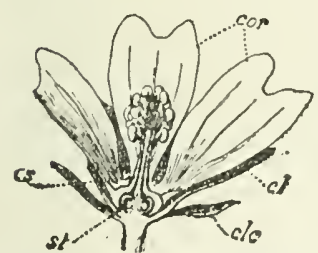

Coupe d'une tleur de dlauve : $c l c$, ealicule: $c l$, calice ; cor, corolle: $t s$, tube des élamines: $s t$, style.

Fig. 228. par ses feuilles à nervation ordinairement pálmée et par ses lleurs (Fig. 228) construites sur le type 5 . Le calice est doublé de bractées formant une sorte de calice supplémentaire appelé calicule. Les étamines très nombreuses, soudées par la partic infericure de leurs filets. forment une sorte de manchon qui entoure le pistil (Fig. '22S).

Le genre Mauve (Malva), qui a donné son nom à la famille, ne comprend que des espèces herbacées.

Le genre Lavalera comprend, à còté d'espèces herbacées, quelques plantes ligneuses.

Le LAYATERA DHYERES (Lavalera olbiu L.) Figs. 229), le plus commun en Algerie, est un arbuste dont la hauteur peut atteindre 4 mètres; les tiges rougeitres portent des feuilles poilues veloutées échancrées en trois ou cing lobes et 
des fleurs roses très grandes disposẻes en longues grappes fcuillées.

Le Lavatela anbonescext (Lavalera arborea L.) est, comme

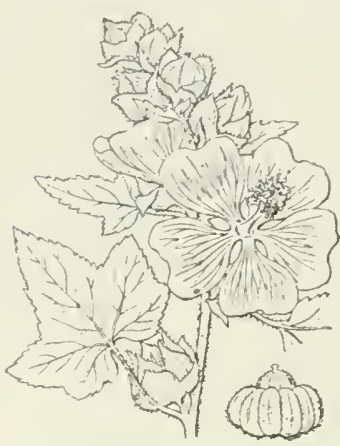

Lavatera olbia.

Fig. 229.

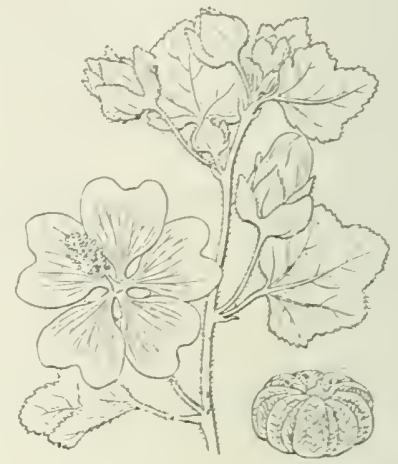

Lavatera maritima.

Fig. 230.

la précédente, une plante puissante. On la cultive assez souvent dans les jardins, mais elle est assez rare à l'état spontané (cap Matifou), ainsi que? le Lavatera rLPestre (Lavalera rupestris Pom.) dont on cite une station au Garrouban région de Tlemcen). Le Latatera Maritiue (Lavatera marilima L.) (Fig. 230) se développe sur les rochers ealcaires (Oranie, Cherchell, Djurdjura, etc.).

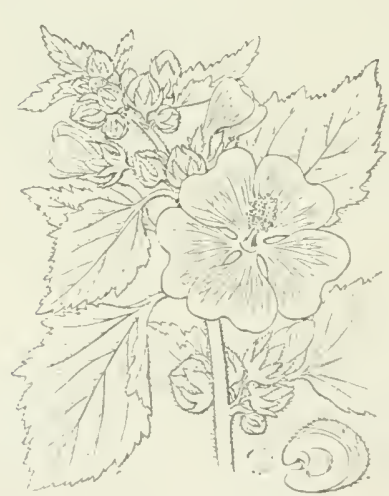

Althæa officinalis.

Fig. '231.

La GUIMAUYE (.1lhara officinalis L.) (Fig. 2:31, que l'on cultive souvent dans les jardins, se rencontre aussi à l'état spontané dans les prairies humides et dans les marais, notamment dans la Mitidja.

Il existe également en Algéric deux espèces de Ketmie (IIibiscus) depuis longtemps introduites et

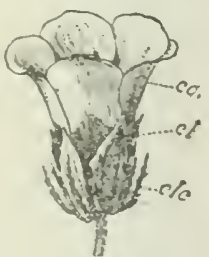

Fleur d'Hibiscus rosens : clc, calicule: $c l$. calice: $c 0 r$, corolle.

Fig. 232. 
qui sont devenues subspontanées: l'Hibiscusroseus Tho. Fig.232), d'origine américaine (marais de Bòne et à l'est de Bougie, et le Gombo (Hibiscus esculentus L.), dont le fruit est comestilsle. Plusicurs lietmies sont cultivées comme plantes diornement.

C'est aussi dans la famille des Malvacées que se place le genre Gossypium ou Cotonsier dont les graines sont recouvertes d'un duvet blanc jaunâtre qui constitue le coton. Le Gossypium herbaceun L. a déjà été autrefois cultivé en Algérie; de nouveaux essais, dont les résultats semblent encourageants, sont tentés actuellement. Le Cotonnier est quelquefois subspontané dans le voisinage des lieux où sa culture est pratiquée. Les Cotonniers cultivés en vue de la production du textile sont annuels.

La famille des GARYOPHYLLÉES ne comprend en Algérie que derares espèces ligneuses. L'CEildet de Portegal (Dianthus lusitanicus L.) est une plante vivace, à peine ligneuse, que l'on reneontre sur la frontière marocaine. Citons encore le Buffonia Duvaljonvii Batt. qui croìt dans la région montagneuse, notamment dans les environs de Médéa, au Djurdjura, etc., et le Buffonia macropetala Willk. que l'on trouve sur les rochers d'El Kantara.

A la famille des PARONYCHIÉES, voisine des Caryophyllées, appartiennent deux plantes ligneuses à la base : l'Hernatre de Desfontanes (Herniaria Fonlanesi Gay ou $H$. fruticosa L.), à feuilles opposées, petites, ovalaires. émettant à leur aisselle des glomérules de petites fleurs verdàtres. On a distingué plusieurs variétés répandues en Oranie et dans le Sud.

Le Polycarpon peploides D. C. (Figg. 233) à feuilles un peu charnues qui croît sur le littoral de la région Bòne à La Calle.

I.e Lilas des Inines ou de Chine ou Margousier (Melia Azedarach L.), de la famille des MÉLIAGEES, est une essence introduite en Algérie où elle est cultivée sous le nom de Melia. Cet arbre de 10 il 15 mètres, présente des ranseaux terminés par des bouquets de feuilles bipennées (éest-a-dire deux fois pennées) à folioles opposées dentées et courtement 
pétiolées. Les fleurs, disposées en grappes composées, odo. rantes, ont une couleur lilas bleuâtre. Les fruits, d'une saveur

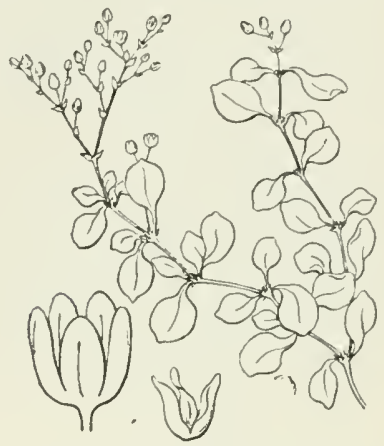

Polycarpon pep'oides. Fig 233.

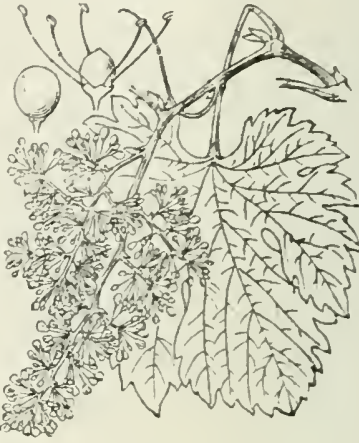

Vitis vinifera.

Fig. 234 .

amère, sont purgatifs et mème vénéneux à haute dose; la racine est un excellent vermifuge.

La famille des AMPELIDÉES est représentée par la VIGNE (Vilis vinifera L.) (Fig.

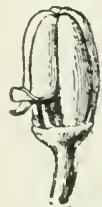

Fleur de Tigne dont les pélales commencent à se détacher par Ia base.

Fig 235.

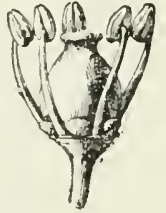

Fleur de Vigne epanoule dont la corolle estlombée.

Fig. 2:36. 234) dont la culture est très répan. due en Algéric et que l'on y ren. contre aussi très souvent à l'état spontané. Celte plante bien connue présente des rameaux grimpants à laide de vrilles et portant des feuilles alternes, dentées, à stipules caduques, et les grappes de petiles lleurs vertes. Au moment de lépanouissement de la fleur, les pétales, toujours réunis par leur partic supérieure, se détachent du réceptacle et sont soulevés par les étamines comme une sorte de capuchon qui ne tarde pas à tomber (Fig. 233) et 236 . Le fruit de la Vigne sauvage est verdàtre el acidulé.

La famille des ACERINEES est importante au point de vue forestier. Les Érables (Acer) sont des arbres à feuilles 
opposées longuement pétiolées, à limbe à nervation palmée, échancré en 3 à 7 lobes. Les fleurs, petites et d'un jaune verdâtre, possèdent 5 sépales, 5 pétales, 8 étamines et 2 carpelles, donnant à maturité 2 samares longuement ailées.

L'ÉRABLE CHAMPÈTRE (Acer ('ampestre L.) (Fig. 237) est un arbre de taille moyenne, présentant une écorce brun jaunàtre finement écailleuse et des feuilles à 3 à 5 lobes séparés

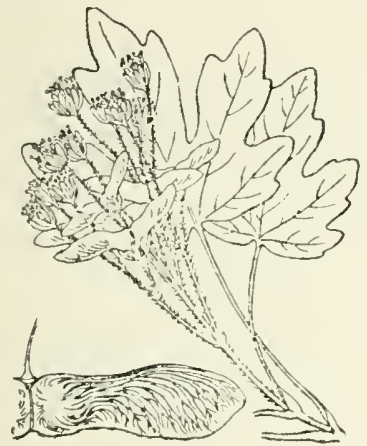

Acer campestre.

Fig. 237.

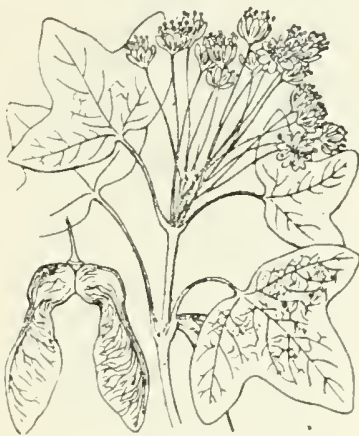

Acer monspessulanum

Fig. 238.

par des échancrures profondes; c'est une espèce rare en Algérie, on ne l'observe que dans les grandes forêts de l'Est (Guerrouch, près de Djidjelli)

L'ÉRABLEDE MONTPELLIER (A cer monspessulamum L.) (Fig. 238) est un arbuste de" 4 à 5 mètres de hauteur qui reste même souvent à l'état de buisson étalé et dilfus; son écorce est lisse et d'un gris jaunâtre, ses leuilles mates et glauques sur la face inférieure. Cette espèce est répandue dans la région montagneuse de l'Algérie: dans le Djurdjura, à Teniet, etc.

L'ERABLE A FEUILLIES D'(OBIER (A cer opulifolium Vill.) (Fig. 239), rare en Allgérie (Djurdjura, Zaccar), est un arbre de (6) à 7 mètres de hauteur souvent buissonnant; son écorce, lisse et grise au début, devient ensuite écailleuse et brun jaunàtre ; ses fenilles, assez grandes et en coeur a la base, sont mates et glanques eñdessous, et échancrées à 5 à 7 lobes.

L'ERABLE NAPOIITAIN (Acer obtnsalmm W'ild.) (Fig. 240) diffère peu de l'espèce précédente; ses feuilles sont plus petites, velues en dessous; il est assez répandu en 
montagne, en particulier dans la Kíalylic du Djurdjura et dans la Kabylie des Babors.

D'une façon générale, le bois des Érables est d'excellente qualité et d'aspect agréable; il a les usages les plus variés. Non seulement on en fait des meubles massifs, de belles frises

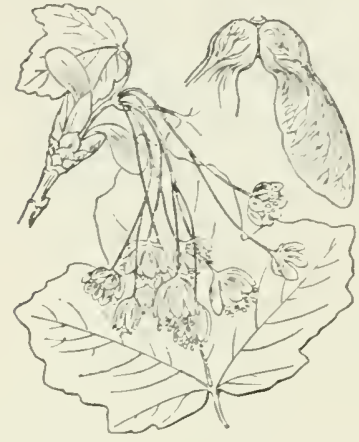

Acer opulifolım.

Fig. 239.

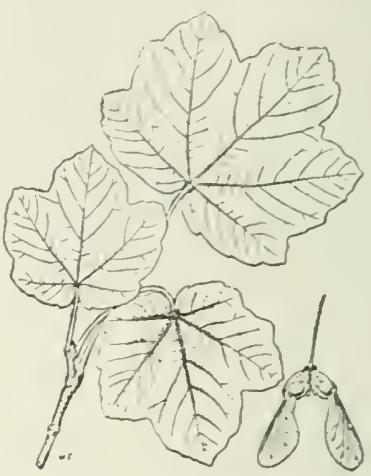

A:er obtusatum.

Fig. 240.

de parquet, mais il est utilisé pour la fabrication des pianos, du fond et des còtés des violons; certains arbres, présentant une fibre ondulée, sont particulièrement recherchès comme bois de résonance; c'est ce qu'on appelle le "bois ondé ".

Les Érables sont sourent cultivés pour l'ornement; la plupart des espèces présentent des formes à fruits et à feuilles rouges.

Ils nont pas une grande importance au point de vue économique en Algérie. où ils sont confinés dans quelques massifs montagneux.

Le CORROYERE A FEUILLES DE MYRTE (Coriaria myrlifolia L) (Fig. 241) de la famille des GORIARIÉES en est le seul représentant dans la région méditerranéenne et en Algérie. Ciest un arlorisseau de 2 à 3 mètres de hauteur. sans poils, à rameaux grisîtres quadrangulaires, à feuilles entières, ovales lancéolées. courtement pétiolées, opposées ou par verticille de trois. Les lleurs sur le type 5 ont moins de 4 millimè- 
tres de largeur et sont disposées en grappes dressécs. Le fruit est charnu, d'abord vert, puis noir et luisant.

Cet arl,risseau, assez commun dans les broussailles humides, émet de nombreux rejets allongés et ramifiés, ce qui permet de l'utiliser pour la fixation desterrains en pente. Les feuilles renferment du tanin et sont employées avec le Sumac ou le tan pour la préparation des cuirs. On les mêle quelquefois

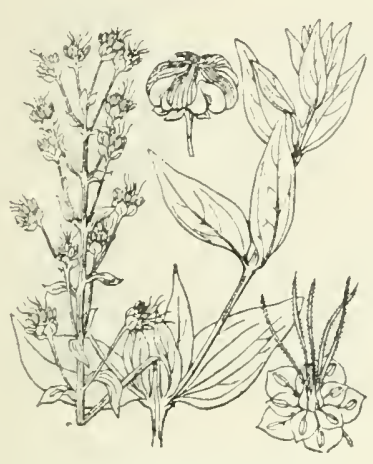

Coriaria myrtifolla.

Fig. 241 .

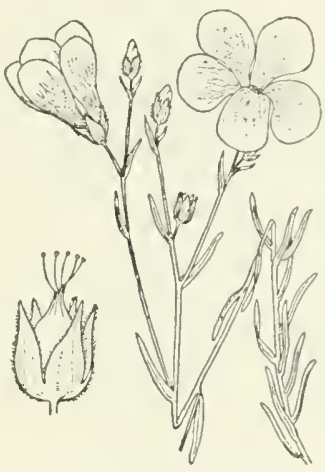

Linum suffruticosum.

Fig. $2+2$.

frauduleusement au Séné. Elles contiennent, ainsi que les fruits, un glucoside extrêmement vénéneux : la coriarine.

Les LINÉES sont des plantes grèles à feuilles simples. étroites et sans pétiole, à fleurs sur le type 4 ou 5 ; les pétales, tordus dans le bouton, se détachent facilement. Le fruit est une capsule.

La plupart des espèces sont herbacées; nous citerons seulement deux espèces sous-ligneuses dans le genre Lin (Linum), caractérisé par les lleur's sur le type 5 et les leuilles alternes.

L.e Linum anstriacum L.. à tiges courtes et tombantes, et le Linum suffrulicosum L. (Fig. 2t2), à tiges dressées, sont des plantes des Hauts Plateaux signalées en particulier à Boghar et au Garrouban.

La famille des RUTAGÉES est représentée en Algérie par deux espéces sous-frutescentes appartenantau genre Rula. 
La Rue des yontagies (Rula monlana L.) (Fig. 243, est une plante vivace, ramifiée, d'un vert glauque à fleurs en grappes serrées, la centrale sur le type 5, les autres sur le type 4. Elle est très commune dans toute la région montagneuse et cultivée parfois dansles jardins.

La Rue a feullees Étroites (Rula angustifolia Pers.

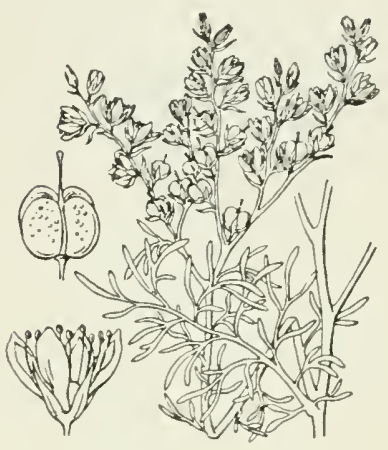

Ruta montana.

Fig. 243.

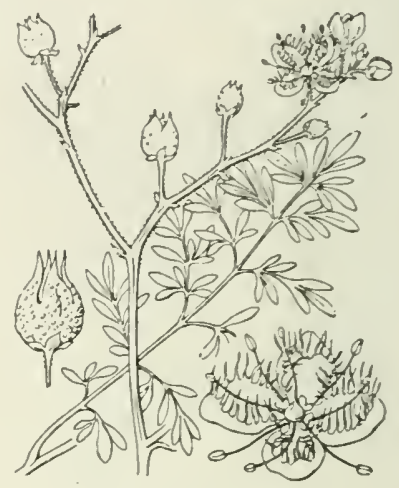

Ruta angustifolia.

Fig. 244.

(Fig. 244) qui se distingue par ses fleurs plus grandes et ses pétales ciliés, existe dans le Tell algérois (Maillot, Boghar, etc.).

Les Rues sont des plantes à odeur forte; à faible dose, elles constituent un enménagogue puissant et un antihelmintique; à haute dose, elles peuvent déterminer la mort. Ia Rue des montagnes peut produire des pustules sur la peau des gens qui la récoltent.

C'est dans la famille des AURANTIACÉES que l'on range le genre Oranger (Citrus) qui comprend en Algéric un certain nombre d'espèces introduites. Ce sont des arbrisseaux ou de petits arbres souventépineux, originaires de l'Inde orientale; l'écorce du trone est grise; celle des jeunes rameaux verdàtre; les feuilles alternes ont un pétiole plus ou moins ailé; les fleurs (Fig. 245), grandes, blanches ou rosées, sont très odorantes et comprennent généralement j sépales, j pétales de très nombreuses étamines et un oraire à plusicurs loges 
donnant à maturité une baie (Fig. 246) renfermant une pulpe acidulée, sucrée ou amère. Comme espèces principales, citons

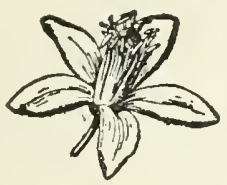

Fleur de Citrus Aurantium.

Fig. 245.

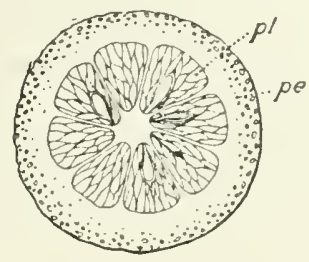

Coupe d'une orange montrant la paroi du fruil pe qui porte à sa surface interne les poils charnus $p l$ formant la partie comeslible de l'orange.

Fig. 246.

l'Oranger doux (Cillus Aurantium L.), l'Oranger aner ou Bigaradier (Cilrus Bigaradia Duham.), le Citronner (Citrus Limonium Riss. et Poit.), le Cédratier (Cillus medica L.).

La famille des HYPERICINEES comprend deux espèces à citer : le Millepertuis D’Afrique (Iypericum

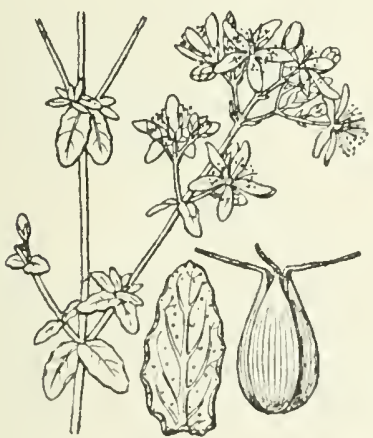

Hyfericum afrum Fig. 247.

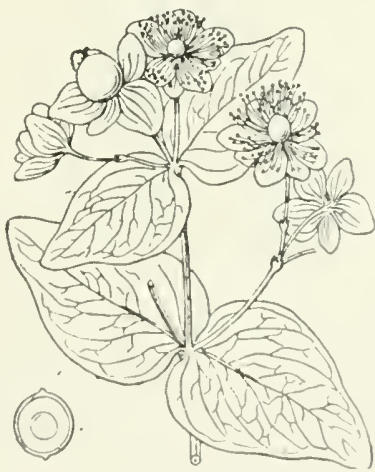

Androsæmum officinale. $\mathrm{Fig}, 248$.

afrum Lam.) (Fig. 247), espèce sous ligneuse qui existe depuis l'Akladou (Kabylie) jusqu'en 'Tunisie, et l'Axunosise orteCINAl (Audrosamum officinale All • (Fig. 248), sous-arbrisseat 
rameux de 50 à 80 centimètres de hauteur, rappelant un peu un Chèrefeuille par son port. Les feuilles sessiles, ovales, en cœur à la base, sont portées sur des rameaux présentant deux lignes saillantes. Les fleurs jaunes à j sépales, 5 pétales et 5 faisceaux d'étamines donnent un fruit charnu.

Cette espèce est localisée dans les stations humides de la ré gion montagneuse (ruisseau des Singes près Blida, forèt de Mizrana près Dellys, Akfadou près Azazga, Guerrouch près Djidjelli).

\section{\$ 2. - Dialypétales calyciflores.}

Le FUSAIN A LARGES FEUILLES (Evonymus lalifolius Scop.) (Fig. 249), de la famille des GÉLASTRINÉES, est un arbrisseau haut de 2 à 4 mètres, mais qui dans des condi-

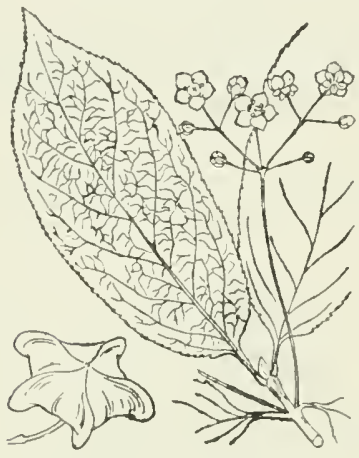

Evonymus latifolius.

Fig. 249.

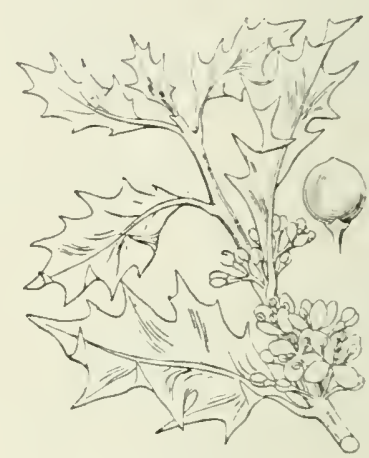

Ilex Aquifolium.

Fig. 250 .

tions favorables peut atteindre 7 metres. Les rameaux jeunes sont arrondis, luisants, verts et lavés de rouge brunsurune face. Les feuilles sont ovoïdes, finement dentées: les lleurs, très petites, longuement pédonculées, donnent à maturité des capsules roses dont la forme anguleuse a fait donner au Fusain le nom de "bonnet de prêtre ".

Le Fusain est rare en Algérie : on le rencontre sur les chaines du Djurjura et des Babors et sur les sommets de l'Atlas de Blida.

Son bois, de couleur jaune clair, très homogène, facile à 
travailler, peut ètre utilisé comme celui duFusain commun répandu en France pour la fabrication d'ouvrages de marqueterie; carbonisé en vase clos, il donne le Fusain à dessiner. Les fruits el les feuilles sont vomitifs et purgatifs; on emploic aussi les fruits (15 à 30 grammes par litre d'eau) pour lotion contre la galle.

A la famille des ILIGINÉES ${ }^{1}$ appartient le HOUX (Ilex Aquifolium L.) (Fig. 250). C'est un arbuste ou un petit arbre haut de 2 à 10 mètres, à écorce lisse, grise sur les branches, verte sur les jeunes rameaux à feuilles persistantes alternes, coriaces, dentées, épineuses, courtement pétiolées.

Les fleurs blanches ou rosées sont disposées en petits groupes à l'aisselle des feuilles et présentent le type 4 ou 5 ; le fruit est charnu et d'un joli rouge corail à maturité.

Le Houx repousse bien de souche et présente une longévité considérable. Il se développe bien sur tous les sols, mais de préférence sur ceuxqui ne sont pas calcaires. En Algérie, il est très répandu dans la zone du Cèdre et exceptionnellement dans les forêts de Chènes à feuilles caduques.

Le bois du Houx est dur, homogène, et convient aux mêmes usages que celui des Érables; il prend bien la couleur noire et est susceptible d'un très beau poli qui le fait ressembler à l'ébène. On l'utilise pour la tabletterie, le tour, la fabrication des instruments de mathématiques; il vaut jusqu’à 30 franes les 100 kilogrammes.

L'écorce du Houx renferme du lanin, de la résine et une matière très visqueuse, la glu, avec laquelle on prend certains oiseaux. Ses fruits sont vomitifs et lortement purgatifs. La décoction des feuilles (30 à 60 grammes par litre d"eau) est lègèrement sudorifique et fébrifuge.

La famille des RHA MÉES comprend en Algérie deux genres spontanés.

1. La silnalion des Célastrinées, Ilicinées, Rhammies, ele., qui se plaxent ì la limite des Thal:mullores al des Calycillores est assez indécise el varie aree les lores consuliees.

Pour la commodite du lecteur pui pourra avoir occasion de se reporler aux ouvrages de M.M. Batlandier et Trabul, nous arous classe ces fimilles parmi les Calyeillores comme l'ont fiat les autcurs de la lilore d'Algérie. 
Le genre Nerprun (Rhamnus) est représenté par plusieurs especes. La plas commune est le NERPRUN ALATERNE (Rhammus Alaternus L.) (Fig. 251), arbrisseau dioĩque

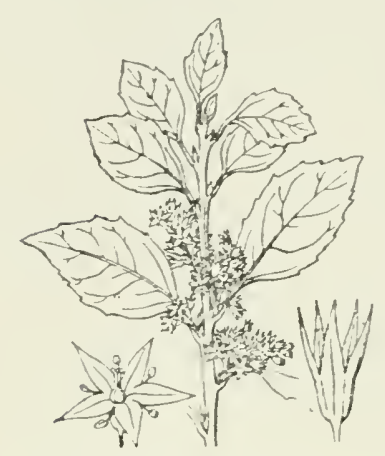

Rhamnus Alaternus.

Fig. 251.

a feuilles persistantes, coriaces, luisantes, lâchement dentées. Les fleurs, disposées en grappes à l'aisselle des feuilles, sont dépourvues de pétales; le fruit est rouge, puis noil'; cette espèce repousse abondamment de souche; elle est commune dans les broussailles du Tell.

Les feuilles sont astringentes; les baies passent pour purgatives.

La variété couchée (Var. prostrata), dont certains botanistes font une espèce spéciale sous le nom de $\mathrm{N}_{\mathrm{ER}}$ PHCN A FECILles DE MYRTE (Rhamnus myrtifolia Willk.) diffère beaucoup du type précédent par son port: c'est un arbrisseau à feuilles très petites et à rameaux étroitement appliqués sur les rochers. On le trouve çà et là en montagne (Djurdjura, El Kantara).

Le bois de l'Alaterne est très lourd, très homogène, d'un grain extrèmement fin et très propre pourourrages de tour et d'ébénisterie.

La graine de Perse, utilisée en teinturerie, provient, parait-il, de cette espèce.

La BOURDAINE ou Bois noir (Rhamnus Frangula L.) (Fig. 252) est un arbrisseau de 2 à 4 mètres, très commun en France, mais beaucoup plus rare en Algérie, où on ne le trouve guère que dans l'Est, dans les terrains marécageux près de La Calle ; ses feuilles sont entières, luisantes en dessus, ses fleurs blanchâtres, son fruit globuleux, rouge, puis noir.

Le bois de cette essence fournit un charbon très léger utilisé dans la fabrication des poudres noires. L'écorce a des propriétés purgatives et fournit une matière colorante rougeàtre .

Le Nerprux des Alpes (Rhamnus alpina L.) (Fig. 253) et le Nerprun purgatif ou Nompnex (Rhammus cathartica L.) sont, comme le précédent, des arbrisseaux communs en France, 
mais rares en Algérie; le premier ne se rencontre que sur les montagnes éle vées et le second est localisé dans un "Matmor \# de la crête du Tababor.

Le suc des fruits du Noirprun sert à préparer la couleur connue sous le nom de vert de ressie; l'écorce peut servir à

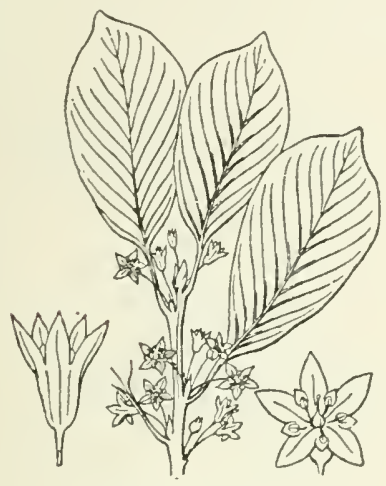

Rhamnus Frangula.

Fig. 25.

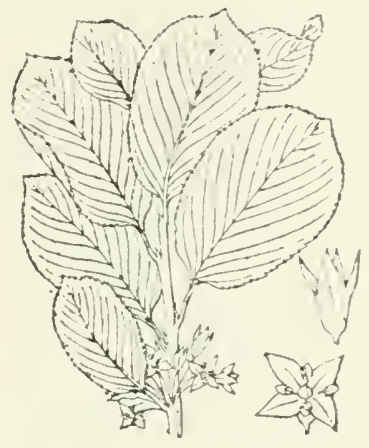

Rhamnus alpioa.

Fig. 253.

teindre en jaune ; le bois a une teinte rosée remarquable, mais il ne présente que de faibles dimensions.

Le Nerprex Faux-Olivier (Rhamnus oleoides L.) est assez commun sur les calcaires du Tell et mème du Sud Oranais; il forme des buissons épineux.

Le Nerprun Faux-Lxciet (Rhammus lycioides L.) est un petit arbrisseau à feuilles linéaires que l'on troure dans les fentes des rochers, dans la région des Hauts Plateaux.

Les Jujubiers (Zizyphus) sont des arbrisseaux à feuilles ovales, dentées, puurrues à la base de stipules épineuses; les fleurs sont petites et construites sur le type j.

Le JUJUBIER SAUVAGE (Ziryplus Lolus L.) est une des broussailles les plus communes de l'Algérie; cet arbrisseau drageonne avec une facilité remarquable à l'aide de longues racines traçantes dont l'extraction fournit aux Arabes du bois de cliauffage ; ses fruits sont comestibles.

Les branches sont utilisées par les indigènes pour faire des clòtures autour des liabitations. 
Le Jujciren cultúe (Ziryphus vulgaris Lam.) (Fig.254) est souvent subspontané au voisinage des lieux où on le cultive ; c'est un arbrisseau ou un arbre qui peut atteindre 8 mètres et présente jusquà 2 mètres de circonférence.

Cette essence drageonne facilement et fournit un bois com-

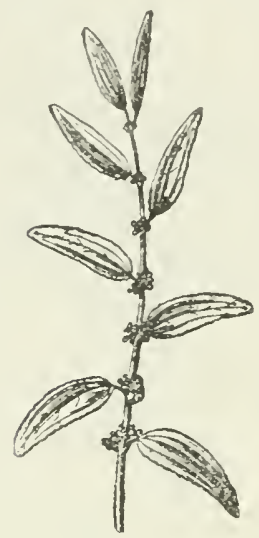

Zizyphus vulgaris.

Fig. 254.

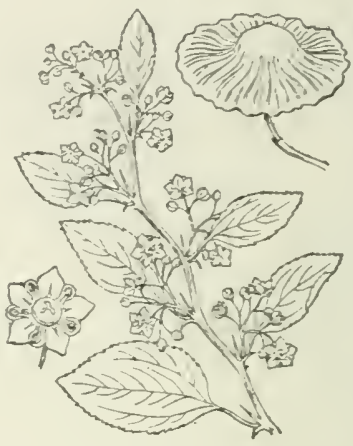

Paliurus australis.

Fig. 255.

pact, homogène, susceptible d'un très beau poli et d'une couleur aussi rouge que l'acajou; on l'emploie en ébénisterie et on en tire aussi un charbon de première qualité.

Les fruits, du volume d'une grosse olive, connus sous le nom de Jujubes, sont sucrés et comestibles, on en fait un sirop et une pàte.

Le Paliure (Paliurus anstralis Gœrtn.) (Fig. 25j) est, comme le précédent, un arbrisseau cultivé et sourent subspontané; il s’en distingue à son fruit aplati, bordé d'une aile membraneuse.

La famille des TÉRÉBINTHAGÉS comprend des arbustes à feuilles alternes composées, à lleurs pelites réunies en grand nombre en grappes rameuses.

Les Pistachiers (Pistacia) sont des arbres ou des arbrisseaux diöques à folioles entières, à fleurs dépourvues de pétales; les lleurs màles possèdent jo sépales et jo étamines; les fleurs 
femelles 3 à 4 sépales et un ovaire surmonté de 3 styles; le fruit est une drupe.

Le LENTISQUE (Pistacia Lenliscus L.) (Fig. 256) est un arbuste qui peut atteindre 4 à 6 mètres de hauteur sur 1 à 2 de diamètre, mais on l'observe rarement en cet étal ; fréquemment mutilé, il repousse vigoureusement de souche et se présente à l'état de buissons épais. Cette espèce est extrêmement

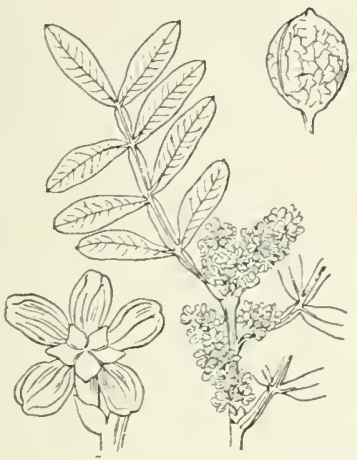

Pistacia Lentiscus.

Fig. 256.

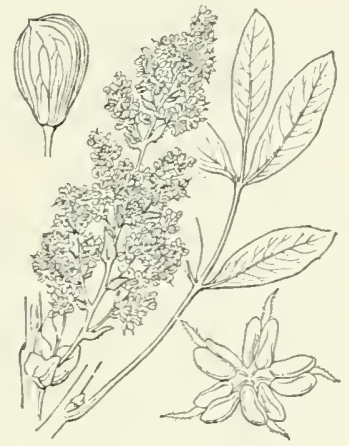

Pistacia Terebinthus.

Fig. 25\%.

abondante dans le Tell, où elle forme un des éléments prineipaux des broussailles.

Le Lentisque contient une résine qui est parfois exploitèe pour la préparation des vernis.

Les fruits renferment une amande comestible d'où l'on a cherché à tirer une huile de table et d'éclairage; les feuilles servent quelquetois, comme celles des Sumacs, à préparer une matière tannante; le bois dur, de couleur rose, suscepiible d'un beau poli, est utilisé en ébénisterie et en menuiserie et fournit un excellent combustible. Les rejets peuvent ètre employés pour la vannerie.

Le PISTACHIER TÉRÉBIYTHE (Pislacia Terebinthus L.) (Fig. 257) est moins commun que le précédent, surtout sur le littoral; il peut atteindre une taille plus élevée (jusquà 15 mètres) et une circonférence plus grande; son bois est d'un beau brun marron et sert aux mèmes usages que celui du Lentisque. 
L'écorce fournit une résine qui constituait autrefois la vraie térébenthine. La piqùre d'un insecte forme fréquemment sur le Pistachier térébinthe une grosse galle simulant un fruit de Caroubier et connue sous le nom de Caroube de Judéc. Elle renferme $60 \%$ de tanin et $15 \%$ d'acide gallique.

Le PISTACHIER DE LATLAS (Pislacia allantica Desf.) est souvent considéré comme une variété puissante de Térébinthe, à feuilles plus petites. Il faut, d'après M. Battandier, considérer le Pislachier de l'Atlas comme une espèce spéciale, se distinguant facilement du précédent par l'examen du bord de ses feuilles qui, grossi 20 fois, est nettement velu.

Ce bel arbre, qui ressemble assez au Frêne avec lequel on le confond quelquefois, se rencontre çà et là dans le Tell intérieur et sur les Hauts Plateaux; il est abondant dans les Dayas et mêne dans le Tell, vers la frontière marocaine.

Les Sumacs(Rhus) sont des arbrisscaux à feuilles caduques, à lleurs polygames petites, jaunâtres, comprenant à l'ètat complet 5 sépales, 5 pétales, 5 étamines et 1 pistil à une seule loge surmonté de trois styles donnant une drupe à maturité. Ce sont des plantes odorantes contenant de la térébenthine el du tanin.

Le Sumac des conroyeuns (Rhus Coriaria L.) (Fig. 258) est un arbrisseau de 3 à 4 mètres à feuilles imparipennées, à lleurs blanchâtres, à fruit laineux d'un brun pourpre; c'est une plante rare en Algérie, citée comme existant à la Bouzaréa, près d'Alger.

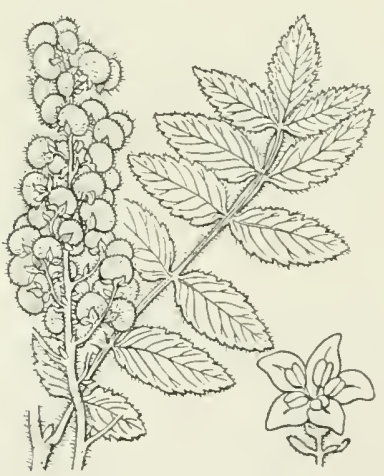

Rhos Corfaria.

Fig. 258.

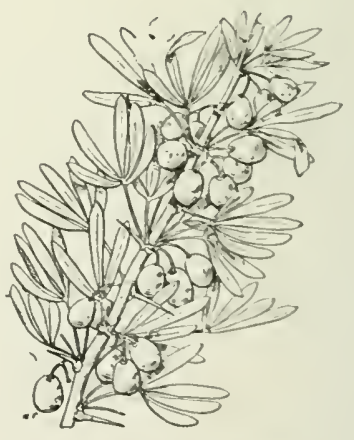

Rhus pentaphylla. Fig. 25!). 
Cette espèce rejette de souche et drageonne vigoureusement.

Son écorce fournit une matière colorante jaune ou rouge qui sert à la peinture des cuirs et des étoffes, mais son bois, assez mou, cassant, n'est pas utilisé. Les feuilles et les jeunes pousses donnent un tan très estimé. Les fruits, conservés dans le vinaigre, sont mangés comme des càpres.

Le SUMAC THÉZÉRA (Rhus pentaphylla Desf.)(Fig. 259) est un arbrisseau de 4 à 7 mètres dont l'aspect rappelle l'Aubépine. Ses feuilles sont persistantes et son fruit jaune rougeàtre présente trois petits tubercules au sommet. On le rencontre dans la vallée du Chéliff et en Oranie.

Son écorce, très recherchée lans l'industrie, renferme une matière tinctoriale rouge et du tanin. Elle sert à la préparation des cuirs maroquins.

Le Sumac Áubépine (Rhils oxyacantha Cav.) sert aux mêmes usages que le précédent; il croit dans le Tell de la province de Constantine, plus à l'Ouest au pied du Chenoua, près de Cherehell, et surtout sur les Hauts Plateaux et dans le Sahara.

La famille des Térébintlacées comprend, en outre, deux espèces introduites d'un certain intérêt. Le Polvaen D'A AúmQUe (Schinus molle L.) est un arbre à rameaux grêles et retombants à feuilles composées de 15 à 20 paires de folioles étroites dentées. Les fleurs petites, unisexuées, sont disposées en longues grappes pendantes; les fruits, petites drupes rougeâtres, ont une grosseur et une saveur rappelant celles du grain de poivre. Cet arbre est utilisé pour garnır les jarclins et les avenues à cause de l'élégance de son feuillage et de ses longues panicules de fruits. Le Moldé a feurles de TériBINTHE Schinus terebinthifolius Radd.) est beaucoup moins répandu; son feuillage plus dense rappelle celui du Len. tisque.

La famille des PAPILIONACEES renlerme de nom. breuses plantes ligneuses; elle est caractérisée des plus nettement parl'aspect et la constitution de la fleur. Les sépales sont au nombre de cinc et souvent groupés en deux lèves; les pétales sont en mème nombre et offrent une disposition tout à fait particulière (Fig. 260) : le pétale supérieur, plus déreloppé, 
forme l'étendard qui recouvre les 2 pétales latéraux appelés les ailes qui, à leur tour, recouvrent les 2 pétales inférieurs. Ces derniers sont rapprochés et courbés, simulant par leur ensemble une coque de navire; ils forment la carène. Les étamines, au nombre de 10 , sont très rarement libres; presque

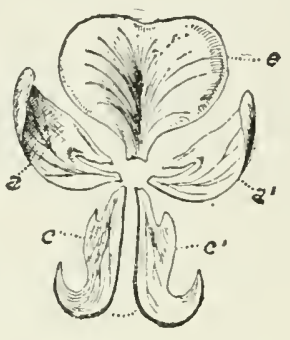

Corolle de Papilionacie (Pois) dont les pétales ont été isolés : $e$, étendard; $a, a^{\prime}$, ailes ; $e, c$, pélales qui cohérents entre eux forment la carène.

Fig. 260.

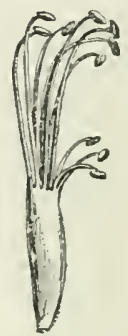

Étamines de Papilionacèe soudèes par leurs tilets.

Fig. 261.

tonjours elles sont complètement soudées (Fig. 261) ou toutes soudées, sauf une, à la base par leurs filets en un tube qui entoure le pistil. Ce dernier comprend une seule loge et se prolonge par un style unique. A maturité, le fruit s'ouvre en général par 2 valves : c'est ce que l'on appelle une gousse; quelquefois cependantil reste indéhiscent ou se divise en articles Iransversaux qui se séparent à maturité.

Les Papilionacées ligneuses l'Algérie se répartissent en un certain nombre de tribus que l'on peut distinguer d'après le tableau suivant :

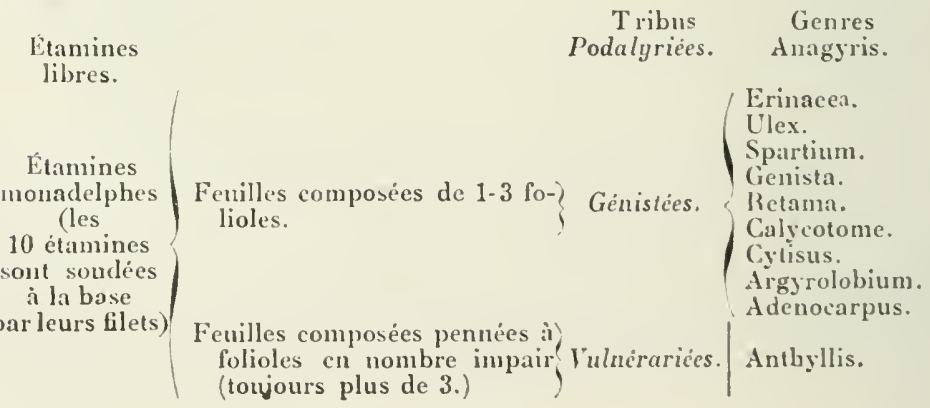




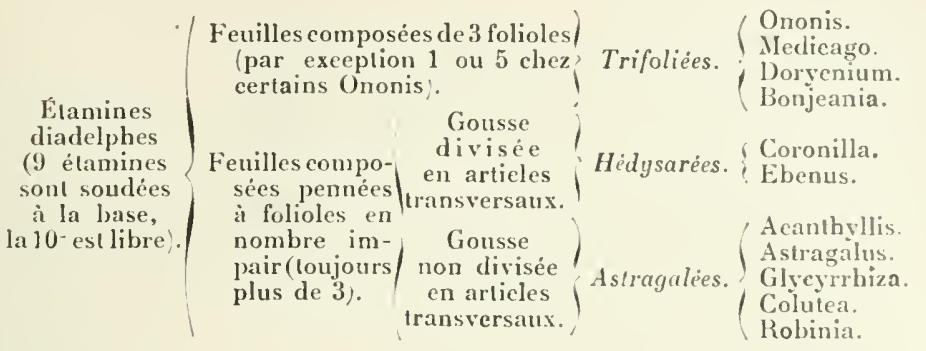

Tribu des Podalyriées. - L'ANAGYRE FÉTIDE ou Bois puant (Anagylis foctida L.) (Fig 262) (Caroubier de chicn des indigènes) est un arbrisseau de 1 à 3 mètres, d'une odeur fétide, à feuilles composées de trois folioles sessiles, clliptiques entières, finement poilues sur leur face inférieure

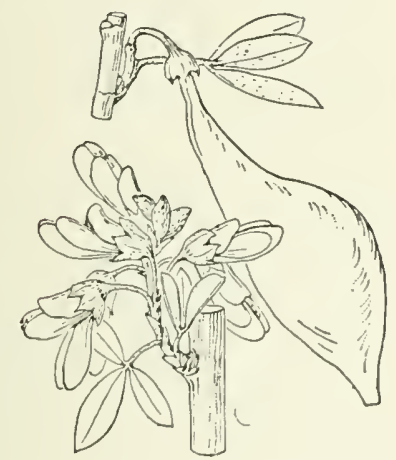

Anagyris foetida.

Fig. $2\left(i^{\circ}\right)$.

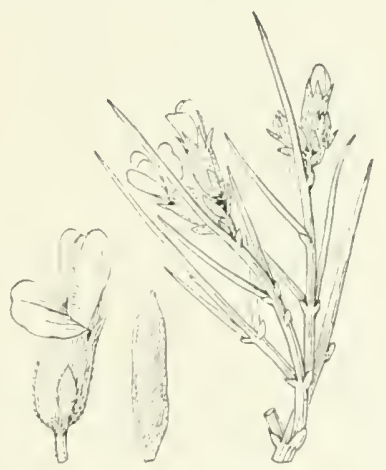

Erinacea pungens.

Fig. 263.

seulement. Les fleurs jaunes, disposées en courtes grappes, ont un étendard taclıé de noir.

C'est une espèce assez répandue dans le Tell; ses graines sont vénéneuses.

Tribu des Génistées. - Le Genre Érinacée (Erinacea), est représenté par une seule espèce.

L'ÉRINACÉE PIQUANTE (Erinacea pungens Boiss. (Fig. 263) ou Hérisonne est un sous-arbrisseau formant des buissons touffus hémisphériques garnis dẻpines que l'on 
rencontre dans l'Aurès, et en général sur les montagnes du Sud. Il existe aussi au Tababor.

Les Ajoncs (Ulex) sont des plantes très épineuses, à fleurs jaunes solitaires ou par deux, à calice fendu en deux lèvres jusqu'à la base ou presque.

L'AJonc D'Europe (Ulex europxus L.) a été signalé seulement à Fort-National, où il a été sans doute introduit.

L'AJonc D'Afrieve (Ulex africanus Webb.) et l'Llex W'ebbianus Coss. serencontrent en Oranie, le premier sur le littoral, le second dans les massifs montagneux dela région de Tlemcen, au Garrouban, etc.

Le GENET D'ESPAGNE (Spartium junceum L.) Fig. 264),

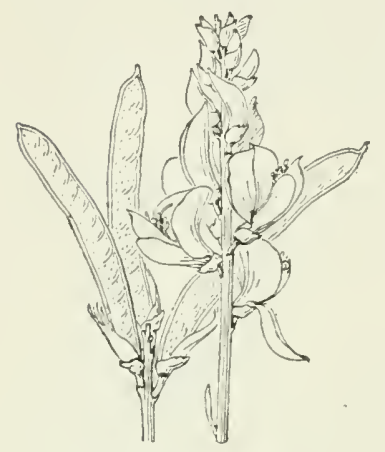

Spartium junceum.

Fig. 264. seul représentant du genre $S$ partium en Algérie, est un arbuste élevé inerme à rameaux jonciformes robustes, glauques, striès, à feuilles unifoliolées, à fleurs jaunes odorantes grandes.

Il est peu abondant, mais répandu dans les trois provinces.

Les sommités fleuries et les graines sont diurétiques à petite dose, purgatives et romitives a forte dose.

On cultive parfois le Genêt d'Espagne comme arbrisseau d'ornement à cause de l'abondance de ses lleurs; le liber des jeunes rameaux fournit une matière textile, et les pousses donnent un assez bon fourrage.

Les Genêts (Genista) sont des arbrisseaux ou sous-arbrisseaux très répandus en Algérie où il en existe une vingtaine d'espèces. On les rencontre généralement dans les broussailles; en forêt, ils occupent surtout les clairières et les vides. Se multipliant quand les arbres disparaissent, ils favorisent la reconstitution du boisement en protégeant les jeunes semis contre la dent du bétail, les espèces épineuses tout au moins, comme c'est le cas pour beaucoup d'entre eux.

Le GENET FÉROCE (Genisla ferox Poiret), que l'on troure sur le littoral d'Alger à la Calle, est un arbuste à grandes fleurs odorantes, de 1 à 3 mètres de lıauteur, pourvu de longues 
épines vulnérantes ; ses feuilles sont trifoliolées, de même que celles du Genisla Vepres Pomel, des forêts de l'Est, et du Genista spinulosa Pomel, connu seulement dans le Dahra (Medjaher), espèces de taille et d'importance moindres.

Les autres Genêts épineux sont unifoliolés et forment de petits arbrisseaux se présentant souvent sous la forme de buissons bas plus ou moins rameux.

Le GENÊT A TROIS POINTES (Genisla tricuspidata Desf.) (Fig. 265) est l'un des plus communs; il supporte bien

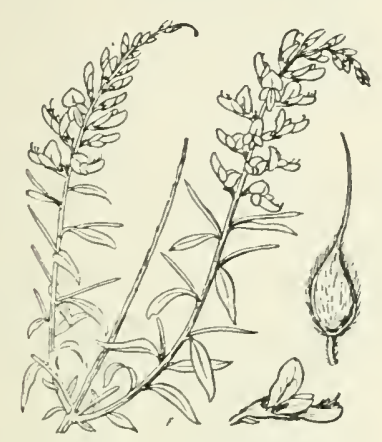

Genista tricuspidata.

Fig. 265.

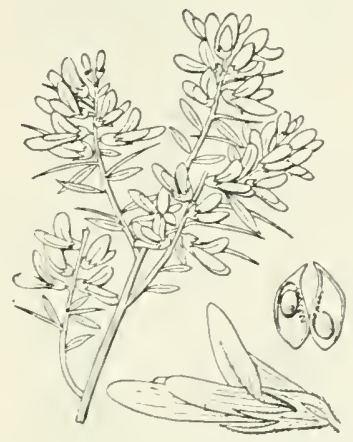

Genista Duriæi.

Fig. 266.

le couvert de la forêt. On le rencontre dans les massifs du littoral et du Tell; les épines dont il est pourvu font défaut à la variété à petits fruits (Var. microcarpa) que l'on trouve en abondance dans la forêt de la Reghaïa. Une autre variété dite de Duriec (Var. Durixi) (Fig. 266) présente, en plus de la grappe de fleurs qui termine la tige, de nombreuses grappes latérales.

Le Genèt de L'Atras (Genisla allanlica Spach (Fig. 267) et le Genetr a rameaux talneux (Genista erioclada Spacli) (Fig. 268) ont, comme le précédent, des épines fortes et longues, simples ou à trois branches. On les rencontre principalement dans la région de Tlemcen et sur les Hauts Plateaux oranais. Le Genete a Feullues d’Ajonc (Genista ulicina Spach.) (Fig 26!) possède des épines grêles et très rameuses: il est commun dans l'Est de l'Algérie, à partir de Bougie. Le Gextr aspalatuome: 


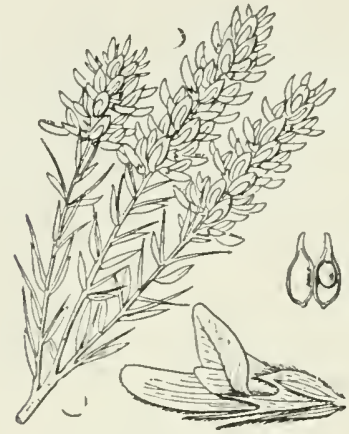

Genista atlantica.

Fig. $26 \bar{t}$.

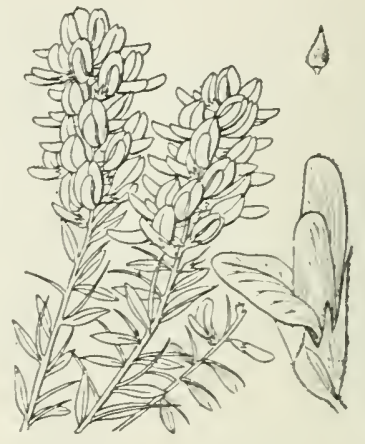

Genista exioclada

Fig. 268.

(Genislaaspala'hoides Poiret), beaucoup plus rare, a été signalẻ dans la région de la Calle et à Saïda.

Le Genèt a Capiteles (Genista cephalanta Spaclı) (Fig. 270)

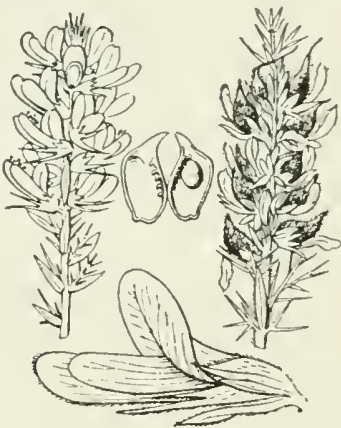

Genista ulicina.

Fig. 269.

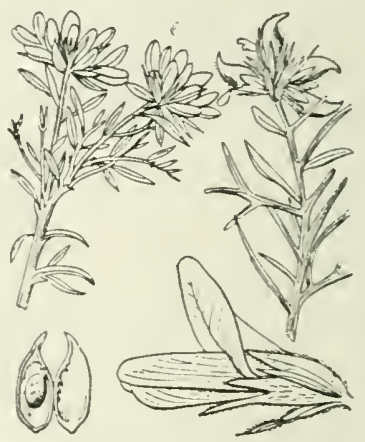

Genista cephalanta.

Fig. 270 .

(Oran, Arzew) et le GeNèt a petits capitules (Genisla microceplaala Coss.) (Sud du département de Constantine, El Kantara, ete.) (Fig. 271) sont aussi des Genêts épineux ; ils se distinguent des précédents par le mode de groupement de leurs fleurs.

Nous retrouvons les mêmes dispositions florales dans le groupe des Genêts inermes (sans épines) chez le Gexìt a Qu'ATRE fleurs (Genista quadriflora Munby! (Fig. 272) des Hauts Pla- 


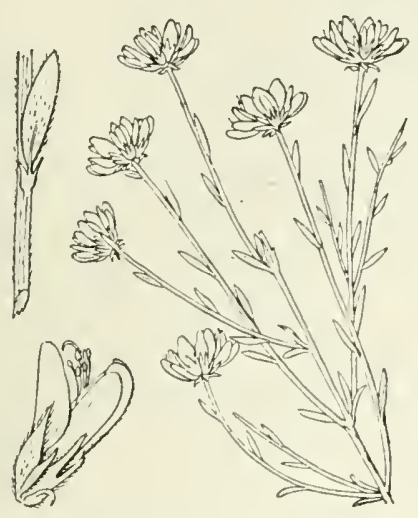

Genista microcephala.

Fig. 271.

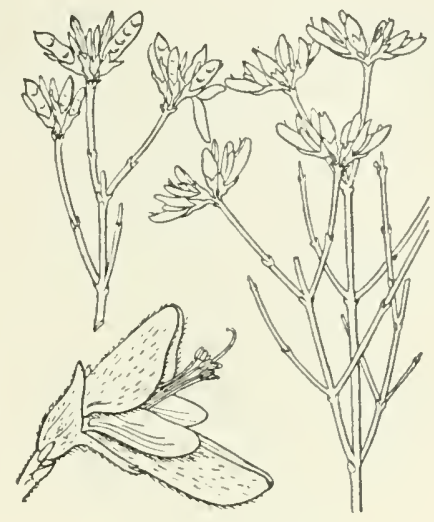

Gentsta quadriflora.

Fig. 27\%.

teaux de l'Oranie et le Genèt en oxbele (Genisla umbellata Desf.), que l'on rencontre d'Oran à Mostaganem.

Les autres Genêts non épineux ont leurs fleurs en grappes :

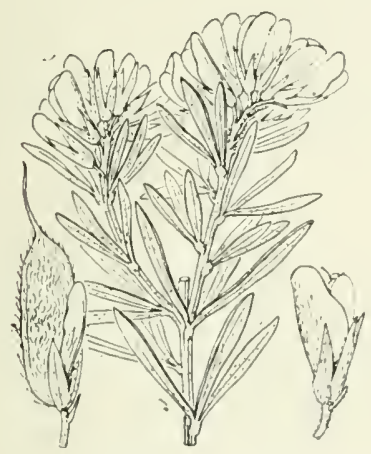

Genista linifolia.

Fig. 273.

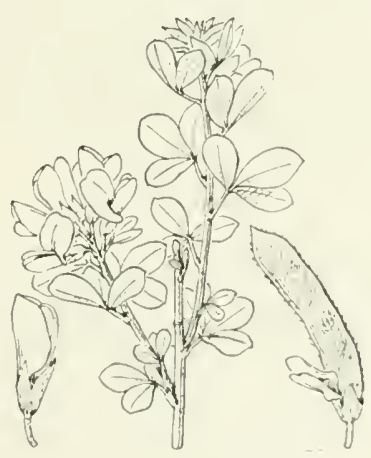

Genista candicans.

Fig. 274.

le GENET A FEUILLES DE I.IN (Genisla linifolia L.) (Fig. 273) et le GENET BLANCHATliE (Genisla candicans L.) (Fig. 27t) se rapprochent beaucoup du genre Cylisus dans lequel les rangent certains auteurs; ce sont des espèees assez communes en Algérie, surtout la première qui reste toutefois cantonnée à peu de distance du bord de la mer. 
Le Genèt Faux-Retam (Genista retamoides 1 Spa ch), de la région de Tlemcen, Bibans, Maillot, et le Gexêr Fau x Spartiek (Genista spartioides Spach) (Fig. 275) du Dahra et de la région

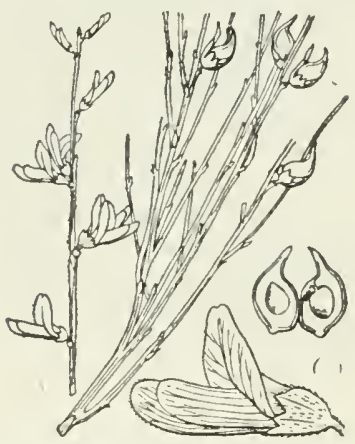

Genista spartioides.

Fig. 275.

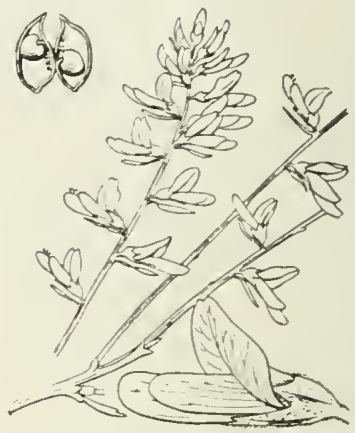

Genista numidica.

Fig. 276.

d'Oran, sont des espèces à feuilles linéaires rapidement cad uques.

Le GENET DE NUMIDIE (Genista numidica Spach) (Fig. 276), que l'on rencontre sur le littoral constantinois où il atteint d'assez grandes dimensions, a également les feuilles caduques. Une variété (Var. sarotes) de ce Genêt existe dans

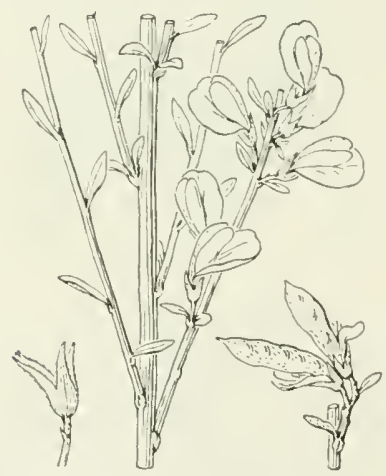

Genista cinerea.

Fig. 277.

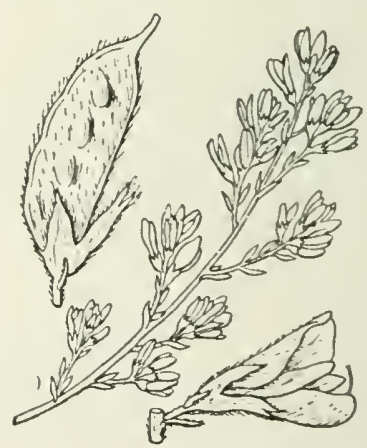

Genista pseudopilosa.

Fig. 27 s.

1. On distingue quelquefois sous le nom de Genèt de Cosson ( $G$. Cossoniana Ball.) un Genèt de très grande laille, voisin du G. relamoides. 
la région de l'Oued Djer (à l'ouest d'Alger). Mentionnons enfin le Genêt cendé (Genisla cinerea D. C.) (Fig. 27T) des Plateaux constantinois, le Genèt rameux (Genista ramosissima Desf.) des Hauts Plateaux oranais (Tlemcen, Saïda), et enfin le Genista pseudopilosa Coss. (Fig. 278), petit arbrisseau décombant de l'Aurès et autres montagnes du Sud.

Les Retams sont des arbrisseaux inermes à longs rameaux verts soyeux, presque nus par suite de la chute précoce des feuilles; les fleurs sont en grappes le long des rameaux.

L'Algérie possède 3 espèces de ce genre sans grande importance forestière, le Retama spharocarpa Boissier (Fig. 279),

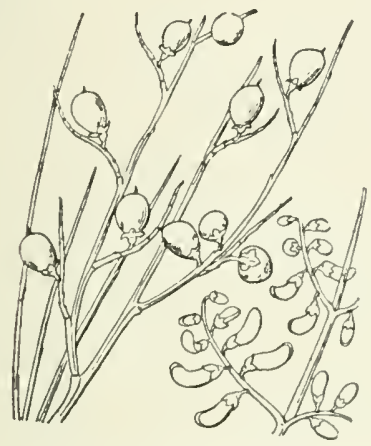

Retama sphærocarpa.

Fig. 279.

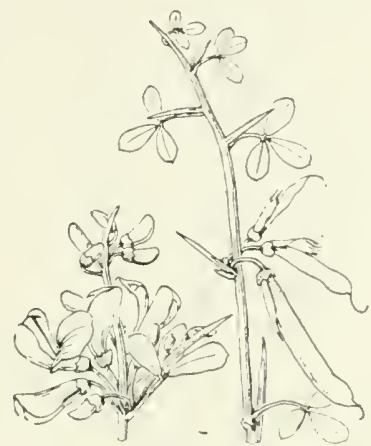

Calycotome spinosa.

Fig. 280.

espèce des Hauts Plateaux, est assez commun en forêt dans la région de Bouïra-Aumale; le Retama Retam Webb est une espèce saharienne; le Retama Bovei Spach se rencontre dans les sables du littoral où il concourt à la fixation des dunes; d'après M. Mathey, cette espèce précède et prépare la forêt de Genévriers.

Le genre Calycotome renferme des arbrisseaux à rameaux fermes épineux, à lleurs jaunes, très répandus dans les broussailles du Tell.

Le CALYCOTOME EPINEUX (Calycolome spinosa Lam.) (Fig. 280) se trouve dans tout le Tell algérien. Le Casycotome veuU (Calycotome villosa L.) se rencontre dans le 'Tell constantinois et le Calycotome intermídane (Calycolome intermedia Lam.) est asse commun en Oranie. 
Genre Cytise (Cylisus). - Six espèces représentent en Algérie le genre Cytise, si, comme nous l'avons fait, on range dans le genre Genista les types placés à la limite des deux genres: le Cylisus linifolius Lam. et le Cyylisus candicans D. C.

L'espèce la plus répandue en Algérie est le CY'TISE A TROIS FLEURS (Cylisus triflorus L'hér.) (Fig. 281) commun dans

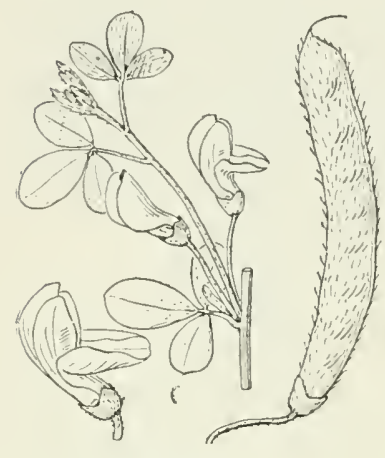

Cytisus triflorus.

Fig. 281. les broussailles et dans les sousbois des forêts du Tell, surtout dans les massifs de Chêne zéen et de Chène-liège. C'est un petit arbuste à fleurs jaune pâle dont l'étendard est taché de brun; les feuilles, composées de trois grandes folioles elliptiques, soyeuses, noircissent par la dessiccation.

Le Cytise en arbre (Cytisus arboreus Desf.), répandu dans les trois provinces, est surtout commun aux environs d'Alger; les autres espèces sont plus rares : Cylisus Balansie Boiss. et Reut. (Aurès, Malidids, Lella Khadidja), Cylisus Fonlanesi Spach (de l'Ouarsenis aux Bibans, etc.), Cylisus sessilifolitus L. (Babor), Cytisus bolicus Webb (d'Oran au Dahra).

Les Argyrolobes (Argyrolobium Linnxanum Walp. et Argyrolobium uniflorum Jaubert et Spach) sont de très petits arbrisseaux à feuilles trifoliolées et d'aspect général blanc argenté.

Le premier se rencontre çà et là sur les montagnes du Tell, surtout dans l'ouest; le second est une espece saharienne que l'on trouve quelquefois sur les Hauts Plateaux.

Le genre Adenocarpus, très voisin du précédent, comprend en Algérie 3 espèces :

L'Adenocarpus decorlicans Boiss. (de Tlemcen au Garrouban) est un arbrisseaubuissonnant rappelant l'Ajone d Europe mais sans épines; ses intlorescences en grappes compactes dun beau jaune d'or en font une plante très ornementale. LiAdenocarpus commutatus Guss. n'est connu en Algérie que sur l'Akfadou en Kabylic. LiAdenocarpus umbellatus Coss. et Dur. est igalement 
très localisé, on ne l'a rencontré jusqu'ici qu'aux Andalous près d'Oran.

Tribu des Vulnérariées. - Le genre Anthyllis est représenté en Algérie par 4 espèces ligneuses clont aucune n'a d'importance au point de vue forestier.

L'Anthylus Faux Cytise (Anthyllis cytisoides L.) (Fig. 282), arbrisseau de 30 à 80 centimètres à rameaux blancs tomenteux, à feuilles généralement composées de 3 folioles dont la terminale est plus grande, à fleurs jaunes disposées en petits fascicules de 2-5, existe à Bougie, à Tlemcen, au Garrouban.

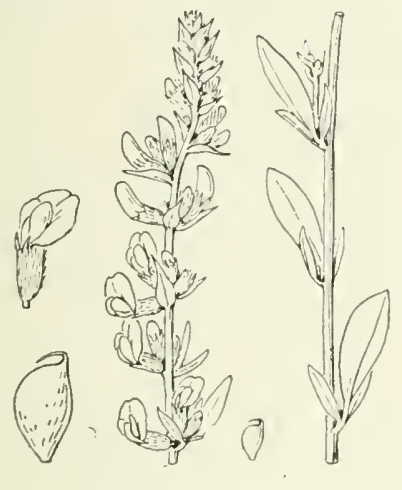

Anthyllis cytisoides.

Hig. 282.

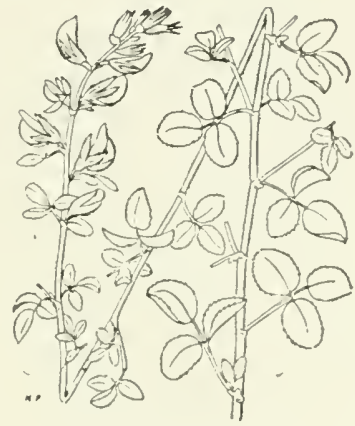

Ononis hispida.

Fig. 283.

L'Antuyluis barbe de Jupiter (Anthyllis Barba-Jovis L.) et l'ANthyllis a Nombreux capitules (A. polycephala Desf.) sont des plantes à tiges dressées ligneuses à la base, portant des folioles toutes égales ; la première a été signalée au cap de Garde, près de Bòne, et à la Calle; la seconde sur les rochers calcaires de la région de 'Tlemeen, en particulier au Garrouban.

L'Antuyllis de Montagne (A. montana I.) est une plante gazonnante, à tiges ligneuses, des sommets du Djurjura et de la crête du Tababor.

Tribu des Trifoliolées. - Les Bugranes ou Ononis, que nous avons à citer, sont des arbrisseaux ou sousarbrisseaux inermes ou épincux à lleurs roses ou jaunes que l'on rencontre généralement en Algérie dans la région montagneuse; il existe de nombreuses espèces herbacées. 
L'Oxoxis LigNeux (Ononis frulicosa L.) est un sous-arbrisseau de 3 à 10 décimètres à tige dressée très rameuse, à fleurs grandes, purpurines, ornementales, rare à l'état spontané (Boghar). On le cultive parfois dans les jardins.

L'Onoxis des Axciess (Ononis antiquorum Coss. ou O. pungens Pom.) que l'on rencontre à Bel Abbès, Tlemcen, Garrouban, est armé de nombreuses et fortes épines.

L'Oxoxis Hérissé (Ononis hispida Desf.) (Fig. 283) est un arbuste assez élevé à tiges dressées, raides, très hispides, des broussailles de la région montagneuse.

L'Ononis D'Aragox (Ononis aragonensis Asso) est une rareté en Algérie; il est localisé au sommet de Lella Khadidja point culminant du Djurjura).

La Luzerne arborescexte (Medicago arborea L.) est un élégant arbrisseau atteignant un mètre et même exceptionnellement 4 mètres de haut, à fleurs jaune vif, à feuilles trifoliolées vertes en dessus, blanchâtres en dessous, légèrement dentelées: c'est une espèce très rare en Algérie lenvirons de Bòne), mais que l'on cultive parfois comme plante d'ornement.

Le Dorycsicu sous-Frutescent (Dorycnium suffrulicosum Villars) est un arbrisseau ligneux très rameux en buisson à folioles petites, velues, linéaires, aiguës au sommet. Les fleurs sont disposées en tête et présentent une corolle blanche avec une carène d'un bleu noirâtre au sommet. On le rencontre çà et là sur les Hauts Plateaux.

La Bonjéanie droite (Bonjeania recta Reich.) ou Lotier droit est une plante à tiges dressées ligneuses à la base. Les fleurs, petites, sont disposées en têtes comme dans l'espèce précédente; c'est une plante commune en Algérie au bord des ruisseaux.

Tribu des Hédysarées. - Le genre Coronille (Coronilla) est représenté par 5 espèces dont les unes : Coronilla valentina L., Coronilla pentaphylla Desf., Coronilla glauca L., sont de petits arbrisseaux, et les autres : Coronilla juncea L., Coronilla minima L., des plantes un peu ligneuses à la base.

La CORONILLE DE VALENCE (Coronilla valentina L.) (Fig. 284) est un arbrisseau de 6 à 15 décimètres très rameux, à feuilles glauques composées de $3-4$ paires de folioles à tleurs 
jaunes disposées en ombelles de 6-12 fleurs. C'est une espèce assez commune dans le Tell.

La Coronille a cine folioles (C. pentaphylla Desf.) et la Coronille glaugue (C. glauca L.) sont très voisines de la précédente. On les rencontre la première dans le Sahel et les montagnes du Tell (la Chiffa, Kabylie), la seconde dans l'ouest, entre Oran et Ténès.

La Coronille a branches de Jong (Coronilla juncea L.) (Fig. 285) est encore plus répandue que la précédente; on la

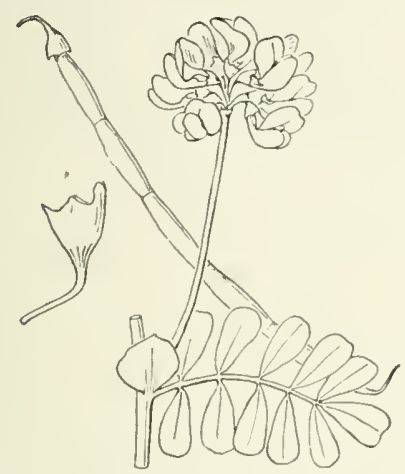

Coronilla valentina.

Fig. 284.

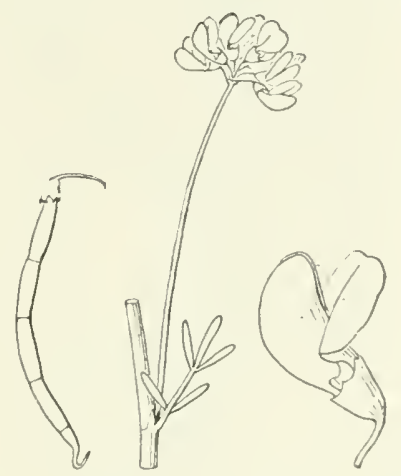

Coronilla juncea.

Fig. $28 \%$.

reconnaît facilement à ses rameaux simulant le Jonc, très verts. striés, à ses feuilles étroites composées de 1 à 3 paires de folioles, à ses fleurs jaunes groupées par j- 8 en ombelles. La Petite Coronille (C. minima L.) croît sur les Hauts Plateaux, tandis que la précédente est surtout une espèce des broussailles du Tell.

Citons encore l'Ebenus pinnala L., sous-arbrisseau de 36 décimètres à tiges raides dressées à 3.4 paires de folioles allongées soyeuses, à fleurs purpurines en grappes serrées, commun dans les broussailles.

Tribu des Astragalées. - L'Acanthyllis armata Lam. (que l'on subdivise parfois en A. mumidica et $A$. tragacanthoides) est un sous-arbrisseau très épineux à folioles linéaires que l’on rencontre surles Hauts Plateaux et les montagnes élevées du Tell.

Le genre Astragale (Astragalus) comprend deux espèces à tige ligneuse à la base. 
LiAstragalus Gombo Coss., plante veloutée laineuse à grosses tiges, haute de 4 à 10 décimètres et à fleurs jaunes, se rencontre sur les Hauts Plateaux et dans tout le Sahara.

L'Astragale de Moxtpellier (Astragalus monspessulanus L.) (Fig. 286), commun dans les broussailles du Tell, diffère du pré-

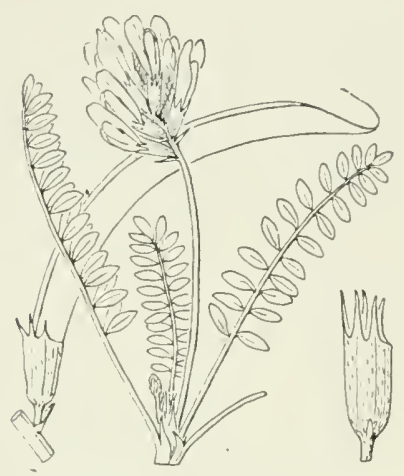

Astragalus monspessulanus.

Fig. 286.

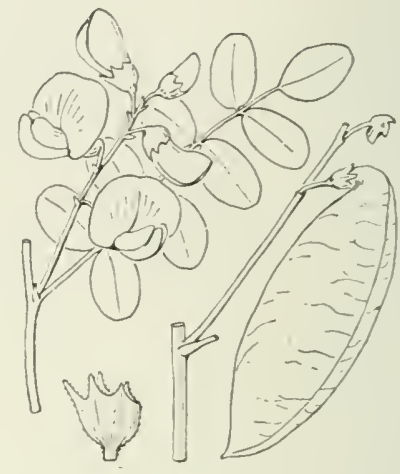

Colutea arborescens.

Fig. 287.

cédent par sa taille plus faible, ses feuilles presque glabres et des fleurs rougeâtres violacées.

Le BAGUENAUDIER (Colutea arborescens L.) (Fig. 287) est un arbrisseau atteignant 2 mètres, à tige rameuse, à feuilles composées de 7-13 folioles elliptiques, à fleurs jaunes disposées par 2-6 en grappe longuement pédonculée. Le fruit en ballon est très caractéristique.

On le rencontre principalement dans les broussailles sur les calcaires de la région montagneuse.

La RÉGLISSE FÉTIDe (Glycylrhiza fortida Desf.), plante à tiges robustes de 3 à 6 décimètres, à fleurs jaune pàle, se rencontre assez fréquemment, en particulier dans les champs de la région de Miliana et de Mascara.

Quelques espéces ligneuses de Papilionacées ont été introduites en Algérie. Citons une Astragalée: le Robixier Faux Acacia (Robinia Pseudo-Acacia L.), originaire de l'A mérique du Nord, qui a été cultivé dans toute l'Europe et en Algérie, où il est devenu subspontané. C'est un arbre d'une grande longé- 
vité qui peut atteindre 20 à $\mathbf{2 5}$ mètres de hauteur sur 2 à 3 mètres de circonférence quand il est isolé; les feuilles, composćcs, comprennent 5-12 paires de folioles et sont accompagnées de stipules transformées en fortes épines. Les fleurs blanches, en grappes pendantes, sont odorantes et comestibles. Cctte essence, dont le bois est excellent pour le travail, n'est cultivée en Algérie que pour l'ornement ou quelquefois pour maintenir la terre des talus, mais n'y présente pas d'intérêt forestier.

GÉSALPINIÉES. - Cette famille est représentée par le CAROUBIER (Ceralonia Siliqua L.) (Fig. 288). C'est un arbre dioĩque, ou polygame, trapu, qui peut atteindre 8-12 mètres de hauteur, à feuilles composées de 6-10 folioles entières, coriacées luisantes, en dessus, mates en dessous.

Les fleurs, très petites, sont disposées en grappes dressées comme des chatons; les sépales, au nombre de 5 , sont caducs; la corolle manque; les étamines, au nombre de 5 , sont opposées aux pièces du calice : l'ovaire donne à maturité une gousse

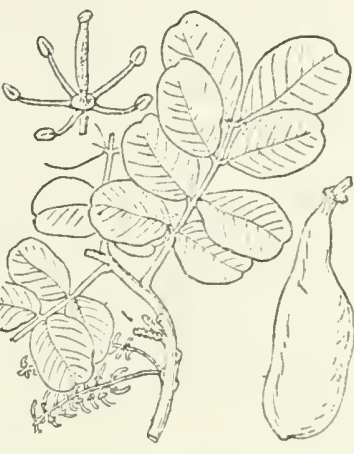

Ceratonia Siliqua

Figs. 288. allongée de 10-20 centimètres, pendante, flexueuse, contenant des graines brunes. La floraison a lieu en septembre-octobre.

Le Caroubier est une des espèces les plus caractéristiques de la région méditcranéenne; en Algéric, il est très commun dans le Tell; il croît dans tous les terrains, sauf dans les sols très humides, et repousse abondamment de souche. Son bois est dur, et coloré de rouge rosé à l'état parfait; on le recherche pour le charronnage, la menuiserie, l’ébénisterie. Il fournit un bon combustible et un charbon estimé. I.e fruit, connu sous le nom de caroube, est utilisé pour la nourriture du bétail et quelquefois consommé par les indigènes.

L'AnBre de Judée (Cercis Siliquastrum L.). Originaire de l'Asie oceidentale, est assez souvent cultivé comme arbre d'or. 
nement à causes des jolies lleurs roses qui le courrent complètement au printemps et de son beau feuillage.

MIMOSEES. - Cette famille n'est représentée dans le Tell et sur les Hauts Plateaux que par des plantes introduites du genre Acacia; ce sont des arbres ou des arbustes originaires surtout de l'Australie et des régions plus méridionales de l'Afrique; une espèce, l'A cacia tortilis Hayne, est même spontanée dans l'extrême Sud de l'Algérie et de la Tunisie.

Les feuilles sontcomposées et deux fois divisées (bipennées) ou réduites à leur pétiole qui est alors aplati et simule une feuille simple, entière ; c'est ce que l'on appelle un phyllode. Il est à remarquer que les feuilles des jeunes rejets sont snuvent très différentes de celles des sujets adultes.

Les fleurs petites, régulières, avec un nombre d'ètamines indéfini, sont généralement disposées en capitules jaunes ou jaunes blanchâtres, bien connus sous le nom de "Mimosa n. 'Toutefois l'une des espèces fréquemment cultivées en Algérie, l'A cacia lophanta V'illd., est caractérisée par des étamines à longs filets verdàtres, et une autre, l'A cacialongifolia Willd., présente des fleurs jaunes disposées en épis. On remarquera facilement sur ces deux Acacias que les pièces du périanthe sont soudées entre elles, bien que les Mimosées appartiennent aux Dialypétales.

Le fruit est une gousse.

Les Acacias produisent de la gomme; l'un d'eux, l'A. arabica Willd., fournit la gomme arabique; leur culture est reeommandée en vue de la production des extraits tannants.

Les feuilles, les fruits, l'écorce et le bois sont astringents par le tanin quils renferment.

La plupart des Acacias cultivés en Algérie y présentent un trone incliné qui les rend difficilement utilisables pour l'ornement desjardins et surtout des avenues.

Parmi les nombreuses espèces introduites dans la colonie, nous mentionnerons:

$1 \circ$ Acacias à phyllodes :

L'ACacia a longues feulles (Acacia longifolia Willd.), dont les phyllodes à plusieurs nervures saillantes ont 12 à 15 centimètres de longueur sur $S$ à 10 millimètres de largeur et portent 
à leur aisselle 1 ou 2 épis allongés. L'Acacia trinervis Hort. n'est qu'une variété du précédent à phyllodes plus réduits (11 à 12 centimètres sur 8 à 9 millimètres) et plus coriaces. L'Acacia à longues feuilles se reproduit facilement en Algérie.

L'Acacia cultriformis Cunn. est une espèce ornementale, facilement reconnaissable à ses courts phyllodes glauques.

L'Acacia pycnantha Benth. ou Acacia petiolaris Lehm., c'està-dire Acacia a longs PÉtioles, est recommandé comme plante tannifère; le $\mathrm{D}^{\mathrm{r}}$ Trabut indique les sujets à tronc rouge comme étant particulièrement riches en tanin.

L'Acacia melanoxylon R. Br. ou Acacia A Bors NoIr se rencontre assez fréquemment aux environs d'Alger, mais l'Acacia cyanophylla Lind ou Acacia a FEullees blevatres est encore plus répandu. L'Acacia leiophylla Benth. n'est qu'une variété du précédent à feuilles étroites, son écorce est trẻs riche en tanin.

L'Acacia retinoides Schlecht, ou Acacia floribunda Hort.

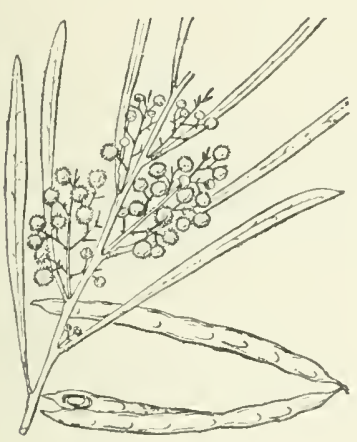

Acacia retinoides.

Fing. 289.

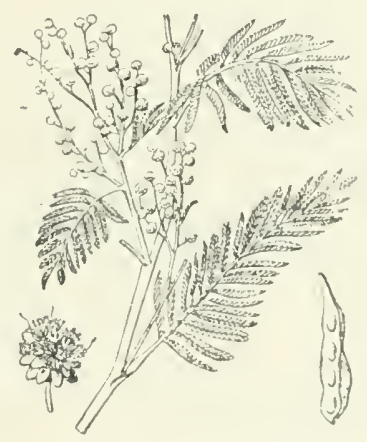

Acacia dealbata.

Fig. 290.

(Fig. 289) est cultivé pour ses lleurs qui font l'objet d'un commerce important dans le Midi de la France.

$2^{\circ}$ Acacias à feuilles composées :

L'Acacia Élégant (A. lophanta Willd.), dont les fleurs à longues étamines ressemblent à des houppes, est le mieux naturalisé; il se multiplie quelquefois au point de former des fourrés. (Ex. : forêt de l'Oasis près Djidjelli.)

L'Acacia ternible (Acacia horrida Willd.), ou Acacia cbur- 
nea Willd., facilement reconnaissable à ses grandes épines d'un blane ivoire, est souvent employé pour faire des haies.

L'Acacia Farnesiana Willd., connu sous le nom de Cassie, présente des épines plus fines et produit des fleurs très odorantes; la gousse est cyllindrique, très rolumineuse; cette espèce est très cultivée pour la parfumerie.

L'Acacia decurrens Willd., l'Acacia mollissima Willd. et l'Acacia dealbata Lam. (Fig. 290), non épineux, se ressemblent; les deux derniers en particulier sont confondus; leur teneur en tanin serait eependant très diffèrente; ces trois espèces sont cultivées pour leur feuillage et leur floraison.

ROSACÉES. - La famille des Rosacées est représentée en Algérie par un certain nombre de genres qui peurent être répartis en plusieurs tribus.
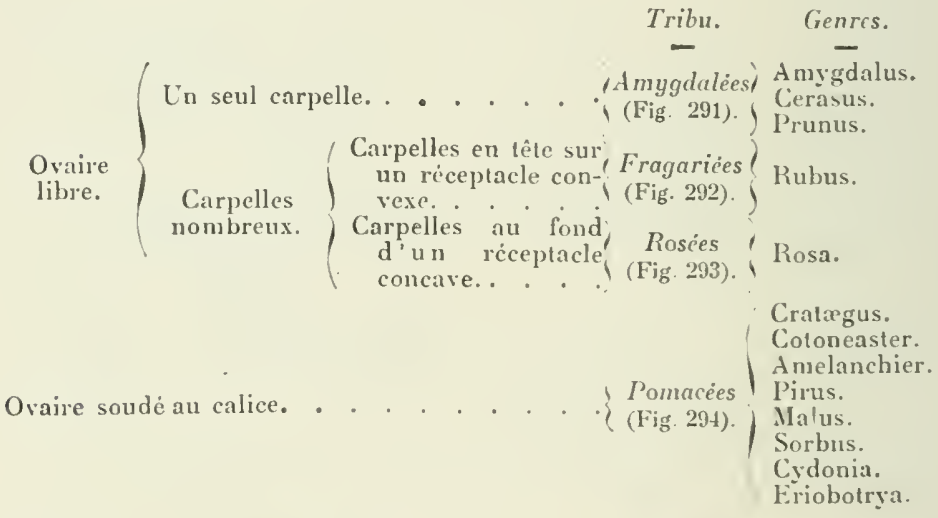

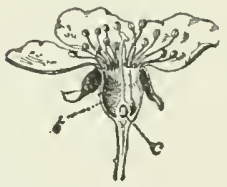

Coupe d'une fleur d'Amygdale (Nerisier): c, oraire; t, calice.

Fig. 291.

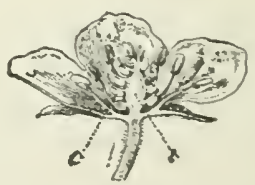

Coupe d'une fleur de Fragarice (Fraisier): $r$ réceptacle ; $c$, carpelles.

Fig. 292 


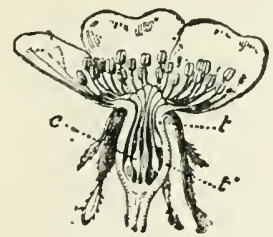

Coupe d'une fleur de Rosée (Rosier) : $t$, réceplacle concave : $t$, calice; $c$, carpelles.

Fig. 293.

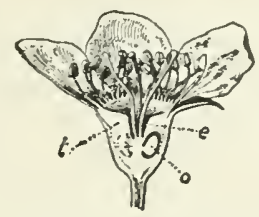

Coupe d'une fleur de Pomacée (Poirier):

$t$, ovaire; o, orule; $e$, slyle.

Fig. 294.

Tribu des Amygdalées. - L'AMANDIER COMMUN (Amygdalus communis L.) (Fig. 295), très cultivé en Algérie, y parait récllement spontané sur divers points, notamment, d'après Battandier, dans le Zacear de Miliana, dans la forêt des OuledDahn, près de Guelma, à Tadjenent, dans les Bibans, à Saïda, etc. ; c'est un arbre de 8 à 12 mètres à rameaux glabres d'un vert clair. Les fleurs elliptiques, à stipules caduques, sont dentées, glabres et luisantes en dessus; les fleurs blanches ou rosées naissent avant les feuilles sur des pédoncules presque nuls; le fruit, bien connu, a un aspect vert velouté et ren-

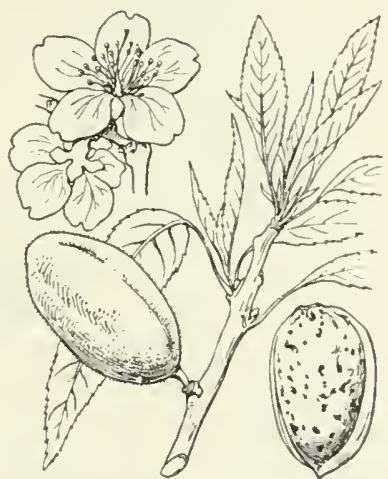

Amygdaius communis.

Fig. 295. ferme un noyau sillonné de fentes étroites qui contient 1 ou 2 amandes douces ou amères.

L'Amandier commun a produit par la culture un grand nombre de variétés. Les amandes douces sont comestibles. Le bois de cet arbre est remarquablement dur et lourd; il est susceptible d'acquérir un très beau poli; il est employé en marqueterie et forme aussi un très bon combustible.

LeCERISIER SAUVAGE(Cerasus avium Moneh)(Fig. 296) ou Merisier se rencontre en Algéric, principalement dans les forêts de la région montagneuse.

Ses feuilles ovales, dentées, présentent au sommel du pétiole 
deux glandes rougeâtres; ses fleurs blanches sont disposées en petits groupes de 2 à 6 sortant de bourgeons à écailles non foliacées (c'est-à-dire n'ayant pas l'apparence et la consistance d'une feuille).

Le bois du Merisicr est rouge brunâtre clair, veiné et sus. ceptible d'un beau poli ; il est recherché pour la fabrication des meubles et des chaises.

Le genre Prunier (Prunus) est représenté en Algérie par trois espèces dont la plus commune, très répandue dans les broussailles du Tell, est le PRUNIER SAUVAGE (Prunus

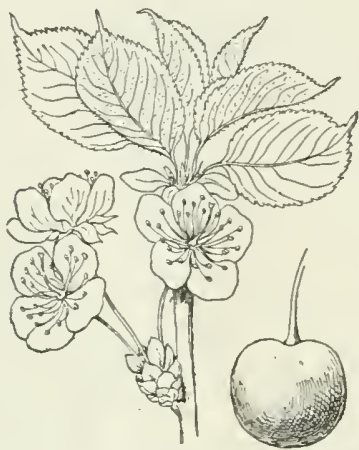

Cerasus avium.

Fig. 2.6 .

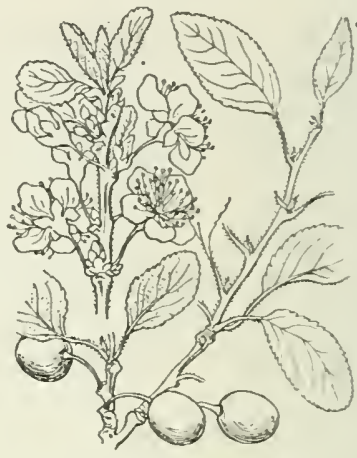

Prunus insititi

Fig. 297.

insititia L ) (Fig. 297), arbuste de 2 à 5 mètres, un peu épineux à branches étalées à fleurs blanches assez grandes naissant sur des pédoncules poilus; le Pruneldier (Prunus spinosa L.), très rare dans la colonie (Beni Ismail, près Drâ-el-Mizan), en diffère par ses rameaux très épineux, par son écorce d'un brun noir et lustré qui lui fait donner souvent le nom d'Épine noire et enfin par ses fleurs petites naissant sur des pédoncules glabres ou presque: ses fruits, connus sous le nom de prunelles, servent à la préparation de liqueurs alcooliques.

Le Prunus prostrala Labill., que l'on trouve dans la haute montagne, est un petit arbrisseau à fleurs roses, ce qui le distingue nettement des espèces précédentes; les feuilles arrondies, finement dentées, sont couvertes en dessous d’un tomentum blanchâtre. 
A la tribu des Prunées, appartiennent diverses espèces cultivées dans les jardins : le Prunier commux (Prunus domestica L.), le Prumus divaricata Led., le Pêcher commun (Persica vulgaris Mill.) à fleurs rose vif, solitaires ou par deux, presque sessiles, à fruit velouté, et l'ABricotier commux (Armeniaca vulgaris Lam.) à fleurs blanches ou rosées et à fruit également velouté, mais à noyau lisse et non creusé, conme dans ce dernier, de profondes anfractuosités.

Tribu des Fragariées. - Cette tribu, qui comprend comme espèce herbacée le Fraisier, très cultivé dans les jardins, n'est représentée en Algérie que par deux plantes ligneuses appartenant au genre Ronce (Rubus).

La RONCE DISCOLORE (Rubus discolor IVeihe) (Fig. 298) est extrêmement commune en Algérie; les tiges, très longues, présentent de forts aiguillons et portent des fenilles pourvues de 3 ou 5 folioles; les fruits sont noirs, constitués par de nombreuses petites drupes comestibles disposées sur un receptacle conrexe. La Ronce be Numide Rubus numi-

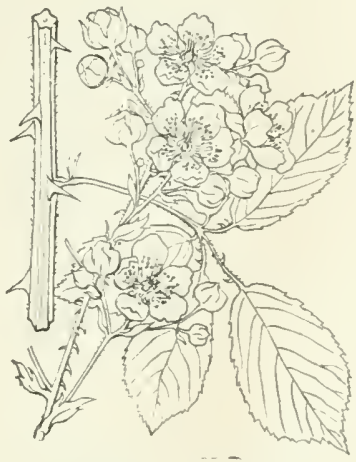

Rubus discolor.

Fis. 2ys.

dicus Focke) possède des tiges plus grêles, portant des aiguillons faibles et des feuilles généralement trifoliolées; les fruits sont rouges. Ciest une plante des grandes forêts du Tell oriental : Akfaclou (près Azazga), ete.

Tribu des Rosées. - La tribu des Rosées ne renferme qu'un seul genre, le genre Rosier (Rosa), avec neuf espèces. Les Rosiers sont des plantes ligneuses souvent sarmenteuses à tige armée d’aiguillons, à feuilles composées imparipennées, à fleurs grandes, à réceptacle creux formant à maturité une enveloppe charnue rouge ou noirâtre autour des akènes. Sur les bords de la cupule formée par le réceptacle, sünsèrent le périanthe, formé de 5 sépales et de 5 pétales, ainsi que de nombreuses étamines.

Liespèce la plus commune que l'on reneontre dans les broussailles et les haies du Tell est le ROSIER TOUJOUkS 
VERT (Rosu sempervirens L.) (Fig. 299). C'est une plante sarmenteuse à tiges grêles, à feuilles glabres vertes et brillantes sur les deux faces persistantes en hiver, à fleurs blanches en corymbes.

Les Rosa canina L. et Rosa Pouzini Tratt. sont assez com-

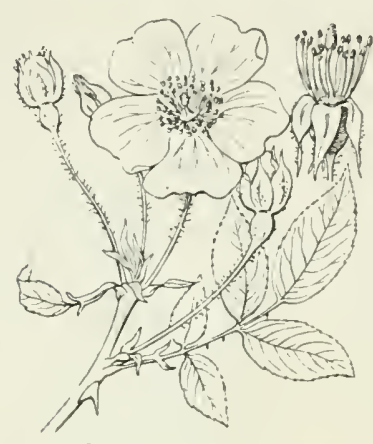

Rosa sempervirens. Fig. 299.

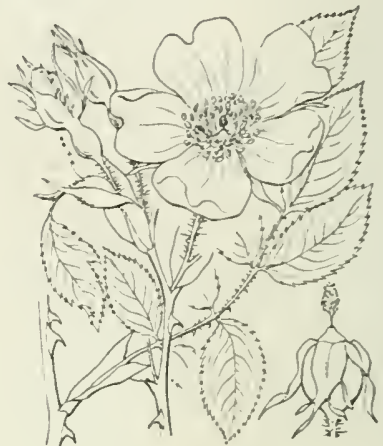

Rosa stylosa.

Fig. 300 .

muns en montagne; les autres espèces sont plus rares : Rosa stylosa Desv. (Zaccar, Dira près Aumale) (Fig. 300), Rosa monlana Chaix (Djurdjura, Tababor), Rosa sicula Tratt. (Djurdjura, Aurès, Djebel Dréat), Rosa micrantha Sm. (Djebel Tessala près Sidi-bel-Abbès, 'Tiaret, ctc.), Rosa agrestis Savi (Djurdjura, région de Médéa). Le Rosa moschala L. se rencontre aux environs d'Alger, notamment à la Bouzarèa, mais cette espèce n'est probablement que subspontanée; elle doit provenir d'anciennes cultures des Maures.

Tribu des Pomacées. - Cette tribu comprend plusicurs genres :

Les Aubépines (Cratxgus) sont des arbrisseaux épineux à écorce d'abord lisse, d'un gris argenté, puis écailleuse et gerçurée; les feuilles sont souples, profondément échancrẻes en lobes; les fleurs sont disposẻes en corymbes; le fruit charnu, rouge ou jaune, est couronné par les dents du calice.

L'espèce la plus commune est l'AUBÉPINE MONOGYNE (Crategus monogyna Jacq.) (Fig. 301). C'est un arbrisseau, parfois un petit arbre, très rameux, quivient dans tous les sols 
même très secs. On le rencontre en grande abondance dans les broussailles du Tell : on le confond souvent avec l'AUBÉPINE ÉPINEUSE (Cralxgus oxyacantha Jacq.), trés voisine, qui est beaucoup plus rare et se distingue de la précédente par ses feuilles à nervures convergentes, plus luisantes, d'un vert plus foncé, et par ses fruits à plusieurs noyaux.

L'AUBÉPINE LACINIÉE (Cralagus laciniala Ucria), à feuilles velues sur les deux faces, est une espèce de haute monlagne; l'Aubépine de Roussillon (Cralagus ruscinonensis Gr. et BI.) (Fig. 302) est fort peu répandue

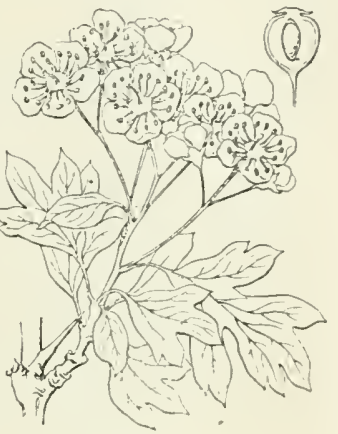

Cratægus monogyna. Fig. 301. (Djebel Dréat).

L'AZEROLIER (Cralagus Azarolus L.) (Fig. 303) est assez commun dans le Tell méridional; cette espéce se présente

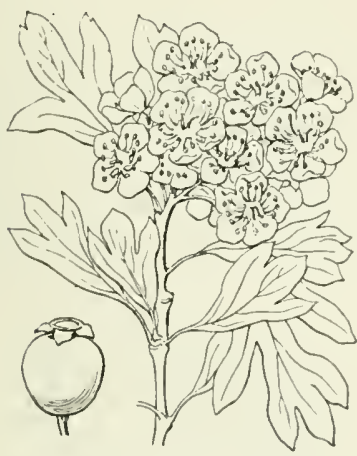

Cratrogus ruscinonensis.

Fing. 30 (

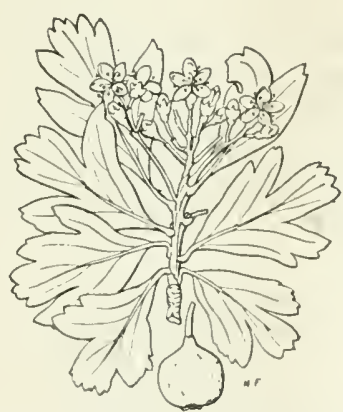

Cratæegus Azarolus.

Fig. 3013.

fréquemment à l'état d'arbuste, mais peut parfois atteindre les dimensions d'un arbre d'une dizaine de metres de hauteursur 1 à 2 de circonférence; ses fruits, semblables à une pomme minuscule, sont comestibles.

Le bois des Aubépines est lourd, dur, compact, sans souplesse ; il peut recevoir un beau poli et convient aux ouvrages 
de tour ; mais il est extrêmement sujet à travailler et à se gercer. C'est un très bon combustible qui produit du charbon de première qualité.

Le genre Cotonéaster (Cotoneaster) comprend des arbustes non épineux à feuilles entières cotonneuses au moins en dessous que l'on trouve sur les montagnes de l'est de l'Algérie.

Le Cotonéaster de Desfontanes (Cotoneaster Fontanesi Spach) et le Cotonéaster a Fecilles rovies (Cotoneaster nummularia Fisch. et Mey.) constituent deux espèces extrêmement voisines, la première (Djurjura, Aurès) n'étant peutêtre même qu'une variẻté de la seconde (Babors, Garrouban, au sud de Tlemcen, etc.). On a quelquefois fait une espèce

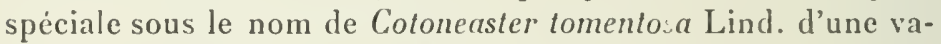
rićté du Cotonéaster de Desfontaines, existant dans le Sud, dont les feuilles sont cotonneuses sur les deux faces.

Les deux genres précédents forment une première section de Pomacées caractérisée par l'existence autour des graines d'un noyaux osseux dur. Dans les genres qu'il nous reste à examiner, les graines ou pépins sont enfermées dans des cavités dont la paroi est mince et a une consistance cartilagineuse.

L'Anélancher commux (Amelanchier vnlgaris Mœnch) (Fig. 304) se rencontre sur les hautes montagnes de l'Algérie (Djurdjura, Dréat, Aurès). C'est un arbrisseau à feuilles elliptiques glabres en dessus, tomenteuses en dessous, finement dentées, à fleurs blanches disposées en corrmbe, à fruit glo-

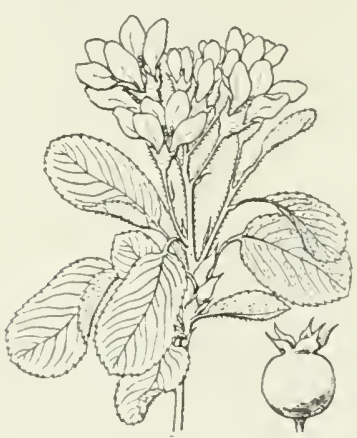

Amelanchier vulgaris.

Fig. 304 .

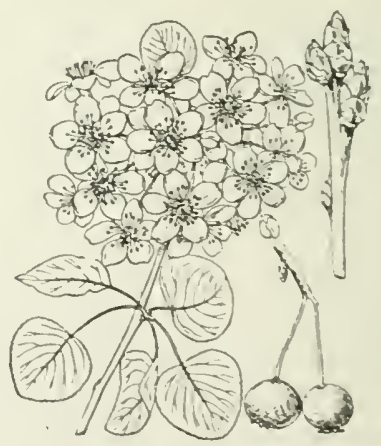

Pirus longipes.

Fig. 30j 
buleux noir bleuâtre de la grosseur d'un gros pois. Les fruits sont comestibles.

Le genre Poirier (Pirus) n'est représenté en Algérie que par une se ule espèce spontanée, le POIRIER LONGIPÈDE (Pirus longipes Coss.) (Fig. 305) des forêts de l'Aurès ; c'est un arbre élevé, peu épineux, à feuilles longuement pétiolèes, dentées, ovoïdes ou presque rondes à fleurs assez grandes en corymbes. Les fruits sont très petits, de la grosseur d'une cerise, portés par un pédoncule trois fois plus long qu'eux, particularité qui a valu à l'espèce le qualificatif de longipéde. Le Poirier de Syrie (Pirus syriaca Bois.), qui a les pédoncules plus courts, existe dans les forêts de Tunisie, mais n’a pas été signalé en Algérie.

Le Poirier commun (Pirus communis L.), planté dans les jardins, se trouve à l'état subspontané dans le voisinage des cultures.

Le Pommer comuux. (Malus communis Poir.) est, comme le précédent, une espèce introduite.

Le genre Sorbier comprend deux sections: la section des Sorbiers proprement dits caractérisée par des feuilles composées, et la section des Alisiers qui possèdent des feuilles simples dentées ou lobées.

Le Sorbier domestique (Sorbus domestica L.) est un grand arbre à bour geons gros, visqueux, glabres, à feuilles imparipennées composées de folioles dentées, à fleurs blanches en corymbes, donnant à maturité des fruits gros comme une petite noix. Cette essence est très rare en Algérie. On la rencontre dans le massif du Babor en petits buissons et aux environs d'Alger, à Bouzaréa, mais sa présence dans cette dernière station est peut-être due à l'intervention de l'homme.

Les Alisiers sont cantonnés sur les montagnes. L'ALISIER BLANC (Sorbus Aria Crantz ou Aria nivea Host) (Fig. 306) est un arbre de taille moyenne à feuilles ovales ou elliptiques doublement dentées ou légèrement lobées, blanches, tomenteuses en dessous; les fleurs en corymbe sont blanches et les fruits de la grosseur d'une petile cerise verte, puis rouge. Le bois de celle essence est dur, lourd, trés lomogène ; il convient aux ouvrages de tour: c'est un très bon combustible. Litisier blanc est en Algérie un compagnon du Cèdre.

L'ALISIER TORMINAL (Sorbus torminalis Crantz) ou Ali- 
sier des bois (Fig. 307), diffère du précédent par ses feuilles vertes et glabres sur les deux faces en cœur à la base et profondément échancrées; son bois resscmble bcaucoup à celui de

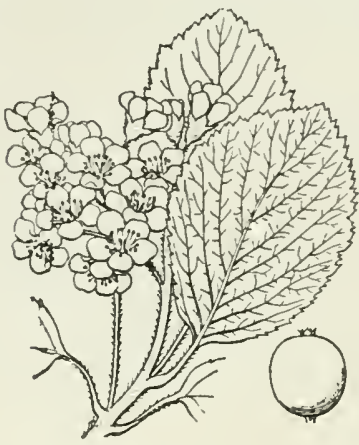

Sorbus Aria.

Fig. 306

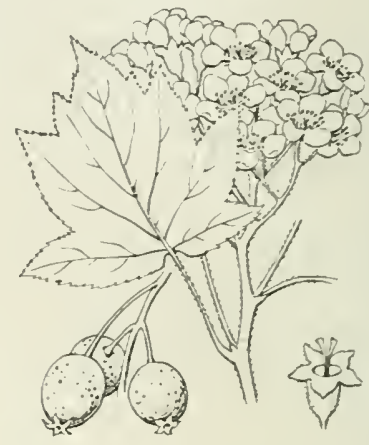

Sorbus torminalis.

Fig. 307 .

l'Alisier blanc et convient aux mêmes usages; ses fruits blossis sont comestibles et fournissent aussi par la distillation une liqueur alcoolique appréciée. Cet arbre est assez répandu sur les hautes montagnes de la Kabylie, de Tamentout jusquau Djurdjura oriental.

L'Alisier a larges feuilles (Sorbus lalifolia Pers, ou Aria latifolia Spach), signalé au Garrouban, présente des caractères intermédiaires entre les deux précédents, notamment par la forme et les incisions de ses feuilles, par la couleur et la consistance du fruit.

Parmi les espèces introduites, il importe encore de citer le Cognassier comicy (Cydonia vulgaris Pers.) et le Néflier du JAPON (Eriobotrya japonica Lindl.). Le premicr est un petit arbre à feuilles molles entières, cotonneuses en dessous; les lleurs blanches ou rosées solitaires sur des pédoncules presque nuls produisent un gros fruit en forme de poire, odorante, que l on utilise pour faire des confitures. Le Néflier du Japon est un bel arbre originaire du Japon et des Indes orientales qui est cultivée en Algérie et dans le midi de l'Europe. On le reconnait facilentent à ses feuilles très grandes, 25 à $30 \mathrm{~cm}$. de longueur, d'un vert brillant en dessus, à ses jeunes pousses courertes, ainsi que les pédoncules floraux, d'un feutrage roux très épais ; 
son fruit jaune orange possède une chair juteuse agréable et quatre grosses graines brunâtres.

Les MYRTAGEES sont des arbustes ou des arbres de grande taille, très florifères, à feuilles odorantes entières, coriaces, persistantes, renfermant à leur intérieur des glandes huileuses. Cette famille, qui est abondamment représentée dans les régions tropicales et subtropicales, ne compte en Algérie qu'une seule espèce spontanée, le MYRTE COMMUN (Myrtus communis L.) (Fig. 308).

Le Myrte, répandu dans toute la région méditerranéenne, est très conımun dans les broussailles du Tell oriental jusqu'à Tunis. C'est un arbuste toujours vert, à petites feuilles opposées aromatiques, glabres et luisantes; ses lleurs blanches solitaires possèdent cinq sépales, einq pétales, de nom-

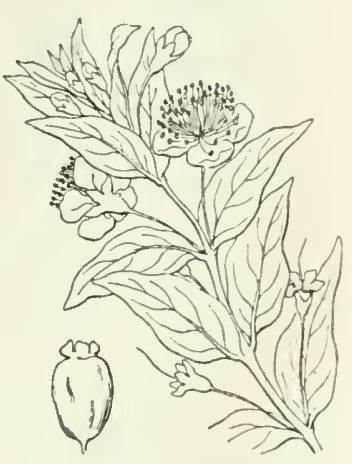

Myrtus communis.

Fig. 308. breuses étamines et produisent une baie ovoüde d'un noir bleuâtre. Les feuilles de cette plante varient beaucoup; certains pieds ont des feuilles très petites, ne dépassant pas 1 centimètre de longueur; on en a fait parfois une variété spéciale, la variété microphylla.

Le bois du Myrte est lourd, dur, remarquable par la finesse et l'homogénéitẻ de son grain. Il est entièrement gris rougeìtre clair ; il se travaille bien et est employé à la fabrication des articles de marqueterie, de tour, ete. Il fournit un bon combustible et un charbon de première qualité. Le fruit du Myrte est estimé et mangé par les Arabes, malgré son goùt ìpre et résineux. A petite dose, il aromatise agréablement le cognac.

Diverses espèces de Myrtacées ont été introduites en Algérie, en particulier les Eucalyptus ou Gommiers, genre australien qui ne comprend pas moins de 1.200 espèces. Plantés pour la $1^{\text {re }}$ fois en Algérie en 1863 au jardin du Hamma, on estimait leur nombre à 1.500 .000 pour l'ensemble de la colonie en 1876 .

Ces arbres, en génèral de grande hauteur, portent des feuilles persistantes entières renfermant de nombreuses 
glandes. Si l'on observe la fleur à l'état jeune (Fig. 309), on

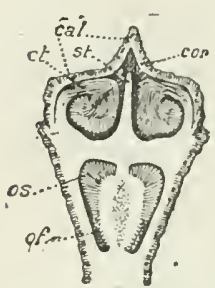

Coupe d'un bouion floral d'Eucalyplus : cal, ealice ; cor, corolle; $e l$, élamines; $s l$, slyle ; os, of, ovules.

Fig. 309. constate que la partie supérieure du périanthe forme un opercule, sorte de couvercle qui se détache au moment de l'épanouissement en laissant une sorte de coupe qui porte sur ses bords les étamines très nombreuses et au centre un pistil à plusieurs loges.

Les Eucalyptus peuvent présenter deux sortes de feuilles: chez l'Eucalyptus globulus par exemple, lés feuilles des jeunes plantules provenant de graines (Fig. 310), celles des branches gourmandes et des rejets sont opposées, glauques et sans pétiole, tandis que chez les sujets adultes, les feuilles deviennent alternes, pétiolées, en forme de faux (Fig. 311).

L'Eucalyptus possède un enracinement puissant, une croissance très rapide. On cite en Australie des sujets atteignant 150 mètres de hauteur. La transpiration intense de

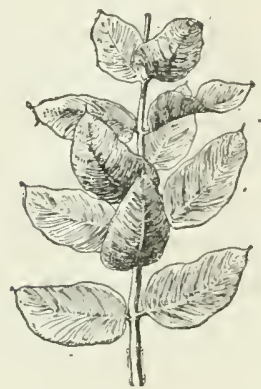

Tige feuillée d'un jenne Eucalyptus globulus.

Fig. 310 .

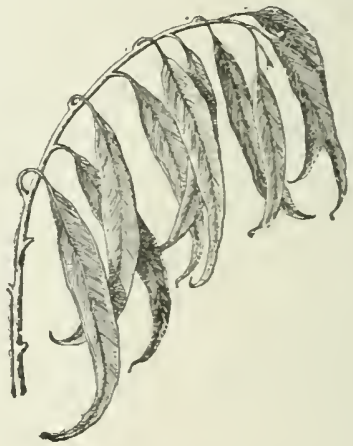

Branche feuillée d'un Eucalyptus globulus âgé.

Fig. 311.

ces arbres assèche le sol, ce qui permet de les utiliser pour l'assainissement des régions lumides insalubres. On a appelẻ non sans raison l'Eucalyptus " l'arbre de la colonisation ". Le bois a la fibre tourmentée ; il est très dur, tenace et difficile à travailler; il peut être utilisé comme bois de construction et de 
chauffage; dans certaines espèces, où il est plus hoınogène, il convient à l'ébénisterie. L'écorce se détache souvent en lanières qui donnent au tronc un aspect peu ornemental. Toutes les parties de l'arbre, les feuilles surtout, fournissent une essence riche en Eucalyptol qui a des effets analogues à ceux de l'essence de térébenthine. Elles sont fort employées dans le traitement des maladies des voies respiratoires. Ingérées en masse, ces feuilles et l'écorce sont astringentes, toniques et fébrifuges par le tanin qu'elles renferment; on les emploie aussi en lotions et en injections comme antiputrides. Ces plantes, très florifères, contribuent à l'entretien des ruches : par contre, on leur a fait le reproche d'abriter d'innombrables moineaux pillards de récoltes. De nombreuses espèces ont été introduites en Algérie; nous n'en mentionnerons que quelques-unes :

L'Eucalyptus comion (Eucalyptus globulus Labill.) (Fig. 312) ou Gommier bleu, en anglais Blue gum est une des plus répandues et des plus anciennement introduites. C'est un grand arbre irrégulier à croissance très rapide, mais assez sensible au froid et à bois de qualité inférieure; on distille ses feuilles.

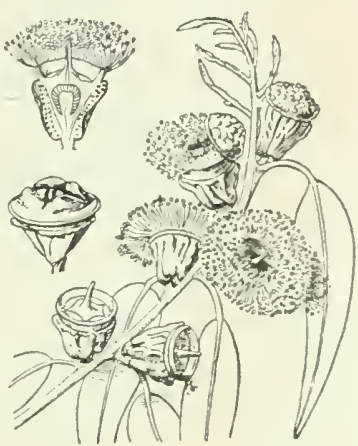

Eucalyptus globulus.

Fig. 312.

L'Eucalyptus rostrata Schlecht. que l'on tend à lui substituer dans les plantations et que l'on désigne souvent sous le nom anglais de Red gum, c'est-à-dire Gommer rovge, est de moindre taille et présente une croissance moins rapide, mais il est aussi moins exigeant sous le rapport du sol, résiste mieux au froid. Son bois coloré est plus apprécié que celui de l'Euculyplus globulus et peut être employé pour l'èbénisterie.

Citons encore : l'Eucalýptus a reutlles d'Osier (E. viminalis Lab.) (en anglais Manna gum) dont le bois est médiocre, mais qui présente l'avantage de bien résister au froid ; l'Euculyptus cilriodora Hook. (Lemonscended gum) dont les feuilles à odeur de citronnelle contiennent une huile volatile facile à distiller; l'Encalyptus polyanthema Schauer, c'est-à-dire à fleurs 
nombreuses (Red box tree), dont le feuillage rappelle celui du Peuplier ; l'Eucalyptus cornula Lab. (Y'ale tree); l'Eucalyptus amygdalina Lab, ou à feuilles d'Amandier, dit aussi Eucahyptes Mexthe polvée, qui diffère beaucoup des précédents par ses petites feuilles; l'Eucalyplus corynocalyx F. v. Müll., c'est-à-dire à calice en massue (Sugar gum), dont l'écorce est blanche sur le tronc, rouge sur les rameaux; enfin l'Eucalyplus rudis Endl. qui produit avec l' $E$. roslrata un hybride répandu dans la colonie sous le nom d'Eucalyptus n'Algérie (E. Algeriensis Trab.). L'opercule du bouton floral présente une forme en bec moins amincie que chezl'E. rostrala, mais moins conique que chez l'E. rulis.

Les espèces australiennes ne se naturalisent pas en Algérie; les hybrides au contraire sont, d'après le $\mathrm{D}^{\mathrm{r}}$ Trabut, susceptibles de s'y perpétuer sans l'intervention de l'homme; il en résulte qu'il pourra se former dans l'Afrique du Nord une flore d'Eucalyptus très différente de celle du pays d'origine.

I a famille des GRANATÉ:S est très voisine de celle des Myrtacées; elle ne comprend en Algérie qu'une espèce d'ailleurs introduite, le Grfinabler comsex (Punica Granalum L.). Cet arbuste originaire de l'Orient est cultivé soit pour la beauté de ses fleurs, soit pour son fruit, la grenade La tige rameuse porte des feuilles opposées, atténuées en pétioles, glabres et luisantes. Les fleurs sont grandes, sessiles, d'un rouge écarlate; le fruit gros globuleux, contient un grand nombre de graines à tégument rouge translucide renfermant une pulpe acidulée comestible. - Les fleurs (en infusion de 15 à $30 \mathrm{gr}$. par litre d'eau) et l'écorce du fruit (en décoction de 30 à $60 \mathrm{gr}$. par litre d'cau) sont employés contre la diarrhée, la dysenterie et les maux de gorge. L'écorce de la racine est un bon vermifuge.

Le genre Tamaris (Tamarix) est en Algérie le seul représentant ligneux de la famille des T A MARISCINÉES. Les 'Tamaris, souvent désignés à tort sous le nom de Tamarin', sont des arbres ou arbrisseaux toujours verts à feuilles très petites en

1. Le mot Tamarin sert à disigner en pharmacie la pulpe du fruil du Tamarinier (Tamarindus indicus), arlore des rigions tropicales. 
forme d'écailles à lleurs pelites, en grappes simples, à graines surmontées d'une aigrette.

Le TAMARIS D'AFRIQUE (Tamarix africana Poiret) (Fig. 313) est une plante très commune dans la colonie, et qui forme parfois des peuplements forestiers: les feuilles sont

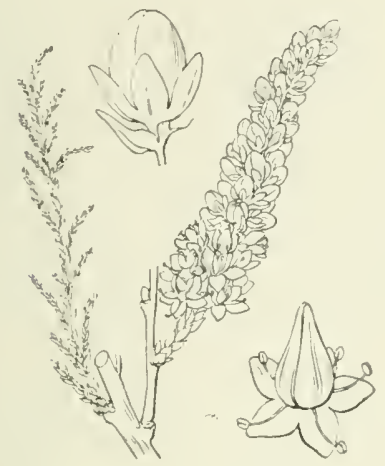

Tamarix africana. Fig. 313 .

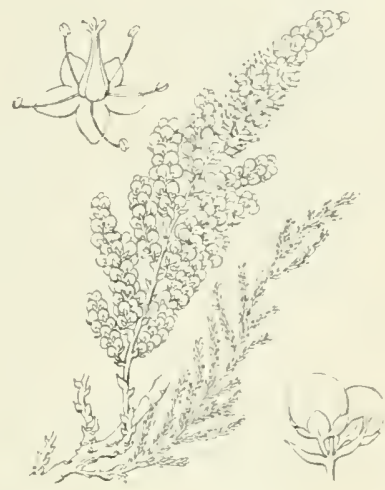

Tamarix gallica.

Fig 31 t.

Iransparentes sur les bords: les fleur's naissent souvent sur de gros rameaux et forment des épis courts et épais.

LE TAMARIS DE FRANCE (Tanarix gallica L.) (Fig. 314) qui est aussi une espèce très répandue et que l'on rencontre surtout au bord du lit des ruisseaux en diffère par ses feuilles entièrement opaques, ses lleurs plus petites, ses grappes grêles, portées sur des rameaux grêles.

Les trois autres espèces se rencontrent : le T. rubella Batt. dans la région de Batna, le T. Boveana de Bunge à Arzew, Misserghin, etc., le T. Bomnopóa J Gay, dans les lieux salés de l'intéricur.

Parmi les CRASSULACEES, une seule espèce spontanée possède une tige robuste sous-ligneuse : le Sednm mulliceps Coss. et Dur., plante très feuillue à feuilles lineaires toutes couvertes de papilles eristallines lormant d'épaisses rosettes au sommet des rameaux, et produisant des tiges llorifẻres sinueuses portant des grappes de lleurs jaunes. On trouve eette espece en montagne entre Bougie et Collo. Le Semperni- 
rens arboreum Desf. est une Crassulacée introduite et sou. vent cultivée comme plante d'ornement.

C'est à la famille des GACTÉES quappartient le Nopal,

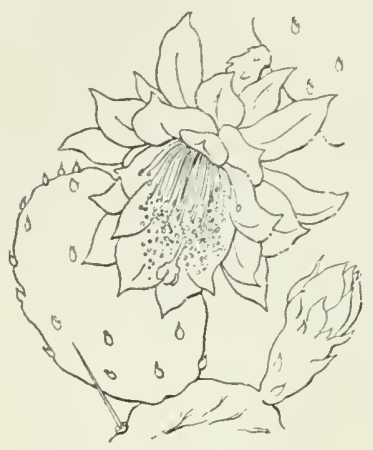

Opuntia Ficus-indica

Fig. $31 j$. bien connu sous le nom de Figcien de Barbarie Opuntia Ficus-indica Haw.) (Fig. 315), espèce d'origine américaine depuis longtemps introduite par les Espagnols et actuellement subspontanée en bien des endroits; sa tige est composée de raquettes, articles cliarnus très épais, comprimés, hérissés de faisceaux de soies piquantes; les fleurs jaunes sont grandes $(5-6 \mathrm{~cm}$.), insérées et sessiles sur le rebord des articles supérieurs; les fruits, gros comme un cuf, forment une part importante de la nourriture des Arabes.

Les Kabyles en cultivent une race inerme comme fourrage.

Les GROSSULARIÉES, représentées en Algérie par le genre Ribes, sont de petits abrisseaux à feuilles alternes pal-

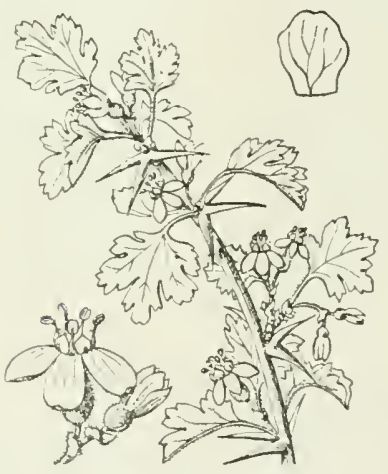

Ribes Uva-crispa.

Fig. 316 .

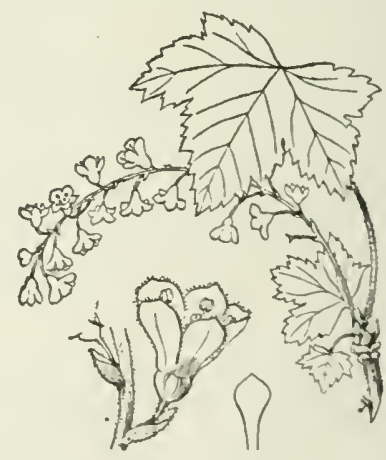

Ribes petræum

Fig. 317.

matilobées (c'est-à-dire découpées en forme de main) à fleurs régulières hermaphrodites, parfois unisexuées, verditres ou 
rougeâtres, comprenant 5 sépales soudés à la base, 5 pétales, 5 étamines et un ovaire adhèrent donnant à maturité une baie globuleuse.

Le Groseiller a Maqueread (Ribes Una-crispa L.) (Fig. 316) se reconnaît facilement aux épines trifurquées à trois branches) qu'il présente, à ses fleurs solitaires ou par deux, à ses fruits asse\% gros, verdâtres, jaunâtres ou rougeâtres. C'est une espèce rare en Algérie; on la rencontre sur les hauts sommets du Djurjura et de l'Aurès.

Le Groseillier des hochers (Ribes pelrium $\mathrm{W}^{\mathrm{T}} \mathrm{ulf}$.) (Fig. 317) en diffère par l'absence d'épines et par ses fleurs en grappes, par ses baies rouges plus petites ; c'est également une espèce très localisée en Algèrie; on la trouve uniquement dans le Djurdjura (Djebel Aïzer, Ait Ouabane).

La famille des OMBELLIFĖRES renferme de très nombreuses espèces herbacées: quelques-unes, telles que la Férule ${ }^{1}$ (Ferula communis L.), possèdent une tige puissante pouvant s'élever jusqu'à 3 mètres de hauteur et sont très répandues dans le Tell et les Hauts Plateaux. Les espèces ligneuses sont de taille beaucoup moindre et se rangent toutes dans le genre Buplèvre (Bupleurum).

Le BUPLÈVRE ARBRISSEAU (Bupleurum frulicosum L.) (Fig. 318) est un arbrisseau pouvant atteindre juscqu'à '2 mètres de liauteur à tiges rougeâtres, à feuilles coriaces persistantes sans pétiole, vertes en dessus, glauques en dessous, veinées en réseau, munies d'une bordure étroite transparente. Les ombelles possèdent

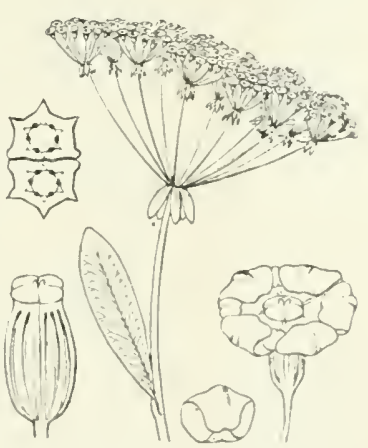

Bupleurum fruticosum.

Firtion. 318 . de nombreux rayons (8-20). Cette espèce se trouve dans le 'Tell çà et là, au bord des rivières, dans les broussailles des montagnes, etc.

1, La Firule est utilisée par les indigènes pour allumer le feu el pour confectionner des carges destincées au transport des volailles el des fruits. 
Le Buplève de Gibraltar (Bupleurum gibraltaricum Lam.) en differe par ses feuilles glauques sur les deux faces, ses intlorescences plus rameuses. On le rencontre seulement dans la province d'Oran.

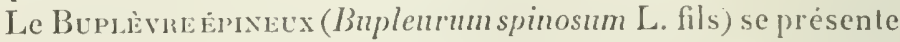
sous l'aspect de buissons ligneux hémisphériques, très épineux, à feuilles un peu fermes. Il existe sur les montagnes dans toute l'Algérie, au-dessus de 1.400 mètres.

Le Buplère des montagnes (Buplenum montanm Coss.) est aussi assez répandu dans la zone montagneuse (Djurdjura, Dréat, Teniet, Aurès); il est dépourvu d'épines et possède des feuilles molles à nervures parallèles semblables à celles des Graminées, des ombelles à nombreux rayons (10-20). Le Buplève sous-ligxeux (Bupleurnm fruticescens L.) qui s'en rapproche par ses feuilles en diffère par ses ombelles à rayons beaucoup moins nombreux ( 4 a 5 ). On le trouve assez communément dans les broussailles du Tell.

Le Buplève rade (Buplenrum rigidum L.) et le Búplìvre a feuilles de Plantain (Bupleurum plantagineum Desf) ont des feuilles à nervures parallèles comme les précédents, mais très saillantes; le premier se rencontre sur les Hauts Plateaux; le second semble assez localisé ; on l'a signalé dans la région de Bougie.

Le Bupleturum oligactis Bois. est une espèce du Sud-Oranais, de l'Aurès, etc.

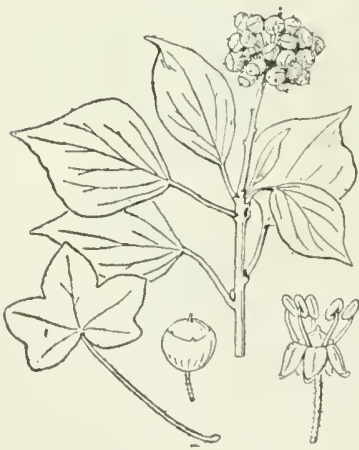

Hedera Helix.

Figr. 319 .
Les ARALIACÉES sont généralement des plantes ligneuses qui croissent dans les pays tropicanx: le Lierre grimpaxt (Hedera Helix L) (Fig 319) est la seule Araliacée indigène; c'est un arbrisseau toujours vert, à rameaux allongés, portant sur une de leurs faces des racines crampons au moyen desquelles ils sèlèvent le long des rochers et sur le trone des arbres; les rameaux grimpants portent des fenilles pétiolées a limbe d'un vert brillant et divisé en 3 a j lo- 
bes; les rameaux fleuris sont dépourvus de crampons et portent des feuilles entières et des lleurs petites, jaunes-verdâtres, disposées en ombelles; le fruit est une baie globuleuse noire douée de propriétés purgatives. Le Lierre est très commun dans les forêts humides, surtout dans les peuplements de Chène zéen, sur les escarpements rocheux, ete.

\section{CHAPITRE XI \\ LES GAMOPÉTALES}

$\S$ I. - Gamopétales à ovaire infère.

La famille des GAPRIFOLIA GÉES comprend 3 genres en Algérie, formés, sauf une exception, de plantes ligneuses; la tige peut être volubile. Les feuilles sont opposés ; les fleurs présentent un pistil (ovaire à $3-5$ loges) et jótamines, le calice et la corolle ont dordinaire 5 divisions. Le fruit est une baie.

Dans le genre Sureau (Sambucus, la moelle de la tige est très développée, la feuille est composée.

Le Sureau xolr (Sambucus nigra L.) (Fig. 320), assez

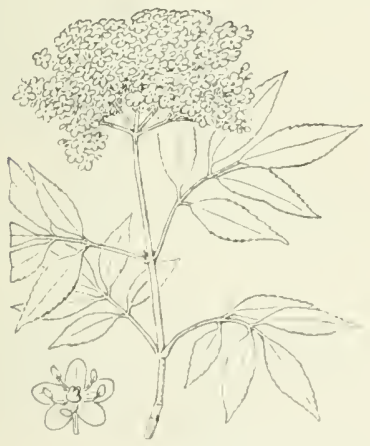

Sambucus nigra

Fig. 321).

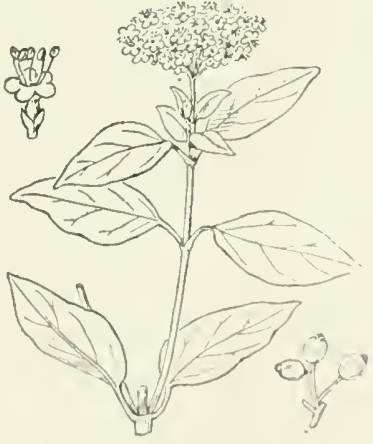

Viburnum Tinus.

Fig. 321 .

commun au voisinage des habitations, n'est probablement pas indigene. Ses feuilles sont composées de 5 à 7 folioles pointues. 
dentées en scie. Les fleurs aromatiques, réunies en une ombelle à 5 rayons, sont blanches; le fruit est noir.

C'est une espèce qui rejette vigoureusement.

La moelle est utilisće dans les laboratoires et dans les ateliers d'horlogerie.

Toute la plante possède des propriétés purgatives: on emploie surtout l'écorce des jeunes rameaux, quelquefois les feuilles ou l'huile de la graine. Les baies servent à teindre les peaux et le fil en violet.

Le Sureau Yèble (Sambucus Ebulus L.) est une plante herbacée, fétide, pouvant atteindre 2 mètres de hauteur, que nous citerons pour mémoire. L'ombelle est à 3 rayons; celte plante est assez commune daus les lieux frais du Tell, surtout en monlagne

Les Viornes (Tiburnum) sont des arbrisseaux à feuilles simples dont l'inllorescence, également en forme d'ombelle, présente 7 rayons principaux.

La VIORNE TIN (Viburnum Tinus L.) (Fig. 321), sourent appelée Laurier Tin, a des feuilles persistantes entières, poilues aux aisselles des nervures en dessous. Les lleurs sont blanches, sans odeur: le fruit, d'un bleu métallique, a des propriétés purgatives.

Cette espèce est très commune dans les forèts de Chèneliège et dans les lieux frais du Tell. Au contraire, la lionxe FLexible (Viburnum Lantana L.) est localisée sur la crète du Tababor ; la Vionne Orter (Viburnum OpulusL.) a été signalée autrefois également au Tababor.

Les Chèvrefeuilles (Lonicera) sont des arbrisseaux ou des lianes à feuilles entières. La fleur est à deux lèrres, présentant l'une un seul lobe, l'autre 4 divisions.

Le Ciièvefeullle en arbre (Lonicera aiborea Bois., des montagnes de l'Aurès, et le Chévrefeunle de Kabrua (Lonicera kabylica Rehder) des sommets du Djurdjura, sont deux arbrisseaux, très voisins, à tiges non volubiles, tandis que les espèces suivantes ont l'aspect de lianes.

Le CHEVREFEUILLE I)ES BALEARES (Lonicera implexa L.) (Fig. 322), de beaucoup le plus répandu en Algérie, et le CHEVREFEULLE D'ETRURIE (Lonicera etrusca Santif (Fig. 323), assez commun en montagne dans les dépar- 


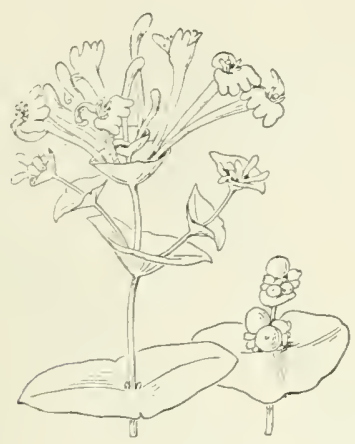

Lonicera implexa. Fig. 322.

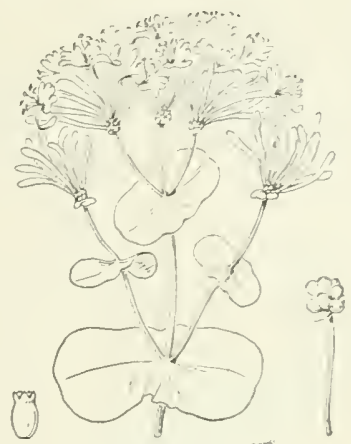

Lonicera etrusca.

Fig. 323.

tements d'Alger et de Constantine, portent des baies rouges.

Les fruits du ChÈvefeulle blanchatre (Lonicera biflora Desf.), plante de l'Oranie, sont d'un noir bleuàtre.

Les RUBIACÉES sont des plantes à feuilles simples, opposées ou verticillées, généralement entières et munies de stipules. Le calice et la corolle sont d'ordinaire à 4 divisions, le fruit à 2 logges. Les espèces citées produisent une baie, mais beaucoup de Rubiacées donnent un fruit sec.

Les Putoria sont des sous-arbrisseaux rameux, fétides, à tiges couchées, à leuilles opposées et coriaces. La corolle, de couleur pourpre, a la forme d'un entonnoir prolongé à la base par un

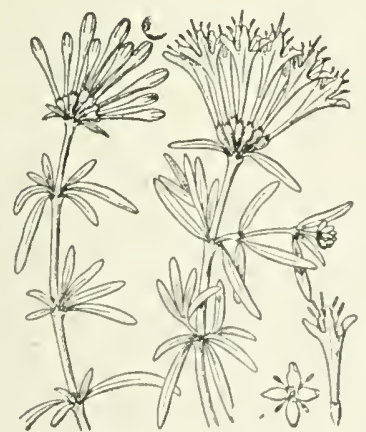

Putoria calabrica.

lig :324.

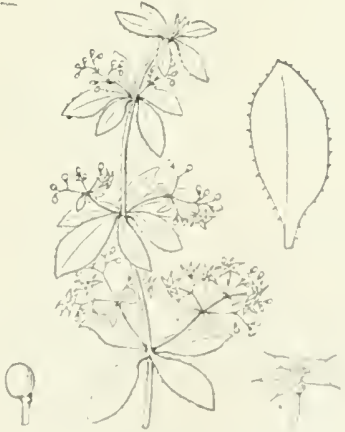

Rubia peregrina.

Fin. 325. 
long tube. L'espéce la plus répandue est le Putona ne Catadbre (Puloria calabrica Persoon (Fig. 324), qui habite surtout les stations rocheuses. Le Puroma a feculles cocres (Putoria brevifolia Cuss.), dont les tiges sont veloutées, se reneontre surtout a Santa-Cruz (près d'Oran); on peut y rattacher le Putoria microphylla Pomel, plante en petites touffes, à feuilles d'un $1 / 2$ centimètre au plus, de Ḱalaa, à l'est de Mascara, et le Puloria tenella Pomel, à très petite corolle (5 à $6 \mathrm{~mm}$.), du Garrouban et des Beni Snous, près de la frontière marocaine.

\section{La GARANCE VOYAGEUSE (Rubia peregrina L.)} (Fig. 325) est une plante grimpante au moyen de ses aiguillons, fréquente dans les haies et broussailles du Tell et de la région montagneuse.

Dans la famille des COMPOSÉES (ou Sỵnanthérées), les lleurs sont réunies en capitules, c'est-à dire que le sommet de l'axe de linllorescence est aplati et étalé en un réceptacle q̨ui porte des fleurs petites et souvent nombreuses, serrées les unes contreles autres; leurs pédoncules sont tellement réduits que l'ensemble des lleurs et des bractées qui les entoure est souvent pris pour une seule

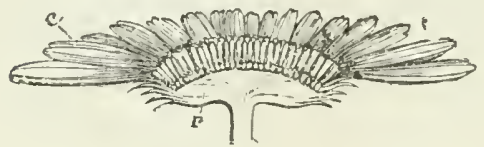

Capitule de Marguerite : coupe en long. montrant le receptacle $r$ qui porle au centre des fleurs en tuive et sur le pourtour des fleurs en languette $c$.

Fig. 326.

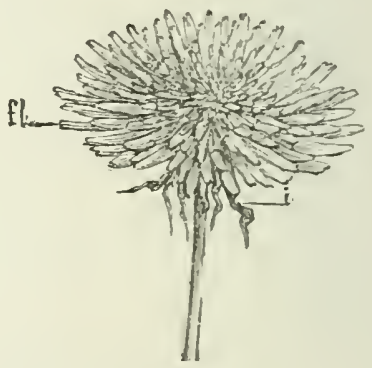

Capitule de Jissenlit: 1, involucre; $\lambda$, fleurs.

Fig. 32-

lheur et l'axe de l'inflorescence pour un pédoncule. La Marguerite (Fig. 32(i), le Pissenlit Fig. 32ī). sont des exemples bien connus de plantes à lleurs groupées en capitule.

Chacune de ces petites lleurs (Fig. 32S et 329) comprend: un calice dont les dents sont sourent représenties par une aigrette poitue qui, par la suite. couronne le fruit : une corolle qui a tantot la forme dun tube a 4 ou 5 dents (Fig. 320?), tan- 
tôt celle d'une languette (Fig 328). Les étamines, en mème nombre que les dents de la corolle, sont fixés sur celle-ci par leur filet. Les anthères allongées et soudées entre elles forment

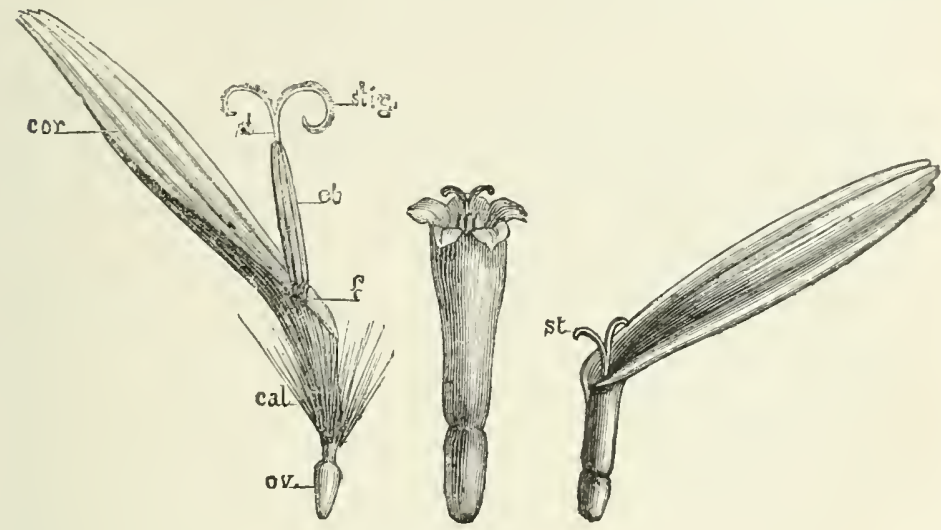

Fleur de Pissentit: cal, calice Fleuren tu- Fleur femelle en languette du formé par une aigrette de be du mipoils ; cor, corolle enlanguet- lieu d'un te; el, étamines; $f$, filets des capitule ètamines; sl, slyle; stig, de Marpourlour d'un capitule de Marguerite : st, sligmate. stigmales; ov, ovaire.

Fig. 328. gnerite.

Fig. 329.

Fig. 330 .

un tube dans lequel passe le style, qui est généralement divisé en deux, vers l'extrémité. Le fruit est un akène.

Les fleurs peuvent être à pistil et à étamines (hermaphrodites) ou seulement à pistil (Fig. 330) (unisexuées); celles qui se trouvent sur le pourtour du capitule sont souvent stériles.

Charne capitule est entouré d'un ou plusieurs rangs de bractées libres ou réunies entre elles, toutes de même forme ou de formes différentes suivant le rang qu'elles occupent. Les fleurs sont souvent séparées les unes des autres par des poils ou des écailles.

Les lleurs réunies sur un même capitule peuvent être toutes en forme de lube tubuleuses) ou toutes en languetle (ligulées), ou partie en tube et partic en languette; d'où 3 tribus :

Flenrs loutes en tuhes, dites flenrons

Style rentle sous les stigmates
Trilu des Carduncees Exemple: Chardon. 
Fleurs toutes en languetles dites demi-flemrons

Tribu des Chicoracies.

Exemple : Chicorée.

Fleurs du pourlour en languelte, celles du centre en tube Style non renflé sous les stigmates

Tribu des Corymbifères. Exemple : Marguerite.

(Les fleurs en languelte peuvent avorter).

Cette grande famille qui comprend près de 10.000 espèces, c'est-à-dire $1 / 10$ environ des plantes Plranérogames connues, a peu de représentants parmi les végélaux ligneux de l'Algérie; nous n'avons à citer que des sous-arbrisseaux sans grande importance forestière.

Tribu des Carduacées. - Celte tribu comprend la plupart des plantes vulgairement connues sous le nom de Chardons. Leur tige peut acquérir une hautenr assez considérable et une certaine consistance, mais ils ne présentent aucun intérêt forestier. Seules, quelques espèces peurent mériter le nom de sous-arbrisseaux : citons les Atractylis serratuloides

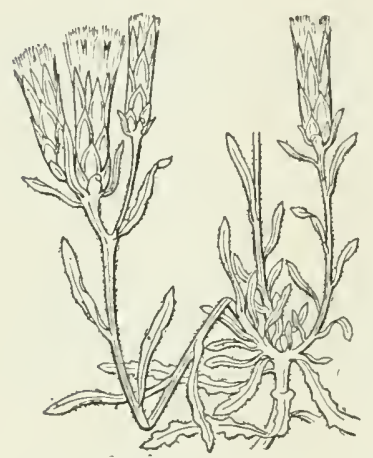

Stæhelina dubia.

Fig. 331 .

Sieber et echinala Pomel des Hauts Plateaux et l'Atraclylis phacolepis Pomel, signalé à Djelfa et à Taguin, localité au sud de Chellala, el le Cardoxcelle de Ponel (Carduncellus Pomeliamus Batt.), espèce rare du Djebel Antar (près Méchéria) et de Beguirat.

Parmi les plantes non épineuses, mentionnons la STÉHÉliNe doutecse (Slechelina dubia L. (Fig. 331), sousarbrisseau touffu atteignant $0 \mathrm{~m}$. 50 , à feuilies étroites, peu découpées, cotonneuses en dessous, que l'on rencontre dans les broussaitles ou en sous-bois. Les rameaux de la Stéliéline sont dressés; chacun d'eux porte un on deux capitules à involucre long et étroit. Les lleurs sont roses: les achaines sont munis d'aigrettes atteignant 5 fois leur longueur.

Le genre Centaurée (Centanrea), représenté par de nombreuses espéces, comprend surtout des plantes herbacées. Cependant la CextaunéEa petrtes fleurs (Centanrea parviflora Desf.) asse\% répandue dans la région Alger-Médéa-Bouira, prẻs de Maseara, etc., est sous-ligneuse à la base, et la CextacréE 
Toujours verte Cenlanrea sempervirens L.), grande plante de la Chiffa et de Mouzaïa, présente des tiges de consistance ferme.

Tribu des Chicoracées. - Les Scolymes, plus connus sous le nom de Chardons à fleurs jaunes, appartiennent à cette tribu, qui ne renferme pas de plantes ligneuses importantes. Le Calananche cespilosa Desf., plante sans tige, à fleurs jaunes, présente une souche épaisse et des feuilles en rosette; c'est une espèce des Hauts Plateaux.

Le LaITEron délicat (Sonchus lenerrimus L) (Fig. 332), plante quelque peu ligneuse sarmenteuse, est répanclue dans les haies sur les murs et les rocher's; le LaiteRoN ÉPlNEux (Zollikoferia spinosa

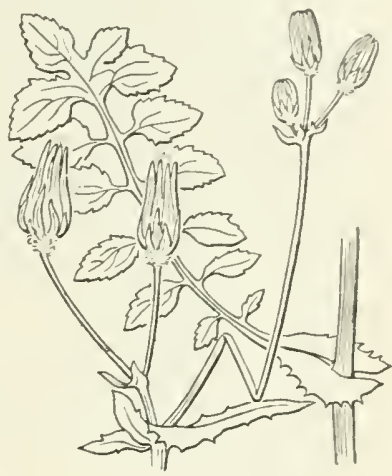

Sonchus tenerrimus

Fig. 332. Bois.) estune espèce sous-ligneuse de 10 à 30 centimètres de hauteur, rameuse, habitant les Hauts Plateaux. Une espèce voisine de l'Oranie, le Laiterox alzboRESCENT (Zollikoferia arborescens Batt.), forme des buissons atteignant 1 mètre de hauteur dans la région de Nemours et au sud d'Aïn Sefra.

Tribu des Corymbifères. - Le Genre Inule est reprèsenté pardeux espèces :

L'INULE VISQUEUSE (Inula viscosa Ait.) (Fig. 333 est une plante odorante, gluante, ligneuse à la base, pouvant dépasser 1 mètre de hauteur. Les feuilles, à dents séparées par des échancrures arrondies, sont sessiles ou mème embrassent la tige par leur base. Les capitules (de 1 à $2 \mathrm{~cm}$.) sont jaunes et réunis en une grappe lâche. Cette plante, très commune, occupe quelquefois des champs entiers.

L'INULE FAUX-CRITHMUM (Inula crilhmoides L.), plante de 0,50 à 1 mètre, a des feuilles charnues, entières tridentées. On la rencontre fréquemment dans la région do()ran, au bord de la mer, elle est rare dans les autres régions littorales.

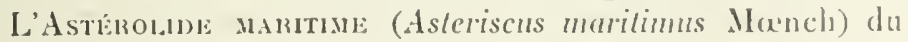




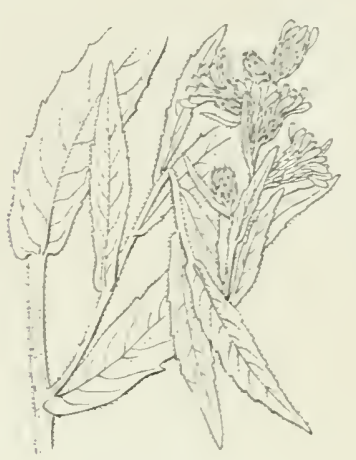

Inula viscosa.

Fig. 333 .

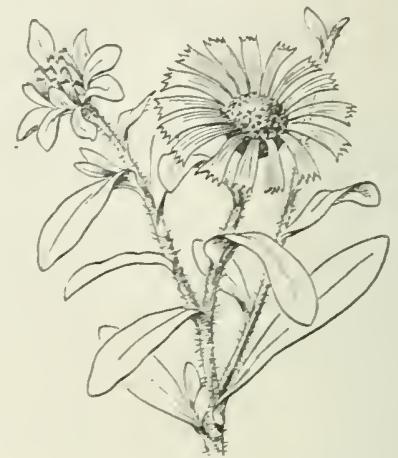

Asteriscus maritimus.

Fig. 334.

genre Astèrolide (Fig. 334) est une plante à souche ligneuse, à gros capitules jaunes entourés de feuilles, commune au bord de la mer.

Dans le Genre Phagnalon, mot qui signifie plante cotonneuse, le capitule est entouré d'écailles nombreuses, membraneuses et transparentes, autrement dit scarieuses, au sommet. Ce sont des plantes simplement ligneuses à la base et ne dépassant guère 40 centimètres de hauteur. Le Piagialox des rochers (Phagnalou saxatile Cass.) (Fig. 335) el le Phagralon RUPESTRE (Phagnalon rupestre D. C.) sont communs dans les broussailles et sur les rochers; le Phagsalox sondide

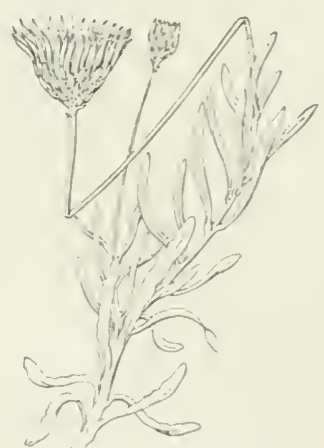

Pharnalon saxatile.

Fig. 333 .

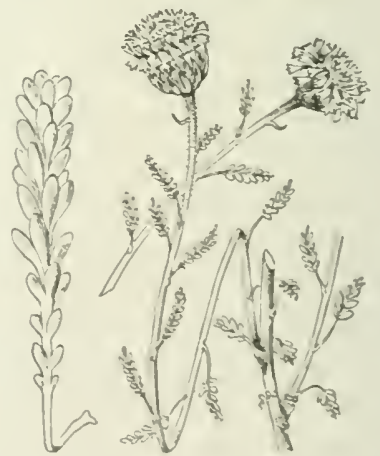

Santolina Chamaecy parisgus.

Fin. 336. 
(Phagnalon sordidum D. C. ne se rencontre que çà et là sur les rochers.

Le genre Immortelle caractérisé par ses capitules brillants, à écailles scarieuses, comprend une plante sous-ligneuse : l'Innortelle de Desfoxtanes (Helichrysum Fonlunesi Camb.), qui atteint 60 centimètres de hauteur. On peut rattacher à cette espèce très commune en Algérie plusieurs types voisins et fort peu tranchés.

Les Santolines sont des sous-arbrisseaux dont les rameaux à fleurs, dressés et réunis en touffe, portent chacun à leur sommet un capitule de fleurs jaunes. La Saxtoline PetrT Cyprès (Santolina Chamayparissus L.) (Fig. 336), ou Santoline d'Afrique, est usitée comme insecticide. C'est une plante des Hauts Plateaux, vulgairement appelée Camomille de Malıon.

La Santoline blanchatre ou à feuilles de Romarin ( $S_{a l l}$ tolina rosmarinifolia $\mathrm{L}$.) se rencontre surtout en Kíbylie, dans l'Aurès, et sur l'Atlas Saharien.

Les espèces du genre Camomille ${ }^{1}$ que nous avons à citer présentent des capitules jaunes entourés de ligules blanches.

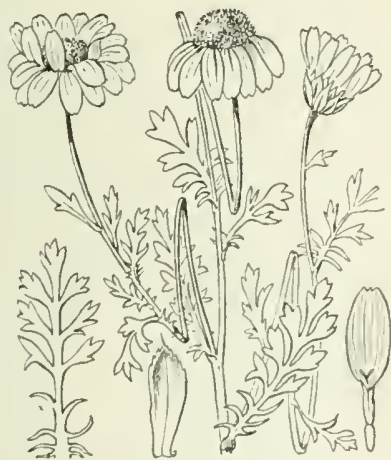

Anthemis maritima.

Fig. 337.

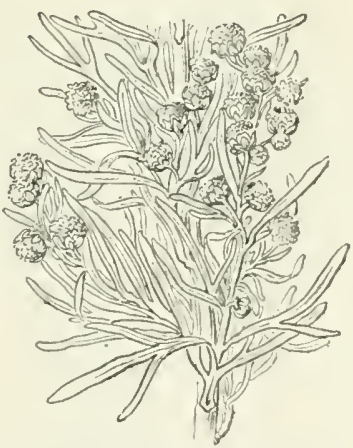

Artemisia arhorescens.

Fing. 338.

La Canomile manutrate (Anthemis maritina L.) (Fig. 337) est une plante ligneuse à la base, odorante, de la région litto-

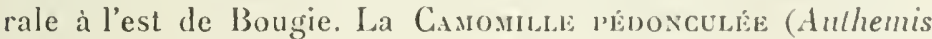

1. Lespèce la plus usitée en plarmacie est la Camomilte romaine (Anthemis nobilis L.); elle existe dans la région d'Oran. 
pedunculata Desf.), quelquefois également sous ligneuse, est commune en montagne (surtout région de Blida-Médéa.Miliana et Oranie).

Dans le genre Plagie, remarquable par ses capitules sans ligules, il faut mentionner le PLAGIE RAIDE (Plagius virgalus D. C.), plante sous-ligneuse commune dans les forêts de Chêne-liège.

Parmi les espèces du genre Armoise citons d'abord : L'ARMOISE EN ARBRE (Arlemisia arborescens L.) (Fig. 33S) plante commune au bord de la mer; sa tige peut acquérir un diamètre assez considérable. Elle a, mais à un moindre degré, les mêmes propriétés toniques, fébrifuges, etc., que l'Absinthe (Artemisia Absinthium L.), espèce non ligneuse que l'on rencontre en montagne en France et en Algérie (Djurdjura, Babors).

L'ARMOISE HERBE BLANCHE (Artemisia herba alba

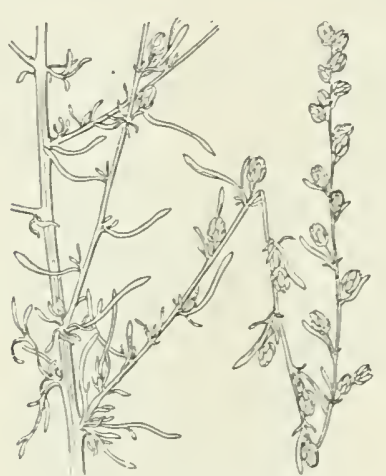

Artemisia campestris.

Fig. 339.

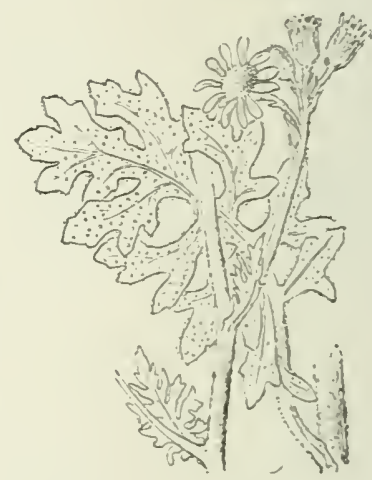

Senecio Cineraria.

Fig. $3 \pm 0$.

Asso.), très répandue sur les Hauts Plateaux, connue sous le nom de Chih par les indigènes, appelée souvent Thym par les colons, présente une odeur caractéristique (Semen contra); elle . est employée comme vermifuge.

L'Armorse de l'Atras (Artemisia allantica Coss.) est une plante du sud, ligneuse à la base: l'Armorse des champs (Artemisia campestris L.) (Fig. 339), assez commune sur les Hauts Plateaux, est à peine ligneuse. 
Rappelons que l'Estragon, cultivé dans les jardins, est une Armoise (Artemisia dracunculus L.).

Le genre Séneçon comprend de nombreuses espèces herbacées; le Séxeçox a feullees de Lix (Senecio linifolius 1D. C.) qui habite les carrières de Santa-Cruz près Oran et le Śéceçon Cinérare (Senecio Cineraria D. C.) (Fig. 340) qui croît sur les falaises maritimes de Cherchell, Ténès, etc., sont ligneux à la base.

Enfin le genre Souci renferme deux espèces un peu ligneuses: le Souci de Monard (Calendula.Monardi B et R.) et le Souci sous-ligneux (Calendula suffruticosa Vahl.), existant le premier entre le Mazagran et le Corso et le second à Oran, Mostaganem, Stora, etc... Une forme grêle (variété marocanı) croît dans les steppes de l'Oranie.

\section{§ 2. - Gamopétales à ovaire supère.}

La famille des ÉRIGAGÉES comprend, en Algérie, des plantes ligneuses, à feuilles simples, persistantes. Les fleurs sont réguliẻres, à 4 ou 5 divisions, avec étamines en nombre double.

Dans le genre Arbousier, les feuilles sont alternes, dentées, de plusieurs centimètres de largeur; les fleurs présentent 5 divisions; le fruit est une baie rouge. L'ARBOUSHER COMMUN (Arbulus Unedo L.) (Fig. 341) est un arbuste ou un arbrisseau touffu, à jeunes pousses rouges, fleurissant tout

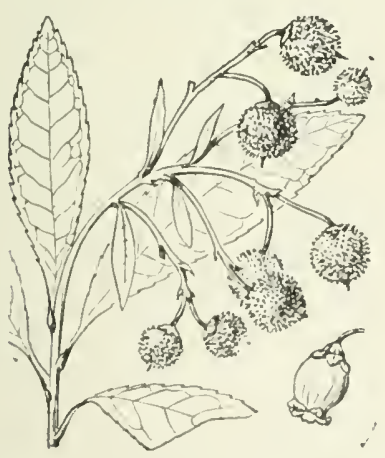

Arbutus Unedo. Figr. 341 .

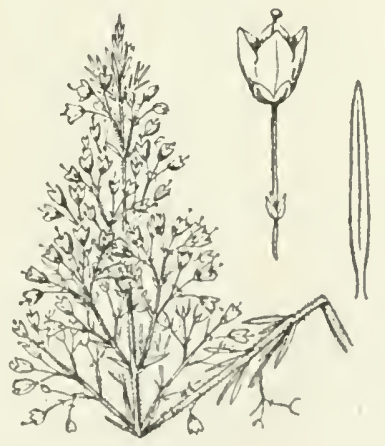

Erica arborea.

Fig. 342. 
l'hiver. Les fleurs, disposées en grappe, sont blanches; l'aspect du fruit a fait surnommer l'Arbousier "Fraisier en arbre".

Cette espèce, abondante dans les forêts humides du Tell, rejette facilement de souche; son bois rougeâtre peut acquérir un beau poli, mais est cassant. C'est un bon combustible.

Les feuilles sont employées en Orient pour le tannage des peaux.

Les Bruyères ont des feuilles en aiguilles réunies par 3-6; les lleurs ont $\downarrow$ divisions; le fruit est une capsule.

La BRUYERE EN ARBRE (Erica arborea L.) (Fig. 342), est la plus répandue en Algérie; elle peut acquérir un gros tronc et atteindre 5 à 6 mètres de hauteur. Elle forme souvent dans les forêts de Chène-liège un sous-bois impénétrable, qui constitue un grave danger d'incendie pendant la saison sèche. Son bois ressemble à celui de l'Arbousier, mais est plus rouge ; les souches font l'objet d'exploitations importantes. Elles sont transformées dans des scieries voisines de la forêt en ébauchons qui sont exportés pour la fabrication des fourneau. de pipes; les indigènes en font du charbon pour la forge.

La BRUYERE A BALAI (Erica scoparia L.) (Fig. 343),

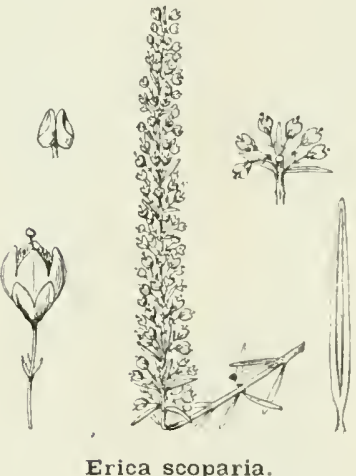

Fig. 343.

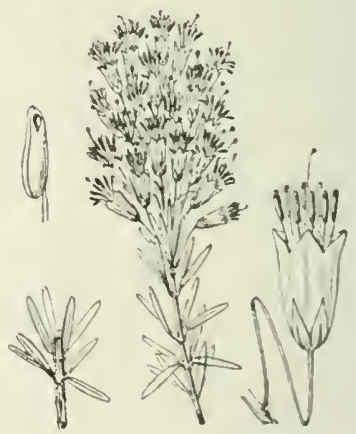

Erica multiflora

Fig. 34 .

mélangée à la précédente sur le littoral constantinois, n’atteint pas d'aussi grandes dimensions.

C'est généralement au printemps que lieurissent ces deux espèces; au contraire, la Brerine a fleurs yombrecses (Erica multiflora L.) (Fig. 34t) fleurit en autonne. Les Bruyeres sont 
des plantes sociales et envahissantes, caractéristiques des sols siliceux; toutefois l'Erica multiflora fait exception et se rencontre dans les sols calcaires des collines du Tell.

La famille des OLEAGÉES comprend des arbres et arbustes à feuilles opposées (sauf le Jasmin). La fleur est régulière, et comprend un calice et une corolle à 4 divisions, rarement plus (5-8 Jasmin), deux étamines soudées à la corolle, un ovaire à deux loges. Le calice et la corolle peuvent manquer.

Celte famille peut se diviser pour l'Algérie en trois tribus: Jasminées, Fraxinées et Oléinées ; toutefois nous réunirons le Jasmin aux Oléinées.

Les Fraxinées comprennent le genre Frêne (Fraxinus), caractérisé par des feuilles composées, caduques et un fruit see dit samare.

Le FRENE OXYPHYLLE (Fraxinns oryphylla Bieb.) (Fig. 345) est un grand arbre très commun en Algérie, à lleurs sans corolle ni ealice, disposées en grappes lâches, à feuilles grandes comprenant d'ordinaire 5 à 11 folioles dentées.

Ce Frène est très voisin du Frêne comuun (Fraxinns excelsior L.), mais il n'atteint pas d'aussi grandes dimensions; ses folioles sont souvent ponctuées de noir en dessous, à dents espacées ${ }^{1}$ et moins nombreuses que chez son congénère (5-11 au lieu de 9-13). Ses bourgeons, moins gros et moins foncés, non veloutés, permettent également de le distinguer du Frêne commun assez souvent planté dans la colonie.

Le Frêne oxyphylle a la ramification peu serrée, le couvert léger. C'est une essence disséminée qui exige un bon sol assez meuble et qui n’existe à l'état de bouquets que dans les terrains fertiles.

Le bois de Frêne se reconnaît à son aspect brillant; il est recherehé pour le charronnage, la menuiseric, les construetions navales et l'ébénisterie, en particulier pour la fabrication des elaises.

1. Chez le Frêne commun, chaque uervure des folioles correspond à deux dents el aboulit a leur intervalle; dans le liverue oxyphylle, nue nerrure aboutit a la pointe de chaque denl (Mathicu al liche, Flore forestiere. 4' édilion, p. 245). 
Les feuilles sont purgatives; elles servent, en Kabylie surtout, à la nourriture du bétail.

Le FRENE DIMORPHE (Fraximus dimorpha Coss.)

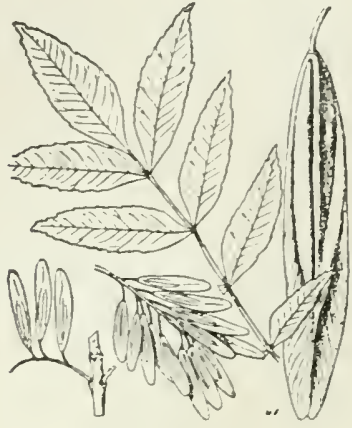

Fraxinus oxyphylla.

Fig. 345.

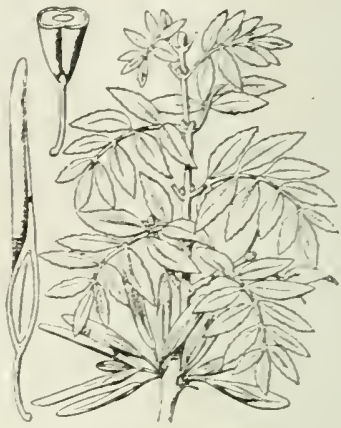

Fraxinus dimorpha.

Fig. 346.

(Fig. 346) est un arbre à fleur sans corolle, à calice petit, persistant avec le fruit; les feuilles des premiers rameaux sont réduites à 2-3 paires de folioles arrondies; celles de la partie supérieure, beaucoup plus grandes, comprennent 3-5 paires de folioles aiguës.

Ce Frêne est un arbre de montagne à croissance lente; dans les sols secs, il reste à l'état buissonnant; sa ramification devient très serrée; les feuilles se déreloppent peu. Ses rameaux durs l'ont fait appeler Frène épineux. Répandu dans l'Aurès, cet arbre a été aussi signalé au Djebel Mzi (rẻgion d'Ainn-Sefra). Un pied unique, qui avait été découvert autrefois près de Toudja (à l'ouest de Bougie), n'a pu être retrouvé.

Chez les Oléinées, les feuilles sont simples (ou trifoliees chez le Jasmin); le fruit est charnu (drupe violacée chez l'Olivier, noirâtre dans le genre Philaria, baie noire pour le Jasmin).

L'OLIVIER D'EUROPE ou commun (Olea europxa L.) (Fig. 347) est la seule espèce indigène du genre, ou tout au moins la seule qui puisse ètre considérée comme telle, car certains auteurs la disent originaire de Syrie, introduite par l'homme en Algérie.

L'Olivier est un arbre, souvent un arbuste ou mème un 
buisson à rameaux grisâtres, quelquefois durcis, presque épineux.

Les feuilles entières et coriaces sont blanchâtres en dessous, ce qui donne au feuillage son aspect cendré. Les fleurs sont blanches. Les variétés cultivées sont nombreuses.

L.Olivier, très répandu en Algérie, rejette vigoureusenent de souche.

Le bois est jaune, veiné de brun, très dur et susceptible d'acquérir un beau poli; il fournit un excellent chauffage et un charbon de première qualité.

Les Philarias n'ont pas le feuillage cendré de l'Olivier, lcurs feuilles étant vertes sur les deux faces. Il en existe trois espèces très voisines que l'on considère généralement comme une essence unique. Cependant le PHILARIA A LARGES FEUILLES (Phillyrea latifolia L.) (Fig. 348) se distingue facilement à ses feuilles (au moins les inférieures), un peu en cœur à la base, fortement dentées.

Le PHILARIA INTERMÉdIAIRE (Phillyrea media L.)

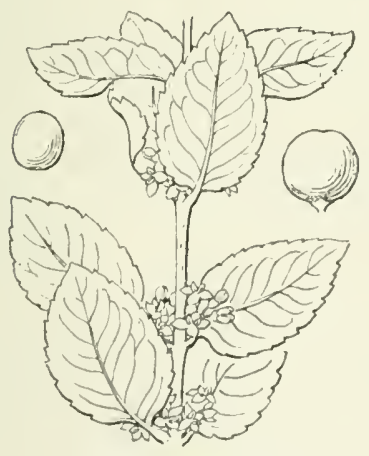

Phillyrea latifolia. Fig. 348.

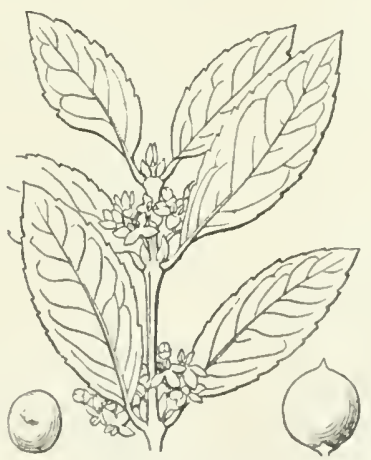

Philly rea media.

lig. 349.

(Fig. 349) a les feuilles souvent dentées légèrement, tout au moins à la pointe. 
Ces deux espèces sont communes, tandis que le PHILARIA A FEUILLES ÉTROITES (Phillyrea anguslifolia L.) (Fig. 350), à feuilles entières munies d'une étroite bordure transparente, et à peu près sans pétiole, est beaucoup plus rare.

Le JASMIN ARBRISSEAU (Jasminnm fruticans L.)

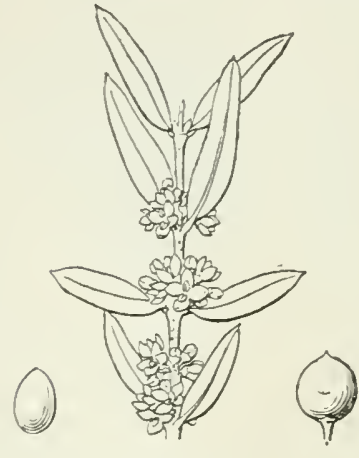

Phillyrea angustifolia.

Fig. 350 .

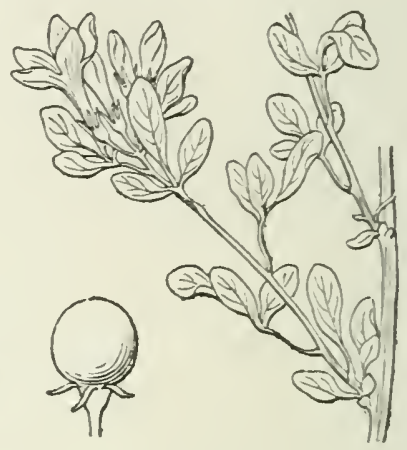

Jasminum fruticans.

Fig. 351.

(Fig. 351) est un arbuste à rameaux verts, anguleux et allongés, à feuilles luisantes, simples ou formées de 3 folioles. Les fleurs jaunes et odorantes sont réunies par 4 au plus à l'extrémité des rameaux. Cet arbrisseau est assez commun dans les broussailles du Tell. Divers Jasmins sont cultivés, en particulier le Jasmin officinal, espèce à lleurs blanches.

La famille des APOCYNEES comprend des plantes à feuilles persistantes, entières, coriaces, opposées ou groupées par 3. Les fleurs sont régulières à 5 divisions, 5 étannines ct 2 carpelles.

Le NÉRION (Neriam Oleander L.) (Fig. 352), plus connu sous le nom de LAURIER-ROSE, est un arbuste ou un arbrisseau à feuilles ćtroites, mates, opposées ou par 3, à lleurs roses groupées au bout des rameaux. Les deux carpelles distincts deviennent des follicules (eapsules s'ourrant sur une ligne longitudinale) contenant des graines velues, munies d'aigrettes.

Le Laurier-rose croit dans les stations humides, surtout le 
long des cours d'eau, ce qui a fait dire qu'il engendrait la fièvre; il est vénéneux. Ses feuilles sont employécs pour détruire les parasites. Son bois donne un charbon qui peut être utilisé pour la fabrication de la poudre. Les fibres des Nérions sont textiles.

Les Pervenches sont des plantes à tiges grêles, rampantes;

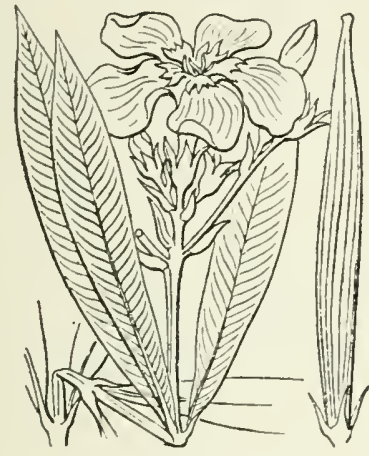

Nerium Oleander.

Fig. $35^{\circ} 2$.

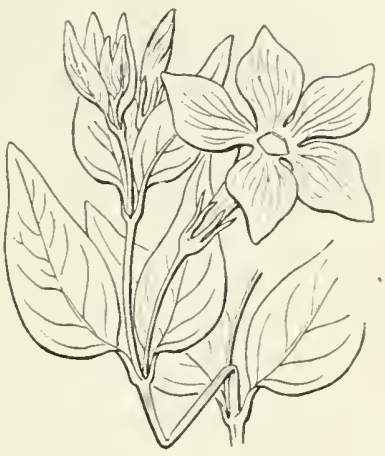

Vinca media.

Fig. 3.33.

celles qui portent des fleurs seules se redressent. La PERvenche intermédiaire (Vinca media Link et Hoff.) (Fig. 353), à fleurs généralement d'un bleu très pâle, est commune dans les forêts de Chêne-liège à l'est de Bougie; la Pervenche a gRANDES Fleurs (Vinca major L.), qui se distingue de la précédente par ses feuilles poilues, ciliées sur les bords et souvent en cour a la base, se rencontre échappèe des cultures.

La famille des ASCLÉPIADEES se distingue de la précédente par les étamines généralement soudées entre elles et adhérentes au stigmate. Le pollen est réuni dans chaque anthère en 2 (quelquefois 4) masses dites pol-

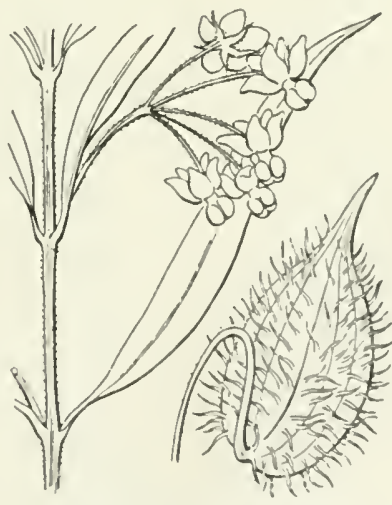

Gomphocarpus fruticosus. Fig. 3it. 
linies qui restent suspendues à 5 glandules disposées sur le pourtour du stigmate, entre les anthères. Les feuilles sont opposées.

Le Gomphocarpe fruticuliux (Gomphocarpus frulicosus R. Br.) (Fig. 354) est une plante ligneuse à la base, et atteignant 2 mètres de hauteur, localisée dans l'est de la colonie. Les fleurs sont blanches, les fruits en vésicules couvertes de pointes molles.

Le Periploca lievigatu Aïton est un arbuste du Sud et du littoral oranais à fleurs purpurines bordées de jaune.

Les plantes de ce genre ont les fibres libériennes très résistantes; on les utilise dans l'Inde.

Les GONVOLVULACEES ont des fleurs régulières à corolle en entonnoir, tordue avant l'épanouissement. Les Liserons (Convolvulus) sont des plantes très répandues, généralement volubiles. Mentionnons seulement le Liseron de Biscaye (Convolmulns cantabrica L.), à tiges un peu ligneuses à la base, non volubiles et à fleurs roses, répandu dans le Tell.

La famille des BORRAGINÉES comprend des plantes à feuilles alternes généralement hérissées de poils; les fleurs, d'ordinaire régulières, sont à 5 divisions et à 5 étamines. L'ovaire, extérieurement divisé en 4 parties, se transforme en 4 akènes libres ou soudès.

Le genre Grémil (Lithospermum), à tige couverte de poils longs et raides, renferme en Algérie 2 sous-arbrisseaux à fleurs bleues. Le Lithospermum rosmarinifolium Tenore, dénudé dans le bas, à rameaux souvent tombants, a ses feuilles couvertes à la partie supérieure de petites taches blanches; cette espèce a été signalée à Bône et à Bougie. Le Lithospermum consobrinum Pomel, que l'on rencontre entre Oran et Arzew, a ses tiges dressées, rameuses et les leuilles sans taches blanches. Il est à remarquer que les feuilles de cette dernière espece ressemblent plus que celles de la précédente aux feuilles de Romarin.

Les SOLANÉES ont une fleur régulière ou peu irrégulière à 5 divisions et 5 étamines. Le calice persiste souvent: l'ovaire est à 2 loges; les feuilles sont alternes. Les Solanées 
sont généralement vénéneuses (Ex.: fruits de la Belladone); toutefois de nombreuses espèces présentent des parties comestibles et sont cultivées (Pomme de terre, Tomate, Aubergine, Poivron, Piment).

Le genre Solanum, auquel appartient la Pomme de terre, comprend deux espèces à citer : la Morelle Douce-Anère ou Vigne de Judée (Solanum Dulcamara L.) (Fig. 355), plante sarmenteuse, atteignant 1 à 2 mètres, à feuilles ovales, terminées en pointe (celles du haut quelquefois divisées en 3), à fleurs

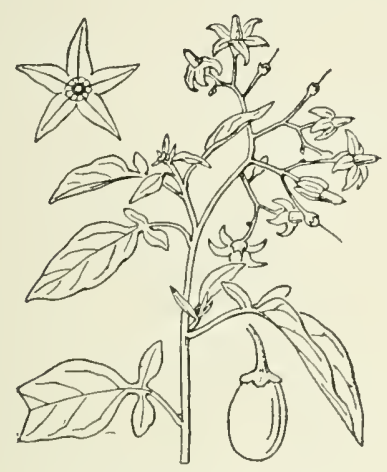

Solanum Dulcamara.

Fig 35j.

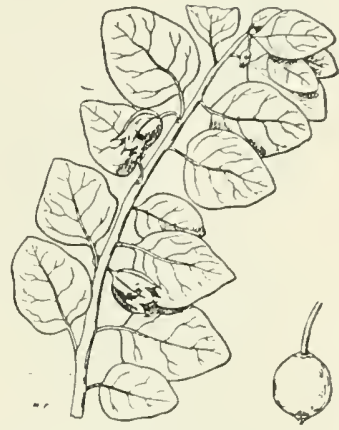

WIthania frutescens.

Fig. $3 \check{5} 6$.

violettes, à baies rouges, ovoïdes, est assez commune dans les haies et les endroits marécageux. Elle tire son nom de la saveur de son écoree d'abord amère, puis douce. La tige et les feuilles passent pour dépuratives; le fruit est vénéneux.

La Morelle de Sodone (Solanum sodomxum L.), très rarement spontanée, sauf peut-être dans l'Est, s'échappe quelquefois des jardins; e'est un arbrisseau très épineux à gros fruit jaunàtre également épineux.

Les Physalis ou Coquerets, non spontanés en Algérie, sont cultivés; leur calice, très développé, est ornemental. Le Coqueret A lkékenge (Plyssalis Alkekengi L.), à calice rouge vif, donne une baic de même couleur, comestible et purgative; on trouve aussi, échappé des cultures, le Coquenet pubescent (Physalis pubescens L.) ou Groseillier d'Amérique.

Le Withania frulesecus Pauq. (Fig. 356), commun dans le 
Tell Oranais, est un arbrisseau à rameaux blanchâtres, à feuilles luisantes entières, en cœur, ovales ou presque rondes, courtement pétiolées. Les fleurs, penchées et réunies par 1-3, sont verdâtres ainsi que les fruits.

Le genre Lyciet (Lycium) est représenté en Algérie par des arbrisseaux à écorce blanchâtre, à rameaux souvent terminés en épines.

Le Lyciet entrecroisé (Lycium intricatum Boiss.) est un arbrisseau du littoral oranais, à rameaux enchevêtrés portant de grosses épines feuillées. Les feuilles sont charnues, les fleurs bleuâtres.

Le LYCIET D'EUROPE (Lyciun europxum L.) (Fig. 35̄7)

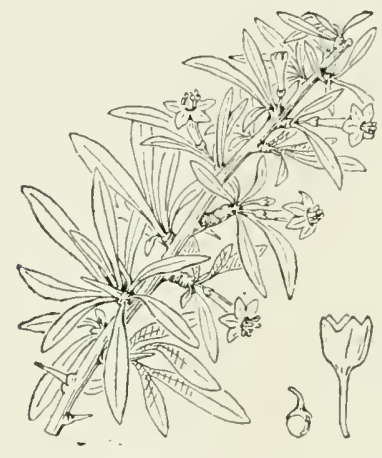

Lycium europæum.

Fig. 3.57.

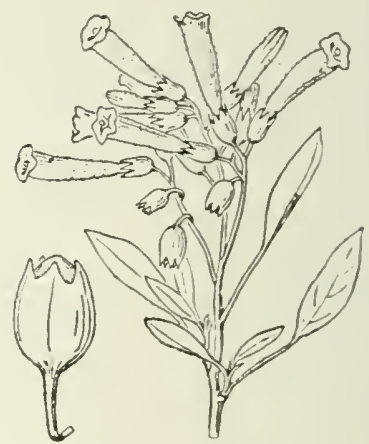

Nicotiana glauca

Fig. 3,8.

présente, ainsi que les espèces qui suivent, des feuilles groupées à la base des épines; c'est une plante très répandue. Le Lrciet de Barbarie (Lycium barbarum L.) et le Lyciet d Afrique (Lycium afrum L.) sont au contraire rares.

Le genre Nicotiana comprend surtout des plantes herbacées parmi lesquelles le Tabac (Nicoticula Tabacum L). Une espèce ligneuse, originaire de l'Amérique du Sud, s'est répandue sur le littoral algérien: le TABAC GLAUQUe (Nicoliuna glanca Graham) (Fig. 358) est un arbuste atteignant 4 metres de liauteur; la corolle est jaune et longuement tubuleuse. Il tire son nom de l'aspect des feuilles.

Les SGROFULARINEES sont des plantes à fleurs 
irrégulières d'ordinaire à 4.5 divisions; la corolle, souvent bossue ou éperonnée, présente fréquemment 2 lèvres. Les étamines sont au nombre de 2 ou 4 ; dans ce dernier cas, deux sont plus grandes. L'onaire. est à denx loges.

Cette famille comprend de nonbreuses espèces herbacées. (Ex. : le Muflier ou Gueule de Loup) (Fig. 359). Le genre Véronique, également très conmu, comprend une espèce sous-ligneuse croissant sur les hautes montagnes du Tell et de l'Atlas Saharien, au Garrouban (près Tlemcen), etc., la VéroNique rose (Veronica rosea Desf.), qui porte de belles fleurs bleues, devenant roses en herbier.

Le genre Anarrhinum, contrairement au précédent, présente des fleurs à corolle tubuleuse et nettement à deux lèvres. L'Anarrhinum fruticosum Desf., à tiges longues et

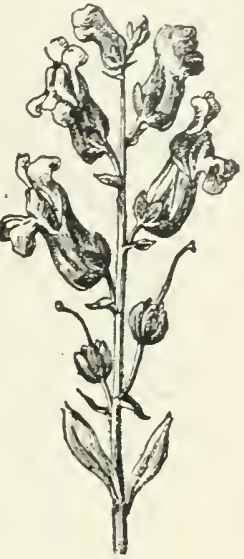

Muflier

Fig. 359. effilées, ligneuses à la base, atteint près de 1 mètre de hauteur. Les feuilles sont entières et étroites: les fleurs sont très petites. On rencontre cette espèce à Tlenıcen

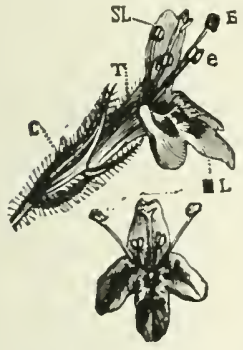

Fleur de 'Thym el corolle vue de face : $($, calice; $\mathrm{T}$, lube de la eorolle; SI, lèvre supérieure; I., levre inféricure; E, grandes étamines; $e$, petiles étamines.

Fig. 360 . et sur les Hauts Plateaux (Aïn Hadjar, près Saïda; Djebel Antar, près Mecheria).

La famille des LA BIEES comprend également des plantes à lleurs irrégulières à $4-5$ divisions, la corolle formant généralement 2 lèvres (Fig. 360,; il existe généralement 4 étamines dont 2 plus grandes (Fig. 360 ), quelquefois 2 seulement (Romarin, Sauge). L'ounire esl à qualre loyges, au milieu desquelles est implanté le style; les fruits sont souvent enveloppés par le calice persistant.

Les feuilles, opposées ou verticillées, sont d'ordinaire couvertes de poils glanduleux : les tiges et rameaux à section carrée.

Dans le genre Germandrée (T'ucrium), la 
lèvre supérieure de la corolle est fendue et les deux parties rejetées sur les côtés, ce qui la fait paraître avortée, tandis que la lèvre inférieure présente 5 lobes.

La GERMANDRÉE LIGNEUSE (Teucrium fruticans L.) (Fig. 361) est un arbrisseau atteignant $1 \mathrm{~m}$. 50, à grandes fleurs bleu pâle, qui croît dans les broussailles.

La Germandrée Faux-Scorodoine (Teucrium pseudo-scoro-

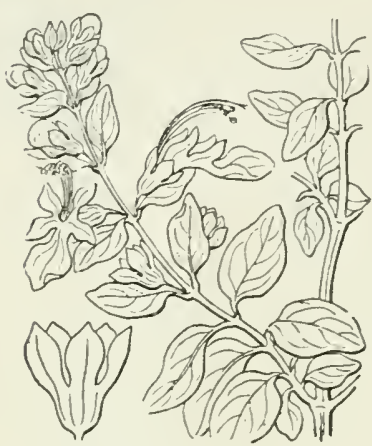

Teucrium fruticans.

Fig. 361.

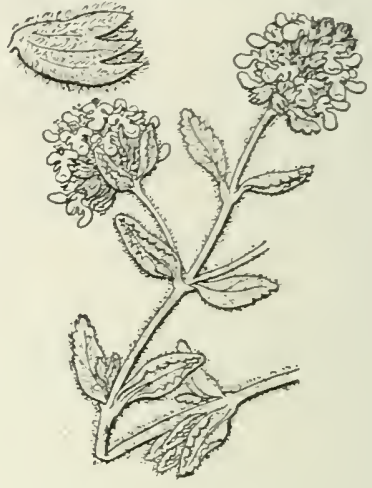

Teucrium Polium.

Fig. $36^{\circ}$.

(lonia Desf.), plante robuste de 3 à 6 décimètres, à fleurs verdâtres, existe en montagne et dans la région d'Oran.

La GERMANDREE POLIUM (Tencrium Polium L.)

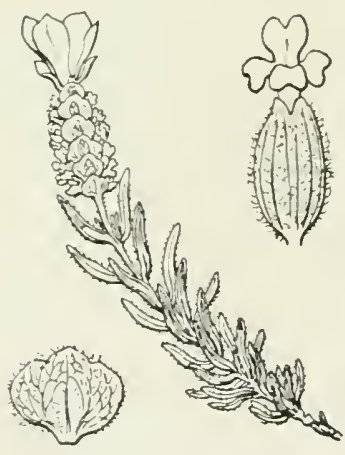

Lavandula Stœchas.

Fig. 363 . (Fig. 362), espèce colonneuse à type très variable, à feuilles presque sans pétioles, à fleurs blanches, jaunâtres. roses ou purpurines, est très répandue dans la colonie.

La Germandrée cotonseuse (Tellcrium albidum Munby) à petites feuilles pétiolées, cotonneuses en dessous, à fleurs jaunâtres, se rencontre aux Cascades de Tlemcen.

Les Lavandes (Lavandula) ont de petites fleurs bleues ou violacées groupées en épis. La LAVANDE STCECHAS (Lavandula Stoechas L.) (Fig. 363) est 
très répandue, surtout dans les forêts de Chêne-liège ; la LAVANDE DENTÉE (Lavandula dentata L.) est fréquente dans le Tell occidental; la LAvande a Feuilles découpées (Lavandula multifida L.) se rencontre çà et là, surtout dans l'Ouest.

On extrait des Lavandes, surtout de la Lavande Spic ou Aspic (Lavandula Spica L.) de France, une huile jaune pâle (huile d'Aspic) d'odeur agréable. L'huile de Lavande Stæchas, que l'on ne fabrique plus, était cependant très estimée chez les Anciens. On emploie les fleurs de cette plante pour la préparation d'un sirop spécial.

Les Thyms (Thymus) sont des plantes basses sous-ligneuses à petites feuilles odorantes, ponctuées, à fleurs en têtes ou en sortes d'èpis. Leur importance forestière n'est pas suffisante pour que nous revenions avec détail sur les espèces citées dans la $2^{\mathrm{e}}$ partie. Il convient toutefois de donner quelques indications sur les stations: le Thymus Fontanesi B. R. (Fig. 364)

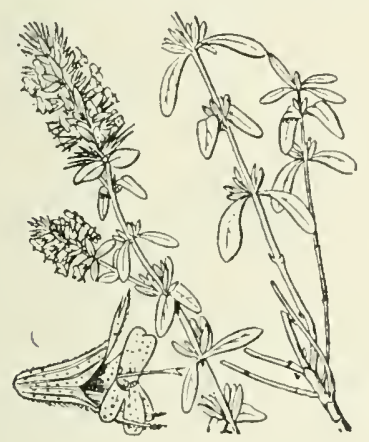

Thymus Fontanesi.

Fig. 36t.

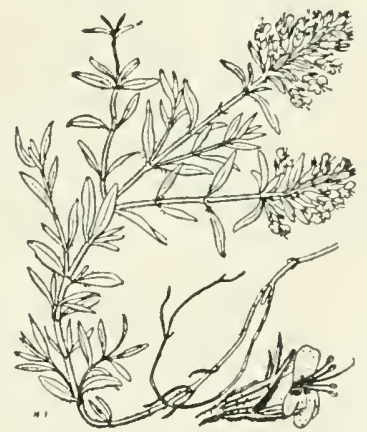

Thymus kabylicus.

Fig. 36,5 .

existe çà et là dans le Tell jusque dans le Sud; le Thymus capilalus Hoffm., paraît localisé à Tlemcen ; le Thymmus cundidissimus Batt. existe au sommet du Nador de Tlemcen; le Thymms cilialus Desf. comprend trois sous-espèces : le Thymus cilialus proprement dit Desf., le Thymus Munbyanus. B. R., et le Thymus coloratus B. R., surtuut répandus en Oranie; le Thymus hirtus Willd., que l'on subdivise également en Thymus pallidus Coss. (sommets de la région d'Aïn-Sefra), Thymus hirtus Willd. et Thymus algeriensis B. R., habitant les régions 
montagneuses; le Thymus Guyonii de Noé (Djelfa, Aflou): lc Thymus dreatensis Batt. (sommet du Dira, près d'Aumale, et du Dréat, d'où il tire son nom); le Thymus numidirus Poiret et sa variété le Th. kubylicus Batt. (Fig. 365) de la région du Djurdjura; le Thymus lanceolatus Desf. de l'Oranie, signalé aussi à Ben-Chicao, localité au sud de Médéa. D’après M. Battandier, ces différents Thyms s'hybrident assez souvent entre eux.

Plusieurs espèces sont employées en cuisine et en décoction pour lotions, bains, etc.

La Micromérie inodore (Micromeria inodor $a$ Benth.) est un sous-arbrisseau des coteaux calcaires rappelant la Bruyère par

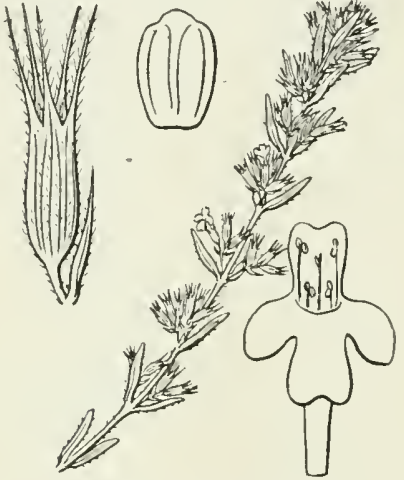

Micromeria græca.

Fig. 366.

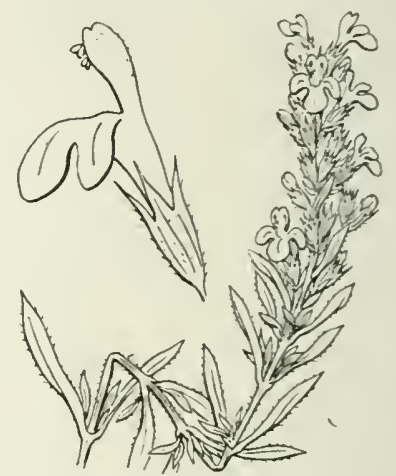

Satureia montana

Fig. $36 \vec{i}$.

ses feuilles en aiguilles. Les autres Microméries : Micromeria Juliana, Benth., Micromeria debilis Pomel (rochers des Hauts Plateaux et du Sud Oranais), Micromeria graca Benth. (Fig. 366) (rochers et broussailles du Tell), Micromeria nervosa Desf. (plante du littoral signalèc à Ténès et à Cherchell), Micromeria Fontanesii Pomel (croît surtout dans le Tell oranais), sont fort peu ligneuses.

La Sarriette des montagnes (Salureia monlana L.) (Fig. 36i) a été signalée sur les coteaux dı Tell par Pomel. Une Sarriette (Salureia hortensis L.) est cultivée et usitée en art culinaire.

Le genre Sauge (Salvia) comprend de nombreuses espèces herbacées; toutefois il faut citer en Algérie comme plantes ligneuses les Salvia Aucheri Benth. (Aurès, Mahdids, mon- 
tagnes du Sud oranais), Salvia Balansæ de Noë (fig. 368) (signalé au pont du Cheliff dans le Dahra), Salvia triloba L. fils; cette dernière Sauge est cultivéc et subspontanée.

Le ROMARIN OFFICINAL. (Rosmarinus officinalis L.) (fig. 369) est un sous-arbrisseau toujours vert, commun dans

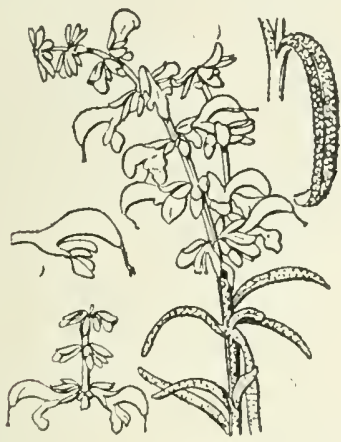

Salvia Balansæ.

Fig. 368.

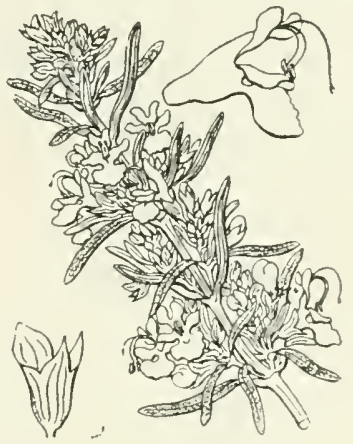

Rosmarinus officinalls.

Fig. 369.

les forêts de Pin d'Alep et les broussailles des coteaux calcaires. Ses fleurs sont en épis bleus; il existe une variété à fleurs blanches.

On utilise le Pomarin en médecine comme stimulant: infusion de 10 à $15 \mathrm{gr}$. par litre d'eau. Pour les douleurs rhumatismales : application de la plante chaude sur la région douloureuse.)

Le Prasium majus L. (fig. 370), arbrisseau sarmenteux à lleurs blanches, est très commun dans les haies du 'T'ell.

Les Crapaudines (Siderilis) ligneuses, que nous avons at citer, présentent, au-dessous des lleurs, des bractées en cueur, épincuses sur les bords; ce sont les Siderilis Gnyoniuna B. R., signalées dans les en virons d'( )ran. à Tlemeen, ete.; S. lencunthe Cav., connue seulement au Djebel Santo, près Oran ; S. luyssopifolic L. (Fig. 371) que l'on rencontre aux environs de Constantine; S. manra de Noë (Dahra, Ouilis); S. Allanlica Pomel, des environs de Constantine; $S$. incena L., croissant dans les lieux sees surtout en Oranie; $S$. ochrolenca de Noë, qui croit surtout sur les Hauts Plateaux oranais. 


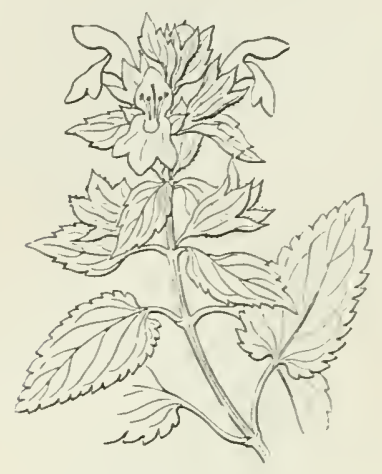

Prasium majus.

Fig. 370.

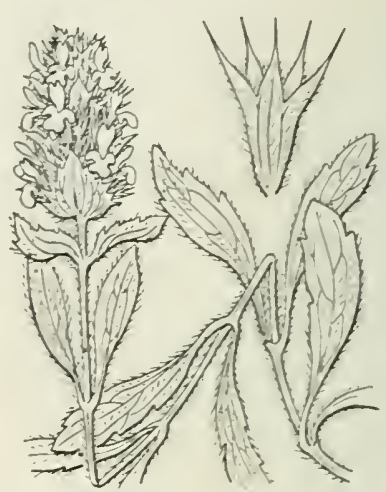

Sideritis byssopifolia.

Fig. 371.

La Ballote hérissée (Ballota hirsuta Benth.) est une plante sous-ligneuse atteignant 2 mètres, mollement velue, à corolle rosée, qui croît dans les haies, entre Oran et Ténès.

La famille des VERBENAGÉE est très voisine de

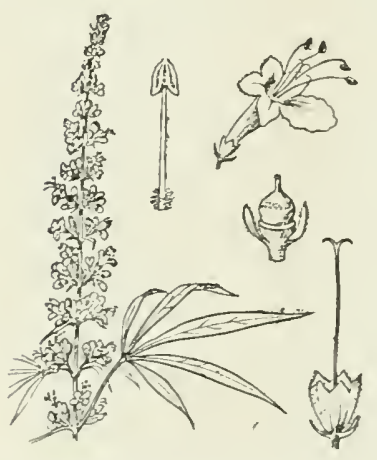

Vitex Agnus-castus.

Fig. $37^{\circ}$. celle des Labiées. Le GATTILIER AGNEAU CHASTE (Vitex Agnuscastus L.) (Fig. 372) est un arbuste exhalant, surtout par ses fruits, une odeur de poivre: d'où son nom d'Arbre à poivre. Ses feuilles, opposées, caduques, sont composées de 3-7 folioles. Les jeunes rameaux ont une section quadrangulaire.

Les fleurs, petites et réunies en une grappe terminale, présentent un calice blanchàtre et une corolle bleue, quelquefois blanche. Le fruit, en partie enfermé dans le calice, est noir rougeàtre.

Cet arbuste se rencontre sur le littoral et dans le Sud ; ses fleurs sont utilisées comme vulnéraire.

Les PLOMBAGINEES ont des fleurs régulières, quel- 
quefois réunies en capitules, comprenant un calice sourent membraneux (scarieux), une corolle à 5 pétales (qui peuvent être libres), 5 étamines, 5 styles (ou quelquefois un seul), un ovaire formé de 5 carpelles contenant chacun un ovule.

Le Limoniastrum monopelalum Boiss. (Fig. 373) est un arbrisseau du littoral, assez rare, à fleurs roses ou violettes par

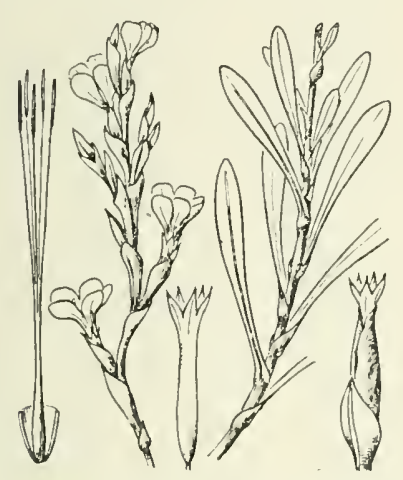

Limoniastrum monopetalum.

Fig. 373.

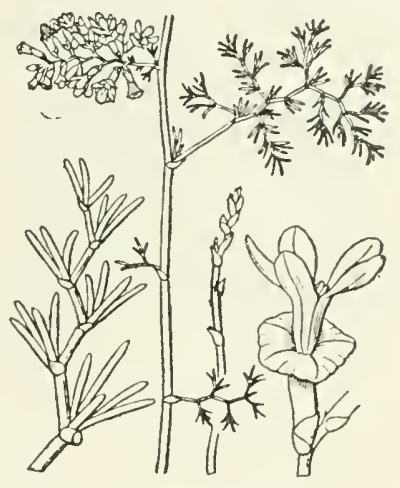

Statice asparagoides.

Fig. 374 .

1-2, éloignèes les unes des autres sur des rameaux creusés aux points où elles s'attachent.

Les Statice sont des plantes à feuilles en rosetteà la base; le Statice asparagoides Coss. et Dur. (Fig. 374), plante des rochers maritimes (Nemours), porte sur ses nombreux rameaux des bouquets de petites aiguilles vertes qui sont des rameaux modifiés : la corolle, à pétales de $1 \mathrm{~cm}$. et plus, est purpurine.

Les PLANTAGINÉES sont caractérisées par des lleurs petites, verdâtres, réunies en épis allongés ou raccoureis. Ces lleurs sont placées à l'aisselle de bractées souvent membraneuses (scarieuses); les enveloppes de la fleur, qui ont fréquemment la même consistance, sont à 4 divisions; il existe 4 étamines ; le fruit est entouré par les sépales persistants. Tout le monde connaît les Plantains (Planlago). Quatre espèces algériennes peuvent être citées comme ligneuses:

Le Plantan blanchatre (Planlago albicans L.) (Fig. 375), 
velu et soyeux, est très commun en Algérie et constitue un aliment important pour les moutons sur les Hauts Plateaux.

Le Plantain a grosse racine (Plantago macrorrhiza Poiret)

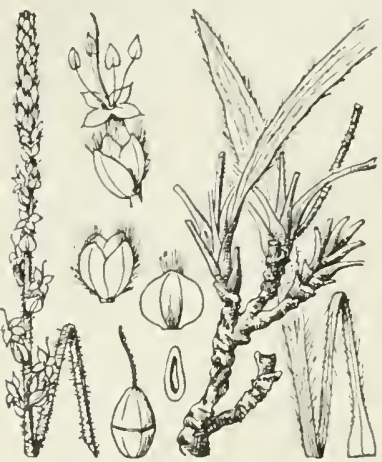

Plantago albic ns.

Fig. 375.

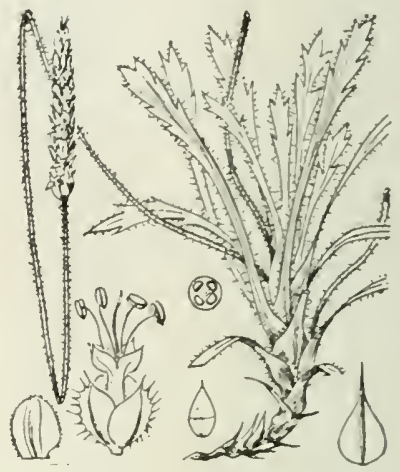

Plantago macrorrhiza.

Fig. 376.

(Fig. 376) présente une grosse souche; c'est une plante charnue répandue sur les falaises maritimes.

Le Plantain de r'Atlas (Plantago allantica Batt.) à souche ligneuse, écailleuse, à feuilles non charnues, est une espèce de montagne (Teniet-el-Had, Ouarsenis, Achaoun).

Le Plantain de Mauritanie (Planlago malitanica B. R.) constitue un tout petit buisson touffu, à rameaux florifères herbacés, croissant dans les montagnes du Djurdjura, et de la

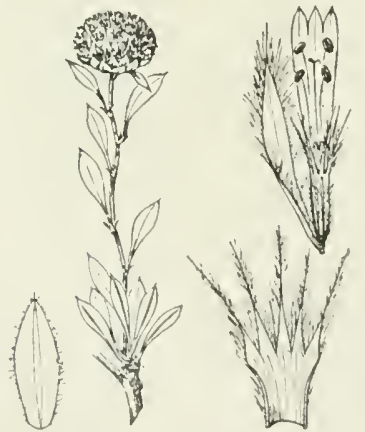

Globularia Alypum. Ijig. 377. région de Tlemcen.

La famille des GLOBULARIÉES est formée de plantes à feuilles sinuples, alternes, à lleurs irrégulières disposées en un capitule ressemblant à celui des Composées, mais les fleurs ne comprennent que $t$ étanines insérées vers le haut de la corolle.

La seule espèce algérienne, la GLOBULAnz: 'Turntrin Globuluria Alypum L ) (Fig. 37T) ou Sénédes Arabes, est 
un sous-arbrisseau des lieux arides à feuilles grisàtres, coriaces et persistantes, élargies et souvent à trois dents vers le sommet, qui porte toute l'année des fleurs bleues.

Les feuilles, employées à petite dose, donnent une décoction purgative.

\section{CHAPITRE XII}

\section{NOTIONS DE GÉOGRAPHIE BOTANIQUE. - RÉPARTITION DES ESSENCES FORESTIĖRES EN ALGÉRIE.}

La géographie bolunique est l'étude des différentes contrées de la terre au point de vue de la régétation qui les recouvre.

Les espèces ne sont pas répandues indifféremment sur le globe et l'aspect de la végétation varie beaucoup avec les contrées. Le climat, le sol et l'action des êtres rivants contribuent à déterminer cette répartition.

GLIMAT. - On appelle almosphère l'enveloppe gazeuse qui entoure la terre; elle est constituée par l'air ' mélangé de vapeur d'eau en proportion variable. Lorsque la vapeur d'eau est trop abondante, elle se condense et se déverse sous forme de pluie, de neige, de grêle, de rosée, de givre ou de verglas. L'atmosphère est sujette à des variations de température, d'éclairement, d'état électrique; il s'y produit des mouvements qui se manifestent sous forme de vents. De sa manière d'être au point de vue de l'humidité, des pluies, de la température, de l'éclairement, des vents et des orages résulte le climat. Nous distinguerons le climal géographique et le climal local.

Le prenier dépend de la latitude, e'est-a-dire de la distance du lieu à l'équateur; plus on se rapproche de celui-ci, plus le climat est chaud; en se dirigeant vers e pôle, au contraire, on traverse des \%ones de plus en plus froides. Le elimat local résulte surtout de l'altitude et de l'exposition. A mesure qu'on s'élève sur un versant la température devient de plus en plus froide; l'air devient très sec sur la lraute montagne.

1. Voir la note de la page 53. 
Les versants exposés au nord et à l'est, sont les plus humides et les moins chauds; ceux qui font face au sud et à l'ouest sont au contraire desséchés et brûlés par les rayons du soleil. Cette influence de l'exposition diminue à mesure qu'on s'élève dans la montagne.

Le voisinage de la mer augmente l'humidité de l'air et régularise la température; les grands massifs boisés ont le même rôle. La proximité des déserts agit en sens inverse.

La température influe surtout sur la répartition des espèces. tandis que l'humidité détermine le type de végélution. Ces types sont assez nombreux; citons seulement la forêt, les buissons, les prairies. Les régions humides sont les seules où l'on troure des forêts réellement bien développées.

SOL. - La terre végétale est un mélange de terre mincirale et de terreau; elle repose sur le sous-sol. La partie minérale du sol est le résultat de la décomposition des roches : elle peut s'être formée sur place; elle est alors de mème nature que son support; ou bien elle a pu être amenée par les eaux sous forme d'alluvions, ou par le vent sous forme de dunes.

Suivant leur nature, les roches donnent naissance à une terre oủ domine l'argile, le calcaire ou la silice. Rarement on trouve dans la nature un sol composé uniquement de l'un des trois éléments : ils sont en mélange et les noms de terrains argileux, calcaires, siliceux, indiquent simplement l'élément qui, étant plus abondant, attribue ses qualités à l'ensemble.

Les terrains siliceux. formés de sable plus ou moins fin. sont très perméables à l'eau et généralement profonds; ils ont peu de ténacité, ce qui les rend facilement eultivables; quelquefois ils n'offrent pas aux arbres une base d'une solidité suffisante.

Les terrains calcaires, c'est-i-dire riches en chaux, sont souvent pierreux et sans profondeur; ils sont perméables et peu tenaces, mais plus riches en éléments utilisables pour la nourriture des plantes que les terrains siliceux; ils séchaullent vite.

Les terrains argileux sont au contraire imperméables, froids et d'une culture difficile ; desséchée, l'argile devient dure et se crevasse. Si elle est mêlée de calcaire, elle prend le nom de 
marne; deux parties de sable et une d'argile forment le sable gras, très favorable à la forêt. Le mélange des trois éléments constitue la terre firanche.

Le terreau résulte de la décomposition des débris organiques; il corrige les défauts des sols, en conservant la fraìcheur aux uns, en ameublissant les autres; il les colore en noir et leur fournit d'abondants éléments nutritifs.

Le sous-sol influe également sur la qualité d'un terrain : non seulement il détermine la pente de la couche arable qu'il supporte mais, suivant qưil est compact ou fissuré, i] augmente on diminue l'hunidité de celle-ci.

Selon la quantité d'eau qu'ils renferment, les terrains sont dits marécagenx, monillenx, linmides, frais et secs.

La forêt est peu exigeante sous le rapport de la composition de la terre minérale et elle se contente des sols les plus pauvres; c'est de l'abondance du terreau que dépend surtout la qualité d'un sol forestier. L'épaisseur de la couche arable a aussi une grande importance : les sols profonds donnent aux arbres une croissance rapide, des fùts élancés. Un sous-sol fissuré, susceptible d'être pénétré facilement par les racines, peut suppléer au manque de profondeur de la terre végétale.

La composition chimique du sol influe beaucoup sur ba répartition des essences : la chaux est nuisible à certaines plantes quisont localisées sur les terrains siliceux, tandis qu'elle paraìt en attirer d'autres. Le Chène-liège, le Châtaignier. par exemple, sont dits culcifuges, parce qu'ils craignent le calcaire. Le Pin d'Alep au contraire parait préférer les terrains calcaires : il est dit calcicole ${ }^{1}$. 1) autres espèces, le Chène vert par exemple, acceptent les sols de toute composition ?.

On appelle essences sociules celles qui, vivant en grande masse, sont susceptibles de lormer des peuplements d'une seule espèce dits peuplements purs (exemple: Jes l’ins, les Chènes);

1. De même cerlaines plantes dites halophiles sont localisées au hord de la mer où la présence du sel marin soppose à la croissance de la pluparl des espéces de la tlore terrestre.

22. I'elle espece qui ne peut supporter le calcaire "n plaine le tolire bien en montagne ou il pleul davanlage ; les qualites pluysiques des terrains calcaires, souvent secs 't sins profondeur, doivent done aussi entrer en ligne: de comple. 
ce groupe, qui est le plus important, comprend tous les résineux. D'autres espèces ne se rencontrent que par pieds isolés; on les appelle essences disséminées (ex. : l'Orme, le Frène); ce sont les plus exigeantes au point de vue du sol et c'est ce qui explique leur isolement; elles ne peuvent subsister par groupes que dans les terrains très fertiles.

Les espèces sociales sont au contraire frugales, et on les rencontre en abondance dans les terrains pauvres en éléments nutritifs; non seulement elles y constituent la futaie, mais elles se développent abondamment en sous-bois si le couvert est peu épais (Bruyères, Genêts, etc.). La flore des terrains calcaires est beaucoup plus variée comme nombre d'espéces.

AGTION DES ETRES VIVANTS. - Nous nen dirons que quelques mots ; nous sarons déjà que les différentes espèces ont des exigences variables vis-à-vis du sol et que les jeunes arbres ont un besoin de lumière également très variable avecl'essence : de plusil est des espèces arbustives ou herbacées qui peuvent vivre et se reproduire sous le couvert de la futaie, tandis que d'autres exigent le plein découvert; ces dernières sont dites heiliophiles.

La concurrence vitale qui s'exerce entre les diflërents arbres d'un peuplement d'une même essence a dẻjá été mentionnée: elie se produit aussi entre les sujets d'espèces différentes. Les mycorhizes sont plus utiles à certaines essences qu'à d'autres: leur abondance peut intluer sur l'issue de la lutte pour l'occupation du sol !.

Les animaux contribuent particulièrement à la destruction de certaines espèces vẻgétales; ils peuvent au contraire favoriser la multiplication des plantes en transportant le pollen ou en disséminant les graines. L'homme joue un ròle considérable sur lequel il est inutile d'insister.

AIRE. - STATION. - ASSOGIATIONS. - Aux confius des régions glacées du pòle, on rencontre les Bouleaux, les Pins, les Mélézes, etc., occupant des surfaces considerables; dans la zone tempérée, les essences feuillues dominent

1. Diapres Wiener et Stahl. L'utilite des myeorhizes est contestee par d'autres auleurs. 
(Chênes, Hêtres, Charmes, Châtaigniers, Tilleuls, Frênes. Ormes, Peupliers), elles sont à feuilles caduques pour micux supporter les hivers dans l'Europe septentrionale, à feuilles persistantes dans la région méditerranéenne. Dans les pays plus chauds encore, l'aspect change : ce sont les Palmiers, puis les Bananiers et les grands arbres de la forêt vierge qui apparaissent avec les lianes et tout le cortège de la végétation tropicale et équatoriale.

Chaque espèce occupe done sur le globe une surface limitée: c'est son aire ; elle n'y croît d'ailleurs pas uniformément; elle est localisée sur certains points ou stations qui présentent les conditions de végétation qui lui sont favorables.

Une espèce est à l'état spontané dans une région lorsqu'clle y existe sans l'intervention de l'homme. Ex.: le Chêne-liège est spontané en Algérie; les Eucalyptus, au contraire, y ont été introduits ${ }^{1}$. Les espèces qui habitent une même station peuvent être considérées comme formant une association.

L'association est définic par les plantes qui y dominent, mais il suffira souvent de désigner une ou deux des espèces sociales qui s'y trouvent pour donner l'aspect général de la végétation; en forêt, on choisit naturellement comme caractéristiques les arbres appartenant à des espèces sociales.

Certaines plantes accompagnent généralement le Chêne-liège (Bruyère, Arbousier); d'autres ne l'accompagnent que dans une partie de son aire (Myrte). Il en est de même pour chaque cssence; quelques végétaux lui sont invariablement associés, ce sont les conslanles de l'association d'autres habituellement: certains enfin n'existent que dans des conditions spéciales.

Les membres d'une mème association réagissent les uns sur les autres; cette influence, pour être moins apparente dans le règne végétal que dans le règne animal, et surtout que dans les sociétés humaines, n'en est pas moins profonde. L'étude des associations forestières et de leur rapport avec les conditions de végétation est donc d'un grand intérêt pour le forestier; elle constitue une science appelée licologie forestière ou Dendrécologie.

1. Une plante introrluile qui s'èclappe des cultures et se propage sans l'intervention de lhomme esl dile subsponlanic. 
Toute action exercé sur un ou plusieurs membres d'une assoriation végélale se répercule sur les autres espèces qui la constiłnenl. Le forestier doit done, avant d'effectuer une opération quelconque portant sur une partie de l'association, s'inquicter des eflets qui en résulteront pour le surplus de celle-ci.

\section{REPARTITION DES ESSENCES FORES-} TIERES EN ALGERIE. - On divise ordinairement l'Algérie en trois régions :

$1^{\circ}$ Le Tell occupe le versant nord du vaste massif montagneux qui couvre la colonie. C'est le pays de l'Olivier et du Diss (Ampelodesmos lenax).

Le Tell, bien arrosé par les pluies à l'est d'Alger, est beaucoup plus sec et plus cliaud dans l'Algérie occidentale, ou abonde le Palmier nain.

$2^{\circ}$ Les Steppes s'étendent vers le faite du massif, à une altitude de 700 à 1.100 mètres, et constituent la région des Hauls Platenur, beaucoup plus nette vers l'ouest que dans le département de Constantine. C'est le pays de l'Alfa.

3o Le versant méridional du massif forme le Sahara algérien, caractérisé par la culture du Palmier-Dallicr.

Les principales montagnes de l'Algérie se groupent en deux chaines: l'Allas sularién ou Grand Allas, qui s'étend sur la limite suddes Hauts Plateaux, et l'Atlas Tellien ou Pelil Allas, qui occupe une partie du Tell et forme un bourrelet à la limite nord des Hauts Plateaux.

C'est dans le Tell et sur les clraînes de montagnes que se trouvent les forêts; les steppes de l'Oranie et les plateaux de Sétif sont déboisés; il faut cependant citer dans les steppes le Pistachier de l'Atlas qui forme les forêts des Dayas.

L'essence algérienne la plus importante au point de vue économique est le Chêne-liège : cet arbre croît surtout sur les terrains paureses en calcaire de l'est de l'Algérie ${ }^{1}$, il occupe surlout le littoral, de Dellys au cap Serrat en Tunisie, et s'étend au sud jusque vers Constantine, Guelma et SoukAhras.

Dans l'ouest, le Chêne-liège a moins d'importance; les pluies

1. En particulier sur les grès numidiens. 
ne sont pas assez abondantes. Encore assez répandue aux environs de Cherchell, cette essence ne constitue en Oranie que quelques petits massifs souvent mêlés d'autres essences, l'un à Guedara, non loin d'Oran, les autres sur les versants nord des montagnes de la région de Tlemeen et de Mascara.

Ce Chêne s'élève quelquefois, dans la colonie, à 1.300 mètres d'altitude, mais il ne prospère en général que jusque vers 1.000 mètres.

Le sous-bois de la forêt de Chène-liège est d'ordinaire haut et serré; la Bruyère en arbre, l'Arloousier, les Philarias, y dominent avec des espèces de moindre taille telles que les Cytises, les Genèts et les Cistes. Le Myrte est abondant sur le littoral de l'Algérie orientale.

Le Pin marilime forme quelques petits massifs englobés dans les forêts de Chène-liège depuis le cap Cavallo (près Djidjelli) jusqu'en 'Tunisie; on rencontre aussi le Chàluignier à l'Edough (près de Bòne).

Le Chène Kermès existe sur tout le littoral, généralement à l'état de broussailles.

Le Chêne zéen se mélange au Chêne-liège dès le bord de la mer; mais e'est dans les stations humides de la moyenne montagne, vers 1.000 mètres, qu'il constitue surtout des massifs importants; il est quelquefois mêlé de Chènes A furès. Cette dernière espèce n’existe en abondance que dans la Kabylie du Djurdjura (ou Grande Kabylie) et dans la Kabylie des Babors (ou Petite Ḱabylie), mais on la rencontre, à l'état disséminé, jusqu'à la frontière tunisienne.

Le sous-bois est très réduit sous l'épais ombrage du Zèen, et on ne tronve souvent sous la futaie de ce Chène qu'un tapis de feuilles mortes; les espèces ligneuses, et en particulier la Bruyère, lorsque l'altitude le permet, sont plus développées sous le couvert de l'A farès.

Le Chene verl est aussi un arbre de montagne, mais il est moinsexigeant que le Chêne Afarès, et surtout que le Chène zéen sous le rapport de l'humidité; il ne demande pas comme ce dernier un sol profond et s'accommode des terrains calcaires ou siliceux. Il est souvent mêlé au Pin d'Alep et peut exister en sous-étage dans les forèts de cette essence.

Le Pin d'Alep habite surtout les sols calcaires et est en 
général répandu à des altitudes plus basses que le Chêne vert. Il abrite d'ordinaire sous son couvert un tapis de Cistes et de Romarins parsemé de Genévriers, de buissons de Lentisques, etc.

Le Pin d'Alep et le Chêne vert occupent une place très importante dans la partie méridionale du Tell et dans l'Atlas saharien.

Le Thnya d'Algérie tend à se substituer au Pin d'Alep à mesure que l'on s'éloigne d'Alger vers l'ouest; il est surtout important en Oranie.

Les Genévriers Oxycèdre el de Phénicie sont également abondants dans cette dernière région, dans le sud des Hauts Plateaux et dans l'Atlas saharien.

Des espèces buissonnantes, parmi lesquelles domine le Lentisque, accompagnent l'Olivicr, très répandu en dehors des forêts. Le Frêne, le Caroubier, les Peupliers blanc et noir, le Figuier, le Micocoulier, existent à l’état disséminé dans le Tell.

Enfin le Cèdre est spontané dans la haute montagne (audessus de 1.200 ou 1.400 mètres). Dans le département de Constantine cet arbre forme d'importantes forèts dans l'Aurès, le Belezma, les Maadids; il occupe le sommet du Babor, du Tababor et de quelques pies voisins. Dans le département d'Alger, le Cèdre s'étend sur le Djurjura d'Azerou ev' Tohor, près Tirourda jusqu'au Drâ Inguel qui domine Boghni, puis constitue un petit massif au-dessus de Blida et enfin la forèt renommée de Teniet-el-Haad. On rencontre encore cette essence à l'état d'arbres isolès sur une crête de l'Ouarsenîs, mais le Cèdre manque dans le département d'Oran, on ne le retrouve vers l'Ouest que sur les montagnes du Maroc; on trouve avec lui plus ou moins répandues des espèces d'Europe telles que: l'If, le Houx, l'Amélanchier, des Sorbiers, des Érables, l'Épine-vinette, un Cotonéaster, et mème, dans les Babors, le Peuplier tremble et le Sapin de Numidie. 


\section{CHAPITRE XIII}

\section{USAGE DES TABLEAUX DE LA FLORE. - HERBIERS.}

\section{USAGE DES TABLEAUX DE LA FLORE. -} On appelle flore d'une région l'ensemble des plantes croissant dans cette région. Par extension, on applique ce terme aux ouvrages qui renferment la description de ces plantes ou tout alt moins des tableaux ou clefs permettant de les déterminer, c'est-à-dire de trouver leur nom.

Les tableaux servant à la détermination des plantes peuvent ètre établis sur des modèles assez différents; nous prendrons pour type ceux qui sont donnés dans la suite de cet ouvrage.

La détermination d'une espèce doit se faire en principe à l'aide d'échantillons comprenant, outre les rameaux et les feuilles, des flenrs et des fruils. Le nombre des plantes ligneuses de l'Algérie n'étant pas considérable, on pourra souvent utiliser cette flore sans être muni d'échantillons aussi complets; toutefois, il est nécessaire de recommander aux débutants de n'utiliser que de bons échantillons pour leurs premières déterminations, et de laisser tout d'abord de côté les espèces qui présentent des fleurs très petites ou difficiles à étudier. Il est même très utile de s'accoutumer à la lecture des clefs à l'aide de plantes dont on connaît le nom à l'avance.

Supposons qu'il s'agisse de ehereher le nom du Merisier' que nous avons déjà pris comme exemple. Il faudra d'abord consulter la Clef générale (page 209). Nous y lisons dans la première colonne à gauche les questions suivantes :

+ Fleurs ayant des étamines avec ou sans pistil.

+ Fleurs ayant un pistil mais pas d'ilamines.

Nous avons le choix entre les deux questions; le Nerisier possède des lleurs ayant des étamines; nous adoptons done la première question; en face est une accolade avec deux nouvelles interrogations : nous continnons comme précédemment en remarquant que la lleur du Merisier a de'ux cinceloppess florales de couleur el de consistunce differenles, que sa corolle liest pas papilionace'e, que ses fleurs ne sonl pas groupées en 
capitules et que ses pétales sont séparés jusqu'à la base; nous lisons alors à droite du tableau section II, page 214.

Nous nous reportons à la page 214 et, suivant dans le nouveau tableau la même marche que dans le premier, nous sommes amenés à lire à droite de la page : Rosacées, page 262, ce qui signifie qu'il s'agit d'une plante de la famille des Rosacées.

Cherchant alors la page 262 , nous y appliquons le procédé déjà expliqué, et d'accolade en accolade nous arrivons finalement en face des mots Cerrasus Avium, dont le nom français est Merisie ${ }^{*}$. Les initiales placées à côté $T . F$. indiquent que la plante existe en Tunisie et en France. Au-dessous du nom est indiquée la répartition de l'espèce en Algérie.

La plante esl délerminée.

Remarquons encore à droite du nom latin du Merisier et des renseignements sur sa répartition les indications (p. 149). (fig. 296), et reportons-nous aux endroits indiqués dans la première partie de la Flore. Nous y trouverons des renseignements sur l'espèce et une figure permettant de complèter lidentification.

Toute autre plante ligneuse du Tell ou des Hauts Plateaux pourra être étudiée de la même façon.

A défaut de lleurs et de fruits, les espèces importantes pourront encore être déterminées à l'aide de la deuxième clef donnée à la page 289 et qui est baséc uniquement sur les caractères des organes végétatif's, c'est-a-dire de la tige, des rameaux et des feuilles.

Enfin la troisième clef (page 305) permet la détermination des espèces à feuilles caduques pendant l'hiver.

Lorsqu'on a acquis une certaine habitude, on reconnait le plus souvent, après un coup d'œil jeté sur la fleur, à quelle lamille appartient la plante. Il suffit alors de chercher directement la page où est étudice cette famille.

Si un doute existe entre deux familles roisines, on se reportera au lablean abrégé des caractères des fanilles (page 323).

1. Cerasus Avium signifie Cerisier des Oiseaux, mais le nom latin $11^{2}: 1$ pas toujours été traduit littéralement lorsqüil existe une autre dénomination française plus connue ou plus liacile à retenir. 
REGOLTE DES ÉGHANTILLONS. - Il n'est pas toujours possible d'étudier la plante sur le licu même où elle croît; il faut alors emporter soit un ramean, soit même la plante tout entière, si elle est de petite taille. L'échantillon doit autant que possible porter à la fois des fleurs et des fruits. Si la plante est dioïque, il est préférable de recueillir deux rameaux, l'un mâle, l'autre femelle.

Si l'on veut récolter un certain nombre de plantes au cours de la même excursion, il faut les numéroter au fur et à mesure à l'aide d'une petite étiquette et noter sur un carnet en face du numéro de chaque plante; la date et le lien de récolte, la station (forêt, haie, prairie, bord d'un chemin, etc.), l'altitude, l'exposition, et, si possible, la nalure du sol.

Les échantillons sont placés dans une boite en fer-blanc que l'on porte en sautoir; elle doit être peinte extérieurement d'une couleur claire et vernie, afin d'empêcher les plantes de se llétrir sous l'action de la chaleur.

Il est bon, en été, de placer une éponge humide au fond de la boîte.

On peut encore placer les échantillons dans un cartable, sorte de grand portefeuille renfermant du papier et serré par deux courroies. Les plantes sont disposées une à une entre les leuilles de papier et fortement comprimées à l'aide des courroies.

PRÉPARATION DES PLANTES. - Si l'on veut comparer les plantes entre elles, les étudier et les revoir á loisir, il faut les conserver. Le plus simple est de les sécher. Dans ce but, on les place dès le retour dans des feuilles de papier (du papier jaune ou papier paille par exemple).

Sur la première feuille contenant un premier échantillon, on met quelques feuilles vides placées l'une dans l'autre el disposées en sens inverse. Au-dessus de ce coussin, on pose une nouvelle feuille contenant un échantillon, et ainsi de suite. Enfin on met sur le paquet une planche et une grosse pierre ou despoids. On peut encore établir une presse en serrant les échantillons et les coussins entre deux planches à l'aide de sangles ou de courroies; cette presse ressemble à un cartable; on trouve d'ailleurs daus le commerce des presses plus perfectionnées et plus légères. 
Chaque jour, on étale les feuilles contenant les plantes et les coussins pendant une heure dans un endroit sec, puis on remet en tas et on continue ainsi jusqu'à complète dessiccation des échantillons.

Si l'on fait sécher les plantes dans du papier buvard, il est bon d'avoir un double jeu de coussins et de remplacer chaque jour, au début de la dessiccation du moins, les coussins humides par les coussins secs. Les premiers, sẻchés au soleil ou au feu, serviront à remplacer, le lendemain, les seconds devenus humides.

Herbiers. - Les plantes sèches sont mises en herbier, c'est-à-dire rangées dans des cartons contenant un nombre variable de feuilles d'un même format $(45 \mathrm{~cm} . \times 28$ centim. par exemple) garnies de plantes. On peut laisser l'échantillon dans la feuille qui a servi à le sécher ou le placer dans une autre feuille plus propre; souvent on le fixe sur la 'feuille à l'aide de bandelettes de papier gommé (ajouter un peu d'acide phénique dans la gomme pour éviter les moisissures); une étiquette collée au coin du papier, d'ordinaire en bas et à droite, porte le nom de la famille de l'espèce et les renseignements recueillis sur le terrain. Exemple:

\section{CUPULIFERES}

Quereus Suber L.

Chêne-liège.

Récolté le 15 avril 1909 , dans la forêt de

Mizrana, région de Dellys (Ḱabylie),

à l'altitude de 600 mètres, exp. nord, sur Grès numidien.

Chaque feuille double ne doit contenir qu'une espèce, mais elle peut renfermer plusieur's échantillons de la même espèce séparés par des feuilles simples ou fixés sur celles-ci. Les leuilles sont classées dans l'ordre de la llore, et l'on inscrit surchaque carton le nom des groupes auxquels il est consacré.

Les plantes sont assez rapidement mangées par les insectes; 
on évitera cet inconvénient en mettant dans les cartons ou dans l'armoire qui les renferme de la naphtuline, du camplure ou de l'acide phénique.

Souvent on empoisonne les plantes en les trempant dans une solution de sublimé corrosif dans l'alcool ( 40 grammes de sublimé par litre d'alcool). On peut encore soumettre les paquets de plantes aux vapeurs du sulfure de curbone, mais un matériel spécial est nécessaire, sinon ces vapeurs peurent s'enflammer et produire une explosion.

Les fruits ou les inflorescences sont quelquefois trop rolumineux pour ètre placés dans l'herbier (cône de Pin, etc.) : il faut alors en faire une collection séparée. Les fruits pulpeux ou charnus peurent se conserver dans l'alcool.

Les collections de graines, de bois ${ }^{1}$, de produits végétaux divers, présentent également un grand intérèt pour le forestier. Les morceaux de bois sont débités sur un modèle uniforme, puis polis. Les graines et certains produits végétaux se conservent dans des tubes ou des flacons étiquetés.

1. Voir pour la détermination des bois, la clef de la page 313. 



\section{DEUXIENE PARTIE}

\section{TABLEAUX SYNOPTIOQUES HLUSTRES}

$1^{\circ}$ Clef permettant la détermination de toutes les espèces ligneuses munies d'organes de reproduction. . . . .

2o Clef permettant la détermination des principales espèces ligneuses à l'aide des caractères des rameaux et des fenilles.

$3^{\circ}$ Clef permettant la détermination en hiver des arbres et de la plupart des arbrisseaux à feuilles caduques.

40 Clef permettant la détermination des principaux bois indigèues. . . . . . . . . . . . . . . . 313

50 Tableau sommaire des caractères des familles. . . . 323

Nota - I é signe + placi à côté des noms de familles, genres ou especes indique que lon se Ironse an presenee de plantes introluites, ciost-à-dirr nappartenant pas a la llowe ligneuse spontanere de lidgeric

Les lettres T. MI. F. situeses à la suite dü nom français indiquent que la plante se rencontre aussi en Tunisie ( $T$ ', au Maroc $M$ et en France $F$

Des indications entre parentheses ( ) placées à còté der noms des especes renvoient au texte et aux ligures de la premicre partie. 
;

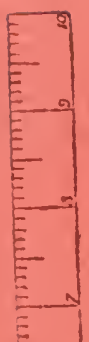

E

E

$E$

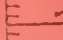

E

E

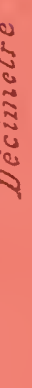




\section{PREMIERE CLEF}

\section{TABLEAUX SYNOPTIQLES IILUSTRES}

POUR LA DÉTERMINATION DES ESPÈCES LIGNELSES DE L'ALGÉRIE

EN CTILISANT LES CARACTĖRES DES

FLEURS ET DES FRUUTS 



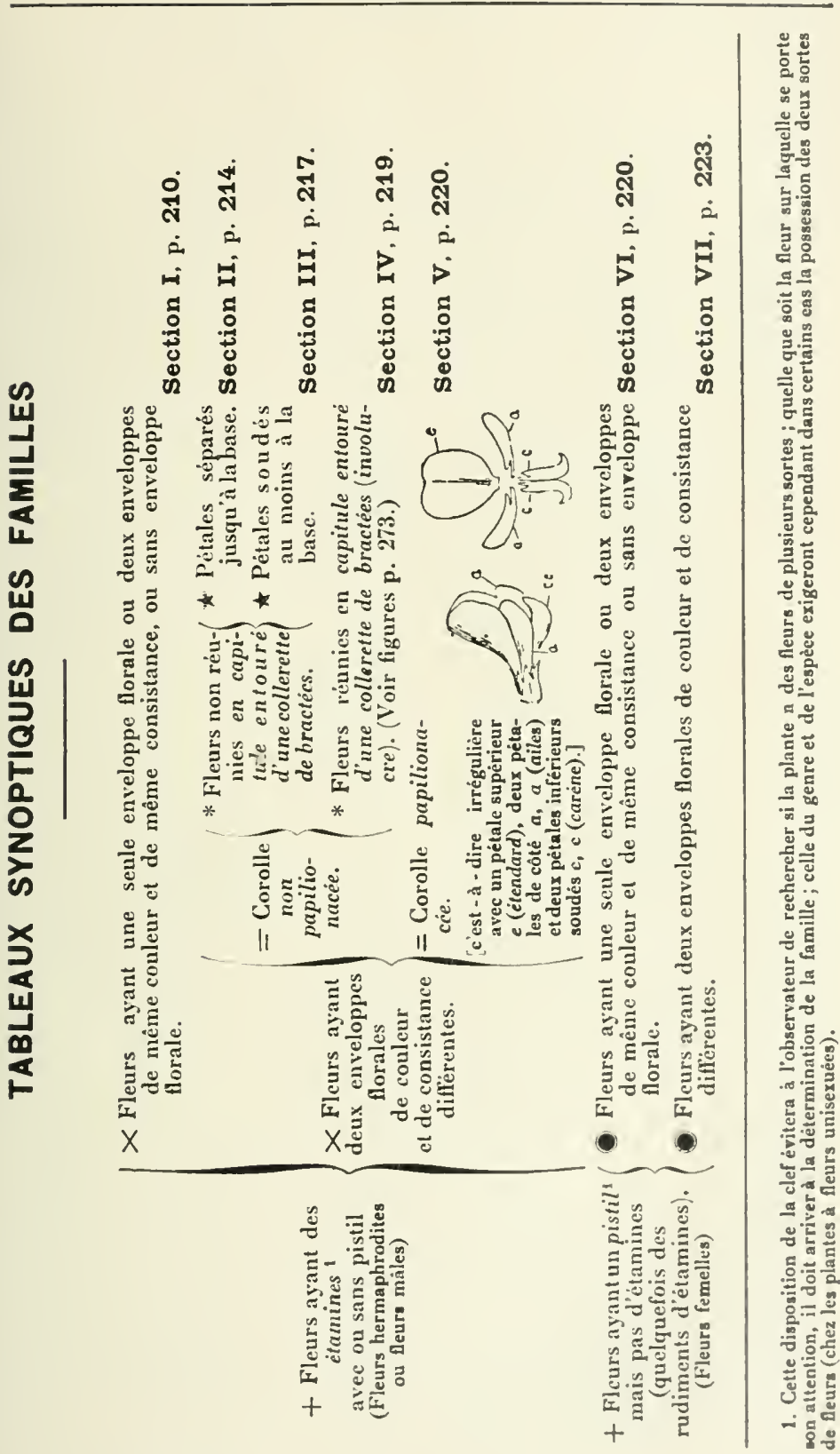

FLORE FORESTIÈHE. 


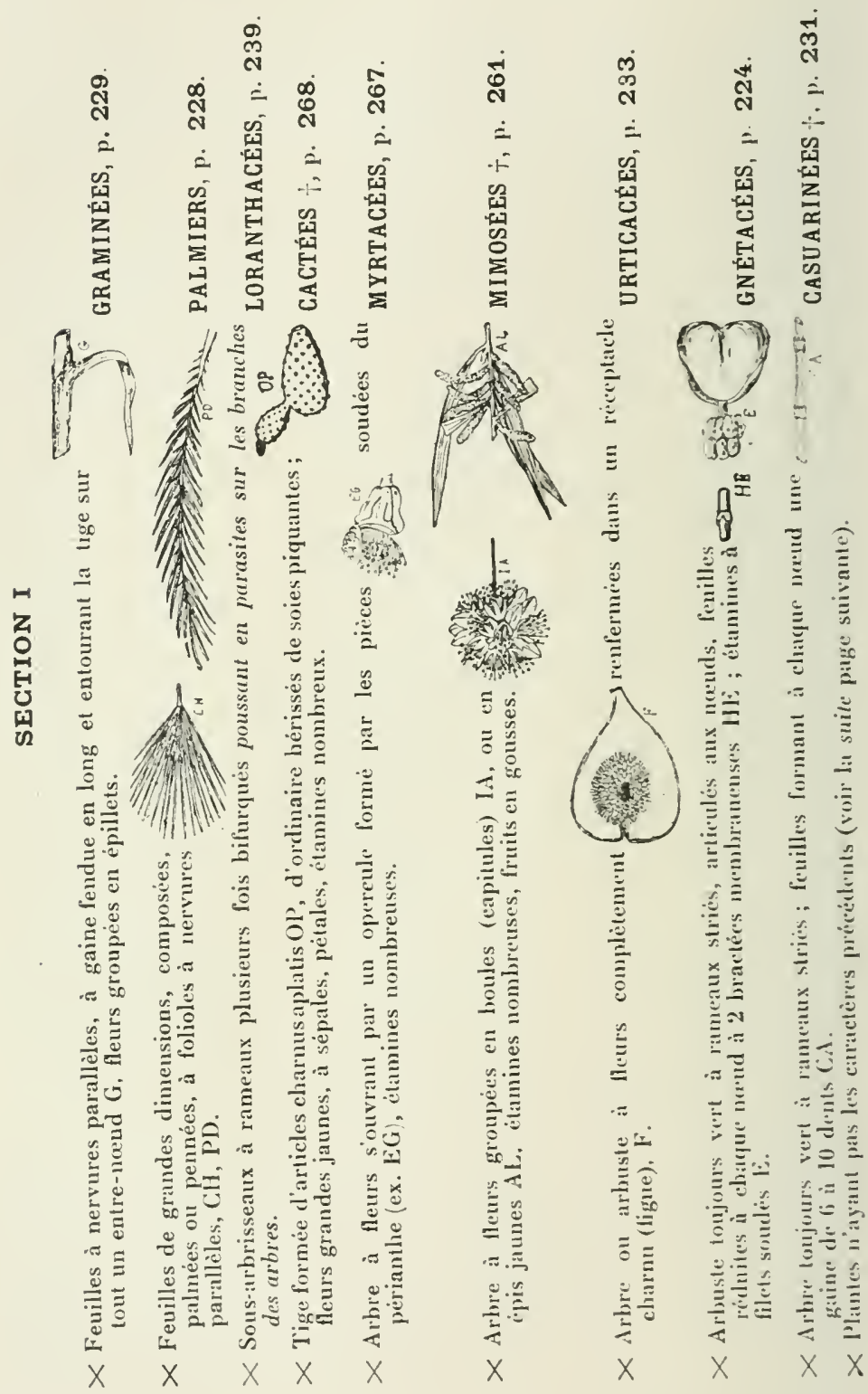




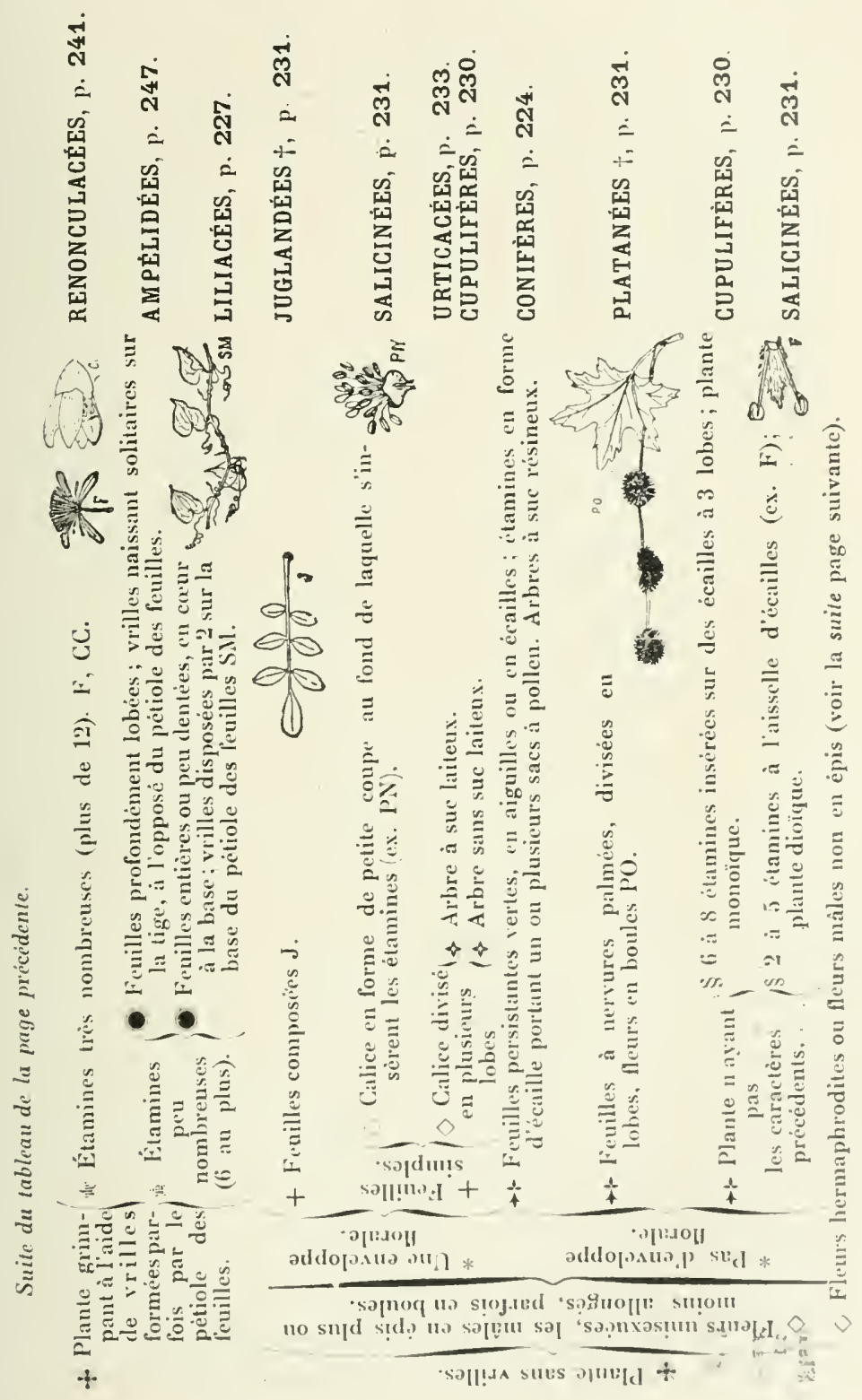




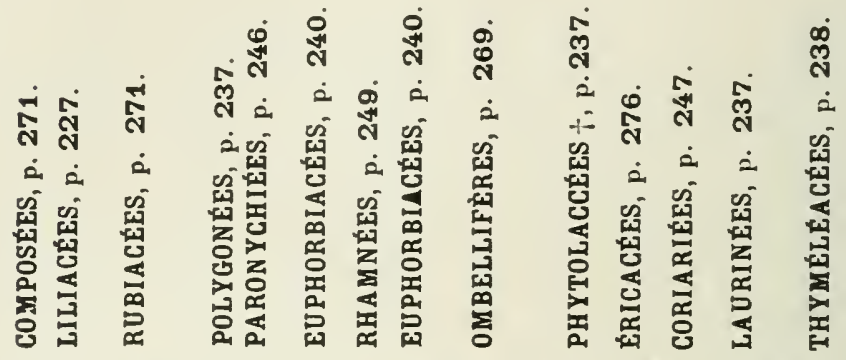

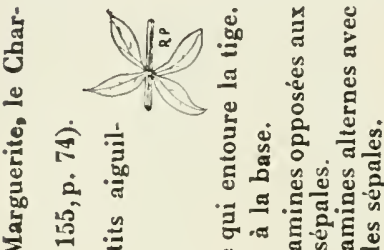

वे व

ज㱐

है

e

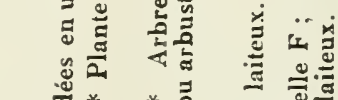

ฮัँ

วิ

ॠ

:

ב

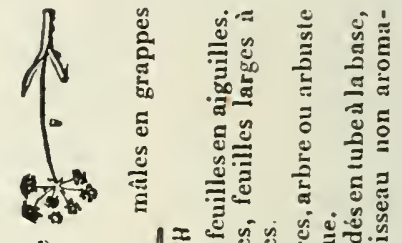

巳

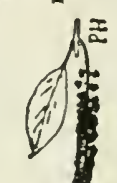

एक में

苞 งั. हَّ

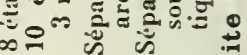

\section{* *}

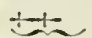




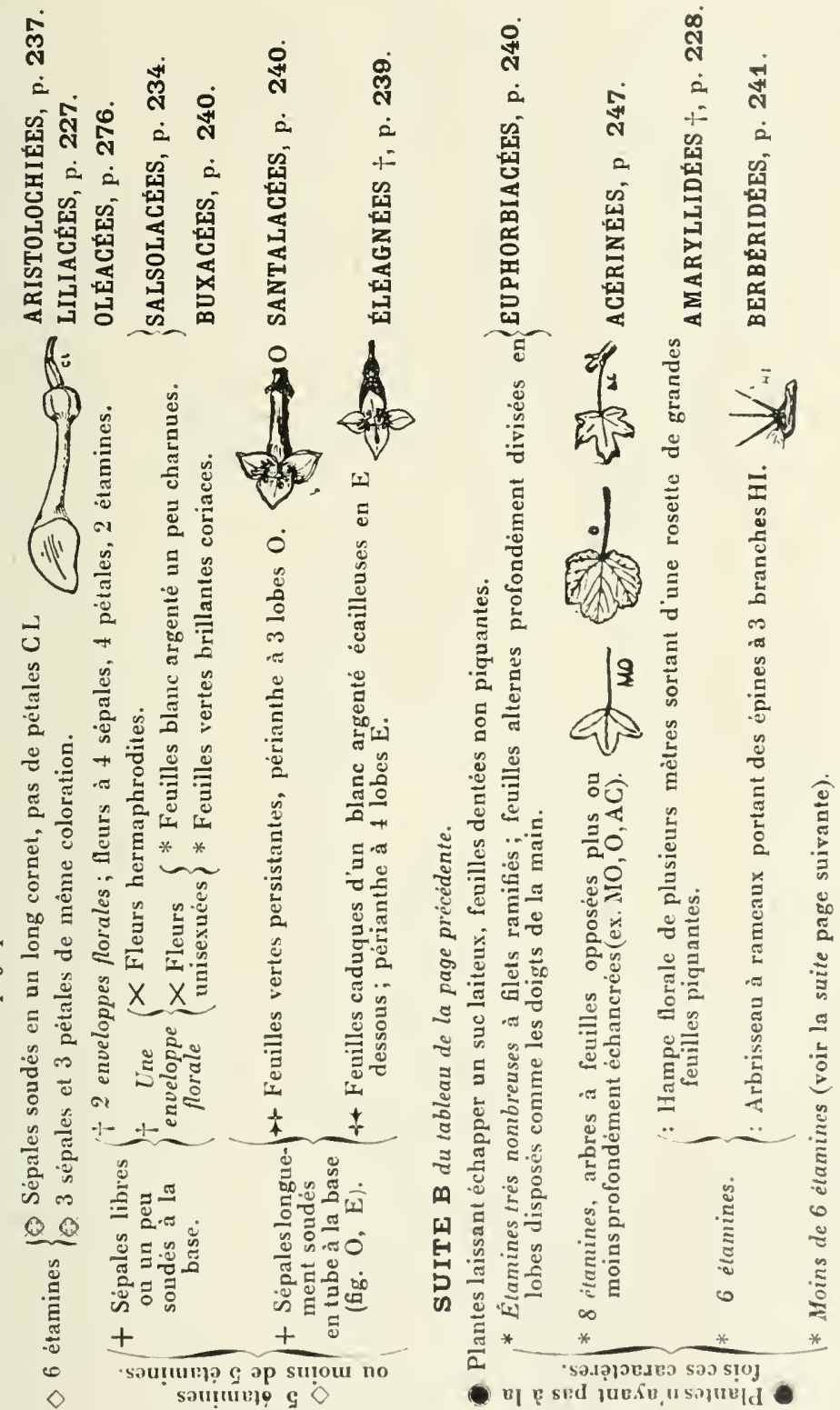




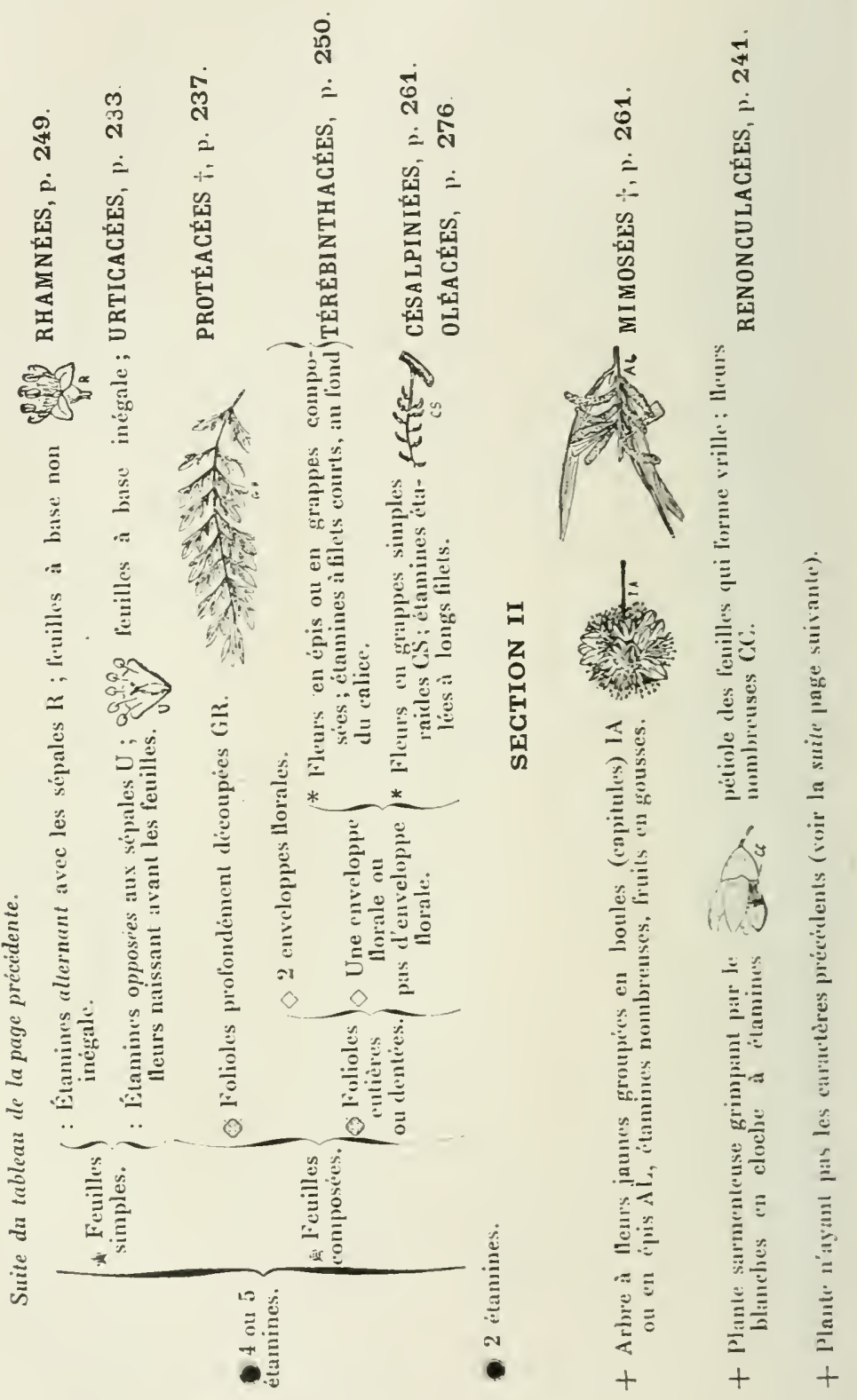




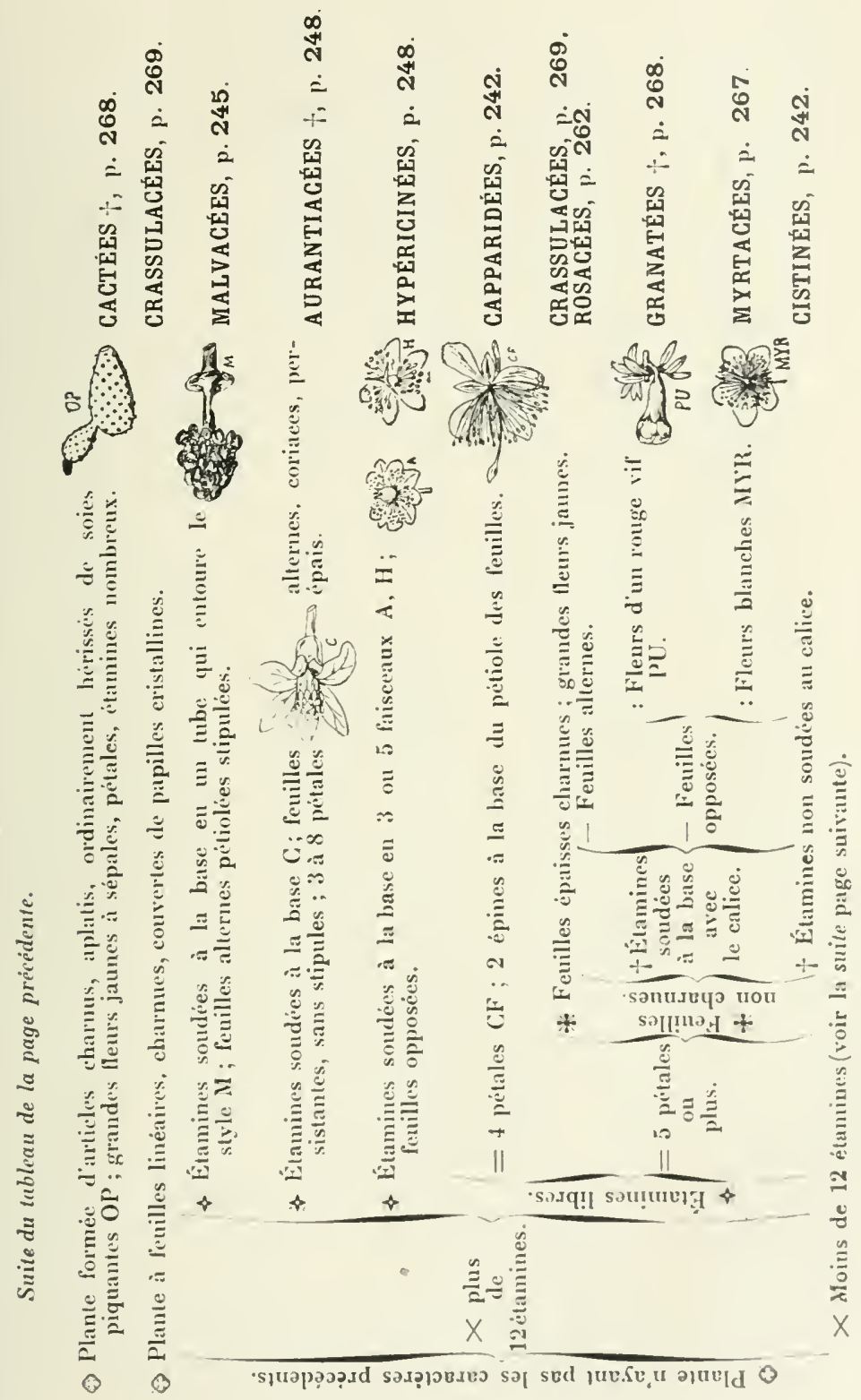




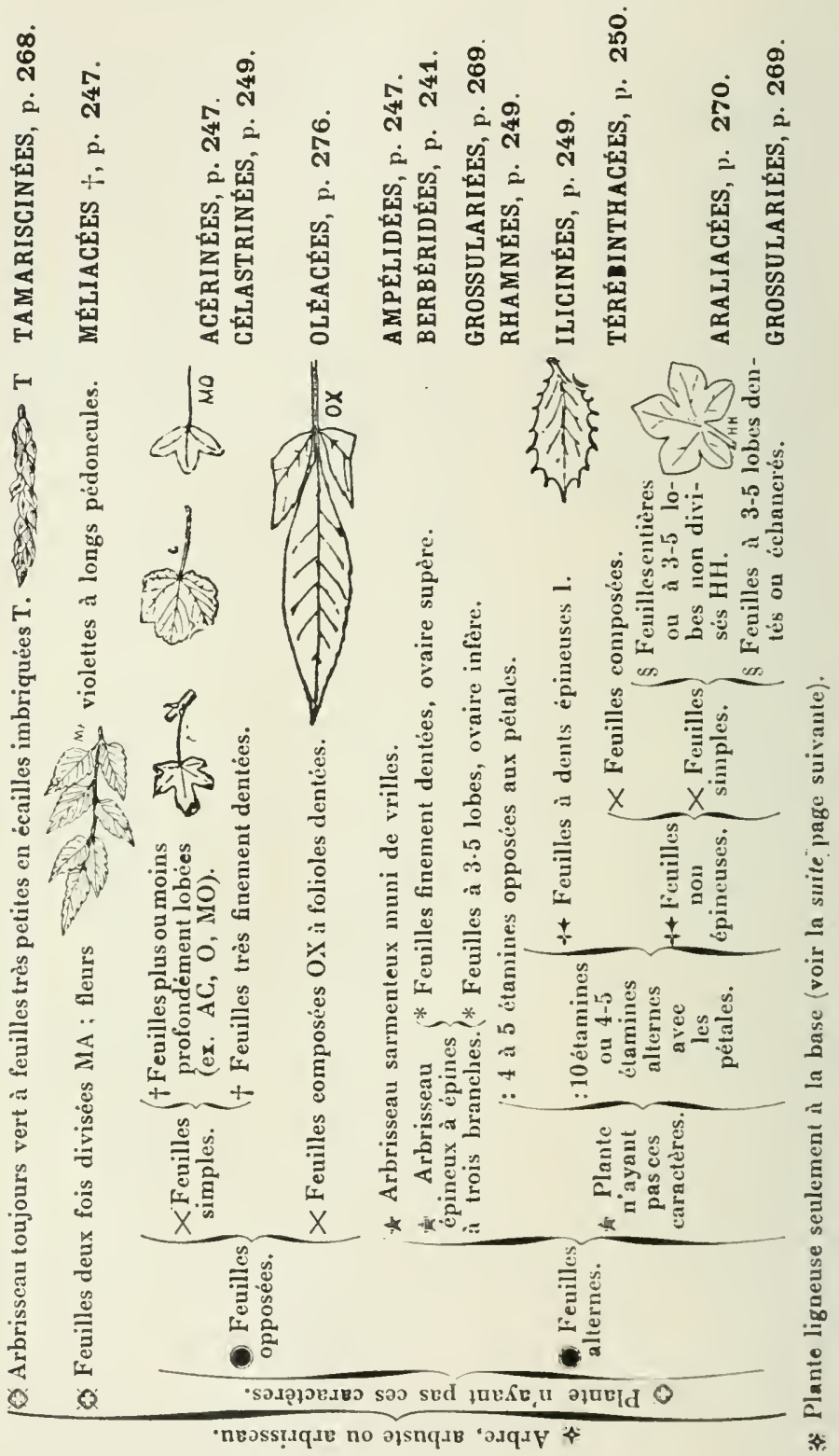




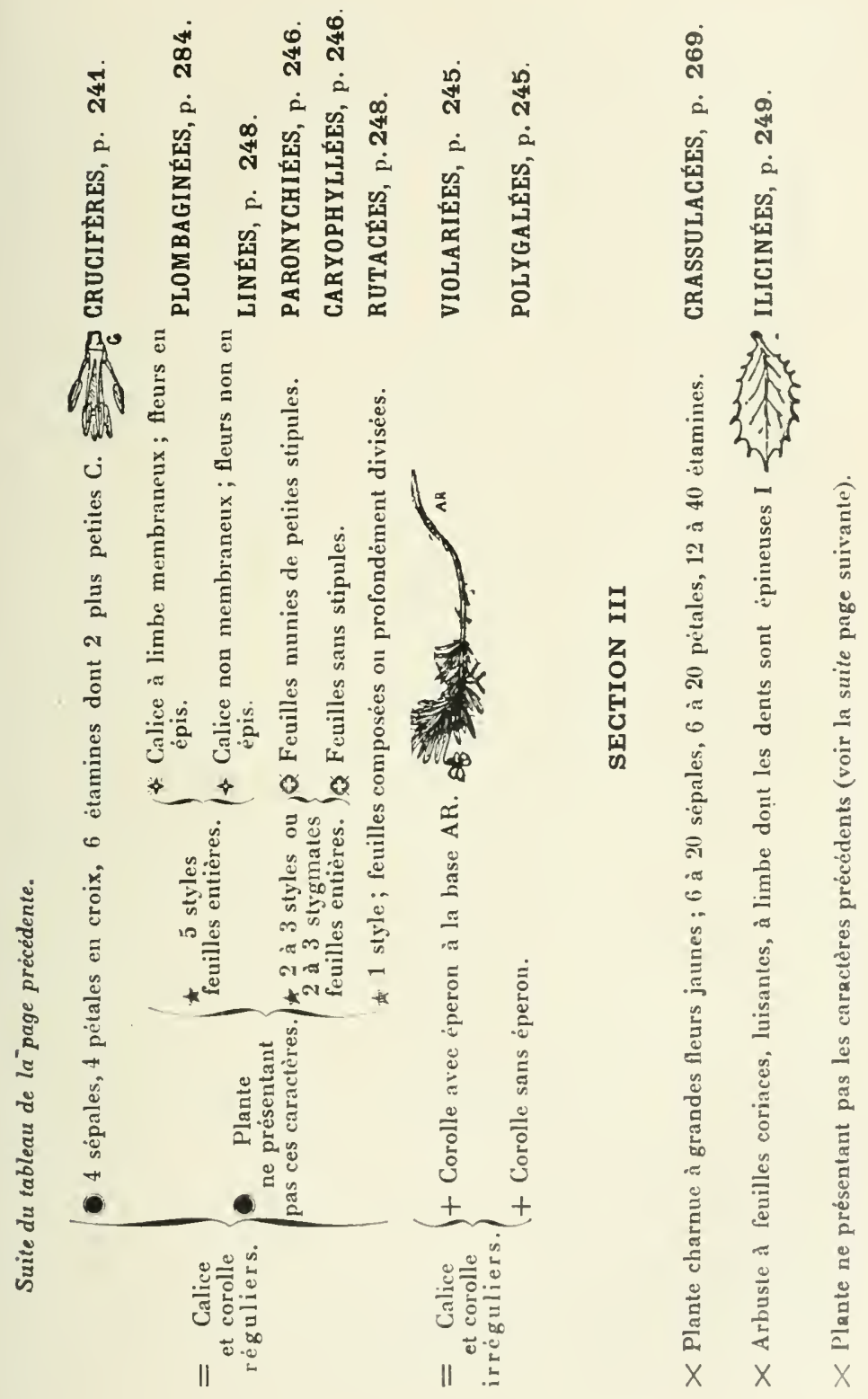




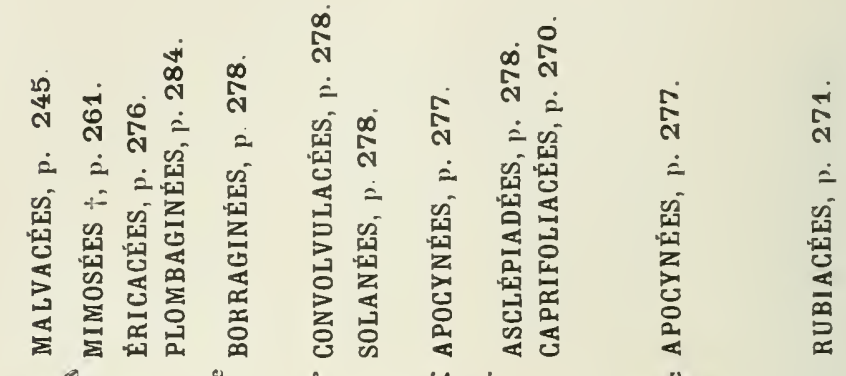

$$
\text { 章 }
$$
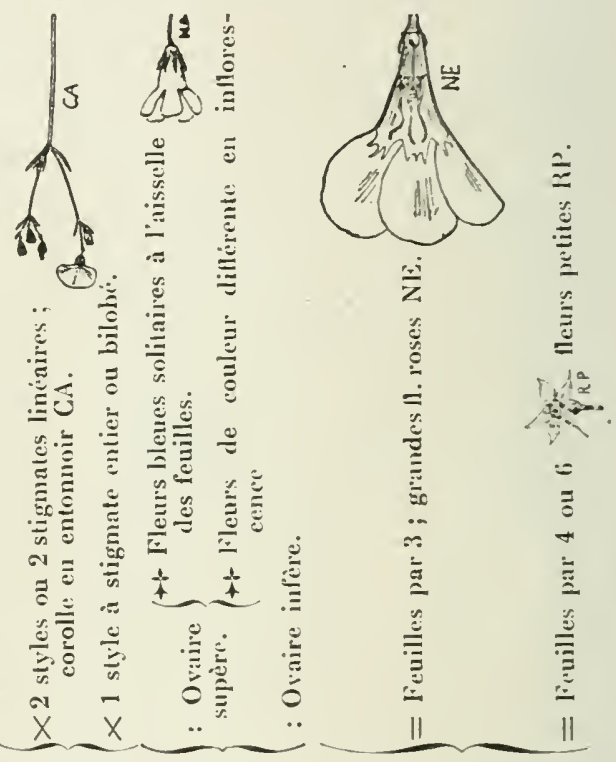

ב⿱艹

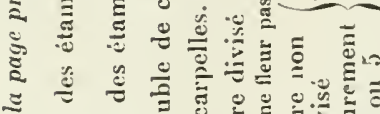

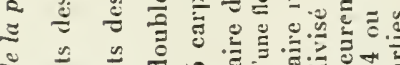

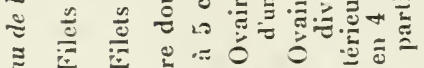

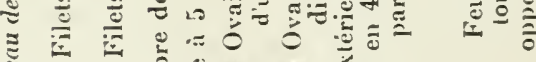

苋 $\cdots$

$\equiv$

¿
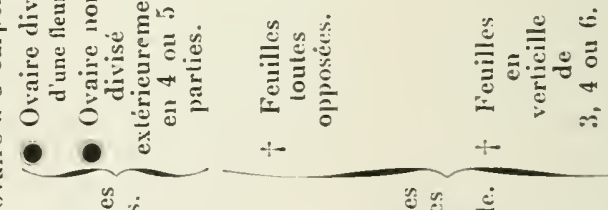

$=$

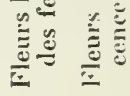

$+\frac{1}{4}$

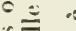

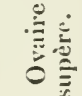

. 


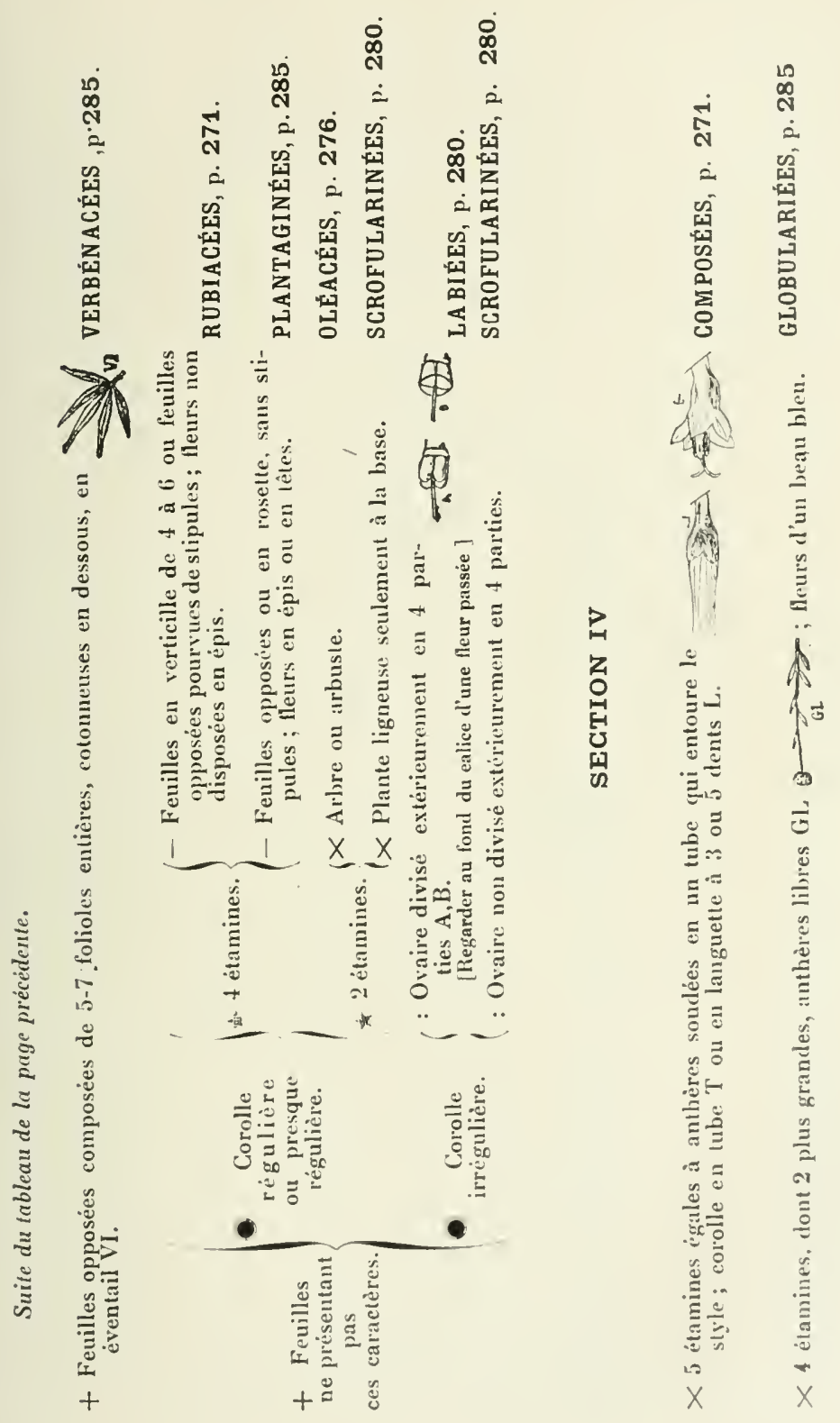




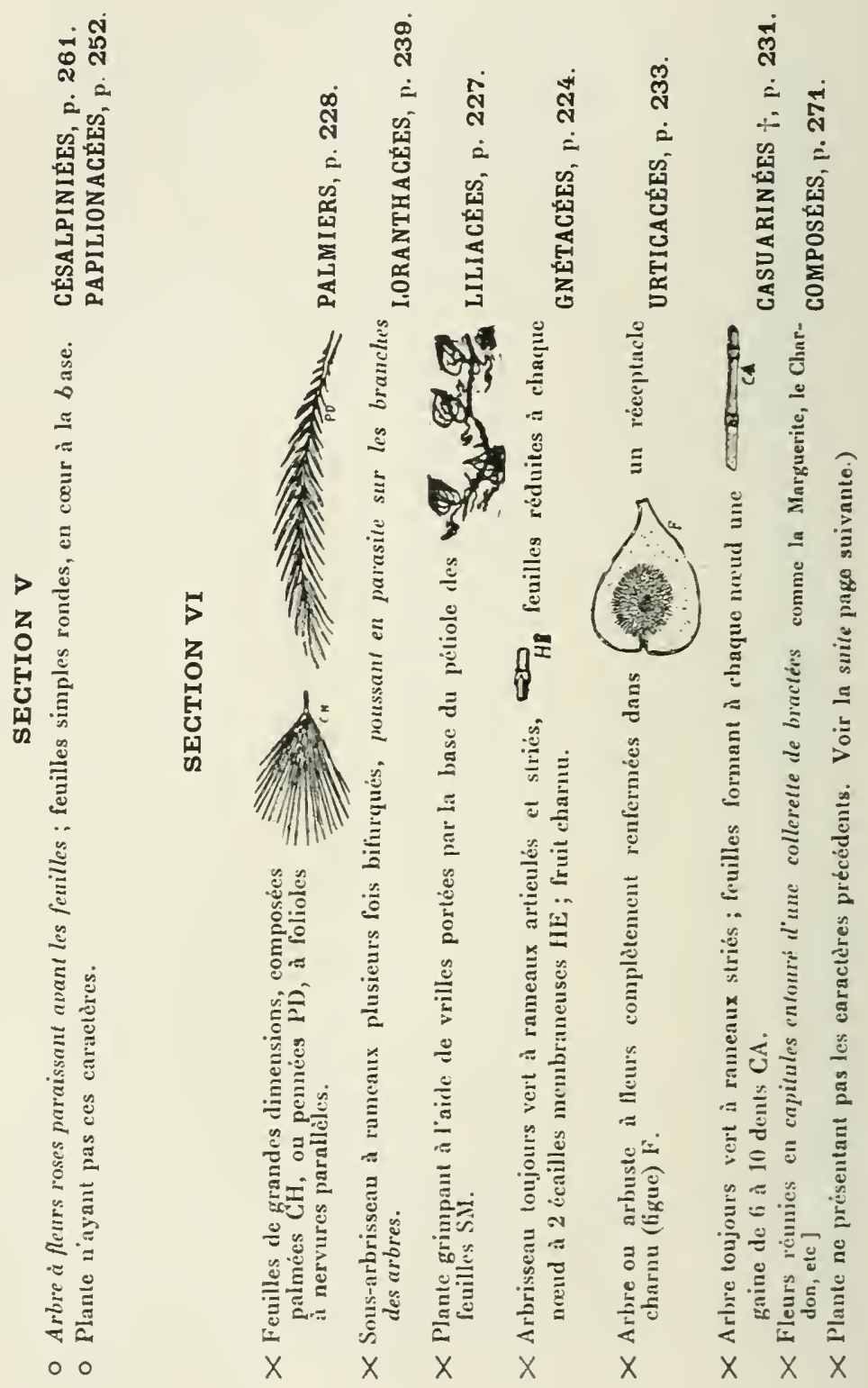




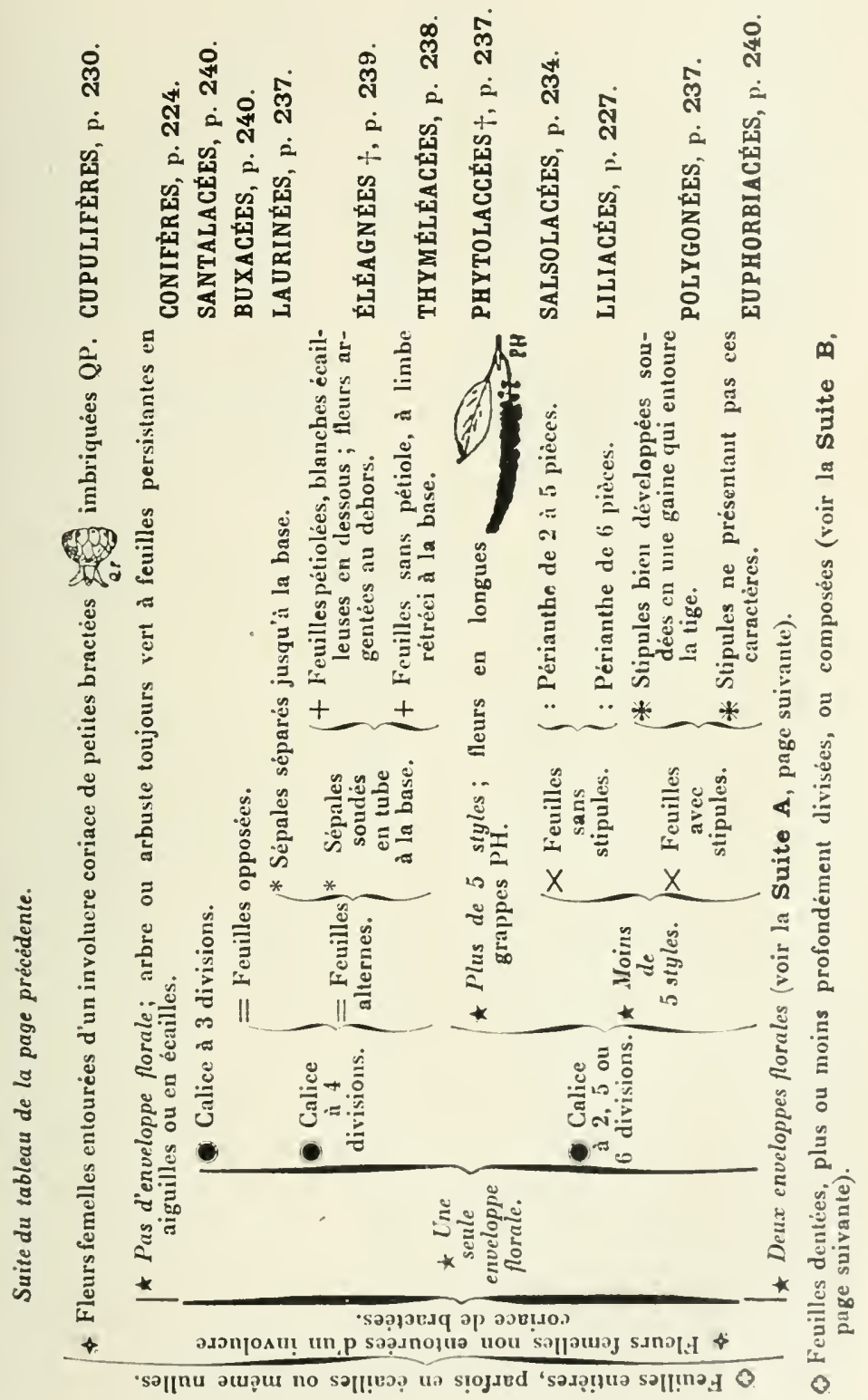



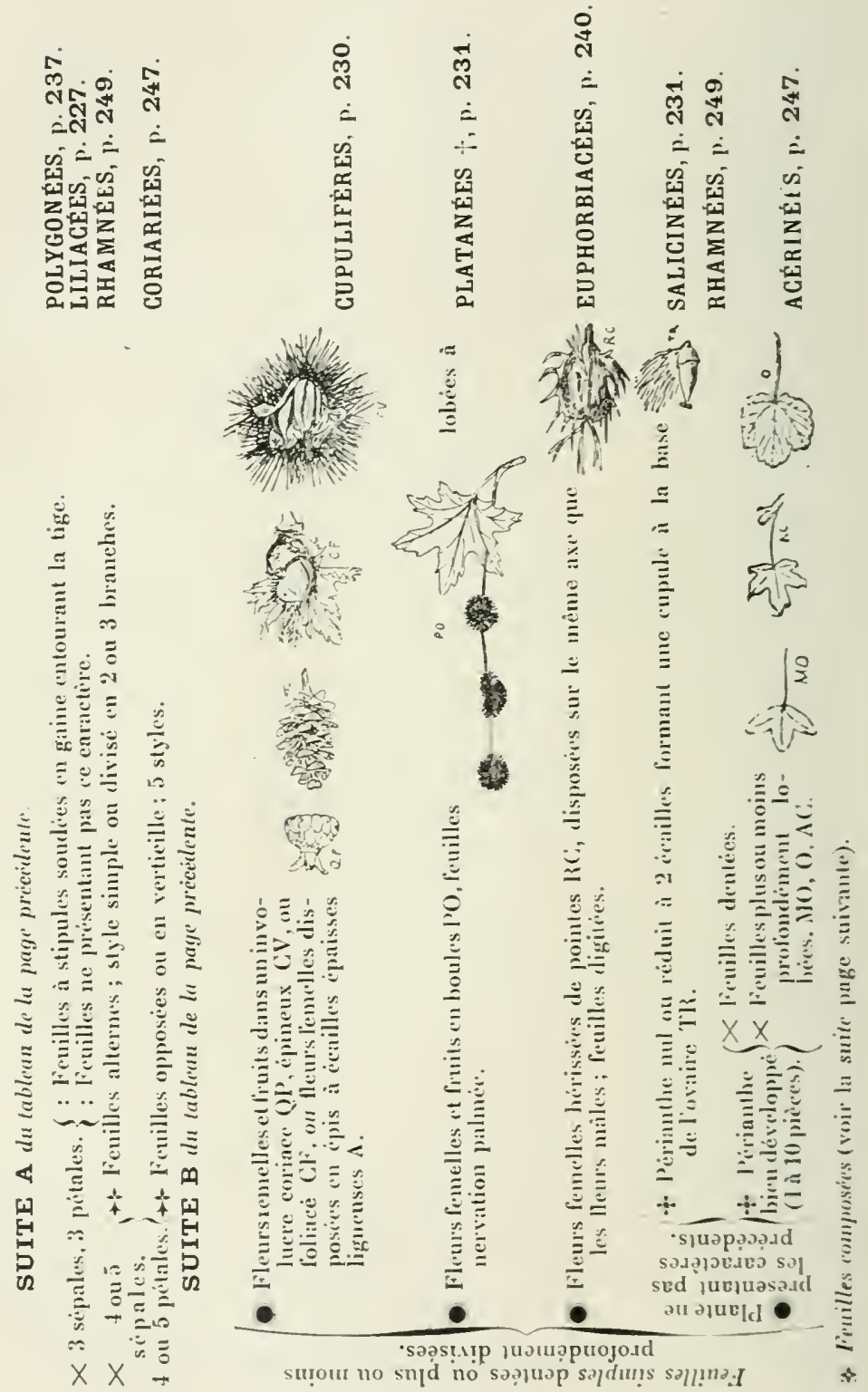

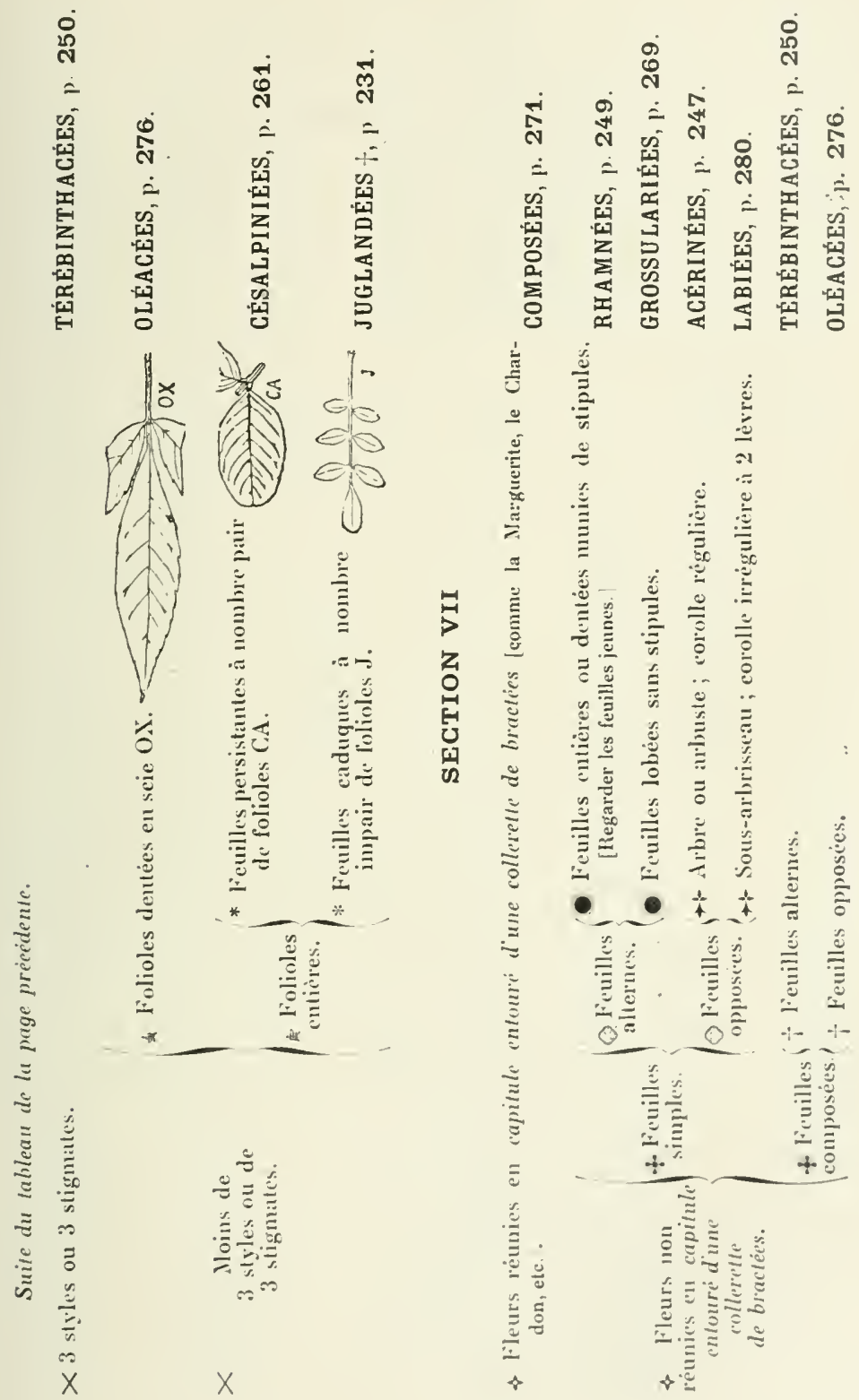


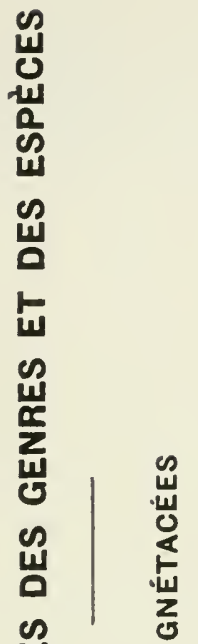

형

ث. क्षै

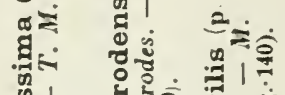

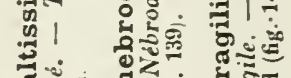

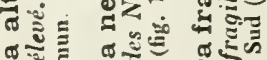

ซี

बํํㅇ

둥응

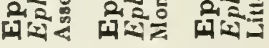

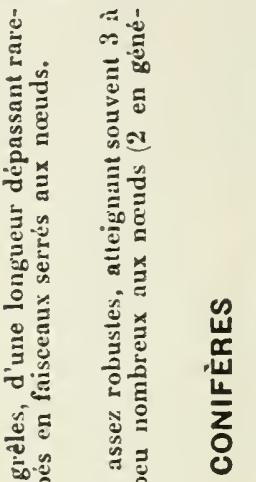

$\dot{8}$

2

产

$\stackrel{0}{=} \stackrel{0}{x}$

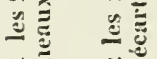

豆

ఏํ..

$\infty$

ज行

ำ

3.

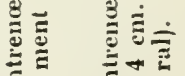

1 i

है

胥

*

*

产응 范

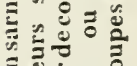

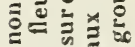

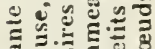

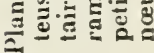
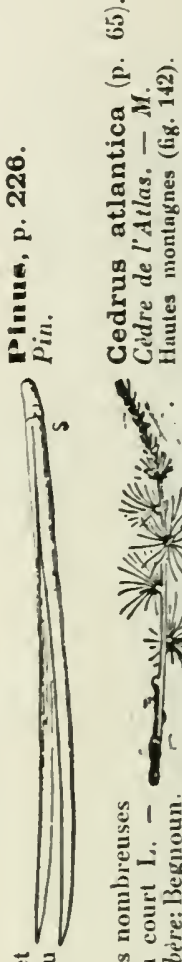

1

पivi

vet

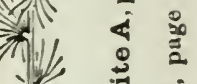

源

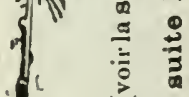

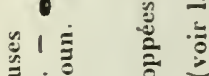

¿

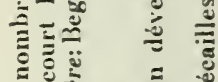

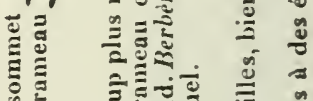

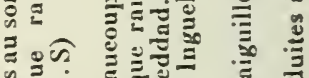

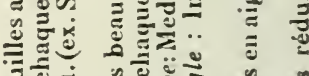

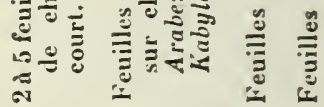

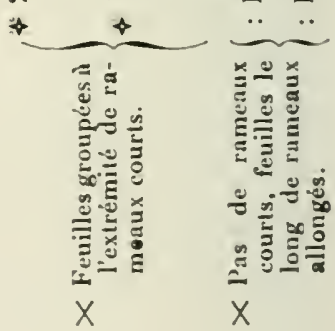




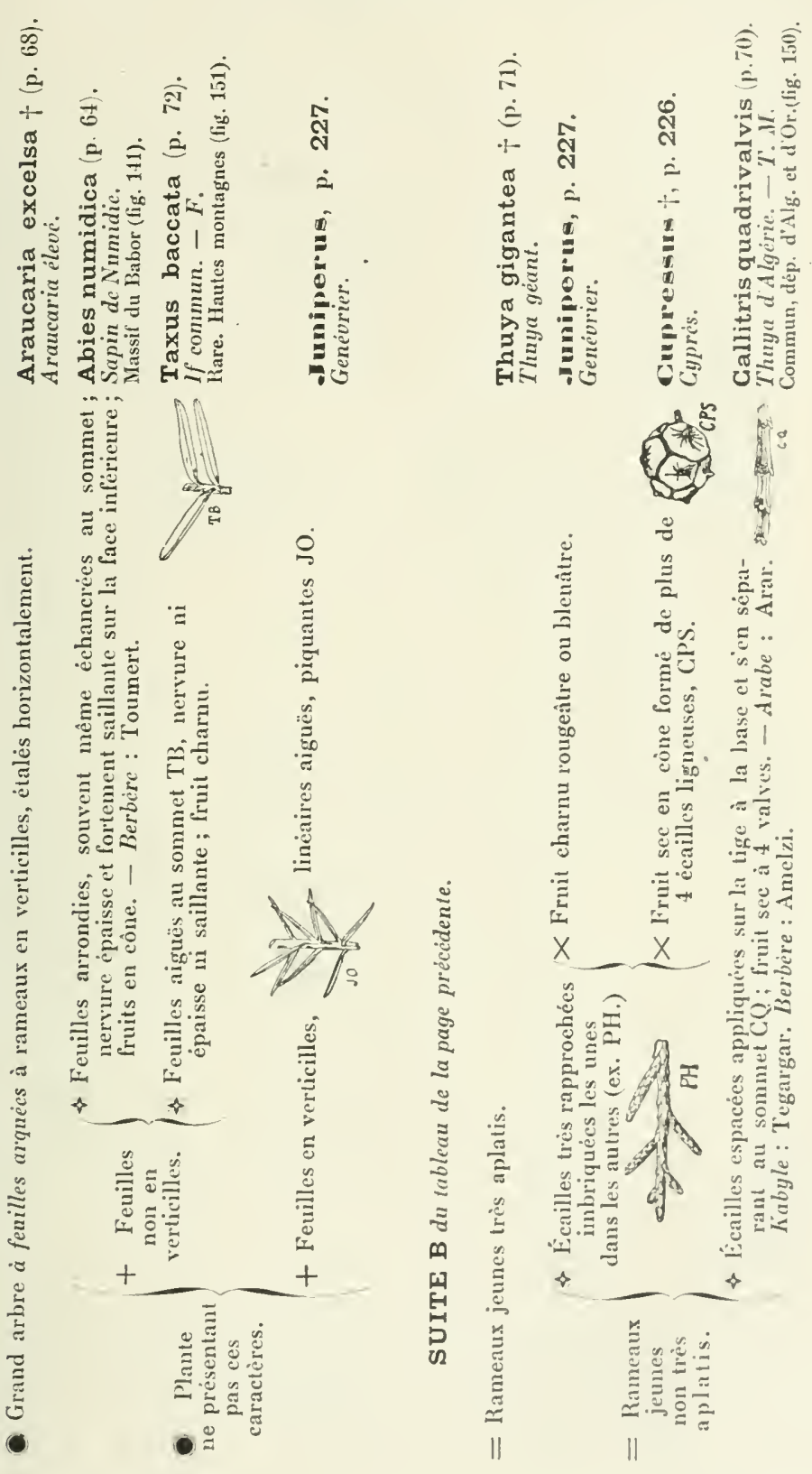

FLORE FORESTIERE. 


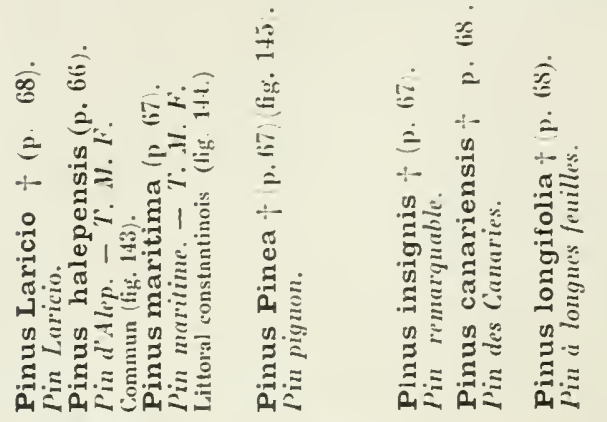

$0^{2}=$

$\because \quad 0$

列

:

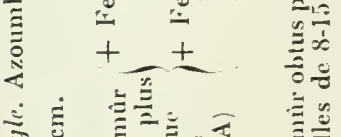
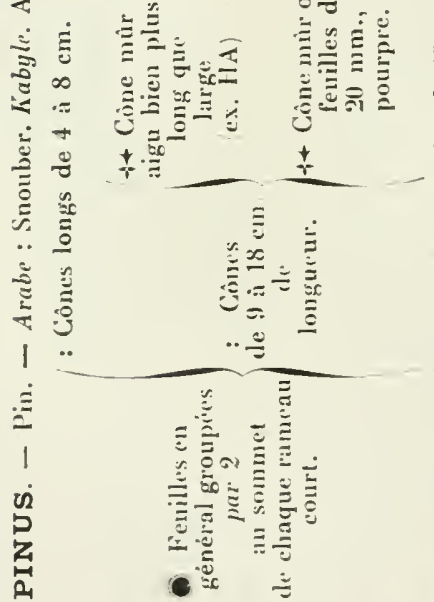

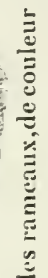

三

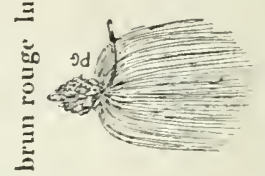

सी

政

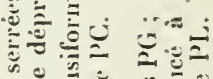

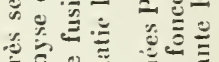

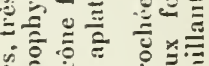

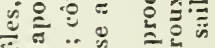
घ.

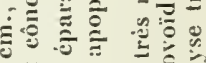

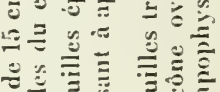

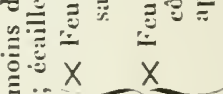

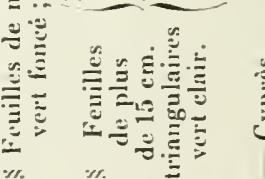

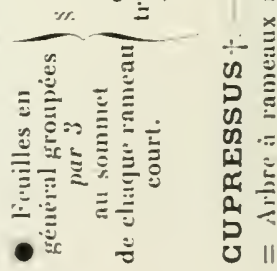

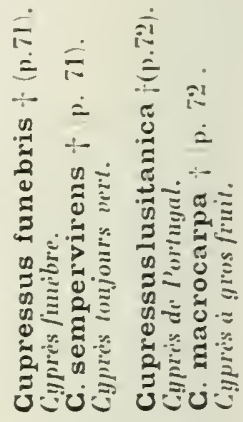

를 $\dot{\delta}=$ 三衣 인

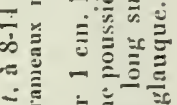

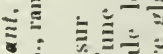
$\Xi \equiv \equiv \equiv \equiv$

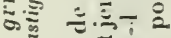

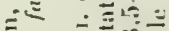
$\bar{\Xi} \equiv \div \div$ 구 $\approx \equiv 1 \geqslant \ldots$

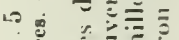
跣 ए $X \div \equiv \equiv x=$ ๘ $\div \div \div$ -1 $\div \dot{0}=0$ $\stackrel{2}{2} \approx \mathcal{E}$

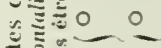

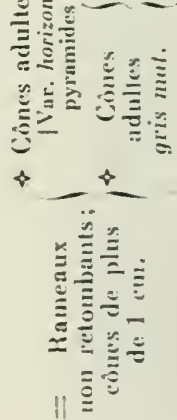




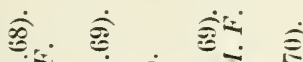

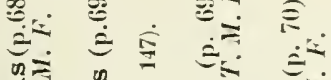

क्रु

गु। द्वा

㐫.

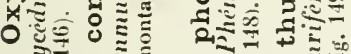

n

ปั 5

0.)

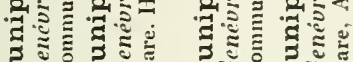

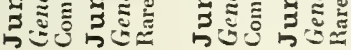

궁 ค을

$\Xi$

$\stackrel{0}{\dddot{\Xi}}$

$\stackrel{5}{\longleftarrow} \quad \stackrel{0}{5}$

כ

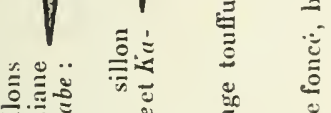

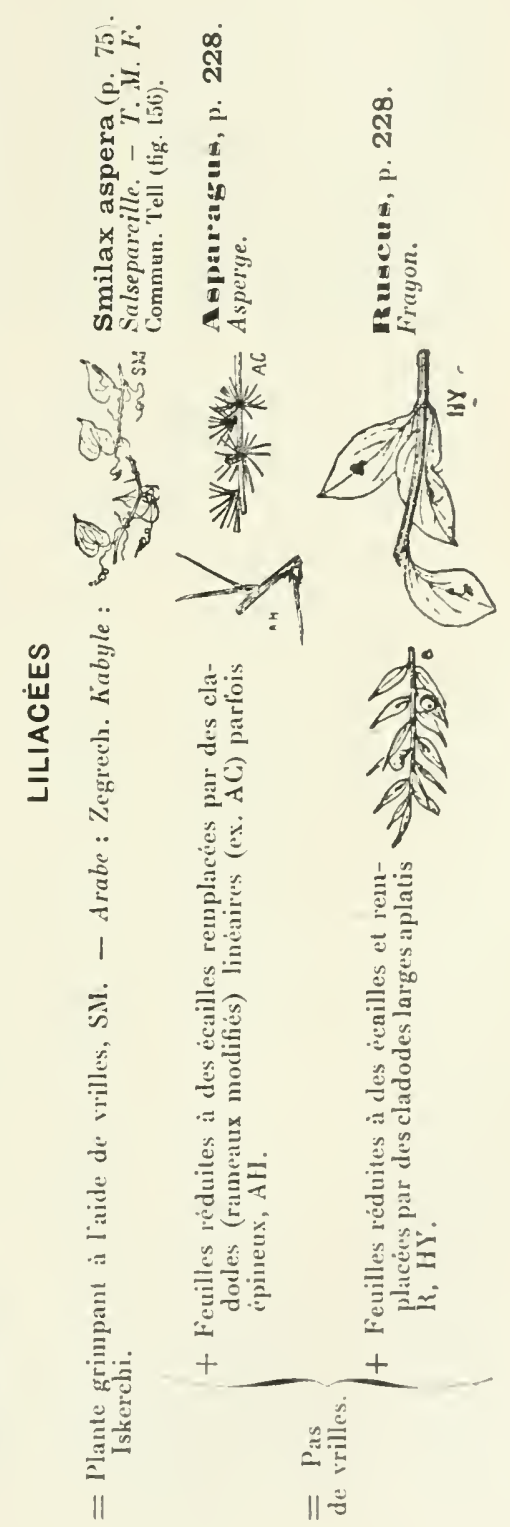

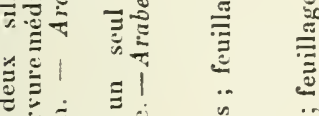

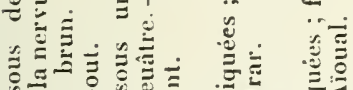

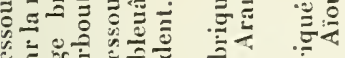

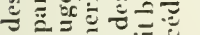

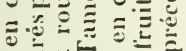

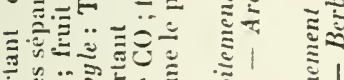

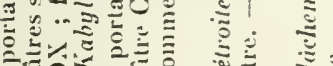

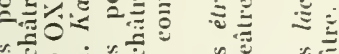

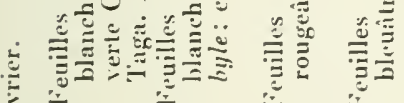

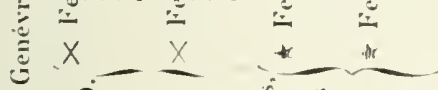

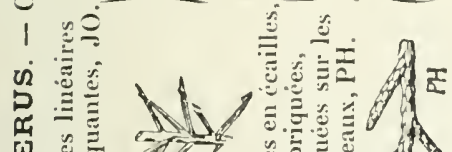

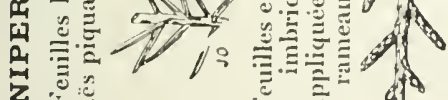

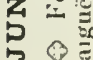

运 do

115 


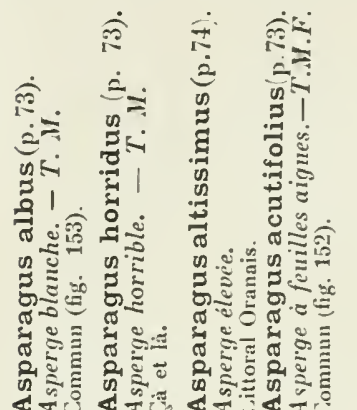
गै

稆

,

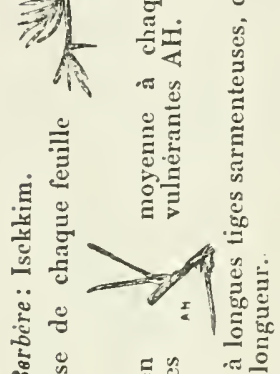

๑

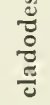

和二

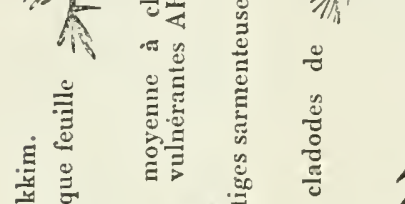

$\stackrel{\Xi}{=}$

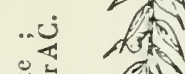

क्ष.

ह่

हैं

.

管

$1 \cong$

$\infty_{0,}^{\circ}$

$\frac{0}{4} \cdot \frac{0}{3}$

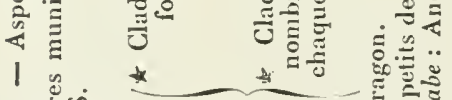

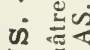

ป

4

\& ${ }_{80}^{2}$

कि:

40

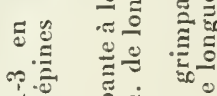

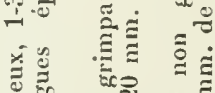

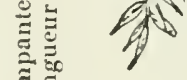

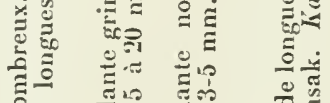

:

○的

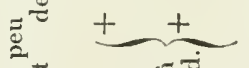

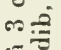

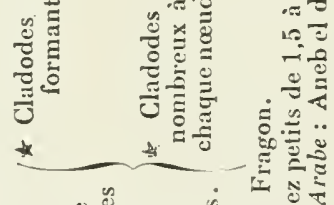

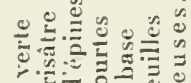

0

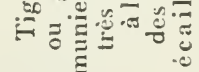

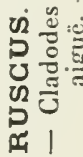

$Q$

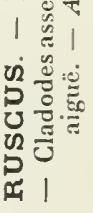




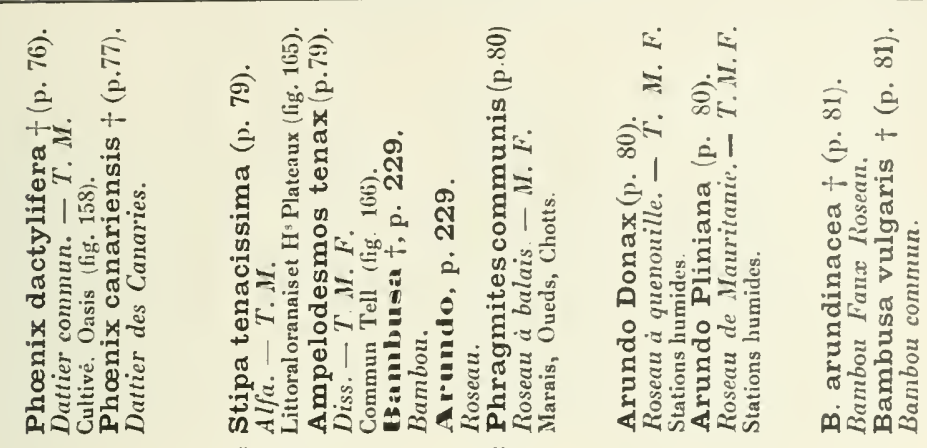

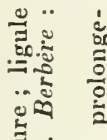

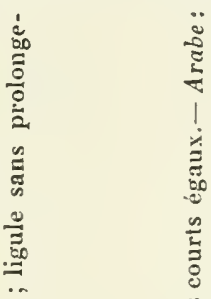

范

$\ddot{2}$

है

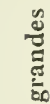

:

苞

$\stackrel{0}{\Xi}$

.

+े

究苋

栨

a $X$

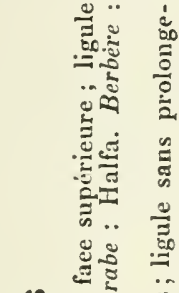

2 


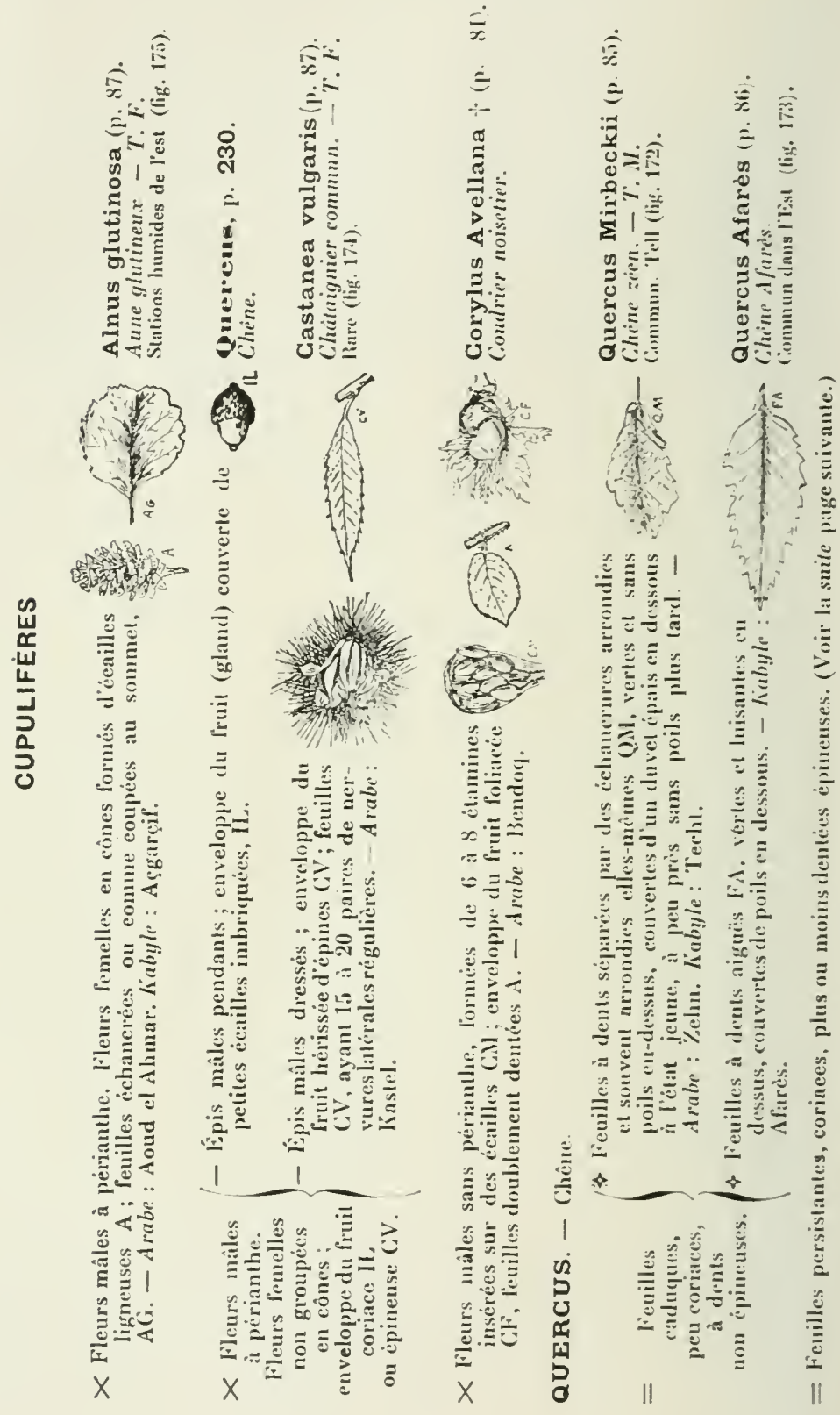




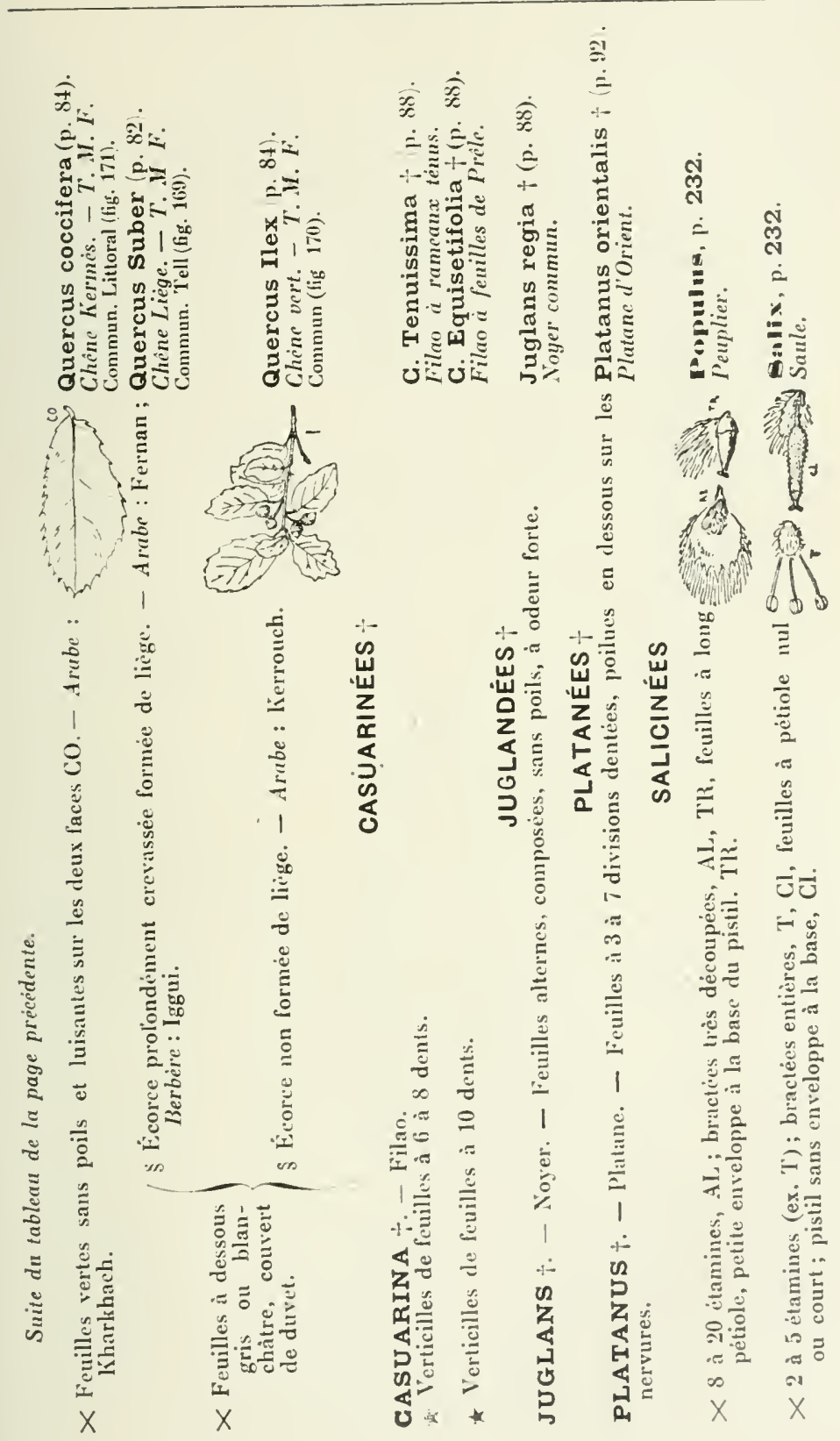



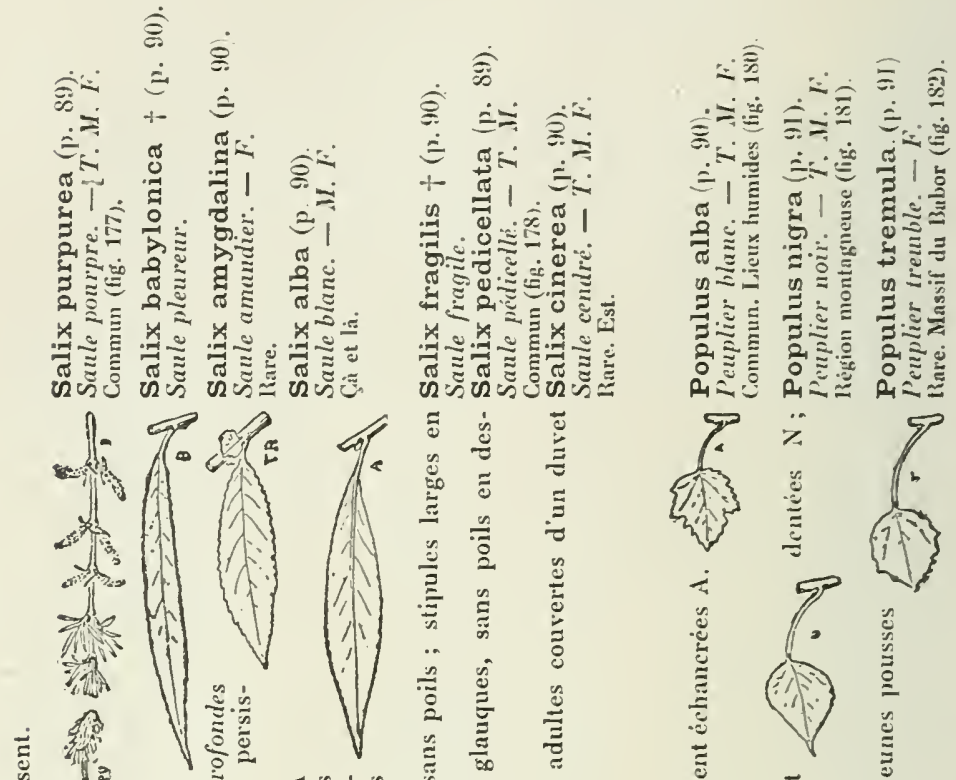

ב

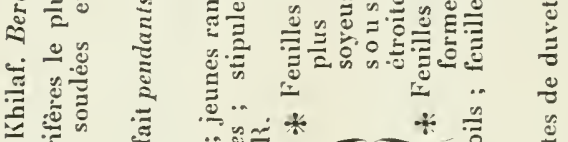

15

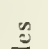

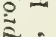

प 2 is $n$

. n .

$\because$ ๖ छ

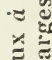

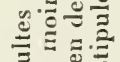

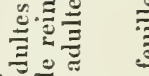

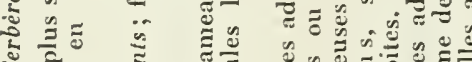

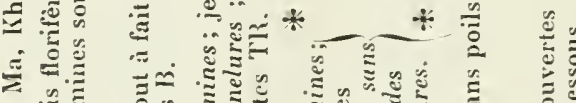

ए.

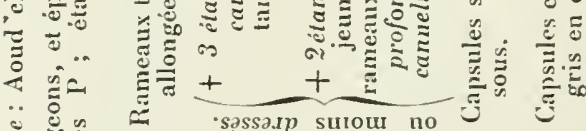

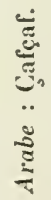

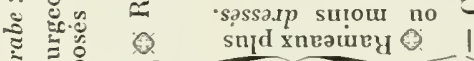
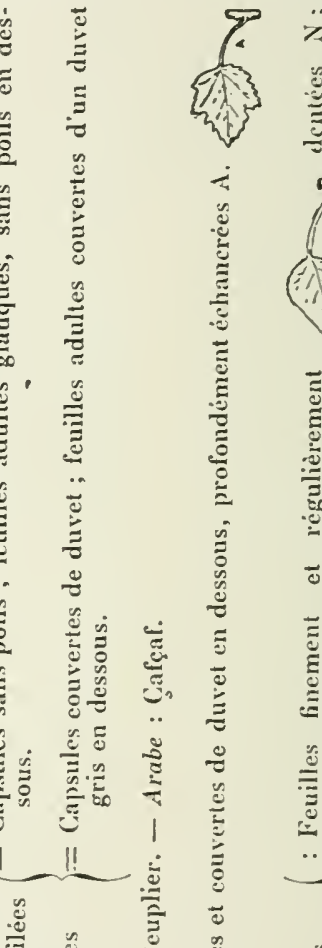

בֶׁ
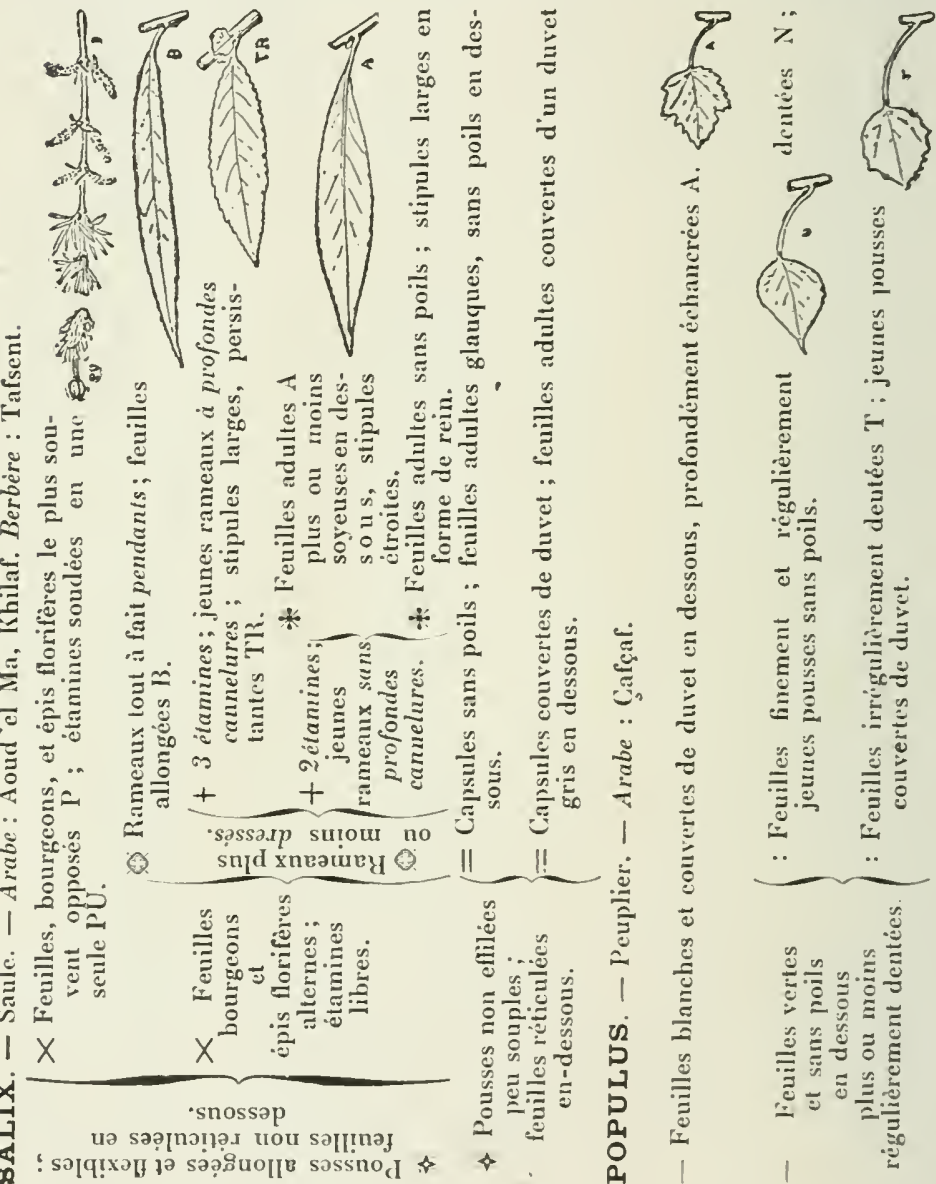

\&

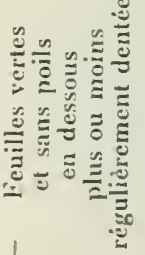




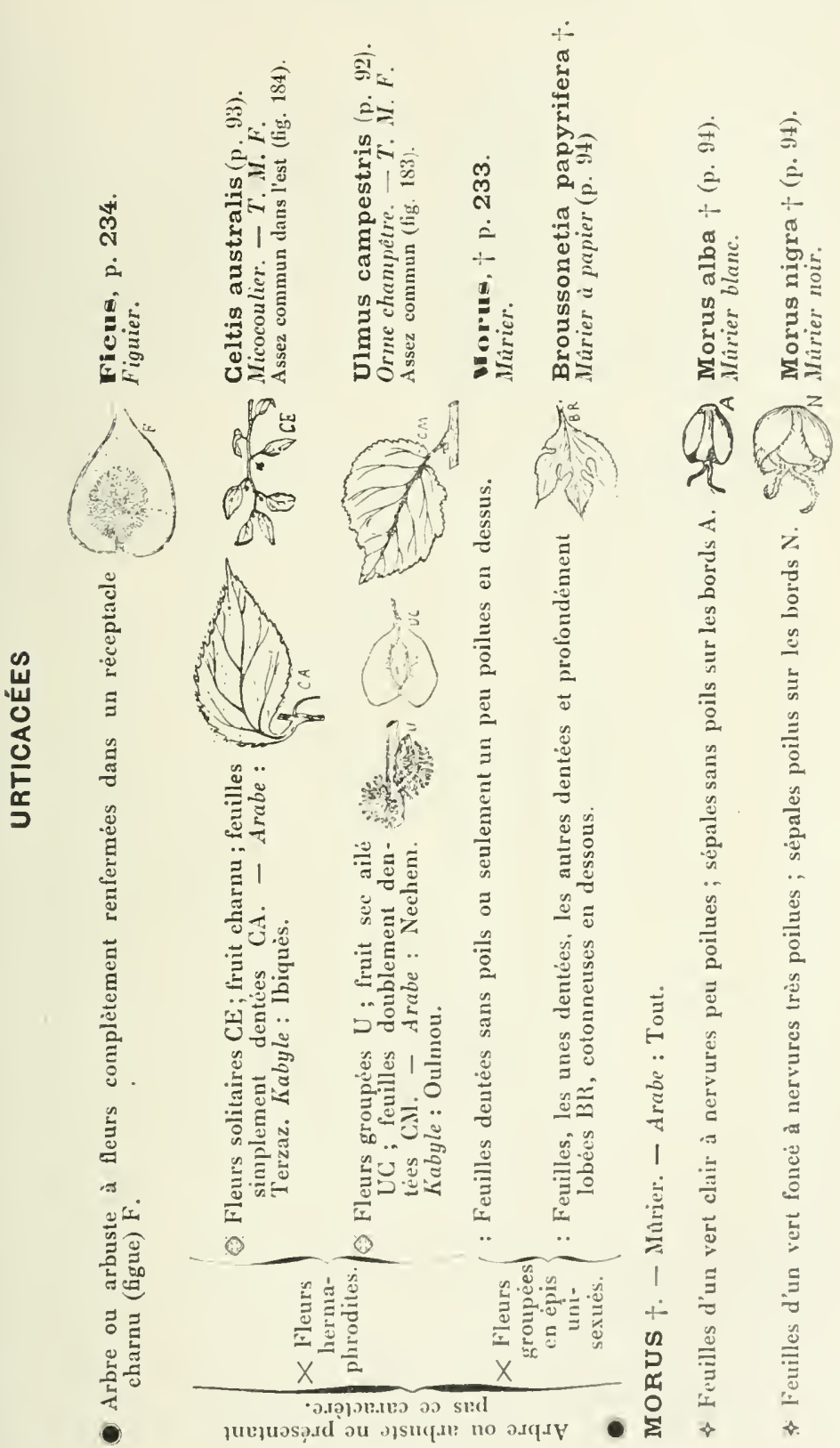



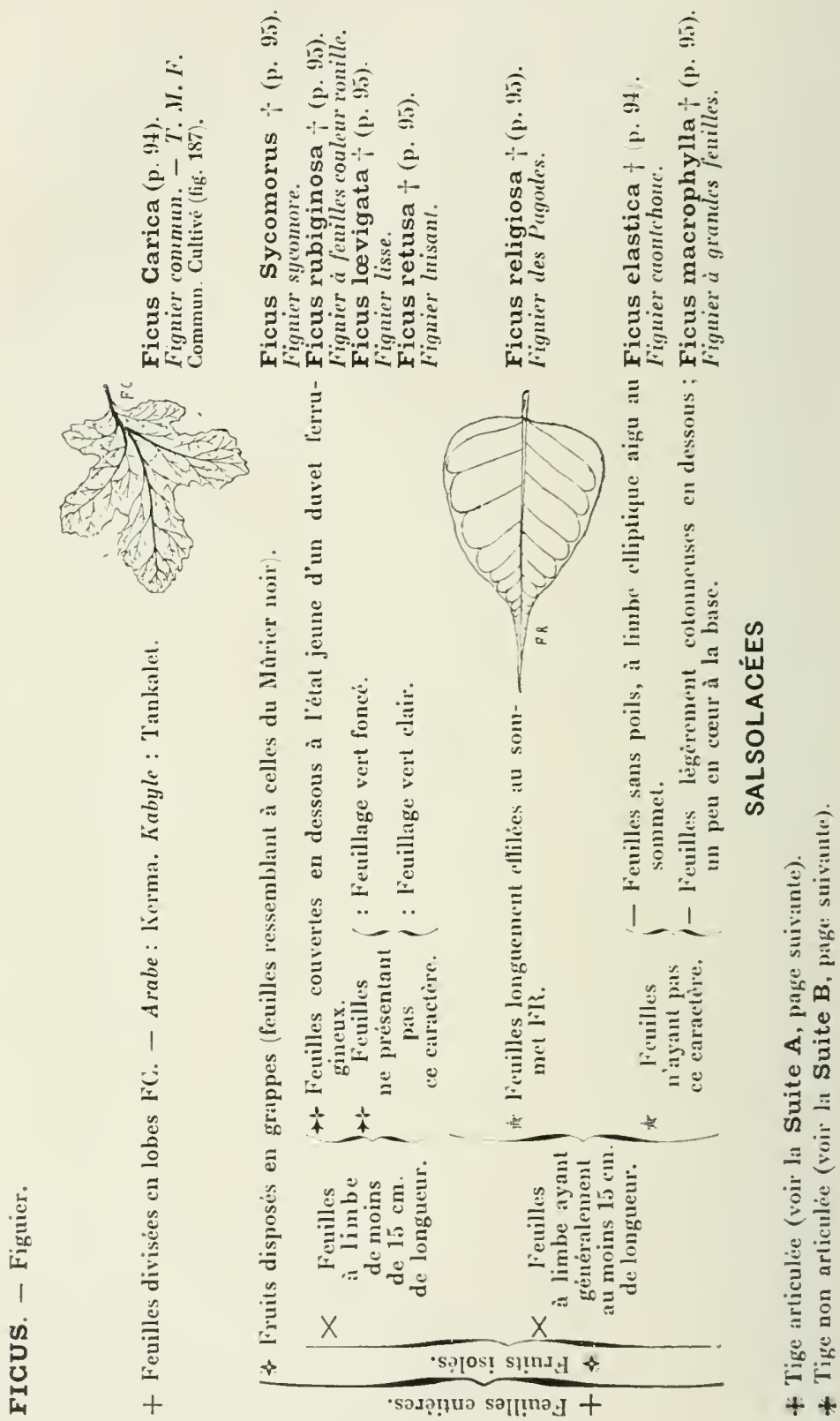


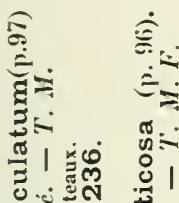

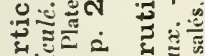

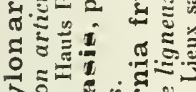

해

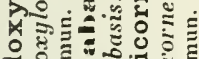

สำำ

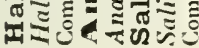
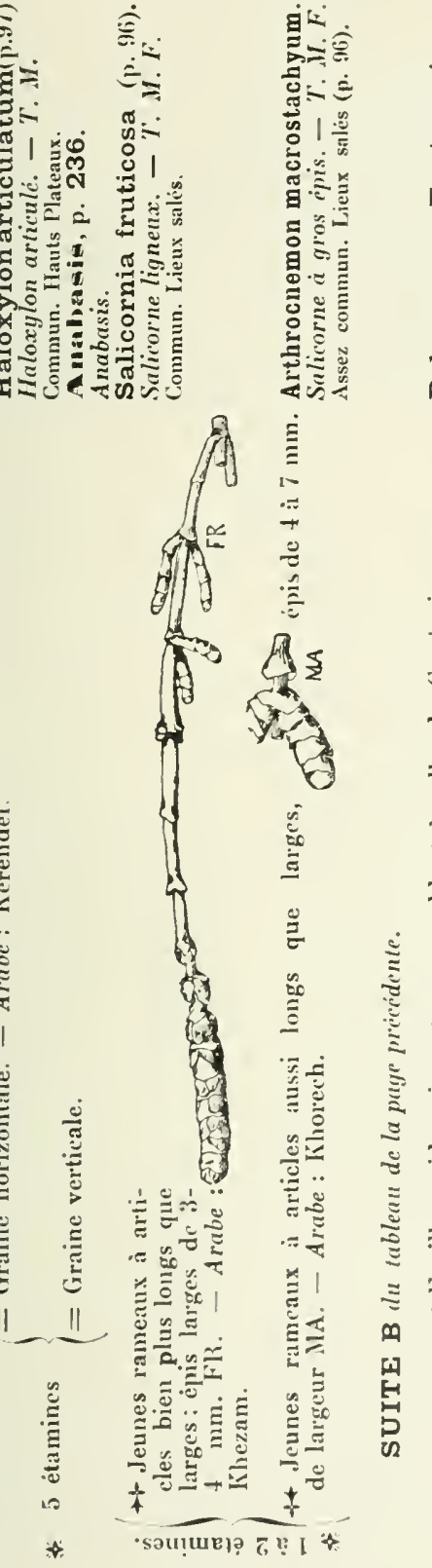

(1)

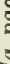
? . (1) (n) (1)

罢

品 
के $\dot{\bar{\varepsilon}}$

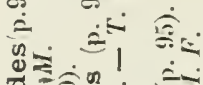

0.

,

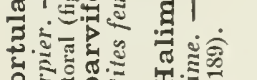

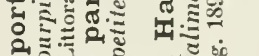

$x=4 . x, x=$

ฉับ

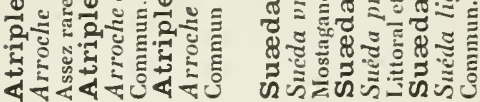

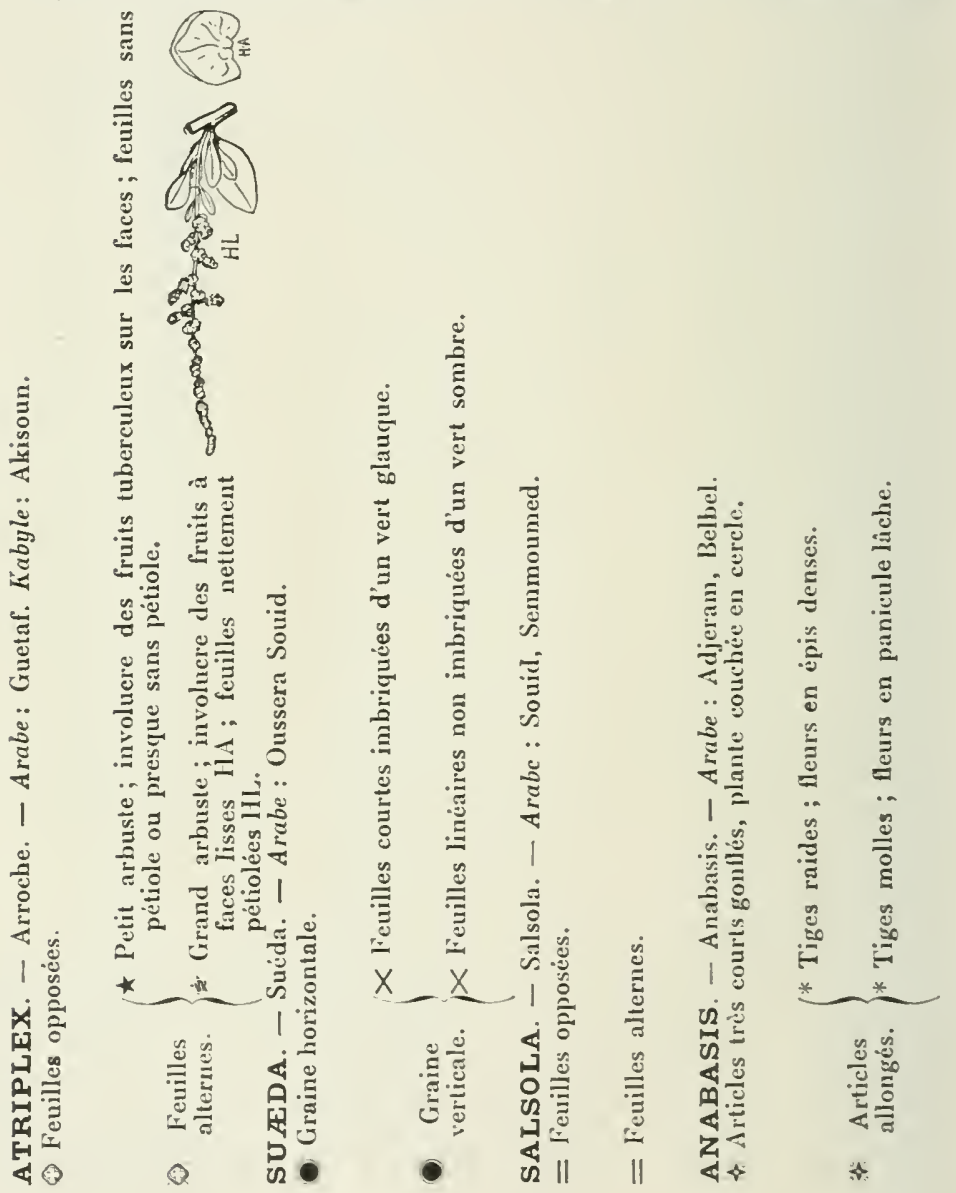




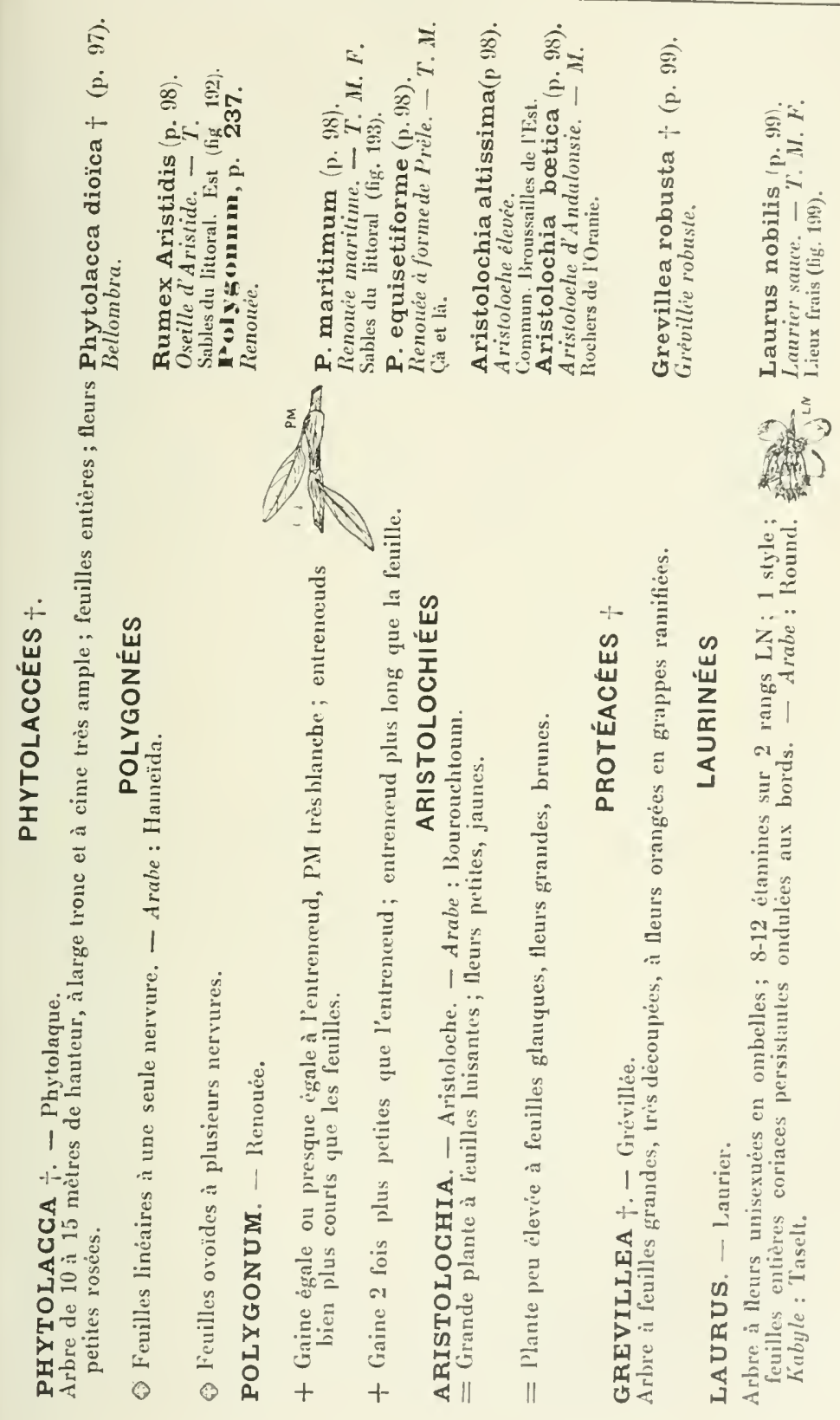




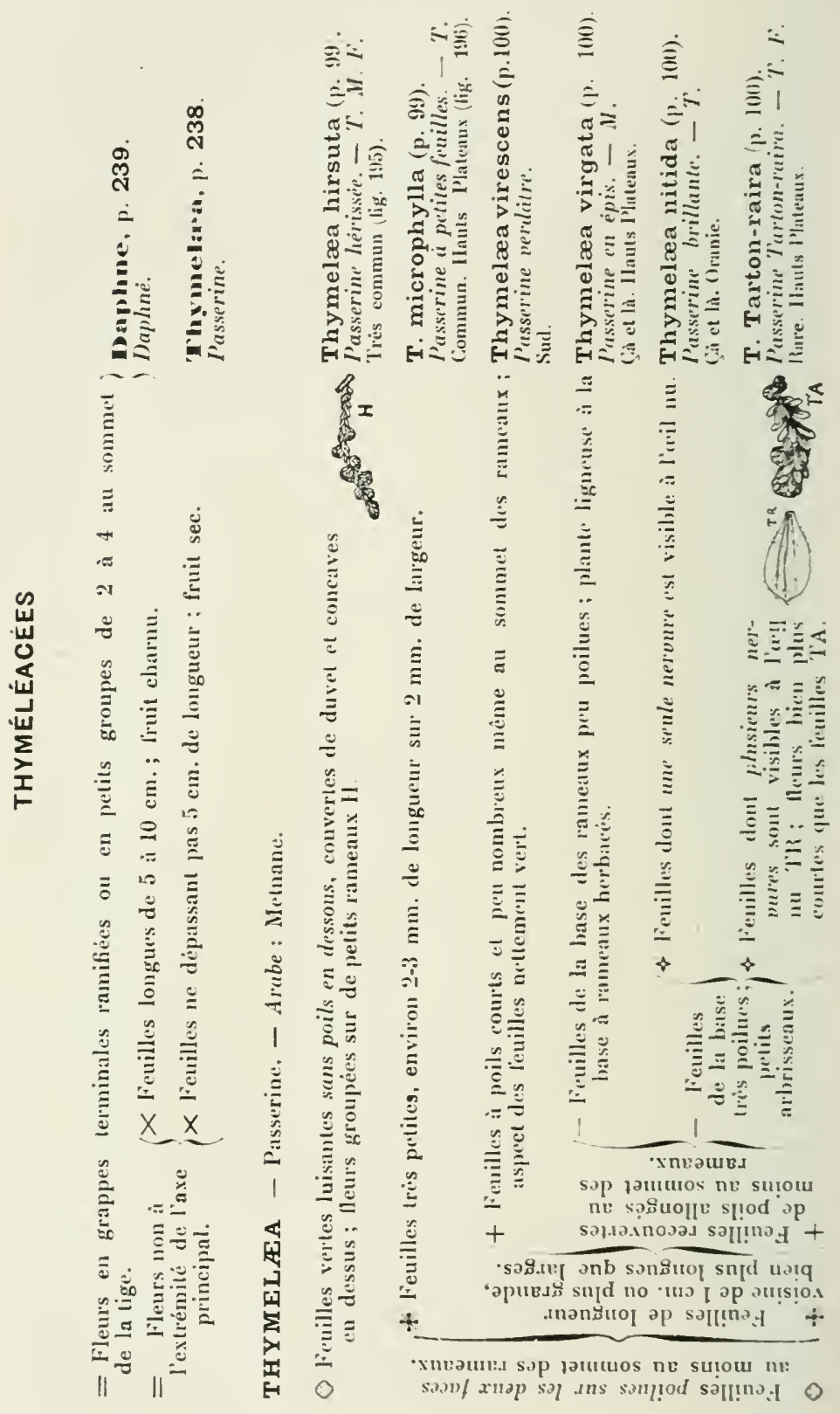




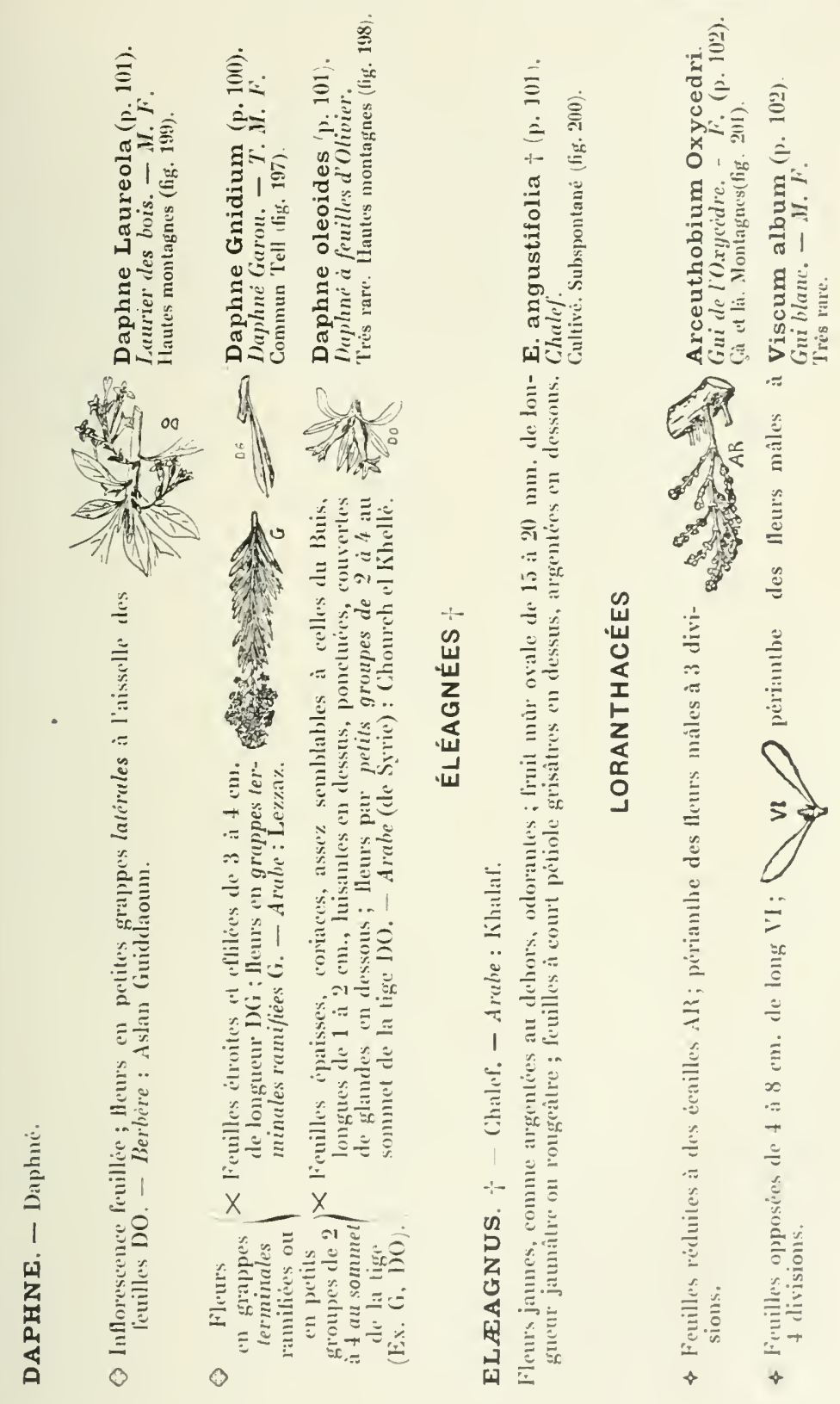




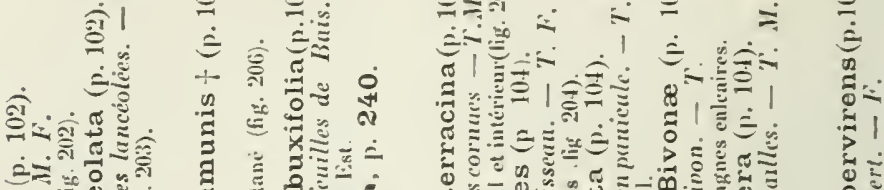

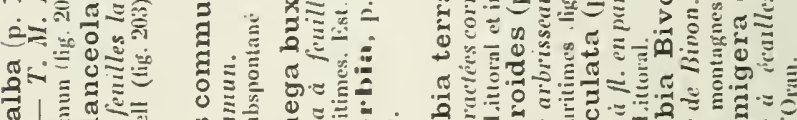

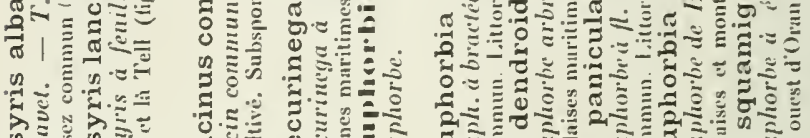
कึ

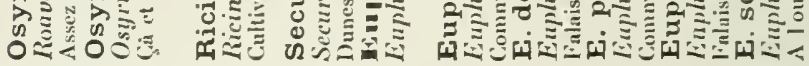

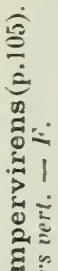

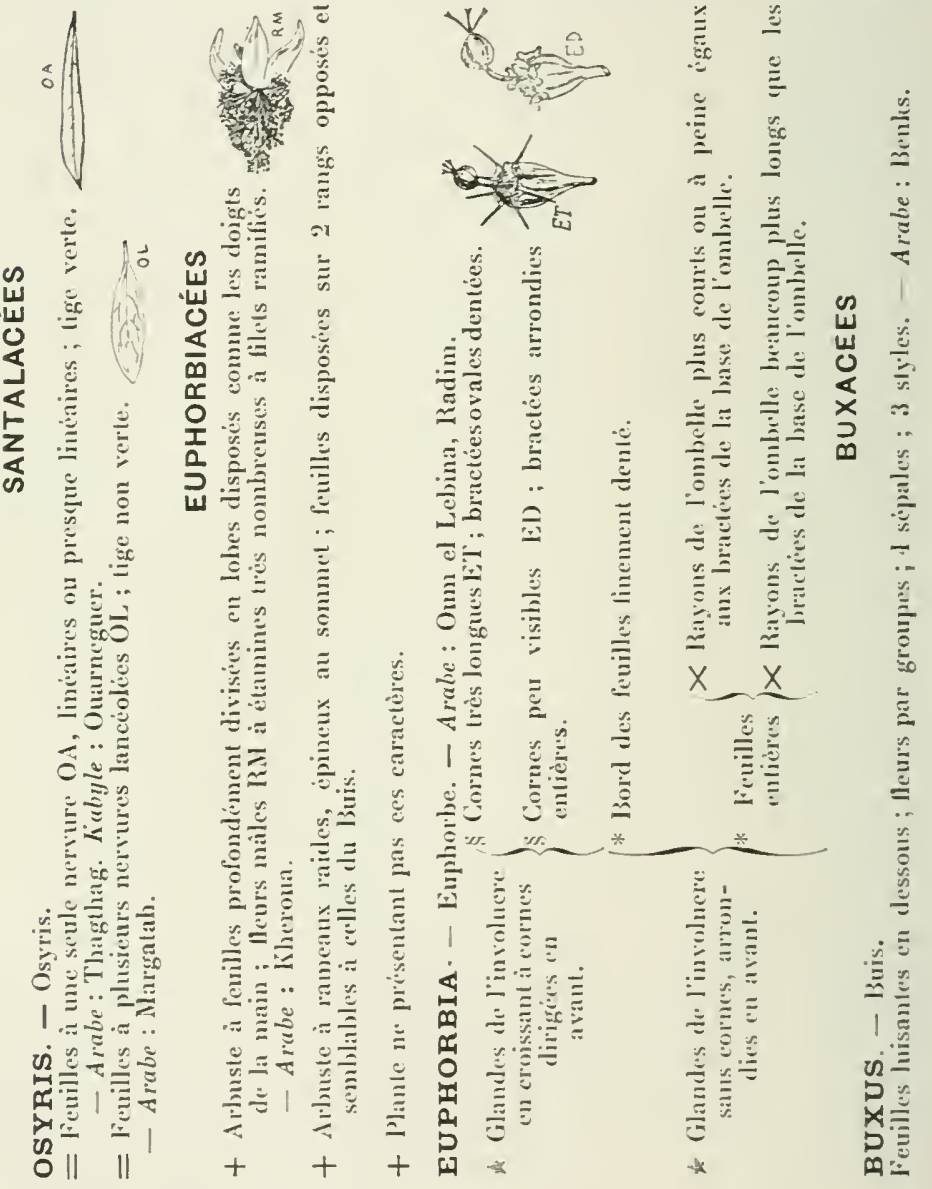




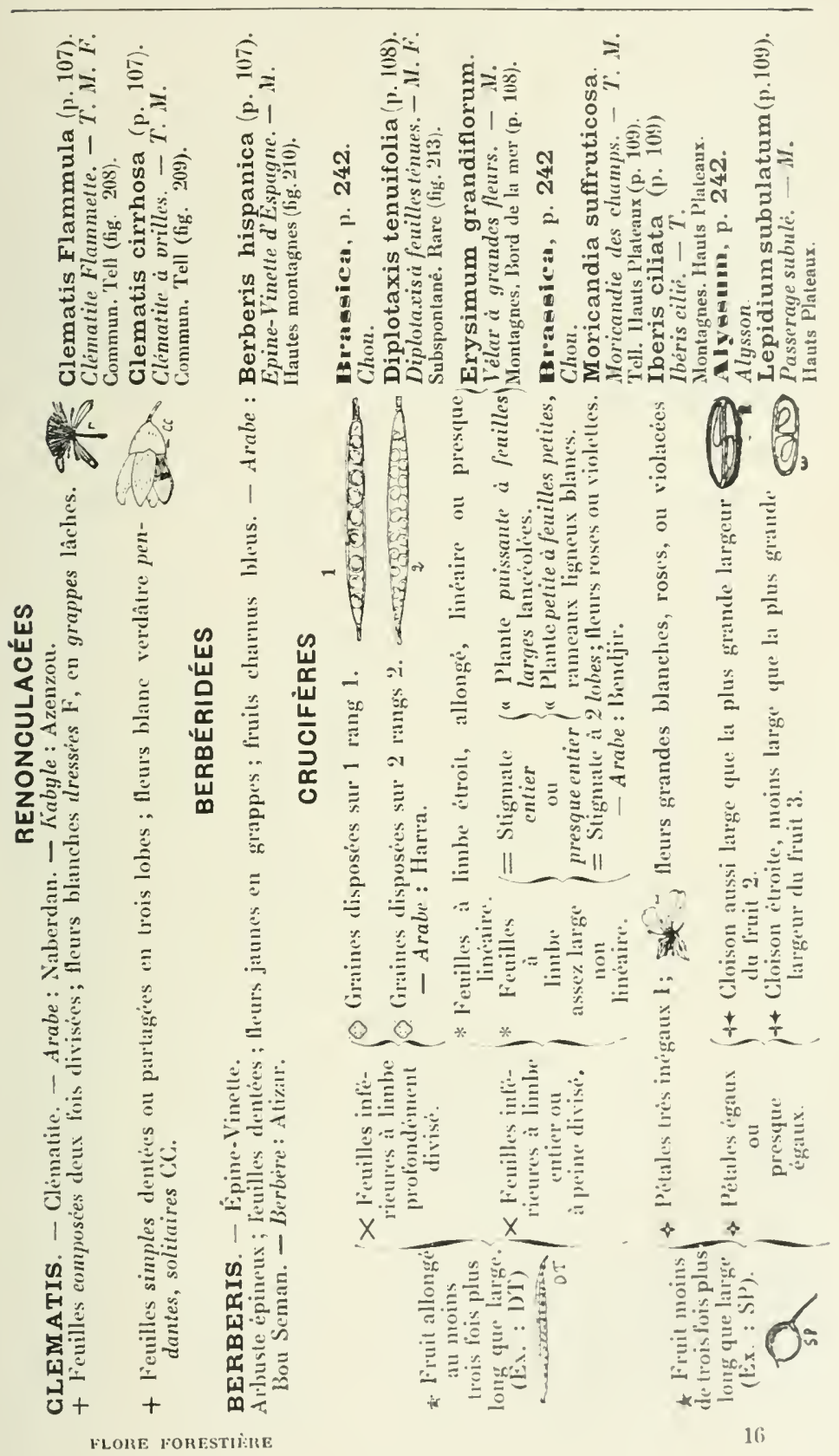




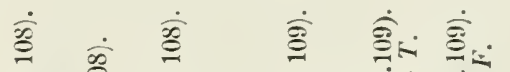

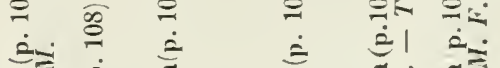

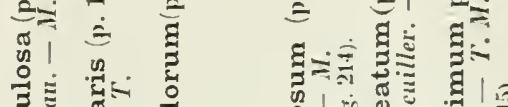

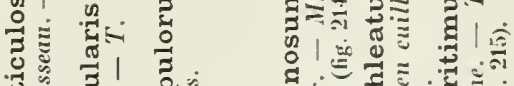

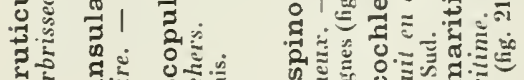

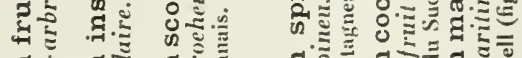
ฮิ ฮิ

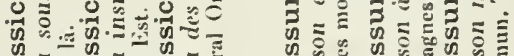

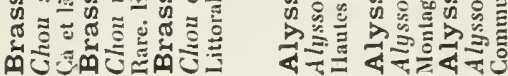

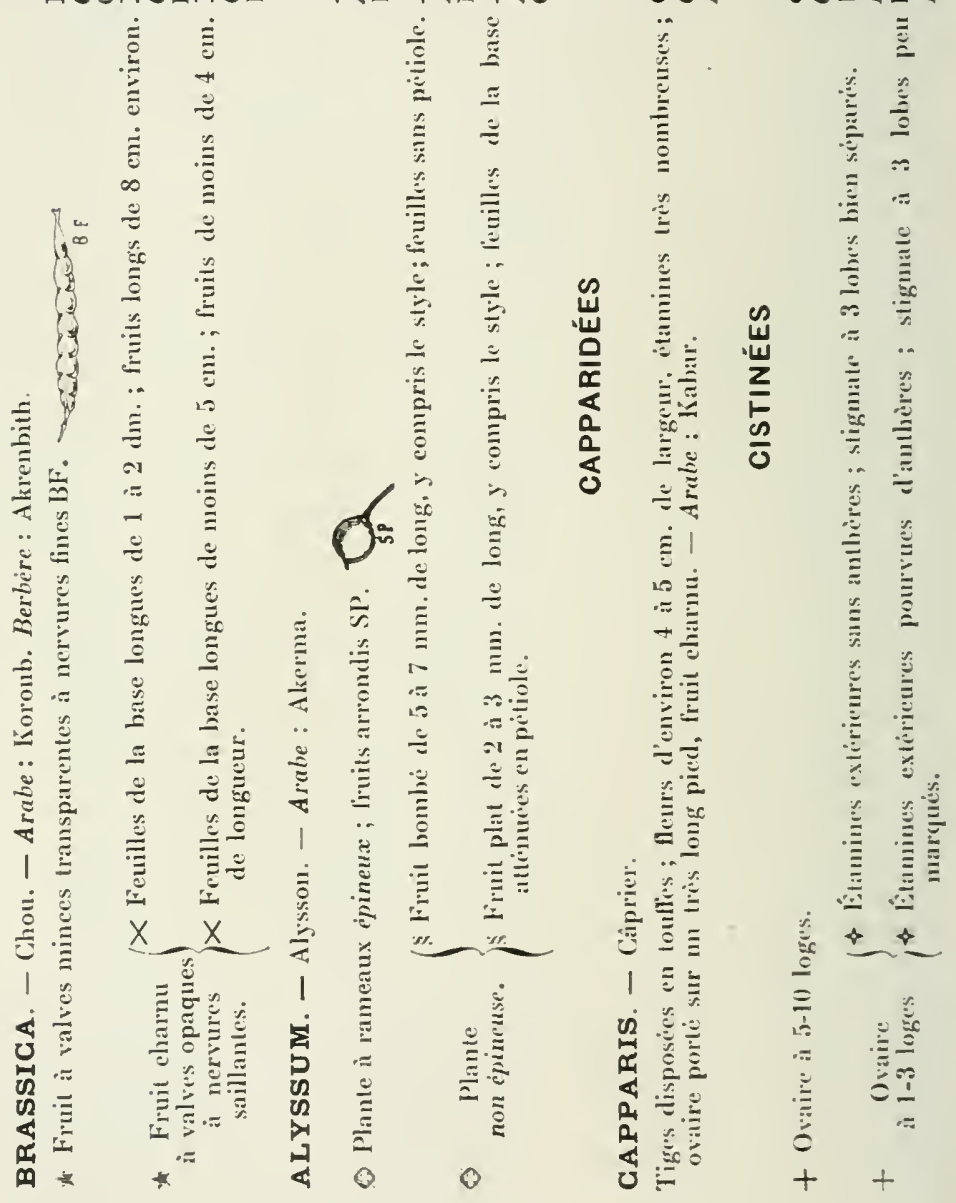




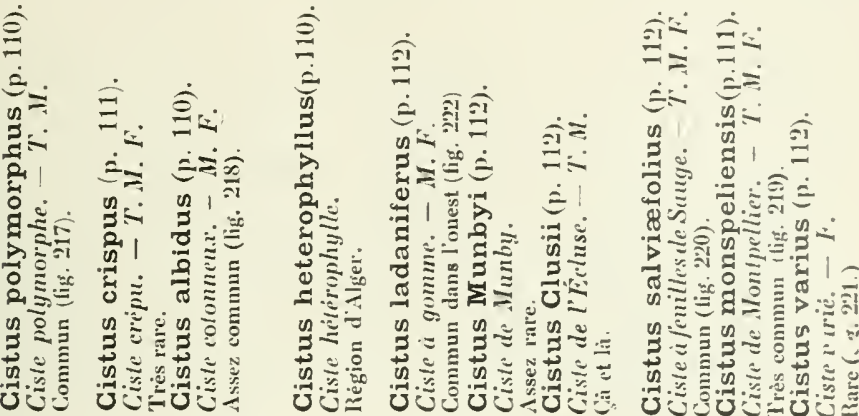

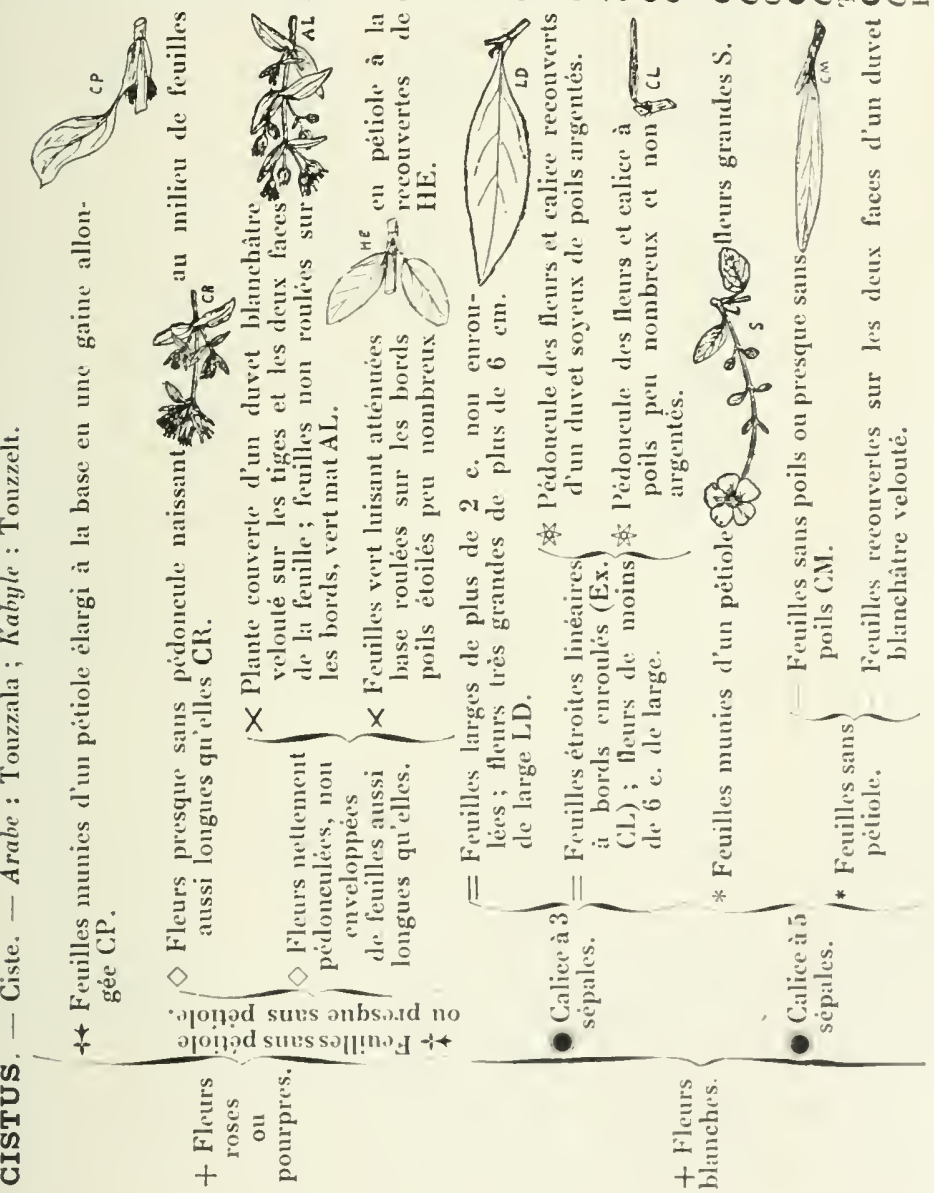




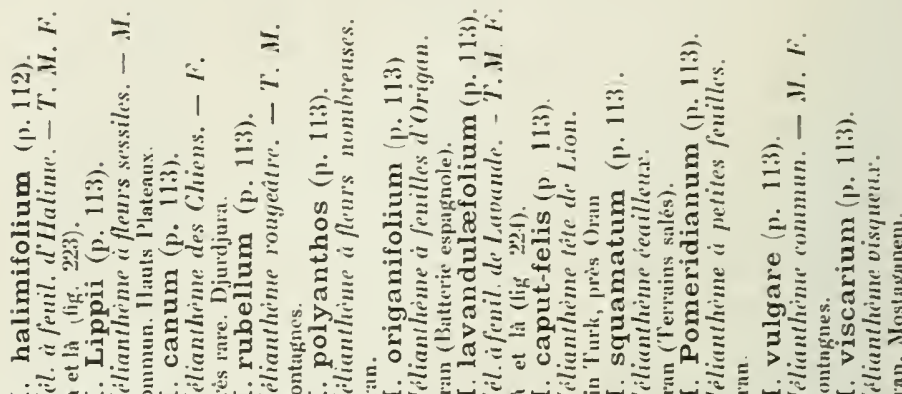

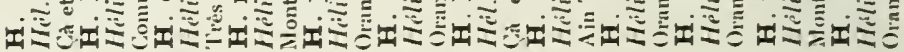

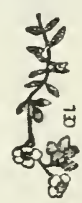

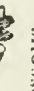

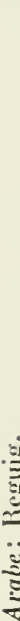

si

然

空

两

空

要

Z

4

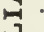

至

됴

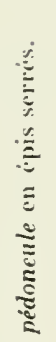

ڤั

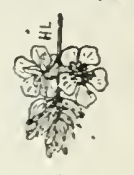

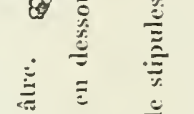

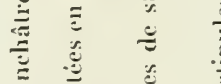

莽

๖

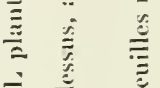

¿

全

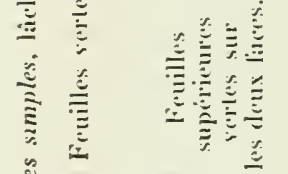
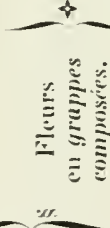

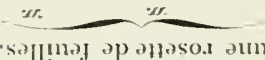

snos julssı

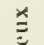

$\stackrel{5}{\frac{1}{5}}$

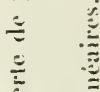

.

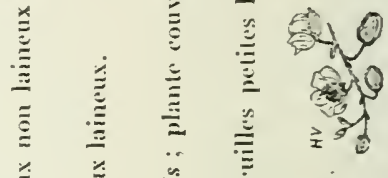

㭉

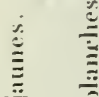

$\stackrel{\frac{1}{E}}{\underline{E}}$

$\therefore+$

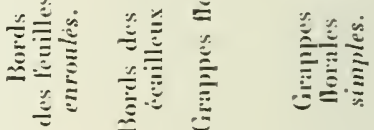

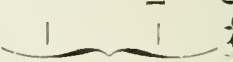

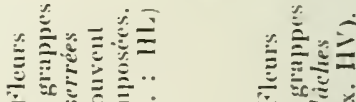

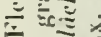
$\equiv$ 


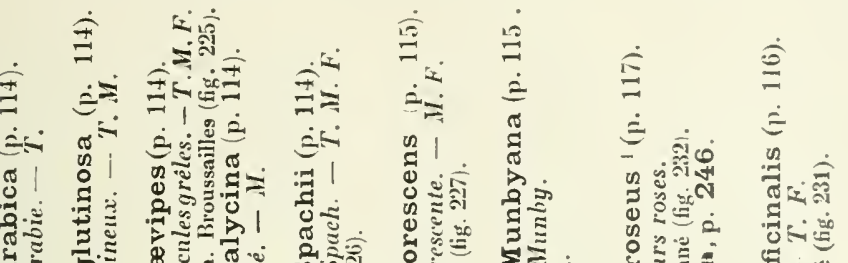

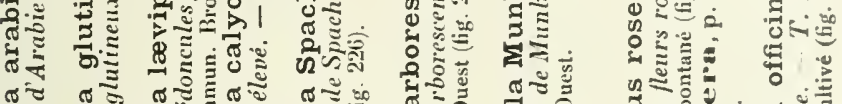

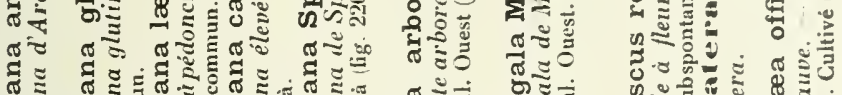
๔ర<smiles>C=CCCCC</smiles>

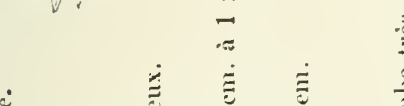

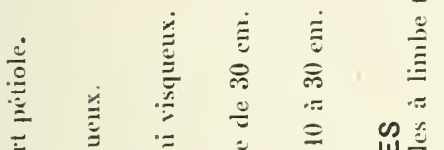

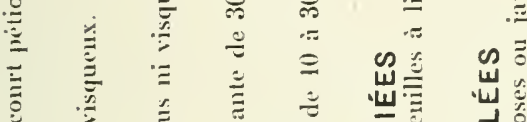

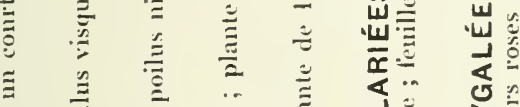

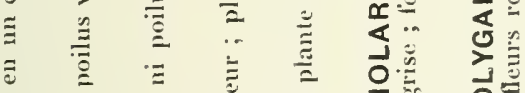

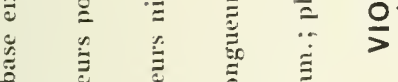

$\therefore$ :

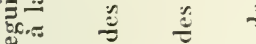

范

已.

+ -

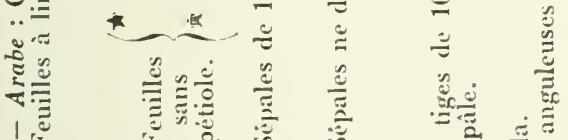

1

1. कि

花

崫 0

\begin{abstract}
(1)
\end{abstract}

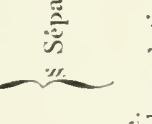

$=\frac{a}{2}$

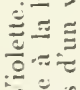

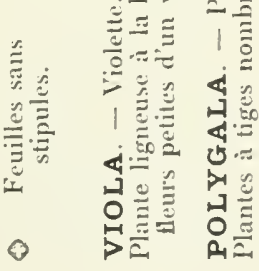

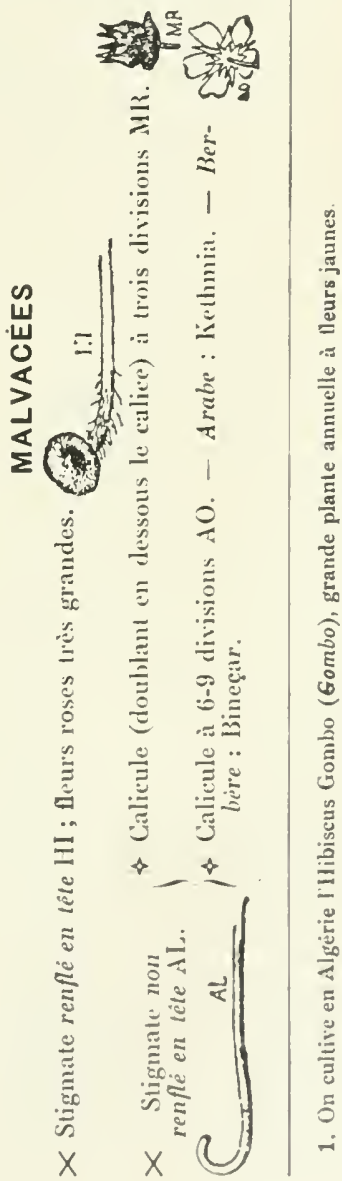



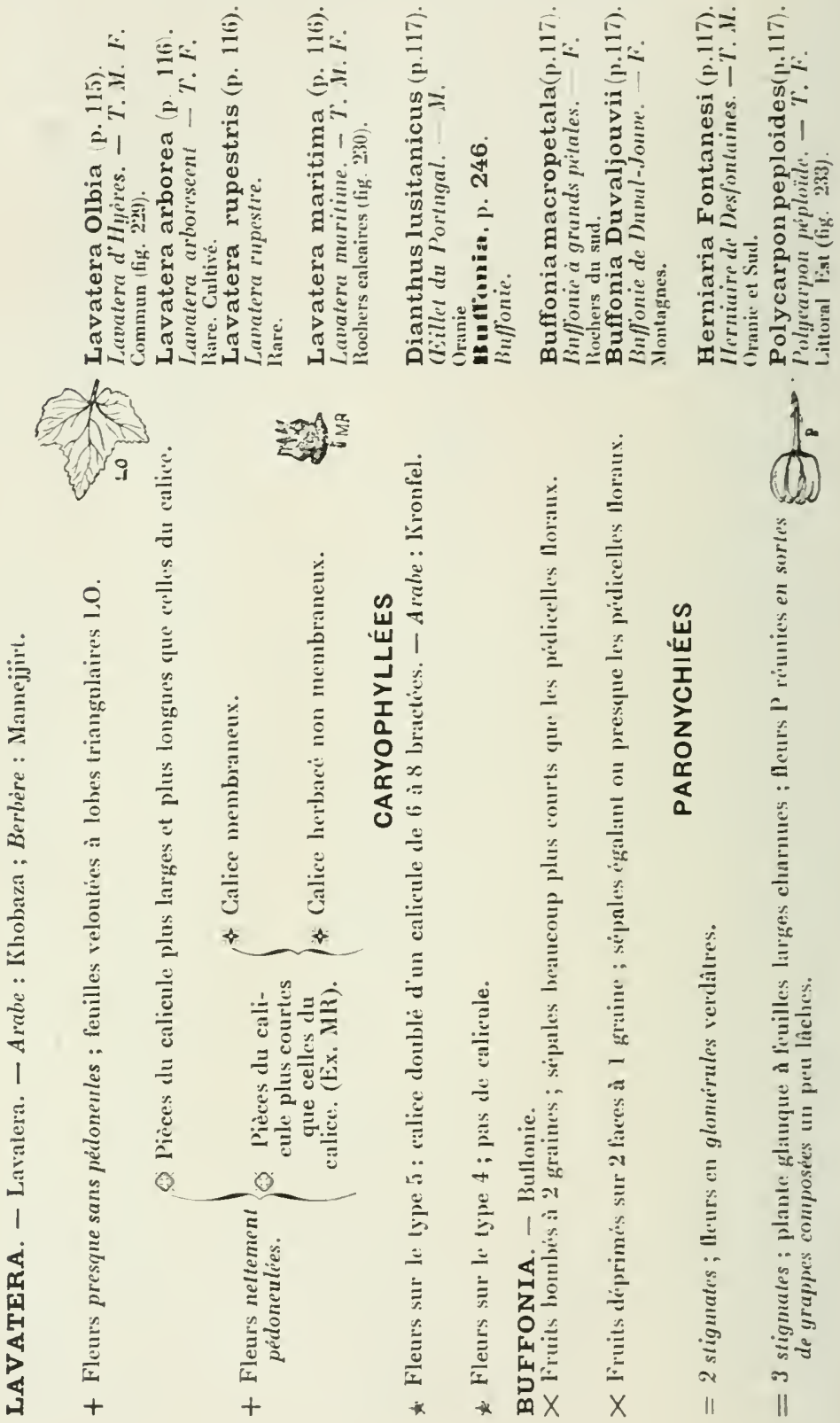
MÉLIACÉES. - AMPÉLIDÉES. - ACÉRINÉES. - CORIARIÉES 247

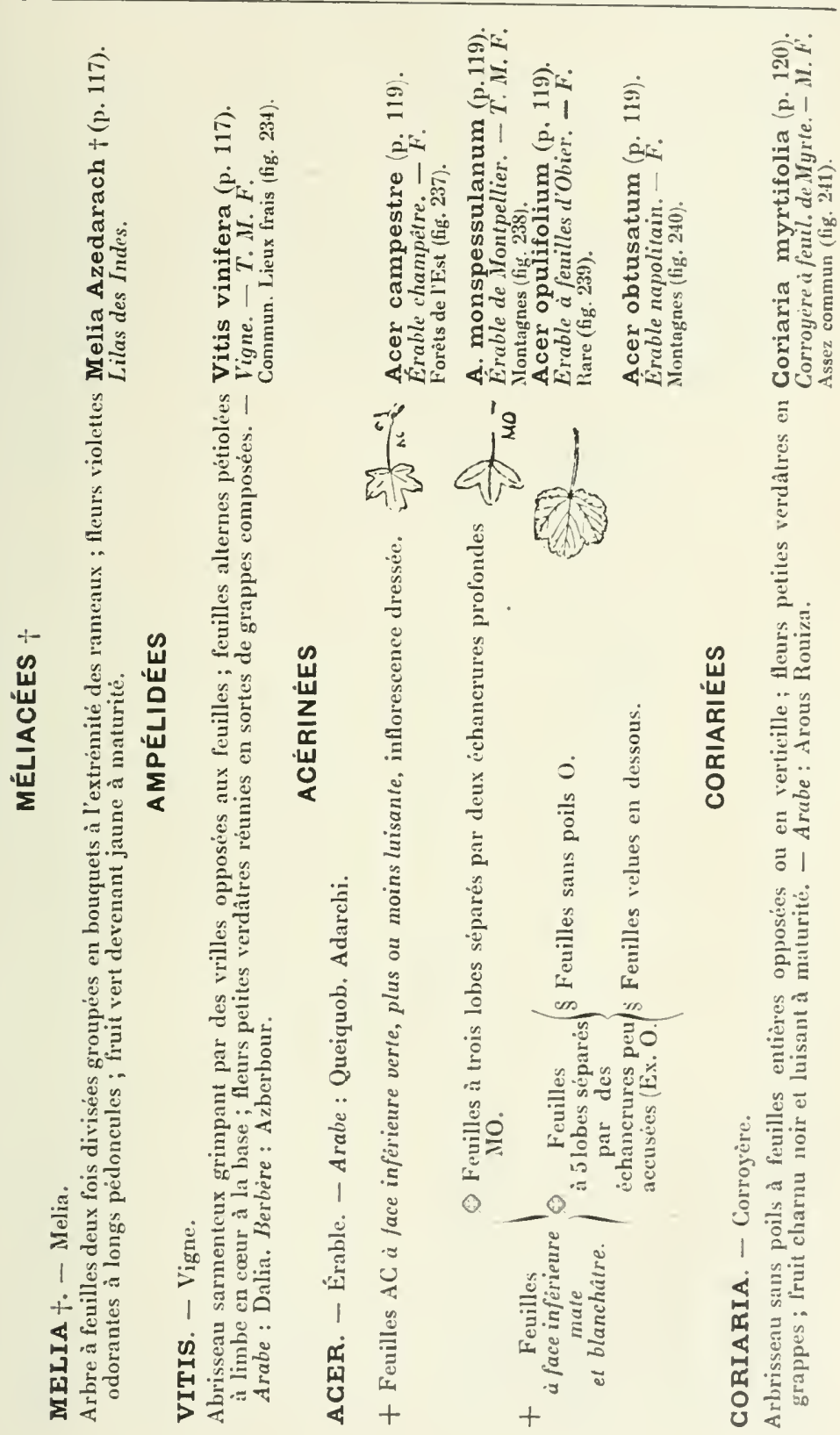




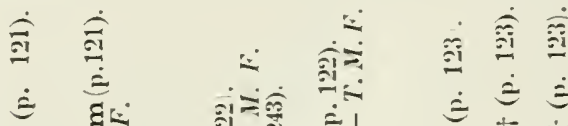

घ द्वृ

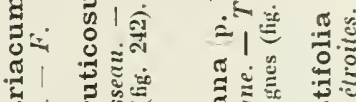

我.

क.

a

궁

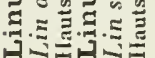

กู

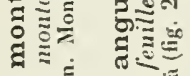

ฐํㅊ

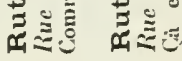

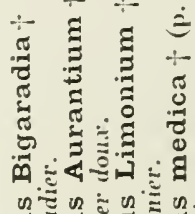

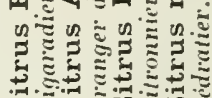

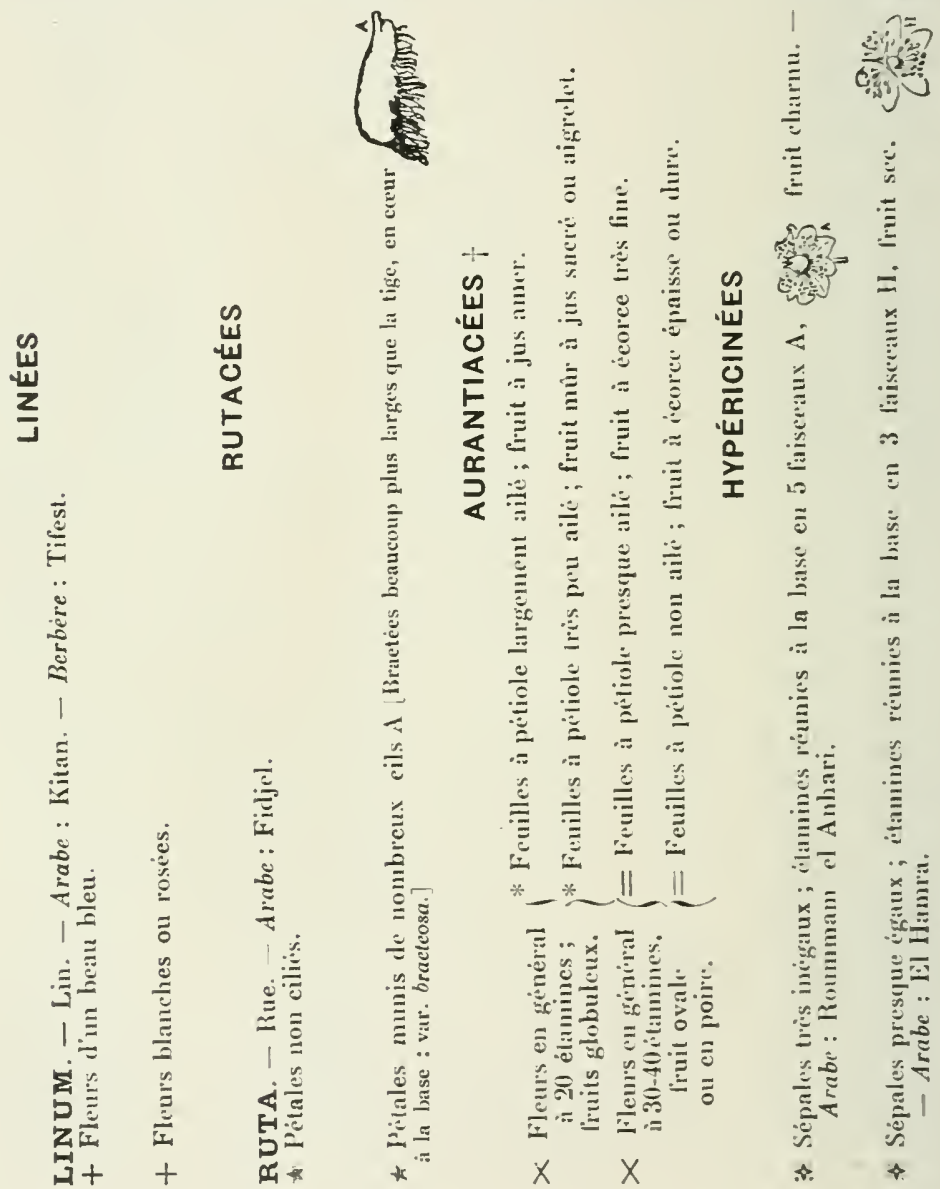




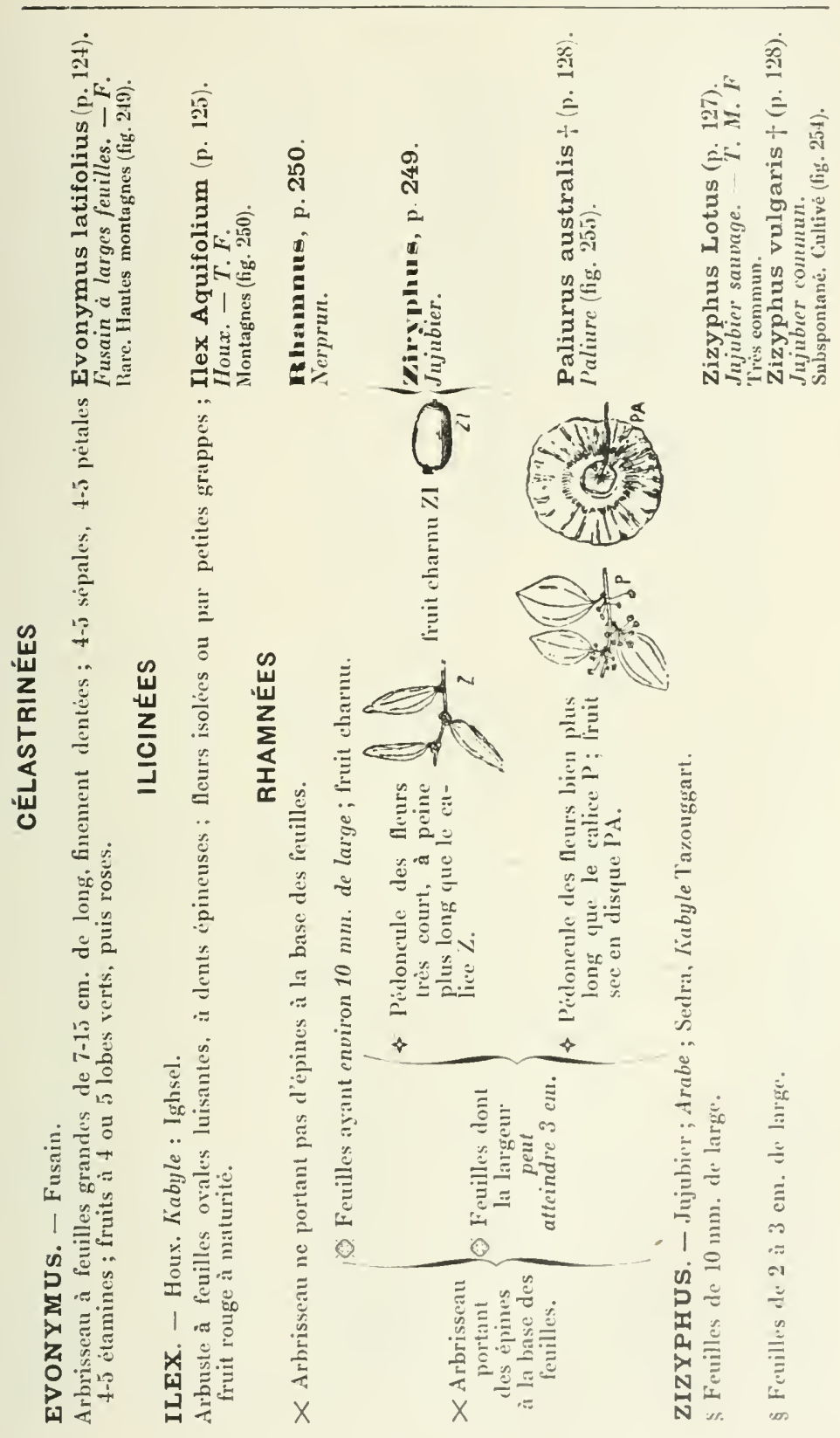




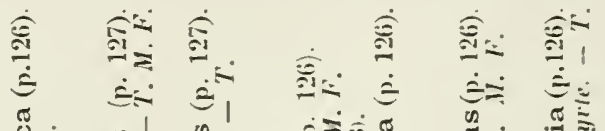

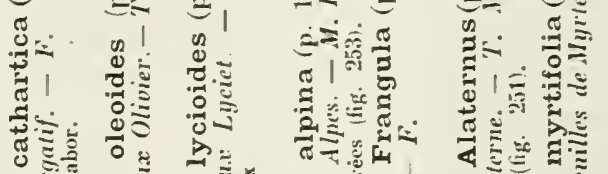

ชึ

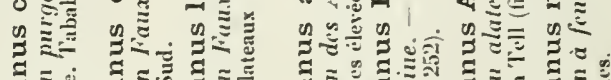

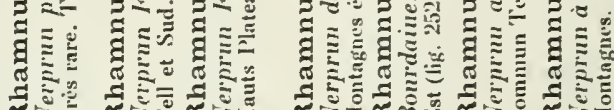

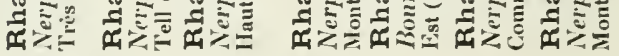

Af

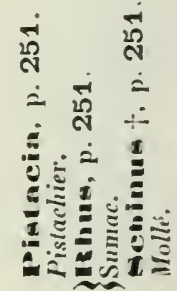

(.)

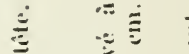

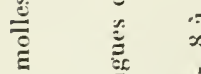

ב

$\therefore$ 苛

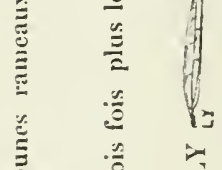

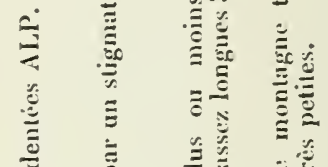

$. \frac{5}{3} \div$

$\stackrel{3}{=}$

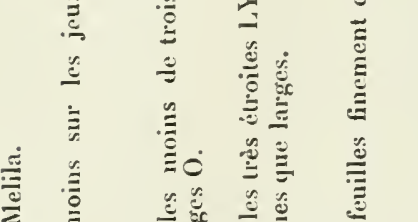

三

产

z

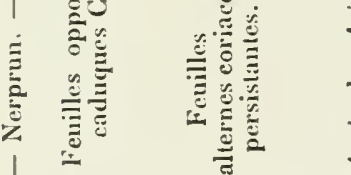

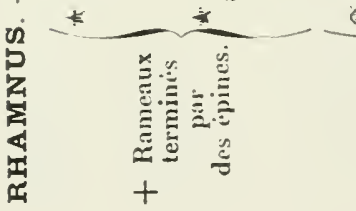

0

妾 产

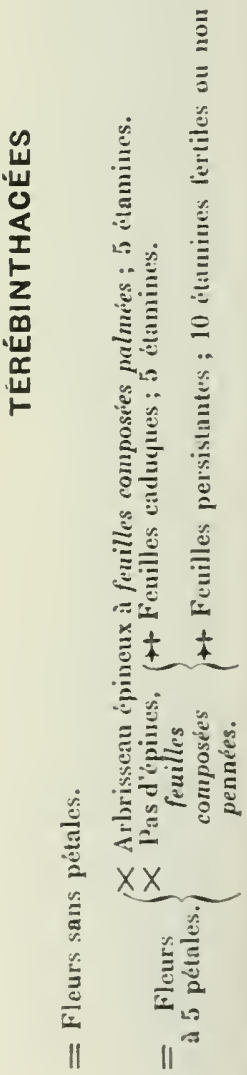




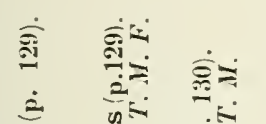

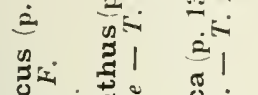

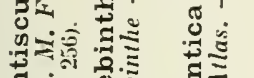

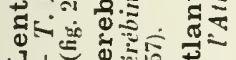

1)

g

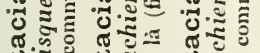

कि

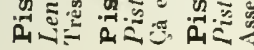

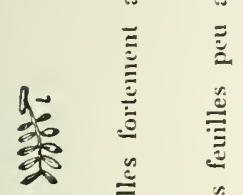

言

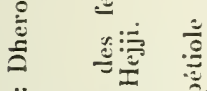

รั้

है

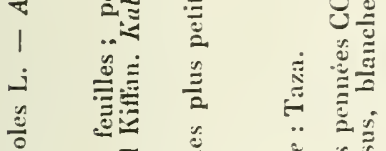

范

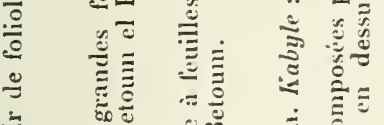

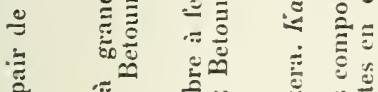

슬

ก

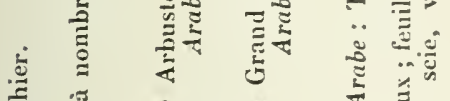

告

然

戈

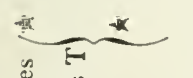

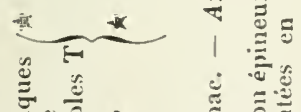

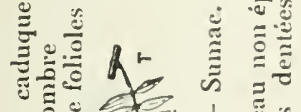



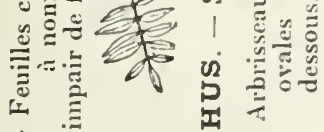

新

क 0

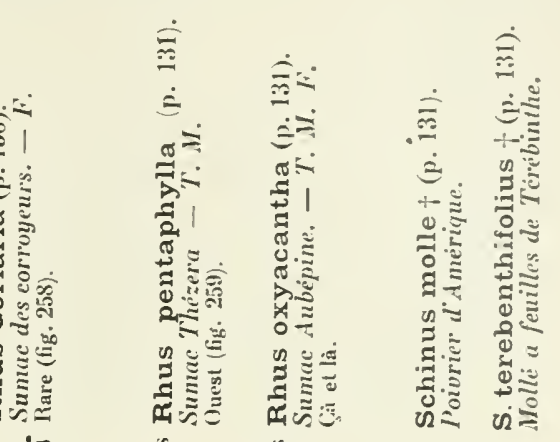


PAPILIONACÉES

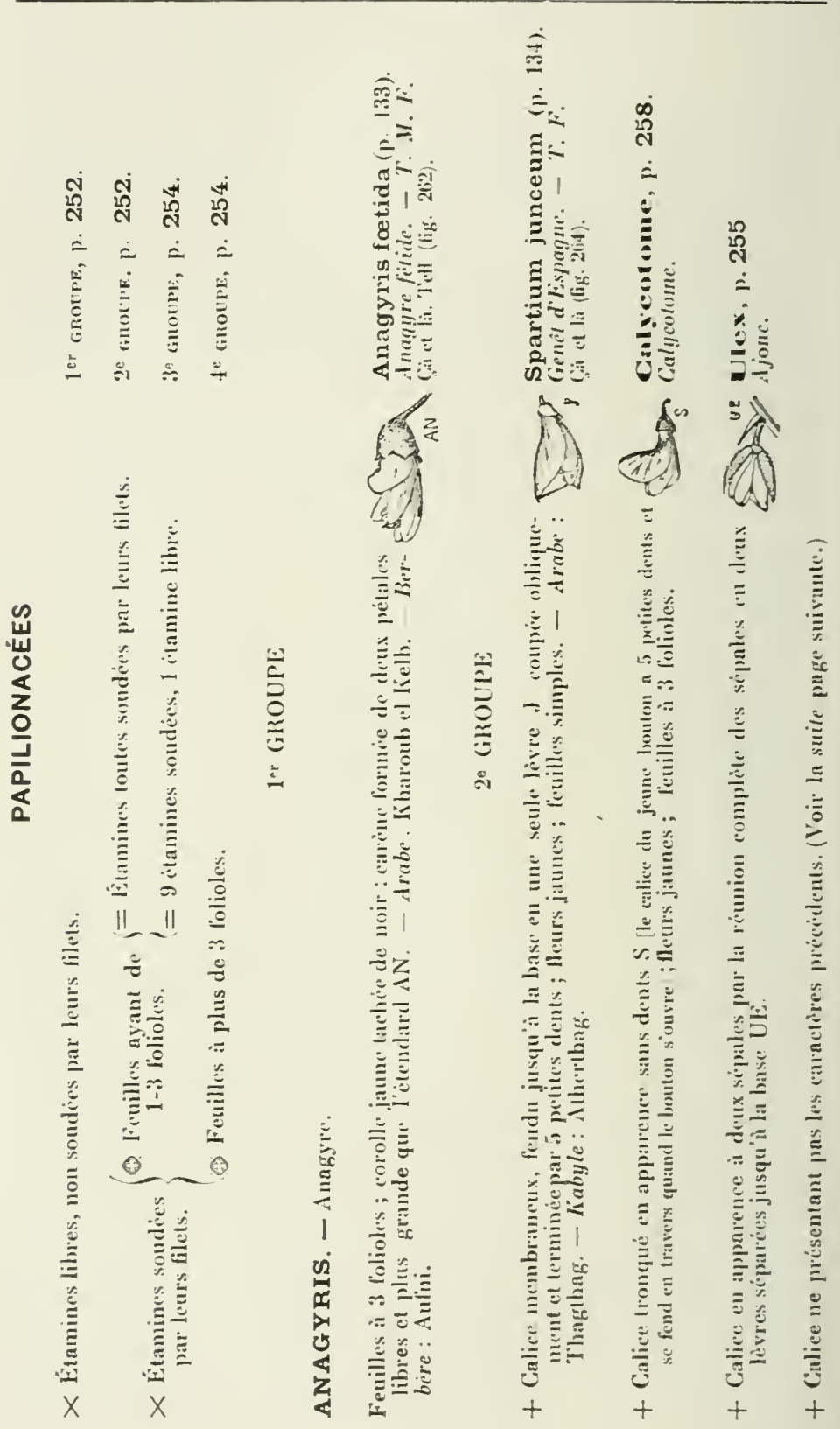




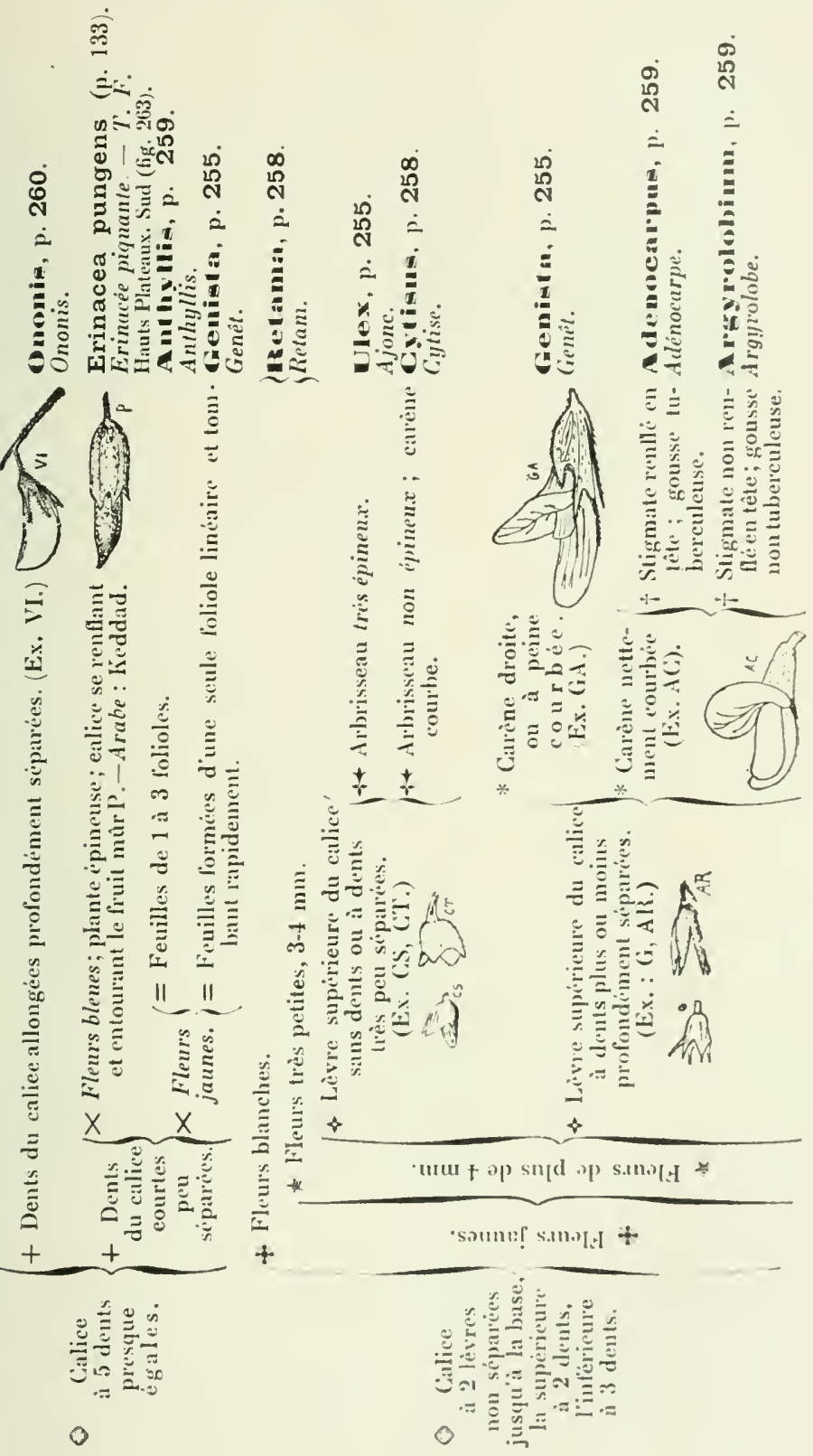




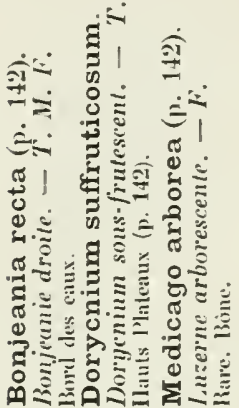
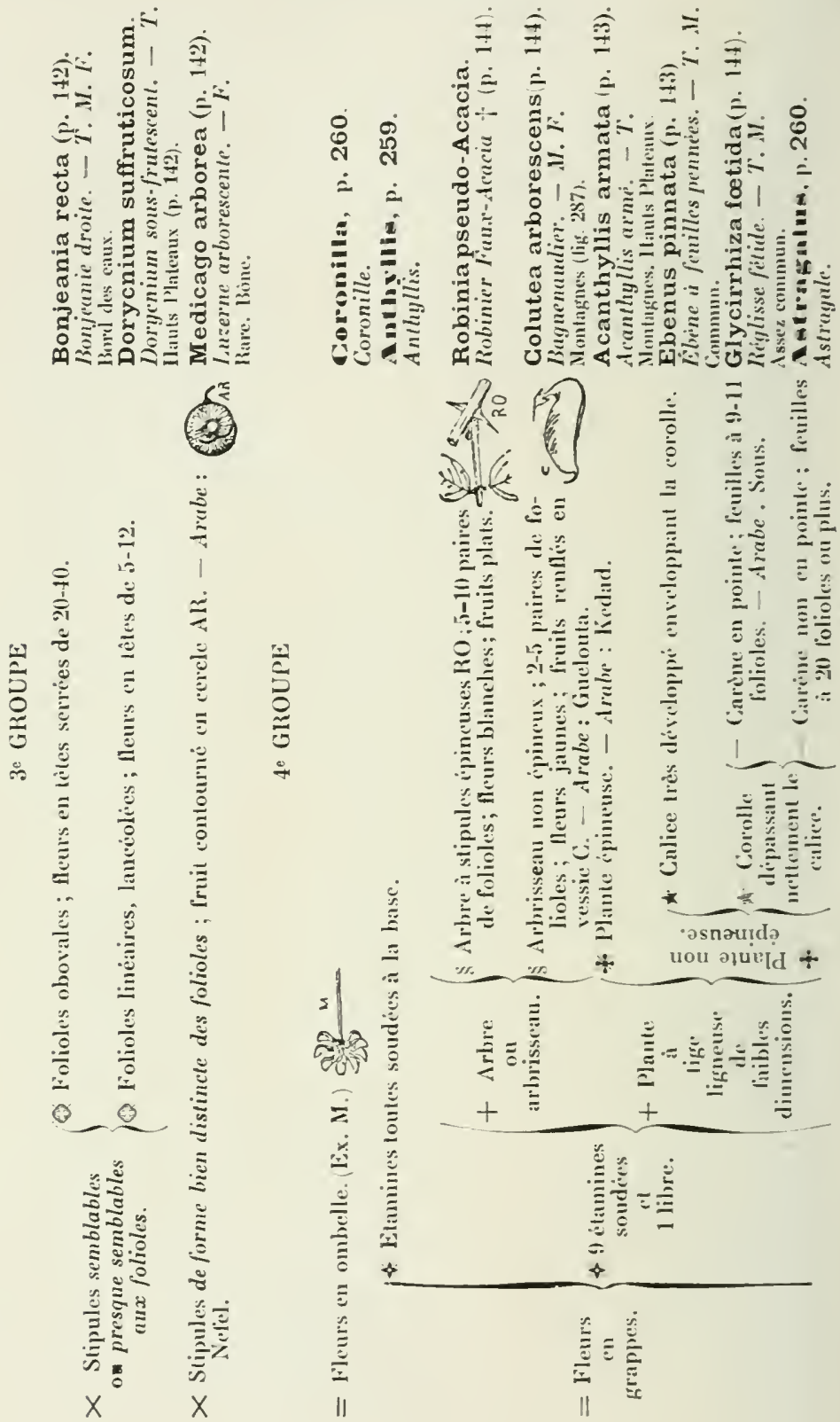


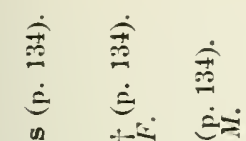

营

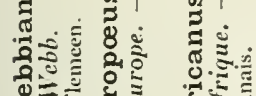

उ。

范

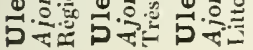

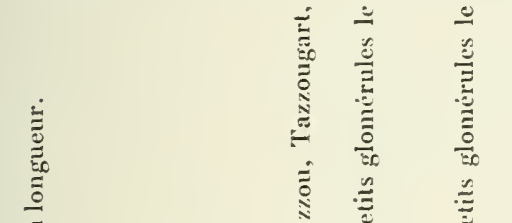

草

ะ

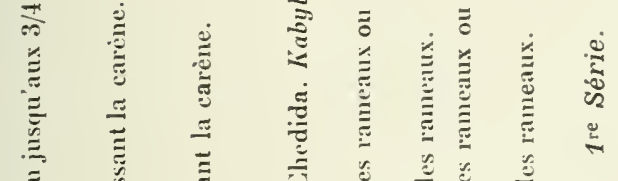

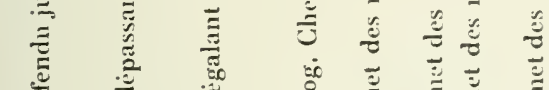

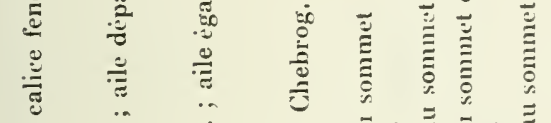

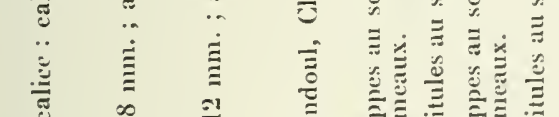

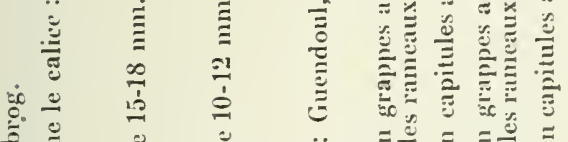

势

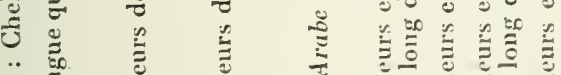

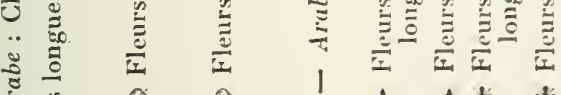

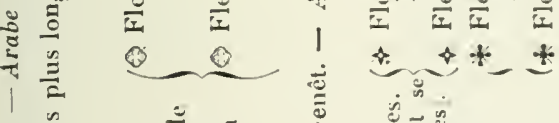

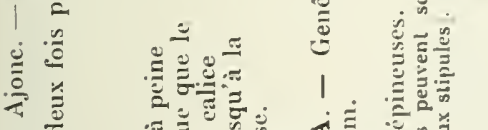

突

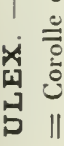

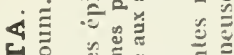

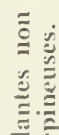

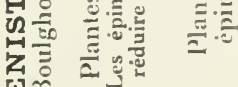

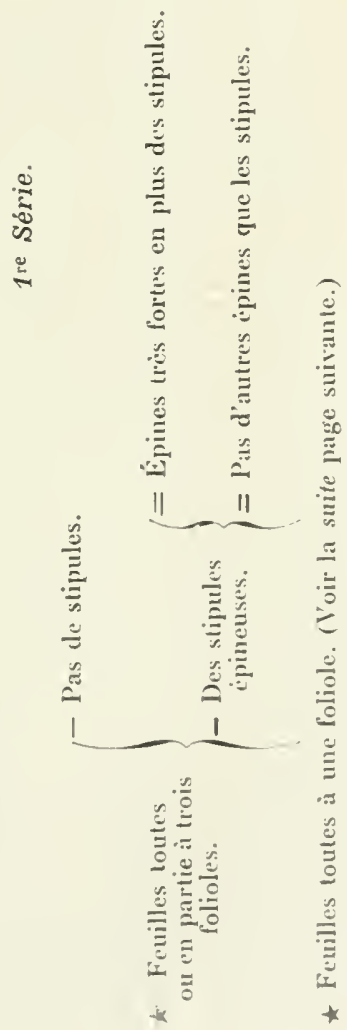




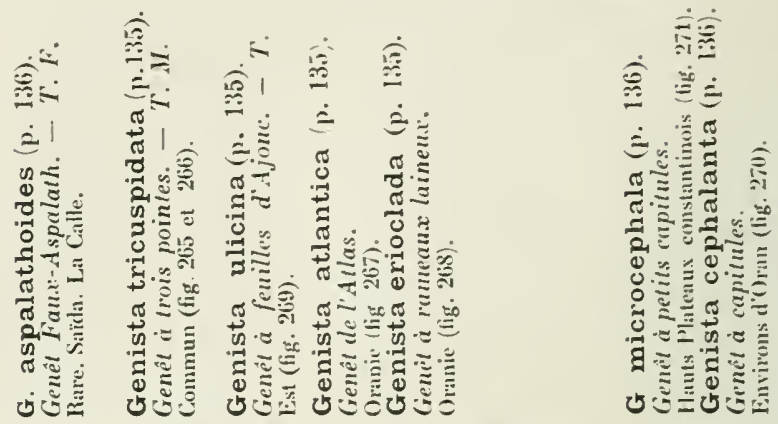

בֶ.

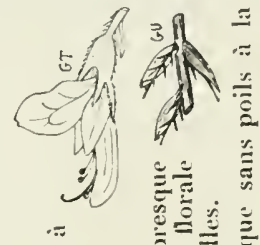

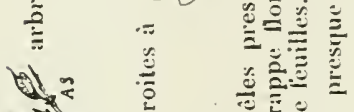

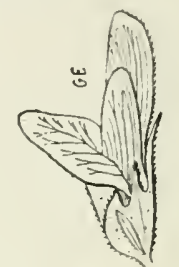

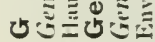
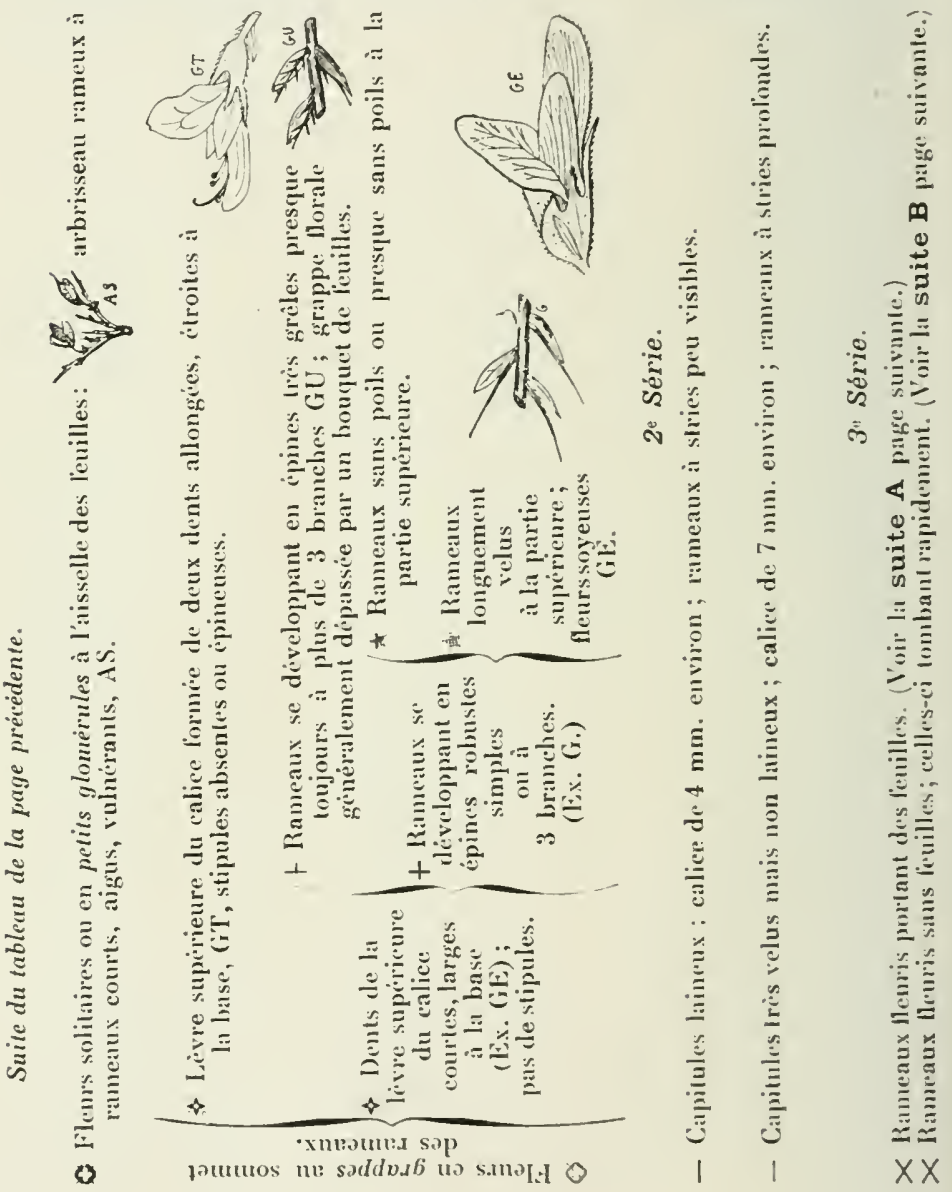


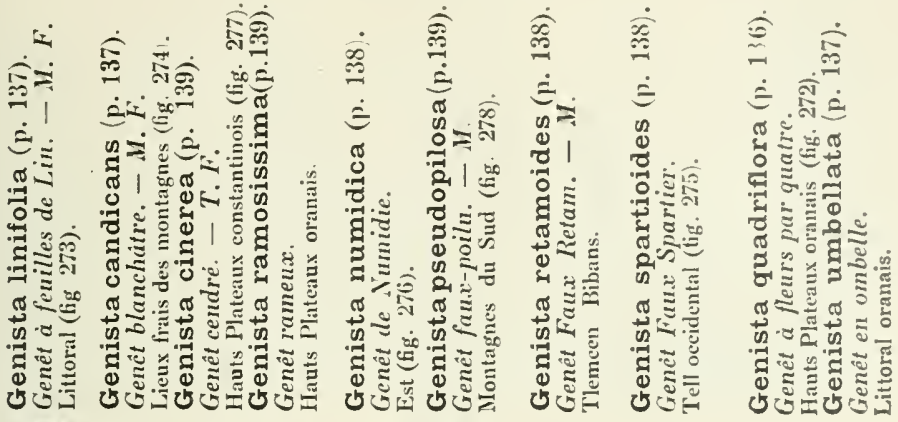

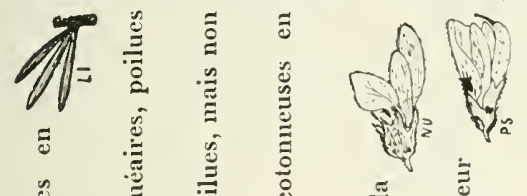

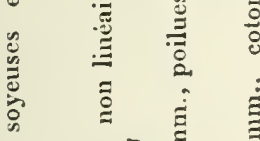

尊

W. $\overrightarrow{0}$

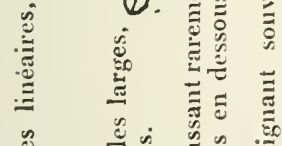

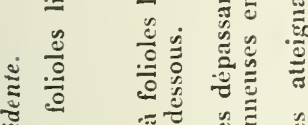

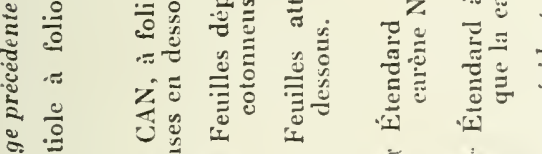

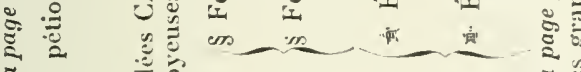

¿ s.

要

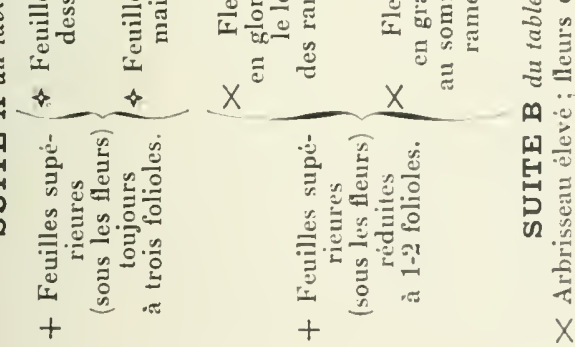

FLORE FORESTIÈRE

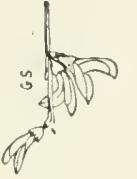

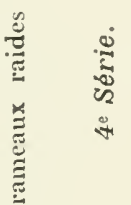

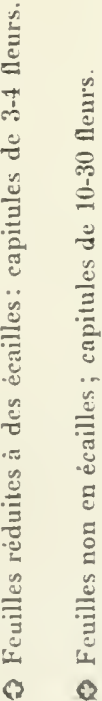




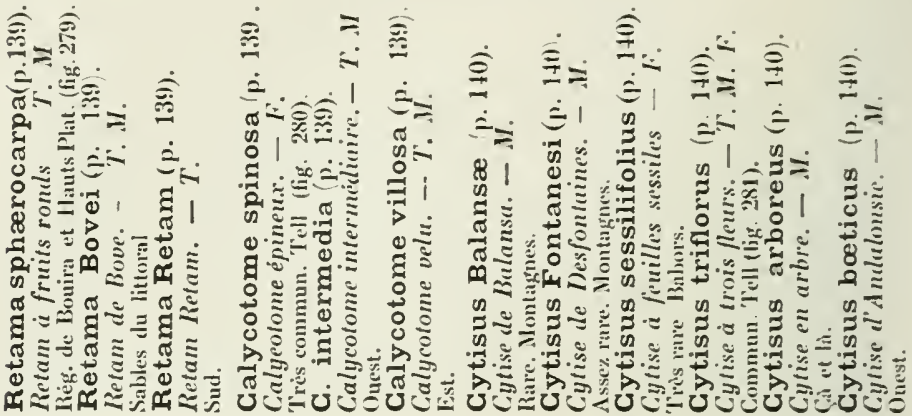

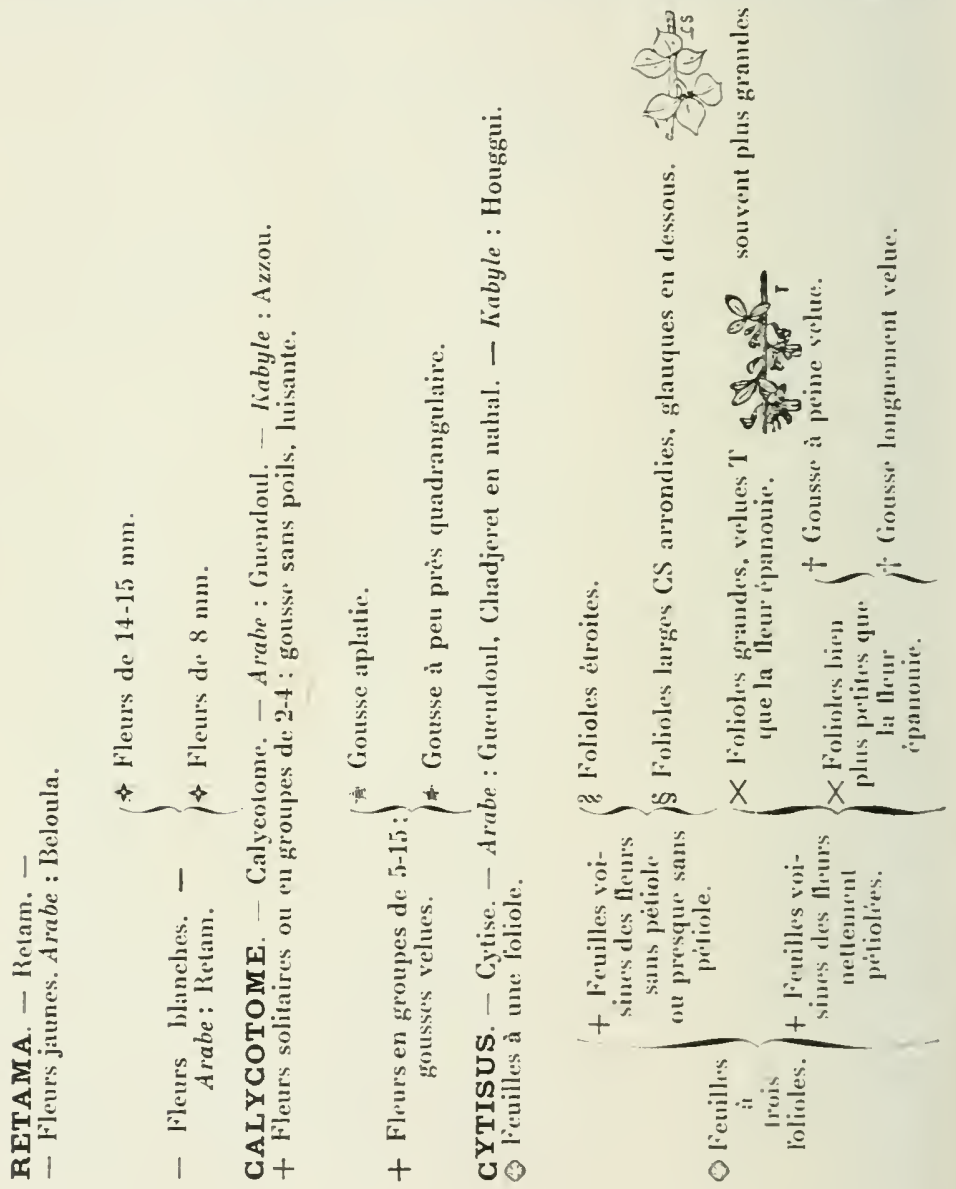




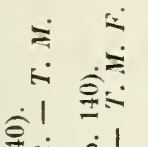

运 $\doteq$ !

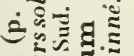
ฉ ㄷำ व.

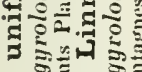

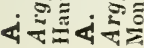

竎

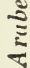

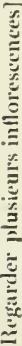

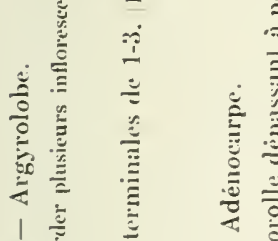

跣苋

क क

m.

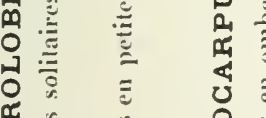

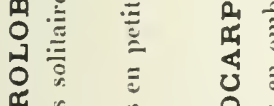

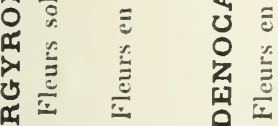

40

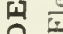

\&

今气

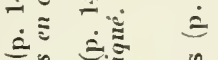

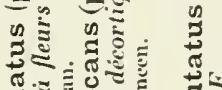
ส.

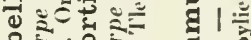

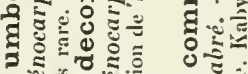
ब

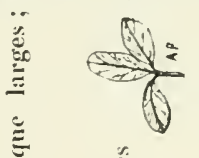

ह

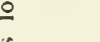

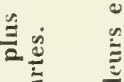

ङ

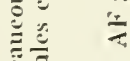

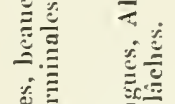

包

总产

㱐

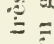

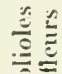

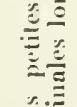

$$
+
$$


家宁

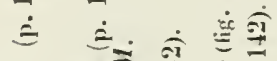

解

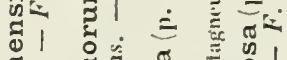

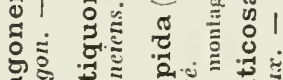

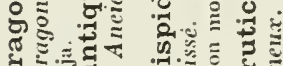

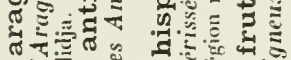

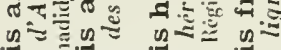

茨.

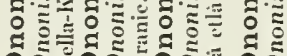

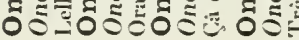
ప

童

de

항

ב

ت

궁

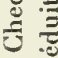

है

1 昰

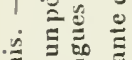

范

ह

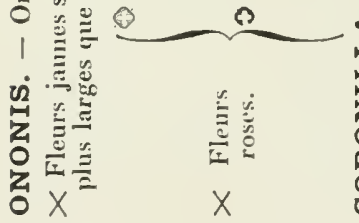

ธo

\#

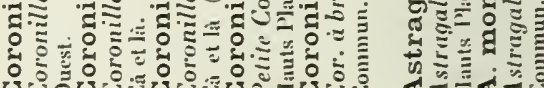

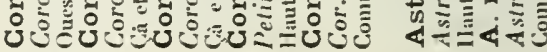

芒

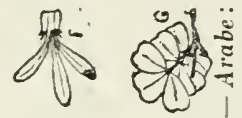

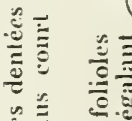

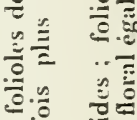

so

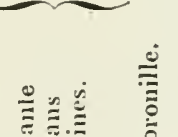

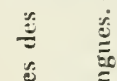

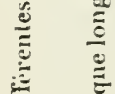

氖 苍

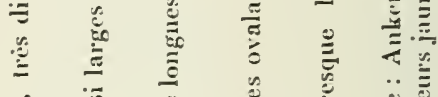

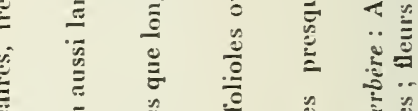

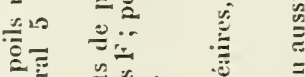

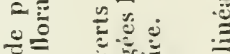

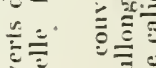

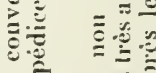

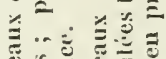

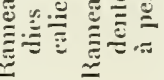

II II

का

䓂

$\geq z$

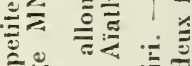

急

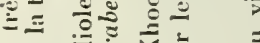

ํำ

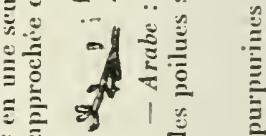

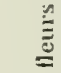

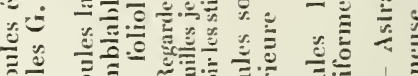

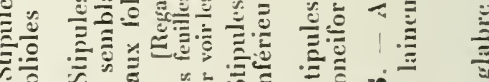
.

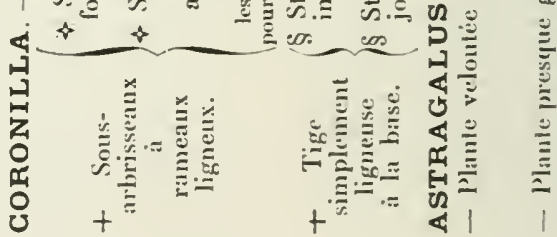



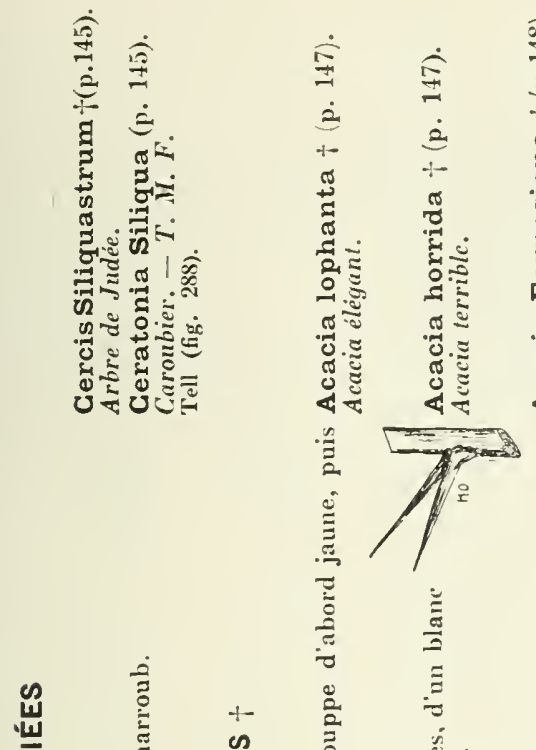

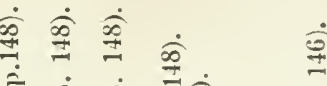

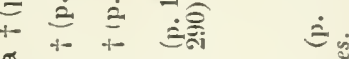

ส ป

जี่

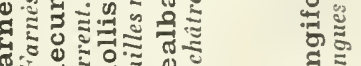

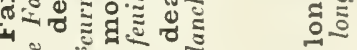

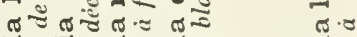

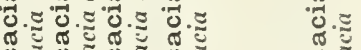

४

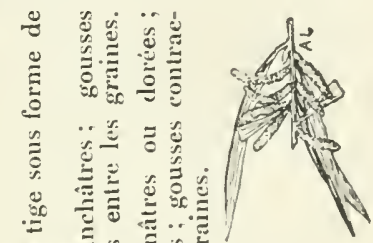

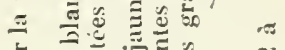

出

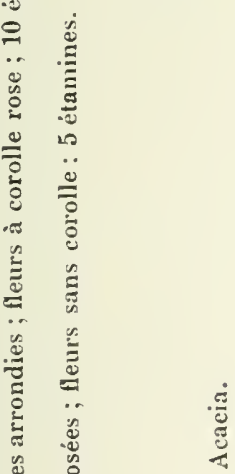

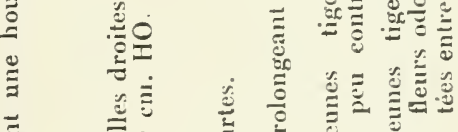

$\Rightarrow$ 赵

$2 \quad$ 玹

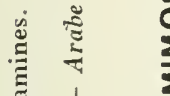

茯

$5 \quad$ वें

ป

$\rightarrow \quad 5-$

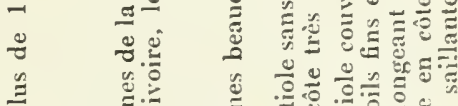

‥

รีำ

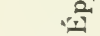

言

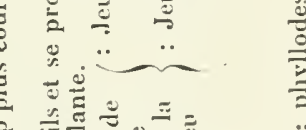

ב

\%

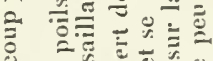

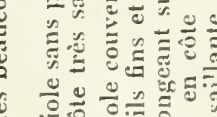

运造

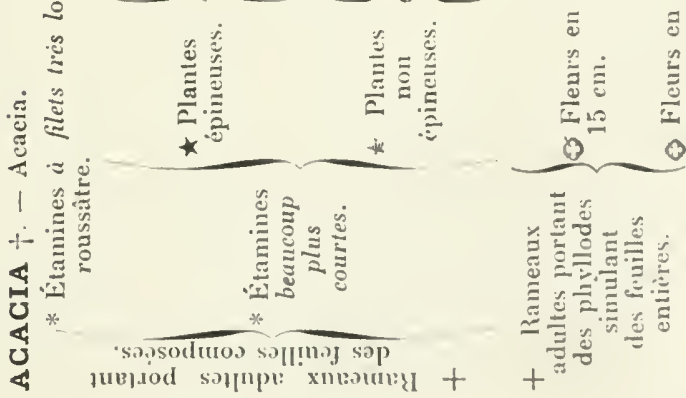




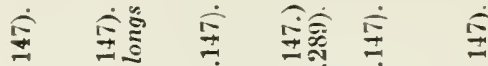

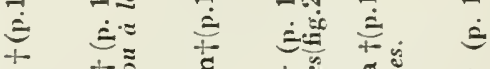

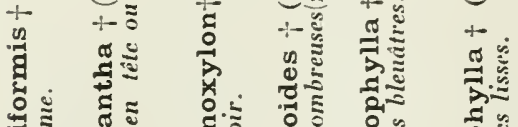

पुछ

范

ส

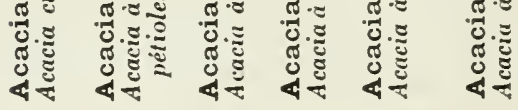

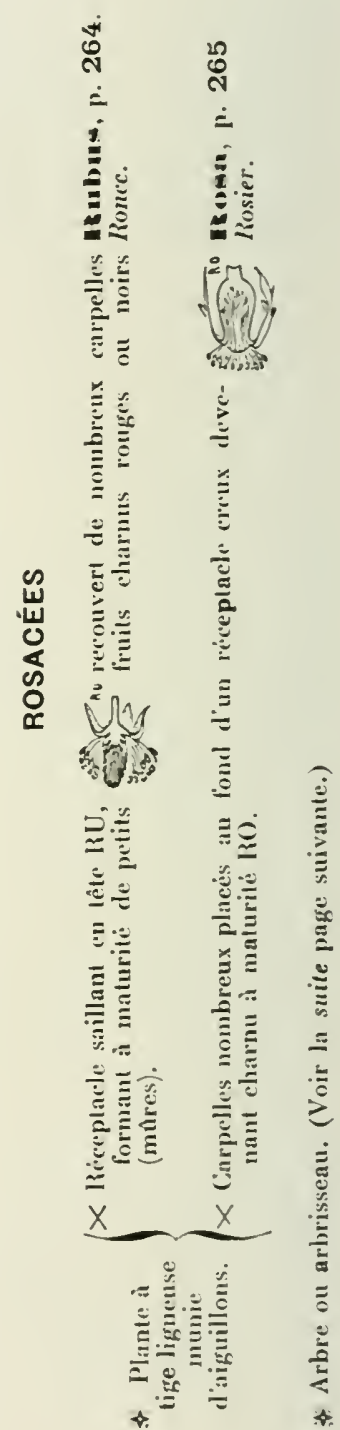




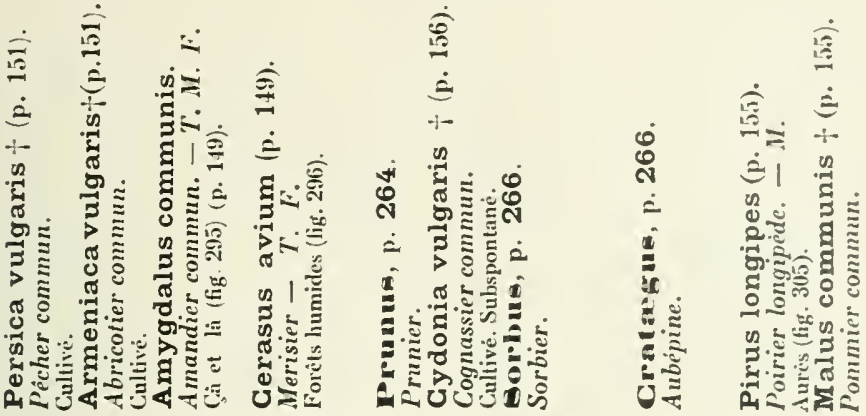

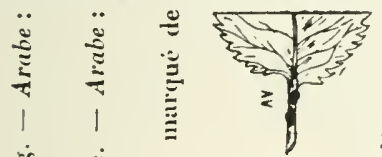

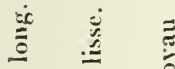

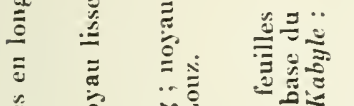

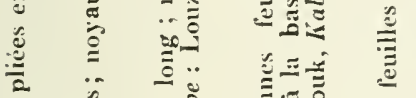

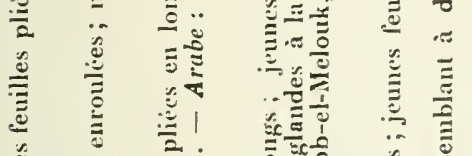

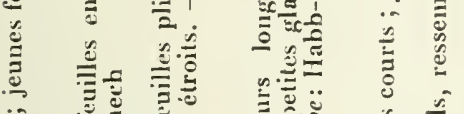

$\cdots \quad$

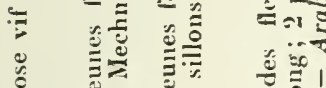

०

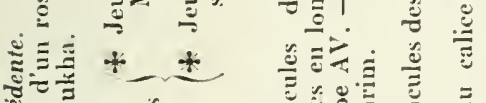

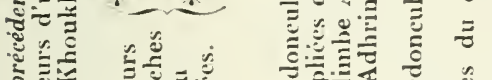

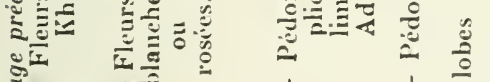

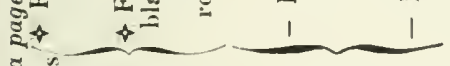

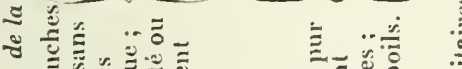

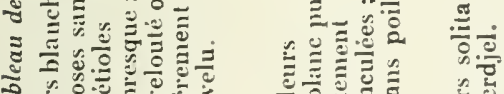

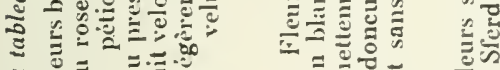

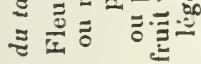

$\stackrel{\Xi}{\tilde{\Sigma}}+$

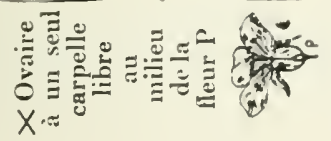

0

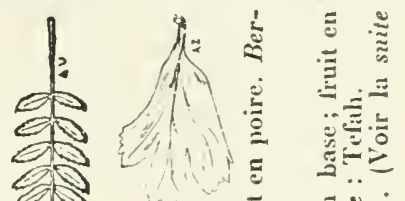

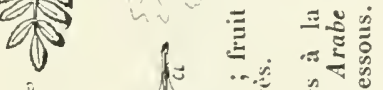

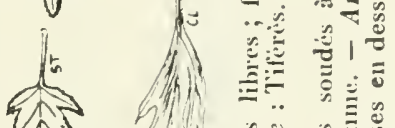

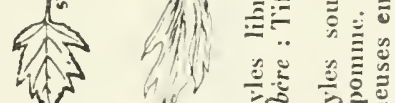

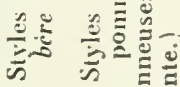

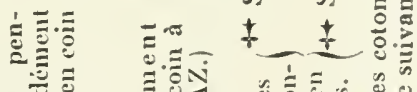

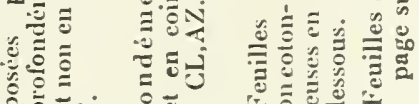

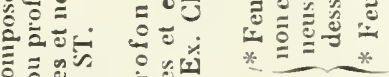

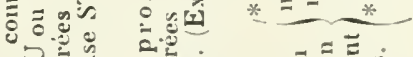

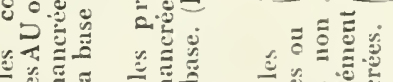

II

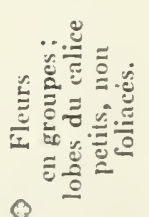

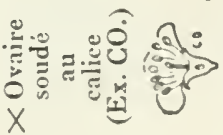




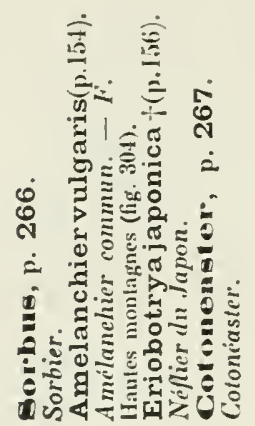

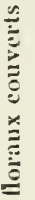

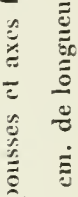

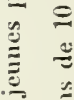

$\therefore \stackrel{\Xi}{\approx}$

气ุ

药

苛言

0 른

政

i

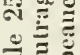

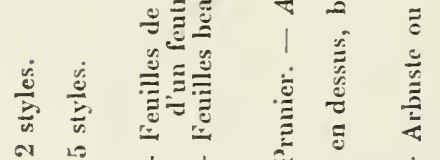

$\approx$

I. 1

ॠ

$\stackrel{乛}{\Xi}$

$+$
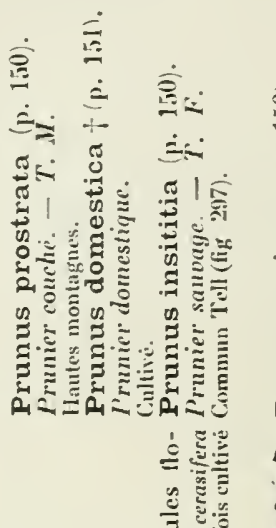

는

อ

:

ڤ

$\stackrel{3}{3}$

$\because \quad$ כ.

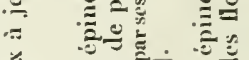

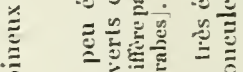

즐

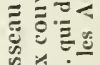

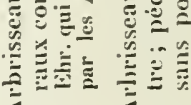

范

$\Xi \vdots$

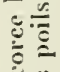

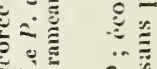

$=$

$\because \bar{\sigma}$

$\bar{\sigma}$

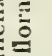

$\frac{2}{3}$

$2=$

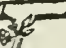

3ै

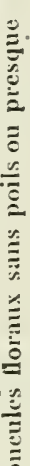

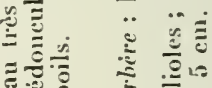

¿

इำ

我

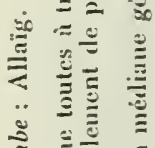

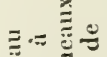

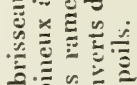

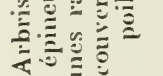

$+\stackrel{.}{\circ}$

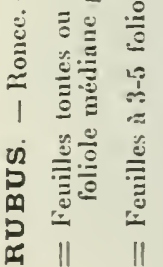

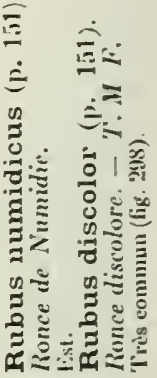

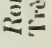

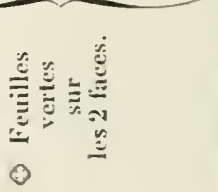
$\underset{*}{* 0}$
象 
$\therefore$ 宊主

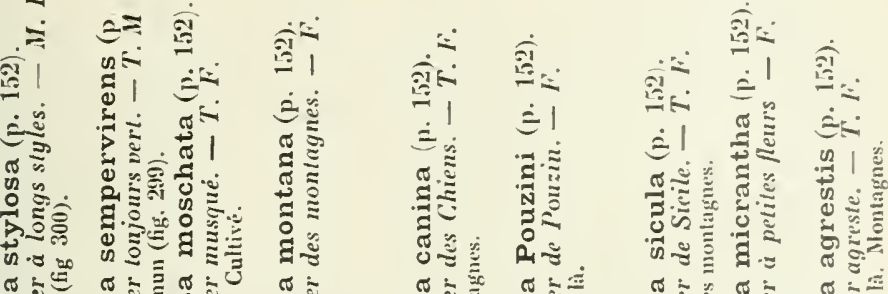

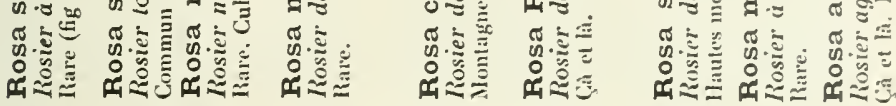

$\stackrel{5}{\frac{5}{2}}$

$\Xi \stackrel{\dot{0}}{\approx}$

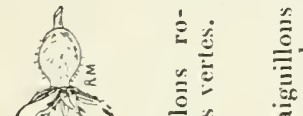

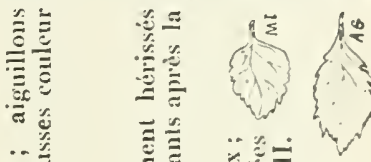

$\approx$

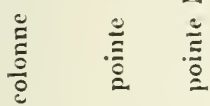

$\stackrel{1}{=}$

ํํำ

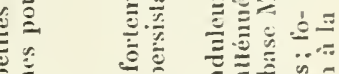

$\because \quad$ ह

-

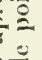

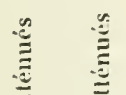

อ

远

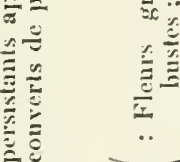

管

然

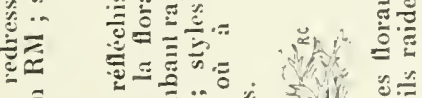

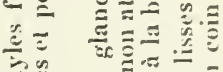

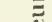

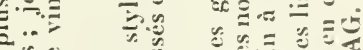

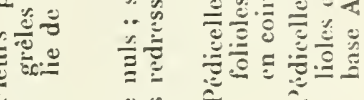

亏ัँ

运的

递市

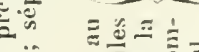

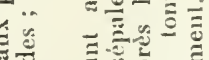

先.

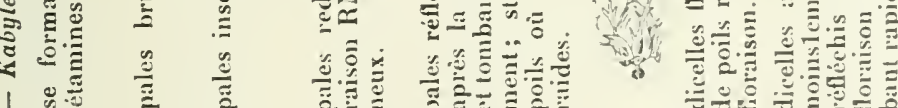

1.

造爮导

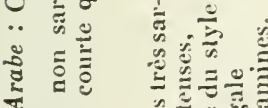

1 苛告

मे

芯高 兰

○

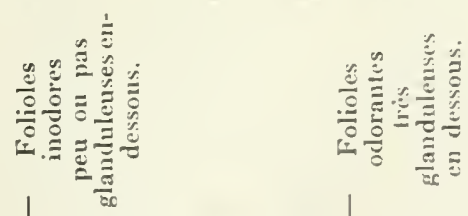

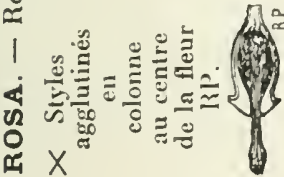

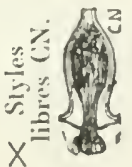




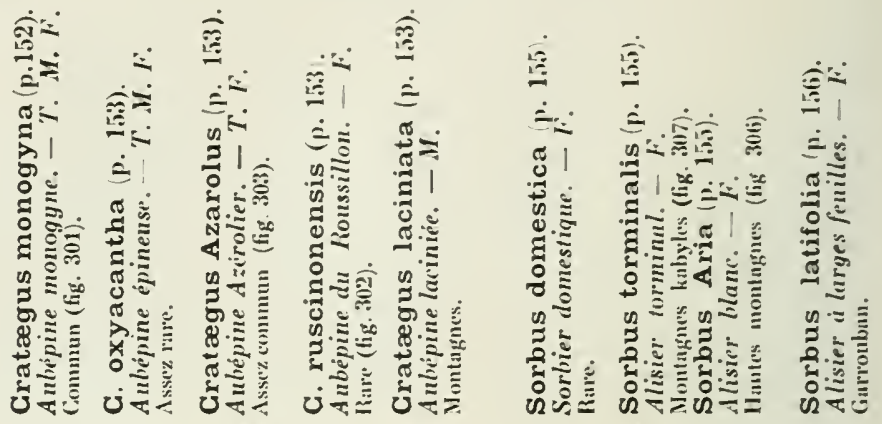

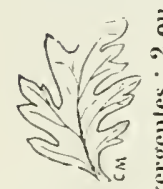

‡ฏ

范

$\ddot{3} \quad$

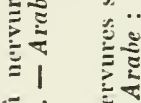

$\because \dot{\Xi}$

$\overrightarrow{8}$

을

드둥

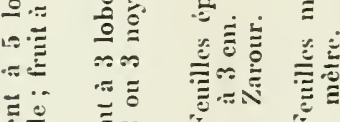

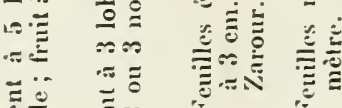

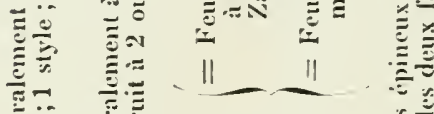

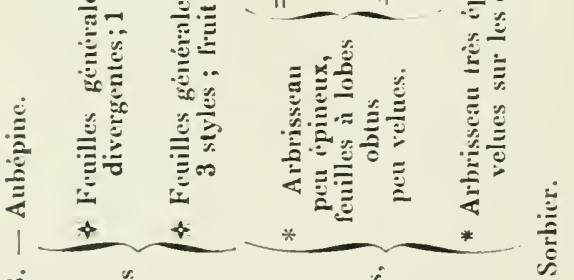

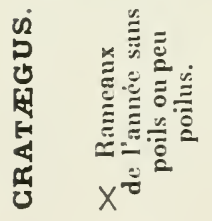

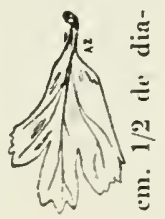

छัฒ

$\because \frac{5}{\square}$

㭉产

范晜

身

1

范

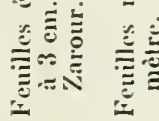

in

ב⿱艹

$\therefore$

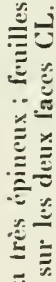

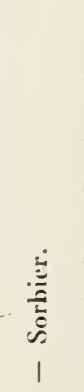

范

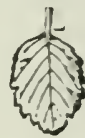

응

至

तD

Qu

莣

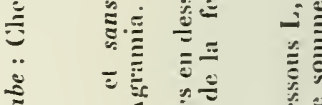

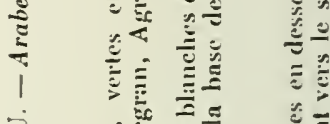

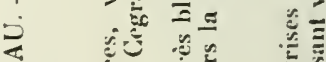

常

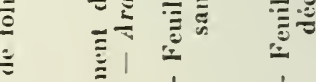

ב⿱艹

倠

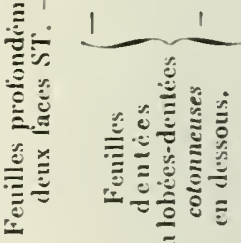

.. 


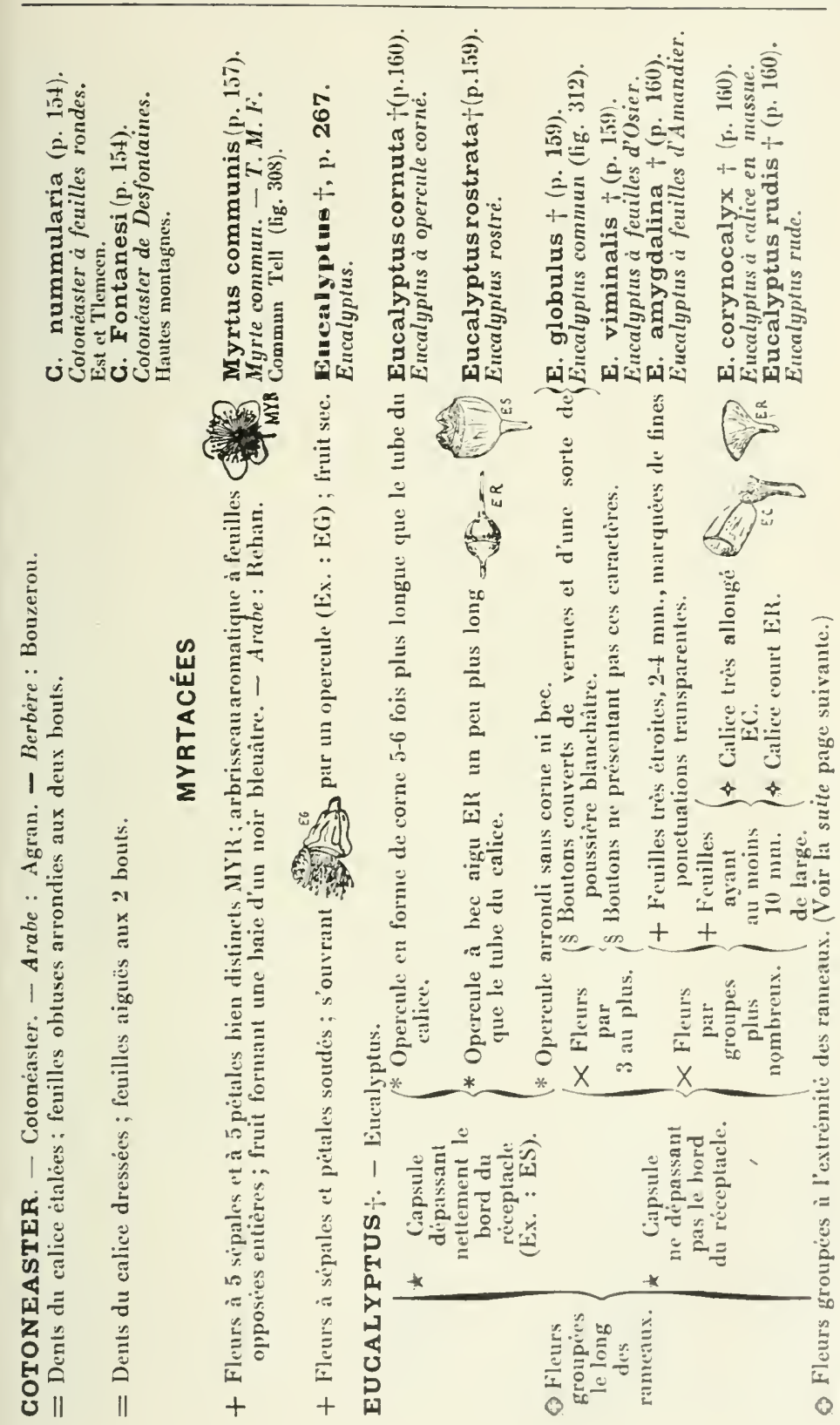


实高

要

ज्ञ

$\div-\overline{0}$

ฮชั

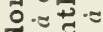

正

$\rightarrow=$

苟

ด园国

ڤ

葛

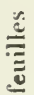

E

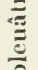

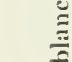

ن

ป

ล

$\circlearrowleft$ 气

ํㅡㄹ

$\cong$

$\approx$

छัँ

चี

जี

\section{(1)}



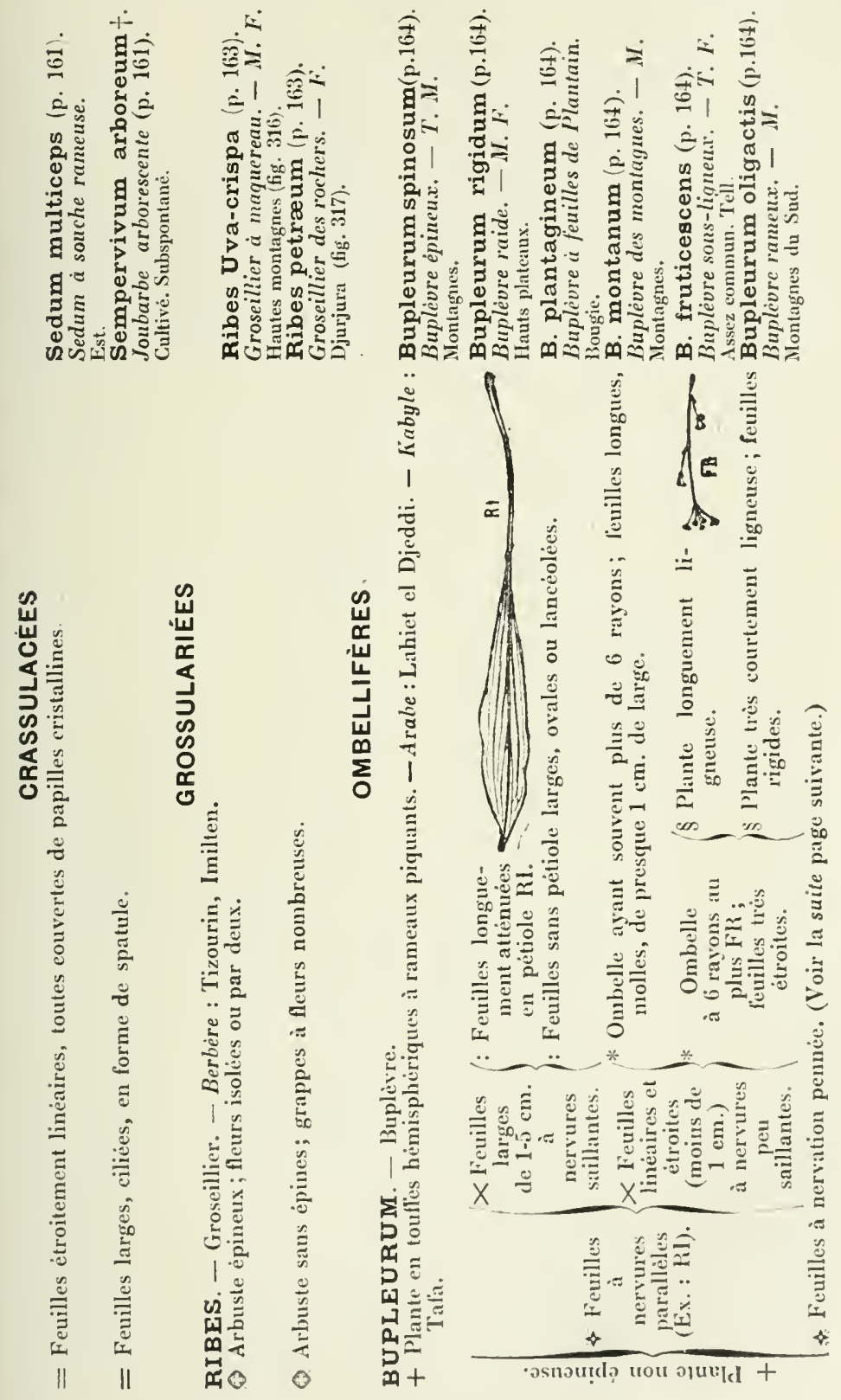

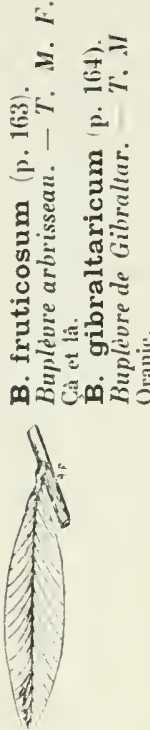

..

Е

文

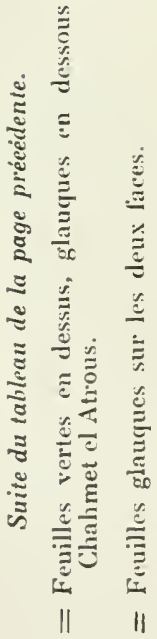

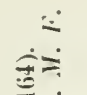

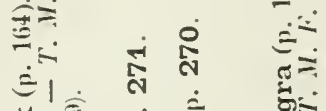

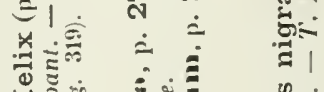

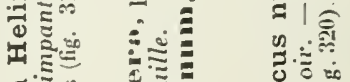

สำ

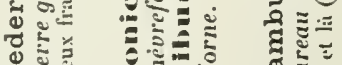

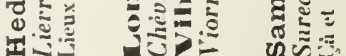

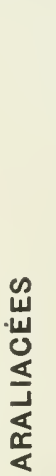

ฮ

造

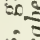

ế

(

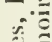

全.

遂

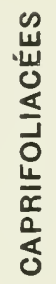

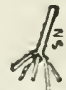

ing

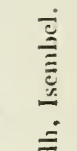

竞

芯

:

$\stackrel{0}{2}$

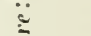

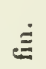

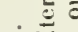

흐

(气)

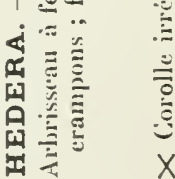
$+\frac{1}{2}+\frac{1}{3}$

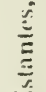

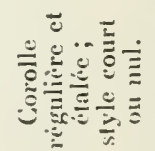

完
言 $\stackrel{\dot{\hat{E}}}{\dot{\Xi}}$

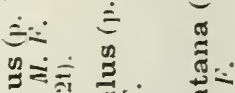

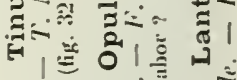
छ व․ 马를 ใดำ

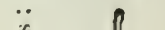
$=$ 刍

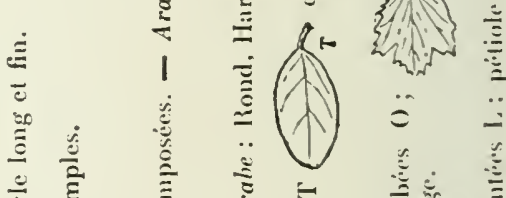
$\therefore$

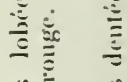

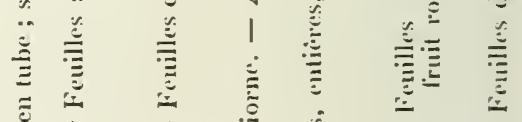
II 11

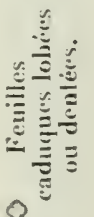




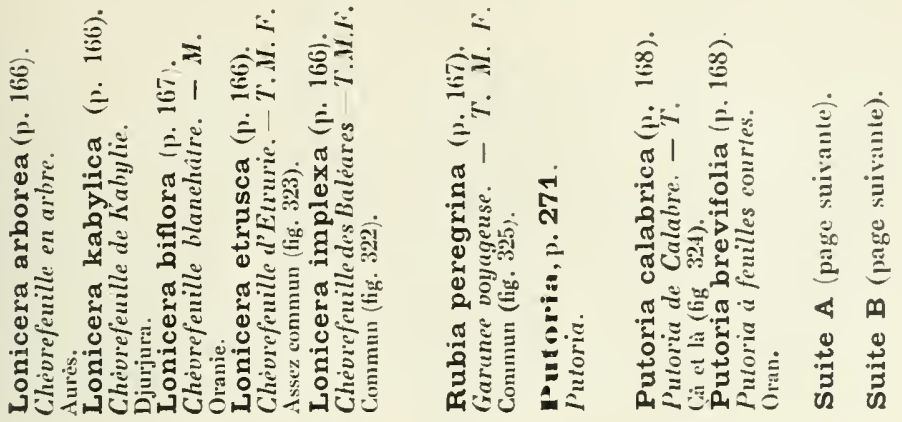

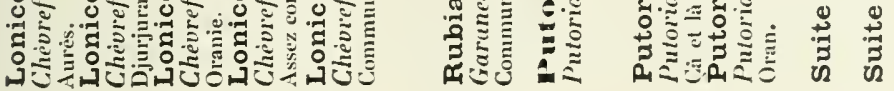
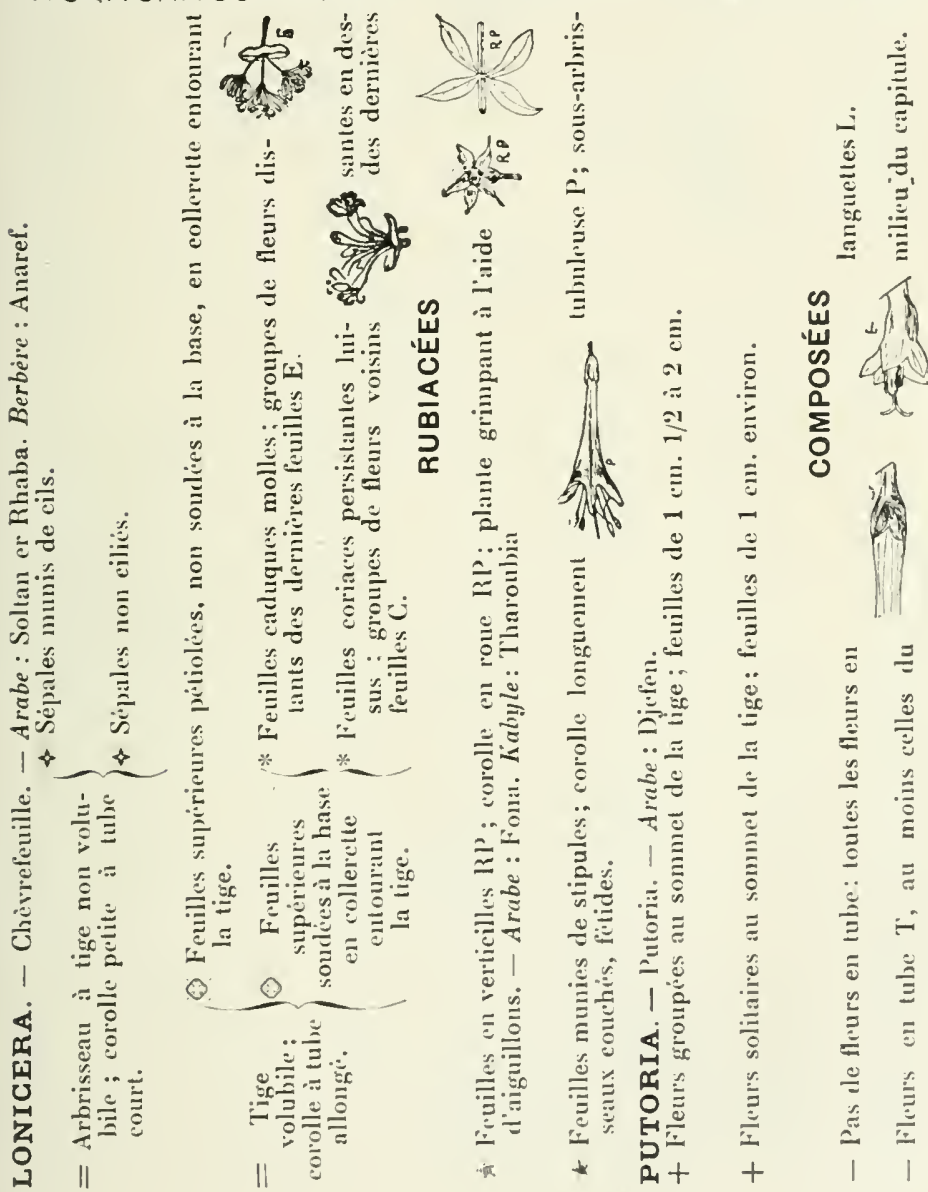


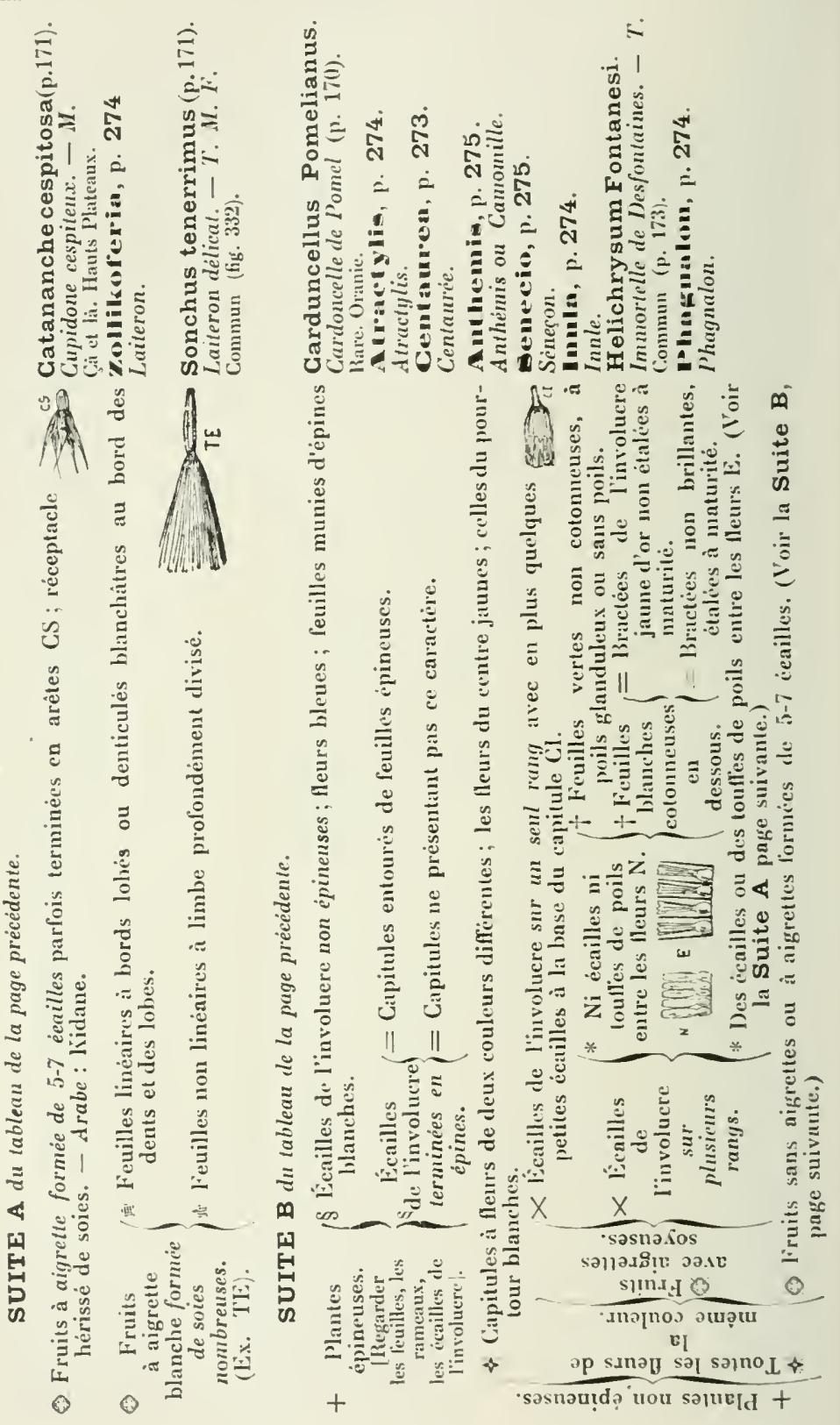




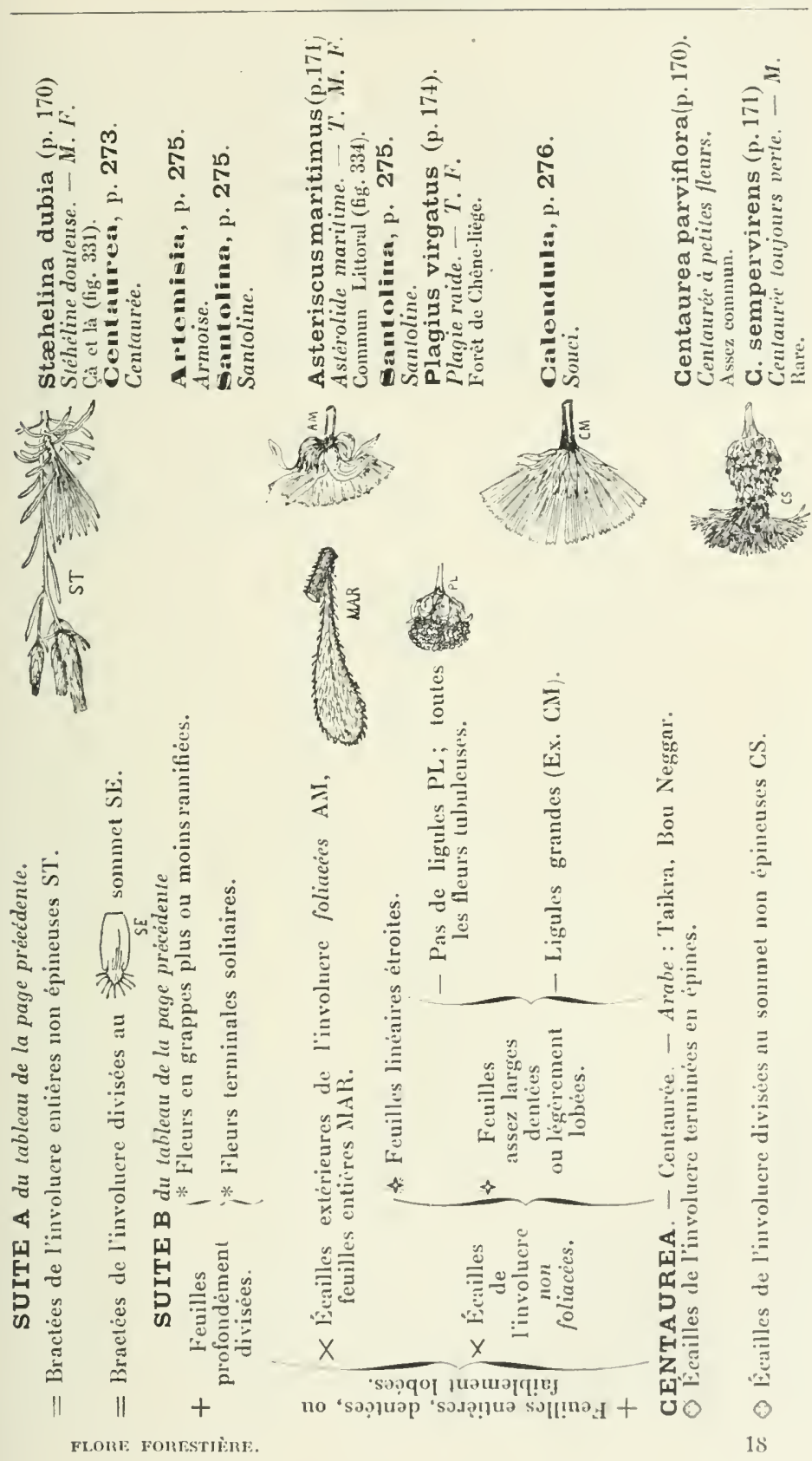



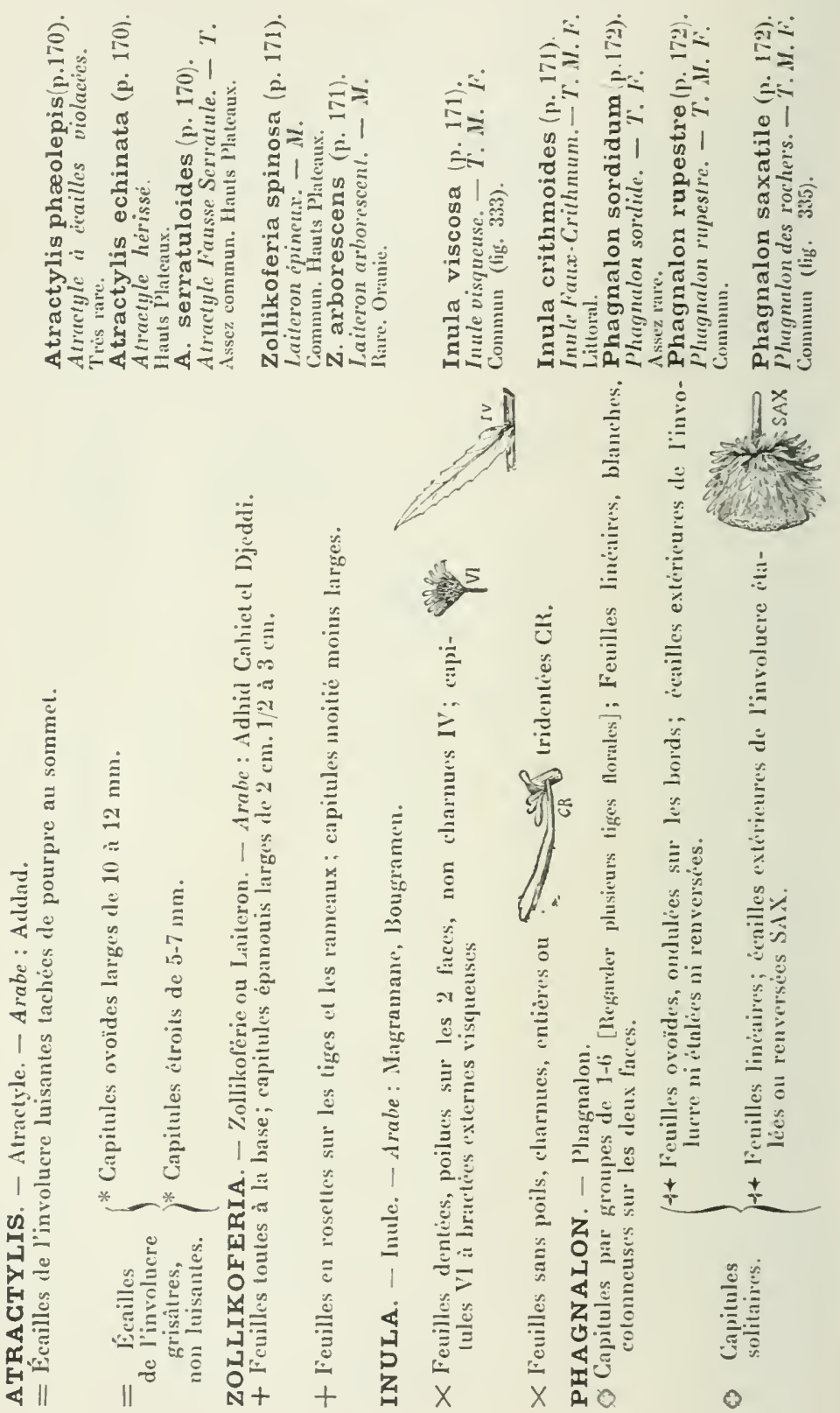


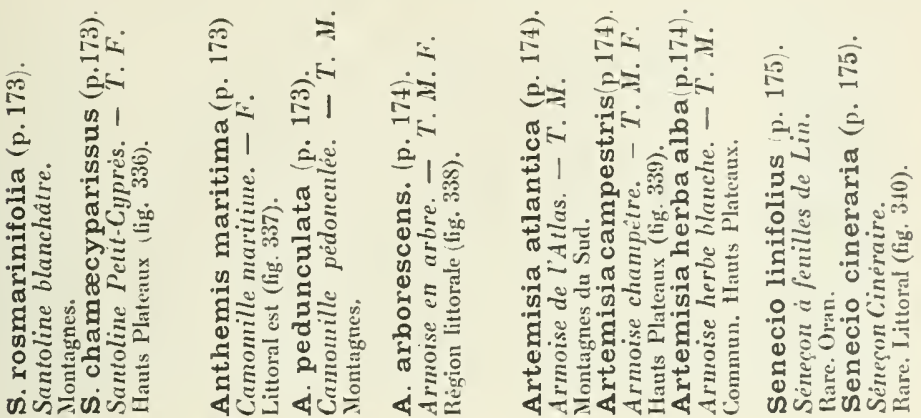

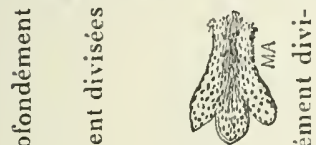

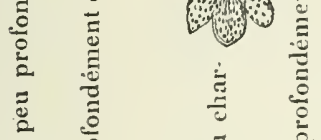

$\therefore \frac{0}{2}$

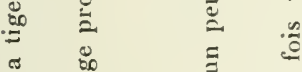

¿

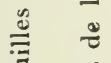

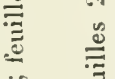

…

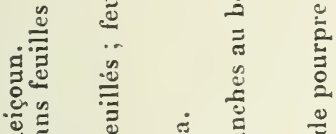

ปั

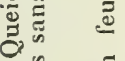

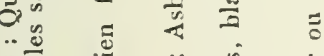

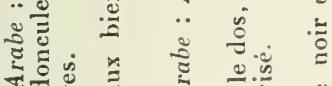

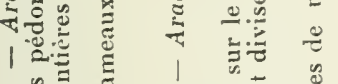

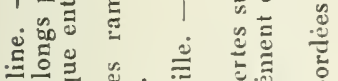

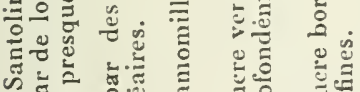

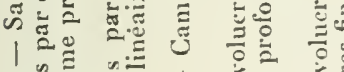

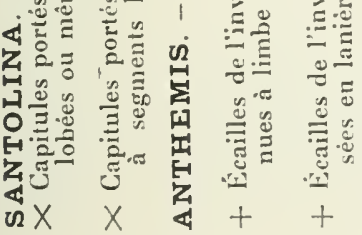

14

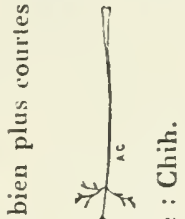

ป चौर

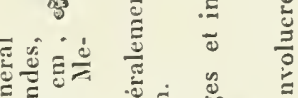

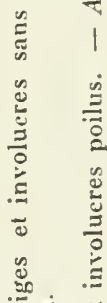

क

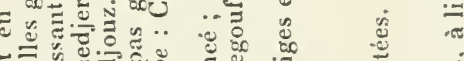

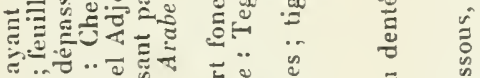

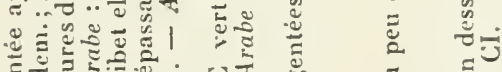

हैं

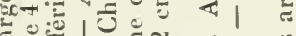

ही

.

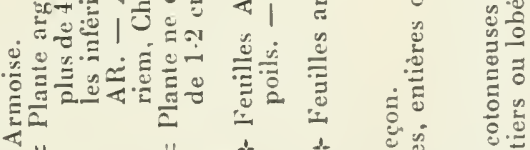

$111-\underline{11}+\frac{1}{4} \stackrel{0}{0}$

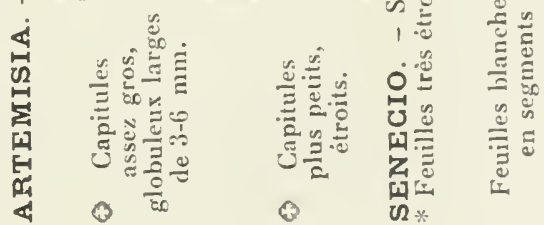




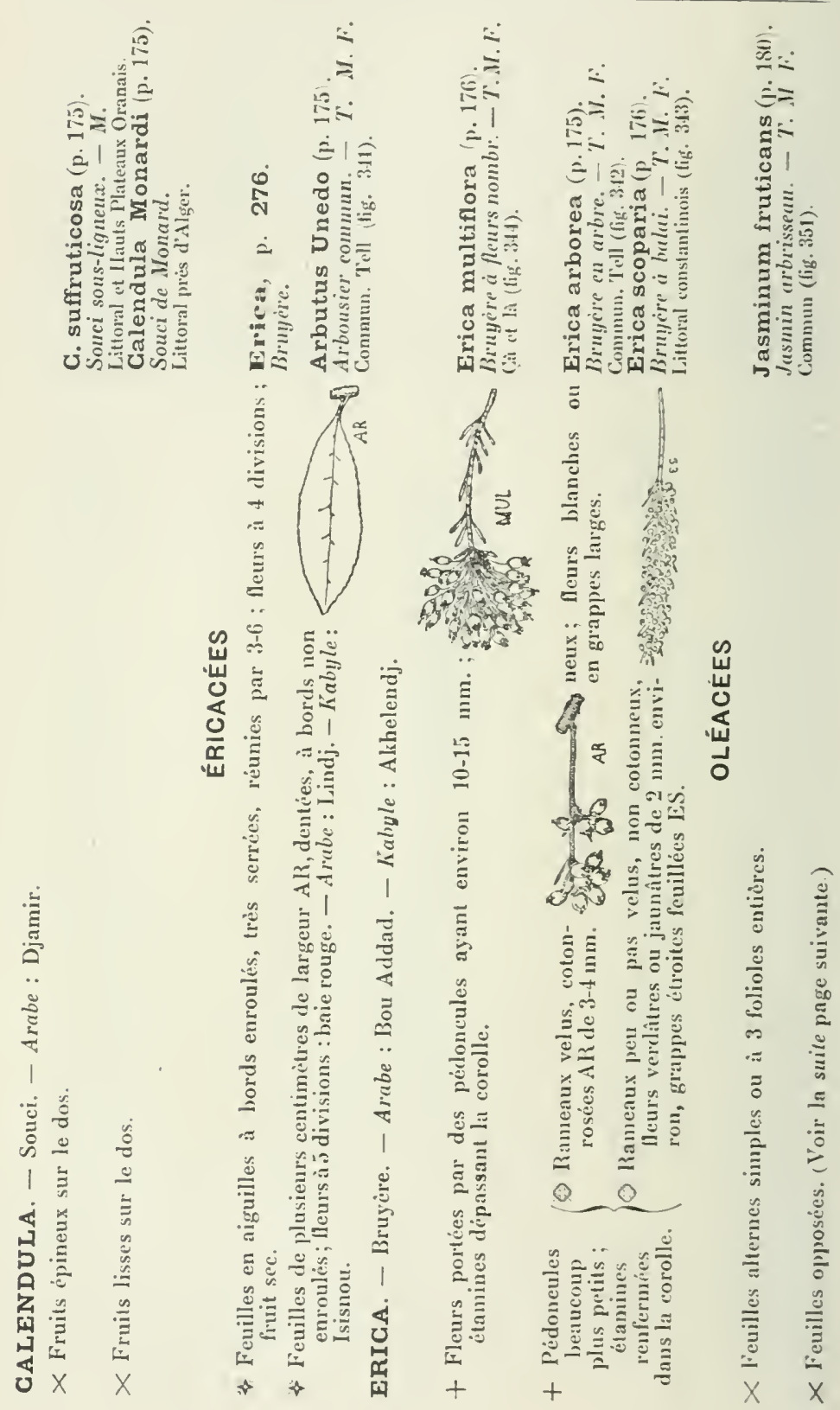




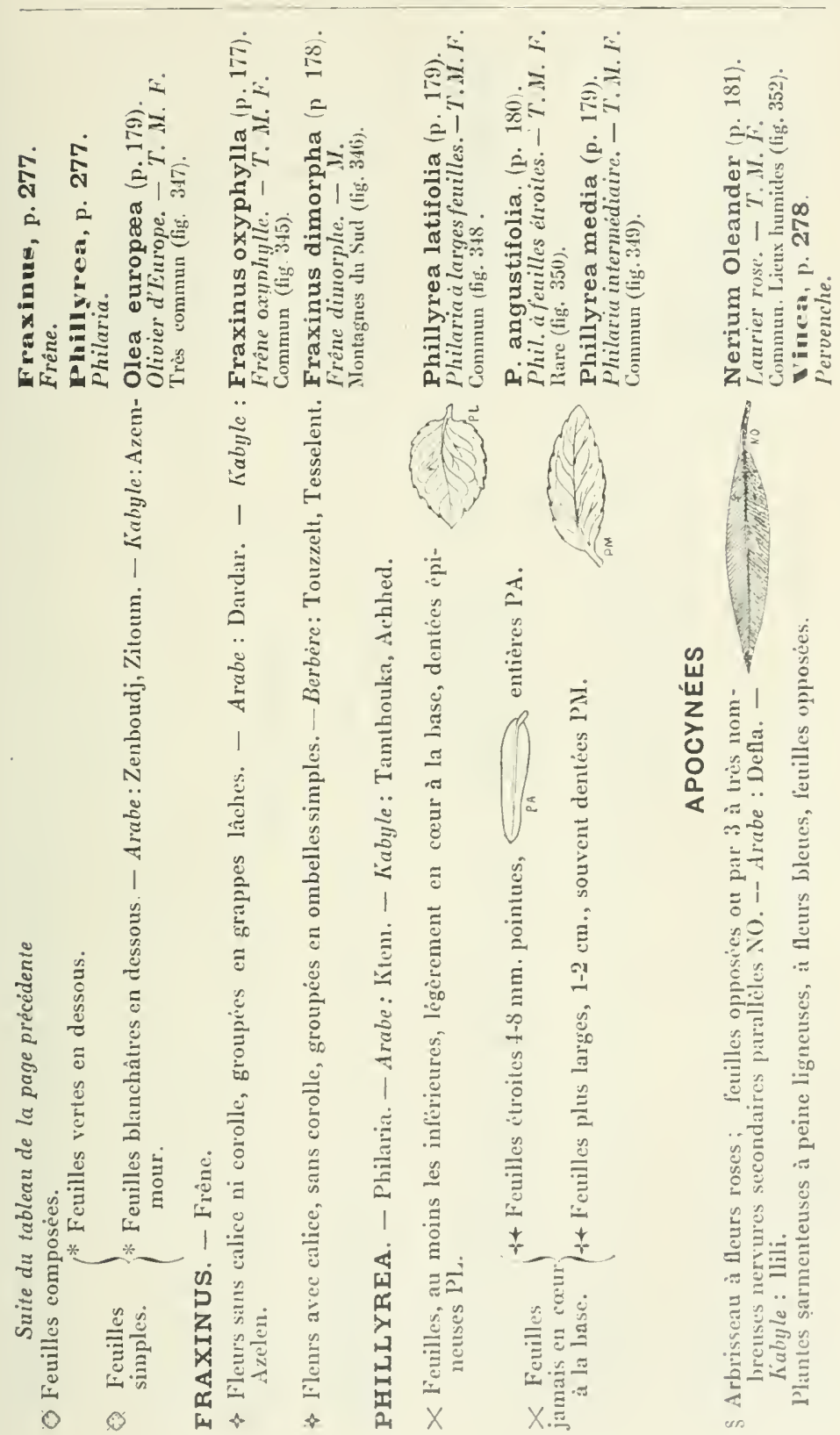




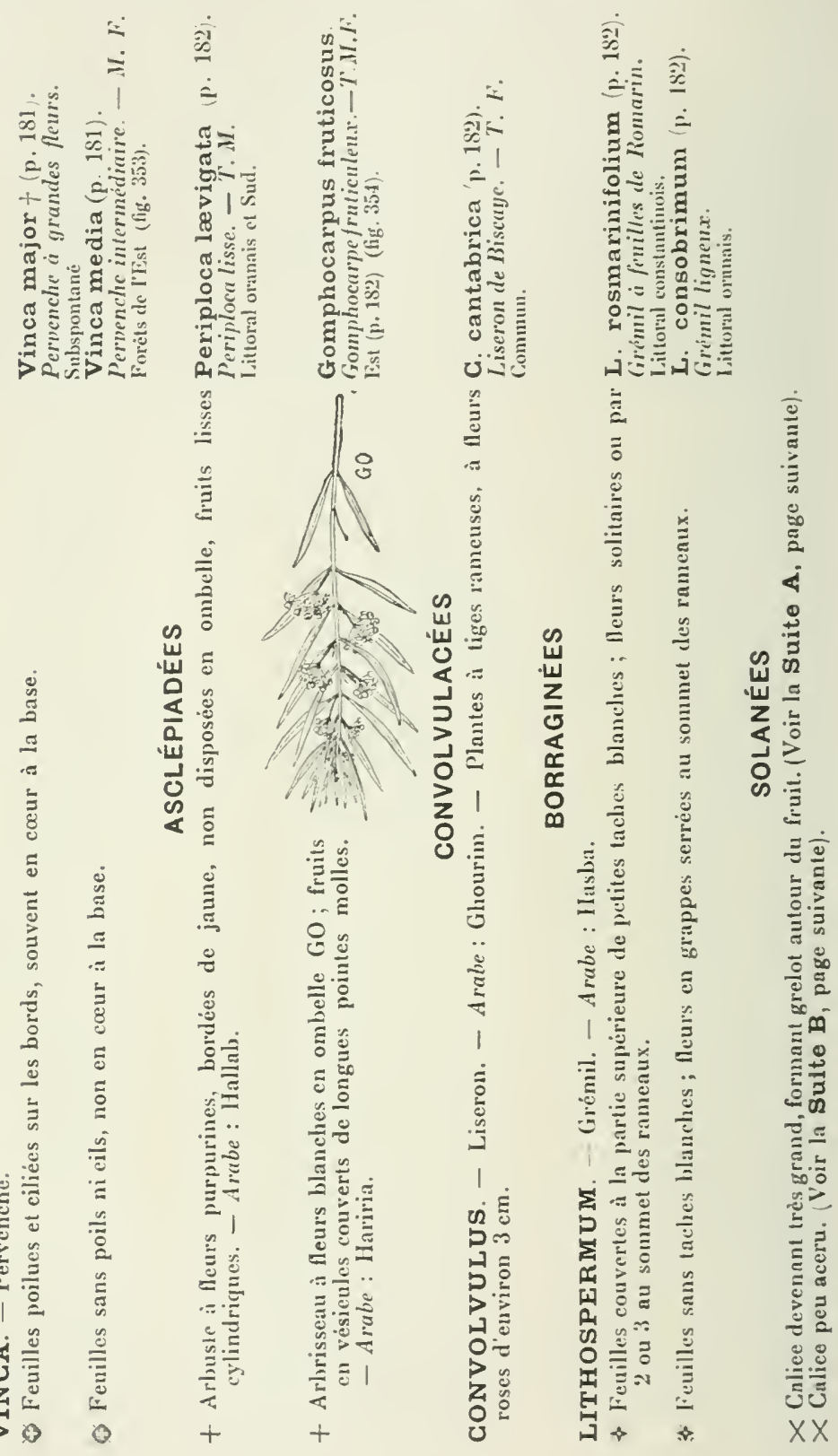



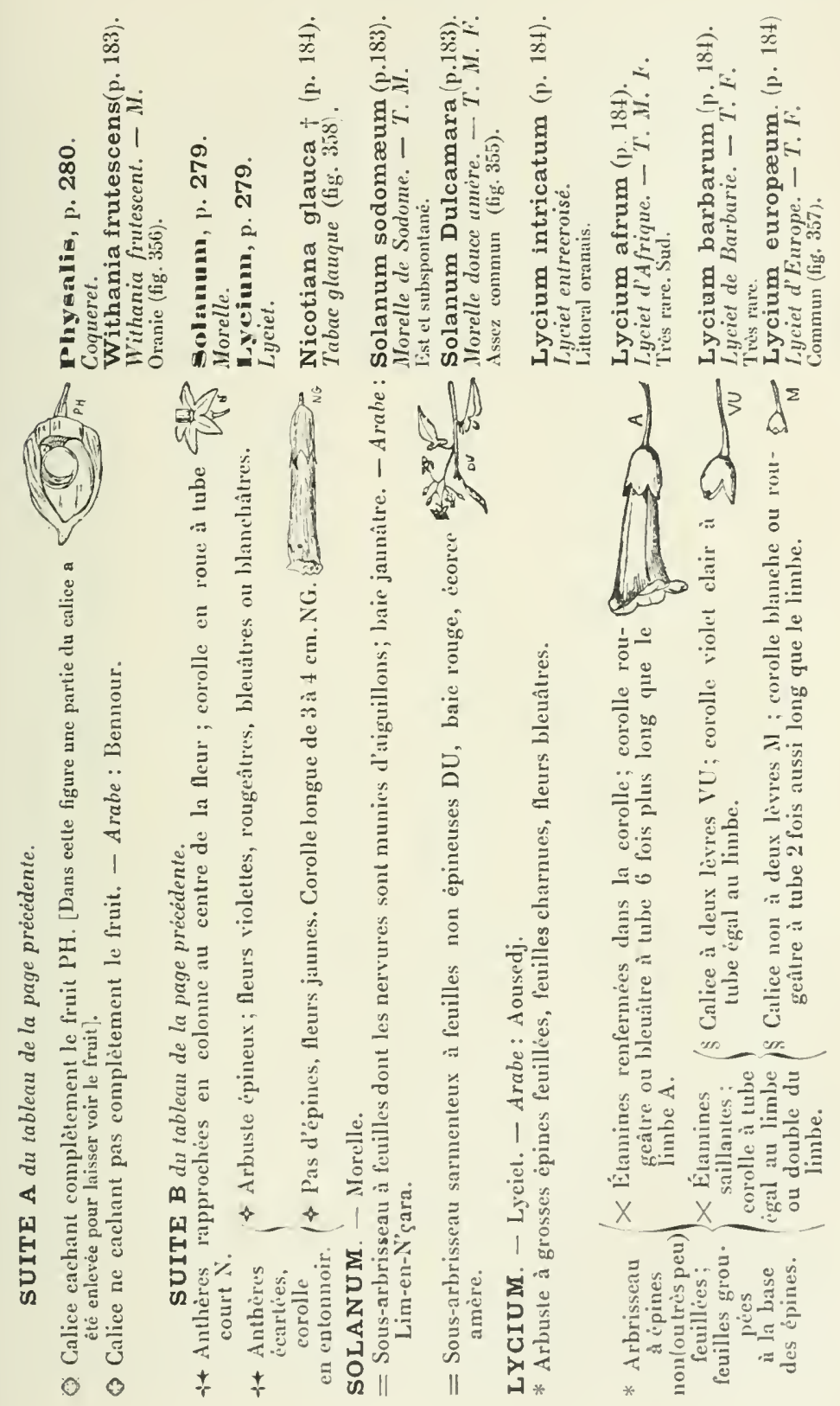

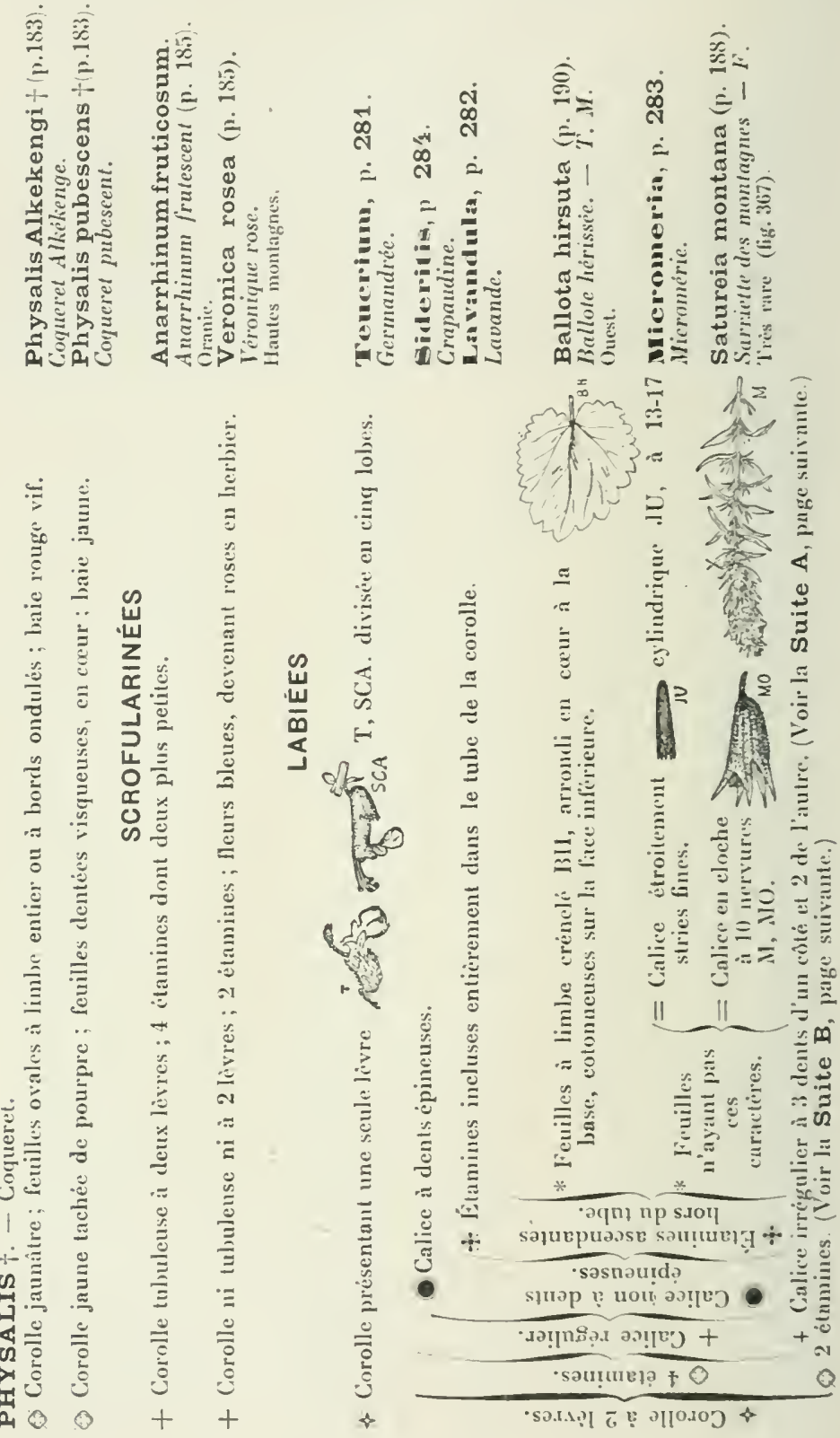


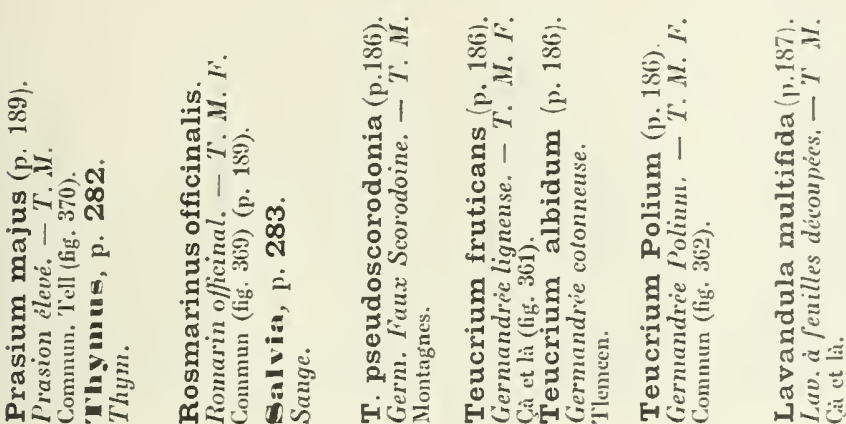

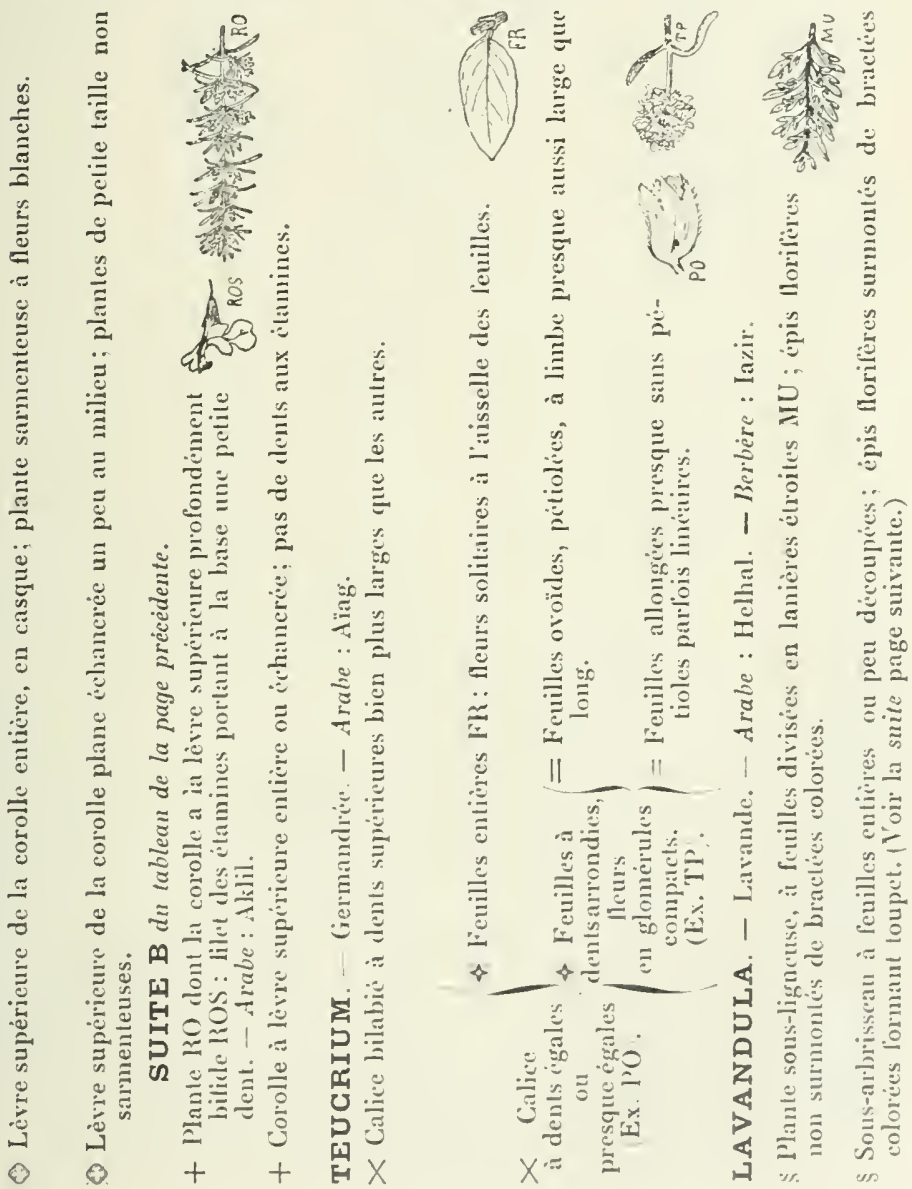



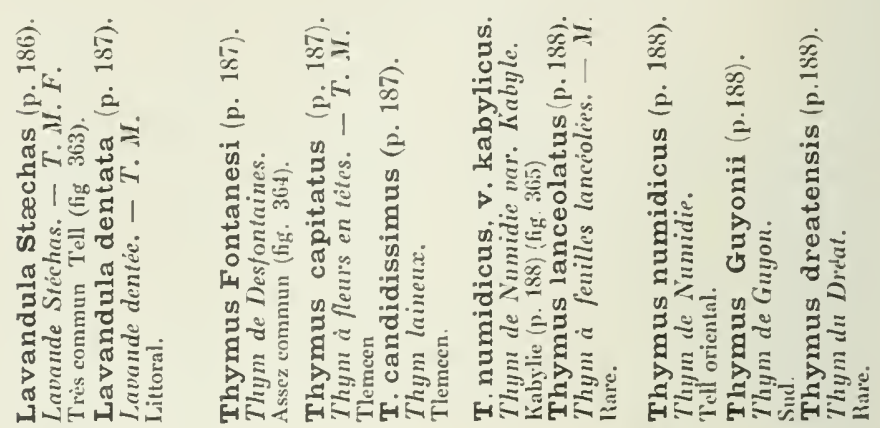

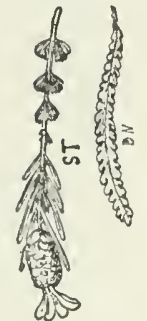

in $\frac{\dot{0}}{3}$

范

\&

ส

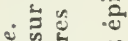

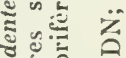

远

远.

㱒

¿ํㅛㅇ

ऽ

ชั.

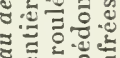

\%

है

ร.

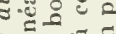

․․․․

天

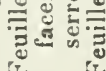

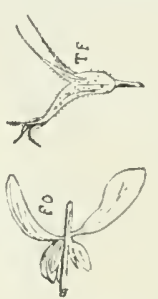

홍

을

ฮี ญ

\&...

红

일

ए 웅

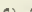

플

Q

ฮ. एँ

है

$\dddot{y}_{00}^{\circ} 0$

동

욜

을

듄 웅

ह

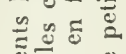

䒕:

12.

告

选

空

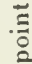

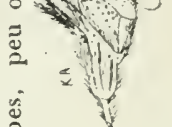

:

$\stackrel{9}{=}$

ส

$\stackrel{\mathscr{e}}{\mathscr{G}}$

๕๐

อ. สี

ร็ำ

로

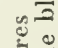

ํํㄹ

这

.

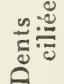

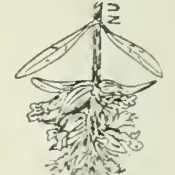

$\div$

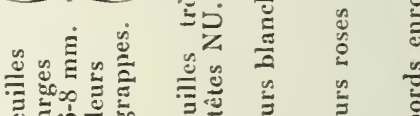

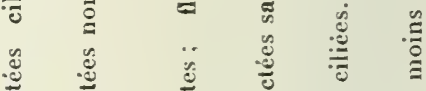

แับ

$\bar{\sigma}$

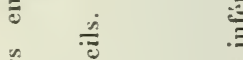

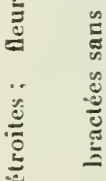

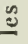

$\stackrel{n}{\circ}$

รี

อ

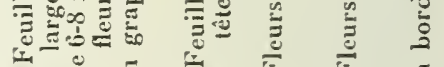
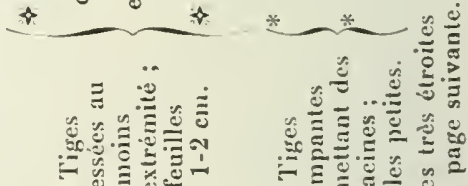

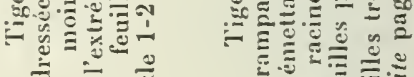

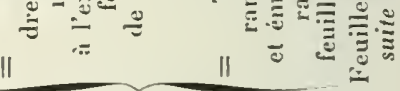

-sagino.rua uou sanejd sall!nat ++

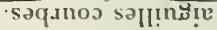

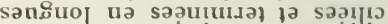

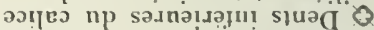

0

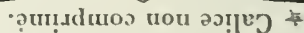

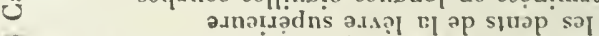

" $\mathrm{YY}$ әqщ ә 


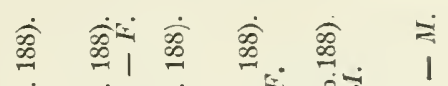

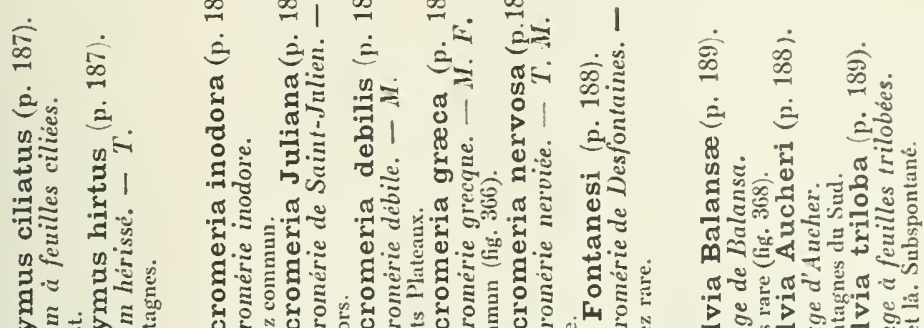

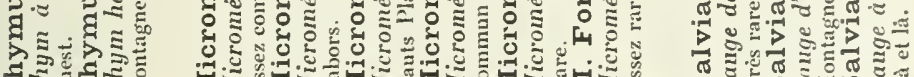

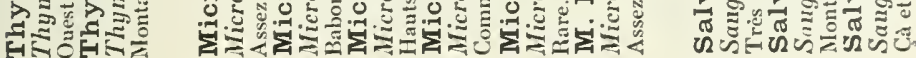

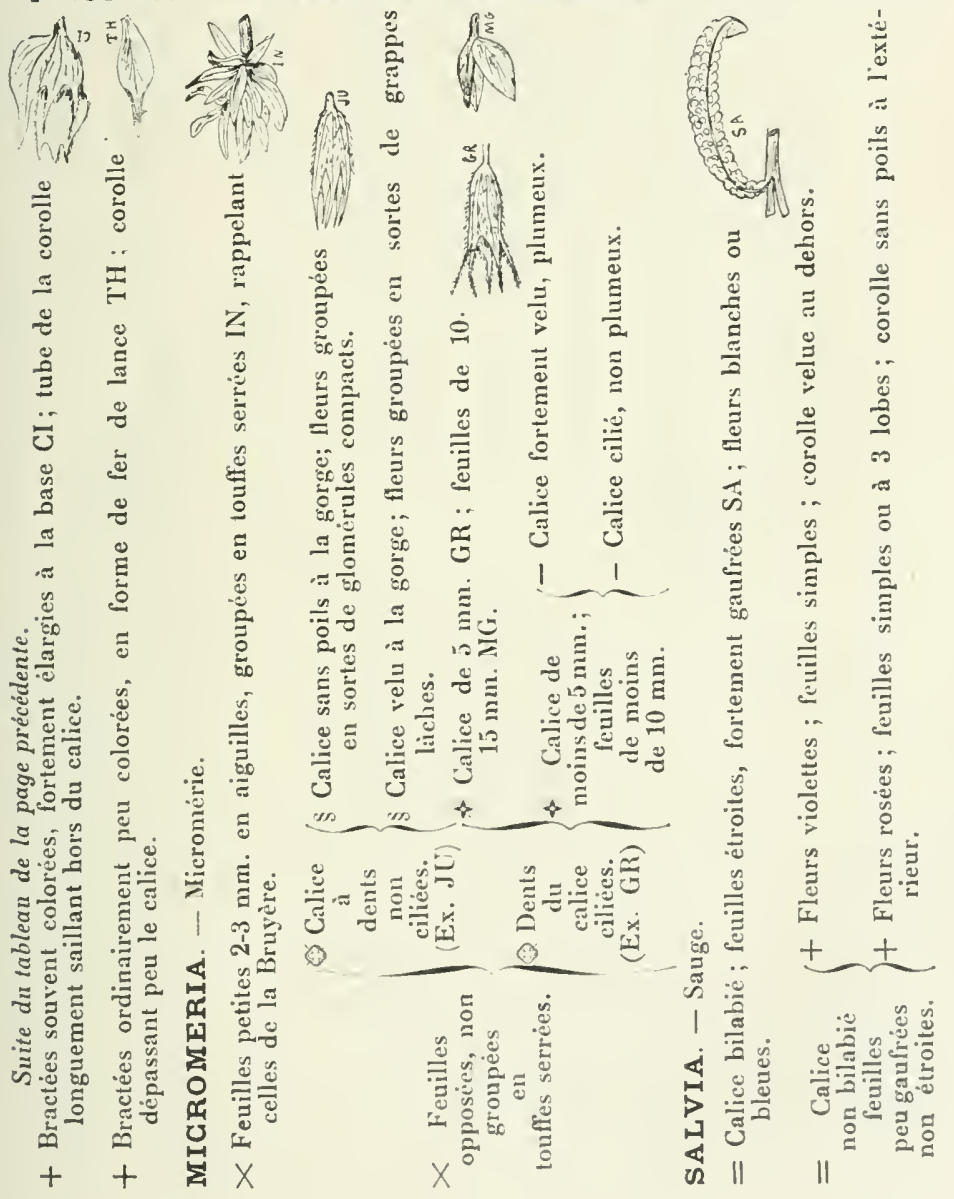



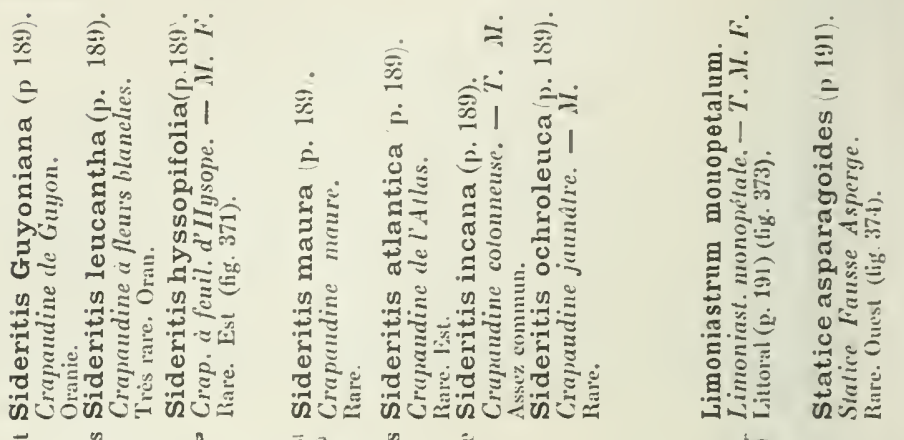

ए
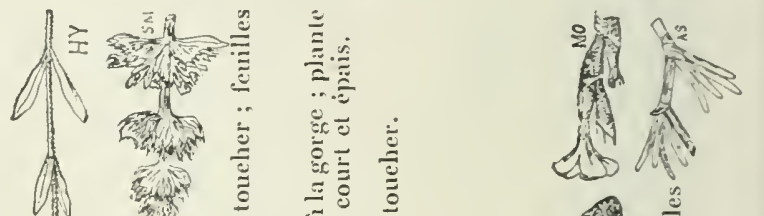

כ)

है

$\stackrel{\circ}{2}$

节

क्ष

I

$\because \vec{E} \quad \xi$

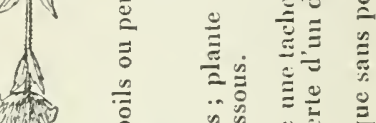

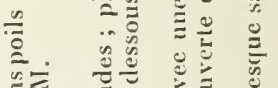

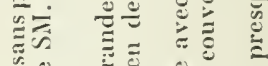

$\div \cdot \frac{1}{0}$

$\because 0$

co 0

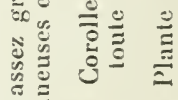

¿

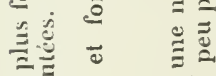

焉

苞范

롤.

$\therefore$

$\infty=\infty$

政

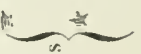

๑ 을

$\stackrel{\bar{\Xi}}{\Xi}$

$\because \therefore$ 次

ص.

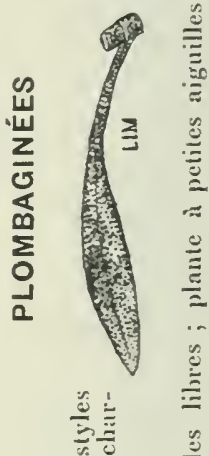

节

Q.

$\stackrel{\infty}{\stackrel{0}{\bar{z}} \frac{0}{0}}$

궁 
V'ERBÉNAGÉES. - PLANTAGINÉES. - GLOBULARIÉES ¿85

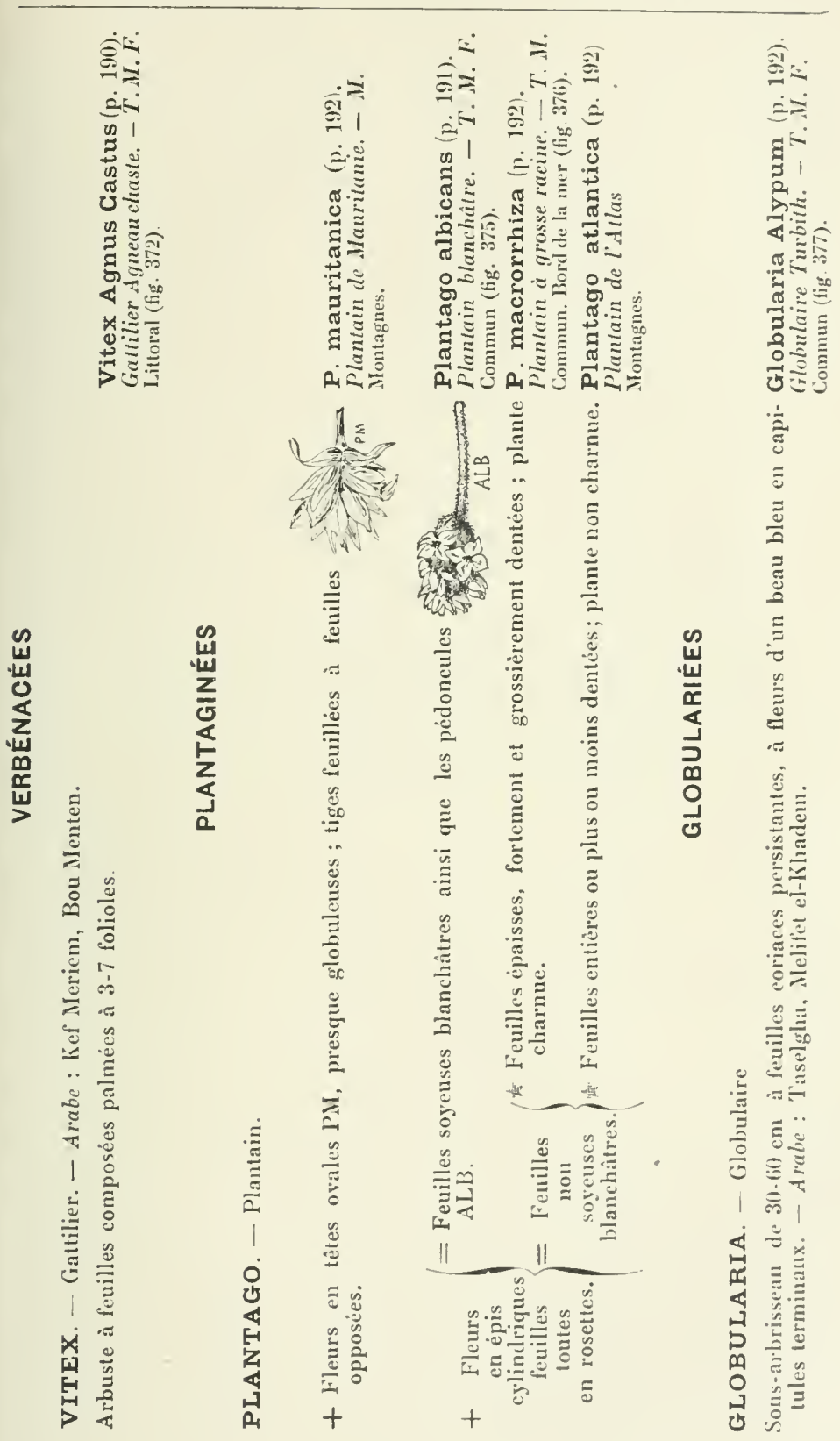





\section{DEUXIEMIE CLEF}

\section{TABLEAUX SYNOPTIQUES ILLUSTRES}

POUR LA DÉTERMINATION DES ESPÈCES LIGNEUSES

LES PLUS IMPORTANTES DE L'ALGÉRIE

D'APRÈS LES CARACTÈRES DES ORGANES VÉGÉTATIFS

(PRINCIPALEMENT DES FEUILLES) 


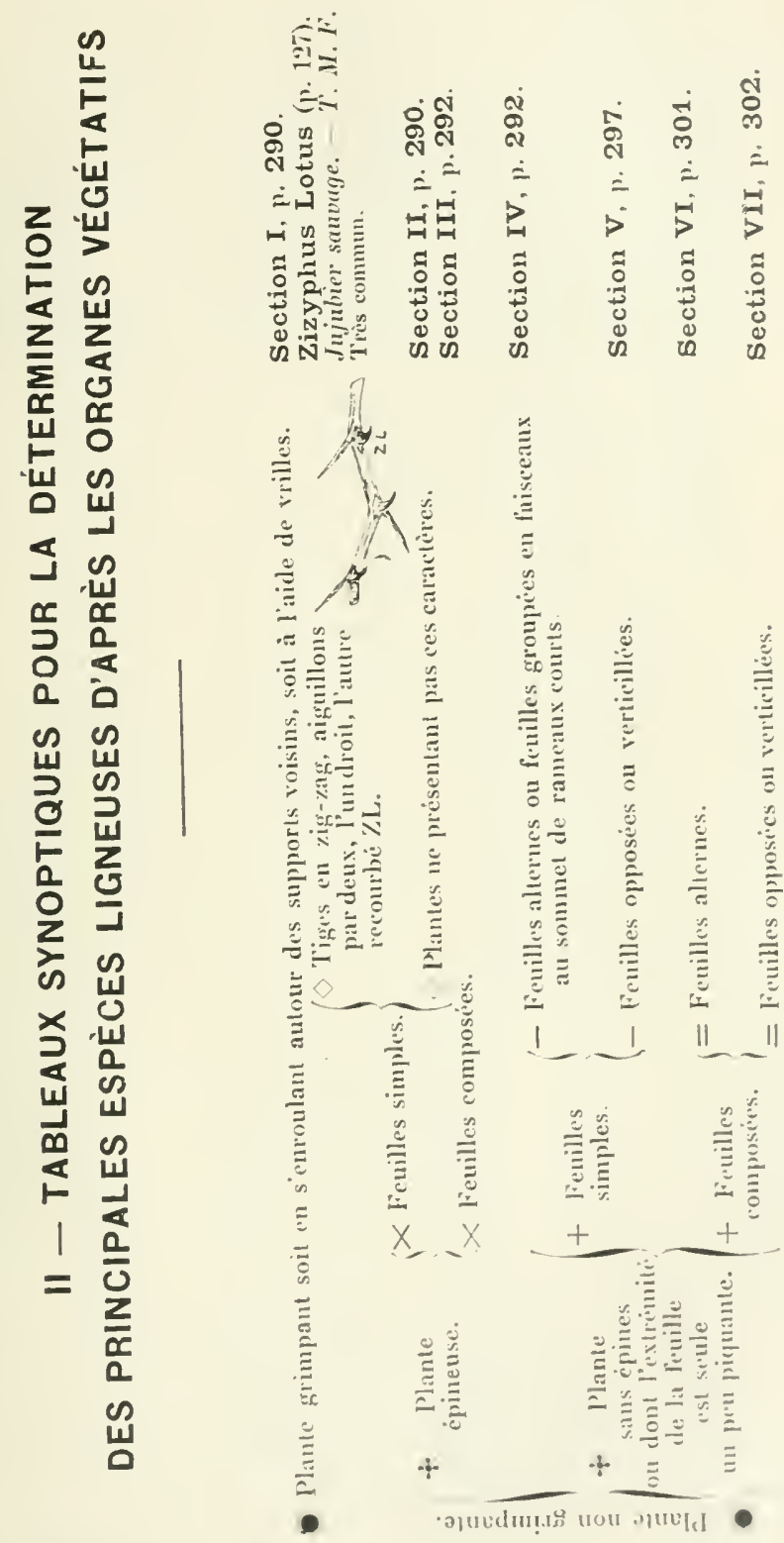


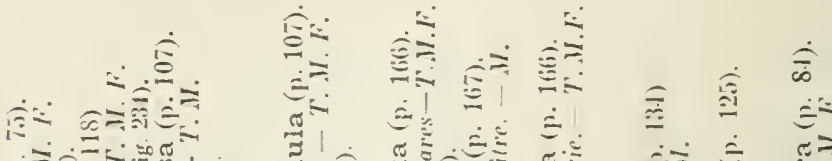

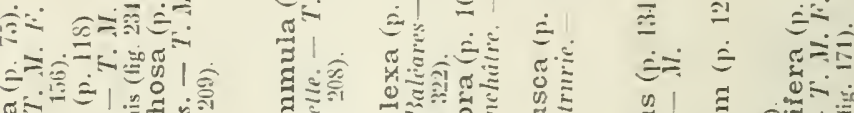

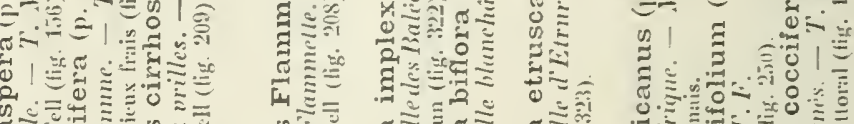
क

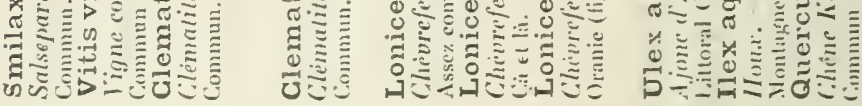

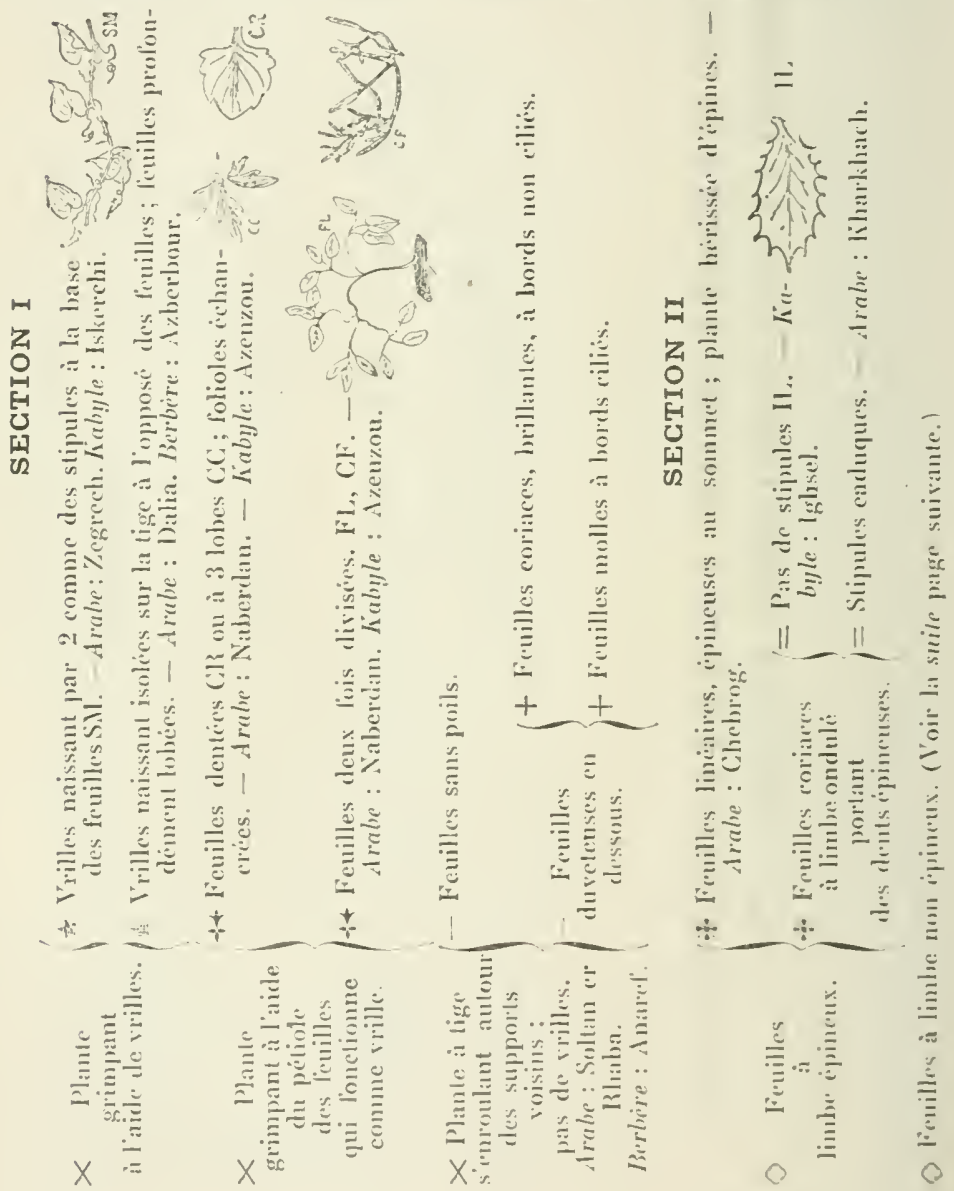




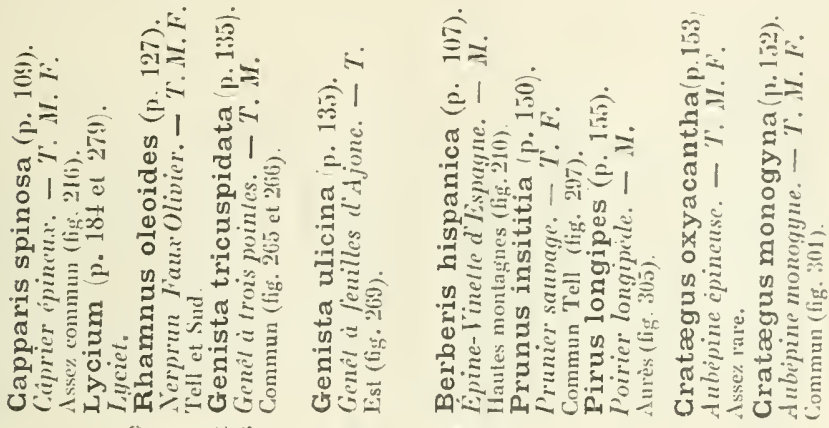
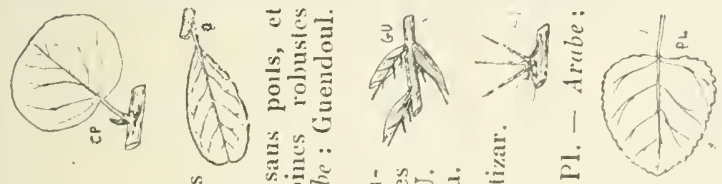

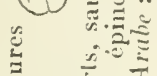

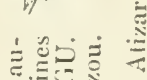

$\bar{a}$

$\stackrel{5}{3}$

-

छำ

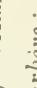

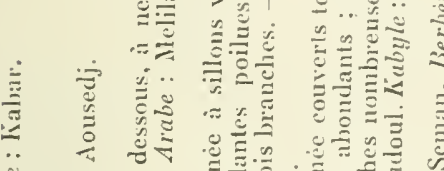

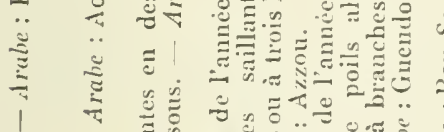

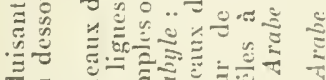

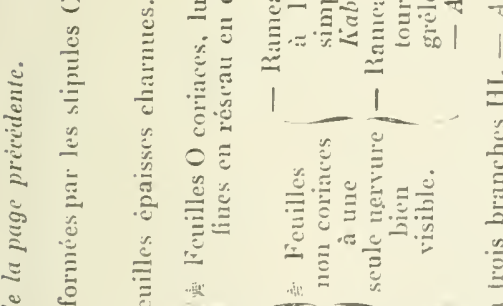

ฯ 0 है

$\stackrel{3}{\Xi}$

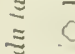

$+$

sapnd!ns som mo

(ी)

$\dot{\square} \mathrm{G}$

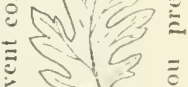

$\{, 3$

$\Xi$
$\vdots$
0
0
0
0

$=\sqrt{2}$

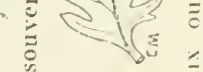

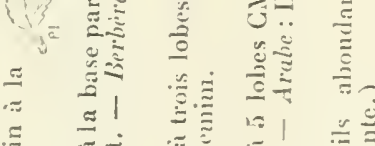

¿

-

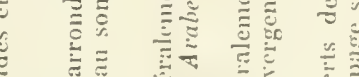

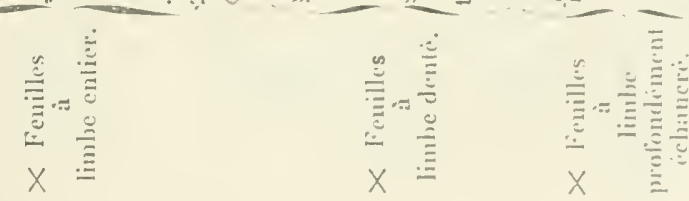




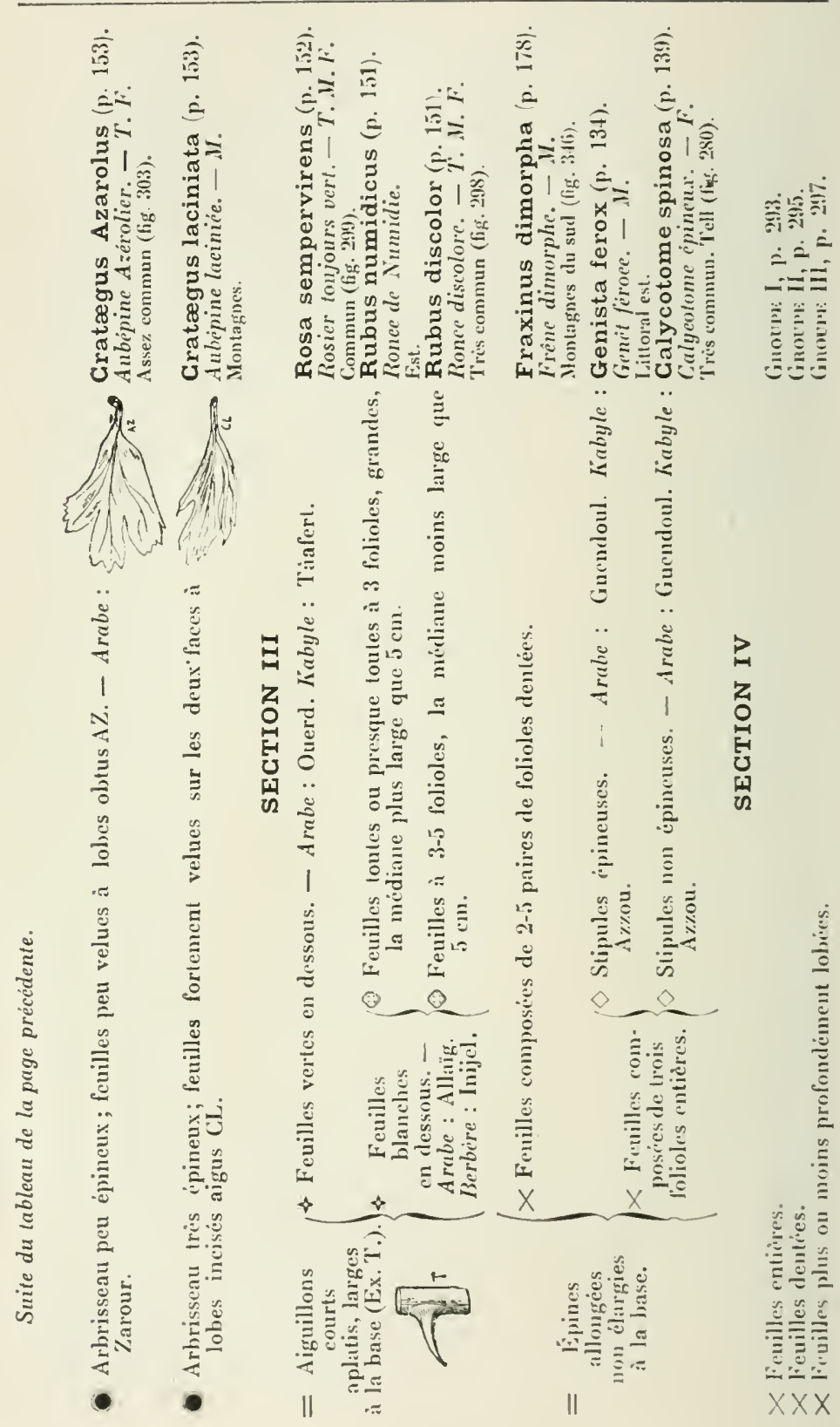




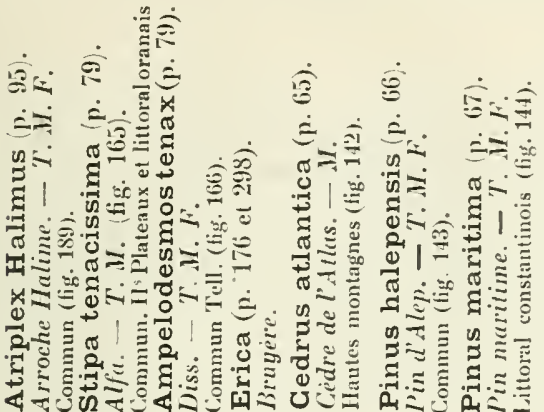

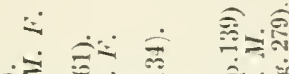

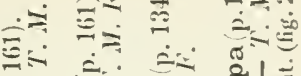

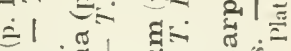

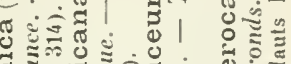

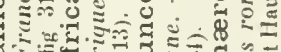

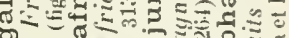
$x$ 을

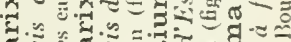
สำ

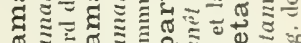

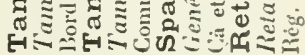

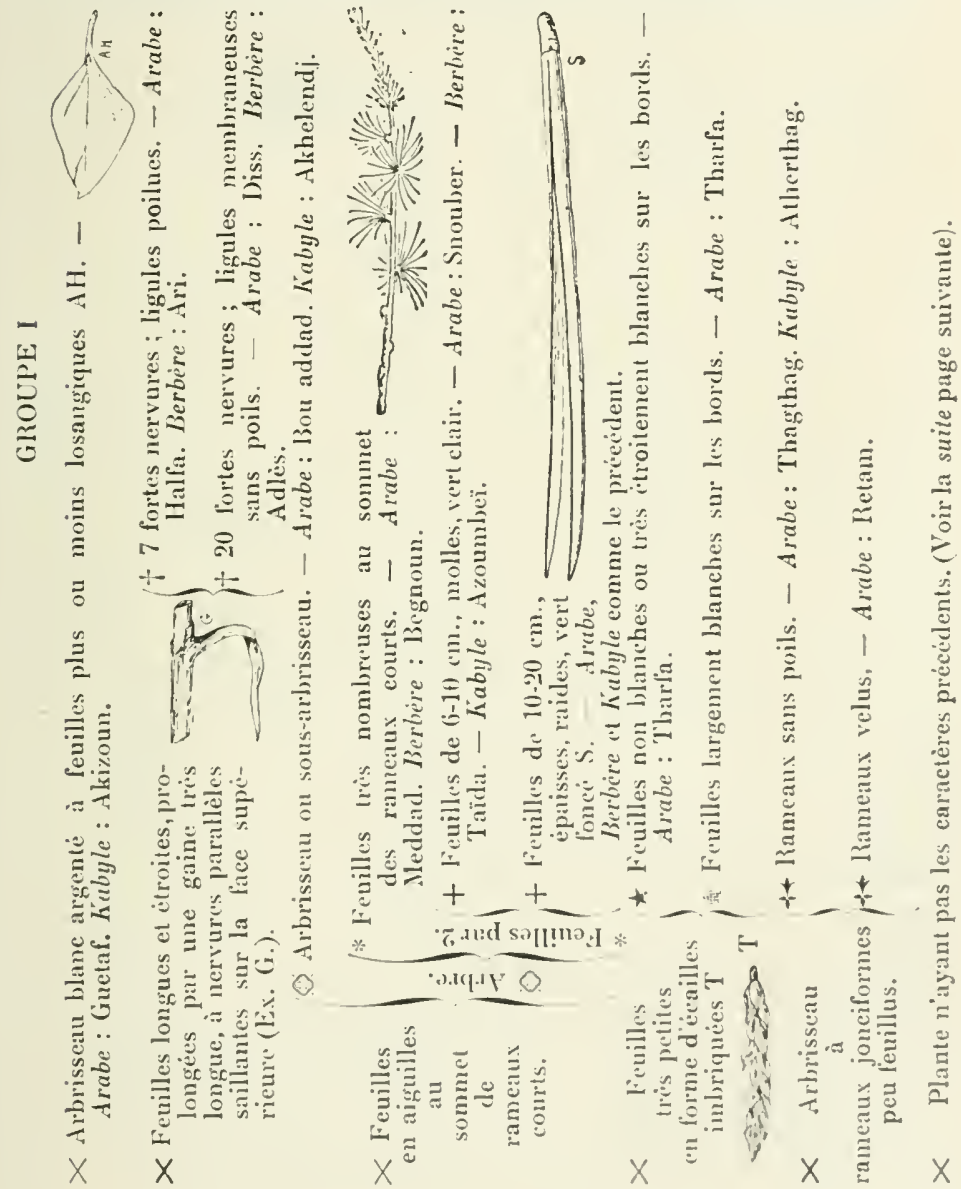




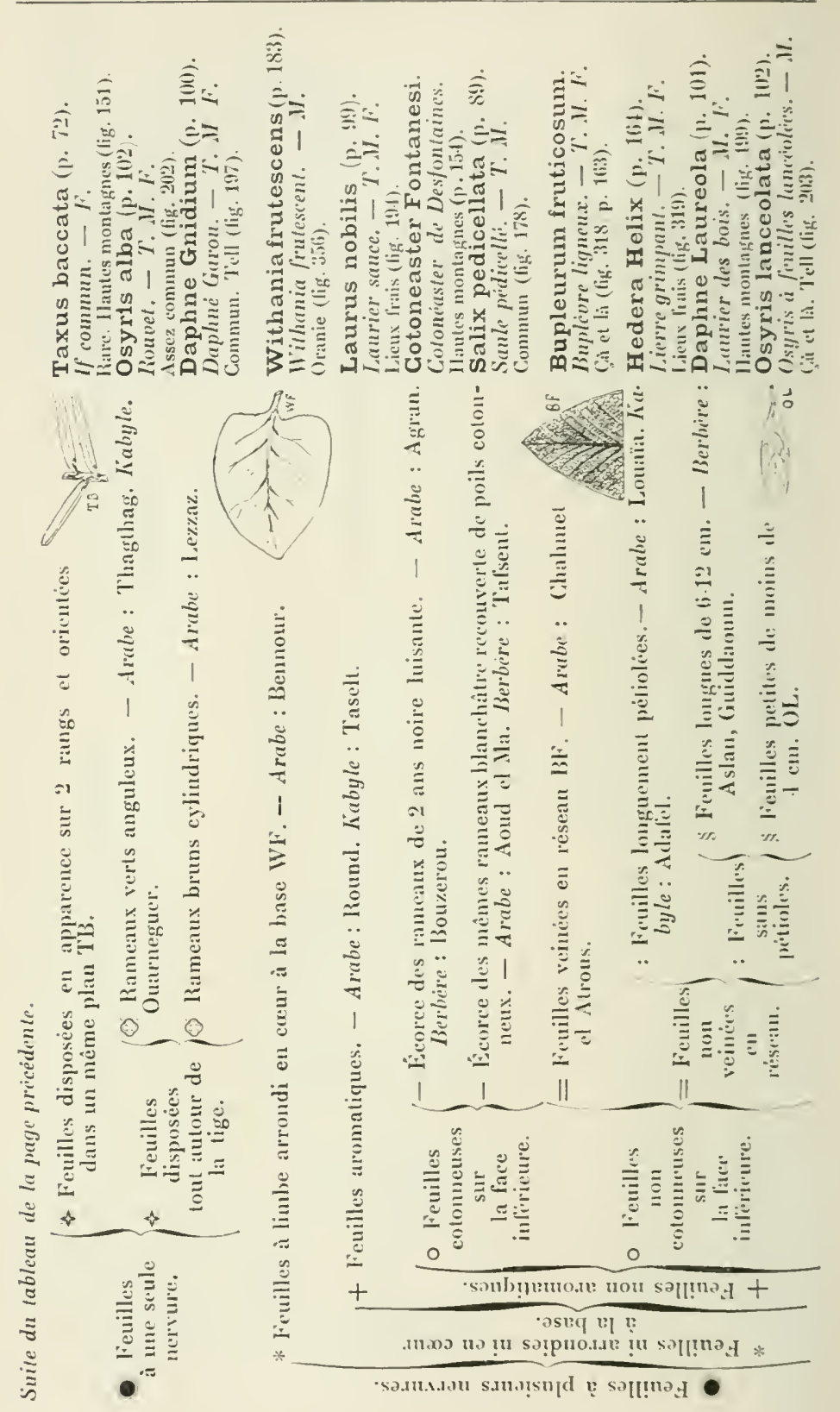




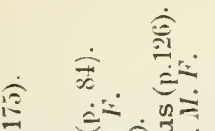

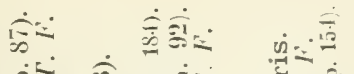

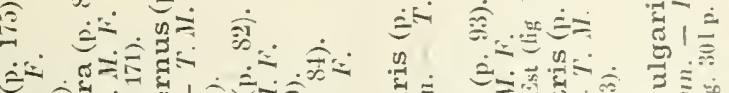

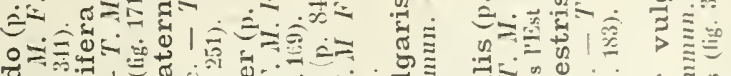

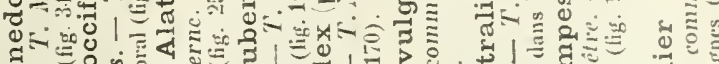

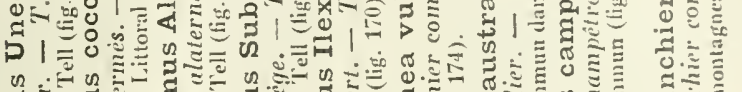
ต

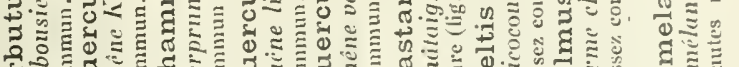

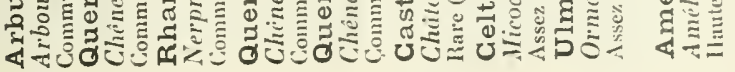

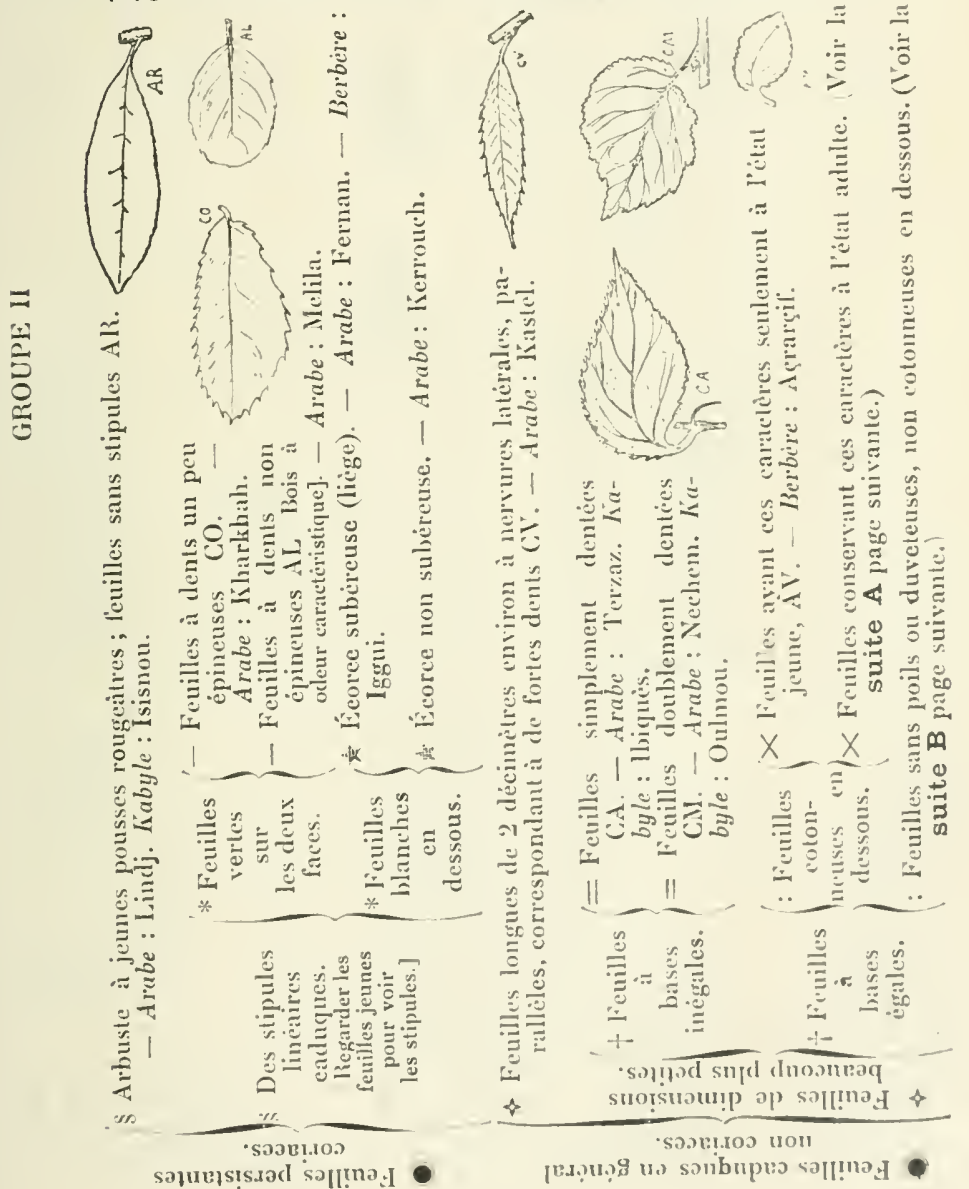



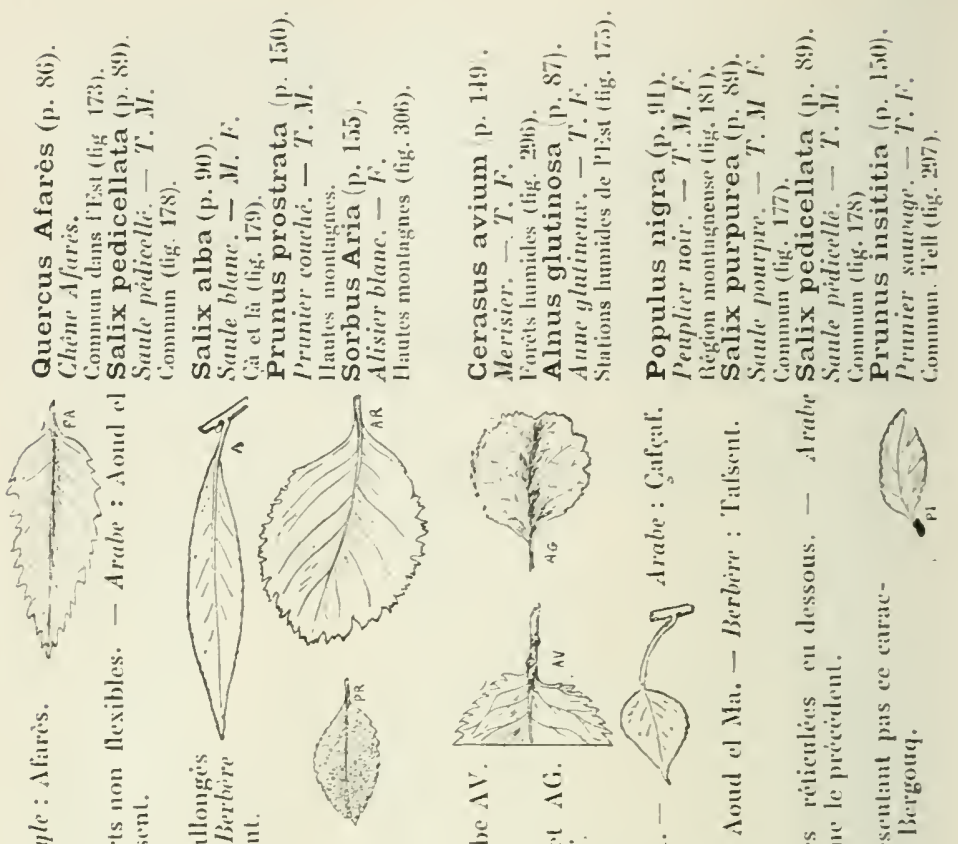

过

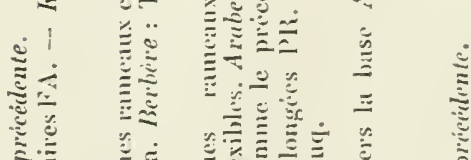

$\stackrel{\varrho}{\Xi}$

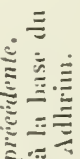

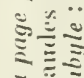

$\approx \frac{\bar{x}}{2}=$

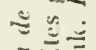

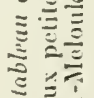

$\Xi \frac{0}{\vdots}$

$\infty \equiv$

म1

要

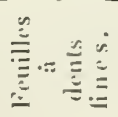

竞:

$\equiv$

产苛

!

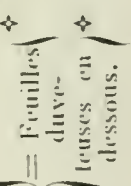

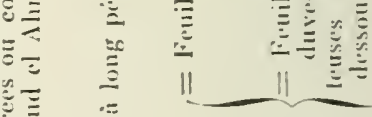

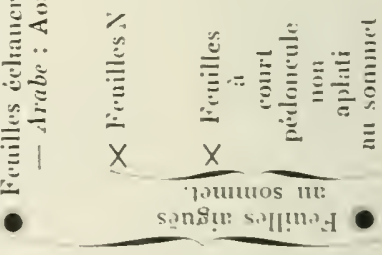

"खquा! иp asta v?

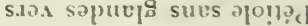



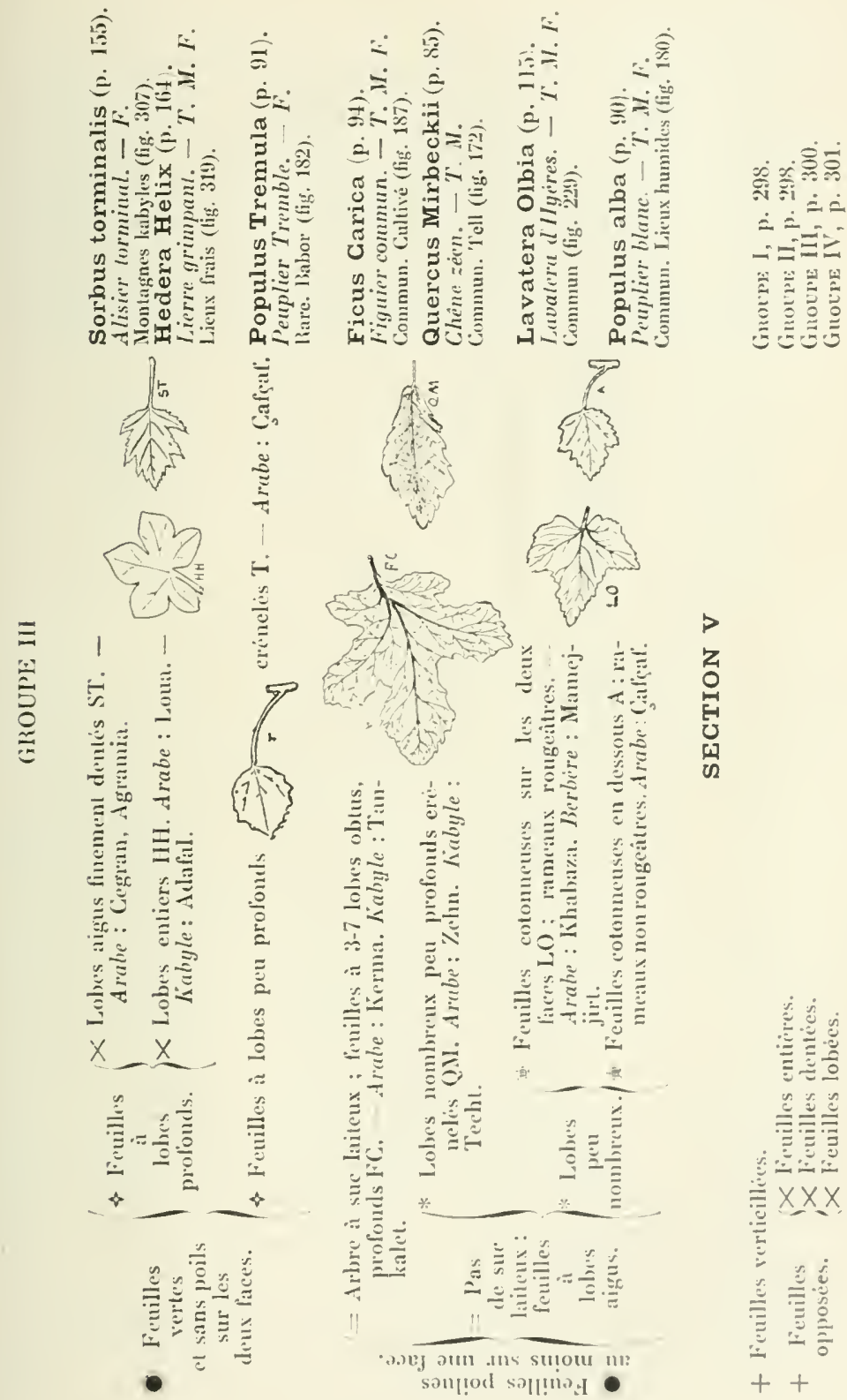


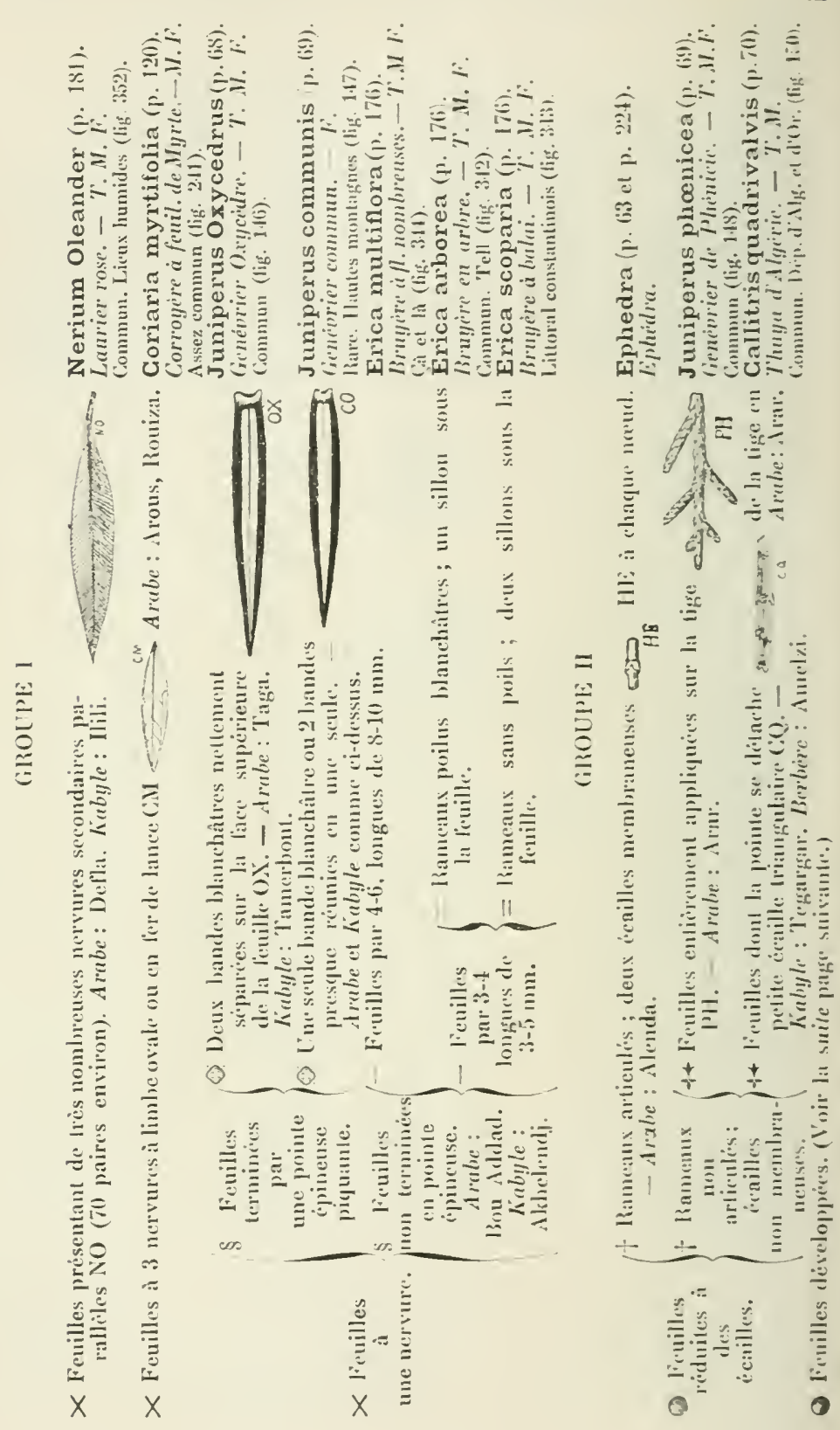




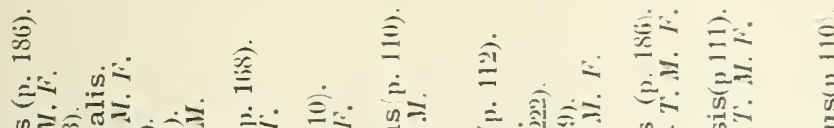

mon

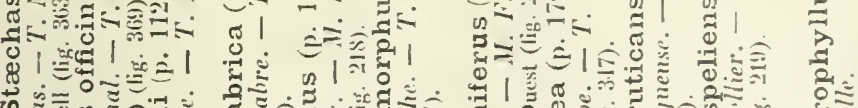

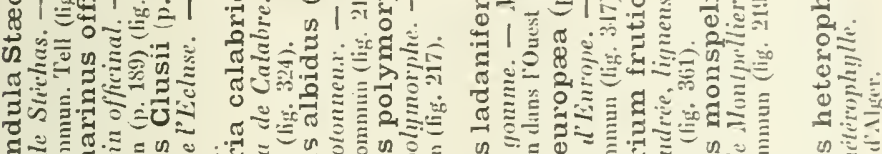
สำ

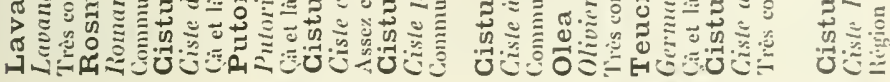
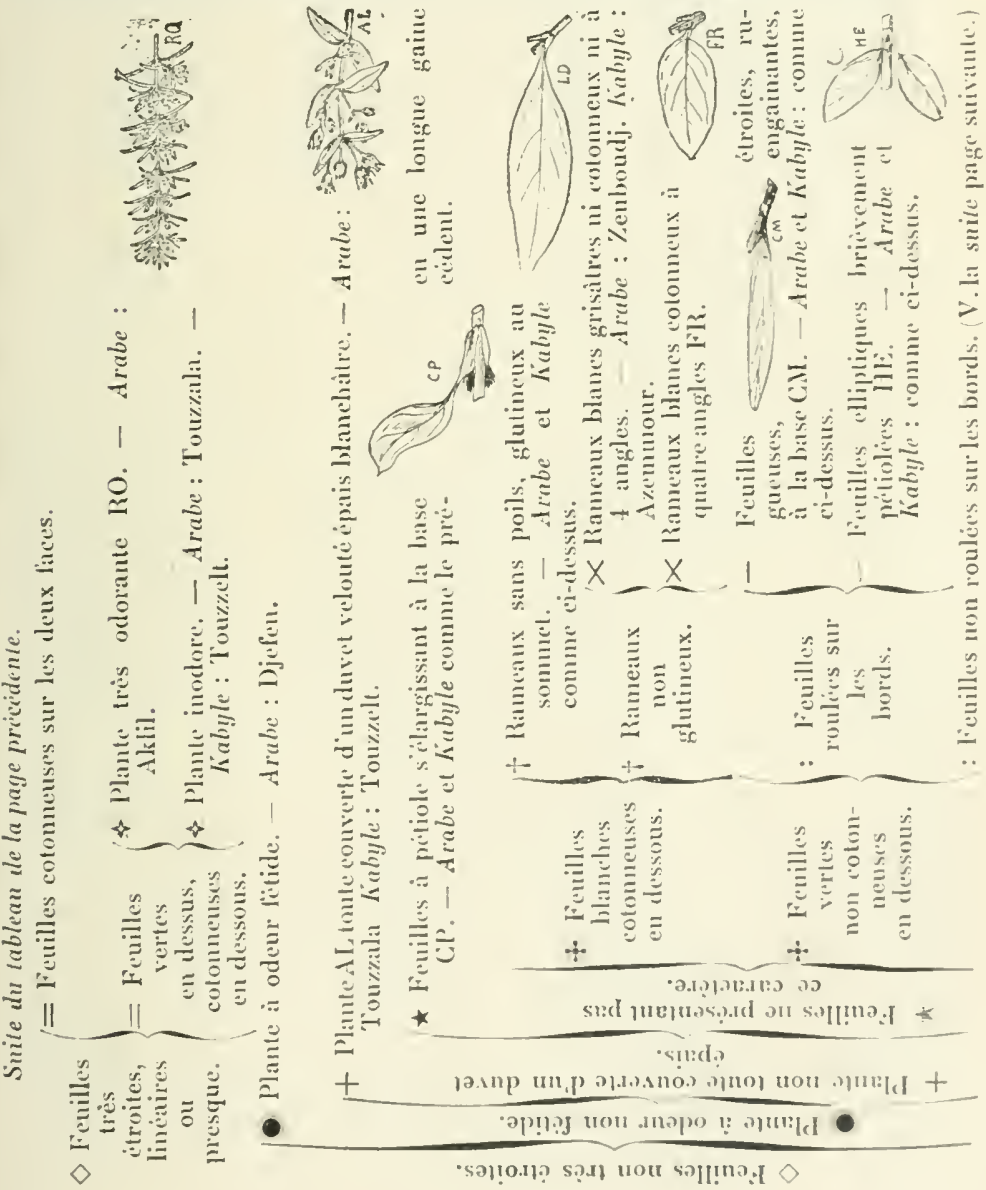


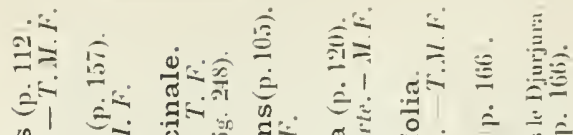
哟

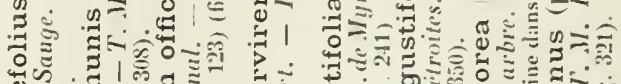
8 更 б

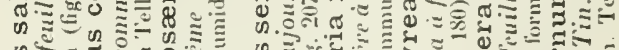

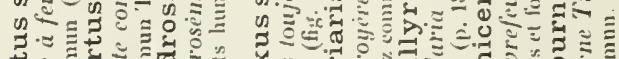

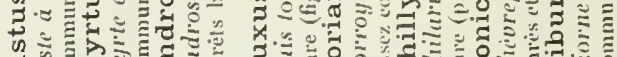

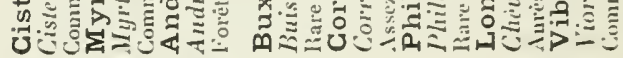
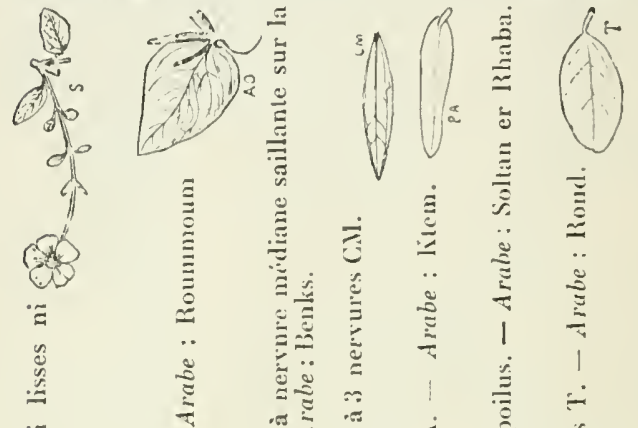

$\ddot{a}$

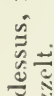

辛
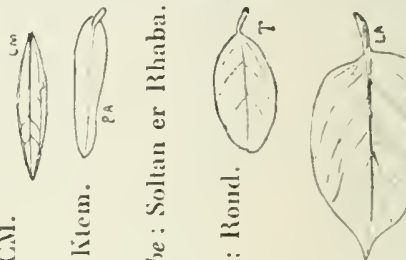

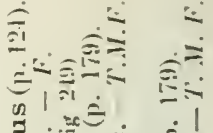

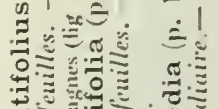
तै

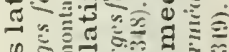

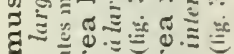

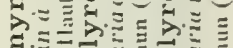
긍 $>\quad \exists \Xi \Xi \Xi \tilde{\Xi}$

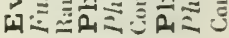

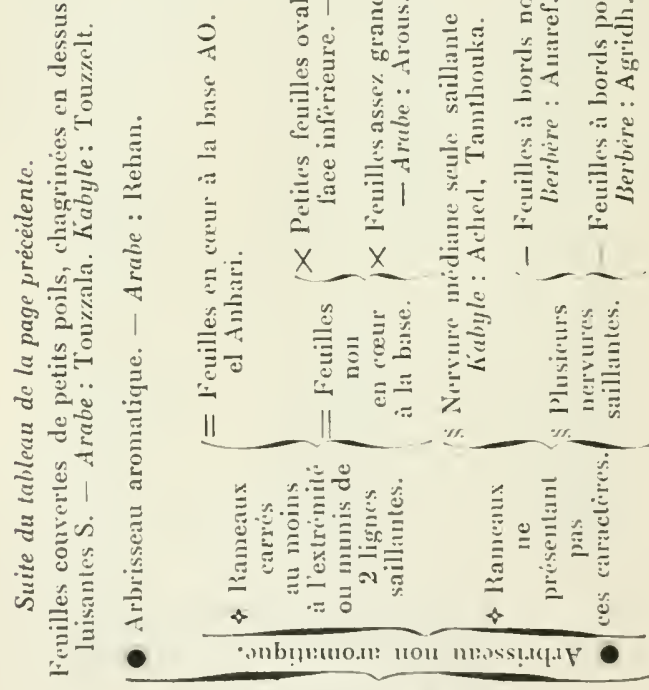

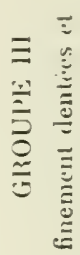

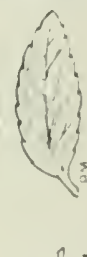

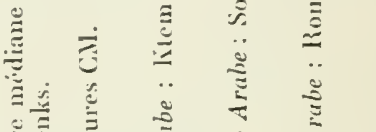

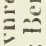

范 $\frac{5}{4}$

$\stackrel{\circ}{\stackrel{5}{0}}$

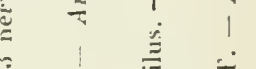


$\dot{s}$

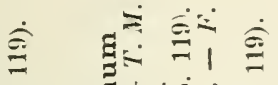

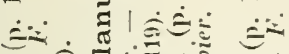

\&1

范造 000

ह

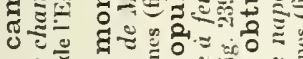

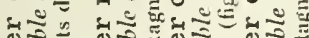

की

Uू.

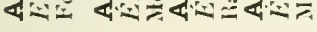
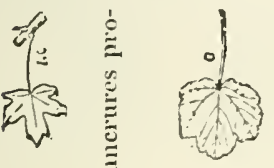

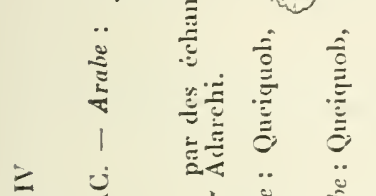

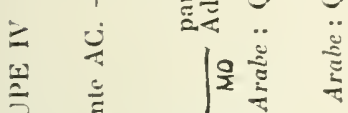

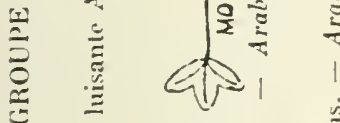

苛

ప

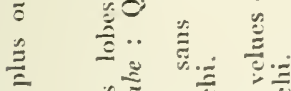

c

花

范

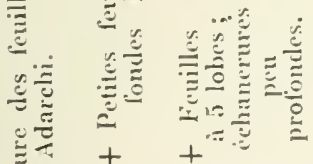

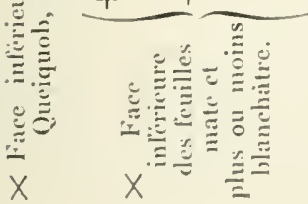

$\therefore$ 灾

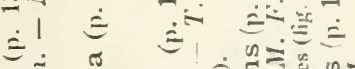

先

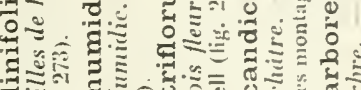

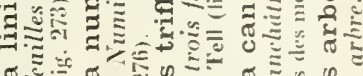

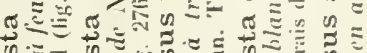

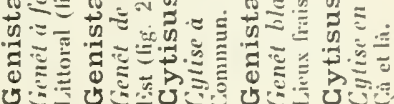

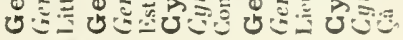

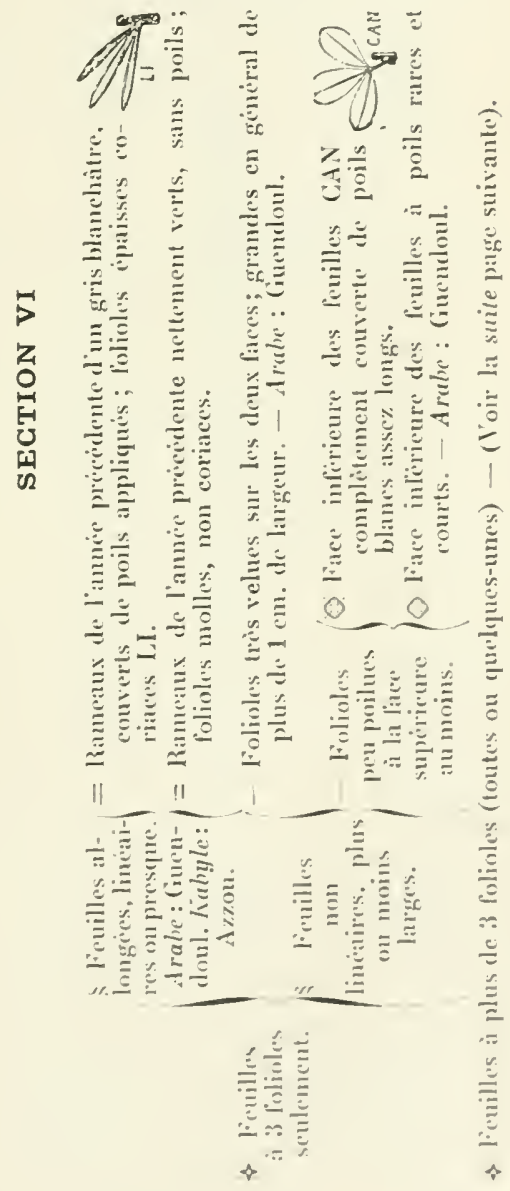




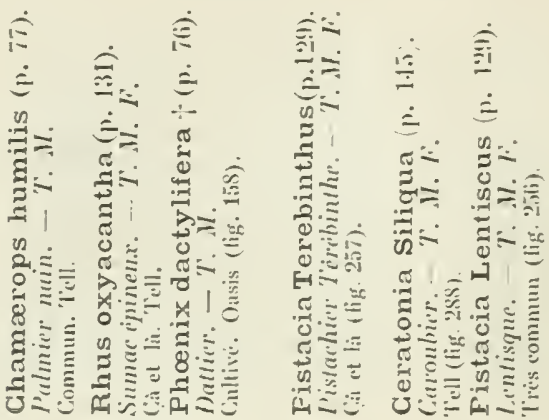

言亡

$\therefore$ 息

a. $\doteq \because$

ชิ

$n=\dot{a}-1$

₹

6) 00 $4 \div 0 \equiv$ x.

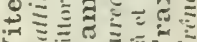
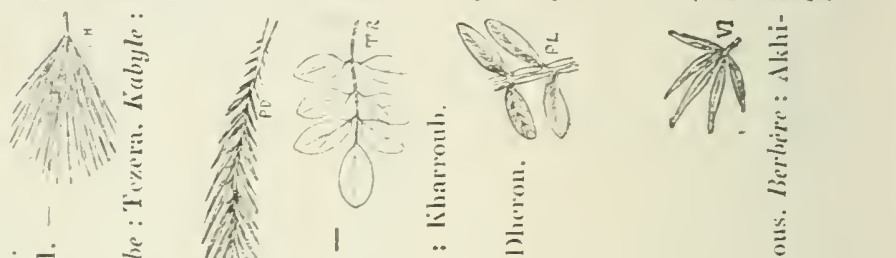

·

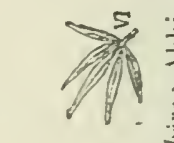

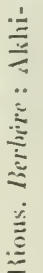

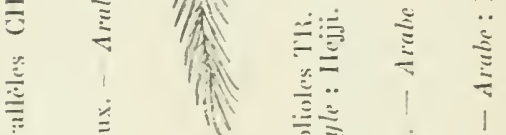

㖕

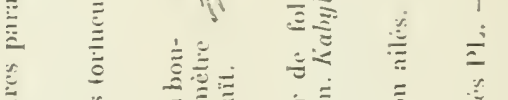

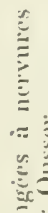

(

施

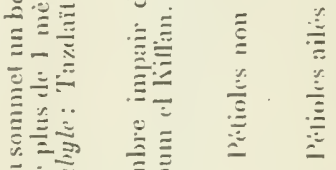

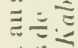

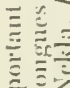

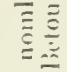

$11+1 !$

엔 $=1$

U

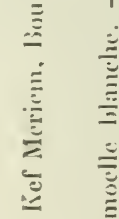

¿

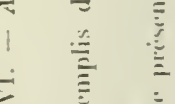

ఏ

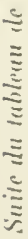

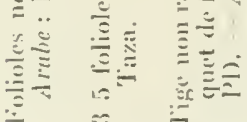

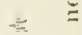

$\mathrm{x}$

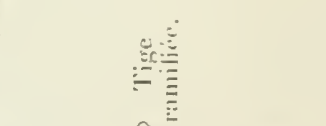

(1)

$+$

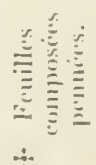

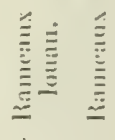

$\pm+$

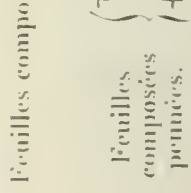




\section{TROISIEMIE CLEF}

\section{TABLEAUX SYYOPTIQUES ILLUSTRES}

PERMETTANT LA DÉTERMINATION

EN IIIVER

DES ARBRES ET DE LA PIUPART DES IRBRISSEAUX A FECILLES C.IDCQLES DE L'ALGERIE. 



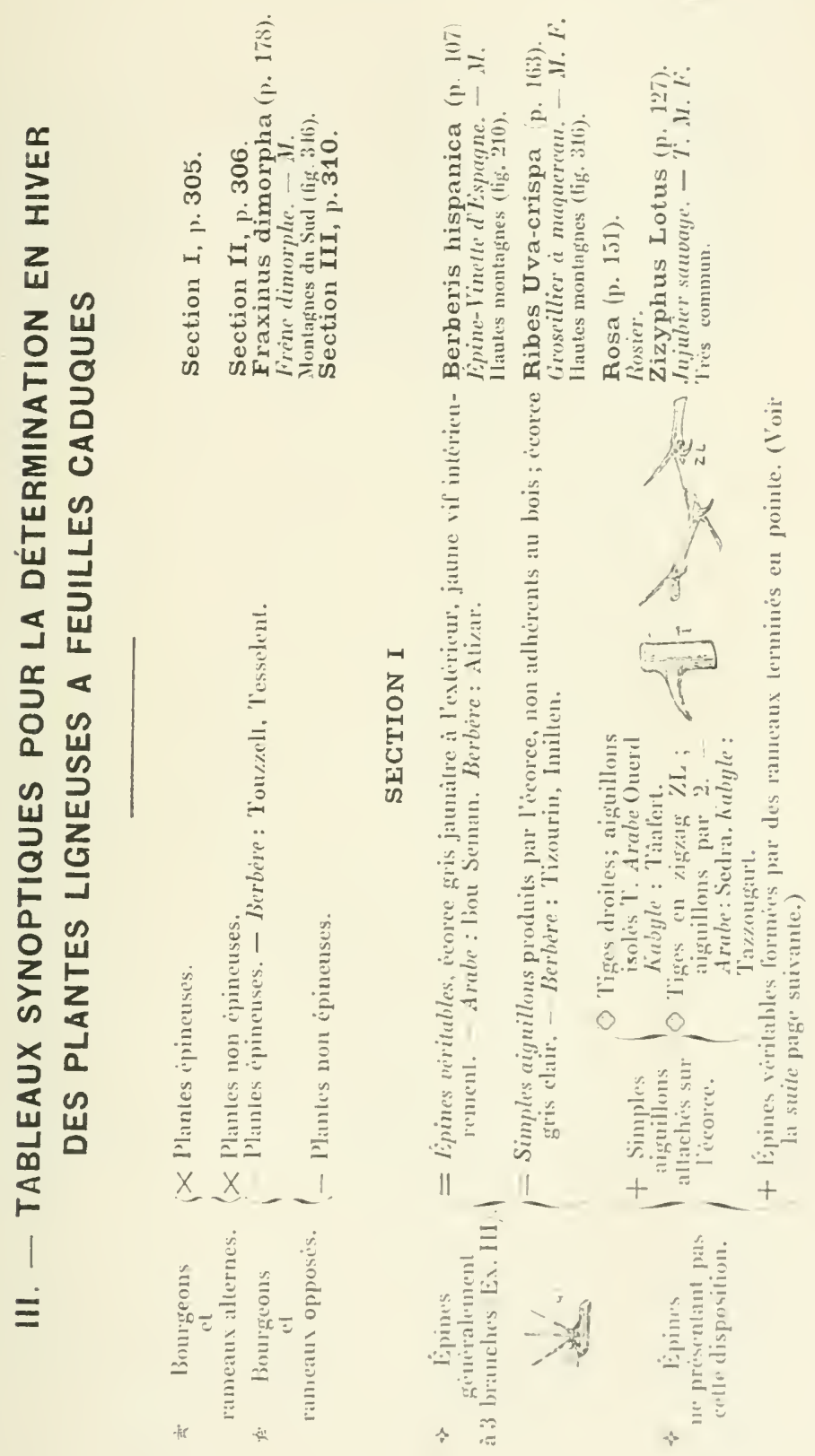

FLOW: FOLESTIIRE: 


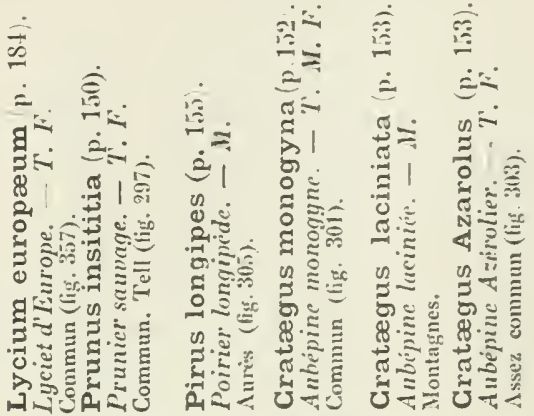

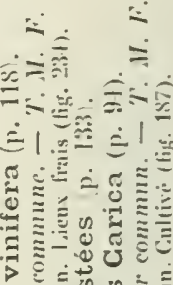

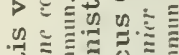

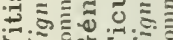
इ 1 हि

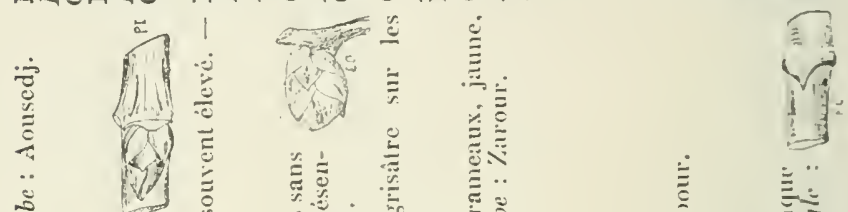
光

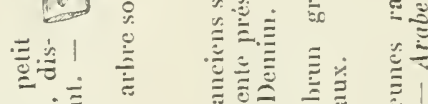

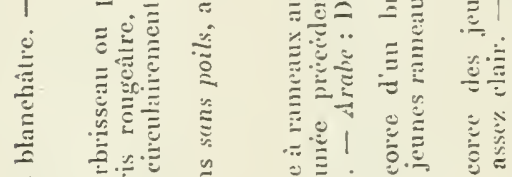
苛

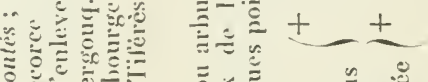

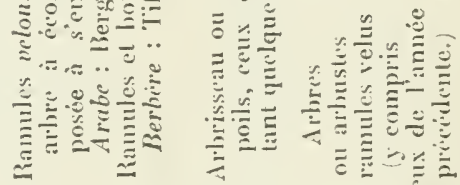
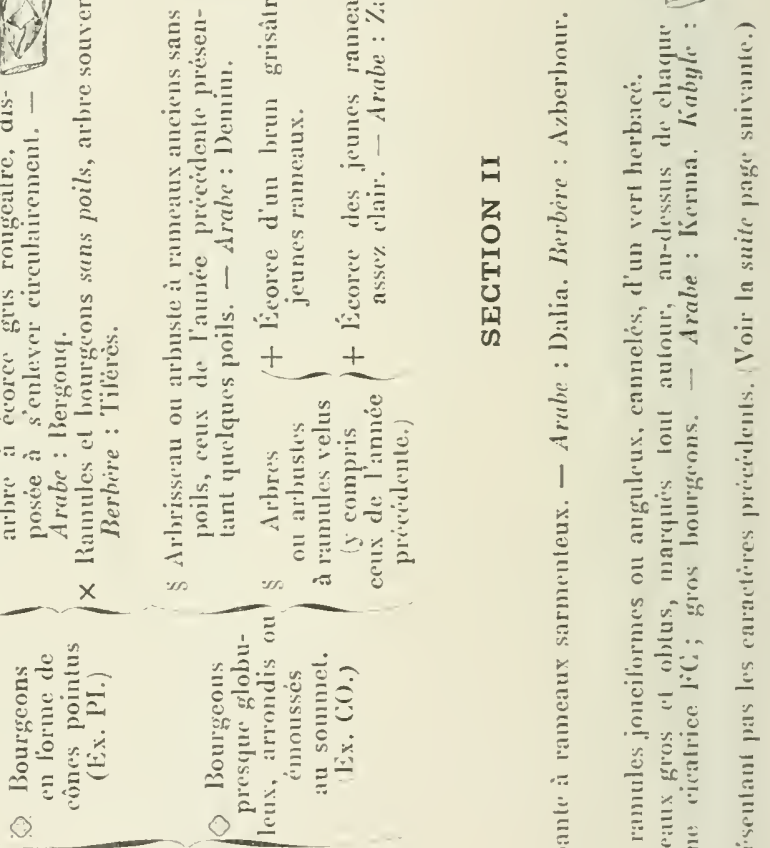

ฐ

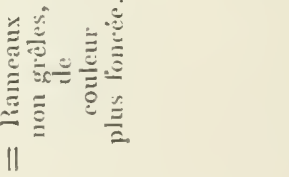




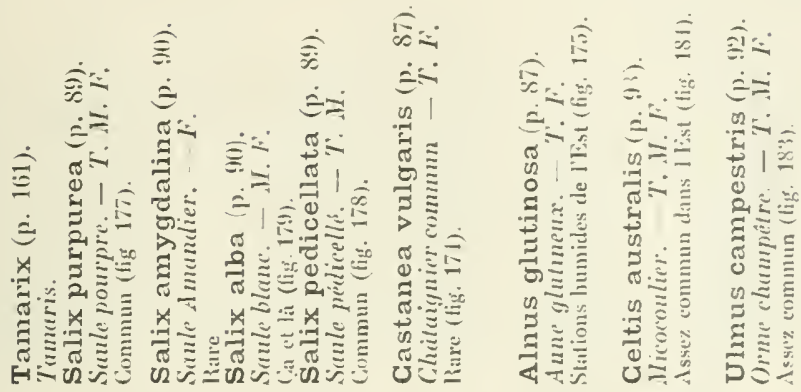

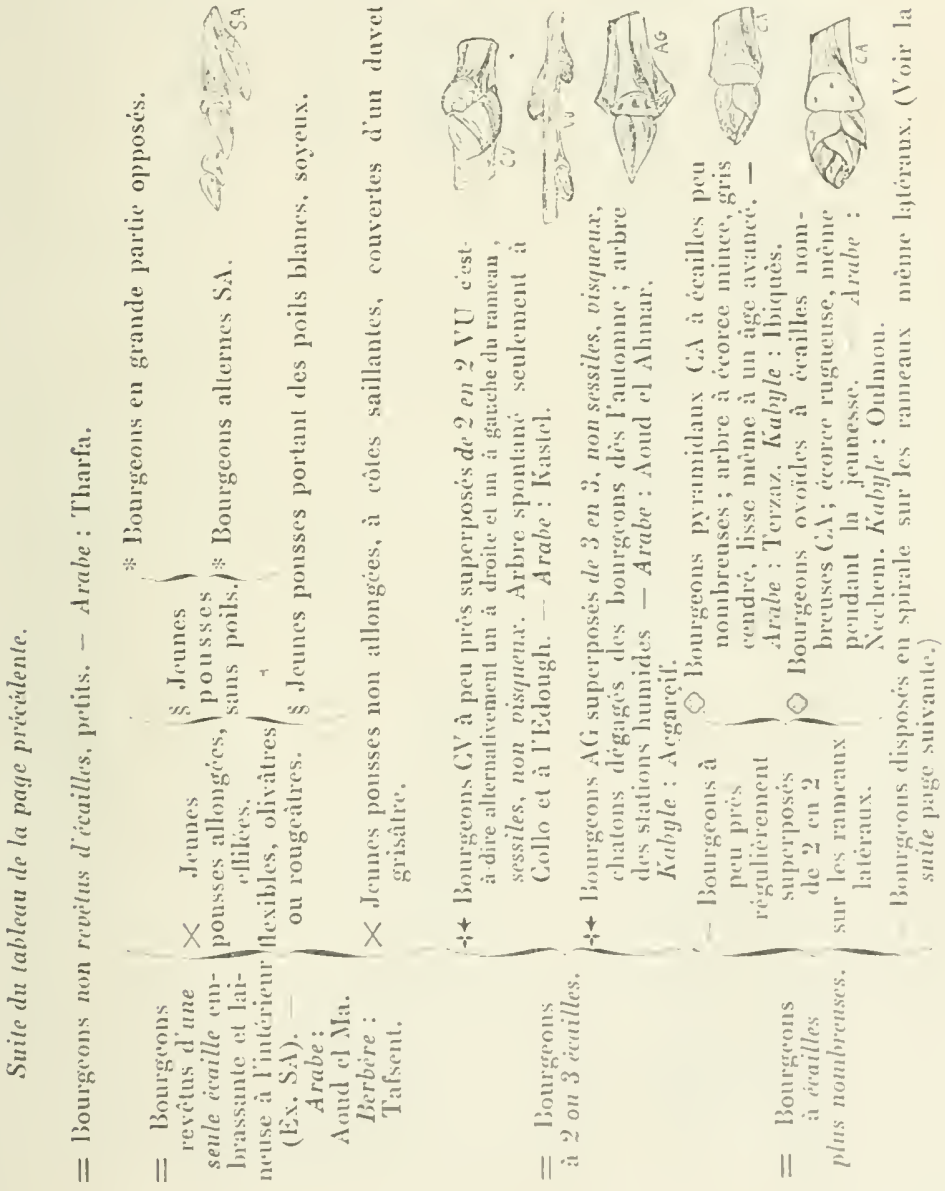




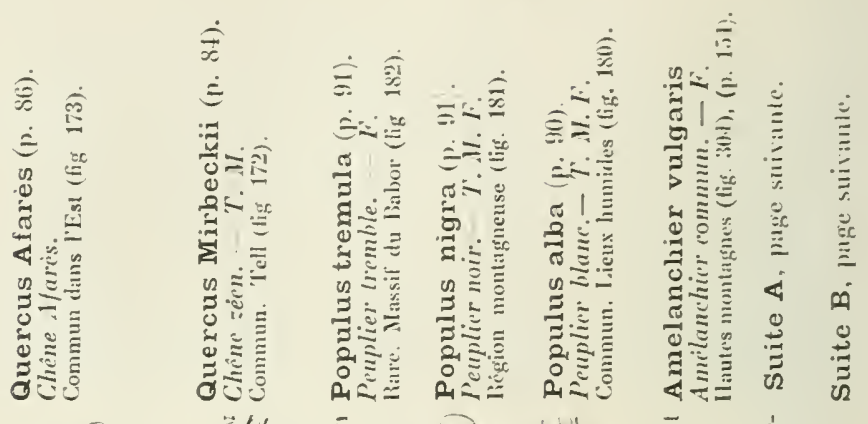

?

(1)

कृ

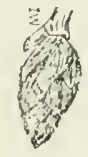

三

A

का

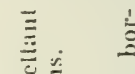

窇

की

吾

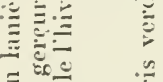

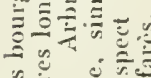

象:

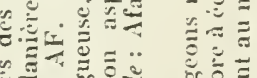

פ

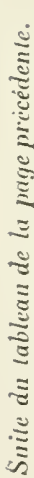
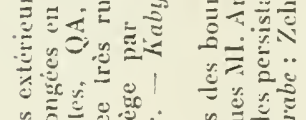

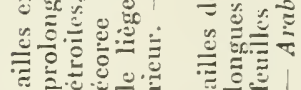

$=$

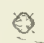
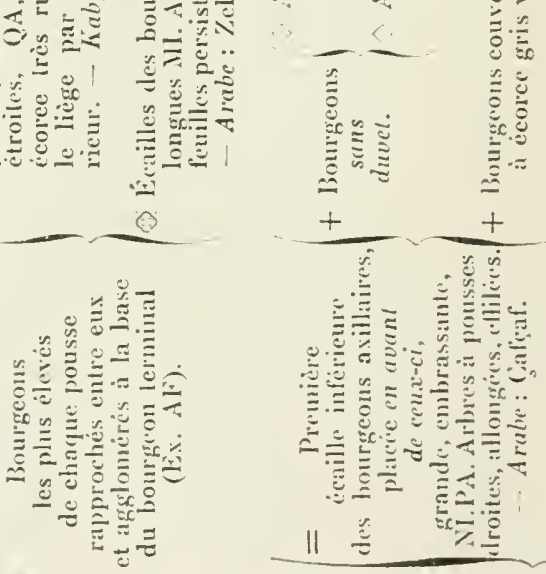

产产引

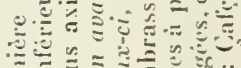

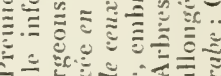

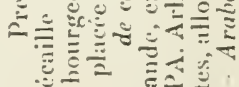

$11 \stackrel{0}{=}$

至蓄

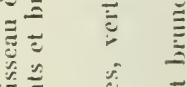

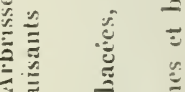

$\stackrel{\Xi}{\Xi}$

$\Xi$

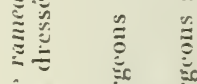

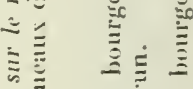

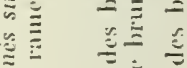

焉

닝

$\frac{\infty}{3-0}$

竞

产产亲

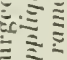

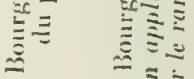

$+\equiv$

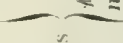

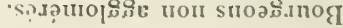

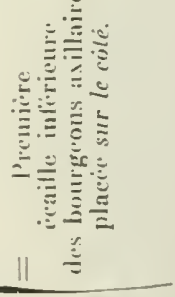




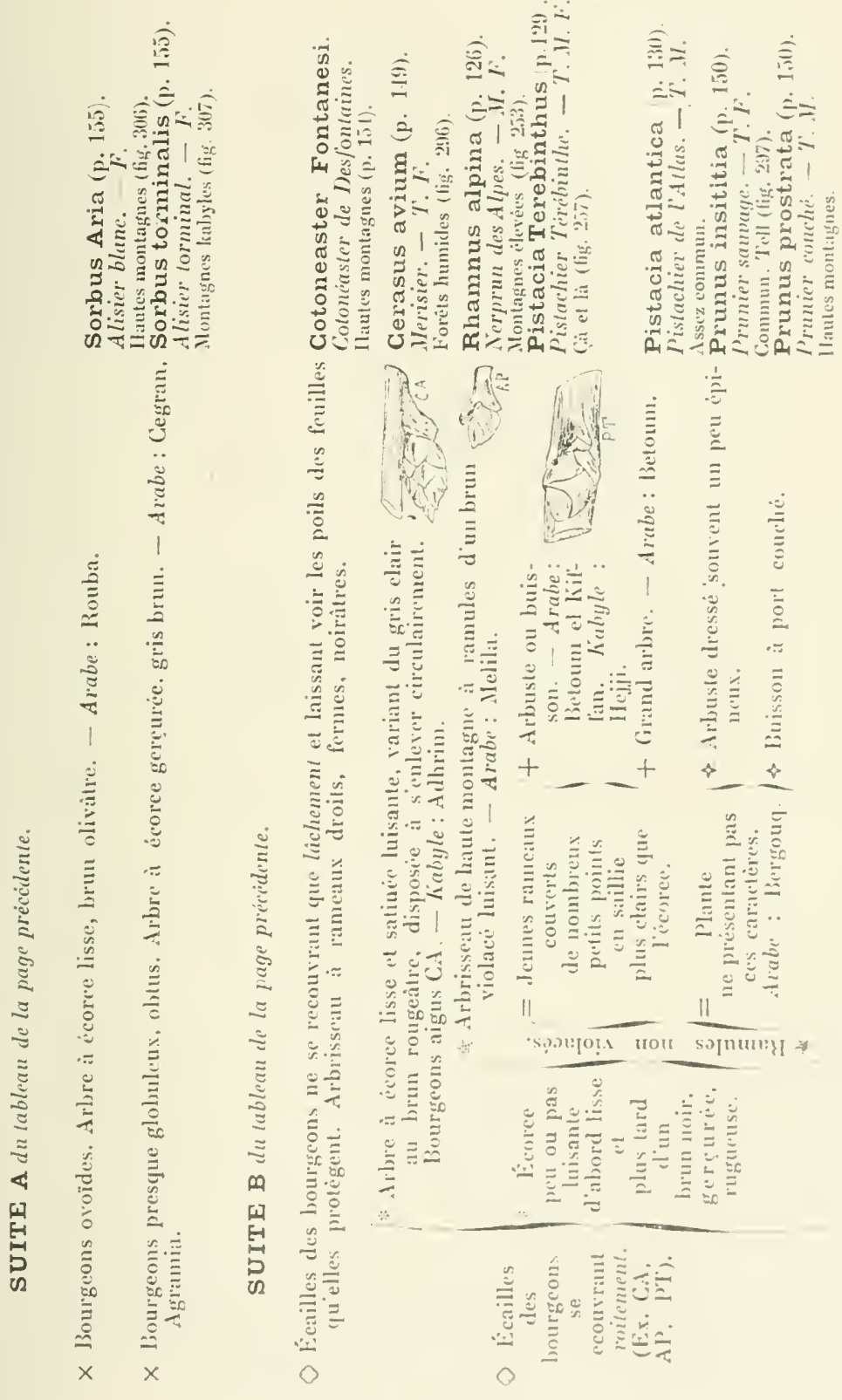




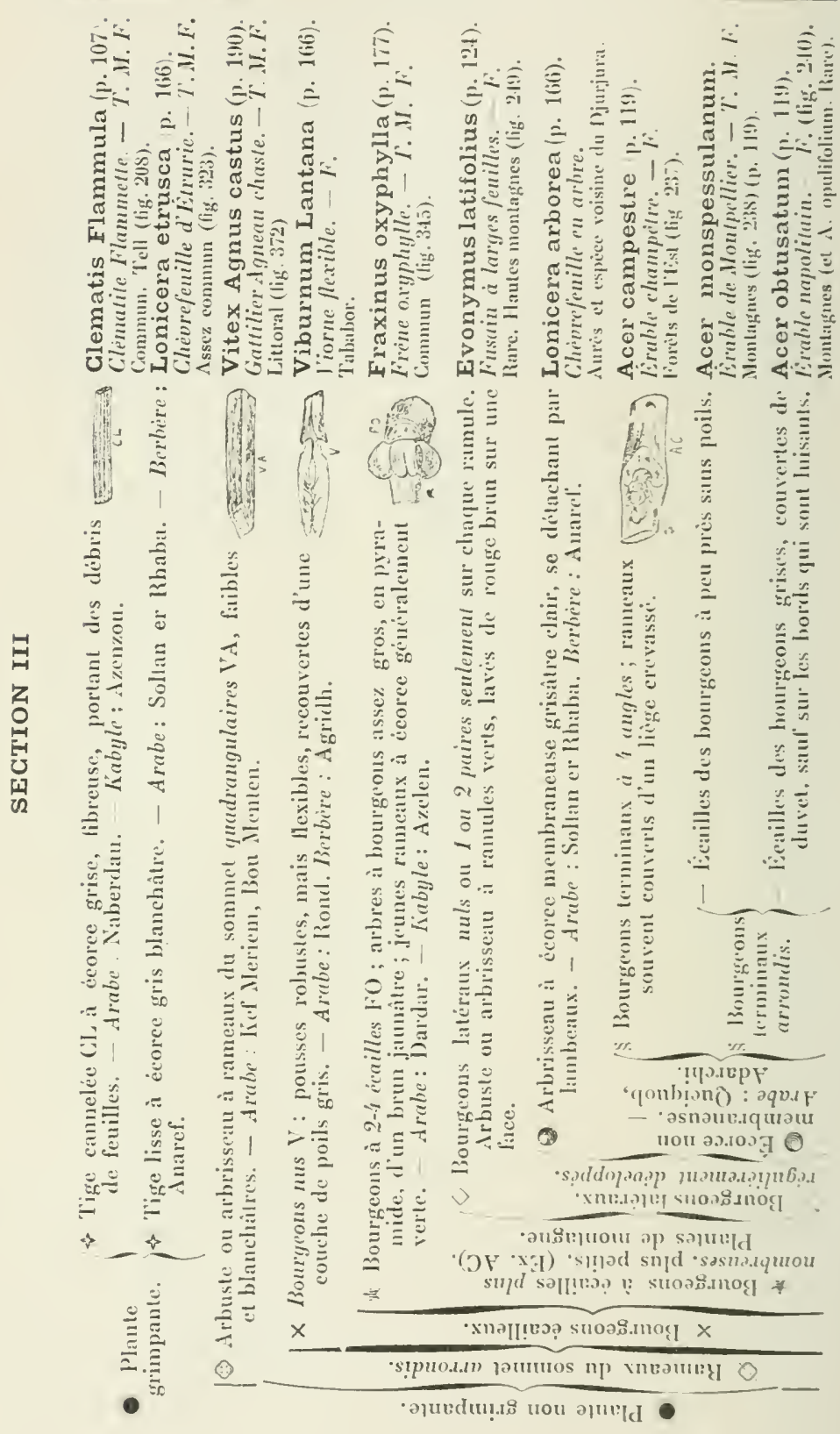




\section{QUATRIĖIE CLEF}

\section{TABLEAUX SYNOPTIOUES ILLLSTRES}

PERMETTANT LA DÉTEIIMINATION

DES BOIS DES PRINCIPALES ESSENCES DE L'ALGÉRIE (d'après la méthode de Mathien et Fliche). 



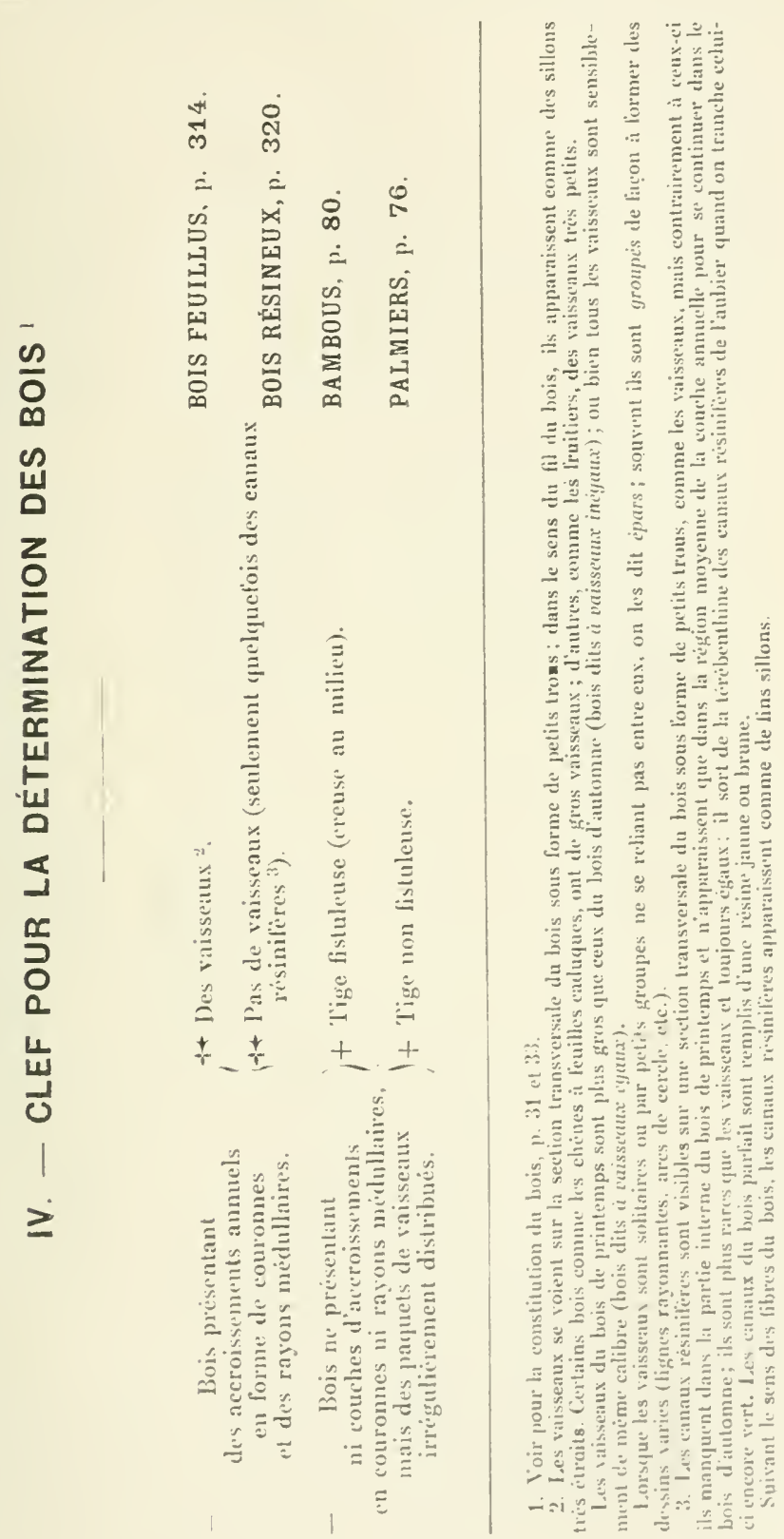




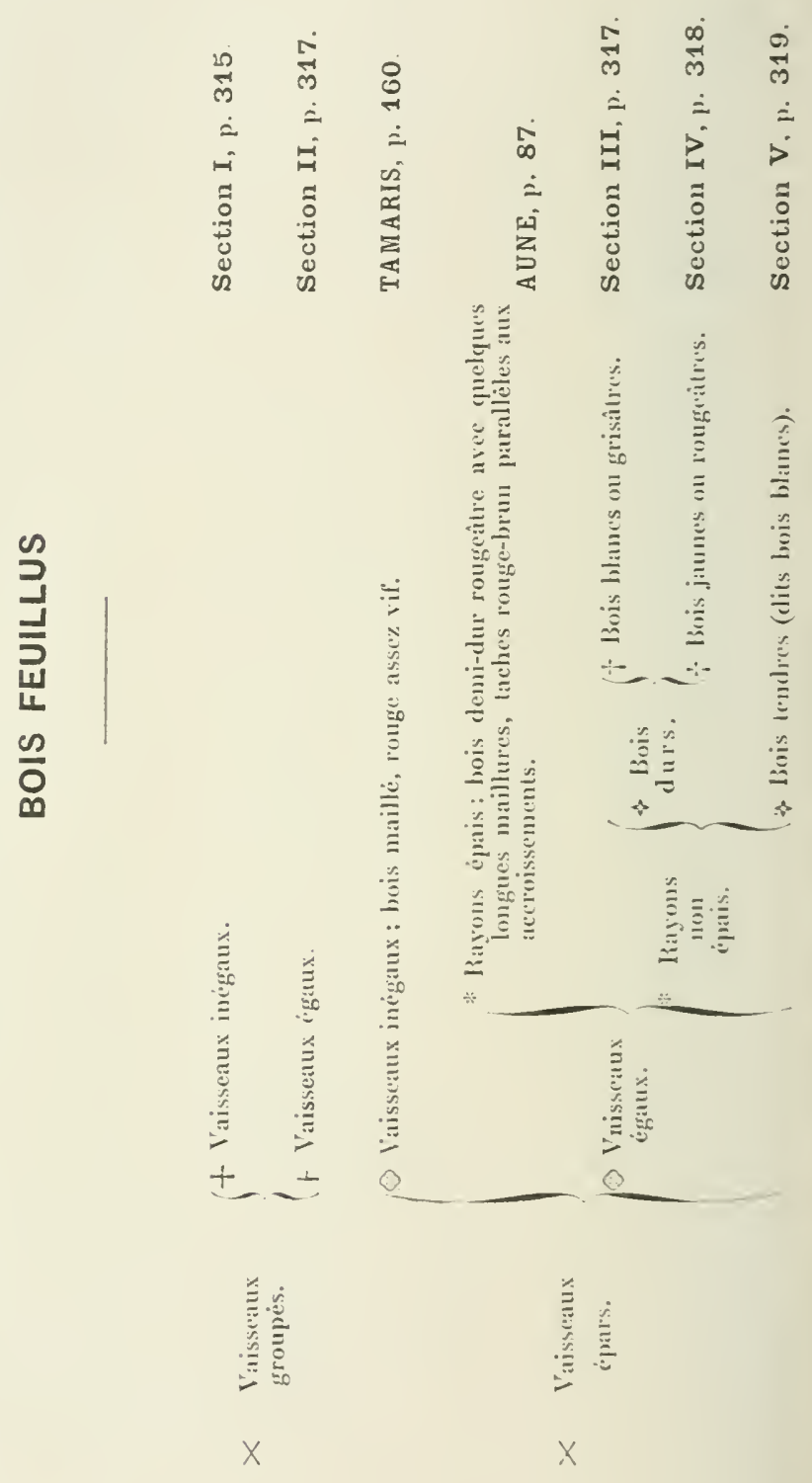




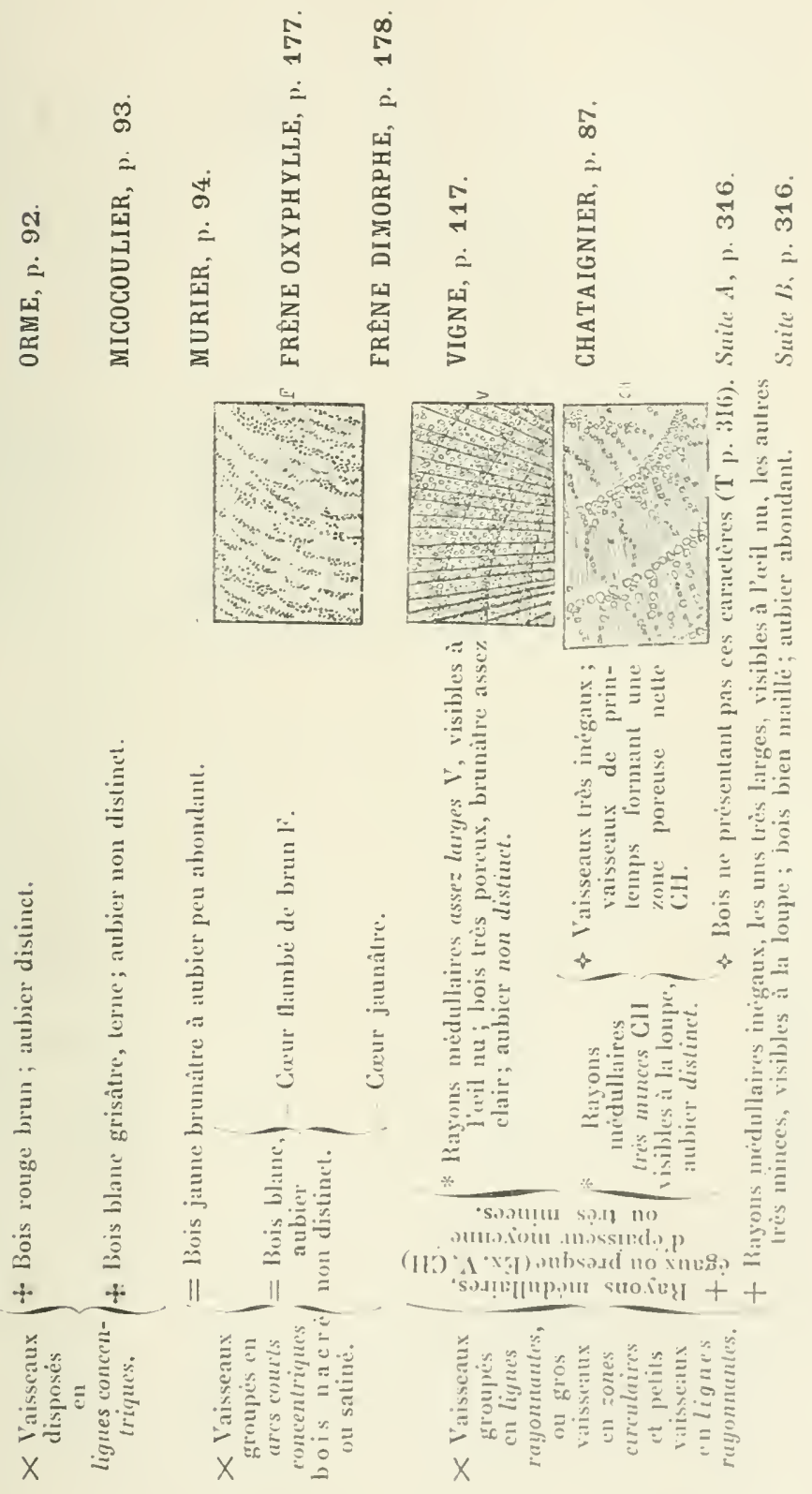




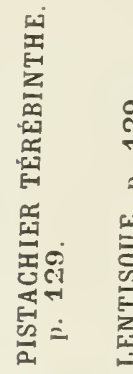

ज्ञ

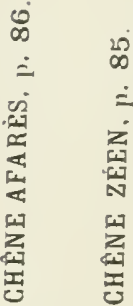
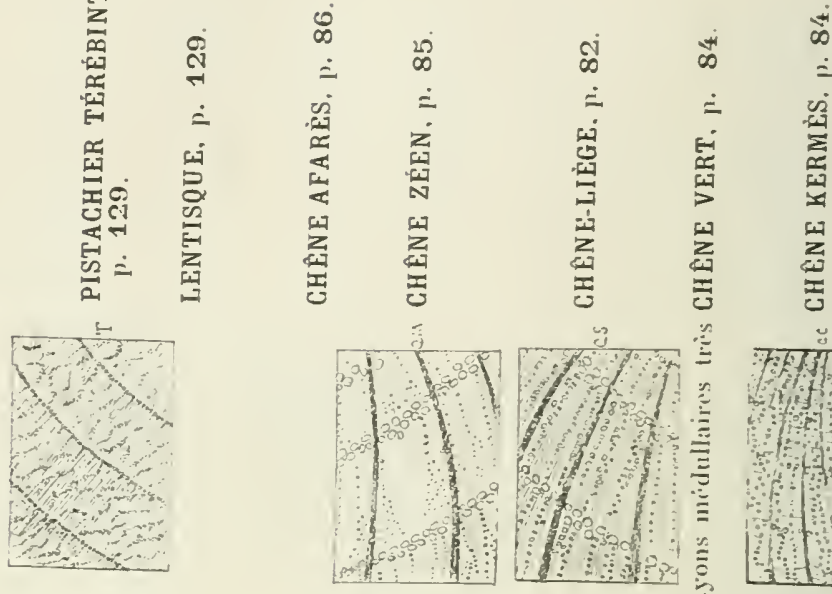

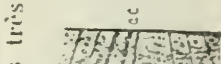
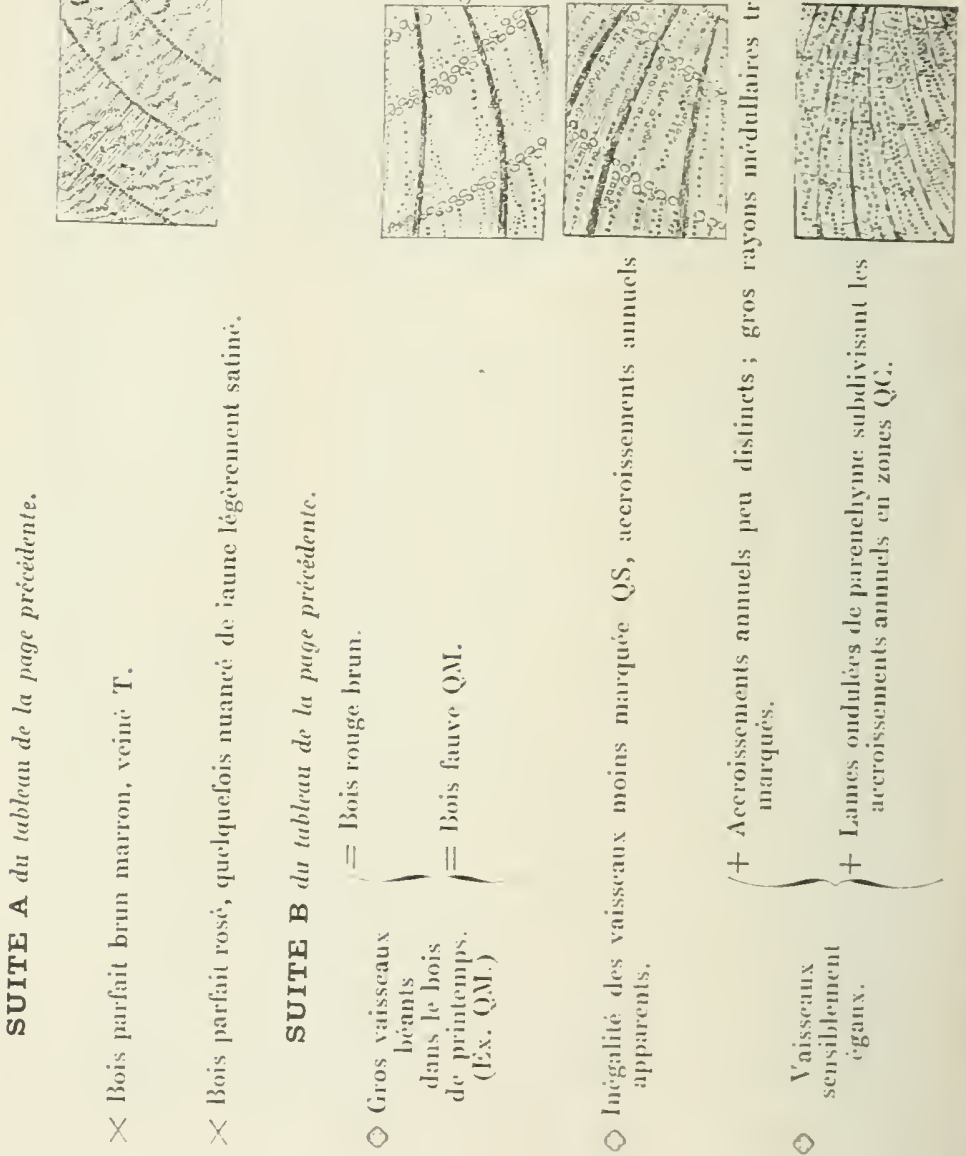

$\equiv$

:
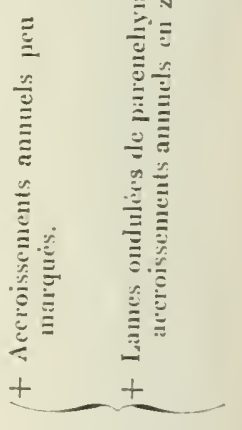


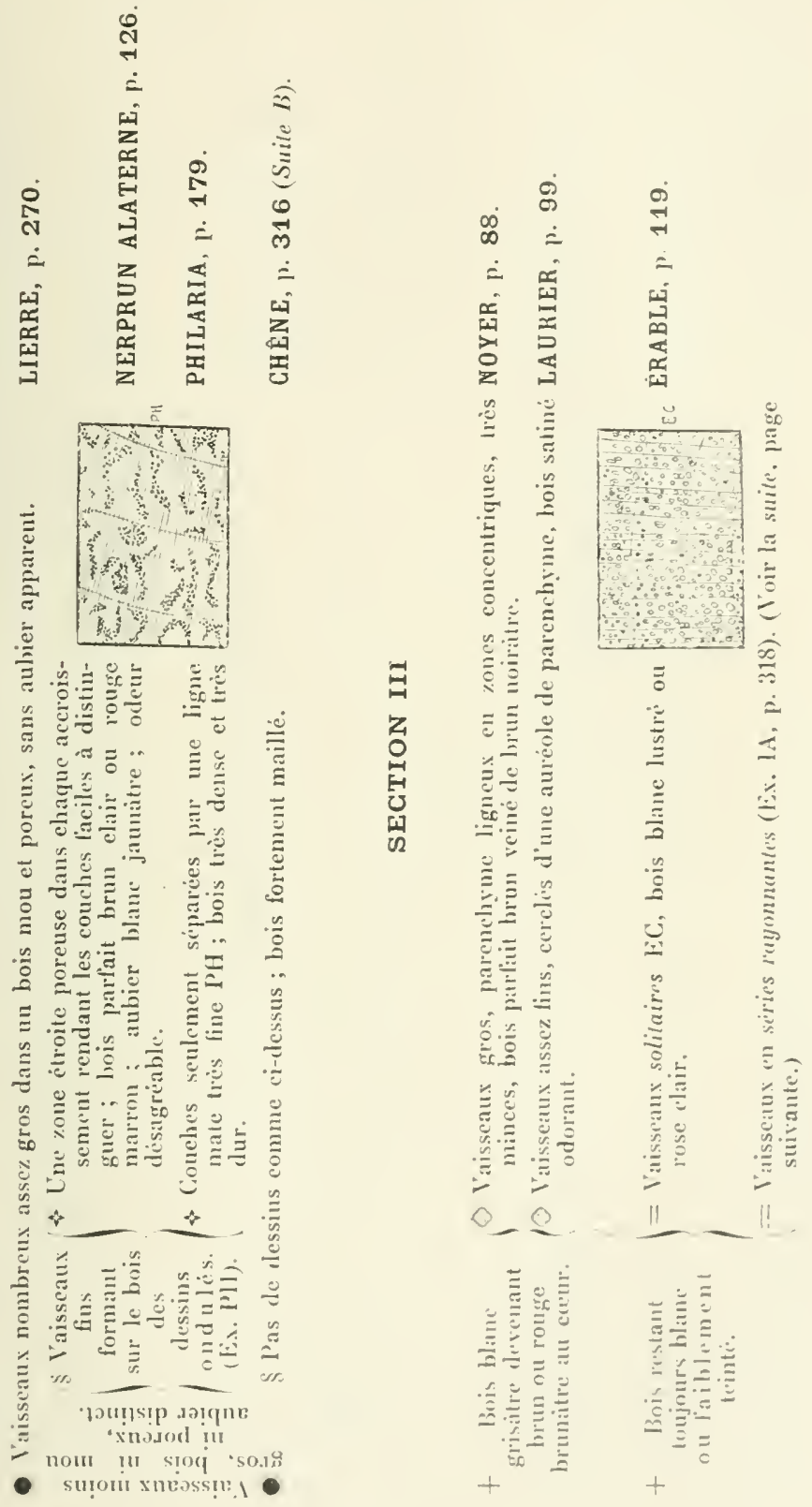




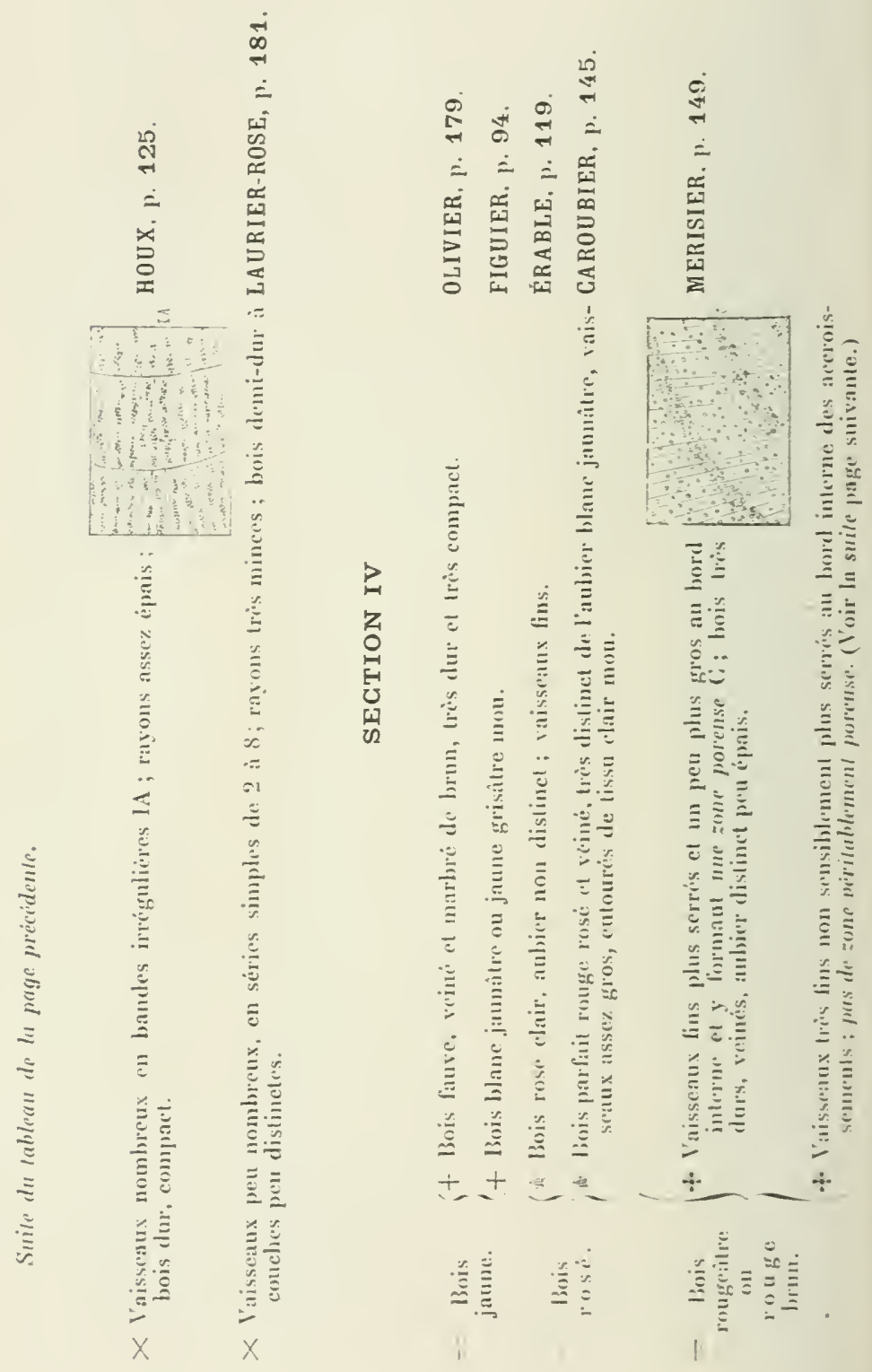




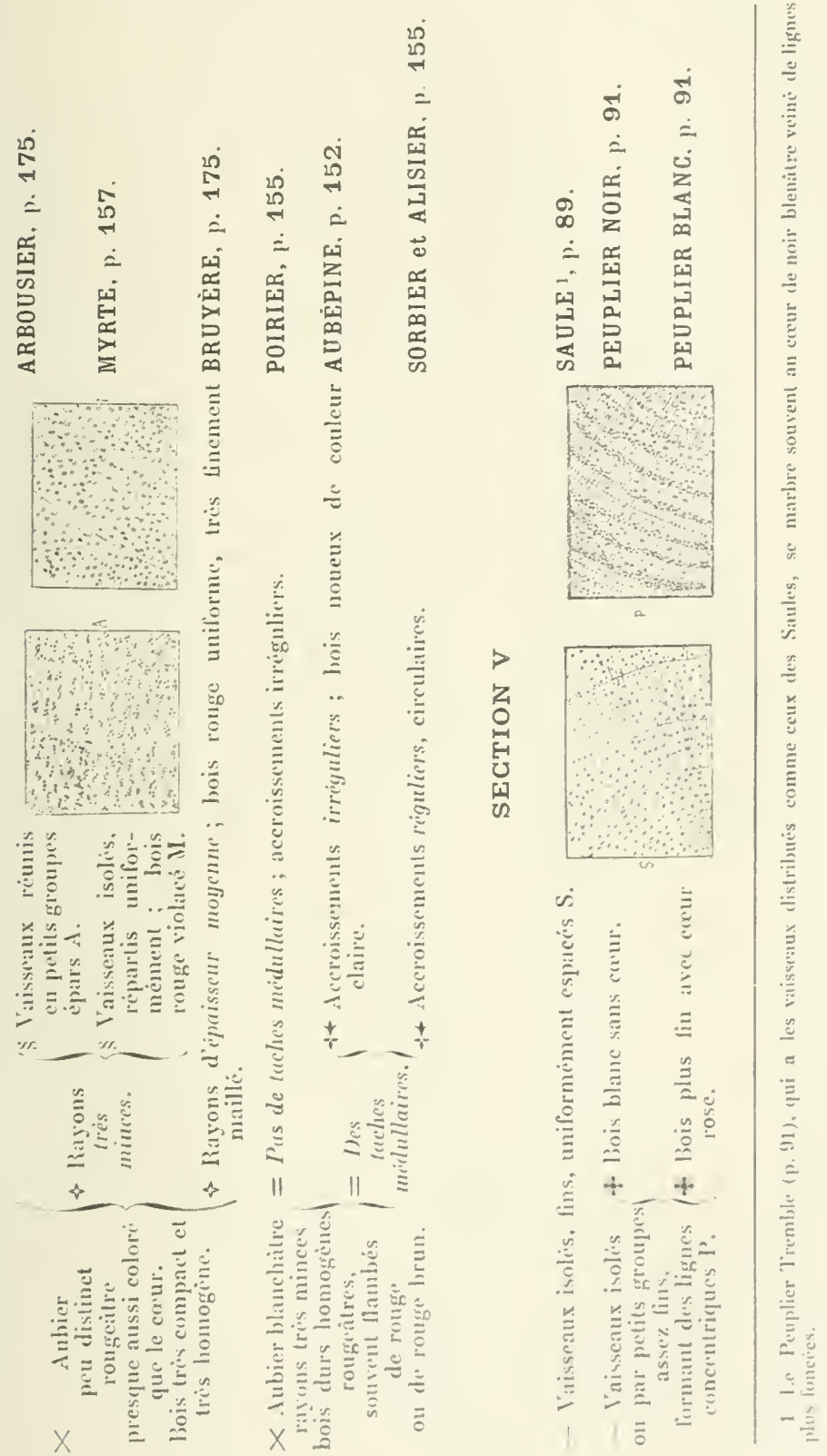




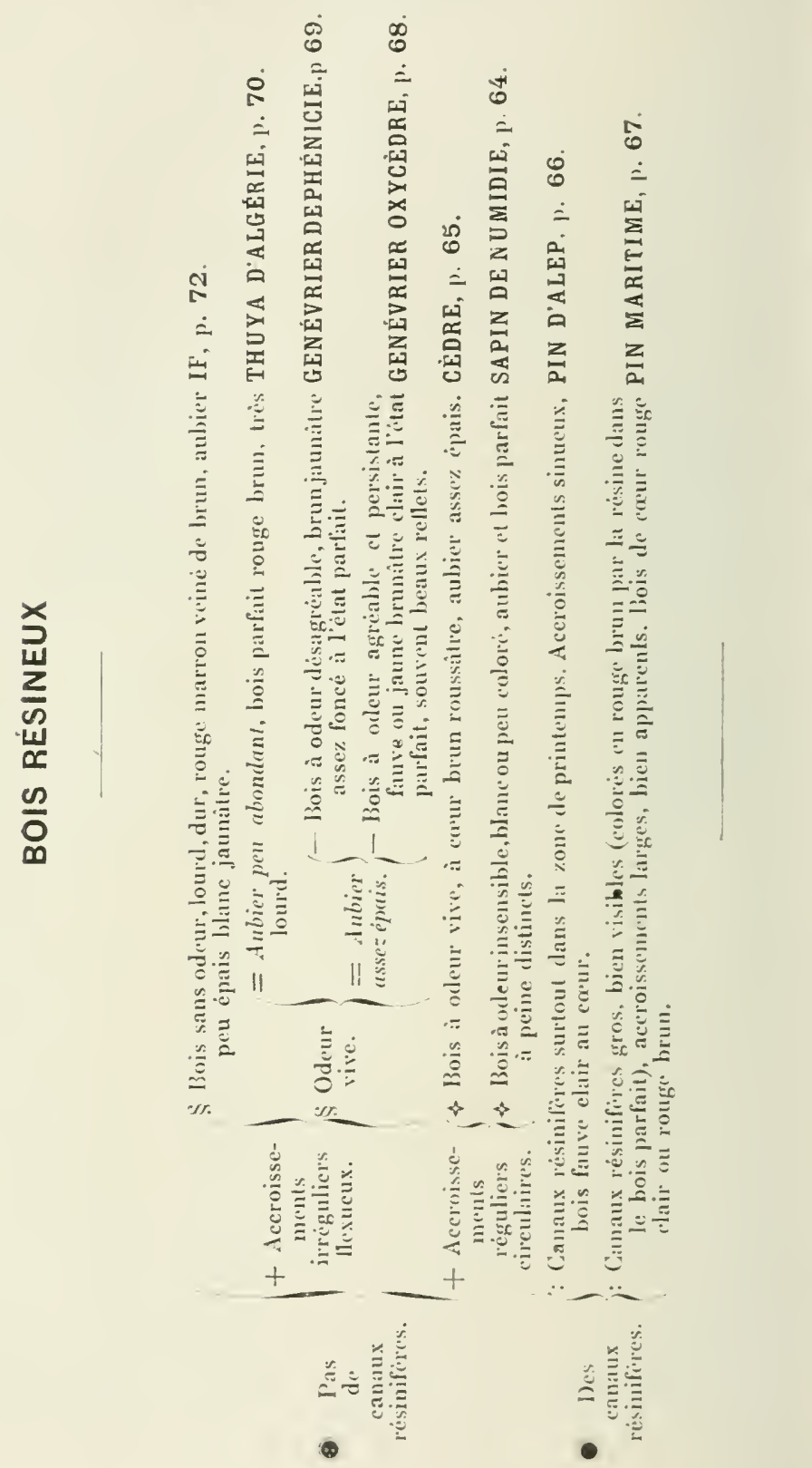




\section{TABLEAU SOMNIARE}

DES

\section{CARACTERES IES FAMILLES}

Il est très utile de s'initier à l'aide de ce tableau aux caractères principaux des familles, en commençant par les plus importantes qui sont indiquées en grosses lettres.

En les etudiant sur des plantes dont on connaît le nom, on arrive à fixer ces caractìres dans sa mémoire sans grand effort.

Dès que l'on sait recomnaitre, d'un coup d'ccil, ì quelle famille appartient une plante ligneuse, il suffit, pour acherer la détermination, de consulter le tableau des genres et des espèces à la page correspondant à cette famille. I.es recherches sont ainsi beaucoup plus faciles et plus rapides. 



\section{'TABLEAL' DES FAMILLES}

(Voir la nole de la page précédente).

\section{I. - GYMNOSPERIMES Caractères généraux, pages 58 el 63 ;.}

1. GNÉTACÉES (p. 63 et 224).

Ln seul genre (Ephédra ou Crelte) : Arbusles sans feuilles apparentes à rameanx verls articulés, quelquefois sarmenteux, à port de Prêle. - Orule entouré d'une enveloppe ouverte à la parlie supérieure.

\section{CONIFËRES (p. 64 et 224).}

Arbres ou arbrisseanx généralement résineux à fenilles en aiguilles on en écailles, celles-ci appliquées contre les rameaux. - Orules nus. - Ex. : Pins, Genévriers. (Ne pas confondre avec les Casuarinces $[8$ et les Tamariscinèes [53.)

II. - MONOGOTYLÉDONES (Caractìres généraux, page 59).

3. LILIACEES (p. 73 et 227).

Herbes, plantes grimpantes ou arbrisseaux à feuilles tantòt bien développées, tantôt réduites à des écailles et remplacées par des cladodes, fleurs régulières, à six divisions pour les genres étudiés, généralement à 6 ètamines (Asperge, Salsepareille), 3 seulement dans le genre Fragon. Ovaire non soudé au calice (supère).

$$
\text { 4. AMARYLLIDIES } \because \text { (p. 7.) et } 228 \text { ). }
$$

Herbes bulbeuses ou grandes plantes à fenilles charnues, épineuses sur les borkls (Agave). Fileurs régulieres, it (i divisions, fi étamines. Ovaire sondi au calice (infëre).

\section{PALAIIERS (p. 76 et 228 ).}

Arbres à tronc (slipe) couvert des restes des anciennes leuilles et surmonté de grandes feuilles en bouquet, divisées par. déchirure du limbe, ou buisson à grandes feuilles en éventail (Palmier nain).

Inflorescence en régime. 


\section{GRAMINEES (p. 77 et 229).}

Plantes à cluanues de hauteur variable, quelquefois ligneux. Feuilles longues et ćtroites, généralement à gaine fendue sur. le coité.

Fleurs membraneuses brunitres ou rerdatres groupces en épillets.

III. - DICOTYLÉDONES (Caractères généraux, page (î).

\section{A Apétales amentacées}

7. CUPULIFERES (p. 81 et 230).

Arbres ou arbrisseaux à feuilles simples, alternes, à fleurs (fig. 167-165) màles et femelles sur le mime arbre: les premières groupées en chatons. Fruit ì cupule (gland, chàtaigne, noisette), sauf chez les Bétulées (Aune).

S. castaméé † (p. 88 et 231).

Un genre introduil (Calsuarinal ou Filato); arbres a ramean verls, furs et allonges, portant des couronnes de petiles écailles représentant les linilles. Épis miles à l'extrémité des rameaux; épis f'emelles ovoīdes ou globuleux. (Ne pas prendre ces arbres pour de's Conil'ères.)

9. JUGLAXDÉES † (p. SS el 231).

Lne espice introduite (Noyer commun): arbre à fenilles alternes, composées odorantes. liteurs màles at femelles sur le mème arbre et disposies en chaton.

\section{SALICINEES (p. S9 et 231).}

Arbres ou arbustes à feuilles alternes généralement dentées. Fleurs mailes et fentelles en chatons sur des pieds differents. - Fruit souvrant par 2-1 valves (Saules, Peupliers).

$$
\text { 11. PLATANÉs - (p. } 92 \text { et '231). }
$$

Lne espiece introduite (Platane d'Orient); arbre a fenilles présentant des nervures en éventail el 3-5 lobes. - Flenr's en masses globuleuses.

\section{B) Apétales non amentacées}

\section{URTICACEES (p. 92 et 233 ).}

Fleursśverdàtres ordinairement petites et régulières. - Fruit ne s'ourrant pas, gènéralement petit. - Les + tribus ćtudièes ne compremnent que des arbres ì feuilles caduques. Orme et 
Micocoulier (lleurs hermaphrodites à 4-5 divisions); Mlùriers $\dot{-}$ (fleurs unisexuées à 4 divisions); Figuier (fleurs unisexuées dans 1 réceptacle charnu.)

\section{SALSOLACÉES (p. 95 et 234).}

Plantes herbacées ou arbrisseaux surtout répandus dans les lerrains salés.

Fleurs plus on moins vertes, composées de 2-5 pièces libres ou peu soudées, autant d'étamines, ovaire en général non soudé au calice, fruit à 1 graine (Ex. : Arroches.)

\section{PHYTOLACCÉES † (p. 97 et 237 ).}

L'n grand arbre introduit (Bellombra). Fenilles alternes, ovö̈les. - Flenrs verdâles, unisexuées: élamines sur un disque charnu, carpelles verlicilles.

\section{POLYGoNéEs (p. 97 et 237).}

Herbes, quelquefois sous-arbrisseaux, ì lige souvent noueuse, articulé, fenilles alternes, munies d'une gaine. Flenrs comprenanl 3-6 sćpales dont 3 peuvent envelopper le fruil; 4-16 élanines. (Ex.: Oseille.)

\section{ARISTOLOChiÉEs (p. 99 et 237 ).}

Un seul genre (Arisloloche) comprenant des especes herbacees, d'atutres it tige volubile plus on moins ligneuses. Enveloppe llorate en forme de cornet renflé au bas el lerminé par une languette. Élamines soudées en colonne avec les styles.

\section{LAURINÉES (p. 99 et 237 ).}

Un arbre aromalique (Laurier-sauce). Fcuilles alternes, entieres, coriaces, persistanles.

Fleurs régulières, d'ordinaire diö̈ques, blanchâtres ou verdatres en oublelles, $\$-12$ étamines. Baie noire à 1 graine.

\section{THYMÉL ÉACÉES (p. 99 et 238).}

Arbrisscaux à feuilles tantôl développées (Daphnés), lantól réduiles à des écailles (Passeriues). Fleurs à $4-\bar{o}$ sépales, 8-10 étamines, ovaire libre d'ortinaire à 1 loge.

$$
\text { 19. PROTÉACÉ }- \text { (p. 99 et 237). }
$$

Arbres et arbrisseaux surtout repandus dans les regions australes. Perianthe à 4 divisions, 4 chamines. Un arber souvent plante an avenues, a fevilles dicoupees (Grivillere roluste). 
20. ÉLÉAGXÉES † (p. 101 et 239).

Arbres on arbrisseaux, couverts de poils en écusson, présentanl un aspect blanc argenté. P'érianthe appliqué sur l'ovaire el resserré au-dessus de lui. L'n petil arbere sourent cultive (Chalef) à fleurs argentées au dehors, jaunes en sledans.

\section{LoRANThaCÉEs (p. 101 et 239).}

Deux especes parasites sur les rameanx des arbres à liges plusieurs foin hifurquées. Rameatux articulés, feuilles opposies. Fleurs ordinairement dioï (ques. (Ex.: Gui.)

\section{SANTALACÉES (p. 102 et 240).}

Herbes ou arbustes parasites sur les racines d'autres plantes. Un genre cité (Osyris), comprenant 2 espèces dioïques à fleurs jaunes, les mâles groupées à 3-t étamines, les femelles soli taires à 3 stignates, fruits rouges.

\section{EUPHORBIACEES (p. 103 et 240).}

Herbes ou arbustes souvent $\dot{a}$ suc laiteux. Flcurs unisexuées (les mâles et les femelles réunies dans un involucre commun chez les Euphorbes). Calice libre, ovaire à 2-3 coques. Le fruit en capsule s'ouvre en laissant une colonnette sur la tige.

\section{BCXacées (p. 105 et 240 .}

L'n arbuste (Buis) odorant à fenilles opposies, petiles, entières, coriaces, luisantes el persistantes. Fleurs jaumâtres, monoïques, 'n boules. Ovaire ì 3 loges, it 2 orrules.

\section{C) Dialypétales thalamiflores}

\section{RENONCULACÉS (p. 106 et 241).}

Plantes herbacécs, quelquefois ligneuses et grimpantes, ayant en général de nombrenses étamines dont les anthères sont cournées en dehors. Carpelles libres, au moins au sommet.

Un genre cité (Clématite) comprenant des espèces sarmenteuses à 4 sépales colorés; fruits à aigrette plumeuse.

\section{Bв:RBÉridéEs (p. 107 et 241).}

Un arbrisseau à épines trifurquies (Epinc-Vinclle). Fleurs ì $4-6$ divisions. Antheres s'ourmut par de pelites vilses, l'ruil charnu. 


\section{CRUCIFÈRES (p. 107 et 241).}

Herbes, quelquefois plantes ligneuses, dont les lleurs ont (i) étamines, dont 2 plus courtes (fig. 211), 't sépales, 't pétale's. Fruit souvent à 2 valves (silique ou silicule). (Ex. : Chou.)

28. CAPPARIDÉES (p. 109 et 242).

Lu arbrisseau (Càprier) dont les feuilles portent 2 épines à la base. Fleurs du type des Cirucifires, mais avec de nombrenses élamines.

29. CISTINÉES (p. 110 et 242).

Herbes ou sous-arbrisseaux (Ex. : Cistes) à feuilles simples généralement opposées.

Fleurs régulières, comprenant de nombrenses étamines, 5 pétales chiffonnes dans le bouton et tombant facilement, 5) sépales dont deux ordinairement plus petits.

$$
\text { 30. violakiées (p. } 114 \text { et } 245 \text { ). }
$$

Plantes generalement herbaciés. Fleurs irrigulicres à 4 -\$ pétules profondiment divisés, lun à iperon, $4-8$ sépales, $7-40$ étamines. Une espèce frutes"ante à lige conchér (Violetto ligneuse).

$$
\text { 31. Polygatées (p. } 115 \text { et } 245 \text { ). }
$$

Plantes géneralement herbatcés. Flenss irrigulières à jópales dont 2 plus grauds colorés, pétales plus on moins sondes, 8 itmmines i anthres somblies

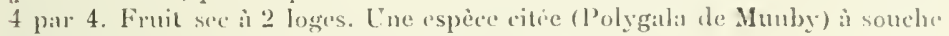
ligueuse, il lleurs roses ou jaunes on papillon.

$$
\text { 32. MALYACEES (p. } 115 \text { et 24.j). }
$$

Plantes mucilaginenses (Ex. : Guimauve); fenilles it nervures ordinairement en évenlail (palmées). Fleurs régulières sur le type 5; calice doublé de petites bractées formant un calicule. Étamines nombreuses soulées en muchon, chacune à 1 seule loge.

$$
\text { 33. CARYOPHYLLEES (p. } 117 \text { et 246). }
$$

Plantes rarement ligneuses, it feuilles opposées, lige renflie it leur point d'attahe. Fleurs régulières, à style libre, à ovaire non divisé, souvent ś pétales, 5 sépales, 10 étamines. (Ex. : (Eillet.)

$$
\text { 34. PAHOXYCHées (p. } 117 \text { el 246). }
$$

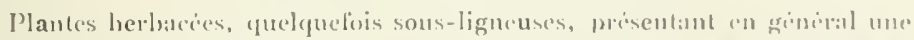

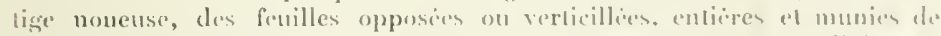
stipules qquelquefois allermes dims le hant: Hemiare). Calice it f-is divisioms. pétiles co mêne nombre, souvent liliformes ou même nul.

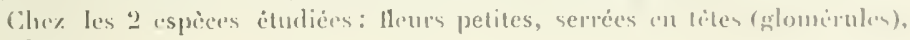
verdities. 


\section{MÉLIACÉES † (p. 117 et 247).}

Un arbre cultivé (Lilas des Indes) ì feuilles 2 fois pennies, ì fleurs violettes en grappes composées.

\section{AMPÉlidéES (p. 118 et 247 ).}

L'ne seule espèce ètudiée (Vigne), plante grimpant par des vrilles, fleurs régulières à jó sépales verts qui restent soudés ensemble par le haut et se détachent de la fleur (fig. 233).

\section{ACÉRINÉES (p. 118 et 247).}

Arbres à feuilles opposées el à nervures disposces en évenlail, fleurs régulières sur le type j̀ comprenant 1 -12 étamines. Fruil à 2 ailes (Genre Érable).

\section{8 coriariées (p. 120 et 247).}

Un arbrissean "(Corroyère) à feuilles entières opposées ou par 3. Fleurs petites sur le type $\check{\jmath}$ en grappes dressées. Fruit charnu.

$$
\text { 39. LINÉES (p. } 121 \text { et } 248 \text { ). }
$$

Plantes grêles, à feuilles simples, étroites, fleurs sur le type 4 ou J. Pítales (5 dans le genre Lin) tordus dans le bouton et tombant ficilement.

Ovaire à 6-8 loges. Le fruit est une capsule.

$$
\text { 40. rutacées (p. } 121 \text { et 248). }
$$

Herbes on plantes sous-ligneuses à feuilles ponctuées. L'n genre étudié (Rue), comprenant des espèces ì odeur forle, à fenilles trés découpées et dont les fleurs, sur le type 4 on 5 , ont des pétales également découpés sur les bords.

$$
\text { 41. AURANTACÉES † (p. } 122 \text { et 248). }
$$

Arbres ou arbrisseaux cultivés, souvent épineux, à feuilles alternes, à fleurs blanches on roses, odorantes, généralement sur le type 5 (fig. 245). Étanines nombreuses; ovaire à plusieurs loges domnant un fruit pulpeux (Orange, (itron, etc.).

\section{HYPÉRICINÉES (p. 123 et 248).}

Herbes ou arbrisseaux ì feuilles opposées ou verticillées, simples, souvent ponctuées (Nillepertuis). Fleurs jaunes sur le type 5 ; étamines nombreuses réunies eи $3-j$ faisceaux.

\section{D) Dialypétales calyciflores}

\section{Célastrinées (p. 124 et 249 ).}

Un arbrissea (Fusain à larges feuilles) à feuilles opposées fiuement dentées. Fleurs régulières: calice it $4-5$ lobes persistants, $t-j$ pétalcs altachés sur un anncau charnu, 4-Ј étamiues, capsule rose. 


\section{4. ilicinées (p. 125 et 249 ).}

Ln arbusle (Houx) à feuilles dentíes, coriaces et épineuses. Fleurs régulières (ype 4-5) et fruil rouge charnu.

\section{RHAMNÉES (p. 125 et 240 ).}

Petits arbres ou arbrisseaux à feuilles simples, alternes ou opposées, ordinairement coriaces, ì stipules souvent caduques parfois transformées en épines. Fleurs sur le type 1-j; calice souvent coriace; pétales courts ou uuls.

\section{TÉRËBINTHACÉES (p. 126 et 250).}

Arbres ou arbrisseaux à feuilles alternes, composées, sans stipules. Petites lleurs unisexuées, sur le lype jo, réunies en grappes composées, pétales quelquefois nuls (genre Pistachier), fruit sec ou charnu.

\section{PAPILIONAGÉES (p. 131 et 252).}

Plantes herbacées ou ligneuses ì feuilles souvent composées et munies de stipules. Fleurs irrégulières (lig. 260) ¿ 10 élanines toutes, on 9 séulement, rémies par lenr filet. (Execpté l'Anagyre fétide dont les étamines sont libres.)

48. CESALPINIELS (p. 145 et 261).

Arbres à feuilles simples arrondies (Arbre de Judée) ou composées (Caroubier). - Corolle ressemblunt it celle des Papilionucées (Arbre de Julée) ou nulle (Caroubier). Calice à $\check{b}$ divisions, (quelquefois caduc, 10 étamines libres, quelquefois moins.

49. MIMOSEES + (p. 146 et 261).

Famille représentée par un genre cultivé (Acacia). Arbres ou arbustes à feuilles composies ou à phyllodes. Flenr's en petites boules ou en ipis, générulement jume nif (execpté YAcacia élégant), à $4-5$ divisions (rarement 33 (6), corolle régulière, élamines nombrenses libres ou presque libres. à filets longs, grains de pollen réunis en 2-6 masses dans chaque logette. 


\section{ROSACEES (p. 148 et 262).}

Herbes, arbrisseaux ou arbres à feuilles simples ou composées, sourent dentées, stipulées, ordinairement alternes, fleurs à corolle régulière, à étamines nombreuses soudées avec le calice. Fruit jamais en gousse, souvent charnu et comestible (I'oire, Pomme).

\section{MYRTACEES (p. $1 \dot{\text { ji }}$ et 267).}

Arbres ou urbustes à fenilles simples, entieres, odorantes el ponctues. Fleurs en grappes sur le type 4-5; ítamines nombreuses, fruit à carpelles en verticille. Un arbrisseau spontané (Myrte) et nombreuses espèces introduites appartenant surtout au genre Eucalyptus.

$$
\text { 52. GRANATÉES † (p. } 160 \text { et 268). }
$$

Mêmes caracteres que les Myrtacées, mis fenilles non poncluees "t fruil formé de deux rangs de loges en verticilles. Ln arbuste cullivè ì grandes tleurs rouges (Grenadier).

\section{TAMARISCINÉES (p. 160 et 268).}

Arbres ou arbustes toujours verts à fenilles très petites en écailles.

Fleurs petites sur le type 4-5. Un seul genre (Tamaris). Ne pas confondre aree les Conifires.

$$
\text { 5t. Crasslatáés (p. } 161 \text { et 269). }
$$

PJantes en général herbacées el charnues. Feuilles alternes chez les rspéces citées. Fleurs prisentant 3 à 20 divisions, élamines en nombre égal ou alouble. Carpelles an mème nombre munis diune écaille à neetar.

\section{5ว. CACTÉEs + (p. 162 et 268).}

[ne espice introduile très répandue, à lige composée de raquelles charnues genéralement hérissées de soies piquantes. (irandes lleurs janme (Figuier de liarbarie).

5)(j. GROSSUlaAriéEs (p. 162 et 269).

Un seul genre (Groseillier) comprenaul des arbrisseaux dont les feuilles non opposées ont des nervures en éventail. Fleurs régulières sur le lype ja pétales plus courls que les sépales. Inflorescence en grippe.

57. OMBELLIFËRES (p. 163 et 269 ).

Plantes généralement herbacées à feuilles alternes munies de pétioles dilatés et engainants à la base. Fileurs petites sur le 
type 5 généralement en ombelles composées. Fruit formé de 2 achaines qui se séparent à maturité.

5S. ARALIACÉES (p. $16+$ et 270).

Une espèce indigène (Lierre), arbrissen grimpant par des racines en crampons. Fleurs régulières sur le lype 5 disposées en ombelles simples. Fruit charnu.

\section{E) Gamopétales à ovaire infère}

59. CAPRIFOLIACÉES (p. 165 et 270).

Plantes ligneuses (sauf une espèce) quelquefois volubiles, à feuilles opposées simples (Chèrrefeuille) ou composées (Sureau). Fleurs sur le type i, quelquefois t, régulières on non.

\section{RUBIACÉES (p. 167 et 271).}

Plantes herbacces yurlquefois grimpantes ou sous-arbrisseaux, à feuilles simples opposées on paraissant verlieillées. Fleur's régulières d'ordinaire it 4t divisions; fruit ì 2 loges; baie chez les espèces cilées (Ex.: (iarance.)

\section{COMPOSEES (p. 168 et 271).}

Plantes généralement herbacées, exceptionnellement arbrisseaux, ayant à la fois les fleurs réennies en capitules et dons chaque fleur les anthères soudées en un tube dans lequel passe le style ; Jitamines; fruits secs souvent surmontés d'une aigrette formée par les dents du calice (Chardon, Laiteron, Camomille).

\section{F) Gamopétales à ovaire supère}

(i2. ERICACEES (p. 175 et 276).

Deux genres (Bruyere, Arbousier) comprenant des arbustes ou des arbrisseaux à feuilles simples, persistantes. Fleur's it 1-5) divisions avec élumines en nombre donble, corolle en grelot on en clochette.

\section{(33. OLEACEIS (p. 177 et 276).}

Arbustes at feuilles opposées (saul le Jasmin). Fleurs

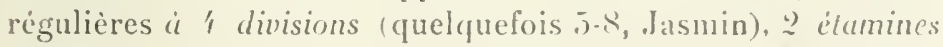
soudces à la corolle. Ovaire à 2 loges. Fruit see (Frène) ou charnu (Olivier, Philaria). 


\section{ApocÝxées (p. 180 et 277 ).}

Famille représentée par un arbuste (Lauricr-rose) et un genre comprenant des plantes rampantes (Pervenche) à feuilles persistantes, enlières, coriaces, opposées on par 3 ; flcurs régulieres sur le lype $\bar{j}$, corollc tordue dans le bouton, 2 carpelles.

\section{ASCLIPIADÉES (p. 181 et 278 ).}

Plantes herbacées ou ligneuses, à suc laiteux, à feuilles d'ordinaire opposíes. Fleurs régulières sur le trpe 5 , étamines genciralement soudécs entre clles el adhérentes au sligmate. Pollen réuni en masses dites pollinies.

\section{CONTOLYulacées (p. 182 et 278 ).}

Plantes s'enroulant souvent autour d'autres tiges. Fleurs régulières, à pétales tordus dans le bouton, soudes en forme d'entonnoir portant an fond les itamines; ovaire à $2-4$ loges. Une espèce cilèe (Liseron de Biscaye).

\section{BORRAGINEES (p. 182 et 278).}

Plantes généralement herbacées et hérissées de poils, à feuilles alternes. Fleurs ordinairement régulières à 5 divisions. 5) ćtanines. Ovaire divisé extérieurement en 't parties, donnant 4 akènes libres ou soudés. (Ex. : Grénil.)

\section{SOLANEES (p. 182 et 27S).}

Plantes herbacées ou arbrisseaux, à feuilles alternes, à fleuts r'égulières, ou peu irrégulières, it jo divisions et jétamines. Calice souvent persistant; ovaire it 2 loges. (Ex.: Douceamère.)

\section{SCPOFLLARINÉES (p. 184 et 280).}

Plantes généralement herbacées, à fleurs irrégulières d'ordinaire ì $4-5$ divisions. Corolle sonvent bossue ou éperonnce, it 2 levres, 4 ítanines, dont 2 pliss grandes ou 2 seulement. Onaire di 2 loges. (Ex. : Mullier.)

\section{LABIEES (p. 185 et 280).}

Plantes herbacées ou petits arbrisseaux a tiges et rameaux plus ou moins carrés, à feuilles opposées ou verticillées, à poils glanduleux, souvent odorantes. Fleurs irrégulieres a 4-5 divisions, corolle généralement $\dot{a} 2$ levres, 4 étumines dont 2 plus grandes ou 2 sculement. Ovaire d $t$ loges. (Ex.: Thym). 


\section{VеRвÉxACÉES (p. 190 et 285).}

Un arbuste à odeur de poivre Gattilier); feuilles opposées a $3-\tau$ folioles en éventail. Fleurs irrégulières bleues ou blanches en grappes terminales; 7 étamines dont 2 plus petites.

\section{Plombiginées (p. 190 et 284).}

l'lantes herbacées ou arbrisseaux: feuilles souvent en rosette a lu buse (Statice), quelquefois couvertes d'uue sorle d'enduit limoniastrum). Fleurs régulières, quelquefois réunies en capitules, caliee sonvent membraneus. corolle à 5 pétales (qui peuvent ètre libres), jètamines, ovuire à jarpelles.

\section{PlaNTAGINÉES (p. 191 et 2রi).}

Plantes herbacies, quelquefois ligneuses on à grosses racines: fenilles sonvent en rosette à la base. Fleurs petites, verditres, à 4 divisions d'ordinaire membraneuses, placées it l'aisselle de bractées membraneuses, réunies en 'pis (Plantain'.

\section{GLOBUlariées (p. 192 et 28J).}

Une espice Globulaire Turbith, sous-itrbrisseau à feuilles coriaces, à fleurs blenes à 2 lèvres, groupées en eapitules, $t$ ittimmes.

Ressemble it une Composée. 



\section{TABLE DES ABREVTATIONS}

\section{$1^{\circ}$ ABRÉVIATIONS DES NOMS D'AUTEURS}

\begin{tabular}{|c|c|c|c|}
\hline \multirow{2}{*}{\multicolumn{4}{|c|}{ Adanson. }} \\
\hline & & Jacq. & Jaequin. \\
\hline A it. & Aiton. & Jaub. & Jaubert. \\
\hline All. & Allioni. & Jord. & Jordan. \\
\hline Barr. & Barrelier. & Juss. & Jussieu. \\
\hline Batt. & Battandier. & L. & Linné. \\
\hline Benth. & Bentham. & Lab. ou L & 1. Labillardière. \\
\hline B.et R.ou & ou B.R.IBoissier et Reuter. & Lag. & Lagasea. \\
\hline bieb. & Mlarschall von Bieberstein & Lam. & Lamaık. \\
\hline Biv. & Iivon. & Led. & Ledehour. \\
\hline Bl. & líanc. & Lem. & Lemau. \\
\hline Bol’. & Boreau. & L'llérit. & l.'Héritier. \\
\hline Bois. ou & Boiss.Boissier. & Lindl. & Lindley. \\
\hline Brot. & lirotero. & Loell. & Lofling. \\
\hline Brous. & Broussonet. & Lois. & Loiselcur. \\
\hline Camb. & Camhessèdes. & Мau. & Manetıi. \\
\hline Carr. & Ciarrière. & lled. & Medick. \\
\hline Cass. & Cassini. & M. Bieh. & Marschall ron Bieberstein. \\
\hline Cav. & Cavanilles. & Mert. & Mertens. \\
\hline Claus. & Clauson. & Mey. & Meyer. \\
\hline Clus. & De l'Écluse. & Mill. & Miller. \\
\hline Coss. & Cosson. & $M, q$. & Noquin-Tandon. \\
\hline Cunn. & Cunningham. & Moric. & Moricand. \\
\hline Cyr. & Cyrillo. & Munh. & Munby. \\
\hline D. C. & De Candolle. & Neck. & Nectiel. \\
\hline Dec. & Decaisne. & Nees. & Nees von Escubeck. \\
\hline Desi. & Desfontaines. & Nut?. & Nuttal. \\
\hline Desv. & Desvalix. & Pail. & Parlatore. \\
\hline Dougl. & bouglas. & Pers. & lersoon. \\
\hline Duf. & Dufour. & Poir. & Poiret. \\
\hline Juham. & Duhamel. & Poit. & Poitcau. \\
\hline Il um. & Dumont de Courset. & Pom. & Pomel. \\
\hline Dure. & Dunal. & Pourr. & Pourvet. \\
\hline Dur. ou 1 & D. P. Durien do Maisonneuve. & Radd. & liaddi. \\
\hline Ecinl. & Ecklon. & li. Br. & liobert lirown. \\
\hline Endl. & Endlicher. & Rieich. & Reichenlsach. \\
\hline Fisch. & Fischer. & lietz. & lietzius. \\
\hline Forsk. & Forskal. & Reut. & lieuter. \\
\hline Forst. & Forster. & lich. & Richard. \\
\hline F. r. Mu & meiler. Ferd. von Mueller. & liiss. & lisso. \\
\hline Gipertn. & Gactner. & liiv. & livière. \\
\hline rod. & Gadron. & lioub. & linxburgh. \\
\hline liren. & Grenier. & Salza. & Salzman. \\
\hline Gillss. & Gussone. & Sauv. & Sallrages. \\
\hline Hartw. & llartweg. & Schilecht. & Schlechendal. \\
\hline II w. & llaworth. & Schreb. & schreber. \\
\hline llochs. & Hochstetter. & Scop. & siopoli. \\
\hline Iloff. ou II & lloffm. Iloffmann. & & Seringe. \\
\hline llook. & llooker. & Sibth. & Sibthorp. \\
\hline IIort. & II urtularormu (des jatluirss) & Sieb. & Sicber. \\
\hline
\end{tabular}




\begin{tabular}{ll|ll} 
Sm. & Smitl. & Trib. & Trinius. \\
Sol ou Soland. & Solander. & Vurr. & Turra. \\
Spr. & Sprongel. & Vent. & Ventenat. \\
Steud. & Steudel. & Vir. & Villars. \\
Ten. & Tenore. & IValp. & Viviaui. \\
Tho. & Thore. & Wendi. & Wendland. \\
Thuil. & Thuillier. & Willd. & Willdenow. \\
Thunb. & Thunberg. & Willk. & Willkomm. \\
Timb. & Timbal. & Wulf. & Wulfen. \\
Tin. & Tineo. & Zeyl. & Zeyher. \\
Tourn. & Tournefort. & & \\
Trab. & Trabut. & & \\
Tratt. & Trattinick. & &
\end{tabular}

\section{$2{ }^{\circ}$ ABRÉVIATIONS CONTENUES DANS LES CLEFS}

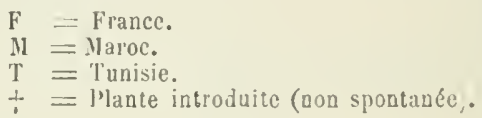




\section{TABLE ALPHABÉTIQUE}

\section{DES TERMES EXPLIQUÉS DANS LA PREMIËRE PARTIE}

(Pour les noms des Cryptogames (groupes, genres, noms vulgaires), roir la table suivante.

A

Adventif (bourgeon)

Aiguilles

Aire.

Akène.

Albumen

Alternes (feuilles?

Amentacées.

Angiosperme. .

Anthère

Apétales . . . . . . . . 60

Arbre . . . . . . . . 29

Arbuste 29

Arbrissean . . . . . . 29

Asque. . . . . . . . 12

Assimilation. . . . . . 55

Association . . . . . . 197

Aubier.

B

Baic. . . . . . . . . 45

Baside. . . 12

Blanc de champignon. . . 10

Bois. . . . . . 31, 33

Bois de coeur. . . . . . 32

Botanique. . . . . . . 2

Bourgeon. . . . . . 29, 30

Bouton. . . . . . 30

Boulurage . . . . . . 52

Bractee. . . . . . . 42

Branche . . . . . . 31

Brin. . . . . . . . . 50

Caduque (leuille). . . . . 39

Calice. . . . . . . 11

Calcicole. . . . . 19.5

Calcifuge. . . . . . 195

Calycillores. . . . . . li1

Capitule . . . . 43

Capsule : . . . . . . $16 \mathrm{i}$

Carpelle . . . . . . 42

Caryopse. . . . . . . 14 i

Cellule. . . . . . . 2., 3

Cellulose. . . . . 2,

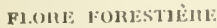

Champignon ..... 111

Chancres. . . . . . . 13

Charnu fruit). . . . . 45

Chaton. . . . . . . $4 t$

Chaume . . . . . . 77

Chevelu . . . . 28

Chlorophylle. : 1,40

Cime : .. 2!)

Cladode : : 38

Classe. . . . . . 7

Coiffe . . . . 27

Collet . . . . . . $2(j$

Composée (feuille). . . . . 36

Còne . . . . . . . 59

Cordée leuille. . . . . . 3.5

Corolle. . . . . . . . 41

Corollitlores. . . (j2)

Corymlse. . . . . . 13

Cotylédon. . . . . . 18

Couvert. . . . . . 57

Culicule . . . . . . . (i

Cutine. . . . . .

Cyme . . . . . . . 42

D

Délieat (brin) . . . . . 50

Dendrécologie. . . . . 197

Dentée (feuille) . . . 36

Deseendance (théorie d $t^{2}$ la). \&

bialypétales. . . . . (ii)

Dicotylerlones . . . . . (ii)

Disilque . . . . . . t?

Drageon1 . . . . . . . . . .

Drupe . . . . . . 45

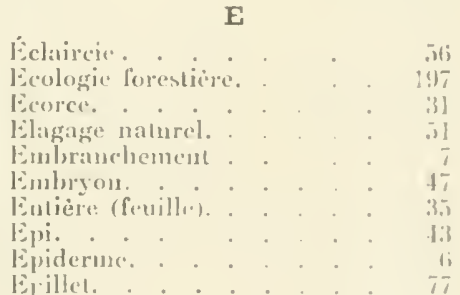


Épine . . . . . . . . 37

Espèce. . . . . . . . . 6

Essence •. • • • • . 79

Essences disséminées. . . . 196

$\begin{array}{lr}\text { Esseuces sociales . . . . . } & 195 \\ \text { Etamine . . . . . . } & 41\end{array}$

\section{$\mathbf{F}$}

Famille. . . . . . . 7

Fécondlation. . . . . . 44

Fcmelle (fleur). . . . . . 42

Feuille. . . . . . . 34-40

Fibres. . . . . . . $t, 33$

Filet . . . . . . . 41

Fleur. . . . . . 41-45

Foliole. . . . . . . 36

Follicule . . . . . . . 46

Forestière (Botanique) . . . $\frac{2}{7}$

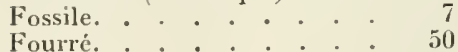

Fourré. • • • • • • • 50

Fruitier : . . . . . 40

Fùt. . . . . . . . . 29

Futaie. . . . . . . 51

G

Gaîne . . . . . . . 34

Gamopétales. • . . . . 61

Gaule, gaulis . . . . 50

Genre . . . . . . 7

Gemnule. . . . . 48

Germination. - . . . $\frac{48-30}{78}$

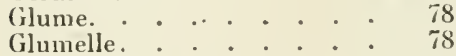

Gourmandes bianches). . . 57

Gousse. . . . . . 46

Graine. . . . . . 47

Grappe . . . . . . 43

Greffage . . . . . . 52

Grimpante (tige). • • . $\quad \frac{28}{58}$

Gymnosperme . . . . . 58

$\mathbf{H}$

Halophile. . . . . . . 195

Héliophile. . . . . . . 196

Herbacée tige). . . . . . 29

Hermaphrodite. . . . . . 42

Houppier. . . . . . . 29

Hybride . . . . . . 44

Hypogynes (étamines). . . 62

I

Infère 'ovaire). . . . . . 61

lnflorescence. . . . . . 42

Involucre. . . . . . 44

L

Lancẻolée (feuille). . . . . 35

Lenticelle. . . . . . 3134

Liber . . . . . . 31-33

Liège . . . . 6, 33
Ligneuse (tige). . . . . . 29

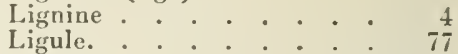

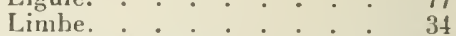

Linėaire feuille). . . . 35

Lobes (d. feuille). . . . . 36

Loges (de I'anthère). . . . 41

M

Mâle (fleur). . . . . 42

Marcescente (feuille). . . 40

Marcottage . . . . . . 52

Méat . . . . . . . . 4

Moisissure. . . . . . . 11

Monocotylédones : . 59

Monoïque (plante). . . . . 12

Mycélium. . . . . . . 10

Mycorhizes . . . . 14, 54

N

Nervation. . . . . . . 34

Nervure , . . . . . 34

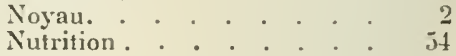

o

Oborale feuille). . . . 35

CEuf . . . . . . . 11

Ombelle . . . . . . . 43

Opposées (feuilles). . . . . 38

Ordre. . . . . . . 7

Organcs sexuels. . . . . 42

Ovaire. . . . . . . 41

Ovale (feuille) . . . . 35

Orule. . . . . . . 41

$\mathbf{P}$

Palmée (feuille). . . . . 36

Palmée (nervation . . . $3 t$

Panicule. . . , . . 77

Papilionacée (corolle). . . 132, 209

Parallèle (nerration). . . . 35

Parasite . . . . . . 12

Parenchyme. . . . . 4

Parenchyme ligneux. . . . 33

Pédoncule. . . . . 41

Pennée (feuille). . . . . 36

Pennée (nervation). . . . . 34

Perchis . . . . . . 51

Périanthe. . . . . . . 42

Péricarpe. . . . . . . 45

l’érigynes (étamines). . . . 62

Persistantes (feuilles). . . . 39

Pétale. . . . . . . 41

pétiole. . . . . . . 34

Pcuplement. . . . \$1. 195

Phanérogame . . . . . s

Phyllode. . . . . . 38

l'igment . . . . . . . 18

Pistll . . . . . . . 41

Pivot. . . . . . . 27 
Pivotante racine . . . . 28

Placenta . . . . 41

Plançon (bouture). . . . 52

Poils radicaux . . . . . . 27

Pollen. . . . . . . . $t 1$

Polygame (plante). . . . . 42

Poricide capsule). . . . . 46

Pourritures. . . . . . 13

Prolonema . . . . . . . 22

Protoplasma. . . . . . . 2

Prothalle. . . . . . . 24

Proventif (bourgeon). . . . 31

Prxide. . . . . . . 46

$\mathbf{R}$

Racine.

Radiation.

Radicelles.

Radicule.

Rameau

Ramule

Rayon medullaire.

Réceptale

Règne végètal

Règne animal.

Rejet

Respiration.

lihizoüde

Rhizome.

Roluste brin.

\section{$\mathbf{S}$}

Sagittée (feuille).

Samire.

Saprouhyte.

Sec (ruit).

Sépile.

Sessile (reuille).

Sève.

Silique.

Sinuere (fenille.

Sore.

Sous-arbrissean.

Sons-irutescente plante).

Sous-ligneuse (plante)

Spatule (feuille).

Spontance (espèce
Spore

8, 22, 21

Sporange. . . . . . . 24

Sporogone. . . . . . . 92

Station. . . . . . . 197

Stionsuate. . . . . . . 41

Stipules. . . . . 36

Stomate . . . . . 40

Style....... . 41

Subéreux tissu . . . . . (;

Subspontane. . . . . . 197

Suc cellulaire. . . . . .

Suçoil. . . . . . . 13

"uprere ovaire'. . . . . lil

Symbiose. . . . . . 20

$\mathrm{T}$

Ta11. . . . . . . 32

Tegrmments..... . . tis

Thalamillores. . . . . (il

Thalle. . . . . . . 4

Tige . . . 28

Tigelle. . . . . . . 48

Tissu . . . . . . . 1

Tracantes (ricines. . . . 28

Trachéides. . . . . Jis

Transpiration. . . . . 53

Tribu. . . 7

Tronc. . . . . . . . 2!)

Tube crible. . . \$3

Tripe de la fleur'. . . . 11

Type de végétation. . . . 194

$\mathbf{U}$

Unisexuc. . . . . . . 42

\section{V}

Vaisseau. . . . . . . 5, 33

V'asculaire tissu. . . . . ह

Varicti. . . . . . . T

Verticille. . . . . . 26i

Verticillies (feuilles). . . . 39

Volubile (lige). . . . . . y

Volve. . . . . 16

Vrille. . . . . . 36

Z

Zoologie. . . . . . . 2 


\section{TABLE DES NOMS DES CRYPTOGAMES}

(Groupes, geNres, NONS velgatres) CITÉS dANS LA PREMIÈre PARTIE.

\begin{tabular}{|c|c|c|c|c|c|c|c|c|c|c|c|}
\hline Adianthum. . & & . & & $\therefore \quad 25$ & Lépiote. & & & & & & \\
\hline Agarie. & & . & 11,1 & 15,17 & Levure. & & & . & & & \\
\hline Algues. & & & & . 17 & Lichens. & & & . & & & 20 , : \\
\hline Amanite. & & & 15,1 & 16,17 & Lyeopode. & . & & & & & \\
\hline illaire. & & & .. & . 17 & Mlanne. . & . & & & & & \\
\hline omycèt & tes & . & . & 12,1 & Mildiou . & . & & . & & & \\
\hline & & & . & . $\quad 2$ & Morille. . & & & & & & \\
\hline & & & & & Mousses . & . & & & & & \\
\hline & & Bact & téries. & & Mucorinées & . & & & & & \\
\hline des. & & & . . . & 11,1 ? & ugnet. . & & & & & & \\
\hline$o m y$ & cèt & & . & . 1 & Iuscinées. & & & & & & \\
\hline & & . & . & & mycète & & & & & . & \\
\hline$\cdot$ & & . & . & . & $n \cdot$. & & & & & & \\
\hline apigno & ons & . & . & - & cètes. & & & & & & \\
\hline lle. & & & . & & )ronge. . & & & & & 1. & 16, \\
\hline & & & . & 12,1 & osporé & es & & & & . & \\
\hline ophyc & rcée & & . & 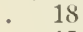 & ycèes & & & . & & & \\
\hline leur. . & . & . & . & . & ote. . & & & . & & & \\
\hline & & . & . & & ore. & . & & & & & 13, \\
\hline gam & & & & & Polystiehum. & . & & & & & \\
\hline & n. va & ascu & dlaires. 1 & 10 & Prêle. . . . & & & . & & & \\
\hline & cées: & & . . . . & . & Pteris . . & & & & & & \\
\hline ées. & 3. . & . & & . & e de eheva & & & & & & \\
\hline & & & & & lophycé & es & & & & & \\
\hline & & . & 12,1 & 13,1 & Rouille. . & & & & & & \\
\hline Orong & ige. & . & . . . & & & & & & & & \\
\hline de $\tan$. & & & & c. & ophytes & & & & & & 9, \\
\hline ères. & & & & & olome . & . & & & & & \\
\hline ére Aigle & & mảle, & , femelle. & & fte & & & & & & \\
\hline - & & . & . . . . & . & Ulve. ${ }^{*}$ & • & & & & & \\
\hline & . & . & . & & Urédinées. & & & & & & \\
\hline tiques & & & 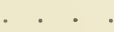 & • & laginées & & & & & & \\
\hline & & . & . & & & & & & & & \\
\hline & & & & & Volvaire & & & & & & \\
\hline
\end{tabular}




\section{TABLE ALPHABÉTIQLE DES FAMILLES ET DES TRIBLS}

(Les noms en italique correspondent aux tribus et les numéros en italiqu: aux pages de la première clef.)

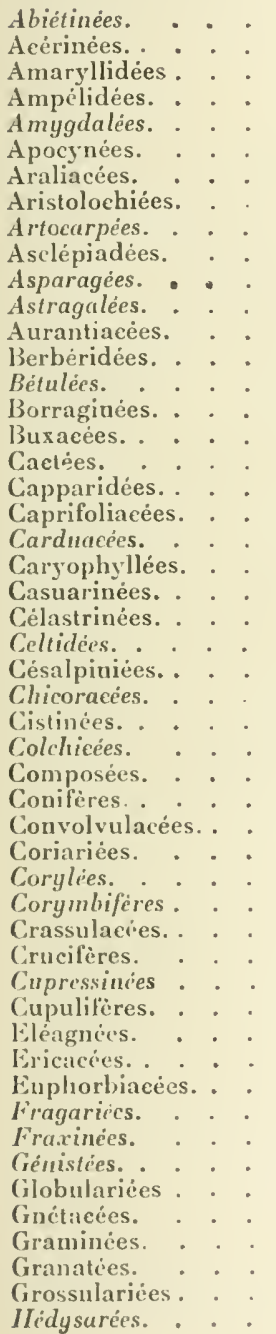

$118+\frac{61}{40}$

$18,217,328$

$7 \overline{7}, 228,323$

$118,21 \%, 328$ 148,149

$180,2 \pi 7,332$

16it, 270,331

$98,237,325$ 94

$181,278,33 \%$ 73

$133,1 \mathrm{i} 3$

$12,2,24,328$

$107,241,326$ 87

182, 278, 33.

$105,260,326$

$16^{\circ}, 268,330$

109, 2ᄂ2, 327

16.), 2ิ70, 331 $1(; 9,170$

1) $7,246,327$

$88,231,324$

$124,24 \%, 328$

$145,261,309$

170. 171

$110,242,327$

168, 271, 3:31

$64,-20 ?, 3,323$

$182,278,332$

$120,247,328$

82

170,171

$161,269,3330$

$107,241,327$

(is

81. 2:30, "1"2

1(1) 23\%, 326;

$17 ., 276,331$

103, 290, 326

148, 1.11 177

$1: 32,1: 3: 3$

$192,28.5,333$

(ii), 24) 1328

77, 229, 324

160. $26 \% 8.33: 30$

$162,269,331$ $133,11^{\prime} 2$
Hypéricinées.

llicinées. .

Juglandèes.

Labiées.

Lamrinées.

Lilies.

Linées

Loranthacées.

Malvacées.

Méliacées.

Mimosées. .

Morées.

IIyrtacées.

Oléacées.

Oleinees.

Oubbellifères

Palmiers.

Papilionncees.

Paronvehiées.

Plıvtolaccées

Platanees .

Plantaginees.

Plomhaginées.

l'odalyries.

l'olygalées.

l'olygonees.

l'omacces.

Protiacies.

Quercies.

Renoneulacées.

Ihamne's.

liosacies.

liosées.

Rubliacios.

Rutucès.

Salicinées

Salsolacees.

Santalacires.

Scrotularinées.

Solaneres.

Tamariscinces

Tuxinies.

10ivinthaces

Tlivmelination.

Trifoliules.

I Tmies.

Uirlicaries.

Virrlunaces

Violariees

Juluerarices
$123,298,328$

$125,29.9,324$

$88,231,324$

$185,280,332$

73, 227, 323

73

$121,218,328$

$101,2 \% \%, 326$

115. 24.5. 32

$117,217,: 308$

$146,26 t .329$

413

$157,26 \%, 330$

$177,276,331$ 177,178

$163,269,330$

$76,228,323$

$131,2.52,329$

$11 \overline{1}, 296,32 \bar{\jmath}$

$97,23 \%, 325$

$92,231,324$

$191,255,333$

$190,28: 4.333$ 132, 133

115, 24, 327

$97,237,325$ 14.5. 1.52

(1) 23:37, 325

82

$1116,291.320$

125. 2 \%!, 32!

$148,2(\% 2.330$

$14 i$, i 11

$167,271.331$

121, 24s, 328

$89,2: 31,321$

9.), 23:3 , 325

1(12.2, 261 326

184, $2011.33^{\circ}-2$

18. $2 \pi 5,332$

1(iv), 26is, 3330

1.25 g-314.

(1), 23: 325 $13: 3,111$

$92,23 \% 3, \quad 321$

$190,285 . \quad 3333$

114, 24.1. :127 1:i: 111 


\title{
TABLE DES NOMS LATINS
}

\author{
(GENRES, ESPECES ET STNONYMES
}

Les chiffres en caractères gras indiquent les numéros dordre de la table. Les nombres en chiffres ordinaires se rapportent aux pages : le premier renvoie à la première partic, le sccond à la prenière clef, les suivants aux "2. $3^{\circ}$ et 4: clefs. - Les synonymes sont écrits en italique ( $=$ signifie symonyme de).

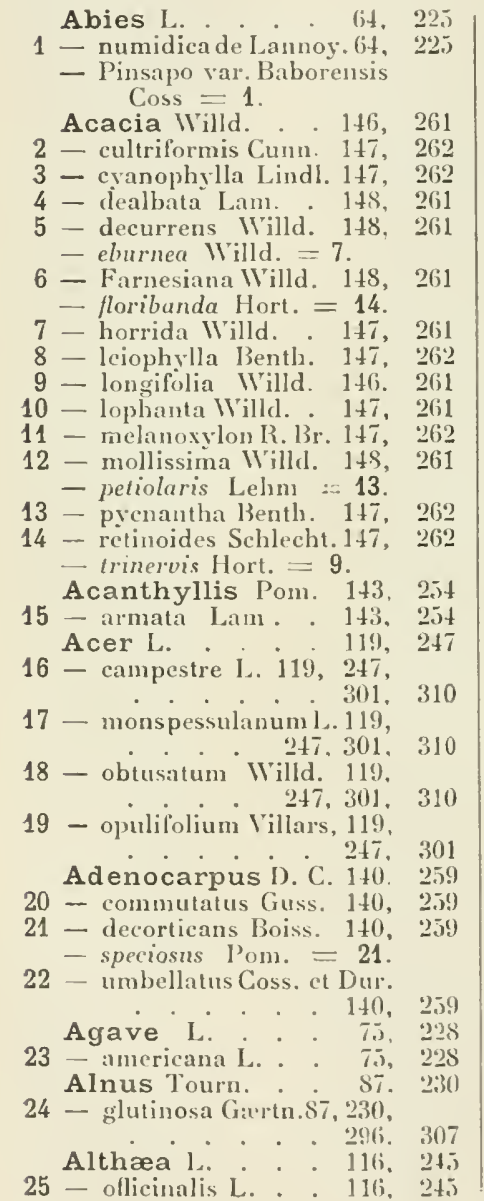

Alyssum L. $109, \quad 24^{\circ} 2$ 26 - cochlcatum Coss. 109, 242 27 - maritimum Lám. 1199, 242 28 - spinosum L. . . 1119. 242 Amelanchier Med. 1.it. 264 29 - rulgaris Iloench. 1,j4. "64, 29.5, 308

AmpelodesmosLink. 79, 229 30 - tenax Link. - 79, '29, 29,3 Amygdalus L. . 149, 263 31 - comnunis L. . 149, 263 - incana Pallas $=346$.

- Persica L $=304$.

Anabasis L. . . $9 \overline{7}, 236$ 32 - aphylla L. . . 97, 236 33 - articulata Moq. . 97,236 34 - prostrata Pom. . 97, ‘236 Axacreles Tourn.

- pedunculatus Pers. $=39$.

Anagyris Tourn. 133, 252 35 - fortida L. . . . 133. 25? -Anarrhinum Desf. 185, 280 36 - fruticosum Desf. 185, 280

Androsamum Allioni

$37.0123,248$

37 - officinale All. 123, 248, 300

Anthemis L. . . 173. 275

- Clausonis Pom. = 39 .

38 - maritima L. . . 173, 27.

39 - pedunculata Desf. 173, 275

- tenuisecta Pom. $=39$.

Anthyllis L. . . 1\$1, 259

40 - Barba-Jovis L. . 141. 25!

41 - rytisoides I. . . 111, 259

43 - Montana L. . . 141, 259

- munidica Coss. $=15$.

- tragacanthordes Coss. = 15 .

43 - polrecphalia Dest. 141, 259

Araucaria Juss. - 6S, 20,5

44 - excelsil R. Br. - (is, 22,

Arbutus L. . . 17i. 2iti

45 - Enedo L. . 175, 276, 294

Arceuthobium .I. Bieb.

1(12. 23 . 23)

46 - Oxycedri M. Bieb. 102, 239 
Argyrolobium Eckl. et

Zeyh. . . . . 140, 259

- grandiflorum Bois. Rent $=47$

47 - Linnxanum Walp. 140, 259

48 - uniflorum Jaub.et Spach

Aris. . . . 140, 259

- latifolia Spach $=428$.

- nivea Host. $=426$.

Aristolochia L. . 98, 237

49 - altissima Desí. . 98, 237

50 - betica L. . . . 98, 237

- glanca Desf. $=50$.

Armeniaca Juss. . 151, 263

51 - vulgaris Lam. . 151, 263

Artemisia Tourn. 174, 275

52 - arhorescens L. . 174, 275

53 - attantica Coss. - 174. 275

54 - campestris L. : 174, 275

55 - Herba-alba Asso. 174, 275

- Saharx Pom $=55$

Arthrocnemon Moq. 96, 236 fruticosum Hoq. $=56$.

- glaucum Bois. $=56$.

56 - macrostachyum Moq.96. 23.5

Arundo L. . . . 80,229

- Bambos L. $=73$.

80,290

57 - Donax L. . 80, 229

- Phragmiles L $=313$.

58 - Pliniana Turr. - 80, 229

- festucoides Desf. $=30$.

Asparagus L. . . $\quad 73,228$

59 - acutifolius L. . * 73, 228

60 - albus L. . . 73, 228

61 - altissimus Munh. 7t, 228

62 - horridus L. . , 73, 228

Asperula L

- calabrica $\mathrm{L} .=350$.

Asteriscus ifench. 171, 273

63 - maritimus Ifench 171, 273

Astragalus L, . 14, 260

- chlorocyanens Bois.Reut. $=65$

- Cossoni De Bunge $=65$.

64 - Gombo Coss. . . 144, 260

65 - monspessulanus L. 14, 260

Atractylis L. . . 170, 27 t

66 - echinala Pom. . 170, 274

- diffusa Coss. $=66$ et 67 .

67 - pharolepis Pour. . 170, 274

- microcephala Coss. $=68$.

68 - serratuloides Sieb. 170,

Atriplex Tourı. . 236

- glancus L. $=69^{\circ}$.

69 - Halimus L. 95, 236, 293

- matritanicus Bois. Reut. $=70$

70 - parvifolius Lowe. 96, 2336

71 - portulacoides L. . 96,2336

Atrop. $\mathrm{l}$.

- frutescens L. $=478$.

Ballota Benth. 190, 280)

- bullata P'om $=72$.

72 - hirsuta Benth. 190, 280
Bambusa L. . . 81, 229

73 - arundinacea Retz. 81, 229

- distorta Nees. $=74$.

- macroculmis A. et Ch. Riv. $=73$.

- madagascariensis Hort $=74$

74 - vulgaris. Wendl. 81, 229

Berberis L. . . 10ĩ. 241

- athnensis .lunb. $=75$.

75 - hispanica Boiss. 107 ,

241, 291, 3305

Bonjeania Reich. 142, 254

76 - recta Reich. . . 142, 254

Brassica Tourn. . 108, 242

- allantica Coss. = 78 .

- Cossoneana Bois. Reut. $=77$

77 - fruticulosa Cyr. . 108, 242

- glaberrima Pon. $=77$.

78 - iusularis Moris. . 108, $2+2$

- mauritanica Coss. $=77$.

- numidica Coss. $=77$.

- radicala Desf. $=77$.

79 - scopulorum Coss. 108, 242

- spinescens Pom. $=79$.

- suffruticos $\alpha$ Desf. $=286$.

Broussonetia Ient. 94, 233

80 - papyrifera Vent. . 94, 233

Buffonia Sauv. 117, 241;

81 - Duvaljouvii Batt. 117, 246

82 - macropetala W'illk. 117, 246

- macrosperma Munb. $=82$.

- perenuis Ifunb. $=81$.

Buputalmes L.

- maritimum $\mathrm{L}=63$.

Bupleuram L. . 1633, 2369

- Balansa Bois. Reut. - 83 .

- exaltatum Coss. $=87$.

83 - Pruticescens 1. . 161, 26!

84 - fruticosum L. 163, 270, 291

85 - gibraltaricum Lam. 164, 270

86 - montanum Coss. 164. 2669

87 - oligactis Boiss. . 164, 266!

88 - plintagineun Desf. 16it, 269

89 - rigidum L . . 164, 269

90 - spinosum L. fils. 16i., 2(69)

Buxus L. . . 105, 2411

91 - sempervirens L. 105,240, 3(111

Cicti's I.

- Opuntia $\mathrm{L}_{\text {. }}=298$.

Calendula L. . 17\%, $27 \%$

92 Monardi Bois. Reut. 17\%, 276

93 - sullruticosa Valul. 17\%, 27t;

Callitris Vent. . . $\bar{i}(1,22$.

94 - quidrivalvis Vent. ill.

2.25. 298

Calycotome Lam. 13!, "258

95 - intermedia Lam. 139, 258

96 - spinosa L:m. 139. 2.5. 29!2

97 - villosa 1... . 139, 258

Capparis. L. . 10!, 212

- ovata Desl. - 98 . 
- rupcstris Sibth. - 98 .

98 - spinosa L. . 109, 242, 2!)1

Carduncellus Adans.

$170, \quad 272$

99 - Pomelianus Batı. 170, 272

Casuarina Forst. . 88, 2:31

100' - equisetifolia Forst. 88,231

101 - tenuissima Hort. - 88, 2:31

Castanea Tourn. . 87, 230

- sativa Seop. = 102 .

- vesca Grertn. = 102

102 - vulgaris Lam. 87, 230,

$295, \quad 307$

Catananche Vaillant.171, 27?

103 - cespitosa Desf. . 171, 272

Gedrus Link. . . $\quad 6.5224$

104 - atlantica Man. 65. 224, 293

- Libani Barr. = 104

Celtis Tourn. . . 93, 233

105 - australis L $93,233,295, \quad 307$

Centaurea L. . . 17), 273

106 - parviflora Desf. : 170, 27:3

107 - sempervirens L. . 171, 273

Cerasus L. . . . 14!, 263

108 -- avium Honeh. 149, 263

296, 309

Ceratonia L. . . 145, 26il

109 - Siliqua L. . 145, 261, 302 Cercis L. . . 145, 261

110 - Siliquastrum L. . 145, 26151

Chamærops L. . 77,228

111 - humilis L. . 77, 228, 302 Cineraria $\mathrm{L}$.

- linifolia Biv. - 414.

Cistus L. . . 110, 243

112 - albidus L. $110,243,299$

- asperifolius Pom. $=115$.

113 - Clusii Dun. 112, 243, 299

- creticus L. $=119$.

114 - crispus L. . . 111, 243

- eriocephalus Viv. $=119$.

- halimifolius $\mathrm{L}=230$.

115 - beterophyllus Desf. 110,

- incanus Lam. = 119.

116 - ladaniferus L. 112, 243, 299

117 - monspeliensis L. 111,

148 - 243, 299

118 - Munbyi Pom. . 112, 243

119 - polymorphus V'illk.110,

- Pouzolzii Delile $=121$,

120 - salviafolius L. 112. 243,

- sedjera Pom. = 113.

121 - varius Pourr. 112, 243 - villosus L. = 119 .

Citrus L. . . . 123, 218

122 - Aurantium L. . 123, 248

123 - Bigaradia Duluam. 123. 2 is

124 - Limonium Riss. et Poit.

123,248
125 - medica L. . . 12:3 248

Clematis L. . . $107,2+1$

126 - cirrhosa L. $107,241,290$

127 - Flammula L. 107. 241,

- semitriloba Lag. $=126,310$

Cistipola L.

- marituma L. $=27$.

Colutea L. . . . 14t, 254

128 - arborescens L. . 144, 254 affinis I'om. = 128.

Convolvulus L. 182, 278

129 - cantabrica L. . 182, 278

Cosš Lesson.

- saxutilis $\mathrm{L}=306$

- rupestris Desf. $=305$.

Coriaria L . . 120, 247

130 - myrtifolia L. $120,24 \bar{i}$,

298, 300

Coronilla L. . . 143,260

- Clusii Duf. = 133.

131 - glauca L. . . 143, 260

132 - juncea L. . . . 143, 260

133 - minima L. . . 143, 260

134 - pentaphylla Desf. 143. 260

- Poneli Batt. $=132$.

135 - valentina L. . . 142, 260

Corylus Tourn. - 81, 230

136 - Avellana L. . . 81, 230

Cotoneaster Medick, 154, 267

137 - Fontanesi Spach. 15t, $267,294,309$

138 - numnularia Fisch, et Mey. . . . 154, 267

Cratægus L. : 152, 266 Aronia Rose $=139$.

139 - Azarolus L. 153,266, 292, 306

- priocarpa Pom. = 140.

140 - laciniata L'cria. 153.266,

- maura L. fils $=142$. $29^{\circ}, 306$.

141 - monogyna Jacq. 152 266. 251, 306

142 - oxvacintha L. $153,266,291$

143 - ruscinonensis Gren. et BI .153 .266

- triloba Poir. = 142.

Cupressus Tourn. 71, 226

- fastigiuta D. C. $=147$.

144 - funebris Endl. 71, 226

- glaucu Brot = 145.

- horisontalis Mill. = 147.

- Harturegii Carr. = 146.

- Lambertiana Carr. $=146$.

145 - Jusitanica Mill. 72. 226

146 - mieroearpa Hartw. 72,228

- pendula staun = 144 .

147 - sempervirens L. . 71, 226

- sillensis Gordon. $=145$.

Cydonia Tourn. - 156, 263

148 - vulgaris Pers. : 156, 263 
149 - arboreus Desf. 140, 25s, 301 - argenteus L. $=47$.

150 - Balansæ Bois. Reut. 140, 258

151 - boticus W' ebl. . 140, 258

- candicans D. C. $=204$.

152 - Fontanesi Spach. 140, 258

- linifolius Lan $=209$.

- purgans Coss. $=150$.

153 - sessilifolius L. . 140, 258

154 - triflorus L'Hér. 140, 258, 301

Daphne L. . . . 100, 2:38

155 - Gnidium L. 100, 239, 294

156 - Laureola L. 101, 239, 294

157 - oleoides Schreb. 101, 239 Dianthus L. . . 117, 246

158 lusitanicus Brot. . 117, 246 Diplotaxis D. C. 108, 241

159 - tenuifolia D. C. 108, 241 Dorycnium L. . 142, 254 - Jordanianum Willk. $=160$.

- rectum $=76$.

160 - suffruticosum Vill. 142, 25t Ebenus L. . . . 153, 2.14

161 - pinnata L. . . 143, 254 Elæagnus L. . . 101, 23!)

162 - angustifolia L.. . 101, 2:39 Ephedra L. - 63, 224, 298

163 altissima Desf. . 63, 224

- Cossoni Stapf $=164$.

- dissoluta IV ebb. = 164.

164 - fragilis Desf. . . 63, 224

165 - nebrodensis Tin. (i3, 204

- Villarsii Gren et God. = 165 .

Erica L. - 175, 276, 293

166 - arborea L. . $175,276,298$

167 - multillora L. $176,276,298$

168 - scoparia 1. $176,276,298$ - vagans Dest. = 167 .

Erinacea Clus. . 13:3, 25,3

169 - pungens Bois. . 133, 2.33 Eriobotrya Lindl. 1.j(i, 2064

170 - japonica lindl. . 1.j(;, 261 Erysimum I.. . . 10S, 241 - australe Gay $=171$.

- elatum l'om $=171$.

- gramineum Pom. $=171$.

171 - crandillorum Desf. 118,

- nervosum l’om. $=171$.

- squerrosum Butt. $=171$.

Eucalyptus Lab. . 160,

172 - amygulalina Lab. $16(0$,

173 - citriodora Hook. 1.59. 268

174 - cornuta lab. . 160, 267

175 - corynocalyx F. v. Miil ler. . . 160,

176 - globulus Lab. . 15\%.

- maculula J. v. Mül. ler. 173.

177 - polyanthem: Schamer.

267

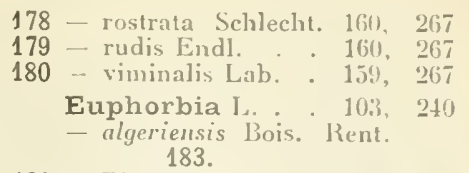

181 - Bivone Steud. . 103. 240

182 - dendroides I. . 104, 240

- dumelorun Coss. $=184$,

- frulicosa Bir. = 181.

- heterophylla Desf. $=185$.

183 - paniculata Desl. 104, 210

- provincialis Willd. =

- rupicola IBois $=184$

- scticornis Poir. 185.

- spinosa Desf. = 181.

184 - squamigera Lois. 10t, 240

185 - terracina L. . . 104, 240

Evonymus Tourn. 124, 249 186 - latifolius Scop. 124, 24\%,

ธิ)(1), 310

FicusTourn. . . 94, 234

187 - Carica I. 94, 234, 297, 306

188 - elastica Roxh. . . 94, 234

189 - levigata lahl. . 9. 9, 234

190 - macrophrlla Roxb. 95. 234

191 - religiosis L. . . 9., 234

192 - retusa 1. . . . 9. 234

193 - rubiginosa Desf - 95, 23'

194 - Sycomorus L, . . 95, 234

Fraxinus lourn. 17T, 꾸 australis Gay. $=196$

195 - dimorpla Coss. 178, $27 \overline{7}, 292, \quad 30,5$

196 - oxyphylla lieb. 17\%, rosirala Ginss. $=196$.

Fumana Spach. . 114, 245 197 - arabica Spach . 114, 24,5

198 - calycina Claus. 114, 215

199 glulimosa liois. 114, 245

200 livipes Spach. 114, 24.5 monlana fom. 201. serparia Pom. 201.

201 - Spachii Giren. (ind. 114, 245 viscida Spach. = 197.

Genista I. . . . 1:31, 25. 202 - aspalathoirles Poiret 13i, 25i

203 - atlantica Spach. 13.5 2.5i

- barbara Munb. 218

204 - candicans 1. 137, 237, 3111

205 - cephalanta Spach. 1:3i, g-56

206 - Charegu Coss. $=20 x$, $15 \div, 268$ 
208 - ferox Poiret. 134, 25.5. 29*2 - firamea l'om. $=211$.

- ischnoclada Pom. $=211$.

- liabylica Coss. $=221$.

209 - linifolia L. . 137, 2.57, 301

210 - microcephala Coss. 136, 256

- monosperma Desf. = 211 et 358

211 - numidica Spach. 138,2.57, 212 - pseudopilosa Coss. 139, 213 - quadriflora Mumb. 137, 214 - ramosissima Desf. 139, 215 - retamoides Spach. 138.

- salditana Pons. = 208 .

- saroles Pom. = 211 .

216 - spartioides Spach. 138,

217 - spinulosa Pom. . 135,

218 - tricuspidata Desf. 135, 256 ,

219 - ulicina Spach. 135, 256,

220 - umbellata Desf. . 1:37,

221 - Vepres Pon. . 135,

Globularia L. . 192,

222 - dlypum L..

- arabica Jaub. Spach. $=222$

- eriocephala Pon = 222.

- vesceritensis Batt. $=222$.

Glycirrhiza L. . 14t, 254

223 - loetida Desf. . 14t, 254

Gomphocarpusli.Br.182,278

224 - fruticosus R. $\mathrm{Br}$. 182, s27

Grevillea R. Br. . 99. 25?

225 - robusta Cunn. . 99,237

Halimium Dnn.

- IIalimifolinm Willk. -230 .

Haloxylon De Bunge, 97, 235

226 - articulatum Boiss. 97, 233

Hedera l. . . 164, 270

227 - Helix L. 164, 270, 294, 297

Helianthemum Tourn.

113 ,

228 - canum Dun. . . 113,

229 - Caput-Felis Bois. 113,

- Clausonis Pom. = 239

- croceum Pers. $=239$

- floribundum Pom. $=236$.

- Fumana Dun. $=201$.

- Fontanesi Bois. $=239$

- glancum l'ers. = 239 .

- glutinosum Pers. $=199$

230 - halimifolium. Willd.112,

- lavipes Willd. $=200$.

231 - lavandulefolium D. C.

$113,24 t$

232 - Lippii Ball. . 113,

233 - origanifolium Lam. 113,

234 - polyanthos Dun. 113. 24.

235 - Pomeridianum I) 11 . 113, 244

- prostratum Pom. $=236$.

- rotundifolium Dur. $=236$.
230 - rubellum Pers. . 113. 244

- sessiliflorum Pers $=232$.

237 - squamatum Pers. $=113$, 24t

- ienuicaule Pom. $=236$.

238 - viscarium Bois. Reut.

$113,2+4$

Helichrysum

240 - Foutanesi Camb. 173,272 rupestre Raft. $=240$.

Herniaria L . . 117, 246 erecte Willk $=241$

241 - Fontanesi Gay. 117, 246

- frulicosa L. $=241$.

- fruticosa L. var. Fontanesi Batt. = 241.

Hibiscus L. . . 117, 245

- palustris Batt. $=242$.

242 - roseus Thore. 117, 245

Hypericum L. . 123. 248

243 - Afrum Lam. . . 123, 248

- Androsamum L. $=37$.

Iberis L. . . 109, 241

- Balansa JorI $=244$.

244 - ciliata L. . 109, 241

- Pruilii Ten. $=244$. umbellata Desf. $=244$.

Ilex L. . . 125, 2

245 - Aquifolium L. 12.5, 249, 290

Inula L. . 171,274

- crebrifolia Coss. D. R. $=246$.

246 - crithmoides L. . 171, 274

247 - viseosa Ait. . . 171, 27t

Jasminum L.. . 180, 276

248 - fruticans L. . : 180, 276

Juglans L . . . 88,231

249 - regiil L . . . 88, 231

Juniperus L . . 68,207

250 - communis I. $69,227,298$

- hemisphirrica l'arl. = 250.

- nana Willd. $=250$

- macrucarpa Sibth.et $S \mathrm{~m} .=251$

251 - Oxveedrus L (iS. $22 \overline{7}, 298$

252 - phruicea L. $69,227,298$

253 - thmifera L. . . 70, 227

Koxig.s. Adans.

- maritima R. Br $=27$.

Lictici 1.
spirosa Lam. $=482$.

Laurus L. . . . 99, 237

254 - nobilis L. . 99. $23 \%, 294$

Lavandula L. . 186, 281

255 - deutatal L. . 187, 282

256 - multifida L. . . 187, 281

257 - Stixchas L. . 186, '9S2, 299

Lavatera L. . 116, 246

258 - arbore:i L. . . 116. 246 hispida Desf. $=260$.

259 - maritima L. . . 116, 246

260 - Olbial L. . 11j, 246, 297 
261 - rupestris Pom. . 116, 246

Lepidium L. . . 109, 241

262 - subulatum L. . 109,241

Letcistiency Tourn.

- Fontanesi Bois. Reut. $=328$.

Lribardi Adans.

- iricuspis Cass. $=246$.

Limoniastrum Mench. 284

263 - monopetalum Bois. 191, 284

Linum L. . . . 121, 248

264 - austriacum L. . 121, 248

- manrilanicum Pom.

- punctalum Presl. $=264$

- squarrosum Munb. $=265$.

265 - sufficticosum L. 121, 248

Lithospermum Tourn. 182. 278

266. - consobrinum l'on 182, 278

- fruticosum Desf. $=266$

267 - rosmarinifolium Ten.

Lonicera L . 166,

268 - arborea Bois. 166,271 , $300, \quad 310$

269 - biflora I)esf. 167, 271, 29)(

- canescens Schousboe $=269$.

- caprifolinm Iesf. $=270$.

270 - etrusca Santi. 166, 271.

$290, \quad 310$

271 - inplexa l. . 166, 271, 990

272 - kabylica Reholer. 166, 271

Lycium L. . 184, 279, 291

273 - afrum 1. . . . 184, 279

274 - barbarum L. . . 184, 279

275 - europarm L. 184, 279, 306;

276 - intricitum bois 184, 279

- mediterranem Dun.- 275.

- vulgare Dun. = 274.

Malus Tomrn. . . 15, 26.3

277 - conmunis Poir. . 15\%, $26 \%$

Medicago L. . . 112, 25

278 arborea 1. . . 142, 254

Melia L. . . . 117, 247

279 Azedirich L. . 117, 247

Mesiruts l.

- iaponica Thunb. $=170$

Micromeria Benth. 188, 28:3

- Burceloillilli $=283$

280 - dehilis Pon1. . 188, 283 filiformis Binth. $=281$.

281 - 1ontanesi P'on. . 188, 283

282 - griucil Jenth. . 138, 283

283 - inodora Bentl. . 188, -24:3

284 - Juliana Bench. 188. 28:3

- mirroplyylla Coss. I).IR. $=280$

285 merrosa Desf. . 188, 28:3

Moricandia I). C. I(19, 241 ulypifolia I'om. $=286$

- arvensis 1). ( . $=286$

- divaricala Coss. = 286.

- longirostris I'om. = 286 .
- pallida Pom. $=286$

- palula Pom. 286

286 - spinosa Pom. 286 .

Morus L. . . . 44,233

287 - alba L. . . . 94, 233

288 - nigra L. . . . 94, 283

Myrtus L. . . 157, 267

289 - communis L. $15 \%, 267.300$

Nerium L. . . . 181, 277

290 - Olemuler I,. 181, 277, 298

Nicotiana Tourn. 184, 279

291 - glauea Grabam.. 184. 279

Noxa Mo4. . . 97, 23.

292 spinosissimalloq. $\quad 97, \quad 23 \%$

OBIoNe Gartn.

- portulacoides Mou. $=71$

Onoviosperum Neck. naritintum Neck. $=63$.

Olea L. . . . 17!, 277

293 - curopira L. $179.277,299$

Ononis L.. . . 1 142, 2(if)

294 - antiquorum Coss. 14", $26(1$

295 - aragonensis Asso, 142, 260

- $u$ rborescens Desf. $=297$.

296 - lructicosa L... . 142, 260

297 - hispida Desf. . 142, 2(60)

- pungens Pont. $=294$.

Opuntia Tourn. . 16\%, '268

298 - licus indica Haw. 162, „26is

Oreobliton Dur. . . $95,23$.

- chenopodioides Coss. 1). R. 299 .

299 - thesioides Jur. et Moq.

9.5. 23.

Osyris L. . . . 102, 2411

300 - alloa L. . . 102, 210 29!

301 - lanceolata Hochs et Steuct. 102. 2411, 29.1

- quadrifida Salzm. $=301$.

- quadripartila Dic. = 301 .

Paliurus Tourı. . 128, 2.1!

- aculeatus Lam. = 302 .

302 - australis Giertu. 128, 2f!

Passmixi L. = Tuymal.

Periploca L. . . 18:, 278

- ungustifolia Lal). - 303.

303 - lavigata Ait. . 142. 27s

Persica Touru. 1,i], 2(ii)

304 - vulgaris llill. . 1.il, 2(i,

Plhagnalon (iilss. . 17\%, 피

- qracum liois. 305 .

- Tipidotum Pon, = 306 .

305 - rupestre 1). C. - 17‥ 27

306 - saxitile Cass. 172. 271

307 - sordidum 1). (. . 172, 27

- Tinorei l'pesl. $=305$.

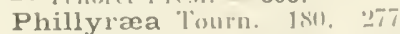

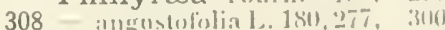

309 - Intifulia 1.. . 17!, 277, :311

310 - nedia i.. $179,275,341$ 
Phænix L. . . . 76, 229 311 - dactylifera L. $76,229, \quad 302$ 312 - canaricnsis Hort. 77, 29? Phragmites Trin. 80, 29 313 - communis Trin. . $\quad 80,29$ Physalis L. . . 183, 280 314 - Alkekengi L. . . 183, 280 315 - puhescens L. . . 183, 280 Phytolacca Tourn. 97, 237 316 - dioica L. . . . 97, 237 Pinus Tourn. . . (6.), 206 317 - canariensis Chr. Snith.

68, 226

318 - halepensis Mill. 66, 2206,

319 - in.ignis Dougl.. 67 ,

320 - Lóricio Poir. . (iis, 226

321 - Iongifolia Roxb. (38, 226

322 - maritima Lam. 67, 226, 293

- Pincrster Solind. $=322$

323 - Pinea L. 67,226 - radiata Don. = 319 .

Pirus Tourn.

324 - Jongipes Coss. 155, 263

- Malus L. $=277$.

Pistacia L. . . 129, 251

325 - atlantica Desf. $130,251,309$

326 - Lentiscus L. 129, 251, $30^{\circ}$

327 - Terebinthus L. 129, $251, \quad 302, \quad 309$

Plagius L'Hér. . . 17t, 273

328 - virgatus D. C. . 174, 273

Plantago L. . . 191, $28 \overline{3}$

329 - albicans L. . . 191, 285

330 - atlantica Bati. * 192, 285

- crithmoides Desf $=331$.

- cynops Desf. $=332$.

331 - nacrorrhiza Poir. 192, 285

332 - mauritanica B. R. 192, 285

- serpentina Munb. $=330$.

Platanus L. . . 92, 231

333 - orientalis L. . . 92, 231

Polycarpon Loell. 117, 246

334 - peploides D.C. . 117, 246

Polycnemon L. . 96,235

335 - Fontanesi Dur. et Moq.

Polygala I 96

96. 235

- Mlunbyana Boiss. 115, 245

Polygonum L. . 98, 237

- Balansa Bois. Reut. = 337

337 - equisetiforme Sibth. et Sm. . . . 98, 237

- Ragellare Spr. $=337$.

338 - maritimum L. - 98. 237

- scoparium Bati. $=337$.

Populus L. . . . 10,232 339 - alla L. . 90, 232, 2!17. 308 340 - nigra L. 91, 232, 296, $30 \mathrm{~S}$

- nivea $\mathrm{Fish} .=339$.

- pyramidalis Rozier $=340$.
341 - Tremula L. 91, 232, 297, 308

Prasium L. . . . 189, 281

342 - majus L. . . . 189, 281

Prunus L. . . . 150, 264

- Armeniaca L. $=51$.

- avium L. $=108$.

343 - divaricata Led. . 151, 264

344 - domestica L. . . 151, 264

345 - insititia L. 150,264 , $291,296,306,309$

346 - prostrata Lab. 150,264 .

296,309

347 - spinosa L. . . 150,264

Punica L. . . 160, 268

348 - Granatum L. . . 160, 268

Putoria Pers. . . 168, 271

349 - brevifolia Coss. . 16is, 271

350 - calabrica Pers. 168, 2 71,299

- cymosa Pom. = 350 .

Quercus L. . . . 86, 230 351 - Afarès Pom. S6, 230, 230

- Ballota Desf. $=353$

- castanexfolia C.A. 11 ever $=351$

352 - coccifera L. $84,231,290,295$

353 - Ilex L. . . 84, 231295

- lusitanica D. C. $=354$.

354 - Mirbeckii Dur. 85,250 , $29 \overline{7}, \quad 308$

- occidentalis Gay. $=355$.

- pseudo-coccifera Desf. $=352$.

- Robur Desf. $=354$.

355 - Suber L. . 82, 231, 295

Retama Bois. . . 139, 258

- allantica Pon. $=358$.

356 - Bovei Spach. . . 139, 258

- Durioi Spach $=356$.

357 - Retam Webb. 139, 258

358 - sphærocarpa Bois. 139,

258,293

Rhamnus L. . . 126, 250 359 - Alaternus L. 126, 22 $11,29 \%$

- Alaternns var. prostrala Bois. $=364$.

360 - alpina L. $126,250,309$

- angustifolia Lange $=363$.

361 - cathartica L. . . 126, 250

362 - Frangula L. . . 126, 250

- libanotica Bois. $=360$.

363 - lycioides L. 12i. 250

364 - mrrtifolia ivillk. 126. 250

365 - oleoides L. . 12 1250,291

Rhus L. . . 130, 251

366 - Coriaria L. : 130,251

- dioica Brous. $=367$.

367 - oxvacantha Car. 131.

251. 302

368 - oryacanthoides Dum. $=367$.

Ribes L. . . . 163, 269

369 - petrium Wulf. : 163, 269 
370 - Uva-crispa L. 163, 269, 305 Ricinus Tourn. . 104, 240 371 - communis L. . 104, 240 Robinia L. . . . 144, 254 372 - Pseudo-Acacia L. 144, 254 Rosa L. . . . 265, 305 373 - agrestis Savi. . . 152, 265 - andegavensis Bast. $=374$.

374 - canina L. . . . 152, 26.5

- Deseglisei Bor. $=374$.

- dumalis Bechst. $=374$.

- dumetorum Thuil. $=374$.

- Fontanesi Pom. $=378$.

- Lntetiana Lem. $=374$.

375 - micrantha Sm. . 152, 265

376 - montana Chaix. . 152, 26.5

377 - moschata L. . . 152, 265

- numidica Gren. $=380$.

378 - Pouzini Tratt. . 152, 265

- prostrata D. C. $=379$.

- scandens Mill. $=379$.

379 - sempervirens L. 152,

- sepinu Thuil. $=373$.

265,292

- Seraphini Coss. $=380$

380 - sicula Tratt. . . 152, 26.5

381 - stylosa Desv. . 152, 26.

- tomentella Lem. $=374$.

Rosmarinus L. . 189, 281

- lavandulaceus de Noé $=382$.

382 - olficinalis L. $189,281,299$

Rubia L. . . . 167, 271

383 - peregrina L. . . 167, 271

Rubus L. . . . . 151, 264

- atlanticus Pom. $=385$.

384 - discolor Weihe. 151 ,

- fruticosus L. $=384$.

$2(\text { it, } 29)^{2}$

385 - numidicus Focke. 151,

Rumex 1. , . . 98. 237

254,

386 - Aristidis Coss. : 237

Ruscus I.. . . . 74, 228

387 - aculeatus $\mathrm{L} . \quad . \quad 74,228$

388 - Hypoglossum L. : 75, 228

- hypophyllum L. $=398$.

Ruta L. . . 122, 118

- bracteosa D. C. $=389$.

389 - angustifolia Pers. 122, 248

- graveolens L. $=389$.

390 - montana L. . . 122, 248

Salicornia L. . . 96, 23.5

391 - fruticosa L. : $96,23.5$

- macrostachya Mloric. $=56$

Salix Tourn. . 89, 28:2

- irsyptiuca Munl, $=397$

392 - albi L. $90,232,296, \quad 307$

393 - anygdalina L. $90,232, \quad 307$

394 - babylonica L. . 9 91, 2:12

395 - cincrea L. . . 90, 232

396 - fragilis L. : 90, 232
397 - pedicellata Desf. 8!, 232 , 294, 296, 30

- pendula Ser. $=396$

398 - purpurea L. 89, 232,

- triandra Duby $=393$.

Salsola L. . . . $9 \bar{t} .236$

- articuluta Forsk. - 33.

- articulata $\mathrm{L}=226$.

- camplorosmoides Desf. $=292$.

- Echinirs Lab. = 292.

- fruticosa Cav $=399$

- longifolia .loq. $=399$.

399 - oppositifolia Desf. 97, 231i 400 - vermiculata Jiorsk. 97,236

Salvia L. . . . 188, 283 401 - Aucheri Bentl?. . 188, 283 402 - Balansa de Noc. 189, 283 403 - trilolıa L. fils. . . 189. 283

Sambucus L. . . 165, 270 404 - nigra L. . . 16.5, 270, 302

Santolina L. . . 173, 275

- africuna Jord. $=405$.

- canescens Lag. $=406$

405 - chanxeypiryssus L.

173,275

406 - rosmarinifolia L. 173, 275 - squarrosa Willd. $=406$.

Satureia L. . . . 188, 280

- capilata L. $=455$.

- filiformis Desf. $=281$

- nervosa Desl. $=285$.

407 - montana J. . . 188, 280

Schinus L. . . 131, 251

408 - molle L. . . 131. 251

409 - tercbinthifolius laaddi,

$131, \quad 2.11$

Securinega Iuss . 114, 240 410 - buxifolia J. Müller. 104, 240

Sedum L. . . . 161. 2(i?

411 - multiceps Coss. et J)

161, 269

Sempervivum L. 161, 2fis

412 - arboreum Desf. . 161, 269

Senecio L. . . 17.) 275

413 - (incruia J). (. . 17\%, 27.

414 - linifolius I). C. . 175, 275

Sideritis I... . . 1 !), 284

- arboresceis Munib. 420.

415 - atlantica l'om. 184 284

416 - Guyoniana IBois. Rrul

- Guillonii Timh. $=417$

417 - Inssopifolial l. . 1s9. 284

418 - incana L. . . 18!. 204

419 - Jencantla Cily. 189. 20.4

420 - mitura D) Noe. 18!. 241

421 - ochrolenealle Nor. 18!.

- pycuostaclyys l'our. 416 .

- virgutu Desf. $=418$. 
Smilax L. . . . 7.), 227

422 - aspera L. . 75, 227, 290

- manritanica Desf. $=422$.

Solanum L. . 183, $2 \overline{7} 9$

- chlorocarpum D. C. $=423$

423 - Dulcamara L. . 183, 279

- miniatum Mlert. et líoch = 433.

424 - sodomaum I.. . 183, 279

- villosum L. $=423$.

Sonchus L. . . . 171, 272

- pertinatus D. C. $=435$.

- spinosus D. C. $=482$.

425 - tenerrimus L. . 171, 272

Sorbus L. . . 155, 266

426 - Aria Crantz, $155,266$.

296,309

428 - latifolia Pers. - 156, 266

429 - torminalis Crantz, 15s, $266,297,309$

Spartium I.. . . 134, 25르

- aspalathoides Iesi". = 232 .

- ferox Desf. $=208$.

430 - junceum L. 134, 252, 293

- ramosissimum Desf. = 214.

Stæhelina L. . . 170, 273

431 - dubia L. . . . 170, 273

Statice Willd. . 191, 284

432 - asparagoides Coss. et Dur. . . . 191, 284

Stipa L. . . . 79, 299

433 - tenacissima L. 79, 229, 293

Suæda Forsk. . . 96, 236

434 - fruticosa I. . . 96, 236

435 - pruinosa Lange. 96, 236

$43 \hat{0}$ - vera Moq. . . 97, 236

Tamarix L. . 161, 268, 307

437 - africana Poir. 161, 268, 293

438 - Bounopea Gay . 161, 268

439 - Boveana De Bunge. 161, 268

440 - gallica L. . 161, 268, 293

411 - rubella Batt. . 161, 268

Taxus Tourn. . 72,205

442 - baccata L. . 72, 225, 294

Tetraclints Benth. et Hook.

- articulata Vahl. $=94$.

Teucrium L. . . 186, 281

443 - albidum Ilunl,. 186, 281

- aureiforme Pom. - 445.

- capitatum L. $=445$

- cephalotes Pons. $=445$.

- compositum Pon. $=445$.

- crispuin Pom. = 446.

- flavovirens Batt. $=445$.

- foliosun Pom. $=445$.

444 - fruticans I. 186, 2281. 299

445 - Polium L. . . . 186, 281

- polycephalum Pom. = 445 .

446 - pseudoscorodonia i)esf.

186,281
- stechadifolium Pon. $=445$.

- thymoides Pon. $=445$.

- virescens $\mathrm{P}$ 'om. $=445$.

Thuya L. . . . . 71,223 - articulata VahI. $=94$.

447 - gigantea Nutt. - $71,22$.

Thymelæa Tourn. 99, 238

448 - hirsuta L. . . 99, 238

449 - microphylla Coss. 99,238

450 - nitida Dest. . . 100, 238

451 - Tarton-raira All. 1100. 238

452 - virescens Coss. . 100, 로

453 - virgata Desf. . . 100, 2:38

Thymus L. . . . 187. '28'

- algeriensis 13. R. $=460$.

454 - candidissimus 13at1. 187, 282

455 - capitatus Hollm. . 187, 282

456 - ciliatus Dest'. . 187. 283

- coloratus Bois. Peut. $=456$.

457 - dreatensis IBatt. . 18s, 282

458 - Fontanesi Bois. Rent.

. . . . . 18̄, 282

- gracillimus Pom. $=456$.

459 - Guyonii De Noé. 18\$, 282

- heterophyllus Batt. = 458 .

460 - hirtus Wahl. . . 187, 283

461 - lanceolatus Desf. 188, 282

- mastichina Desf. $=458$.

- Monardi De Noé $=458$.

- Munbyanus B. R. = 456 .

462 - numidicus Poir. . 188, 2\$2

463 - numidicus var kibylicus Batt. 188, 282

- pallidus Coss. = 460 .

- striatins Nunb. $=460$.

- subulatus Pom. $=456$.

Ulex L. . . . 134, 253 464 - africanus Webb. 134,

253.290

465 - curopaus L. . . 134, 25

466 - Webbianus Coss. 134, 25.5

Ulmus Tourn. . 92, ㄴ.3:3

467 - campestris L. 92,233 ,

295,307

Veronica Tourn. . 185, 280

468 - rosea Desf. . . 185, 280

Viburnum L. . . 166, 270

469 - Lantana L. $166,270,310$

470 - Opulus L. . . 166, 270

471 - Tinus L. . $166,270,300$

Vinca L. : . . 181, 278

472 - major L. : . 181, 278

473 - media Link et Hot1. 181, 279

Viola Tourı. . 115, 245

474 - arboresceus I.. . 11\%, 245 suberosa Desf. $=474$.

Viscum L. . . . 102, 239

475 - album L. . : 102,239

Vitex L. . . . 190, 2S.

476 Agnus-custus L. 190, 285.

$30^{\circ}, \quad 310$ 
Vitis L. . . . 118, 247 477 - vinifera L. 118. 247, 290, 306 Withania Pauqui. $183, \quad 279$ 478 - frutescens Pauqui. 183, $279, \quad 294$
Zizyphus Tourn. 12- 249 479 - Lotus I., 127, 249, 289, 303 480 - vulgaris Lam. . 128, 24? Zollikoferia D. (i. 171, 27t 481 - arborescens I3atl. 171, 274 482 - spinosa Bois . 171, 27t 


\title{
TABLE DES NOMS FRANCAIS DES GENRES
}

\author{
ET DES NOMS YULGAIRES
}

(Les numéros en italique correspondent aux pages de la première elef).

\begin{tabular}{|c|c|c|c|}
\hline \multicolumn{4}{|c|}{ A } \\
\hline Abricotier. & & $\cdot$ & 151,263 \\
\hline Absinthe. & . . & . . & . . 174 \\
\hline Acacia. & & . & 146,261 \\
\hline Acacia (faux) & ). & . . & 144,254 \\
\hline Aeanthyllis. & . & & 143,254 \\
\hline Adénocarpe & & & 140,253 \\
\hline Afarès. & . & 86,230 & 308,316 \\
\hline Agave. & . & . . . & 75,228 \\
\hline Ajone. . & . & 134 & 252,290 \\
\hline Alaterne. . & . & 126 & 250,317 \\
\hline IIIa. . & . & 79 & 229,293 \\
\hline Alisier. . & . & 155 & 266,309 \\
\hline Alkékenge. & . & . . . & 183,279 \\
\hline Alysson. . & . & . . . & 109,241 \\
\hline Amandier. & . & $\cdot \cdot \dot{0}$ & 149,263 \\
\hline Amélanchier & & 154,264 & 294,308 \\
\hline Anabasis. & . & . . . & 97,236 \\
\hline Anagyre. & . & . . & 133,252 \\
\hline Anarrhinum & & . & 185,280 \\
\hline Androsème. & & 123 & 248,300 \\
\hline Anthémis. & . & . & 173,272 \\
\hline Anthyllis. & & . . . & $141,25.3$ \\
\hline Araucaria. & & $\therefore \dot{0}$ & 68,225 \\
\hline Arbousier. & & 175,276 & 294,319 \\
\hline Arbre à poi & & & \\
\hline Arbre de Ju & idẻe. & . & 145,261 \\
\hline olobe. & .. & . . & 140,253 \\
\hline Aristoloche & . & . . & $98,23 \pi$ \\
\hline rmoise. . & . & & 174,273 \\
\hline Arroche. . & & 95 & 235,293 \\
\hline sperge. . & & - $\cdot$ & 73,228 \\
\hline & & . . & $\therefore 187$ \\
\hline Astérolide. & & . . & 171,273 \\
\hline Astragale. & . & . $\cdot$ & 143,260 \\
\hline Atractylis. & & . & 170,272 \\
\hline & & & 152, \\
\hline Azérolier & & & 153,266 \\
\hline
\end{tabular}

B

Baguenaudier. . . . 141, 25\%

Ballotte. . . . . 190, 280
Ballotte (Chêne). . . . . 84

lambou. 81,229

Bellombra (Bella sombra). 97, 237

Bigaradier. . . . . 123, 2/8

Blue gum. . . . . 159

Bois puant. . . . . . . 133

Bonjéanie. . . . . 142, 254

Bonnet de Prêtre . . . . . 124

Bourdaine. . . . 126, 250

Bruvère. $176,276,293,298,319$

Buff̈onie. . . . . . 117, 246

Bugrane. . . . . . . . 141

Buis. : : 105, 240, 300

Buplèrre. . . . 164, 269, 294

\section{C}

Calycotome . . . 139, 252, 292

Camomille. . . . 173,272

Canne. (Voir Roseau.)

Caoutchonc. . . . . 95

Cìprier. . - 109,2 i2, 291

Cardoncelle . . . 170,272

Caroubier. : $145,261,302,318$

Caroubier de Chien. . . . . 133

Casuarina. . . . . 88, 231

Cédratier . . . . 123, 2:4

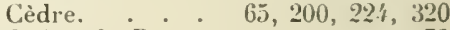

Cèdre de Bussaco. . . 72

Centaurce. . . . 170, 272

Cerisier. . . . . 149

Chalef. . . . 101, 239

Chataignier. $8 \overline{7}, 230,294,30 \overline{7}, 31 \bar{\jmath}$

Chène. . 82, 198, 230, 290, 293 $294,296,297,308,316,317$

Chèreleuille. 116, 270, 290, 300

310

Chou. . . . . . . 108, 2!1

Ciste. . . . 110, 2 :2, 299

Citronnier. . . $123,2 \%$

Clematite. . 106, 2 $1,290,310$

Cognassier. . . 156, 263

Coqueret. . . . 183. 279

Coronille. . . . . 142, $25 \%$ 


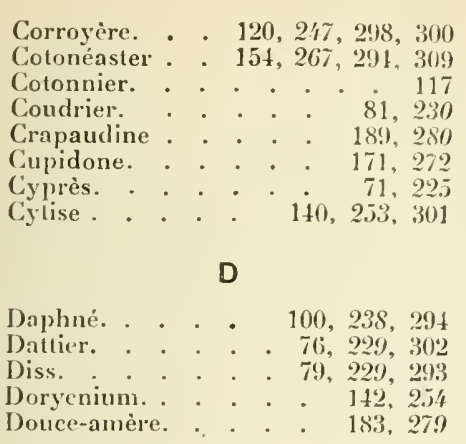

E

Ëbène.

143,254

Ephédra . . . . 63, 22', 298 Epine-vinette. . 107, 211, 291, 305 Erable. 118, 217, 301, 310, 317, 318 Erinacée. . . . . 133, 2.5.\% Estragon . - 175 Eucalyptus. . . . 159, 267 Euphorbe. . . . . 10:, 2:10

\section{$\mathbf{F}$}

Faux Acacia.

144,251

Faux Kiermès.

Faux Poivrier, (Voir Mollé.)

Figuier. - $94,233,297,306,318$ Filao.

Fragon. : * * * * 74,297

Frêne. 177, 277, 292 302, 305, 310, 315 Fumana . . . 114, ?!? Fusian. . . 124, 219, 300, 310

G

Galabré. 2.59

Garance. : $\div \quad 16 \overline{7}, 271$ Garou . . . 100, 239, 294 Gattilier . . 190, 285, 312, 310 Genct . 131, 252, 253, 291, 292 293,301 Genévier. . 68, 200, 225, 298, 320 Germandrie. . . 186, 281, 299 Glohulaire. . . . . 192. 285 Gombo. . . . . . . 144 Gommier. : : : : 137 Gomphocarpe . . . 182.278 Greuadier. . . 160, 268 (irenil. . . . . 182. 278 (irévillie. . . 99, 237 Groseillier. . 163, 26\%, 3015 Groseillier d'Amerique. . . 18:3 Gui. . . . . 1 102, 239 Guimanve. 11(i, 2 彳

\section{H}

Halfa. (Voir Alfa.)

Halime. . . . . 95, 236. 293

Haloxylon. . : : 97,235

Hélianthème. : : $112,2.12$

Hérissonne . . . . 1333

Herniaire. $\quad: 117,266$

Houx . . 125, 249, 200, 318$$
\text { I }
$$

lberis . . . . . 109, 2:1

If. . . $72,225,294,320$

Immortelle. . . . 173, 272

Inule. . . . . 171, 272

J

Jasmin.

Joubarbe $\cdot \cdot \cdot \cdot 180,2 \pi 0$

$127,249,305$

K

Kintuic.

117,915

kirmes. . : 84, 231, 316

L

Latiteron . . . . 171,272

Lalurier des Bois: 101, 231

Lantrier rose. . 181, 27\%, 294, 318

Laurier sauce. 99, 237, 294, 317

Laurier Tin. . . 2 160

Lavande. - . $186,28 \%, 299$

Litvatéral . . . . 115, 215

Lentisque. - 129, 251, 302, 316

licre. $164,270,294,297,317$

Lilas des Indes. . . 117,247

Limoniastre . . . 191, $28 \%$

lin. . . . . . 121, 218

Liseron. . . . . 182.278

Liseron épineux. . . . 75

Lotier droit. . . . 142

lazerne. . . . . 142, 2.31

Lyciet. . . 184, 279, 2911, 3016

\section{M}

Manna gum.

159

Margousier. . . : 117

Maluve. . . . . 11.

Mélia . . . 117

Merisier: 149, 263, 2!1 $6,309,31$ s $^{\circ}$

Mirocoulier. 93, 223, 294, 3117, 315

Micromérie. . . 18s, 2Ni

Millepertuis . . . 12:3, 2/s

Minosa. (Noir Acacia)

Mollé . . . . . 131, 130

Morelle. . . . . 1 133, 2\%!

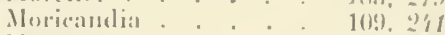

Mnllior. . . . . 1s

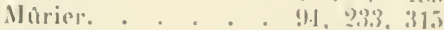

Myrte. - i57, 267, 3011, 31! 


\section{N}

Néllier.

$156,26 \%$

Nérion. . . . . . 180

Nerprun . 126, 2:9, 291, 294, 309, 317

Norea..... . 97, 233

Noirpruu . . . . . . . 126

Noisetier . . . . 87, 230

Noyer . . . . 88, 231,317

\section{0}

(Eillet

$117.2 ! 6$

Olivier. : $179,200,277,299,318$

Olivier de Bohême. . . . 101

Ononis.

$1+1,2.3$

Oranger . . . . 123, 248

Oréobliton . . . 95, 235

Orme . 92, 233, 294, 307, 315

Oseille. . . . . . 98, 237

Osıer. . . . . . . 98

Osyris . . . 102, 240, 294

$\mathrm{P}$

Paliure. . . . . . 128, 249

Palmier . . . . 76, 228, 302

Passerage. . . . . 109, 2/1

Passerine. . . . . . 99, 238

Pêcher. . . . . 151,263

Périploca. . . . . 182, 278

Pervenche . . . 181, 277

Petit Houx. (Voir Fragon.)

Peuplier . 90, 232, 296, 297, 308

Phagnalon

172,272

Philaria

Pin.

$179,277,300,317$

Pistachier. 120, 250, 302. 309, 310

Platine. . . . . . 92, 231

Plagie. . . . . 17t, $27 \%$

Plantain . . . . 191, 285

Poirier. . 155, 263, 291, 306, 319

Poivrier d'Amérique. - 131, 251

Polyearpon . . . . . 117, 246

Polyenemon. . . . . 96, 235

Polygala . . . . 115, 245

Pommier . . . . . 155, 263

Prasion . . . . . 189, 281

Prunellier. . . . . 150, 26\%

Prunier. . 150, 263, 291, 296, 306

309

Putoria. . . . $168,271,299$

\section{R}

Red box tree.

Red gum.

Réglisse

Renoué

Retam.

lRicin

Robinier

Romarin

lionce.

$98,230^{\circ}$

$139,253,293$

104,210

144,254

189, 281, 299

$151,26 \%, 292$ lioseau

80, 229

Rosier. . . 152, 262, 29\%, 305

Rouvet. . . . . 102, 2.19, 294

liue. . . . . . . 122, $2 / 8$

\section{s}

Sainbois . . . . 100

Salicorne. . . . 96, 235

Salsepareille. . . $75,22 \%, 290$

Silsola. . . . . . 97, 23.j

Santoline. . . . . 173, 273

Sapin . . . . 64, 225, 320

Sarriette . . . . 188, 280

Sauge . . . . . 188, 281

Saule . $89,231,294,296,307,319$

Securinega . . . 104, 2:0

Sedum. . . . . . 161, 269

Séneçon . . . . . 175, 2,2

Séné des Arabes . . . 176

Sorbier. . $155,263,296,297,319$

Souci . . . . . 175, 273

Statice. . . . . 191, 28!

Stèhéline. . . . . 170, 273

Suẻda . . . . . 96, 235

Sugar gum . . . . . . . 160

Sumac. . . 130, $250,30^{\circ}$

Sureau. . . . 165, 270, 302

\section{$T$}

Tabac. . . . . 184, 279

Tamarin . ... . 160

Timaris . $160,268,293,307,314$

Térébinthe $149,251,302,309,316$

Thézera. . . . . 131, 251

Thuya. $70,71,200,225,298,320$

Thym. (Voir aussi Armoise.) 187, 281

l'ortillard. 93

Tremble . . . 91, 232, 308

U

Urette. (Voir Éphérlra.)

\section{V}

Vélar. . . . 108, 2:1

Verne. (Voir Aune.)

V'éronique. . . . 185, 280

Vigne . 117, 247, 290, 306, 315

Vigne de Judée. . . . . . 183

Violette. . . . 115. 245

Viorne. . . 166, 270.300.310

\section{W}

Withania . . . 183, 279, 294

144,254

\section{Y}

Yate tree . . . . . . 160

Yeble $: 166$

Yeuse . . . . . . . St

Z

Zéen. . . . $85,230,308,316$ 


\section{TABLE DES NOMS ARABES BERBERES ET KABYLES}

En se reportant aux pages indiquées de la première clef, on tronvera les plantes auxquelles se rapportent les noms indigènes qui figurent ci-dlessous. Toulefois cetle table ne devra être employée pour l'identification des espèces qu'avee prudenee, ear les noms vulgaires des plantes varient souvent avee les localités. Non senlement la même plante peut être désignée d'une fačon différente, mais le même nom peut aussi s'appliquer à des espèces très éloignées l'une de l'autre.

A

Açab.

Achlied.

Aegarȩif.

Açrarçir.

Adafal

Addad

Adhid .

Adjeran

Adhrim

Afurès

Agramia.

Agran

Agridh .

Ainig.

Aĩah.

Aïoual .

Akerma.

Akhelendj.

Akisoun."

Akhilonan.

Aklil.

Akrenbith.

Alenda.

Allä̆s.

Amelzi

Allaref

Anch el Dih.

Ankeraf

toud el Ahmar.

Aoud el Mil.

Aousedj.

Arar.

Areradj.

Ari .

Arous.

Ashia.

Aslan

Alluertas

Atizar

Aufni.
277

2311

295

270

$27 t$

247

는

236

르)

263

230

26 (6i)

267

$-270$

281

260

227

$2+2$

276

233

270

281

242

24

261

225

271

208

2i(i)

2:30

232

27!

$22 \pi$,

227

288

2y99

247

275

239

$2 \pi$

241

2,2
Azberbour.

Azelen .

Azemunour.

Azenzou

Azoumbej : : :

A\%ou . . . . . 250, 258

\section{B}

Begnoun . . . . . 224

Belliel . . . . . . . . 236

Beloula. . . . . . . 25s

Bessdjir. . . . . 241

liendoq. . . . . . . 230

Benecar. . . . . 240

Binlis . . . . . . . 2t0

Bennour. . . . . . 79

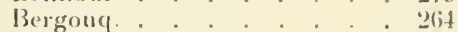

Betoum. . . . . . . . 251

betoum el killan.. . . . . 25l

Bineças. . . . . . . 245

Bou Addad. . . . . . . . 276

Bougramen : : : 274

Bourouthtoum. . . . . . 237

Bou Jenten. . . . 285

linu Neggar . . . . . . 273

Bou Siman. . . . . . 2\$1

Bon\%eron . . . . 2617

G

Cilfsaf . . . . . . 232

Cuhiet el Djeddi. . . 27t

Cegran

Chadjerel en Nahal. . . . 2.is

Chalimet ol Atrous. . 271

(Maibet el dedjou\%. . . . 275

(holorog. . 250

Chedidal 250 26il

Chedjert, Chedjeret . 2liti. 207.)

(hehdbar. og!

Chemsia. . . . . . “li

Chil, . . . . . 275

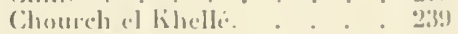


D

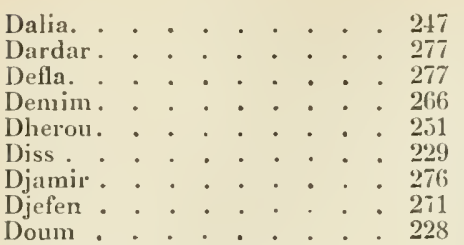

E

El Hanra. . . . . . 248

$\mathbf{F}$

Felgui * . . . . . . 260

Fernan. . . . . 231

Fidjel . . . . . 248

Foua. . . . . . . . 271

G

Ghanim. . 229

Ghourim . . . . . . 278

Guelouta . . . . . . 254

Guendoul : . . 255, 258

Gurtaf . . . . . . . . 236

Guiddaum. . . . . . . 239

$\mathbf{H}$

Habb el Melouk. . . . . 263

Halfa. . . . . . . 229

Hallab. . . . . . . 278

Hameida. . . . . . . . 237

Harami. . . . . . 270

Hariria. . . . . . . 278

Harra . . . . . . 241

Hasba . . . . . . 278

Hejji. . . . . . . . . 2i1

Helhal . . : : 281

Houggui. . . . . . . 258

I

Iazir.

. . . . 281

Thiques. * • . . 233

1ggui. . . . . . . . . 231

Ighsel . . . . . . . . 249

llili . . . . . . . . 277

Imilten. . . . . . . . 269

Inguel . : : $: 0.224$

Inijel. . . . . . . . 264

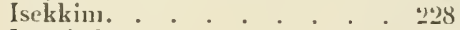

Isembel. : : : : : 270

Iskerchi. . . . . . . . . 227

Isisnou. $: \vdots \vdots \vdots 276$

$\mathbf{K}$

Kabar

Kiastel

liçab.
Kçdir. . . . . . . . . 259

Keddad, liedad. : $253,254,260$

Kef Meriem. . . . . . . . 285

lierendel . . . . . . 23j

Kerma . : : : . 234

Kerrouch . . . . . . . 231

Kethnia. . . . . . 245

Kihalaf. . . . . . . 239

Kharkhach. . . . . 231

Kharoub el Kielb. : : 252

Kiharroub, Ḱharoub . . . 261

liheroua. . . . . 240

lihezam. . . . . . . 235

líhilaf . . . . . . . . 232

Khobaza. : : : 246

Ḱhooziri. . . . . . . . 260

Khorech. . . . . . . 235

Khoukha : . : . . . 263

Kítan. . . . . . . . 248

lidane. . . . . . . 272

koroub. . . . . . . . 212

Kronfel. . . . . . . . . 246

lítem. . . . . . 27

Lahiet el Djeddi. . . . . . 269

Lezzaz . * . . . 239

Lim-en-N'Cara . . . . 279

Lindj . . . . . . . 276

Louaia. . . . . . . 270

Louz. . . . . . . . 263

M

Magramane . . . . . . $27 t$

Mamejjirt. . . . . . . . 246

Margatah. . . . . . 240

Mechmech. . . . . . . . 263

Meddad. . . . . . . . . 224

Nelifet el Khadem. : : 295

Melila . . . . . . . 250

Meriem. . . . . . . . 275

Metuane. . . . . . . 238

Nlimeuch . . . . . . . . 259

lloughir. . . . . . 270

$\mathbf{N}$

Naberdan . . . . . . . 241

Nechem. : : : 233

Neckla . . . . . . . . 2029

Nefel. . . . . 254, 259

o

Ottarneguer . . . . . 240

Ouerd . . : 5265

Oulumou. . . . . . . . 233

Oum el Lebina :

Ousser . . . . . . . 228

Oussera. : $: \div \quad \div \quad 236$ 


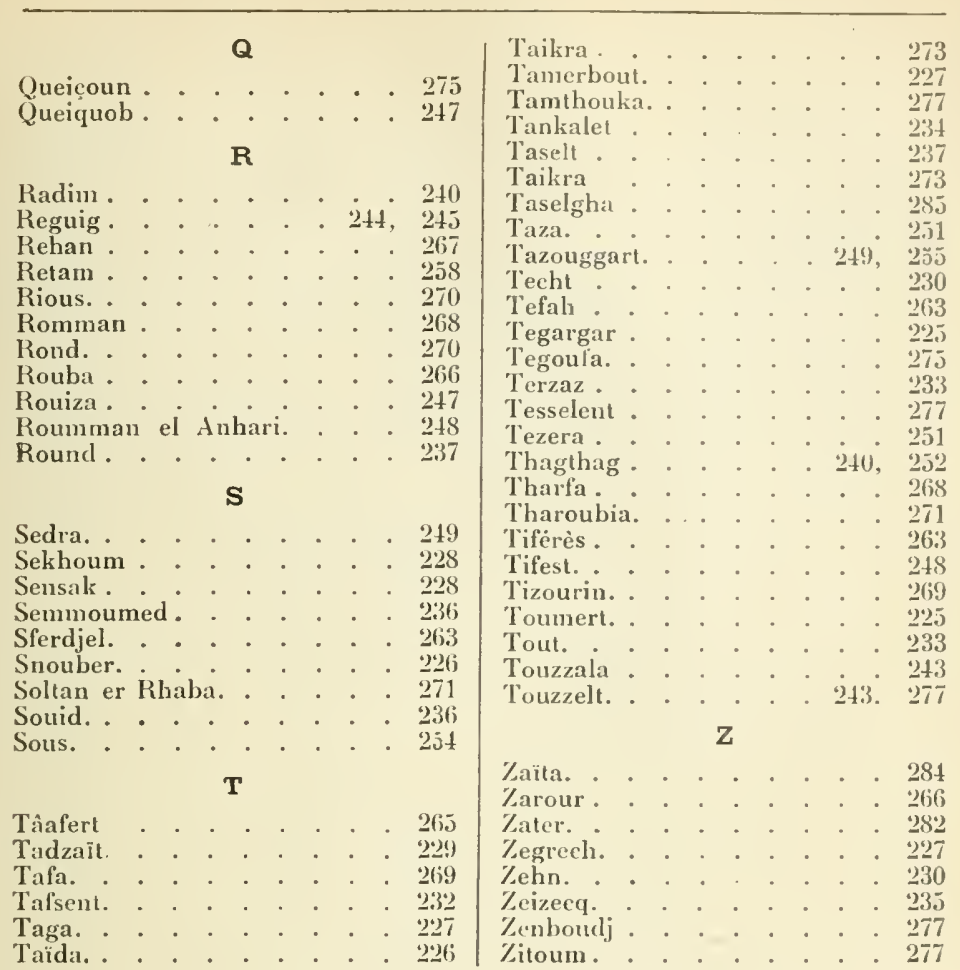




\section{TABLE DES MATIERES}

Avertissenent.

I-IIII

\section{PREMIÉRE PARTIE}

Notions de Botanique appliquée à la Sylviculture

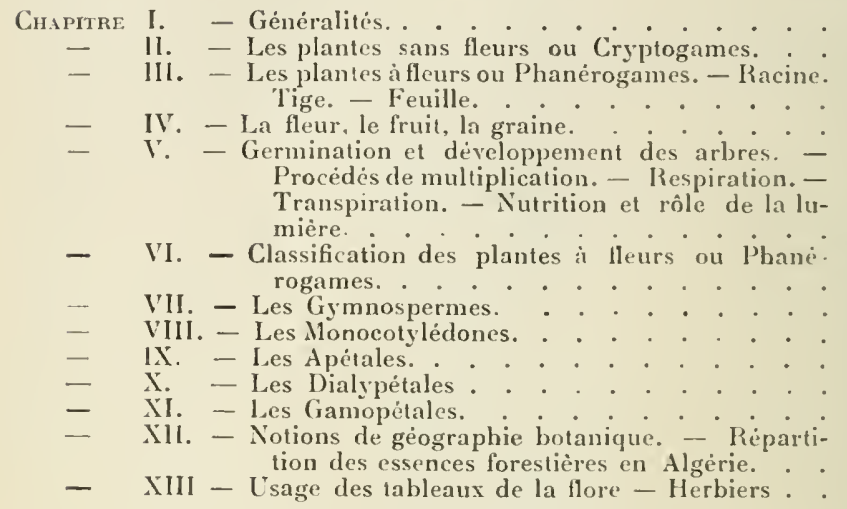

\section{DEUXIËME PARTIE \\ Tableaux synoptiques}

Premine clef : Tubleaux synoptiques pour la determination des principales espèces ligneuses de 1 Algérie en utilisant les carac. tères des fleurs et des fruits.

Deixti̇Me Clef : Tableaux synoptiques pour la détermination des principales espèces ligneuses d'après les organes végétatil's.

Troisizae cheF: Tableaux synoptiques pour la détermination en hiver des plantes ligneuses à feuilles caduques. . . . . .

Quatritie cref: Tableaux synoptiques pour la détermination des bois.

TABLEAT SOMMARE DES CARACTERES DES FAMILIES.

\section{TABLES}

Table des abrèviations.

Table des termes expliqués dans la première partie $. \quad . \quad$.

Table des noms des Cryptogames (groupes, genres. noms vulgaires) cités dans la première partie.

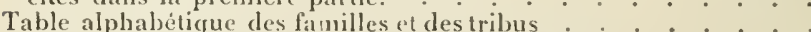

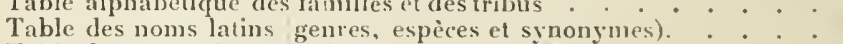

Table des noms francais des genres et des noms vulgaires.

Table des noms arabes, berbères et liabyles.

Table des matières .

Carte de l'Algérie. . . . . . . . . . . . . . . . . . . . 359 


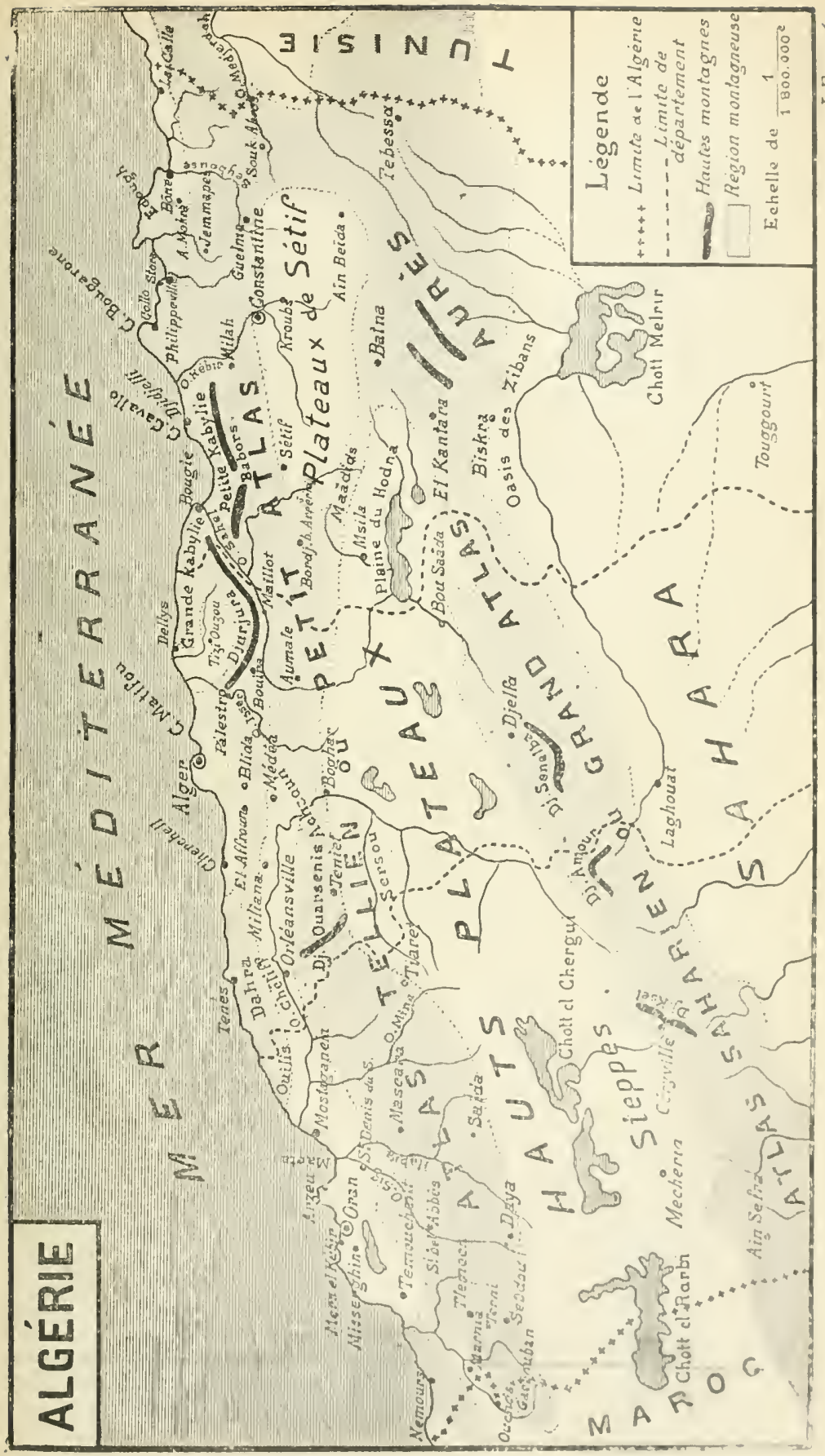




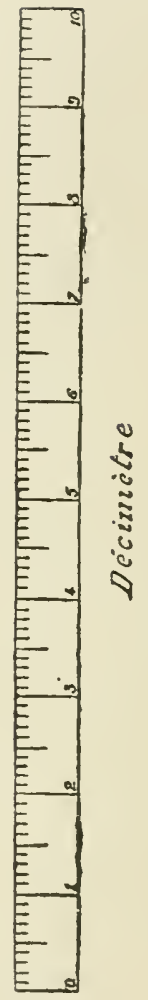


216509

BStity As l. 






\section{DATE DUE}

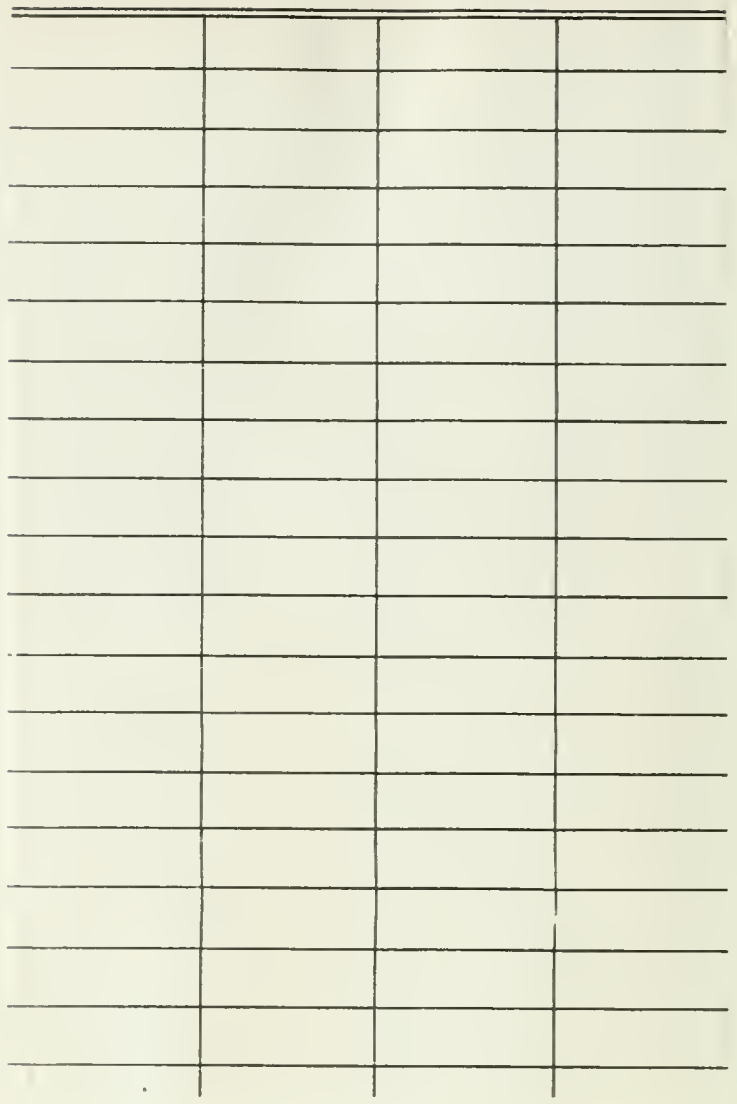


$44006<07 x=28$

Q K 491

A 5

42

\section{AGRICULTURE \\ FORESTRY \\ LIBRARY}

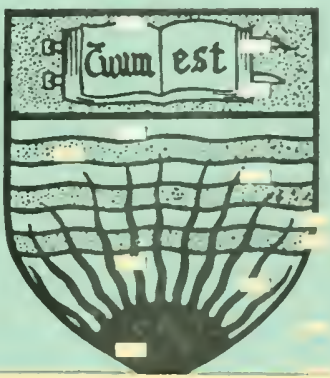


isllin

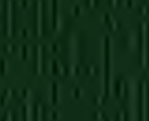

1,

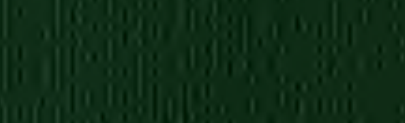

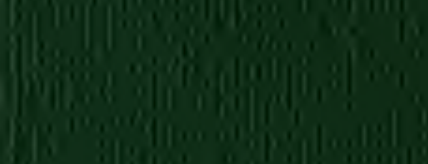

\&

II:

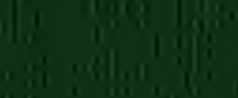

